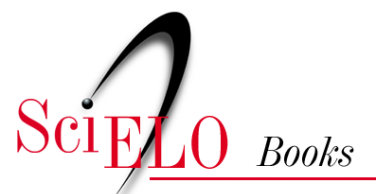

\title{
Crianças, adolescentes e crack desafios para o cuidado
}

\author{
Simone Gonçalves de Assis (org.)
}

\section{SciELO Books / SciELO Livros / SciELO Libros}

ASSIS, S. G., comp. Crianças, adolescentes e crack: desafios para o cuidado [online]. Rio de Janeiro: Editora FIOCRUZ, 2015, 403 p. ISBN: 978-85-7541-554-2. https://doi.org/10.7476/9788575415542.

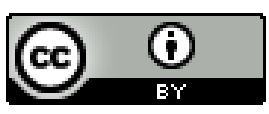

All the contents of this work, except where otherwise noted, is licensed under a Creative Commons Attribution 4.0 International license.

Todo o conteúdo deste trabalho, exceto quando houver ressalva, é publicado sob a licença Creative Commons Atribição 4.0. 
Criançass, Adelescentese C ack desafios para o cuidado 


\section{FUNDAÇÃO OSWALDO CRUZ}

Presidente

Paulo Gadelha

Vice-Presidente de Ensino, Informação e Comunicação

Nisia Trindade Lima

\section{EDITORA FIOCRUZ}

Diretora

Nísia Trindade Lima

Editor Executivo

João Carlos Canossa Mendes

Editores Científicos

Carlos Machado de Freitas

Gilberto Hochman

Conselho Editorial

Claudia Nunes Duarte dos Santos

Jane Russo

Ligia Maria Vieira da Silva

Maria Cecília de Souza Minayo

Marilia Santini de Oliveira

Moisés Goldbaum

Pedro Paulo Chieffi

Ricardo Lourenço de Oliveira

Ricardo Ventura Santos

Soraya Vargas Côrtes 
Simone Gonçalves de Assis Organizadora
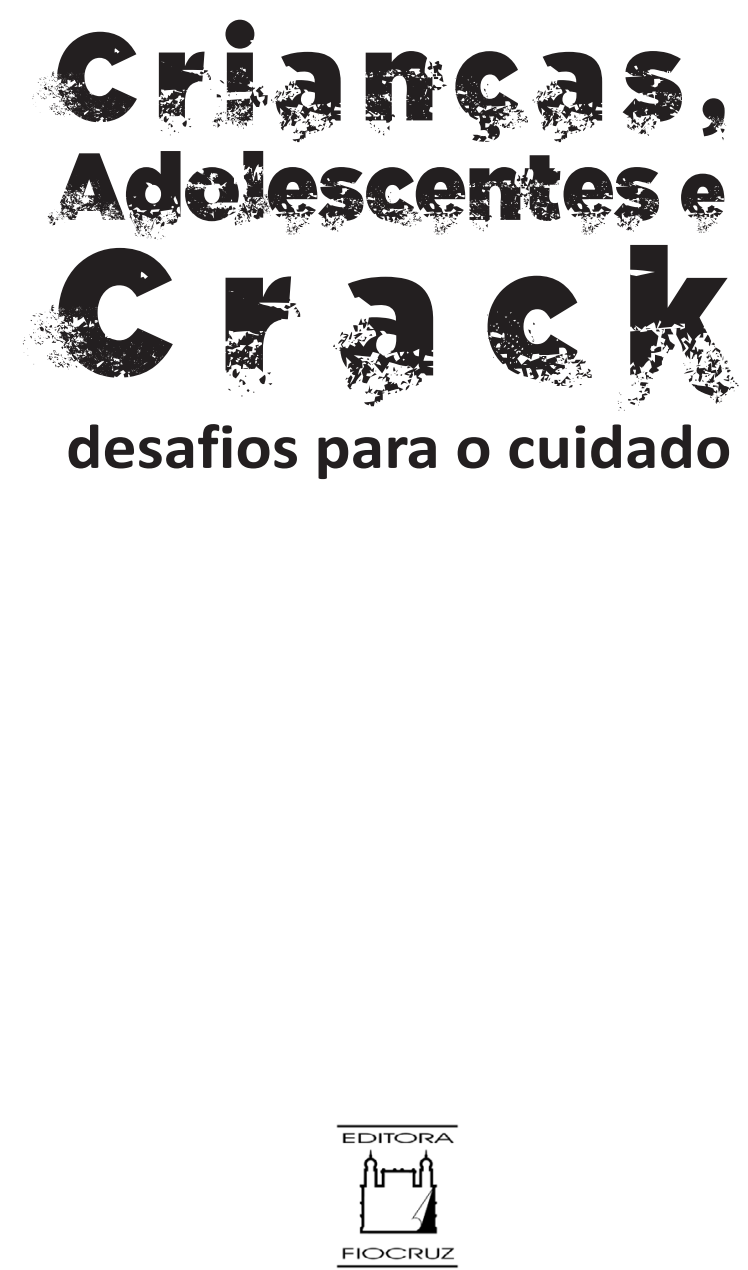
Copyright (๐ 2015 dos autores

Todos os direitos desta edição reservados à

FUNDAÇãO OSWALDO CRUZ / EDITORA

Revisão e copidesque

M. Cecilia G. B. Moreira

Normalização de referências

Clarissa Bravo

Capa, projeto gráfico e editoração

Carlota Rios

Foto da capa

Willam Duarte

(Título: Meninos de Rua, Recife. Técnica: pin-hole, feita com lata de leite em pó.

Projeto Lata Mágica Recife - fotografia artesanal, latamagica.blogspot.com.br). Reprodução autorizada.

Catalogação na fonte

Instituto de Comunicação e Informação Científica e Tecnológica em Saúde

Biblioteca de Saúde Pública

A848c Assis, Simone Gonçalves de (Org.)

Crianças, Adolescentes e Crack: desafios para o cuidado. / organizado por Simone Gonçalves de Assis. - Rio de Janeiro: Editora FIOCRUZ, 2015.

402 p. : il. ; tab.

ISBN: 978-85-7541-471-2

Crack - efeitos adversos. 2. Transtornos Relacionados ao Uso de Substâncias - terapia. 3. Criança. 4. Adolescente. 5. Políticas Públicas. 6. Serviços de Saúde Mental. 7. Comunidade

Terapêutica. 8. Família - psicologia. 9. Centros de Tratamento de Abuso de Substâncias. I. Título.

CDD - 22.ed. - 362.298

2015

EDITORA FIOCRUZ

Av. Brasil, 4.036 - Térreo - sala 112 - Manguinhos

21040-361 - Rio de Janeiro - RJ

Tels: (21) 3882-9039 e 3882-9041

Telefax: (21) 3882-9006

editora@fiocruz.br

www.fiocruz.br/editora

Editora filiada

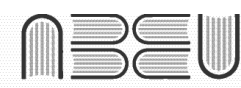

Associação Brasileira das Editoras Universitárias 


\section{Autores}

Andrea Machado Iannelli

Assistente social, doutora em saúde da criança e da mulher pelo Instituto Nacional de Saúde da Mulher, da Criança e do Adolescente Fernandes Figueira da Fundação Oswaldo Cruz.

\section{Angélica Dalla Vechia Biolchi}

Enfermeira, mestre em saúde pública pela Escola Nacional de Saúde Pública Sergio Arouca da Fundação Oswaldo Cruz; auditora de Serviços de Saúde na Secretaria de Estado de Saúde de Mato Grosso do Sul.

\section{Carmen Lúcia Albuquerque de}

SANTANA

Psiquiatra e arteterapeuta, doutora em ciências pela Universidade de São Paulo (USP); pesquisadora da Faculdade de Medicina da USP e da Universidade Federal de São Paulo e professora do curso de especialização em Dependência Química da USP.

\section{Caroline Alves Feitosa}

Psicóloga, mestre em epidemiologia pela London School of Hygiene and Tropical Medicine (Inglaterrra) e doutoranda em saúde coletiva no Instituto de Saúde Coletiva da Universidade Federal da Bahia; docente de epidemiologia na Escola Bahiana de Medicina e Saúde Pública.

\section{Edmara Honório Santos}

Enfermeira, mestre em saúde pública pela Escola Nacional de Saúde Pública Sergio Arouca da Fundação Oswaldo Cruz; enfermeira da Prefeitura Municipal de Glória de Dourados, MS.

Fernanda Mendes Lages Ribeiro

Psicóloga, doutora em saúde pública pela Escola Nacional de Saúde Pública Sergio Arouca da Fundação Oswaldo Cruz (Ensp/ Fiocruz); pesquisadora colaboradora do Departamento de Estudos de Violência e Saúde Jorge Careli da Ensp/Fiocruz.

\section{Francisco Inácio Bastos}

Médico, doutor em saúde pública pela Fundação Oswaldo Cruz (Fiocruz); pesquisador sênior do Laboratório de Informações em Saúde do Instituto de Informação e Comunicação Científica e Tecnológica em Saúde da Fiocruz.

Joviana Quintes Avanci

Psicóloga, doutora em saúde da mulher e da criança pela Fundação Oswaldo Cruz (Fiocruz), com período-sanduíche na Universidade de Cambridge (Inglaterra); pesquisadora do Departamento de Estudos de Violência e Saúde Jorge Careli da Escola Nacional de Saúde Pública Sergio Arouca da Fiocruz. 


\section{Liana Wernersbach Pinto}

Nutricionista; doutora em engenharia biomédica pela Universidade Federal do Rio de Janeiro, com pós-doutorado na London School of Hygiene and Tropical Medicine (Inglaterra); pesquisadora do Departamento de Estudos de Violência e Saúde Jorge Careli da Escola Nacional de Saúde Pública Sergio Arouca da Fundação Oswaldo Cruz.

\section{Luciana Alencar Peixoto}

Psicóloga, mestre em psicologia pela Universidade Federal do Amazonas; psicóloga do Departamento de Proteção Social Especial da Secretaria Municipal de Assistência Social e Direitos Humanos de Manaus e bolsista da Fundação de Amparo à Pesquisa do Estado do Amazonas.

\section{MIRIAM SCHENKER}

Psicóloga, doutora em saúde da criança e da mulher pelo Instituto Nacional de Saúde da Mulher, da Criança e do Adolescente Fernandes Figueira da Fundação Oswaldo Cruz (Fiocruz); pesquisadora colaboradora do Departamento de Estudos de Violência e Saúde Jorge Careli da Escola Nacional de Saúde Pública Sergio Arouca da Fiocruz, professora e preceptora do Departamento de Medicina Integral Familiar e Comunitária da Universidade do Estado do Rio de Janeiro.

Neilane Bertoni

Estatística, doutora em epidemiologia pela Escola Nacional de Saúde Pública Sergio Arouca da Fundação Oswaldo Cruz.

\section{Patricia Constantino}

Psicóloga, doutora em saúde pública pela Escola Nacional de Saúde Pública Sergio Arouca da Fundação Oswaldo Cruz (Ensp/ Fiocruz); pesquisadora do Departamento de Estudos de Violência e Saúde Jorge Careli da Ensp/Fiocruz.
Renata Pires Pesce

Psicóloga, doutora em saúde pública pela Escola Nacional de Saúde Pública Sergio Arouca da Fundação Oswaldo Cruz (Ensp/ Fiocruz); pesquisadora colaboradora do Departamento de Estudos de Violência e Saúde Jorge Careli da Ensp/Fiocruz.

\section{Simone Cortiano}

Pedagoga, especialista em séries inicias do ensino fundamental e saúde mental e em atenção psicossocial a criança e adolescentes; técnica do Centro de Epidemiologia da Secretaria Municipal de Saúde de Curitiba.

Simone Gonçalves de Assis

(organizadora)

Médica, doutora em ciências pela Escola Nacional de Saúde Pública Sergio Arouca da Fundação Oswaldo Cruz (Ensp/ Fiocruz), com pós-doutorado na Cornell University (EUA); coordenadora executiva e pesquisadora do Departamento de Estudos de Violência e Saúde Jorge Careli da Ensp/Fiocruz.

\section{Vera Lidia Alves de Oliveira}

Odontóloga, mestre em saúde pública pela Universidade de São Paulo; chefe da Coordenação de Vigilância de Doenças e Agravos Não Transmissíveis da Secretaria Municipal de Saúde de Curitiba. 


\section{Sumário}

$\begin{array}{ll}\text { PREFÁCIO } & 9\end{array}$

$\begin{array}{ll}\text { APRESENTAÇÃO } & 13\end{array}$

1. Alicerces para o Estudo do Crack na Infância e Adolescência Simone Gonçalves de Assis e Fernanda Mendes Lages Ribeiro

2. Quantas Crianças e Adolescentes Fazem Uso Regular de Crack e Similares nas Capitais Brasileiras?

Francisco Inácio Bastos e Neilane Bertoni

3. A (Des)Atenção às Crianças e Adolescentes Usuários de Crack de Manaus

Patricia Constantino e Luciana Alencar Peixoto

4. O Atendimento a Crianças e Adolescentes Usuários de Crack em Região de Fronteira: a cidade gêmea de Ponta Porã Liana Wernersbach Pinto, Angélica Dalla Vechia Biolchi, Edmara Honório Santos e Simone Gonçalves de Assis

5. O Paradoxo na Atenção ao Crack em Salvador: entre a referência técnica e a fragilidade da articulação na rede Joviana Quintes Avanci e Caroline Alves Feitosa

6. O Município do Rio de Janeiro e o Crack Andrea Machado lannelli e Simone Gonçalves de Assis 
7. Retratos de um Momento Especial na Abordagem ao Usuário de Crack na Cidade de São Paulo

Renata Pires Pesce e Carmen Lúcia Albuquerque de Santana

8. Curitiba: entre o trabalho em rede ideal e o real $\quad 277$ Fernanda Mendes Lages Ribeiro, Vera Lidia Alves de Oliveira e Simone Cortiano

9. Uma Rede em Construção no Município de Porto Alegre Miriam Schenker

10. Crack na Infância e Adolescência: uma ferida candente Simone Gonçalves de Assis 


\section{Prefácio}

É com satisfação que apresento o livro Crianças, Adolescentes e Crack: desafios para o cuidado. Esta obra é fruto de pesquisas feitas na Fundação Oswaldo Cruz e representa uma parcela do engajamento e da preocupação da instituição no debate sobre o uso de drogas, tendo como norte os princípios da saúde pública. Aborda temática atual, relevante para o país e central para a área da saúde: o cuidado oferecido às crianças e adolescentes que usam crack ou a filhos de usuários desta substância. A Comissão Brasileira sobre Drogas e Democracia (CBDD), na declaração "Hora de debater e inovar", ${ }^{1}$ considera que um dos maiores desafios para a criatividade das políticas públicas refere-se aos grupos de "pequenas figuras humanas" que vivem em condição deplorável pelo uso de drogas, especialmente o crack. Estas crianças, adolescentes e suas famílias precisam que seja feito o reconhecimento do problema e rapidamente implementado o devido cuidado.

Ao longo do livro, por meio de estudo com base populacional, emergem das sombras 50 mil crianças e adolescentes usuários de crack em cidades brasileiras, dando concretude ao que dolorosamente se vislumbra hoje nos espaços públicos no Brasil. Já os estudos de caso aprofundam e retratam o ainda frágil cuidado e as limitações presentes na esfera das políticas públicas das cidades de Manaus (AM), Ponta Porã (MS), Salvador (BA), Rio de Janeiro (RJ), São Paulo (SP), Curitiba (PR) e Porto Alegre (RS), ao investigar o cuidado oferecido pela rede de assistência social e saúde às crianças e adolescentes que usam crack ou cujos

\footnotetext{
Disponível em: <www.cbdd.org.br/documentos>. Acesso em: 9 abr. 2015.
} 
pais consomem a droga. Nessas cidades, percebem-se os diferentes contextos e graus de cuidado oferecidos aos usuários de crack, variando das dificuldades enfrentadas na fronteira do país, como é o caso de Ponta Porã, passando pela quase inexistência de rede de atenção em Manaus e pela experiência mais robusta de atendimento em Porto Alegre.

O objetivo dos autores deste livro - identificar quantos e quem são as crianças e adolescentes, vítimas diretas ou indiretas do crack, bem como refletir sobre as formas de atenção existentes nas redes de saúde e assistência social - produz uma ampla e inédita visão sobre o tema do crack na sociedade brasileira.

A invisibilidade do uso do crack na infância é um fato extremamente preocupante. Os efeitos diretos e indiretos nessa fase da vida são variados: a fragilidade dos bebês (alguns ainda na gestação e pós-parto), filhos de pais usuários, e de suas mães, as separações familiares em decorrência do consumo da substância pelos responsáveis, afetadas muitas vezes por prisões, internações ou mortes resultantes da proximidade com o tráfico de drogas. O uso de drogas pelos responsáveis é hoje um dos principais motivos de acolhimento institucional de crianças no país, tomando o lugar que outrora era ocupado pela falta de condições materiais. Entre os adolescentes - faixa etária em que o uso pessoal aumenta bastante -, o consumo do crack leva a estigmas e problemas de saúde, além de propiciar o abandono escolar, o distanciamento familiar, a exploração sexual, o envolvimento em furtos e outros atos infracionais, destacando-se o tráfico de drogas.

Ressalta-se no livro que as questões de saúde provocadas pelo uso do crack nas crianças, adolescentes e suas famílias necessitam ser vislumbradas em paralelo com outros aspectos estruturais e conjunturais. Em acordo com a $C B D D$, reitera-se que o objetivo ilusório de um mundo sem drogas merece ser questionado, também pelos funestos resultados do enfrentamento ao tráfico de drogas e armas e da corrupção. A violência, instabilidade e corrupção geradas pelos mercados de drogas não regulamentados são amplamente reconhecidas como ameaça à segurança e ao desenvolvimento social.

A ideia de um mundo sem drogas, a do proibicionismo, do "diga não às drogas", ainda referendada por diversos setores no país, assenta-se em valores morais e ideologias que fomentam o estigma e o preconceito ao uso e aos usuários de drogas, valores esses que não andam de mãos dadas com os princípios do exercício da cidadania e que retiram do cidadão a responsabilidade pelo cuidado de sua saúde. 
A premissa do proibicionismo referenda medidas punitivas para o uso de drogas cujo fim último é o encarceramento. A lei n. 11.343, de 2006, que instituiu o Sistema Nacional de Políticas Públicas sobre Drogas e trouxe avanços na diferenciação, para fins criminais, entre usuário recreativo e traficante de drogas, não deixa claros os critérios que diferenciam os dois grupos. Os familiares e adolescentes usuários de crack deste estudo podem ter sido enquadrados nessa visão ambígua da lei.

As políticas repressivas sobre drogas geraram problemas sociais e de segurança para a população, como o crime e a violência associados ao comércio ilegal das drogas. A repressão punitiva às drogas maximiza os riscos de saúde, especialmente entre indivíduos mais vulneráveis, como os que se encontram neste estudo. O conceito de drogas licitas ou ilícitas é arbitrário e não está lastreado no campo da saúde pública. Os usuários de substâncias ilícitas são criminalizados, em vez de terem acesso ao serviço de assistência à saúde.

Entretanto, de acordo com a Comissão Global de Política sobre Drogas, ${ }^{2}$ está havendo um movimento lento, mas disseminado de reforma na política sobre drogas, mais vivamente desde 2011 , instituindo políticas mais humanas e eficazes que se baseiam em evidências científicas, nos princípios de saúde pública, nos direitos humanos e na segurança das comunidades. A comissão sugere como objetivos, para a próxima sessão especial da Assembleia Geral das Nações Unidas de 2016, a garantia do acesso da população aos medicamentos essenciais de controle da dor, fim da criminalização e do encarceramento de usuários; em conjunto com estratégias de prevenção, redução de danos (para overdoses fatais, HIV/Aids, hepatite, entre outras doenças) e tratamento direcionados a usuários dependentes.

O exemplo de Portugal pode ser um caminho para o Brasil. Naquele país, após dez anos de política de descriminalização ao uso das drogas, reduziuse a criminalidade, produziu-se baixa expressiva na população prisional e, sobretudo, diminuiu-se o consumo de drogas entre os adolescentes. Com a descriminalização, os consumidores não são encaminhados à justiça criminal; são acolhidos por comissões especiais cujo objetivo é auxiliar o usuário a preservar sua saúde.

2 COMISSÃO GLOBAL DE POLÍTICA SOBRE DROGAS. Sob controle: caminhos para políticas de drogas que funcionam, set. 2014. Disponível em: <www.gcdpsummary2014.com/bemvindo/\#foreword-from-the-chair-pt>. Acesso em: 9 jun. 2015. 
O Uruguai em 2013 tornou-se o primeiro Estado-nação a aprovar a legislação, estabelecendo um mercado legal e regulamentado para a Cannabis não medicinal. A mudança do enfoque sobre o consumo de drogas é, portanto, essencial no Brasil, ancorada no papel da saúde pública. Esse é um passo fundamental para o respeito ao indivíduo e a construção da democracia e da cidadania.

Paulo Gadelha

Presidente da Fundação Oswaldo Cruz, membro da Comissão Brasileira sobre Drogas e Democracia 


\section{Apresentação}

Este livro está integralmente baseado em resultados de pesquisas sobre consumo de crack realizadas por pesquisadores da Fundação Oswaldo Cruz (Fiocruz). A primeira investigação, O Desafio da Rede no Atendimento de Crianças e Adolescentes Usuários de Crack e/ou Acolhidas Institucionalmente pelo Uso do Crack dos Pais/Responsáveis, é um estudo realizado em sete cidades brasileiras nos anos de 2011 e 2012, em unidades de saúde e de assistência social das cinco regiões do país: no Norte, em Manaus; no Centro-Oeste, em Ponta Porã; no Nordeste, em Salvador; no Sudeste, nas cidades do Rio de Janeiro e de São Paulo; e no Sul, em Porto Alegre e Curitiba. Contou com o apoio do Ministério da Saúde, por meio do Departamento de Ciência e Tecnologia (Decit) e do Conselho Nacional de Desenvolvimento Científico e Tecnológico (CNPq). A ideia para esta pesquisa surgiu após se constatar a relevância que o crack começava a apresentar na infância e adolescência pobres no país, a partir da publicação do Levantamento Nacional de Serviços de Acolhimento de Crianças e Adolescentes, estudo realizado entre 2009 e 2010, com financiamento do Ministério de Desenvolvimento Social e Combate à Fome e apoio do Conselho Nacional dos Direitos da Criança e do Adolescente e do Conselho Nacional de Justiça (Assis \& Farias, 2013). Esse levantamento foi efetuado por diversos autores do presente livro, integrantes do Departamento de Estudos de Violência e Saúde Jorge Careli da Escola Nacional de Saúde Pública Sergio Arouca (Claves/Ensp) da Fiocruz.

A segunda investigação a ser apresentada é a Pesquisa Nacional do Crack, desenvolvida com o apoio do Ministério da Justiça (Bastos \& Bertoni, 2014). 
Foi realizada em 2012 por meio de pesquisa domiciliar em 26 capitais brasileiras e no Distrito Federal. Outro componente da investigação foi o levantamento em cenas de uso de drogas nas mesmas cidades, ampliado para as regiões metropolitanas e alguns municípios de pequeno e médio porte. Oferece o panorama epidemiológico mais amplo sobre o uso da substância no país e envolveu pesquisadores do Instituto de Comunicação e Informação Científica e Tecnológica em Saúde (Icict) da Fiocruz.

O conhecimento sobre o crack e suas consequências é ainda recente em diversos países do mundo e no Brasil, o que contribui para o estado atual que vivenciamos de perplexidade social e de inabilidade institucional em atender eficazmente os usuários dessa e de outras drogas. Alguns autores destacam que o consumo de crack tem início nos Estados Unidos na década de 1980, mas apenas no começo dos anos 1990 surgem as primeiras publicações sobre o assunto - geralmente levantamentos qualitativos ou acompanhamento de poucos meses de usuários de drogas. Estudos mais estruturados e longitudinais foram realizados e divulgados a partir da segunda metade dos anos 2000 (Ribeiro et al., 2012).

O crack, por sua composição e forma de uso, tem rápidos impactos sobre a saúde global dos indivíduos, com efeitos clínicos e psiquiátricos comprometedores. Sua produção e comercialização estão associadas a fatores como miséria, exclusão social, delinquência e tráfico de drogas. Seu consumo tanto propicia como alimenta situações de vulnerabilidade social, deixando os usuários mais expostos à violência em suas variadas formas, bem como à prostituição (Amstalden, Hoffmann \& Monteiro, 2010).

Embora possa ser consumido por pessoas de todos os estratos sociais, o crack está intimamente associado ao quadro de desigualdades sociais no país e é um facilitador de exclusão social. A despeito dos precários dados nacionais, constata-se que predominam crianças e adolescentes pobres nas instituições de acolhimento, em decorrência do uso de drogas pessoal ou dos responsáveis (Assis \& Farias, 2013). Além disso, os adultos que usam crack em cenas de uso no país são pessoas não brancas e, em sua maioria, de baixa escolaridade (Bastos \& Bertoni, 2014).

Pouco ainda se conhece acerca dos efeitos diretos do crack sobre o crescimento e desenvolvimento humano. Na infância, os problemas do uso de crack ocorrem substancialmente em consequência do consumo da droga por parte dos pais ou cuidadores. À medida que chega a adolescência, o acesso e o 
uso pessoal do crack torna-se mais comum, especialmente para a população de rua e em comunidades em que o tráfico de drogas impera ou efetua a distribuição da droga. Levantamento nacional a respeito do uso de drogas do Centro Brasileiro de Informações sobre Drogas Psicotrópicas - Cebrid (Galduróz et al., 2005) indica a prevalência do uso de drogas na adolescência. A dependência pode favorecer desequilíbrios de ordem familiar e social (Muraki, 2009).

A adolescência é uma fase caracterizada por extrema curiosidade, movimentos de individuação, especial valorização do grupo de amigos e comportamento rebelde, muitas vezes necessário para iniciar o corte do cordão umbilical familiar pelo jovem (Schenker, Mauricio \& Cavalcante, 2011). O prazer invade o adolescente na descoberta da sexualidade, da afetividade, das amizades e também no compartilhamento do uso de drogas. Essa é uma experiência que geralmente se dá em grupo, ou com um amigo. Os adolescentes estão em busca de novas sensações e não têm, muitas vezes, noção dos perigos que rondam a busca dos resultados almejados. Fato é que, ao consumirem drogas, eles buscam prazer, extroversão, compartilhamento grupal, diferenciação, autonomia e independência de sua família.

O lado negativo do desejo juvenil de obter prazer com o uso de drogas lícitas e ilícitas é o risco de desenvolver dependência e de comprometer a realização de tarefas normais do desenvolvimento dos papéis sociais esperados, a aquisição de habilidades essenciais, a realização de um sentido de adequação e de competência e a preparação adequada para a transição ao próximo estágio na trajetória da vida - a juventude (Schenker \& Minayo, 2005).

Tais especificidades chamam atenção para os desafios de cuidar de crianças e adolescentes vítimas diretas ou indiretas do crack. Nesse sentido, assumimos aqui as tarefas de identificar quantos e quem são esses jovens indivíduos, bem como de refletir sobre as formas de atenção existentes em algumas cidades brasileiras. Para cumprir tais ações, definimos três objetivos.

O primeiro objetivo é dimensionar o envolvimento de crianças e adolescentes com o crack nessas faixas etárias, seja como usuários da substância, seja pelo uso por parte de seus responsáveis. Como se verá especialmente no capítulo 2 e no Anexo, são inúmeros os obstáculos metodológicos para se conhecer a magnitude do problema. A investigação de crianças e adolescentes nesta condição foi realizada por meio de pesquisa domiciliar e da presença nas cenas de uso de drogas e nos Serviços de Acolhimento Institucional ligados à assistência social. Esses serviços lidam com o caráter extremo do uso do crack: 
o acolhimento em instituições públicas. Busca-se, neste livro, uma aproximação com a realidade nas cidades investigadas, sem a ambição de encontrar uma verdade absoluta nos números obtidos.

Um segundo objetivo é traçar o perfil das crianças e dos adolescentes que têm problemas decorrentes do crack, seja pelo consumo próprio, seja de seus pais/responsáveis. $O$ terceiro refere-se a conhecer a rede de serviços necessários para atender a faixa etária infantojuvenil que se envolve direta ou indiretamente com o crack.

Os serviços que compõem a Rede de Promoção, Proteção e Defesa dos Direitos da Criança e do Adolescente são desafiados a cuidarem de crianças e adolescentes e seus responsáveis envolvidos com o crack. Essa rede se consolida por meio do Sistema de Garantia dos Direitos da Criança e do Adolescente, agregando instâncias públicas governamentais e da sociedade civil que atuam na promoção, proteção, defesa e controle dos direitos humanos, nos níveis federal, estadual, municipal e distrital. O sistema agrega as áreas da saúde, educação, assistência social, trabalho, segurança pública, justiça, planejamento, orçamento, relações exteriores, promoção da igualdade e respeito à diversidade (Conanda, 2006 - art. $1^{\circ}$ ).

A atuação em rede proporcionada pelas instituições pertencentes ao Sistema de Garantia de Direitos da Criança e do Adolescente é capaz de fortalecer laços de proteção, tendo capacidade de responder melhor à complexidade de suas demandas. Além disso, as formas articuladas de trabalho tornam-se ou deveriam tornar-se - um modo de organização essencial no atendimento a crianças e adolescentes, como preconizado pelo Estatuto da Criança e do Adolescente (ECA), e consequentemente no sistema. Contudo, reconhece-se que na prática as dificuldades são inúmeras, especialmente de natureza política e administrativa, agregadas ainda à necessidade premente de capacitação profissional sobre o tema revisto.

Algumas instituições da rede foram priorizadas nos estudos de caso referentes às cidades investigadas na primeira pesquisa apresentada. São denominadas no livro de rede socioassistencial e agregam distintas instituições e redes setoriais.

Na área da saúde, destacamos a Rede de Atenção Psicossocial, voltada para pessoas com sofrimento ou transtorno mental e com necessidades decorrentes do uso de crack, álcool e outras drogas, no âmbito do Sistema Único de Saúde SUS (portaria n. 3.088, de 23 dez. 2011). Ainda em fase de implementação, são preconizados os seguintes eixos: atenção básica em saúde; atenção psicossocial 
especializada; atenção de urgência e emergência; atenção residencial de caráter transitório; atenção hospitalar; estratégias de desinstitucionalização e reabilitação psicossocial.

Destacamos ao longo do livro os serviços relacionados à área da saúde mais encontrados ou demandados nos sete estudos de caso efetuados: Centros de Atenção Psicossocial (Caps) - principalmente aqueles voltados para infância e juventude e álcool e drogas ${ }^{1}$-, equipes de Consultório na Rua ${ }^{2}$ e Serviços de Atenção em Regime Residencial, ${ }^{3}$ entre os quais se inserem as Comunidades Terapêuticas.

Duailibi, Ribeiro e Laranjeira (2008) indicam o aumento da demanda que o crack tem trazido para os serviços de saúde. Para esses autores, os serviços ambulatoriais especializados detectaram o crescimento do consumo de crack a partir do início dos anos 1990. Em meados da mesma década, os usuários de cocaína e crack, que compunham inicialmente menos de um quinto da demanda ambulatorial para drogas ilícitas, passaram a ocupar entre $50-80 \%$ das vagas desses serviços do país. Assim como nas unidades ambulatoriais, as internações relacionadas ao consumo de cocaína também começaram a aumentar a partir dos anos 1990. De acordo com o Cebrid, nos primeiros anos da década de 1990 , houve uma elevação de $77 \%$ no número de pacientes internados por esse motivo. A dependência de crack é a causa prevalente de internação por uso de cocaína (Duailibi, Ribeiro \& Laranjeira, 2008).

$\mathrm{Na}$ assistência social, os estudos de caso priorizaram como fonte de informação a Secretaria Municipal de Assistência Social (SMAS), responsável pela organização da rede de atendimento, execução de serviços, programas e projetos

Caps ad: atende adultos ou crianças e adolescentes que fazem uso de crack, álcool e outras drogas. É um serviço de saúde mental aberto e de caráter comunitário. Especificamente o Caps ad III atende pessoas com necessidades de cuidados clínicos contínuos, com funcionamento 24 horas, incluindo feriados e finais de semana. Caps i: atende crianças e adolescentes com transtornos mentais graves e persistentes e aqueles que fazem uso de crack, álcool e outras drogas. É um serviço aberto e de caráter comunitário.

2 Constituídos a partir da Política Nacional de Atenção Básica do Ministério da Saúde (portaria 2.488, 21 out. 2011), por profissionais que atuam de forma itinerante, ofertando ações e cuidados de saúde para a população em situação de rua, considerando suas diferentes necessidades de saúde. Voltado para pessoas em situação de rua em geral, com transtornos mentais, e usuários de substâncias psicoativas. Atuam em parceria com unidades básicas de saúde, Caps, prontossocorros, entre outros tipos de serviços de saúde.

3 O Serviço de Atenção em Regime Residencial destina-se a oferecer cuidados contínuos de saúde de caráter residencial transitório, por até nove meses, para adultos com necessidades clínicas estáveis decorrentes do uso de crack, álcool e outras drogas. Funciona de forma articulada com a atenção básica - que apoia e reforça o cuidado clínico geral dos seus usuários - e com o Caps - responsável pela indicação do acolhimento, acompanhamento especializado durante o período, planejamento da saída e seguimento do cuidado. 
das prefeituras, coordenação e implementação de ações de monitoramento e controle, acompanhamento e avaliação das ações e da prestação de contas das redes pública e privada de assistência social dos municípios. Os Serviços de Acolhimento Institucional (SAls) ${ }^{4}$ são de atribuição especial da SMAS e acolhem crianças e adolescentes com uso pessoal ou familiar de crack em todo o país. Assis e Farias (2013), em levantamento nacional, informam que 45,2\% dos SAls recebem crianças e adolescentes que usam drogas e percentual maior ainda (78\%) acolhe população com vivência de rua. Tal perfil aponta para a relevância das drogas e da vida na rua para o acolhimento institucional no país.

Os Centros de Referência Especializados de Assistência Social (Creas) são outro tipo de serviço relevante para o usuário de crack, destinando-se a famílias e indivíduos que se encontram em situação de risco pessoal e social, por problemas, como abandono, maus-tratos físicos e/ou psíquicos, abuso sexual, uso de substâncias psicoativas, cumprimento de medidas socioeducativas, situação de rua e de trabalho infantil. Essas pessoas requerem acompanhamento individual, maior flexibilidade nas soluções protetivas, comportando encaminhamentos monitorados, apoios e processos que assegurem qualidade na atenção e efetividade na reinserção almejada.

Outras três instituições participantes do Sistema de Garantia de Direitos foram entrevistadas para este estudo, com ações privilegiadas para a proteção de crianças e adolescentes: Vara da Infância e Juventude, Ministério Público e Conselhos Tutelares.

Para o cumprimento dos três objetivos mencionados anteriormente, este livro se organiza da seguinte forma: inicialmente reflete-se sobre a complexidade do problema e os mecanismos pelos quais o crack afeta a população infantojuvenil diretamente ou em decorrência do consumo pelos pais ou familiares. No capítulo 2, apresenta-se a inovadora metodologia da segunda pesquisa, que permitiu obter as estimativas de consumo de crack por crianças e adolescentes por meio de coleta de informações domiciliares em todas as capitais brasileiras e no Distrito Federal. A contagem de usuários em cenas de uso de drogas também foi realizada e é mencionada, de forma complementar. Os dados nacionais mostram a preocupante dimensão do uso da substância na infância e adolescência.

${ }^{4}$ Caracterizam-se pela oferta de atendimento diuturno para crianças e adolescentes que estejam sem familiar/responsável e sob medida protetiva (art. 101, ECA). A legislação vigente prioriza o direito à convivência familiar e comunitária e a excepcionalidade e provisoriedade do afastamento do convívio familiar (Conanda, 2009). 
Seguem-se capítulos com os estudos de casos das cidades de Manaus, Ponta Porã, Salvador, Rio de Janeiro, São Paulo, Curitiba e Porto Alegre (capítulos 3 a 9), oriundos da primeira pesquisa mencionada. Nestes capítulos abordam-se temas como: a árdua tarefa de identificar o número de crianças e adolescentes em SAls que usam drogas ou que estão na instituição em decorrência do consumo de seus pais; as difíceis e marcantes histórias vivenciadas em fase tão precoce da vida e as consequências para a saúde física e mental e para a integração social de crianças, adolescentes e suas famílias; o mapeamento e funcionamento da rede socioassistencial responsável pelo cuidado aos usuários e sua família e a avaliação que os usuários e profissionais fazem desses serviços.

Finaliza-se, no capítulo 10, com uma análise das principais questões abordadas ao longo do livro, destacando-se algumas reflexões sobre a relevância da contagem de usuários de crack, as consequências do uso em cada faixa etária, as diferenças regionais existentes, as fragilidades familiares e da rede de atenção. No Anexo encontram-se informações sobre a metodologia utilizada para os estudos de caso mostrados aqui, priorizando-se: o plano amostral executado e as limitações decorrentes do precário nível das informações institucionais sobre usuários de crack; os instrumentos utilizados na pesquisa; as fases de coleta, processamento e análise dos dados e os procedimentos éticos adotados.

Para a elaboração deste livro, contamos com o apoio do Ministério da Saúde, por meio do Departamento de Ciência e Tecnologia (Decit) e do Conselho Nacional de Pesquisa (CNPq). Foi preciosa a participação de profissionais que dividiram conosco a realização das pesquisas: a esses profissionais, especialmente em universidades e secretarias municipais e estaduais, temos muito a agradecer. E finalmente, nosso inestimável muito obrigado às crianças, adolescentes, familiares e aos profissionais atuantes nos serviços da rede: suas tristes histórias e extremos desafios enfrentados cotidianamente fortalecem a convicção da extrema relevância da investigação e divulgação sobre o crack e suas repercussões nas famílias brasileiras. 


\section{REFERÊNCIAS}

AMStAlden, A. L. F.; HOFFMANN, M. C. C. \& MONTEIRO, T. P. M. A política de saúde mental infantojuvenil: seus percursos e desafios. In: LAURIDSEN-RIBEIRO, E. \& TANAKA, O. Y. (Orgs.). Atenção em Saúde Mental para Crianças e Adolescentes no SUS. São Paulo: Hucitec, 2010.

ASSIS, S. G. \& FARIAS, L. O. P. (Orgs.). Levantamento Nacional das Crianças e Adolescentes em Acolhimento Institucional e Familiar. São Paulo: Hucitec, 2013.

BASTOS, F. I. \& BERTONI, N. (Orgs.). Pesquisa Nacional Sobre o Uso de Crack: quem são os usuários de crack e/ou similares do Brasil? Quantos são nas capitais brasileiras? Rio de Janeiro: Icict/Fiocruz, 2014. Disponível em: <www.obid.senad.gov.br/portais/ OBID/biblioteca/documentos/Publicacoes/329797.pdf>. Acesso em: ago. 2014.

CONSELHO NACIONAL DOS DIREITOS DA CRIANÇA E DO ADOLESCENTE (CONANDA). Resolução n. 113, de 19 abr. 2006. Dispõe sobre os parâmetros para a institucionalização e fortalecimento do Sistema de Garantia dos Direitos da Criança e do Adolescente. Brasília, 2006. Disponível em: <www.direitosdacrianca.gov.br/conanda/ resolucoes/113-resolucao-113-de-19-de-abril-de-2006/view>. Acesso em: ago. 2014.

CONSELHO NACIONAL DOS DIREITOS DA CRIANÇA E DO ADOLESCENTE (CONANDA). Conselho Nacional de Assistência Social. Orientações Técnicas: serviços de acolhimento para criança e adolescentes. Brasília, 2009.

DUAILIBI, L. B.; RIBEIRO, M. \& LARANJEIRA, R. Perfil dos usuários de cocaína e crack no Brasil. Cadernos de Saúde Pública, 24(4): S545-S557, 2008.

GALDURÓZ, J. C. et al. V Levantamento Nacional sobre o Consumo de Drogas Psicotrópicas entre Estudantes do Ensino Fundamental e Médio da Rede Pública de Ensino nas 27 Capitais Brasileiras - 2004. São Paulo: Secretaria Nacional Antidrogas, Centro Brasileiro de Informações sobre Drogas Psicotrópicas, 2005.

MURAKI, S. M. P. Prevalência do Consumo de Drogas Psicotrópicas entre Adolescentes do Ensino Fundamental e Médio do Município de Dourados - MS, 2009. Dissertação de Mestrado, Brasília: Universidade de Brasília.

RIBEIRO, M. et al. Perfil do usuário e história natural do consumo. In: RIBEIRO, M. \& LARANJEIRA, R. (Orgs.). O Tratamento do Usuário de Crack. Porto Alegre: Artmed, 2012.

SCHENKER, M. \& MINAYO, M.C.S. Fatores de risco e de proteção para o uso de drogas na adolescência. Ciência \& Saúde Coletiva, 10: 707-717, 2005.

SCHENKER, M.; MAURICIO, A. \& CAVALCANTE, F. G. Violência, família e sociedade. In: ASSIS, S. G. et al. (Orgs.). Impactos da Violência: Moçambique e Brasil. Rio de Janeiro: Fiocruz/Ensp/Claves, 2011. 


\section{1 \\ Alicerces para o Estudo do Crack na Infância e Adolescência}

Simone Gonçalves de Assis

Fernanda Mendes Lages Ribeiro

crack é derivado da cocaína, substância extraída da folha de coca. Há relatos da prática de mascá-la desde 5.000 a. C. A cocaína, sintetizada em laboratório a partir de 1859, pode chegar até o consumidor como: sal (pó), aspirado ou dissolvido em água para uso endovenoso; base, com aspecto de pedra no caso do crack (volatilizada quando aquecida e fumada em "cachimbos") ou merla, mel ou melado (também fumada); e pasta de coca, fumada em cigarros e tratada com álcali, solvente orgânico e ácido sulfúrico (Seibel, 2010).

O nome crack originou-se do som que emite ao ser aquecido. $\mathrm{O}$ uso provoca efeitos imediatos agradáveis que duram de 5 a 7 minutos, quando o humor rapidamente muda e o usuário é compelido a repetir o processo de forma a recuperar a euforia do clímax. Pouco se conhece sobre os efeitos do crack entre crianças, havendo mais informação do uso por adolescentes e adultos.

O consumo do crack tem-se disseminado em várias partes do país pela facilidade de obtenção e baixo custo. Tendo em vista a proibição do porte, compra e venda de drogas ilícitas, seu comércio expõe os usuários a uma série de riscos. No caso específico de crianças e adolescentes e das situações de vulnerabilidade que os envolvem, por vezes são utilizadas medidas extremas de proteção que os afastam provisória ou definitivamente de suas famílias, como é o caso do encaminhamento para Serviços de Acolhimento Institucional (SAIs).

O uso de drogas, presente historicamente em variadas formações sociais, vem adquirindo diferentes usos e significados - recreativos, rituais, medicinais, 
entre outros. Estratégias de repressão ao consumo de drogas legais ou ilegais surgem também em diversos momentos históricos, como nos mostra o caso emblemático da Lei Seca nos EUA, em 1919, que proibiu o uso de álcool.

No Brasil, o começo do século XIX marca a criação de legislações reguladoras da produção, comércio e uso de substâncias entorpecentes (Carvalho, 2006). Fiore (2005) registra o surgimento, no Império, em 1830, de uma primeira forma de controle legal sobre drogas no Brasil, no caso a maconha. Essa normativa dizia respeito ao desejo de controle da população negra e miscigenada que fazia uso dessa substância, ligada à "bandidagem", e das práticas específicas desse grupo, então considerado perigoso. Novas referências aparecem no Código Penal da República, em 1890, que regulava a saúde pública, condenando à multa a venda de substâncias "venenosas" sem autorização.

Até a década de 1910 o consumo de drogas era tido como hábito de pouca importância, de grupos de jovens oligarcas. Porém, mais tarde, é veementemente repreendido por ser considerado como prática degradante, uma vez que tais substâncias passaram a ser mais difundidas, espalhando-se por segmentos marginais. O surgimento da questão social das drogas esteve, historicamente, ligado a dois eixos principais: criminalização e medicalização. Motivo de atenção das autoridades, os primeiros artigos médicos sobre o tema aparecem em 1915 e em 1918, "discorrendo sobre o 'maconhismo' e o vício na diamba" (Fiore, 2005: 266). O Brasil aderira à Convenção de Haia, que regulamentou a produção e a comercialização da morfina, heroína e cocaína (Convenção do Ópio, de 1912), culminando com a promulgação de um decreto, em 1914, do presidente Hermes da Fonseca (Ribeiro, 2007).

Este breve relato histórico aponta para dois fatos que nos ajudarão a entender a realidade refletida nas pesquisas apresentadas neste livro: a eleição de uma substância como ilegal depende de uma série de fatores históricos, econômicos, políticos, sociais e também de saúde; a principal forma de enfrentar tradicionalmente a questão das drogas é de cunho repressivo, encarcerando aqueles enquadrados no tráfico e tratando os usuários de drogas, mesmo que compulsoriamente - como nas experiências de internação compulsória e de justiça terapêutica.

Como tema de saúde pública, o uso de drogas precisa ser cuidado em equipamentos públicos territorializados, de acordo com as diretrizes de redução de danos, do Ministério da Saúde (portaria n. 1.028/2005). Outra política 
pública relevante refere-se à saúde mental, apoiada na lei n. 10.216, de 2002, para consolidar um modelo de atenção aberto e de base comunitária, que conta com uma rede variada: Centros de Atenção Psicossocial (Caps), ${ }^{1}$ Serviços Residenciais Terapêuticos, Centros de Convivência e Cultura, leitos de atenção integral em hospitais gerais e nos Caps III e programa De Volta para Casa - que oferece bolsas para egressos de longas internações em hospitais psiquiátricos.

Em 2005 foi promulgada a Política Nacional sobre Drogas, que dá continuidade ao trabalho de prevenção, tratamento, recuperação e reinserção social e de redução dos danos sociais (Conselho Nacional Antidrogas, 2005).

Entre os marcos nacionais a respeito das políticas sobre saúde, saúde mental e cuidado às drogas, uma série de legislações balizam as ações brasileiras na atenção a pessoas que fazem uso de álcool e outras drogas. Entre elas estão: o Sistema Único de Saúde (SUS); o Estatuto da Criança e do Adolescente (ECA); a lei n. 12.010/2009, que trata da garantia do direito à convivência familiar a todas as crianças e adolescentes; a lei n. 10.216/2001, que dispõe sobre a proteção e os direitos das pessoas portadoras de transtornos mentais e redireciona o modelo assistencial em saúde mental; a Política Nacional para Pessoas em Situação de Rua; a Política Nacional de Saúde Mental; o Sistema Único de Assistência Social (Suas); o decreto n. 7.179/2010, que institui o Plano Integrado de Enfrentamento ao Crack e Outras Drogas, cria o seu Comitê Gestor e dá outras providências; e o Plano Crack É Possível Vencer, lançado pelo Ministério da Saúde em dezembro de 2011. Outras legislações relevantes² respaldam a rede de atenção psicossocial (portaria n. 3.088/2011).

Como diretriz nacional, a partir do Plano Crack É Possível Vencer, ${ }^{3}$ ocorre uma inovação do Plano Integrado de Enfrentamento ao Crack e outras Drogas, com eixos de atuação no cuidado, autoridade e prevenção, investindo na ampliação de leitos no SUS, no aumento do número de Caps ad e de vagas em Comunidades Terapêuticas, na criação de Consultórios na Rua e no reforço dos Caps.

1 O Centro de Atenção Psicossocial é um serviço de saúde mental aberto e de caráter comunitário. Especificamente o Caps ad III atende pessoas com necessidades de cuidados clínicos contínuos, com funcionamento 24 horas, incluindo feriados e finais de semana. O Caps ad atende adultos ou crianças e adolescentes que fazem uso de crack, álcool e outras drogas. O Caps i é voltado para crianças e adolescentes com transtornos mentais graves e persistentes e para aqueles que fazem uso de crack, álcool e outras drogas.

2 Várias legislações esclarecem sobre as ações dos diversos componentes da rede, bem como estabelecem patamares financeiros. Algumas delas são: decreto $n$. 7.508/11, que garante a atenção psicossocial na região de saúde; e as portarias n. 3.089/11, n. 3.099/11, n. 130/12, n. 121/12, n. 122/12, n. 123/12, n. 131/12, n. 132/12 e n. 148/12.

3 Disponível em: <www.obid.senad.gov.br/portais/OBID/biblioteca/documentos/Publicacoes/ cartilhas/329302.pdf>. Acesso em: 24 abr. 2014. 
Em especial a partir desse plano passa a haver investimento público em Comunidades Terapêuticas, instituições privadas - a maioria de cunho religioso que se propõem a atuar na atenção a usuários de drogas, em regime fechado. Tais instituições, segundo o Plano Integrado de Enfrentamento ao Crack e Outras Drogas ${ }^{4}$ devem cumprir os critérios estabelecidos pela Agência Nacional de Vigilância Sanitária (Anvisa) e pelo Ministério da Saúde, assegurando integração à rede de atenção psicossocial e um ambiente que respeite os direitos dos pacientes e de seus familiares. É necessário também estar vinculadas ao Cadastro Nacional de Estabelecimentos de Saúde (CNES).

Entretanto, uma ação de fiscalização em Comunidades Terapêuticas no país pelo Conselho Federal de Psicologia constatou diversas violações de direitos ocorridas nesses espaços (CFP, 2011). O investimento público nas Comunidades Terapêuticas (de orientação religiosa e sob a ótica da abstinência) traz uma latejante discussão para a lógica de cuidado proposta no país, agregando diretrizes com orientações divergentes:

1) Redução de danos (RD), política oficial do Ministério da Saúde guiada pela perspectiva dos direitos humanos, orientadora dos Caps e demais serviços que prestam cuidados aos usuários de drogas. Busca, com base em um conjunto de estratégias, reduzir os danos associados ao uso/abuso de drogas, considerando a liberdade de escolha do sujeito e a atenção à sua saúde. A abstinência pode fazer parte de um projeto terapêutico em que o individuo é o protagonista, porém não é seu objetivo. As atividades de atenção aos usuários/dependentes visam à melhoria de qualidade de vida e à inclusão de ações direcionadas à sua integração ou reintegração em redes sociais, observando os princípios e diretrizes do SUS e da Política Nacional de Assistência Social.

2) Proibicionismo, geralmente ancorado no método Minessota - Doze passos -, tem a abstinência como princípio. Orienta Comunidades Terapêuticas e outros programas não governamentais, como Alcoólicos e Narcóticos Anônimos.

A coexistência dessas duas tendências no enfrentamento ao consumo de crack no país retrata o grande desafio histórico do cuidado a pessoas que fazem uso de drogas e as orientações diversas em relação aos objetivos do tratamento. O debate sobre as formas de enfrentar o uso do crack ainda está francamente em aberto: "seu curto período de existência ainda não permitiu aos pesquisadores a elaboração de consensos abrangentes sobre o que constitui um programa de

4 Disponível em: <www2.planalto.gov.br/acompanhe-o-planalto/caderno-destaques/marco-2012/ plano-integrado-de-enfrentamento-ao-crack-e-outras-drogas. Acesso em: 28 ago. 2015. 
tratamento eficaz" (Ribeiro \& Laranjeira, 2012: 184). Convivemos hoje, na área da saúde, com a necessidade de conhecer melhor os modelos de cuidado possíveis, discutindo seus limites e potencialidades no cenário brasileiro, com vistas a influenciar de forma mais firme as orientações e gastos públicos governamentais a serem utilizados.

De forma sintética, segundo alguns pesquisadores, algumas bases para a atuação diante da dependência ao crack para adultos incluem (Ribeiro \& Laranjeira, 2012; Laranjeira, 2012; National Treatment Agency for Substance Misuse, 2006):

1) tratamentos médico e psicossocial, organizados a partir de um plano constantemente atualizado com base nas necessidades dos pacientes. A avaliação médica leva em consideração: as alterações decorrentes do consumo ou da síndrome de abstinência de cocaína/crack, sua gravidade e a possibilidade de resposta a alguma intervenção medicamentosa; a presença de comorbidades psiquiátricas e a necessidade de observação dos sintomas após abstinência. Entre as intervenções psicossociais, destacam-se: terapia cognitivo-comportamental, treinamento de habilidades sociais, prevenção de recaídas, abordagens de reforço comunitário, abordagens voltadas para a família, organização do cotidiano e das atividades ocupacionais e abordagens vocacionais;

2) um profissional de referência, responsável pela oferta e integração das atividades oferecidas, pelo encaminhamento aos serviços necessários no andamento do atendimento, pelo contato com os demais profissionais da rede e pela inclusão social do paciente.

A avaliação feita pelo profissional da saúde com o usuário de crack precisa abranger os seguintes aspectos: a) levantamento de riscos relacionados ao uso de drogas (overdose, ambientes de consumo violentos), riscos de autoagressão, autonegligenciamento (por exemplo, sexo em troca de crack) e de causar danos a terceiros (por exemplo, violência doméstica, agressão a crianças); b) avaliação clínica do consumo de crack e dos critérios de gravidade; c) verificação da motivação para a mudança de expectativas em relação ao tratamento; d) investigação dos fatores de proteção e de risco, com o objetivo de elaborar a melhor rede de apoio possível; e) avaliação psiquiátrica e da necessidade de medicação específica para a dependência química; f) avaliação clínica geral, visando a complicações físicas decorrentes do consumo e outras preexistentes agravadas pelo uso da substância; g) avaliação neuropsicológica, em busca de alterações cognitivas (Ribeiro \& Laranjeira, 2012). 
Pode-se perceber que tais estratégias não diferem do tratamento proposto para dependentes de outras drogas. Tais premissas servem de balizamento para a reflexão sobre as frágeis formas de atuação apresentadas nos estudos de caso relatados nos capítulos 3 a 9 deste livro, que indicam a precariedade do cuidado oferecido às crianças e adolescentes nas várias cidades estudadas, bem como às suas famílias.

\section{DADOS SOBRE CRACK, INFÂNCIA E ADOLESCÊNCIA}

Pesquisas a respeito do uso de drogas por crianças e adolescentes indicam, em primeiro lugar, a elevada prevalência das drogas lícitas - álcool e tabaco - seguidas por ilícitas, como a maconha. Alguns estudos demonstram a experimentação de drogas por crianças com baixa idade, o que se relacionaria ao uso, abuso e dependência ao longo da vida, assim como ao uso na família, ocasionando consequências diretas para suas vidas. Pesquisas específicas sobre uso de crack são relativamente recentes no país.

Segundo Marques e Cruz (2000), até a década de 1980 os estudos epidemiológicos não encontravam taxas significativas de consumo de drogas entre jovens estudantes. Desde então, percebe-se uma tendência de aumento. Entre as drogas ilícitas, em meados dos anos 1990, os usuários de cocaína e crack passaram a ser o grupo que mais procurava tratamento nos ambulatórios e serviços de internação para dependência de substâncias psicoativas (Duailibi, Ribeiro \& Laranjeira, 2008). O Centro Brasileiro de Informações sobre Drogas (Cebrid) mostrou que existia uma tendência à elevação do consumo de inalantes, maconha, cocaína e crack entre estudantes em determinadas capitais (Galduróz, Noto \& Carlini, 1997). Contudo, o álcool e o tabaco ocupavam o primeiro lugar entre as drogas mais utilizadas, não só no mês anterior à pesquisa mas também ao longo da vida, e apresentavam ainda mais problemas associados, como, por exemplo, os acidentes no trânsito e a violência.

O crack se dissemina com facilidade na população dos socialmente excluídos, com destaque para os adolescentes em situação de rua e os usuários de drogas injetáveis. Inicialmente atingia mais populações do Sul e Sudeste, mas constatou-se tendência ao aumento progressivo em outras regiões do país como o Nordeste, indicando a dispersão da disponibilidade de derivados da coca no país. Pouco se sabe acerca do uso de crack pelas classes mais abastadas, como, por exemplo, a prevalência do consumo, os locais de compra e tratamento na 
esfera privada da saúde. Percebe-se que a distribuição e o consumo de crack estão intimamente relacionados a questões sociais.

Outro impacto do crack no grupo infantojuvenil é o aumento do risco de infecções pelo HIV e outras DST, tendo em vista que o consumo e dependência da substância facilita o número elevado de parceiros e o sexo sem proteção, em consequência da troca de sexo por crack ou por dinheiro para comprar a substância. O uso do crack é considerado como porta de entrada para riscos à saúde como prostituição e gravidez precoce (Duailibi, Ribeiro \& Laranjeira, 2008). O estudo de Melotto (2009) mostra o surgimento de doenças como hepatite pelo compartilhamento de cachimbos com o uso do crack. Debilitação física, emagrecimento, poucas horas de sono e descuido com a higiene pessoal são outras características encontradas nos usuários desta substância independentemente da idade e do estrato social.

A idade de iniciação ao uso de drogas é cada vez mais baixa. Estudos brasileiros mostram que o consumo por adolescentes do sexo feminino e masculino começa por volta dos 12 anos para o álcool e o tabaco; com relação à maconha, à cocaína, ao crack, aos solventes orgânicos, aos ansiolíticos e aos tranquilizantes, o início ocorre em torno dos 13-14 anos (Galduróz, Noto \& Carlini, 1997; Noto et al., 2003; Galduróz et al., 2005). Os usuários de crack costumam ser poliusuários ou usuários com antecedentes de consumo de outras substâncias que adicionaram o crack a seu padrão de abuso e o adotaram como droga de escolha (Narvaez, 2010).

A presença de comorbidades com um segundo diagnóstico psiquiátrico é comum entre os usuários de crack. A depressão e os transtornos ansiosos são as mais observadas em estudos brasileiros (Duailibi, Ribeiro \& Laranjeira, 2008).

São escassos os estudos acerca da prevalência do uso do crack entre a população geral e, especificamente, entre crianças e adolescentes. Tampouco dispõe-se de investigações sólidas sobre os impactos deste uso, abuso e dependência para a vida da população infantojuvenil e para os serviços de saúde e assistenciais que os atendem. ${ }^{5}$

Algumas investigações realizadas com a população infantojuvenil de diferentes municípios auxiliam a compreender um pouco mais o tema. Silva e colaboradores (2006) pesquisaram as taxas de prevalência de consumo de

No capítulo 2 apresentam-se dados da Pesquisa Nacional do Crack, realizada em 2012, primeiro estudo de âmbito nacional que apresenta estimativas de consumo para crianças e adolescentes das capitais brasileiras e Distrito Federal. 
substâncias psicoativas entre 1.041 escolares do ensino médio no município de São José do Rio Preto/SP e sua distribuição por sexo e período escolar. As prevalências do consumo ao longo da vida foram: álcool - 77\%, tabaco - 28,7\%, solventes - 18,1\%, maconha - 12,1\%, anfetamínicos - 3,7\%, cocaína - 3,3\%, alucinógenos - 3,1\%, e crack - 1,4\%. O sexo masculino consumiu mais álcool, maconha, cocaína e crack que o feminino. Os autores assinalam que a fase de 14 a 16 anos de idade é aquela em que se encontra maior uso de drogas ilícitas e tabaco.

Santos, Pietro e Xavier Filho (2008), investigando o uso de drogas por adolescentes de 13 a 24 anos, em escolas públicas e privadas de Aracaju/SE, aferiram que $92 \%$ faziam uso frequente de drogas, entre elas as lícitas - álcool $(33,6 \%)$ e tabaco (22\%) - e as ilícitas - maconha (19\%), cocaína (1\%), crack $(6 \%)$ e medicamentos controlados (3\%). Os pesquisadores levantaram ainda as fontes de dinheiro utilizadas pelos jovens para acesso às drogas: $42,6 \%$ praticavam atos ilegais como roubos e furtos, $21,8 \%$ obtinham dos pais/ parentes, $12,8 \%$ vendiam drogas e $12,2 \%$ se prostituíam.

Muraki (2009) investigou a prevalência do uso de drogas entre 1.021 adolescentes escolares do ensino fundamental e médio, de 12 a 18 anos, em Dourados/MS, e encontrou os seguintes resultados: álcool - 75,2\%; energéticos - 30\%; tabaco - 26,2\%; solventes - 21,2\%; anfetaminas - 9,1\%; tranquilizantes $-7,3 \%$; maconha $-6,7 \%$; crack $-1,9 \%$.

Os levantamentos epidemiológicos com estudantes são importantes termômetros do consumo de substâncias psicoativas. Usuários de drogas nesse grupo encontram-se com maior probabilidade em contextos marcados pela defasagem escolar, falta às aulas, baixo nível socioeconômico, relacionamento ruim com os pais e/ou pais permissíveis ao uso, pais separados, presença de maus-tratos, ausência de prática religiosa (Duailibi, Ribeiro \& Laranjeira, 2008).

A avaliação do consumo de drogas entre grupos em situação de maior vulnerabilidade mostra patamares bem superiores aos verificados em escolas. Pesquisa com 48 adolescentes entre 14 e 18 anos institucionalizados em uma unidade de medida socioeducativa de uma cidade de São Paulo (Priuli, 2005) constatou que grande parte fazia uso de tabaco $(85,4 \%)$, maconha $(83,3 \%)$, álcool $(66,7 \%)$, crack $(66,7 \%)$ e, em menor proporção, cocaína $(39,6 \%)$, tíner $(39,6 \%)$ e cola de sapateiro (29,2\%). Apenas um jovem declarou não utilizar nenhuma substância. Segundo a autora, a maioria afirmou ter experimentado drogas durante a infância. Entre os que mencionaram ter feito uso de alguma droga, apenas 10,4\% relataram já ter realizado algum tipo de tratamento. 
Levantando dados acerca das famílias dos adolescentes, a autora constatou que $58,3 \%$ não tinham consumidores de drogas ilícitas e que $75 \%$ tinham usuários de álcool.

Neiva-Silva (2008) estudou longitudinal e transversalmente o uso de drogas entre crianças e adolescentes em situação de rua em Porto Alegre/RS, buscando identificar padrões de uso e fatores de risco e de proteção. $O$ autor encontrou que "não morar com a família", "passar mais de oito horas na rua" e "estar há mais de cinco anos na rua" relacionaram-se ao uso de drogas ilícitas no último mês e ao início do uso de crack no último ano. A maior parte das crianças/adolescentes em situação de rua eram meninos, morando com a família e frequentando a rua no período de até dois anos. Quanto ao uso de drogas, $83,8 \%$ das crianças/adolescentes investigadas já tinham utilizado alguma durante a vida, sendo as mais usadas as lícitas (álcool 78,7\% e tabaco $58,8 \%)$, seguidas por maconha $(36,6 \%)$ e solventes $(33,8 \%)$. Em relação ao crack, $28,7 \%$ declararam já o ter experimentado.

Mombelli, Marcon e Costa (2010), em estudo em uma unidade de internação de um hospital público do Paraná, identificaram algumas variáveis sociodemográficas associadas ao uso de drogas. A maioria das internações era de adolescentes do sexo masculino (79\%), de 15,5 anos de idade em média, e as drogas mais consumidas eram crack $(87,6 \%)$ e maconha $(85,2 \%)$. O uso combinado de ambas as substâncias foi verificado em $79 \%$ dos casos, em sua maioria por meninos. Um total de $83,2 \%$ já havia sido encaminhado pelo Caps ad e 56,8\% apresentavam histórico de tratamento com internação em hospital, em instituições não governamentais e assistência ambulatorial. Os autores apontaram o escalonamento do uso, com a maconha sendo a primeira droga ilícita de uso. Quanto ao uso de drogas na família, 55\% tinham algum membro que usava alguma substância. Em relação aos amigos, 87,6\% consumiam alguma droga. Todos os adolescentes que faziam uso combinado de crack e maconha já haviam praticado atos ilícitos, entre eles, roubos e furtos (46\%) e homicídios (7,1\%), e 56,8\% tinham sido presos.

Machado e colaboradores (2010), em estudo realizado em instituição especializada em uso abusivo de drogas em Fortaleza/CE, pesquisaram as características sexuais de 69 adolescentes (13 a 17 anos) usuários de drogas, as drogas consumidas e a intensidade do consumo. Os autores detectaram baixos níveis de escolaridade e renda e elevado abandono escolar. As drogas mais consumidas foram maconha e crack. Atividade sexual sob efeito de 
drogas foi relatada por $46,9 \%$ dos adolescentes. Percebeu-se a interferência do uso de drogas na prática do sexo inseguro, deixando os adolescentes vulneráveis às DST/HIV/Aids e à gravidez não planejada. Os autores recomendam que os serviços que lidam com prevenção e tratamento de drogas fomentem discussões sobre os riscos à saúde sexual desse público.

Nonticuri (2010), em pesquisa a respeito de vivências de adolescentes relacionadas ao crack e sua prevenção, contextualiza que seu consumo se inicia com o do uso de outras substâncias, como o álcool, o tabaco e a maconha, assim como se dá em concomitância a outras drogas. A autora identificou a evasão escolar associada ao uso; os impactos sobre a família, o emprego de violência por seu membro usuário e a presença de sentimentos ambivalentes, como vontade de ajudar, raiva, medo e impotência; a influência dos grupos de amigos; o envolvimento com situações de risco, como prostituição, conflitos na família e na comunidade e furtos e roubos. A respeito da prevenção, as principais formas citadas foram: o diálogo na família, com a circulação de informações; a evitação da primeira experiência; a realização de atividades educativas e/ou de esporte extraescolares e na própria escola. Em relação ao tratamento, os usuários entrevistados por Nonticuri destacaram a importância da internação e suas dificuldades de acesso.

Bessa (2012) é um dos poucos autores que fala sobre tratamento para adolescentes usuários de crack, identificando três regimes: 1) em ambulatórios/ hospitais-dia/Caps 2) em hospitais em regime de internação, seguido de tratamento ambulatorial; 3) em Comunidades Terapêuticas. Como condições para internação, este autor considera: risco de comportamento agressivo direcionado a si ou a terceiros ou comportamento suicida; risco de desenvolver síndrome de abstinência ou outras complicações clínicas; necessidade de tratamento de outra comorbidade psiquiátrica; e falha da tentativa de tratamento ambulatorial. Deve-se levar em conta também a gravidade da dependência e da condição social do paciente.

O autor ressalta ainda que o tratamento dos adolescentes usuários de drogas é muito descuidado na sociedade brasileira. Para Bessa, há carência estrutural de instituições e profissionais bem qualificados para o atendimento. Desse modo, os adolescentes se confrontam com a quase total ausência de locais adequados de tratamento ou então com os equívocos conceituais, como defesa do uso de maconha como substituto paliativo ao consumo de crack. $\mathrm{O}$ autor considera que os "Consultórios de Rua", 
na verdade, uma proposta que, atrás do discurso bem-intencionado do respeito à individualidade e à livre decisão, esconde a perpetuação da miséria, da violência e da condenação à vida marginal e sub-humana, uma vez que reforça as condições para que crianças e adolescentes permaneçam vivendo nas ruas. (Bessa, 2012: 629)

Igualmente inadequados, podem-se citar o recolhimento e a internação compulsórios sem a devida fundamentação e plano terapêutico, medidas que impossibilitam o acesso a ações que garantam condições mínimas de continuidade do tratamento individual e familiar, carecendo de apoio dos programas de ensino em período integral e profissionalizante e de livre acesso aos bens culturais, de esporte e de lazer. Isso significa que, em geral, os jovens completam o tratamento sem vislumbrar possibilidade real de vida promissora que possa ser contraposta à sedução do consumo do crack.

Duailibi, Ribeiro e Laranjeira (2008) apontam dificuldades relevantes encontradas pelo usuário de crack na busca e permanência em tratamento: o não reconhecimento do consumo como um problema; o status de utilização ilegal da droga; a proximidade com a criminalidade, muitas vezes associada ao uso de drogas; a estigmatização e os preconceitos decorrentes de seu uso; e a dificuldade de acesso ou a não aceitação do atendimento nos tipos de serviços existentes.

\section{AS FAMÍLIAS DAS CRIANÇAS E AdOLESCENTES USUÁRIOS DE CRACK}

Uma forma bastante grave do consumo de crack é aquela que atinge a criança ainda no ventre materno, com complicações físicas, emocionais e sociais para a díade mãe-filho (crack-babies). Há mais estudos sobre os efeitos da cocaína (pó) na gravidez do que sobre os do crack. O uso de cocaína associase a alterações do ciclo menstrual e pode acarretar amenorreia, alteração da produção do leite materno e até infertilidade. $\mathrm{O}$ uso na fase da $22^{\mathrm{a}}$ semana da gestação até a primeira semana de vida associa-se a maior risco de complicações, como descolamento prematuro de placenta, sofrimento fetal com presença de mecônio, ruptura precoce da bolsa amniótica, estatura e peso baixos ao nascer, além de anormalidades genitourinárias e da parede abdominal.

Sabe-se que aproximadamente 3 a 5\% da cocaína consumida pela mãe entra no sistema circulatório fetal pelo líquido amniótico. Esta exposição pode resultar em taquicardia e hipertensão no feto. Embora seja incomum, é possível 
ocorrer síndrome de abstinência fetal; tal fato é mais provável quando a mãe utiliza cocaína no período imediato ao parto. Ainda pouco se sabe sobre os efeitos sobre o recém-nascido. Pequenas alterações neurocomportamentais de difícil identificação clínica pelos métodos usuais podem ser observadas. Dificuldades intelectuais e cognitivas são sinalizadas em alguns estudos, ainda com incertezas a respeito (Moreira, Mitsuhiro \& Ribeiro, 2012).

Estudo realizado por Mitsuhiro e colaboradores (2009), por meio de teste de fios de cabelo de mil adolescentes entrevistadas em maternidade, observou que $2 \%$ usaram cocaína no último trimestre de gravidez; estima-se que 0,4\% o fez na forma de crack. Os autores registraram que o uso de cocaína/crack pelas jovens está relacionado à idade inferior a 14 anos.

O diretor do National Institute on Drug Abuse, nos Estados Unidos, perante o Comitê sobre Crimes e Drogas, no Senado norte-americano, em abril de 2009, ${ }^{6}$ afirmou que, entre mulheres daquele país na faixa dos 15 aos 44 anos, 3,9\% - 156 mil mulheres - usaram drogas ilícitas no mês anterior à investigação nacional realizada nos anos de 2004 e 2005. Logo, estima-se que 156 mil crianças estiveram expostas a substâncias psicoativas antes de nascerem. Em outra estatística apontada pelo diretor, referente ao ano 2002, 22\% das mulheres grávidas que buscaram tratamento para uso de drogas utilizaram cocaína ou crack; entre as mulheres que procuraram ajuda mas que não estavam grávidas, $17 \%$ consumiram a substância.

Os bebês de mães usuárias de crack podem ter várias dificuldades quanto à saúde e ao processo de desenvolvimento. Vários fatores confluem com o uso de crack na gravidez: consumo de outras substâncias psicoativas, baixo estrato socioeconômico, má nutrição, precário pré-natal e estilo de vida desorganizado. Todavia, hoje sabe-se que os efeitos intraútero da exposição a cocaína/crack não são tão devastadores como anteriormente se pensava, embora haja maior tendência a nascimentos prematuros no caso de mães usuárias dessa substância. Alguns estudos longitudinais com crianças expostas intraútero ao crack mostram problemas com a atenção e com o controle dos impulsos aos 10 anos de idade, aumentando o risco de problemas comportamentais à medida que crescem as demandas cognitivas (National Treatment Agency for Substance Misuse, 2006).

Como se pode perceber nos autores mencionados, há mais incertezas do que certezas sobre os efeitos do uso do crack na gravidez para o bebê e seu

6 Disponível em: <www.drugabuse.gov/about-nida/legislative-activities/testimony-to-congress/2009/04/ restoring-fairness-to-federal-sentencing-addressing-crack-pow>. Acesso em: 28 ago. 2015. 
desenvolvimento. Muitos dos problemas citados, originam-se e agravam-se pela condição de vulnerabilidade dessas mães (má alimentação, saúde debilitada, uso concomitante de várias drogas, prostituição, frágil inserção social e econômica, envolvimento em furtos e roubos, entre outros fatores), tornando difícil a identificação de anormalidades causadas efetivamente pelo uso do crack (Costa et al., 2012). Especialmente os profissionais da saúde, da assistência social e da justiça precisam refletir sobre os múltiplos fatores envolvidos no uso do crack por mulheres grávidas, para não perpetuar preconceitos e impor medidas radicais sem o devido cuidado e respeito aos direitos e ao potencial de recuperação da díade mãe-filho.

Outro tipo de consequência do uso de crack que atinge crianças e adolescentes é o acolhimento em instituições públicas. Levantamento Nacional de Crianças e Adolescentes em Serviços de Acolhimento no Brasil, realizado em 2009-2010, indica que 6.548 estavam acolhidos devido ao uso de substâncias incluindo crack - pelos pais (17,7\%), que deixaram de ser considerados pela justiça como capazes de cuidar dos filhos (Assis \& Farias, 2013). Considerandose apenas a região Sul, $24,5 \%$ das crianças encontravam-se nessa situação. Em levantamento realizado anteriormente (Ipea/Conanda, 2004), verificou-se que 11,3\% de pais ou responsáveis eram dependentes químicos ou alcoólicos. Dados mais recentes do Conselho Nacional do Ministério Público apontam para o problema da dependência química/alcoolismo dos pais e/ou responsável em 81\% dos acolhidos nos SAls do país em 2013 (CNMP, 2013).

Entre as famílias em que há usuários de crack, mesmo sem que se configure a situação de acolhimento em instituição pública, nota-se a fragilidade dos cuidados com as crianças e adolescentes e dos vínculos familiares, especialmente quando os usuários são os pais/responsáveis (Assis \& Farias, 2013). Tais aspectos estarão presentes nos estudos de caso apresentados nos capítulos seguintes.

\section{Rede de PromoçÃo, Proteção e Defesa dos Direitos da CRIANÇA E do Adolescente E Políticas Públicas}

Redes de promoção, proteção e defesa dos direitos de crianças e adolescentes têm sido uma das mais eficazes estratégias utilizadas em vários países para garantir o direito a uma vida digna a eles. No caso específico do atendimento em rede para os usuários de crack, verificam-se muitos obstáculos no cenário nacional, seja pela precariedade dos serviços existentes, concentrados em 
determinados locais, seja pela falta de expertise sobre o tema nesses serviços ou pela ausência de interlocução entre as instituições.

A construção da rede é uma tarefa constante e dinâmica. O suporte no âmbito da saúde mental às crianças e adolescentes usuários de drogas e suas famílias é um fator essencial de cuidado e proteção, no que diz respeito tanto ao fortalecimento dos indivíduos e do núcleo familiar para interromper o consumo, quanto ao acompanhamento de possíveis problemas psíquicos e emocionais resultantes da exposição às drogas, especialmente ao crack. $\mathrm{O}$ apoio à família, que precisa ser acolhida e cuidada para cuidar de seu membro que manifesta o problema, deve fazer parte da dinâmica de tratamento da criança e do adolescente que faz uso de drogas.

Ribeiro e Laranjeira (2012) concebem uma rede de atendimento que inclui como ambientes de tratamento: 1) no nível mais básico da atenção à saúde: ambulatórios gerais e de especialidades, escolas, empresas, albergues, cadeias e prisões, unidades socioeducativas; 2) no nível intermediário: hospital geral, de especialidades, e psiquiátrico (pronto-socorro e enfermarias), hospital-dia (saúde mental e álcool e outras drogas), ambulatórios especializados (álcool e outras drogas) e de saúde mental, unidade comunitária de saúde mental, serviços de reabilitação (profissional de referência), grupos de mútua ajuda, moradia assistida, enfermarias de desintoxicação, internação prolongada (clínicas de tratamento, Comunidades Terapêuticas; 3) centros de excelência como topo na rede de atendimento, em que pesquisa, ensino e tratamento sejam apoiados e tratados integradamente. Estes autores propõem que cada serviço avalie sua inserção na rede e que saiba recorrer às demais instituições quando o caso exigir.

Muitas vezes, por competição entre linhas e modelos terapêuticos ou por ingenuidade ou arrogância, alguns serviços acham-se plenamente capazes de responder a todas as necessidades de seus pacientes, apenas utilizando suas técnicas terapêuticas. Perde-se assim um referencial importante: algumas técnicas e serviços são mais ou menos efetivos de acordo com o estágio motivacional e a gravidade da dependência. (Ribeiro \& Laranjeira, 2012: 202)

A essa concepção de rede de atendimento apontada por Ribeiro e Laranjeira (2012), cabe acrescentar os Consultórios de Rua e na Rua, opção de atendimento presente em diversas cidades brasileiras. O primeiro Consultório de Rua surge em 1999, em Salvador, idealizado pelo Centro de Estudos e Terapia do Abuso 
de Drogas (Cetad), da Universidade Federal da Bahia. Em 2009, o Ministério da Saúde propôs o modelo de Consultório de Rua como uma das estratégias do Plano Emergencial de Ampliação de Acesso ao Tratamento em Álcool e Outras Drogas, incluído, em 2010, no Plano Integrado Nacional de Enfrentamento ao Crack, com o objetivo de ampliar o acesso aos serviços assistenciais e qualificar o atendimento oferecido às pessoas que usam crack, álcool e outras drogas por intermédio de ações de saúde na rua.

Desde então, o Consultório de Rua esteve vinculado à Política Nacional de Saúde Mental. Em 2011, como desdobramento do decreto presidencial n. 7.053/2009, que instituiu a Política Nacional para a População em Situação de Rua e seu Comitê Intersetorial de Acompanhamento e Monitoramento, o Ministério da Saúde adotou o Consultório de Rua como um serviço estratégico da atenção básica. Assim, em 2012, o Consultório de Rua passa a se denominar Consultório na Rua integrando a Política Nacional de Atenção Básica. Não se trata apenas de mudança na nomenclatura ("de" para "na"), mas uma mudança nas diretrizes estratégicas desse dispositivo, atendendo, ainda, a prioridade do governo, de prevenção do consumo e da dependência de crack, álcool e outras drogas. Ambas as iniciativas perduram no país.

No que se refere especificamente à política de saúde mental infantojuvenil, ainda hoje busca-se superar a prática de institucionalização calcada historicamente na ideia de reclusão em abrigos, educandários e hospitais psiquiátricos. O desmonte completo do modelo manicomial é um desafio do presente. As diretrizes e princípios que norteiam as ações voltadas para a atenção à saúde mental deste segmento da população estão inseridos nos movimentos concomitantes da Reforma Sanitária e da Reforma Psiquiátrica, que levaram a um modelo de tratamento aberto e comunitário, privilegiando a inserção social e o atendimento a necessidades clínicas, comunitárias, familiares e de reabilitação, as quais devem ser observadas e propiciadas como parte integrante desse tratamento.

A política pública para saúde mental voltada especificamente para crianças e adolescentes, com abrangência nacional começou a ser estabelecida entre 2002 e 2004, quando foram formalizados os Caps específicos para infância (Caps i) e implementado o Fórum Nacional de Saúde Mental Infantojuvenil. Antes contava-se com assistência de instituições filantrópicas ou experiências no setor público restritas a municípios ou regiões específicas, sem cobertura adequada da população (Lauridsen-Ribeiro \& Tanaka, 2010). Esse início tardio 
e tímido faz com que sejam imensos os desafios para a saúde mental pública dessa população.

Neste contexto de fragilidade da rede de saúde, o Poder Judiciário, tem, muitas vezes, determinado tratamento compulsório recorrendo à internação como recurso imediato de cuidado. Esta judicialização do tratamento é reveladora da inexistência ou da ineficácia da rede local de atenção à saúde mental para tratamento de transtornos decorrentes do abuso de drogas, assim como da desconfiança e descrença em relação aos serviços comunitários (Amstalden, Hoffmann \& Monteiro, 2010). Um exemplo é o município do Rio de Janeiro que implementou o recolhimento compulsório dos usuários que dão entrada em abrigos especializados e em Comunidades Terapêuticas. Essa política foi legitimada pela resolução n. 20/2011 da Secretaria Municipal de Assistência Social, que institui o Protocolo do Serviço Especializado em Abordagem Social. Tal iniciativa vem também sendo implementada também em outros municípios.

O profissional que realiza atenção psicossocial necessita conhecer o território em que atua e onde vive quem demanda atendimento, identificando os recursos disponíveis que podem fazer parte do processo terapêutico a ser construído. A política de saúde mental infantojuvenil preconiza que os serviços que compõem a rede precisam ser atravessados pelo princípio da intersetorialidade e pela noção de território. A ação intersetorial implica acionar todos os dispositivos que fazem parte da vida de crianças e adolescentes (saúde, escola, esporte, lazer, cultura, instâncias jurídico-legais, entre outros). O território, por sua vez, é o lugar psicossocial do sujeito que aglutina experiências pessoais e institucionais nas quais ele está inserido (Amstalden, Hoffmann \& Monteiro, 2010).

Alguns setores e serviços são essenciais para o cuidado de crianças e adolescentes em situação de vulnerabilidade provocada pelo crack. Na saúde, destacam-se os Caps, em especial aqueles específicos para a população infantojuvenil (Caps i) e para usuários de álcool e outras drogas (Caps ad). A rede de atendimento também conta com leitos psiquiátricos em hospitais gerais, pediátricos e serviços de urgência e emergência que possam dar suporte às situações de crise e garantir a presença de familiares e responsáveis para acompanhar o tratamento (Amstalden, Hoffmann \& Monteiro, 2010).

O trabalho integrado com a atenção básica potencializa o cuidado e facilita uma abordagem integral, aumentando a qualidade de vida dos indivíduos e das comunidades. Os Núcleos de Apoio a Saúde da Família (Nasf) podem 
desenvolver ações, em conjunto com os profissionais das equipes que compõem a Estratégia Saúde da Família (ESF) e agentes comunitários de saúde (ACS), para assegurar continuidade aos cuidados e ações de promoção e reabilitação da saúde. A parceria da saúde mental com a atenção básica se faz importante pela possibilidade da busca ativa, identificando situações que não chegam aos serviços de saúde. Além dessas instituições, os Centros de Convivência e Cultura também constituem as redes de saúde mental como espaços de encontros de caráter terapêutico com possibilidades de inserção social, superação do estigma e do isolamento das pessoas com problemas de saúde mental. Os Consultórios de Rua podem funcionar como uma porta de entrada para a rede: por sua tradição em intervenções no território e por sua origem - inicialmente pensado para atender pessoas usuárias de drogas e em situação de rua. A mudança para a atenção básica (Consultórios na Rua) faz eco significativo nessa perspectiva de porta de entrada.

A rede de saúde mental organiza-se e articula-se com a rede mais ampliada, envolvendo os demais setores das políticas públicas voltadas para crianças e adolescentes (escolas, conselhos tutelares, centros de assistência social, dispositivos de cultura, esporte e lazer). No território, esses serviços destinados ao atendimento de crianças e adolescentes usuários de drogas e suas famílias devem estabelecer um fluxo referenciado, dialógico e permanente de informações com todas as instituições no município, podendo-se recorrer a localidades vizinhas na ausência desses serviços, compondo a rede de cuidados e proteção social para esse público.

Outros equipamentos que integram a rede intersetorial no território que atende crianças e adolescentes são: 1) Sistema Único da Assistência Social, que prevê ações e serviços dirigidos ao fortalecimento da família (Centros de Referência de Assistência Social - Cras - e Centro de Referência Especializado de Assistência Social - (reas); 2) Sistema de Justiça e de Direitos Humanos, composto por delegacias especializadas, Varas da Infância e Juventude, e conselhos tutelares; 3) Sistemas de ensino, formado pela rede de educação federal, estadual, distrital e municipal, complementada pelo sistema privado; 4) Sistema Único de Segurança Pública, composto por alguns órgãos no território, como Delegacia Especial de Proteção à Criança e ao Adolescente, Delegacia de Atendimento Especializado à Mulher, Delegacias de Polícia Civil e Militar, Postos de Polícia Rodoviária Federal, Guardas Municipais, Instituto Médico Legal (IML); 5) sociedade civil organizada, cuja participação se dá por 
meio dos Conselhos de Direitos da Criança e do Adolescente, órgãos paritários com representação do governo e da sociedade civil. Essa rede intersetorial, articulada com a saúde, é capaz de integrar políticas e ações governamentais e não governamentais no âmbito local (Brasil, 2010).

\section{CONSIDERAÇÕES FINAIS}

As informações sobre a magnitude do problema do uso de crack entre crianças e adolescentes no país ainda são pontuais e dispersas ao longo dos anos, e raros são os trabalhos que focam no comprometimento familiar decorrente do uso do crack. Também são frágeis as informações disseminadas sobre a rede responsável pelo atendimento das crianças e adolescentes que fazem uso pessoal da droga ou de seus familiares. A importância do investimento na formação dos profissionais da saúde que atuam nos diferentes setores e níveis de atenção é mister para incrementar o cuidado oferecido aos usuários de drogas. Capacitações e ações de educação permanente dos atores da rede precisam enfrentar a falta de conhecimento sobre o crack, as dificuldades para o manejo clínico, a cultura do medo relacionada ao consumo das drogas ilícitas, a visão higienista do cuidado e o estigma em relação às pessoas que consomem drogas (Amstalden, Hoffmann \& Monteiro, 2010).

A constituição da rede no território exige construção de estratégias de cuidados partilhadas entre as instituições, os usuários e as famílias. Reforça-se o papel destas como fator de proteção ao uso de drogas e a relevância do trabalho preventivo com elas. A família é o alicerce que sustenta afetiva, emocional e materialmente o desenvolvimento do ser humano e precisa ser prioritariamente apoiada pelas políticas públicas, assim como estimulada sua integração na comunidade e na sociedade em geral, para que se almeje o enfrentamento do crack entre crianças e adolescentes. 


\section{REFERÊNCIAS}

AMStAlden, A. L. F.; HOfFMAnN, M. C. C. \& MONTEIRO, T. P. M. A Política de Saúde Mental Infantojuvenil: seus percursos e desafios. In: LAURIDSEN-RIBEIRO, E. \& TANAKA, O. Y. (Orgs.). Atenção em Saúde Mental para Crianças e Adolescentes no SUS. São Paulo: Hucitec, 2010.

ASSIS, S. G. \& FARIAS, L. O. P. (Orgs.). Levantamento Nacional das Crianças e Adolescentes em Acolhimento Institucional e Familiar. São Paulo: Hucitec, 2013.

BESSA, M. A. O adolescente usuário de crack. In: RIBEIRO, M. \& LARANJEIRA, R. (Orgs.). O Tratamento do Usuário de Crack. Porto Alegre: Artmed, 2012.

BRASIL. Ministério da Saúde. Secretaria de Atenção à Saúde. Departamento de Ações Programáticas e Estratégicas. Linha de Cuidado para a Atenção Integral à Saúde de Crianças, Adolescentes e suas Famílias em Situação de Violência: orientações para gestores e profissionais de saúde. Brasília: Ministério da Saúde, 2010.

CARVALHO, S. A Política Criminal de Drogas no Brasil: estudo dogmático e criminológico. Rio de Janeiro: Lumen Júris, 2006.

CONSELHO NACIONAL ANTIDROGAS. Resolução n. 3/GSIPR/CH/Conad, de 27 out. 2005. Aprova a Política Nacional Sobre Drogas. Brasília: Gabinete de Segurança Institucional, 2005.

CONSELHO NACIONAL DO MINISTÉRIO PÚBLICO (CNMP). Relatório da Infância e Juventude: Resolução n. 71/2011 - um olhar mais atento aos serviços de acolhimento de crianças e adolescentes no país. Brasília: Conselho Nacional do Ministério Público, 2013.

CONSELHO FEDERAL DE PSICOLOGIA (CFP). Relatório da $4^{\text {a }}$ Inspeção Nacional de Direitos Humanos: locais de internação para usuários de drogas. Brasília: Conselho Federal de Psicologia, 2011.

COSTA, G. M. et al. Gestantes dependentes de crack em uma unidade de internação psiquiátrica. Jornal Brasileiro de Psiquiatria, 61(1): 8-12, 2012.

DUAILIBI, L. B.; RIBEIRO, M. \& LARANJEIRA, R. Perfil dos usuários de cocaína e crack no Brasil. Cadernos de Saúde Pública, 24(4): S545-S557, 2008.

FIORE, M. A medicalização da questão do uso de drogas no Brasil: reflexões acerca de debates institucionais e jurídicos. In: CARNEIRO, H. (Org.). Álcool e Drogas na História do Brasil. São Paulo, Belo Horizonte: Alameda, PUCMinas, 2005.

GALDURÓZ, J. C. F.; NOTO, A. R. \& CARLINI,E. A. IV Levantamento sobre o Uso de Drogas entre Estudantes de $1^{\circ}$ e $2^{\circ}$ Graus em Dez Capitais Brasileiras - 1997. São Paulo: Centro Brasileiro de Informações sobre Drogas Psicotrópicas, Departamento de Psicobiologia da Escola Paulista de Medicina, 1997.

GALDURÓZ, J. C. et al. V Levantamento Nacional sobre o Consumo de Drogas Psicotrópicas entre Estudantes do Ensino Fundamental e Médio da Rede Pública de Ensino nas 27 Capitais Brasileiras - 2004. São Paulo: Secretaria Nacional Antidrogas, Centro Brasileiro de Informações sobre Drogas Psicotrópicas, 2005. 
INSTITUTO DE PESQUISA ECONÔMICA APLICADA/CONSELHO NACIONAL DOS DIREITOS DA CRIANÇA E DO ADOLESCENTE (IPEA/CONANDA). In: SILVA, E. R. A. (Coord.). O Direito à Convivência Familiar e Comunitária: os abrigos para crianças e adolescentes no Brasil. Brasília: Ipea, 2004.

LARANJEIRA, R. Bases do tratamento da dependência do crack. In: RIBEIRO, M. \& LARANJEIRA, R. (Orgs.). O Tratamento do Usuário de Crack. Porto Alegre: Artmed, 2012.

LAURIDSEN-RIBEIRO, E. \& TANAKA, O. Y. Organização de serviços no Sistema Único de Saúde para o cuidado de crianças e adolescentes com problemas de saúde mental. In: LAURIDSEN-RIBEIRO, E. \& TANAKA, O. Y. (Orgs.). Atenção em Saúde Mental para Crianças e Adolescentes no SUS. São Paulo: Hucitec, 2010.

MACHADO, N. G. et al. Uso de drogas e a saúde sexual de adolescentes. Revista de Enfermagem da Uerj, 18(2): 284-290, 2010.

MARQUES, A. C. P. R. \& CRUZ, M. S. O adolescente e o uso de drogas. Revista Brasileira de Psiquiatria, 22, supl. 2: 32-36, 2000.

MELOTTO, P. Trajetórias e Usos de Crack: estudo antropológico sobre trajetórias de usuários de crack no contexto de bairros populares de São Leopoldo - RS, 2009. Dissertação de Mestrado, Porto Alegre: Universidade Federal do Rio Grande do Sul.

MITSUHIRO, S. S. et al. Brief report: prevalence of psychiatry disorders in pregnant teenagers. Journal of Adolescence, 32(3): 747-752, 2009.

MOMBELLI, M. A.; MARCON, S. S. \& COSTA, J. B. Caracterização das internações psiquiátricas para desintoxicação de adolescentes dependentes químicos. Revista Brasileira de Enfermagem, 63(5): 735-740, 2010.

MOREIRA, M. M.; MITSUHIRO, S. S. \& RIBEIRO, M. O consumo de crack durante a gestação. In: RIBEIRO, M. \& LARANJEIRA, R. (Orgs.). O Tratamento do Usuário de Crack. Porto Alegre: Artmed, 2012.

MURAKI, S. M. P. Prevalência do Consumo de Drogas Psicotrópicas entre Adolescentes do Ensino Fundamental e Médio do Município de Dourados - MS, 2009. Dissertação de Mestrado, Brasília: Universidade de Brasília.

NARVAEZ, J. C. M. Trauma Infantil e Função Executiva em Usuários de Crack, 2010. Dissertação de Mestrado, Porto Alegre: Faculdade de Medicina, Universidade Federal do Rio Grande do Sul.

NATIONAL TREATMENT AGENCY FOR SUBSTANCE MISUSE. Models of care for treatment for adult drug misusers: update 2006. Disponível em: <www.nta.nhs.uk/ uploads/nta_modelsofcare_update_2006_moc3.pdf>. Acesso em: dez. 2011.

NEIVA-SILVA, L. Uso de Drogas entre Crianças e Adolescentes em Situação de Rua: um estudo longitudinal, 2008. Tese de Doutorado, Porto Alegre: Universidade Federal do Rio Grande do Sul.

NONTICURI, A. R. As Vivências de Adolescentes e Jovens com o Crack e suas Relações com as Políticas Sociais Protetoras neste Contexto, 2010. Dissertação de Mestrado, Pelotas: Universidade Católica de Pelotas. 
NOTO, A. R. et al. Levantamento Nacional sobre o Uso de Drogas entre Crianças e Adolescentes em Situação de Rua nas 27 Capitais Brasileiras. São Paulo: Secretaria Nacional Antidrogas, Centro Brasileiro de Informações sobre Drogas Psicotrópicas, 2003.

PRIULI, R. M. A. Perfil Sociodemográfico, Infracional e Relacional de Adolescentes em Conflito com a Lei, 2005. Dissertação de Mestrado, São José do Rio Preto: Faculdade de Medicina de São José do Rio Preto.

RIBEIRO, F. M. L. Justiça Terapêutica Tolerância Zero: arregaçamento biopolítico do sistema criminal punitivo e criminalização da pobreza, 2007. Dissertação de Mestrado, Rio de Janeiro: Universidade do Estado do Rio de Janeiro.

RIBEIRO, M. \& LARANJEIRA, R. O plano de tratamento. In: RIBEIRO, M. \& LARANJEIRA, R. (Orgs.). O Tratamento do Usuário de Crack. Porto Alegre: Artmed, 2012.

SANTOS, A. M. B.; PIETRO, G. \& XAVIER FILHO, L. Uso de drogas por estudantes do ensino médio em Aracaju-SE. Revista Espaço para a Saúde, 10(1): 47-52, dez. 2008.

SEIBEL, S.D. Cocaína e crack. In: SEIBEL, S. D. (Org.). Dependência de Drogas. São Paulo: Atheneu, 2010.

SILVA, E. F. et al. Prevalência do uso de drogas entre escolares do ensino médio do município de São José do Rio Preto, São Paulo, Brasil. Cadernos de Saúde Pública, 22(6): 1.151-1.158, jun. 2006. 


\title{
2 \\ Quantas Crianças e Adolescentes \\ Fazem Uso Regular de Crack e Similares nas Capitais Brasileiras?
}

\author{
Francisco Inácio Bastos \\ Neilane Bertoni
}

\begin{abstract}
Diversos sistemas e projetos de pesquisa voltados para o monitoramento de populações mais vulneráveis a algumas doenças e infecções, como, por exemplo, o HIV e outras infecções/doenças sexualmente transmissíveis, vêm sendo implementados em diversos países, especialmente de renda mais elevada, que reúnem as condições necessárias, em termos de orçamento, disponibilidade de pessoal treinado e capacitado, e regularidade na formulação e monitoramento de políticas públicas, que conferem a essas iniciativas um caráter sistemático e abrangente.

Uma linha complementar de monitoramento sistemático, mais recente e basicamente restrita, por ora, a alguns países de renda elevada, por meio de projetos específicos de pesquisa, muito raramente incorporados às atividades de vigilância de rotina, refere-se ao monitoramento de agravos por doenças/ agravos não transmissíveis, além de eventos sem relação necessária com a saúde, como a logística do sistema jurídico e, em especial, do sistema prisional (por exemplo, o monitoramento de pessoas vivendo em regime semiaberto e em liberdade condicional). Um exemplo muito evidente da maior sistematicidade, abrangência e diversidade desses esforços em países de renda mais elevada pode ser obtido no site referente ao próprio método que abordaremos neste capítulo, o Scale-up Network Method (conhecido por seu acrônimo em língua inglesa como NSUM), onde as publicações e análises oriundas de grupos de pesquisa situados em países de renda elevada dominam
\end{abstract}


amplamente o panorama de aplicações do método a diferentes problemas de saúde, sociais e jurídicos. ${ }^{1}$

Existem diversos métodos desenvolvidos para estimar o tamanho de populações especialmente vulneráveis, habitualmente de difícil acesso ou ocultas, o que não deve ser visto como uma coincidência, mas sim parte de um mesmo conjunto de processos sociais. Os mesmos processos sociais que estigmatizam, marginalizam e, eventualmente, criminalizam determinadas condutas (como o consumo de drogas em diversos contextos), fragilizam essas populações, ao fazer com que seus membros pratiquem hábitos em condições de risco (como usuários de drogas reunidos em locais perigosos e em situações precárias de higiene), evitem o contato com instâncias que poderiam lhes prestar auxílio e cuidados, e se furtem a discutir de forma aberta seus problemas e dificuldades com familiares e amigos.

Há diversos métodos de estimação de populações de difícil acesso ou ocultas, incluindo o método de Captura-Recaptura - clássico e modificados (Jouanjus et al., 2012) -, o método Multiplier e outras alternativas de estimação direta, além de métodos de estimação indireta. Todos apresentam vantagens e desvantagens, que devem ser consideradas e contrastadas em cada estudo específico e com relação a diferentes populações. O que, muitas vezes, acaba por determinar a utilização de um deles é o processo logístico e operacional disponível para desenvolvê-lo e implementá-lo concretamente em um dado contexto e população, assim como sua aceitabilidade por parte dos gestores, além dos custos a eles associados.

A estimação direta consiste em perguntar a indivíduos da população geral se eles fazem (ou não) parte da população-alvo sob análise, ou seja, se eles (os respondentes) têm determinados hábitos ou comportamentos que caracterizam estas populações, por exemplo, se fazem uso de drogas (Unaids, s. d.). Em geral, realiza-se um inquérito domiciliar para tal fim. Este método, por perguntar diretamente à população sobre a prática de atividades frequentemente estigmatizadas e/ou criminalizadas, tende a subestimar a magnitude real da população e seus hábitos, como vem sendo mostrado por diversos estudos internacionais (Gfroerer, Lessler, \& Parsley, 1997; Morral, McCaffrey \& Chien, 2003; Rogers, Miller \& Turner, 1998).

Em estudo realizado em Curitiba, em 2010, para a estimação do número de usuários de drogas ilícitas, com exceção da maconha, ao comparar os achados

1 Disponível em: <http://nersp.osg.ufl.edu/ ufruss/scale-up.htm>. Acesso em: 24 ago. 2015. 
obtidos com base na aplicação de cinco métodos distintos, o método direto gerou estimativas cinco a dez vezes menores, quando comparadas àquelas obtidas mediante a aplicação de outros métodos (Salganik et al., 2011a).

Outro método que vem sendo utilizado recentemente em saúde pública para estimação de populações de difícil acesso é o NSUM. Esta metodologia foi desenvolvida e utilizada inicialmente para estimar o número de vítimas de um terremoto no México, em 1985 (Bernard et al., 1991), e combina conceitos oriundos das ciências sociais (como representações e percepções acerca dos fenômenos sociais, e transmissibilidade ou não de informações de diversas naturezas ao longo de redes sociais e comunidades) com métodos matemáticos refinados de estimação. A natureza híbrida do método é, sem dúvida, fruto da parceria, que permitiu ser elaborado e aperfeiçoado ao longo dos anos, entre um antropólogo norte-americano, H. Russell Bernard, e um dos mais ilustres matemáticos aplicados do século XX, o inglês Peter D. Killworth. ${ }^{2}$

Apesar do propósito inicial bastante específico, as aplicações do método foram se disseminando e, progressivamente, abarcando outros fenômenos e populações de difícil acesso. Desde então, o NSUM tem sido utilizado para estimar a magnitude de diversas populações de difícil acesso, em diferentes países. Ainda no México, o método foi empregado para estimar o número de mulheres que haviam sofrido violência sexual (Bernard et al., 1991) e, em um momento subsequente, o número de crianças vítimas de experiências de sufocamento (asfixia) na Itália (Snidero et al., 2007). Nos Estados Unidos, esta metodologia vem sendo utilizada em diferentes campos, como, por exemplo, para estimar a prevalência do HIV e a população de rua em diferentes comunidades (Killworth et al., 1998a, 1998b), e do uso de heroína (Kadushin et al., 2006).

Mais recentemente, na Ucrânia, diversas populações especialmente vulneráveis ao HIV/Aids (em função da pobreza, marginalização, estigma etc.) foram estimadas mediante o uso desta metodologia, assim como as "populações-ponte" (bridging populations) de transmissão do HIV (ou seja, situações em que o vírus da Aids se dissemina a partir de segmentos com prevalência especialmente elevada, atingindo populações até então menos afetadas e o número de pessoas vivendo com o HIV/Aids (Paniotto et al., s. d.). Trabalhos recentes vêm sendo implementados em populações asiáticas

A biografia de Killworth e um breve sumário dos seus trabalhos estão disponíveis em: <http:// en.wikipedia.org/wiki/Peter_Killworth>. Acesso em: 24 ago. 2015. 
de grande magnitude, como no Japão (Ezoe et al., 2012) e China (Guo et al., 2013), o que, obviamente, traz novos desafios em termos da envergadura, logística e custos.

No Brasil, a despeito de trabalhos anteriores com populações-ponte em HIV/Aids (Hacker et al., 2009) e estimação do número de pessoas vivendo com HIV/Aids a partir da aplicação de métodos clássicos (Szwarcwald \& Castilho, 2000), não há registro do uso anterior do NSUM no âmbito de qualquer estudo nesta área. O único estudo brasileiro nesta área, realizado até o momento com o uso desta metodologia (Salganik et al., 2011a), estimou o número de usuários de drogas ilícitas (que não a maconha) no município de Curitiba, Paraná. O trabalho comparou ainda a estimativa dessa população com os achados de quatro outros métodos, dentre eles, resultados obtidos pelos métodos direto e Multiplier.

A metodologia Network Scale-up produz estimativas de tamanhos populacionais, valendo-se de informações das redes de contatos dos respondentes de inquéritos realizados com uma amostra aleatória da população geral, tendo como pressupostos básicos: 1) todos têm a mesma chance de conhecer alguém de uma dada subpopulação; 2) o tamanho da rede de contatos é constante; 3) todos conhecem bem os comportamentos dos membros de sua rede de contatos (Killworth et al., 1998a, 1998b). Obviamente, tais pressupostos não são necessariamente verificados em condições reais de aplicação, daí a necessidade de lidar com as eventuais violações desses pressupostos e reformular, continuamente, métodos e técnicas de captura de informações, gerência e análise.

Uma das limitações do método se refere à possibilidade de que, em se tratando de um evento relativamente frequente, que tenha lugar em uma população relativamente limitada, haja sobreposição das redes das pessoas entrevistadas. Ou seja, tomando como exemplo um hipotético usuário de uma substância ilícita, é possível que um mesmo indivíduo pertença às redes sociais de mais de uma pessoa entrevistada por um dado estudo. Tal evento é muito pouco provável em se tratando de uma cidade do porte das capitais brasileiras, que tem populações da ordem de milhões de habitantes, mas existem casos (bastante raros) de indivíduos hiperconectados, como, por exemplo, pessoas envolvidas no tráfico de drogas, que podem estabelecer pontes entre diferentes grupos sociais, mesmo em cidades do tamanho de Nova York (como no exemplo da detalhada etnografia de Friedman e colaboradores, 1999). 
Por essa razão, Killworth estabeleceu um limite empírico para a utilização do NSUM, dada a prevalência de um evento em uma população/comunidade. Segundo seus cálculos, ${ }^{3}$ eventos cuja prevalência é inferior a 4\%, em uma dada população, podem ser definidos como raros, e são aqueles em relação aos quais a eventual sobreposição de redes sociais é tão improvável que esta hipótese (real, mas absolutamente improvável) se torna irrelevante do ponto de vista das estimativas. Infelizmente, isso limita a aplicabilidade do método à estimação de hábitos mais frequentes, como, por exemplo, o consumo de bebidas alcoólicas, em relação ao qual o NSUM não pode ser aplicado.

Nos inquéritos que têm por base este método, são feitas perguntas aos respondentes sobre quantas pessoas estes conhecem que fazem parte de subpopulações previamente selecionadas, o que inclui tanto populações com tamanhos conhecidos de antemão (ditas populações enumeráveis, para as quais é possível contar com cadastros) - para estimativa do tamanho da rede de contatos dos respondentes -, quanto subpopulações de tamanho desconhecido - para estimativa do tamanho destas, o que constitui o objetivo primário da aplicação do método.

A Pesquisa Nacional do Crack, realizada pela Fundação Oswaldo Cruz (Fiocruz) em parceria com a Secretaria Nacional de Políticas sobre Drogas $\left(\right.$ Senad) ${ }^{4}$ e, neste componente do estudo, a pesquisa domiciliar com 25.000 entrevistados, a Universidade de Princeton (EUA) utilizou a metodologia Network Scale-up para estimar o número de usuários de crack e/ou similares nas capitais do país, além de outras. Optou-se por este método indireto, em vez do tradicional método direto por diversos motivos:

1) A metodologia indireta reduz substancialmente o erro derivado do estigma de comportamento, pois as pessoas tendem a não falar abertamente sobre seus comportamentos estigmatizados e/ou criminalizados, como, por exemplo, o uso de drogas ( $\mathrm{e}$, ainda que se utilizem métodos auxiliares de coleta como urnas onde seriam depositadas respostas por escrito, esta estratégia se mostra bastante menos efetiva em domicílios privados do que em locais públicos, como escolas).

2) Este método acaba por incluir na estimativa obtida populações em situação de rua, mesmo sendo o estudo de base realizado por meio de um

3 Esses cálculos podem ser vistos de forma bastante sucinta pelo leitor não especializado em matemática em: <http://nersp.osg.ufl.edu/ ufruss/index.html>, acesso em: 24 ago. 2015; bastando clicar na apresentação em powerpoint denominada Honoring Peter Killworth.

4 Disponível em: <www.obid.senad.gov.br/portais/OBID/biblioteca/documentos/Publicacoes/329797.pdf >. Acesso em: set. 2015. 
inquérito domiciliar, exatamente por perguntar sobre comportamentos de terceiros e não do respondente no domicílio pesquisado.

3) Da mesma forma, mesmo não realizando a pesquisa em domicílios coletivos/instituições fechadas ou semifechadas, a metodologia Network Scale-up consegue também contemplar, em suas estimativas, pessoas que estão em tal situação, como aquelas morando em abrigos, clínicas de tratamento para dependência química, presídios etc.

Assim, a pesquisa realizada buscou estimar diversas subpopulações desconhecidas em cada uma das 27 capitais brasileiras, com ênfase no número pessoas que utilizaram crack e substâncias similares na vida, nos últimos seis meses, em, pelo menos, 25 dias nos últimos seis meses.

A metodologia Network Scale-up utiliza procedimentos de simples entendimento, que descrevemos, de forma sucinta, a seguir.

A forma de estimarmos o tamanho da população-alvo é:

$$
\widehat{N_{t}}=\frac{\sum_{i} y_{i}}{\sum_{i} \widehat{d}_{i}} \cdot N
$$

onde $y_{i}$ é o número de pessoas da população-alvo que o respondente i conhece, e $\widehat{d}_{i}$ é o tamanho estimado da rede de contatos da pessoa i, e $\mathrm{N}$ é o tamanho da população geral (Killworth et al., 1998a, 1998b).

Em outras palavras, se, por exemplo, o entrevistado tem 200 pessoas em sua rede de contatos em um dado município, e diz conhecer cinco usuários de crack, sabendo-se que o tamanho da população desse município é de 200 mil pessoas, poderíamos dizer que, neste local, 5/200 x $200 \mathrm{mil}=5 \mathrm{mil}$ pessoas são usuárias de crack. O mesmo procedimento é repetido para cada um dos respondentes do inquérito, em consonância com a amostra da população geral, definida de antemão.

Como a informação acerca do tamanho da rede de contatos do respondente (expressa pelo denominador que consta da fórmula anterior) tende a ser imprecisa, em vez de perguntarmos isso diretamente ao indivíduo, geramos uma estimativa deste número. Faz-se isso, pois, como o tamanho da rede de contato das pessoas em geral é "grande" e frequentemente difícil de precisar, o respondente tende a não enumerar/contar de fato cada um de seus contatos, e sim intuir esse número, o que poderia gerar viés na estimativa NSUM. 
Para estimar o tamanho da rede de contatos dos indivíduos entrevistados, utilizou-se o método da População Conhecida (known population), em que cada respondente reporta o número de pessoas que conhece no contexto de vários grupos de tamanho populacional definível de antemão (ou seja, que conta com cadastro atualizado). Por exemplo, um respondente diz conhecer uma pessoa que trabalha na Prefeitura da cidade X. Sabe-se, a priori, que nessa Prefeitura trabalham 1.000 pessoas. Assim, podemos combinar essas informações para dizer que o respondente conhece $1 / 1.000$ de todas as pessoas da cidade $X$. Se a população desta cidade é de 200 mil pessoas, então o tamanho da rede de contatos deste respondente, nesse local, é de $1 / 1.000 \times 200 \mathrm{mil}=200$ pessoas.

Contudo, para melhorar a acurácia desta estimativa, podemos perguntar sobre diversos grupos populacionais cujo tamanho conhecemos de antemão (com base em cadastros públicos), valendo-nos do seguinte estimador (Killworth et al., 1998a, 1998b):

$$
\widehat{d}_{i}=\frac{\sum_{j} y_{i j}}{\sum_{j} N_{j}} \cdot N
$$

em que $\widehat{d}_{i}$ é o número estimado da rede de contatos do respondente i, yij é o tamanho de conhecidos do respondente i na subpopulação j, Nj é o tamanho da subpopulação j, e N é o tamanho da população geral.

Em geral, utilizam-se 20 subpopulações conhecidas para estimar o tamanho da rede de contato dos respondentes. Nesta pesquisa, foram utilizadas as subpopulações descritas no Quadro 1. 
Quadro 1 - Populações conhecidas utilizadas para estimação da rede de contatos dos indivíduos e fonte de dados de onde serão retiradas

\begin{tabular}{|c|c|}
\hline População & Fonte de dados \\
\hline Meninas menores de 5 anos & Censo 2010 - IBGE \\
\hline Meninos menores de 5 anos & Censo 2010 - IBGE \\
\hline Mulheres com mais de 70 anos & Censo 2010 - IBGE \\
\hline Homens com mais de 70 anos & Censo 2010 - IBGE \\
\hline $\begin{array}{l}\text { Pessoas com } 15 \text { anos ou mais e que não sabem ler ou } \\
\text { escrever }\end{array}$ & Censo 2010 - IBGE \\
\hline $\begin{array}{l}\text { Mulheres menores de } 20 \text { anos que tiveram bebês nos } \\
\text { últimos } 12 \text { meses }\end{array}$ & Censo 2010 - IBGE \\
\hline $\begin{array}{l}\text { Mulheres com } 20 \text { anos ou mais que tiveram bebês nos } \\
\text { últimos } 12 \text { meses }\end{array}$ & Censo 2010 - IBGE \\
\hline $\begin{array}{l}\text { Mulheres com } 4 \text { filhos ou mais (apenas filhos } \\
\text { biológicos vivos) }\end{array}$ & Censo 2010 - IBGE \\
\hline Homens que se casaram no civil nos últimos 12 meses & Censo 2010 - IBGE \\
\hline Mulheres que se casaram no civil nos últimos 12 meses & Censo 2010 - IBGE \\
\hline $\begin{array}{l}\text { Pessoas viúvas (isto é, homens ou mulheres cujo último } \\
\text { cônjuge faleceu e não se casaram no civil novamente) }\end{array}$ & Censo 2010 - IBGE \\
\hline Estrangeiros & Censo 2010 - IBGE \\
\hline Mães que recebem auxílio do Programa Bolsa Família & $\begin{array}{l}\text { Ministério do } \\
\text { Desenvolvimento Social e } \\
\text { Combate à Fome - } 2010\end{array}$ \\
\hline Estudantes do $6^{\circ}$ ao $9^{\circ}$ ano de escolas particulares & Censo Escolar 2011 - Inep \\
\hline Estudantes de ensino médio de escolas públicas & Censo Escolar 2011 - Inep \\
\hline Estudantes de ensino médio de escolas particulares & Censo Escolar 2011 - Inep \\
\hline $\begin{array}{l}\text { Professores de escolas públicas no ensino médio ou } \\
\text { fundamental, isto é, da alfabetização até o } 3^{\circ} \text { ano do } \\
\text { ensino médio }\end{array}$ & Censo Escolar 2011 - Inep \\
\hline $\begin{array}{l}\text { Professores de escolas particulares no ensino médio ou } \\
\text { fundamental, isto é, da alfabetização até o } 3^{\circ} \text { ano do } \\
\text { ensino médio }\end{array}$ & Censo Escolar 2011 - Inep \\
\hline Motoristas de táxi & $\begin{array}{l}\text { Ministério do Trabalho e } \\
\text { Emprego - } 2011\end{array}$ \\
\hline Motoristas de ônibus & $\begin{array}{l}\text { Ministério do Trabalho e } \\
\text { Emprego - } 2011\end{array}$ \\
\hline Bancários & $\begin{array}{l}\text { Ministério do Trabalho e } \\
\text { Emprego - } 2011\end{array}$ \\
\hline
\end{tabular}

Nota: IBGE = Instituto Brasileiro de Geografia e Estatística, Inep = Instituto Nacional de Estudos e Pesquisas Educacionais Anísio Teixeira 
Ressalta-se que as subpopulações conhecidas utilizadas foram padronizadas para todos os municípios estudados. Ou seja, nos valemos dos mesmos cadastros disponibilizados em todas as 27 capitais.

Resta, então, definir aqui, o que significa "conhecer alguém". A definição de "conhecer" utilizada no estudo foi: "pessoas que moram neste município, que você conhece de vista e de nome, que também o conhecem de vista e de nome, e com as quais você entrou em contato, seja pessoalmente, por telefone, correspondência ou e-mail, nos últimos 12 meses".

Cabe observar que a definição escolhida interfere diretamente no resultado a ser obtido, ou seja, dependendo de como se qualifica o que está sendo perguntado, obtêm-se quantitativos distintos. Utilizar períodos maiores do que 12 meses para estimar a rede de contatos de uma pessoa pode levar à subenumeração de seus contatos, uma vez que, em relação a informações referidas a um tempo mais longo, aumenta-se a probabilidade de que o viés de memória maximize a discrepância entre rede real e rede referida. Em contrapartida, períodos muito curtos podem se traduzir em redes muito restritas, pois interações sociais não são necessariamente reiteradas em intervalos breves de tempo, o que pode também interferir na estimação da população-alvo.

O estimador descrito pelo NSUM tem como um de seus pressupostos o fato de que as pessoas sabem tudo a respeito das demais pessoas às quais estão conectadas. $E$ isso pode não ser verdade (e, muito provavelmente, não o é, no mundo real), principalmente com relação a comportamentos estigmatizados ou ilegais, como é o caso do uso de drogas ilícitas. Em outras palavras, uma pessoa pode ter em sua rede social um indivíduo que faz uso regular de drogas, mas não saber que aquele indivíduo faz uso de drogas. Por esta razão, Salganik e Feehan (s. d.) desenvolveram um fator de correção para lidar com este possível viés, denominado "erro de transmissão".

Esse fator de correção foi aplicado aos resultados obtidos a partir da utilização do método Network Scale-up no estudo de Curitiba (Salganik et al., 2011a), sendo então denominado este novo método Generalized Network Scale-up. A forma de coleta de informações para construção deste fator de correção é descrita em artigo anterior (Salganik et al., 2011b), por meio da construção de um jogo lúdico, denominado Jogo dos Contatos, visando a estimar a visibilidade das populações de difícil acesso. Tal jogo, contudo, não foi replicado no âmbito da pesquisa em foco. Portanto, se houver alguma tentativa 
de correção neste trabalho, ela se limitará a tentativas que não guardam relação direta com o Jogo dos Contatos.

Os possíveis ajustes do erro de transmissão no contexto da metodologia Network Scale-up são invariavelmente dependentes das populações específicas e dos contextos em que estão inseridas. Alternativas bastante inovadoras vêm sendo aplicadas em pesquisas recentes, como no estudo japonês anteriormente citado, em que uma taxa de correção denominada coming out rate (que poderia ser traduzida como "taxa de assunção pública de uma dada identidade" - no caso, gay) foi utilizada para corrigir achados referentes a um contexto em que a homossexualidade masculina está, frequentemente, limitada à esfera estritamente privada (Ezoe et al., 2012).

A aplicação do NSUM para determinação de diferentes populações de difícil acesso, em especial a de usuários de crack e/ou similares nas 27 capitais brasileiras, compreendeu um inquérito domiciliar com uma amostra representativa de pessoas com 18 anos ou mais residentes nas referidas capitais e Distrito Federal.

Cabe ressaltar que, apesar do inquérito ter sido feito com maiores de 18 anos, em se tratando de um método de estimação indireto (ou seja, em que o entrevistado fala do comportamento de terceiros), foi possível gerar resultados referentes à população menor de 18 anos, sem que houvesse qualquer infração dos preceitos éticos (ou seja, esta população não foi entrevistada, mas sim referida, de forma não nominal, pelos entrevistados adultos).

A amostra foi selecionada em três estágios em cada uma das 27 capitais: 1) setores censitários com probabilidade proporcional ao tamanho; 2) domicílios por meio de uma amostra aleatória sem reposição; 3 ) morador do domicílio selecionado, maior de 18 anos, com a data de aniversário mais próxima (posterior) à da entrevista.

A base de setores censitários empregada foi a do Censo de 2010, realizado pelo Instituto Brasileiro de Geografia e Estatística (IBGE), e, para o segundo estágio da amostra, utilizou-se o Cadastro Nacional de Endereços para Fins Estatísticos (CNEFE), disponibilizado pelo IBGE em seu website (www. censo2010.ibge.gov.br/cnefe). Por isso, não se fizeram necessárias a contagem e a identificação dos domicílios particulares permanentes por parte dos entrevistadores, uma vez que estes recebiam de antemão o endereço exato dos locais em que deveria ser realizada a pesquisa, reduzindo, assim, o viés de informação do entrevistador nesta etapa. 
Os domicílios que apresentavam endereços incompletos ou que não podiam ser localizados por meio da informação contida no cadastro foram substituídos por outros domicílios, selecionados igualmente de antemão, e definidos como "substitutos", dentro dos mesmos setores censitários. Nos casos em que setor inteiro era composto por domicílios sem endereço completo, o setor era substituído, utilizando-se o mesmo procedimento de seleção amostral do estágio 2.

Para a realização da entrevista, caso o morador selecionado não estivesse presente no momento da primeira visita, faziam-se até duas visitas adicionais, em dias e horários diferentes da primeira. Após a terceira tentativa sem sucesso, o domicílio era substituído por outro selecionado previamente a partir de uma lista de reposição e procedia-se à nova seleção de morador no novo endereço. Se o morador selecionado apresentasse alguma inaptidão para responder ao questionário (por exemplo, algum transtorno mental grave), o domicílio era substituído por outro incluído na lista de reposição. Da mesma forma, eram substituídos domicílios fechados e vagos, ou aqueles em que o morador se recusasse a participar da pesquisa.

Para a seleção do morador dentro do domicílio sorteado, foi utilizado o Método do Próximo Aniversário (next-birthday method) (Salmon \& Nichols, 1983). Na aplicação desta metodologia, procede-se à listagem de todos os moradores do domicílio, segundo a definição de "morador" do IBGE. A listagem podia ser informada por qualquer morador do domicílio com 15 anos ou mais de idade. Registrava-se a idade de cada um deles e a sua data de aniversário (dia e mês). Apenas para fins de caracterização da composição dos domicílios, anotava-se o sexo do morador. Buscava-se dentre os moradores com 18 anos ou mais de idade, o indivíduo que tinha a data de aniversário mais próxima (seguinte) à data de realização da primeira visita. Este indivíduo era então o selecionado para responder ao questionário.

Ao morador selecionado era lido o Termo de Consentimento Livre e Esclarecido, que continha informações sobre o estudo, objetivos, garantia de confidencialidade das informações prestadas pelo respondente e o contato do pesquisador responsável. $\mathrm{O}$ respondente devia consentir verbalmente antes de o entrevistador iniciar a entrevista individual.

A fim de reduzir perdas em nosso estudo, aos domicílios de classe mais elevada, selecionados para a amostra, foram enviadas pela Fiocruz (coordenação central do estudo) correspondências oficiais explicando a pesquisa e a 
importância da participação daquele domicílio no estudo, indicando ainda o entrevistador responsável pela coleta de dados naquele local. Com relação aos domicílios localizados em áreas menos seguras e/ou de difícil acesso, como, por exemplo, comunidades e favelas, a equipe de campo era acompanhada por um facilitador conhecido no local, como um morador da região ou agente comunitário de saúde.

Além das informações contidas no questionário, coletaram-se as coordenadas geográficas dos domicílios visitados, a fim de que fossem realizadas análises com um componente espacial, assim como verificada a consistência entre domicílio designado e efetivamente visitado (ou seja, coordenadas geográficas coincidentes).

Após a coleta de dados, realizada de abril a novembro de 2012, em cerca de $6 \%$ da amostra de cada local, procedeu-se à (re)checagem de algumas informações básicas sobre o domicílio, de modo a validar a entrevista naquele local e controlar a qualidade das informações coletadas pela equipe de campo.

O presente capítulo, e o estudo mais amplo que lhe serviu de base, é o primeiro desenvolvido em nível nacional no Brasil para estimativa indireta do número de usuários de drogas. Pesquisas futuras, de natureza local ou deste mesmo porte, devem ser realizados visando a aprimorar o desenho e a aplicação da metodologia Network Scale-up.

\section{CONCEITOS BÁsicos que NORTEARAM O ESTUdO}

Os usuários de crack integram a população que faz uso de diferentes drogas ilícitas. Porém, este subgrupo ganhou especial visibilidade e se tornou objeto da atenção dos meios de comunicação, da sociedade e dos gestores públicos por consumir a droga em locais públicos/abertos e em grupos, principalmente nos grandes centros urbanos. Usuários dos similares do crack (como pasta base e merla) apresentam comportamento similar e, na verdade, na ausência de exames toxicológicos sistemáticos nas diversas cenas de uso em todo o país, e em se tratando de um mercado ilícito e, portanto, não regulado por nenhuma instância de verificação dos produtos consumidos, não necessariamente a substância referida pelo entrevistado mantém correspondência com algo definido enquanto tal pela análise toxicológica. Portanto, essas denominações por parte dos próprios consumidores (definidas como "êmicas" no âmbito da etnografia) são fluidas, e frequentemente se confundem e se superpõem). 
O consumo de drogas no Brasil e no mundo (com óbvias especificidades regionais e locais) deve ser encarado não apenas como um problema de saúde pública, mas também como uma questão que perpassa outros setores para além da saúde, como a segurança pública e a assistência e o desenvolvimento social de uma maneira mais ampla. Assim, políticas públicas ancoradas num conjunto amplo de evidências empíricas e multissetoriais devem ser a base para a formulação e reformulação de ações voltadas para este grupo populacional, os usuários de drogas de um modo geral, e de crack, de forma específica. Uma etapa essencial à formulação, monitoramento e avaliação destas ações é ter o correto dimensionamento da magnitude e características desta população, ou seja, saber para quem e para quantos estas políticas devem ser formuladas e implementadas.

Este capítulo, e o estudo nacional que lhe serve de base, contemplou um quantitativo de aproximadamente 25.000 entrevistas, com residentes nas capitais do país. Essas pessoas foram visitadas em seus domicílios e responderam a questões sobre suas redes sociais (de uma forma geral e com um foco em usuários de crack e outras drogas) e também sobre seus comportamentos.

No estudo não levamos em consideração os usuários que consomem essas substâncias polvilhadas em cigarros de tabaco ou maconha. Ressalta-se, no entanto, que aquilo que os entrevistados descrevem como similares do crack refere-se, exclusivamente, ao que é fruto das definições dos próprios consumidores e/ou seus conhecidos (membros de suas redes sociais), e não dos resultados de análises toxicológicas.

A razão da não inclusão nas estimativas dos consumidores de crack (ou similares) polvilhado em cigarros de maconha (ou tabaco) se deve a uma limitação intrínseca ao método, referente à visibilidade e possibilidade de "transmissão" acurada de informações acerca de um determinado hábito, comportamento ou prática. Se, por um lado, o consumo do crack fumado ou similares constitui um hábito de grande visibilidade social, a ponto de ser objeto de milhões de acessos nas mais diferentes redes sociais, com forte presença nos mais diversos (ainda que, por vezes, desprovidos de qualquer base empírica e de conteúdo fortemente estigmatizante; mas nem por isso menos acessados) registros fotográficos e vídeos, ${ }^{5}$ o consumo do crack (ou similares) polvilhado em cigarros de maconha e tabaco é de difícil ou impossível visualização por parte de terceiros. Há relatos de natureza etnográfica acerca do seu uso em

A título de exemplo, o próprio leitor pode repetir a busca simples, no YouTube, que, em segundos, gera centenas de links, em: <www.youtube.com/results?search_query=crack $>$. 
diferentes contextos brasileiros (ver, por exemplo, Andrade e colaboradores, 2011), mas nenhum artigo publicado que quantifique esse uso, seja de forma isolada, seja como fração (expressiva?) do consumo do crack e similares nesses mesmos contextos.

Como em toda situação de visibilidade muito limitada e definição imprecisa, o fenômeno pode não ser percebido pelo entrevistado (que pode afirmar saber que um dado amigo fuma cigarros de maconha ou tabaco, sem sequer fazer ideia de que esse cigarro estaria polvilhado de crack ou similar), mas também pode ser exagerado ou distorcido (se alguém é usuário de maconha, por que razão esta maconha não estaria batizada com crack?). ${ }^{6}$ Portanto, este hábito pode ser marcadamente subestimado, mas também marcadamente superestimado pelo entrevistado. Como mencionado anteriormente, diferentes ajustes podem corrigir resultados subestimadas, mas o método se torna inválido se a prevalência de um determinado hábito é superior a $4 \%$ na população pesquisada. Como fumar maconha e cigarros de tabaco tem prevalências superiores a $4 \%$ em todos os levantamentos até hoje realizados com a população brasileira (embora, em relação à maconha haja uma notória indistinção entre uso regular e eventual), o método se defronta aqui com uma limitação intransponível: existe aí uma zona de sobreposição, de extensão ignorada, de um evento com frequência desconhecida, mas, relativamente raro (segundo as etnografias disponíveis) e dois eventos bastante frequentes.

Ainda, para fins deste estudo, utilizou-se a definição de "uso regular" para o uso de droga pelo menos 25 dias nos últimos seis meses, sendo esta uma definição da Organização Pan-Americana de Saúde (Opas), que norteia o conjunto de materiais (como manuais, questionários e listagens de indicadores) da iniciativa Codar, daquela organização. ${ }^{7}$

Cabe observar que não se trata de 25 vezes, mas sim dias, pois usuários de algumas substâncias (como cocaína em pó e crack), frequentemente fazem uso das mesmas de forma repetida, num curto espaço de tempo, no contexto de um mesmo dia.

6 Distorções dessa natureza foram cuidadosamente analisadas em Salganik e colaboradores (2011a). Ver discussão disponível na página 1.194 do referido artigo (em especial, o conceito de "inflação de estimativas", com base na referência de número 32).

7 O leitor interessado poderá obter, gratuitamente, todos esses materiais em: <www.paho.org/hq/ index.php?option=com_content $\&$ view=article $\& i d=853 \% 3$ Aencuestas-de-comportamientoen-consumidores-de-drogas-con-alto-riesgo-codar\&catid=745\%3A----fch-surveillance $\% 2 \mathrm{C}$ monitoring\%2C-and-evaluation\&lang=en>. Acesso em: 24 ago. 2015. 
As estimativas, inicialmente geradas, referem-se ao consumo de "crack e/ou similares" e também a "somente crack". Como era de se esperar, a estimativa referente ao uso de crack e/ou similares é maior do que aquela referente ao uso exclusivo do crack. Contudo, em função do possível erro de informação sobre a substância exata, do ponto de vista farmacológico e toxicológico, utilizada pelo usuário de crack/similares pertencente à rede social do respondente do inquérito domiciliar, optou-se por apresentar os resultados de todas as análises subsequentes com relação ao uso de "crack e/ou similares".

\section{EStimativas RefERENTES AO CONSUMO DE CRACK/SiMILARES POR PARTE DE CRIANÇAS E ADOLESCENTES}

O estudo avaliou o quantitativo de usuários de crack e/ou similares entre crianças e adolescentes. Para as capitais do Brasil, observou-se que dos 0,81\% da população que se estimou ser consumidora regular de crack e/ou similares, 0,14\% eram crianças e adolescentes; e 0,67\% eram maiores de idade (Gráficos 1 e 2). Ou seja, dos 370 mil usuários de crack e/ou similares estimados, temse que cerca de $14 \%$ corresponderiam a menores de idade, o que representa aproximadamente 50 mil crianças e adolescentes que fazem uso dessas substâncias nas capitais do país.

Cabe observar que o consumo de qualquer droga cujas consequências são sabidamente graves por parte de crianças e adolescentes constitui um achado particularmente preocupante. Ressalta-se também que a faixa de menores de 18 anos inclui grupos em que o consumo de crack é nulo (por exemplo, bebês menores de 1 ano) ou muito baixo/praticamente zero (por exemplo, crianças até 8 anos). Isso significa que, se fossem excluídas todas as crianças de idade bastante baixa, o consumo proporcional por parte de adolescentes seria mais relevante e mais elevado, ainda que menor do que o consumo por parte de adultos. 
Gráfico 1 - Estimativas (em percentual) do uso regular nos últimos seis meses de "crack e/ou similares", nas capitais do Brasil, por grupo etário - 2012

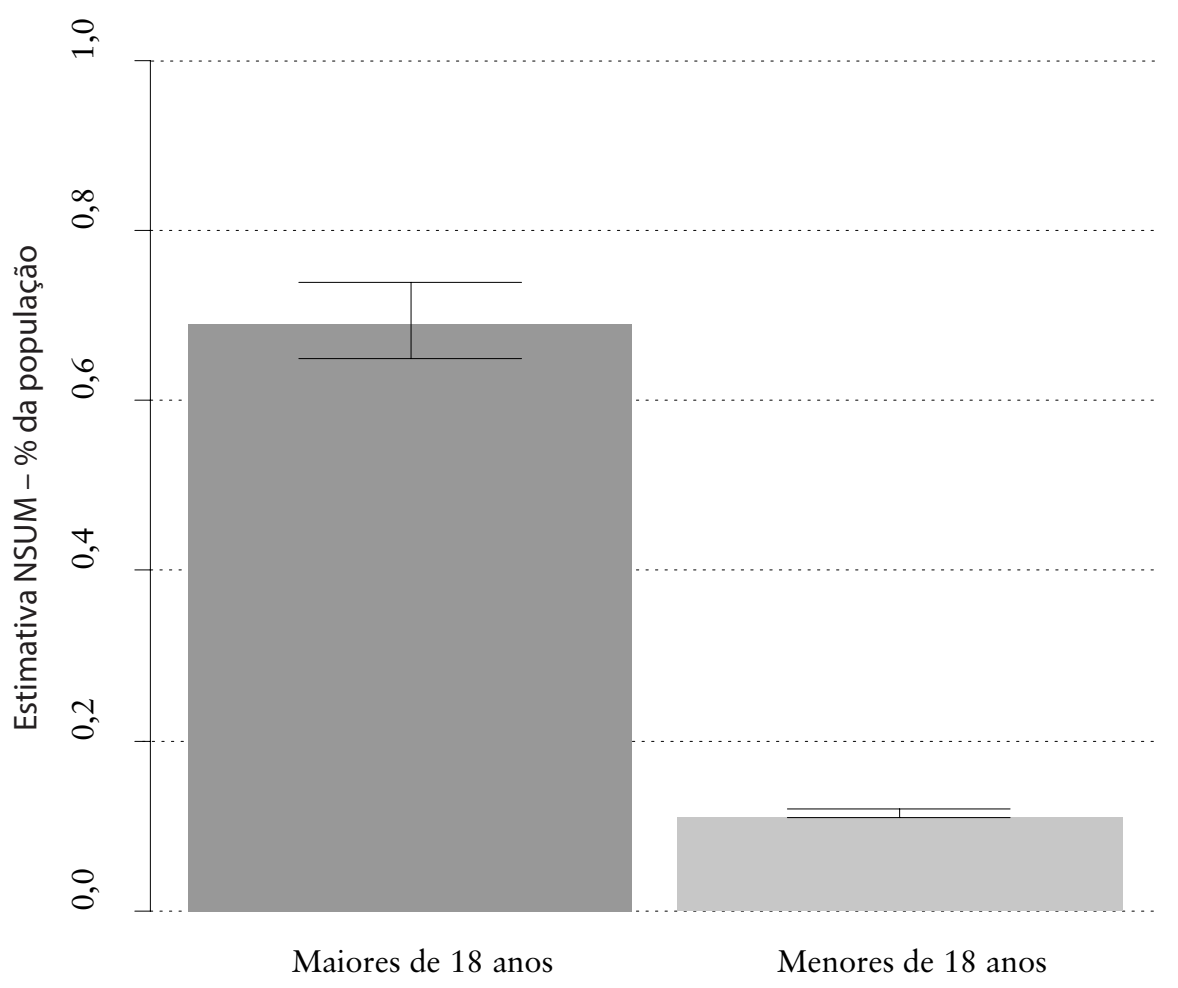


Gráfico 2 - Estimativas (em números absolutos) do uso regular nos últimos seis meses de "crack e/ou similares", nas capitais do Brasil, por grupo etário - 2012

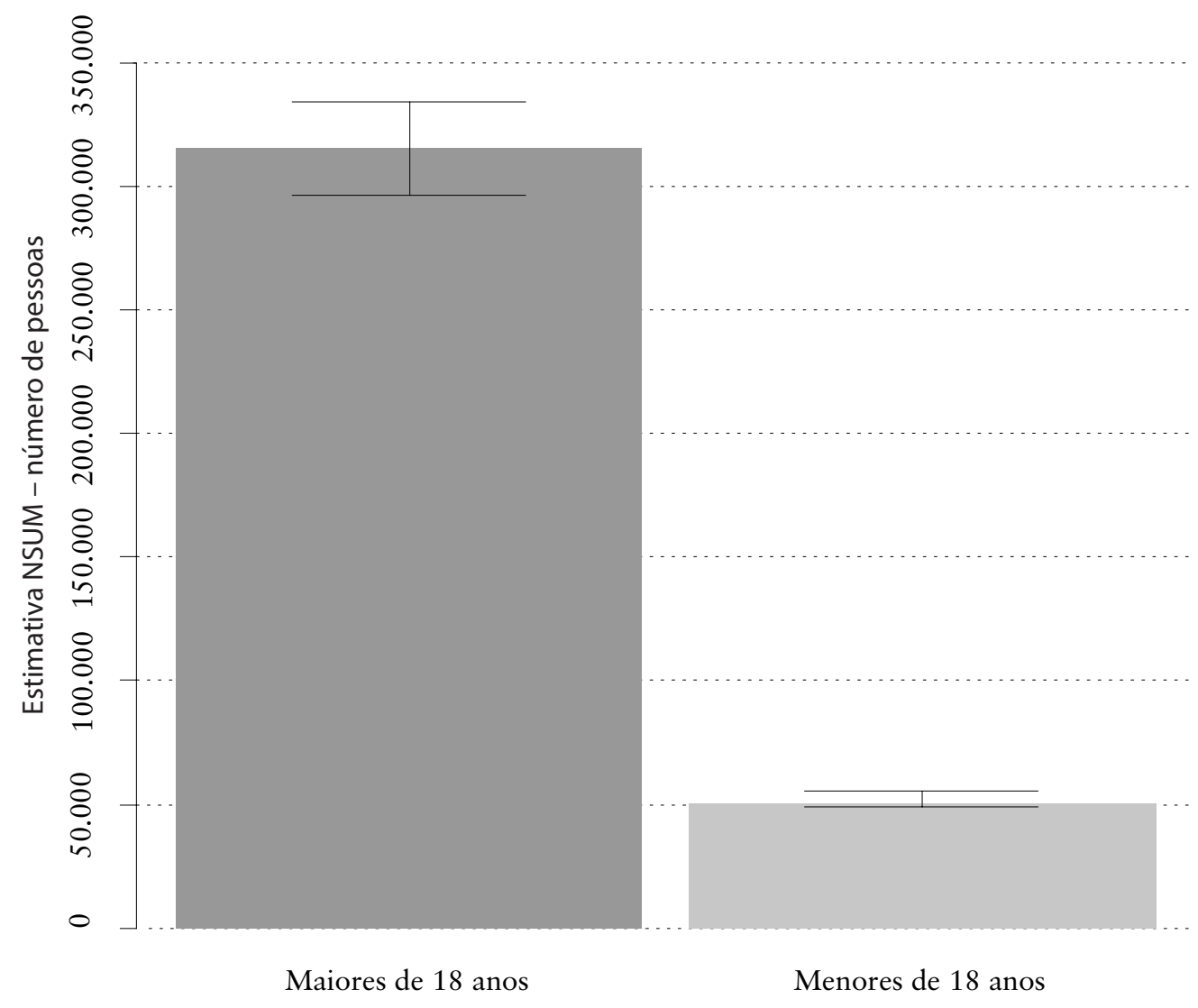

As proporções de usuários menores de idade variam de forma substancial conforme a região do país (Gráficos 3 e 4). As capitais da região Nordeste são as que contam com um maior quantitativo de crianças e adolescentes consumidores de crack e/ou similares, com mais de 28 mil consumidores regulares dessas substâncias. Já nas capitais das regiões Sul e Norte, esse número é levemente superior a 3 mil crianças e adolescentes, em cada uma das regiões. Cabe observar que cada uma das estimativas, agregadas - para as capitais de todo o país - e desagregadas por macrorregião, está inserida nos limites dos seus respectivos intervalos de confiança, e, portanto, não necessariamente a soma aritmética das 
estimativas pontuais de cada macrorregião gera um total idêntico ao resultado referente ao país, bastante mais preciso, por contar com um quantitativo maior de entrevistas.

Gráfico 3 - Estimativas (em percentual) do uso regular nos últimos seis meses de "crack e/ou similares", nas capitais do Brasil, por grupo etário, segundo macrorregião - 2012

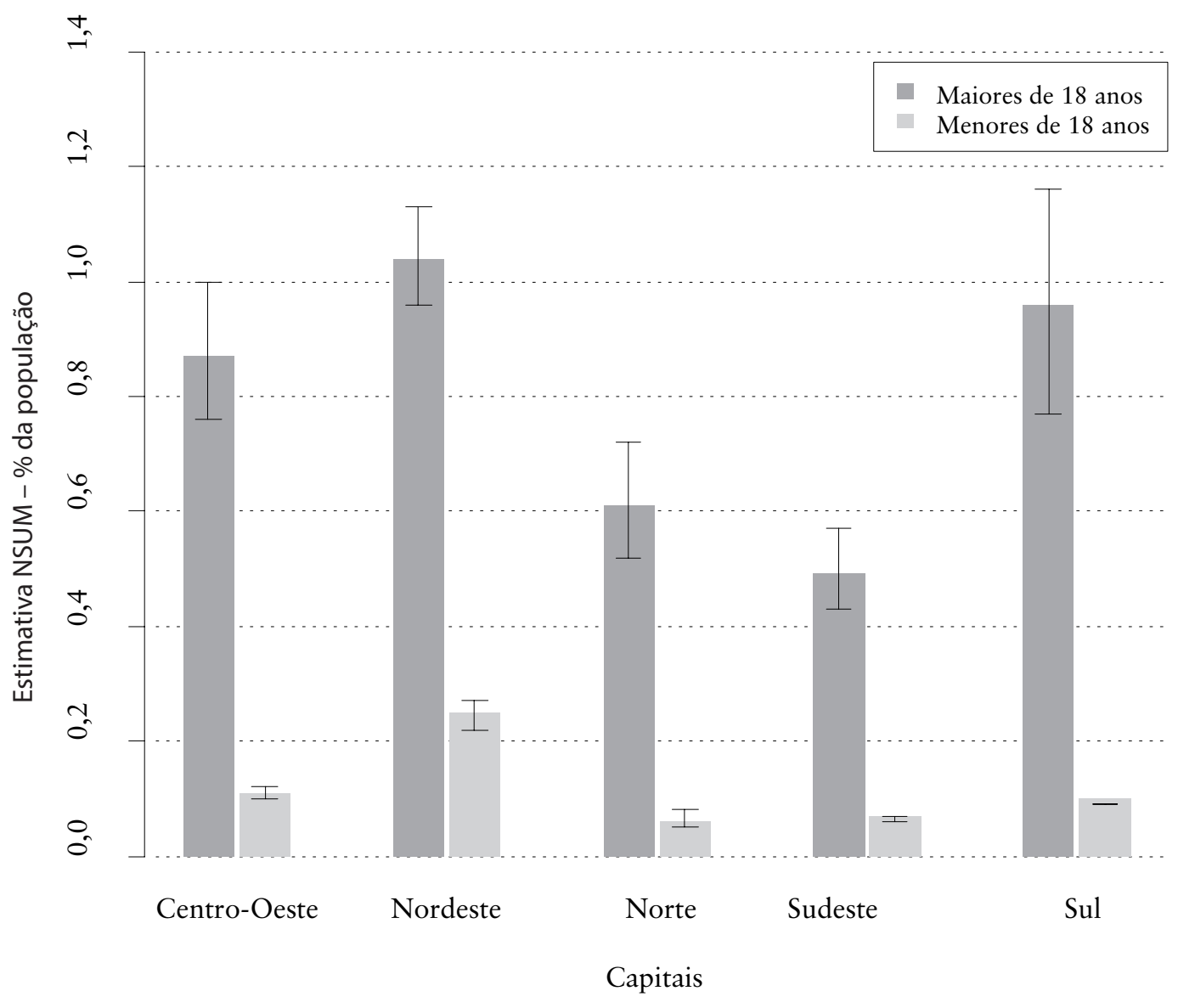


Gráfico 4 - Estimativas (em números absolutos) do uso regular nos últimos seis meses de "crack e/ou similares", nas capitais do Brasil, por grupo etário, segundo macrorregião - 2012

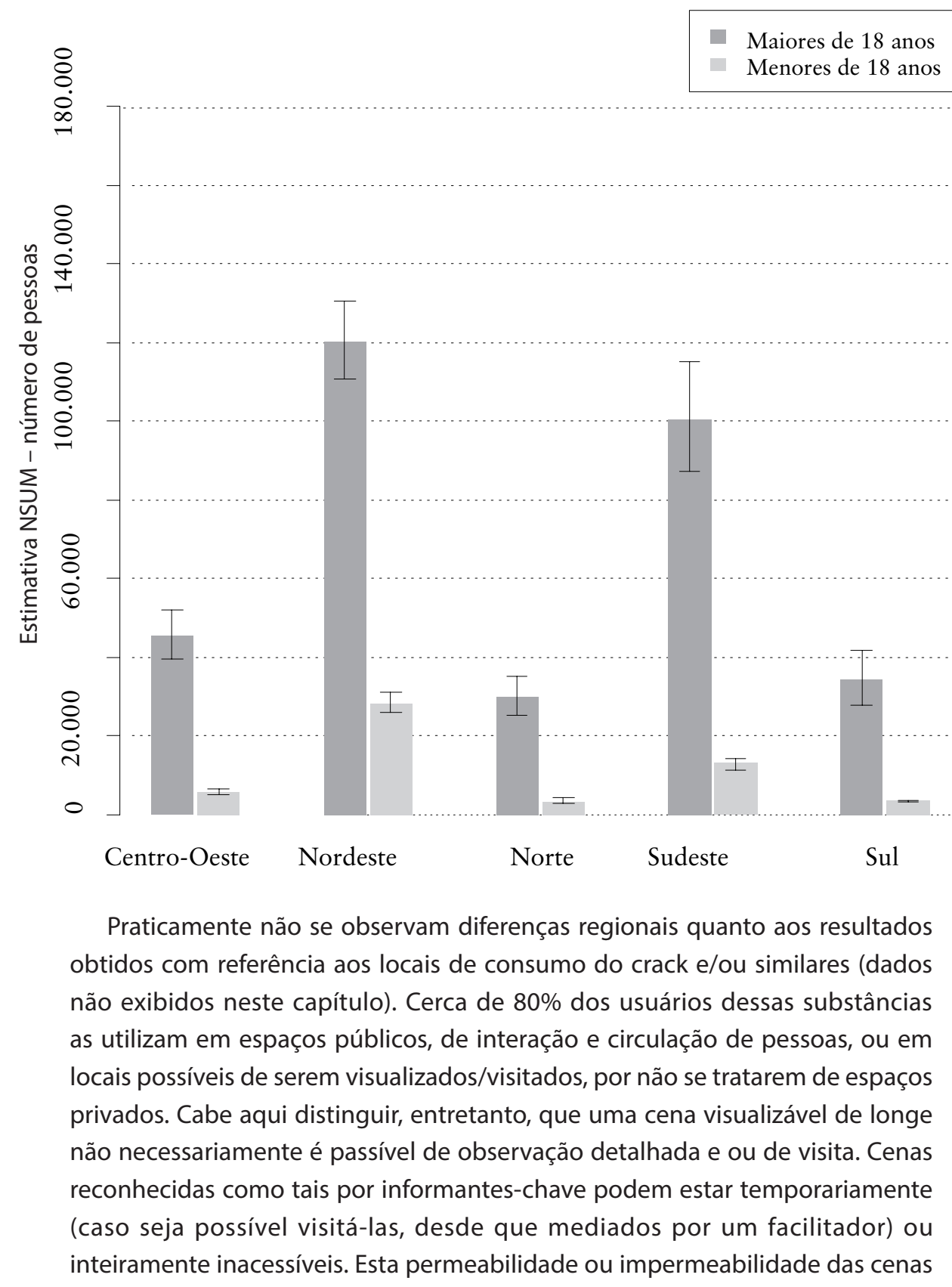


depende das decisões de facções criminosas, de confrontos entre facções ou do confronto entre uma dada facção e as forças de segurança. Portanto, visibilidade não se traduz necessariamente em acessibilidade.

Ressalta-se que tal resultado não indica que esse é o percentual de usuários de drogas que vive nas ruas ou sem moradia fixa, mas reforça a ideia de que realizar inquéritos domiciliares tradicionais para a estimação do número de populações ocultas que são objeto de forte estigmatização e eventual criminalização, como a de usuários de crack e/ou similares, subestimaria o número real desses indivíduos, uma vez que tais métodos, por perguntarem diretamente ao respondente sobre o seu próprio uso de drogas, dificilmente conseguiriam encontrar os usuários em seus domicílios no momento de realização das entrevistas, além de terem de contornar as barreiras evidentes à explicitação de um comportamento fortemente estigmatizado.

\section{INFORMAÇÕES ADICIONAIS}

A Pesquisa Nacional do Crack não entrevistou diretamente crianças e adolescentes nos seus dois componentes, referentes ao inquérito domiciliar por meio da metodologia Network Scale-up, e no inquérito epidemiológico realizado com mais de 7.300 indivíduos maiores de 18 anos nas cenas de uso. A autorização para realizar essas entrevistas não nos foi concedida pelos diferentes Comitês de Ética a que ela foi submetida, em função do eventual constrangimento e caráter extremamente sensível das diversas perguntas feitas aos entrevistados.

Entretanto, as entrevistas foram precedidas por um trabalho longo e minucioso de verificação e descrição de cada uma das cenas onde as entrevistas foram realizadas em todo o país. Esse trabalho foi coligido em milhares de arquivos referentes a Cadernos de Campo, que estão sendo escaneados e analisados, com auxílio do software de gerência de dados qualitativos Atlas.ti ${ }^{\circledR}$.

Estes Cadernos de Campo sistematizam informações relativas às cenas (variáveis contextuais), embora não contemplem entrevistas de quaisquer indivíduos específicos. Entre as informações de natureza ecológica (não individual) coletadas, os observadores procederam à contagem das pessoas presentes em cada uma das cenas visitadas, discriminadas por turnos/dia de visita (ou seja, levando em conta não apenas o local, mas o momento específico do registro de cada local visitado). 
Por ora, apenas a análise referente à cidade do Rio de Janeiro foi inteiramente concluída, e gerou resultados em tudo similares às estimativas obtidas pela metodologia Network Scale-up. Trata-se de uma análise por triangulação das informações, uma vez que os Cadernos de Campo lidam com cenas de pequeno, médio e grande porte, mas mesmo cenas de grande porte congregam algo como uma, no máximo, duas centenas de indivíduos, que, por essa razão, podem ser contados, num dado local e momento. Já o NSUM gera estimativas (e não contagens), referentes a populações de grande magnitude e não passíveis de enumeração, e se vale de informações obtidas de modo indireto, que dizem respeito não aos entrevistados, mas sim a membros das suas redes sociais.

A despeito de todas essas óbvias diferenças, os achados convergem no sentido de que crianças e adolescentes enumerados (mas não entrevistados) nas cenas de uso se distribuem nas cenas-turno (locais específicos em diferentes períodos da semana e de cada dia) de forma extremamente diversa, que compreende desde a sua simples ausência, em cenas marcadamente violentas e impermeáveis à observação do público, até sua presença em cenas abertas, em locais mais urbanizados, permeáveis, onde a presença do tráfico armado não é tão ostensiva. Nos primeiros locais, em que a violência é intensa e estrutural, e o acesso bastante limitado, crianças e adolescentes têm presença incidental, basicamente como olheiros e encarregados de tarefas pontuais (como buscar e levar objetos e informações), mas lá não permanecem. No dizer dos próprios líderes do tráfico: "isso não é lugar para criança”. Nas demais cenas, abertas e menos violentas (aquelas visualizadas pela sociedade em geral e pelos meios de comunicação), a presença de crianças e adolescentes é quase sempre registrada nos Cadernos de Campo. A despeito das marcantes variações, em função de local e período, a proporção média de crianças e adolescentes no conjunto de cenas/turno observado se situa em patamar similar, de cerca de $14 \%$ do total de indivíduos enumerados no conjunto de cenas-turno da cidade do Rio de Janeiro.

\section{DiscussÃo}

Cabem aqui algumas observações empíricas e metodológicas. Em primeiro lugar, documentamos neste capítulo a aplicação bem-sucedida de uma metodologia inovadora, de utilização ainda muito pouco frequente no país, especialmente em saúde pública. 
Devemos ter em mente que a pesquisa em foco respondeu a uma demanda do governo e da sociedade para investigar um fenômeno emergente, de fácil visualização (ainda que isso não se traduza, de forma simplista, em fácil compreensão), que foi o aparecimento em grandes áreas urbanas, e também em cidades de menor porte e pior infraestrutura urbana, de cenas abertas de consumo, que, nas cidades de maior porte, foram denominadas "cracolândias" e receberam ampla cobertura dos meios de comunicação e a atenção da sociedade.

Portanto, constitui uma evidência empírica que existiam à época da pesquisa, e, em boa medida, ainda existem cenas abertas de consumo, em locais públicos, de maior ou menor magnitude, permeabilidade e dinâmicas complexas e singulares. A resposta do Poder Público e dos pesquisadores deve ser a de buscar métodos e procedimentos que possam ir ao encontro dessa percepção social, ou seja, desenvolver ferramentas capazes de estimar, com precisão, o número de pessoas que ocupam parte do seu tempo nessas cenas, e, portanto, passam boa parte do tempo, nas ruas, ou mesmo estão em situação de rua, lá residindo em condições precárias.

Quando essa demanda foi formulada, nosso grupo de pesquisa, em parceria com os colegas da Universidade de Princeton, havia terminado há pouco um estudo com finalidade correlata e grande sucesso empírico, documentado pela sua publicação nas revistas mais prestigiosas do mundo, nas áreas de epidemiologia e análise de redes sociais, respectivamente. Portanto, a pesquisa em pauta constitui um desdobramento natural da anterior, que também dizia respeito a usuários de drogas ilícitas, ainda que sem ênfase, naquela ocasião, no consumo de crack. ${ }^{8}$

Duas observações adicionais se fazem aqui necessárias. A plena implementação de novos métodos de pesquisa não invalida, de forma alguma, que os inquéritos clássicos devam ter continuidade e aprofundamento, pois constituem fonte indispensável de dados para séries históricas longas (obviamente, desde que se valham de desenhos amostrais e estratégias de investigação comparáveis

8 O conjunto de publicações, banco de dados e rotinas de análise referente à pesquisa anterior, realizada em Curitiba, está disponível para download, a custo zero em: $<$ http://opr.princeton.edu/ archive/NSUM >. Recentemente, tivemos a grata surpresa de termos nossos dados exaustivamente examinados por um segundo grupo, independente, de pesquisadores norte-americanos, que, valendo-se de estratégias de análise distintas das que havíamos adotado, chegaram a resultados em tudo similares. (Disponível em: <http://nersp.osg.ufl.edu/ ufruss/scale-up/maltiel\%202013. pdf $>$. Acesso em: 24 ago 2015). 
entre si), de que dispõem os países mais avançados em pesquisa, como nas longas séries históricas de pesquisas domiciliares norte-americanas ${ }^{9}$ e europeias. ${ }^{10}$

Entretanto, é fundamental observar que diferentes questões exigem o desenvolvimento de inquéritos que guardam especificidades importantes. Há décadas os inquéritos domiciliares norte-americanos sobrerrepresentam, propositalmente, populações específicas que os pesquisadores e os formuladores de políticas públicas desejam conhecer em maior detalhe, como, por exemplo, diferentes subgrupos da população hispânica. Portanto, caso a pergunta central de um dado estudo se refira ao consumo de álcool e outras drogas por parte de uma dada minoria, seja ela de gênero ou identidade sexual, racial/étnica, cultural ou religiosa, tal especificidade deve ser plenamente incorporada ao desenho amostral do estudo, pois, por definição, dados referentes a quaisquer minorias habitualmente geram observações esparsas, que não possuem o adequado poder estatístico quando o foco primário é exclusivamente a população geral.

Da mesma forma, o consumo de cada substância requer um desenho amostral que possibilite estimar com segurança padrões de uso eventualmente esparsos na população geral. Por exemplo, toda e qualquer pesquisa já realizada no Brasil com quaisquer populações, sejam elas domiciliadas ou "cativas" (na sua acepção técnica, e não do senso comum, ou seja, escolares, população carcerária e pacientes de serviços de saúde não especializados, entre outras), documenta que o álcool é o produto de uso mais prevalente entre todas as substâncias psicoativas consumidas no país. Portanto, amostras de inquéritos referentes ao álcool podem lançar mão de quantitativos substancialmente diminutos, se comparados a estudos que focalizem quaisquer substâncias de uso menos prevalente, especialmente se este uso ocorre majoritariamente em contexto não domiciliar.

Ainda nesta mesma linha de raciocínio, cabe também ressaltar que diferentes substâncias estão associadas a diferentes taxas de não-resposta e a diferenciais expressivos de mensuração em função das estratégias de pesquisa utilizadas. Assim, inquéritos domiciliares clássicos devem sempre levar em conta estas especificidades.

9 Consultar, entre outras fontes, o site oficial do NSDUH. Disponível em: <https://nsduhweb. rti.org >. Acesso em: 24 ago. 2015.

10 Disponíveis, entre outras fontes, em: <www.emcdda.europa.eu>. Acesso em: 24 ago. 2015. 


\section{NOTAS FINAIS}

Ainda que os resultados obtidos com o NSUM sejam mais elevados do que aqueles gerados pela metodologia tradicional, não podemos afirmar se há ou não no país uma epidemia do uso de crack e/ou similares, uma vez que uma epidemia só pode ser caracterizada tecnicamente com base em resultados obtidos de uma série histórica de registros de estimativas/contagens do fenômeno sob análise, série esta estabelecida com base em critérios e métodos comparáveis entre si.

Contudo, este estudo nos traz uma dimensão do atual problema do consumo de crack e/ou similares nas capitais do país e pode ser visto como uma linha de base (baseline) para estudos futuros com a utilização de mesma metodologia, com o propósito de gerar séries históricas consistentes e confiáveis.

Além disso, a partir dele é possível pensar em políticas públicas que levem em consideração, por exemplo, as diferenças quantitativas em cada macrorregião para fins de elaboração e implementação de estratégias de tratamento e afins. Ressaltamos também a importância de estratégias voltadas para a população de crianças e adolescentes.

Embora essa população não constitua a maior parte de consumidores regulares de crack e/ou similares nas capitais do Brasil, tem ela particular relevância em função de incidir, no caso de crianças e adolescentes, em uma população cujo processo de desenvolvimento e maturação biológica e psicológica está em curso e em função das vulnerabilidades acrescidas que tal consumo abusivo e/ou dependente pode determinar, com marcantes diferenciais por estrato social, gênero e faixa etária.

\section{REFERÊNCIAS}

ANDRADE, T. et al. 'What a pity!' Exploring the use of 'pitilho' as harm reduction among crack users in Salvador, Brazil. Drugs: education, prevention, and policy 18(5): 382-386, 2011.

BERNARD, H. R. et al. Estimating the size of an average personal network and of an event subpopulation: some empirical results. Social Science Research, 20: 109-121, 1991.

$E Z O E$, S. et al. 2012. Population size estimation of men who have sex with men through the Network Scale-up Method in Japan. Plos One, 7: e31184, 2012.

FRIEDMAN, S. R. et al. Social Networks, Drug Injectors' Lives and HIV/Aids. New York: Kluwer Academic/Plenum Publishers, 1999.

GFROERER, J.; LESSLER, J. \& PARSLEY, T. Studies of nonresponse and measurement error in the national household survey on drug abuse. Nida - Research Monographs, 167: 273-295, 1997. 
GUO, W. et al. Estimating the size of HIV key affected populations in Chongqing, China, using the Network Scale-Up Method. Plos One, 8: e71796, 2013.

HACKER, M. A. et al. Poverty, bridging between injecting drug users and the general population, and "interiorization" may explain the spread of HIV in southern Brazil. Health Place, 15, 514-519, 2009.

JOUANJUS, E. et al. Use of multiple sources and capture-recapture method to estimate the frequency of hospitalizations related to drug abuse. Pharmacoepidemiology and Drug Safety, 21(7): 733-741, 2012.

KADUSHIN, C. et al. Scale-up methods as applied to estimates of heroin use. Journal of Drug Issues, 6: 417-440, 2006.

KILLWORTH, P. D. et al. A social network approach to estimating seroprevalence in the United States. Social Networks, 20: 23-50, 1998a.

KILLWORTH, P. D. et al. Estimation of seroprevalence, rape, and homelessness in the United States using a social network approach. Evaluation Review, 22: 289-308, 1998b.

MORRAL, A. R.; McCAFFREY, D. F. \& CHIEN, S. Measurement of adolescent drug use. Journal of Psychoactive Drugs, 35: 301-309, 2003.

PANIOTTO, V. et al. Estimating the Size of Populations with High Risk for HIV Using the Network Scale-up Method. Kiev: Kiev International Institute of Sociology, s. d. Disponível em: <http://nersp.osg.ufl.edu/ ufruss/scale-up/Ukraine_Final\%20 Report_scale-up_eng_July24.pdf $>$.

ROGERS, S. M.; MILLER, H. G. \& TURNER, C. F. Effects of interview mode on bias in survey measurements of drug use: do respondent characteristics make a difference? Substance Use \& Misuse, 33: 2.179-2.200, 1998.

SALGANIK, M. J. \& FEEHAN, D. Generalized network scale-up method for estimating the size of hard-to-count populations. Princeton University, s. d. (Technical Report). Disponível em: <http://arxiv.org/pdf/1404.4009.pdf>. Acesso em: 25 ago. 2015.

SALGANIK, M. J. et al. Assessing network scale-up estimates for groups most at risk of HIV/Aids: evidence from a multiple-method study of heavy drug users in Curitiba, Brazil. American Journal of Epidemiology, 174, 1.190-1.196, 2011 a.

SALGANIK, M. J. et al. The game of contacts: estimating the social visibility of groups. Social Networks, 33(1): 70-78, $2011 \mathrm{~b}$.

SALMON, C. T. \& NICHOLS, J. S. The next-birthday method of respondent selection. The Public Opinion Quarterly, 47: 270-276, 1983.

SNIDERO, S. et al. Use of the scale-up methods in injury prevention research: an empirical assessment to the case of choking in children. Social Networks, 29: 527-538, 2007.

SZWARCWALD, C. L. \& CASTILHO, E. A. Estimated number of HIV-infected individuals aged 15-49 years in Brazil, 1998. Cadernos de Saúde Pública, 16: 135-141, 2000.

UNAIDS. WHO Working Group on Global HIV/Aids and STI Surveillance. Guidelines on Estimating the Size of Populations Most at Risk to HIV. Geneva: Unaids/WHO Working Group on Global HIV/Aids and STI Surveillance, s. d. 


\title{
3 \\ A (Des)Atenção às Crianças e Adolescentes Usuários de Crack de Manaus
}

\author{
Patricia Constantino \\ Luciana Alencar Peixoto
}

Este capítulo tem como objetivo mapear as ações destinadas à atenção a crianças e adolescentes usuários de crack ou cujos pais/responsáveis utilizam esta substância no município de Manaus, principal centro financeiro, corporativo e econômico da região Norte do Brasil. Serão apresentados dados socioeconômicos da cidade, destacando-se o uso de drogas no território. A institucionalização de crianças e adolescentes por uso de crack e/ou pelo uso de seus pais/responsáveis será aqui analisada, assim como a visão de gestores, profissionais das áreas da saúde, assistência social e justiça. Destacam-se também no capítulo a representação de adolescentes e mães de usuários sobre o consumo e seus efeitos e a avaliação das instituições e serviços destinados aos usuários de crack e seus familiares.

\section{A CidAdE DE MANAUS}

Manaus, capital do estado do Amazonas, é uma cidade portuária, localizada no centro da maior floresta tropical do mundo. Situa-se na confluência dos rios Negro e Solimões. É uma das cidades brasileiras mais conhecidas mundialmente, principalmente pelo seu potencial turístico, o que faz do município o décimo maior destino de turistas no Brasil. Destaca-se pelo seu patrimônio arquitetônico e cultural, com numerosos templos, palácios, museus, teatros, bibliotecas e universidades. 
É a cidade mais populosa do Amazonas e da Amazônia, com uma população de 1.861.838 habitantes, de acordo com estimativas do Instituto Brasileiro de Geografia e Estatística (IBGE) para 2012, sendo também a 131ª metrópole mais populosa do mundo. Manaus aumentou gradativamente a sua participação no produto interno bruto (PIB) brasileiro nos últimos anos, passando a responder por 1,4\% da economia do país. No ranking da revista América Economía, Manaus aparece como uma das 20 melhores cidades no ramo de negócios da América Latina, ficando à frente de capitais nacionais, como São Salvador, Caracas e La Paz.

Originalmente fundada em 1669 com o forte de São José do Rio Negro, foi elevada à vila em 1832 com o nome de Manaus, em homenagem à nação indígena dos manaós, sendo legalmente transformada em cidade no dia 24 de outubro de 1848, com o nome de Cidade da Barra do Rio Negro. Somente em 1856 voltou a ter seu nome atual. Ficou conhecida no começo do século XX, na época áurea da borracha, quando foi batizada como "Coração da Amazônia" e "Cidade da Floresta". Atualmente seu principal motor econômico é o Polo Industrial de Manaus.

Sexta cidade mais rica do Brasil, Manaus possui a maior região metropolitana do norte do país e a décima do Brasil, com 2.210.825 habitantes (IBGE, 2011). Apesar de sua relevância histórica, populacional e econômica, Manaus apresenta grandes disparidades intramunicipais.

O espaço urbano de Manaus, como a maioria dos municípios brasileiros, é extremamente desigual, e a perversidade dessa desigualdade é que ela é completamente explícita. Praticamente não existe barreira alguma (nem mesmo ruas) que dividem esses espaços. Assim, realidades em desenvolvimento humano só encontradas em países de terceiro mundo convivem, lado a lado, com outras que, muitas vezes, ultrapassam os parâmetros dos países mais desenvolvidos. Se são regiões desiguais em renda, são mais ainda em indicadores sociais e principalmente educação. (Amazonas, 2005)

Manaus ocupa o $850^{\circ}$ lugar no ranking nacional do Índice de Desenvolvimento Humano Municipal (IDHM = 0,737 em 2010). Entre 2000 e 2010, o maior crescimento foi em educação $(0,215)$, seguido por longevidade e renda. Em 2000, as Unidades de Desenvolvimento Humano (UDHs) de Manaus (81 unidades espaciais análogas aos bairros dentro do município) com IDH mais alto tinham o mesmo valor da Noruega, país com o mais 
alto índice segundo a Organização das Nações Unidas (ONU). Entretanto, as UDHs do município com os índices mais baixos aproximam-se do valor encontrado para a Bolívia.

\section{Educação}

Em Manaus, assim como no Amazonas e no Brasil, a dimensão com o subíndice mais alto é educação. Um dos indicadores levados em conta no IDHM Educação é a taxa de analfabetismo das pessoas acima de 15 anos, entendendose por analfabeto aquele que se declara incapaz de ler e escrever um bilhete simples, conforme a definição para a pesquisa do Censo.

Observando inicialmente o percentual das pessoas de 15 anos e mais, com menos de quatro anos completos de estudo, chamados analfabetos funcionais, nota-se que, enquanto o total de analfabetos do município de Manaus é de $6 \%$, a taxa de analfabetismo funcional é quase três vezes maior, $17 \%$, o que representa um contingente de 161 mil pessoas.

Em 63\% das UDHs, as taxas são melhores ou iguais à taxa de Manaus (17\%), que, por sua vez, é o município do Amazonas com a taxa mais baixa. Contudo, em 14 UDHs, a taxa de analfabetismo funcional está acima de um quarto da população de 15 anos e mais.

Se o IDHM fosse calculado com as taxas de alfabetização funcional, o índice de Manaus, como o de todas as suas UDHs, cairia de modo expressivo, principalmente naquelas em que o IDHM já era mais baixo. $\mathrm{O}$ número de UDHs na categoria médio-médio aumentaria (de 14 para $23 \mathrm{UDHs}$ ), diminuindo a participação das categorias médio-alto (de 44 para 41 UDHs) e alto (de 24 para $17 \mathrm{UDHs}$ ).

Quanto à taxa de analfabetismo fundamental da população adulta (pessoas de 25 anos e mais que têm menos de oito anos de estudo), Manaus é o município com a melhor taxa do estado, que, porém, chega quase à metade de sua população adulta (49\%). Em 53\% das UDHs, o índice é ainda mais alto. Portanto, na maioria das UDHs, a taxa de analfabetismo fundamental corresponde a mais de $50 \%$ das respectivas populações adultas. Constituem um contingente de 303 mil pessoas, ou seja, superior ao triplo da população total do município de Parintins. Entretanto, constata-se uma queda do número de pessoas com mais de 15 anos analfabetas: em 1991, 8,5\% da população com essa faixa etária não era alfabetizada. Esse número caiu para 5,6\% em 2000 e $3,9 \%$ em 2010. 


\section{Mortalidade infantil}

A taxa de mortalidade infantil em Manaus no ano de 2010 foi de 14,2 para cada 1.000 nascidos-vivos, menor que a do estado do Amazonas $(17,1)$ e menor que a taxa nacional $(16,7)$.

\section{Renda}

Em 2000, a renda familiar per capita de Manaus era de $\mathrm{R} \$ 262,40$, o que o classificava na 864a posição entre todos os municípios brasileiros. Esse valor estava bem acima do verificado para o estado do Amazonas ( $\mathrm{R} \$ 173,92$ ) e mais próximo à média encontrada para o país ( $\mathrm{R} \$ 297,23)$. A desigualdade social manifesta-se claramente: em 2000, as UDHs Nossa Senhora das Graças Vieiralves, Adrianópolis e Flores - Parque das Laranjeiras tinham as maiores rendas per capita do município, $\mathrm{R} \$ 1.356,87$. Esse valor era 16 vezes maior que a menor renda per capita das UDHs Jorge Teixeira - Val Paraíso e Chico Mendes (R\$ 86,00). Nesse ano, verificou-se também que 40\% das UDHs apresentavam renda per capita menor que a média do estado do Amazonas, 62\% menor que a média de Manaus e 70\% menor que a média do Brasil.

Para o município de Manaus, a desigualdade aumentou, como mostra a observação de qualquer um dos indicadores de desigualdade de renda considerados (Gini, Theil e relação 20/40). Considerando que o Brasil apresenta uma das piores desigualdades de renda do mundo, os indicadores de Manaus são praticamente iguais aos do país pelo Gini e pela relação 20/40. Em 2000, enquanto para o Brasil o Gini era de 0,65, e a relação 20/40 (quanto, em média, os $20 \%$ mais ricos ganham em relação aos $40 \%$ mais pobres) era de 21 vezes, em Manaus esses indicadores eram respectivamente de 0,64 e de 20 vezes.

Outra forma de abordar a questão da desigualdade na distribuição de renda do município como um todo é por meio da apropriação da renda por estratos da população. Em 2000, 20\% mais pobres da população apropriam-se de apenas $1,6 \%$ da renda gerada no município, os $20 \%$ mais ricos ficavam com $68 \%$. Subdividindo esse grupo, observa-se que apenas os $10 \%$ mais ricos detinham mais da metade, ou $52 \%$.

Tomando-se então a proporção de pobres, consideradas assim as pessoas que vivem com menos de meio salário mínimo no ano 2000 ( $R \$ 75,50$ ), constatase que eles representam uma proporção de mais de um terço da população de Manaus, um contingente de 445 mil pessoas; desse total, 209 mil podem ser consideradas indigentes (viviam com menos de um quarto do salário, 
$\mathrm{R} \$ 37,75)$ - contingentes bem superiores à população total de qualquer um dos outros municípios do Amazonas.

Acrescenta-se a esse quadro da pobreza dois fatos: primeiro, ela aumentou substancialmente durante a década de 1990, tendo passado de 24\% em 1991 para 35\% em 2000. Segundo, o percentual de indigentes dobrou durante esse mesmo período ( $8 \%$ para $17 \%$ ).

Dados mais recentes sobre o Amazonas mostram que é o estado com a 11ª menor renda domiciliar per capita do país (Censo Domiciliar 2000-2010, Instituto Brasileiro de Geografia e Estatística - IBGE). O Censo Demográfico 2010 indica que, apesar de uma renda média de $\mathrm{R} \$ 668,00,25 \%$ das pessoas tinham rendimento médio nominal mensal domiciliar per capita de até $\mathrm{R} \$ 188,00$, e metade da população recebia até $\mathrm{R} \$ 375,00$, valor inferior ao salário mínimo em 2010 (R\$ 510). Entre os municípios das capitais brasileiras, mantém-se a tendência histórica de melhores níveis de rendimento domiciliar per capita nos estados das regiões Sul e Sudeste. Os valores dos rendimentos domiciliares per capita médios de Manaus representavam em 2010, 40\% do rendimento observado em Florianópolis. Tais informações indicam que, mesmo tendo havido mudanças sociais e econômicas no Brasil na última década, com redução das camadas mais pobres da população, a cidade de Manaus continua com padrão socioeconômico inferior ao observado em boa parte do país. Este quadro de forte desigualdade social ajuda a entender o frágil atendimento dispensado às crianças, adolescentes e famílias em situação de uso de crack, apresentado mais adiante.

\section{Questões relativas às drogas lícitas e ilícitas}

O V Levantamento sobre Consumo de Drogas Psicotrópicas entre Estudantes do Ensino Fundamental e Médio, realizado pelo Centro Brasileiro de Informações sobre Drogas (Cebrid), em 27 capitais brasileiras (Gálduroz et al., 2005), mostra que 23,7\% dos estudantes entrevistados em Manaus usaram drogas (excluindo álcool e tabaco) na vida. Importante notar que o percentual de Manaus é maior que a média das capitais da região Norte $(21,6 \%)$ e maior do que a média brasileira (22,6\%). Na região Norte, Manaus perde apenas para Boa Vista (27,6\%). O uso na vida analisado por faixa etária apresenta Manaus com percentuais maiores que a média da região: 10-12 anos (13,6\%); 13-15 anos $(24,4 \%)$ e $16-18$ anos (25,7\%). O uso no ano aparece em $19,8 \%$ dos estudantes, novamente com percentual acima da média das capitais do Norte 
(18,2\%) e da média nacional (19,6\%). O uso no mês segue a mesma tendência: Manaus $(15,8 \%)$ com o segundo percentual mais alto da região Norte, menor apenas que Boa Vista (17,3\%), acima da média das capitais da região $(13,8 \%)$ e da média nacional (14,8\%). Já em relação ao uso frequente, a tendência muda e Manaus apresenta percentual similar à média da região Norte $(2,4 \%)$ e menor que a média brasileira (3\%).

Os dados levantados na Pesquisa Nacional de Saúde do Escolar - Pense (2009) sobre o uso de drogas, tais como: maconha, cocaína, crack, cola, loló, lança perfume, ecstasy, evidenciam que $8,7 \%$ dos escolares já experimentaram alguma dessas substâncias ilícitas, sendo o maior percentual encontrado na capital Curitiba (13,2\%) e o menor em Macapá (5,3\%). Em Manaus o uso de drogas ilícitas na vida alcançou o percentual de 7,5\%.

Um estudo realizado com estudantes universitários do Amazonas (Lucas et al., 2006) mostra que as drogas psicotrópicas mais utilizadas foram as legais. O uso na vida de álcool foi relatado por $87,7 \%$ dos estudantes, não havendo diferença significativa entre o consumo por alunos do sexo feminino e masculino. O uso na vida de tabaco foi relatado por 30,7\% dos estudantes, sendo maior entre estudantes do sexo masculino. Já entre as drogas psicotrópicas ilegais, as mais usadas na vida foram solventes $(11,9 \%)$, maconha (9,4\%), anfetamínicos $(9,2 \%)$, cocaína $(2,1 \%)$ e alucinógenos $(1,2 \%)$. Também foi mencionado por 2,1\% dos estudantes a utilização de esteroides e anabolizantes. As faixas etárias com as maiores proporções de uso inicial da droga foram as de: 16 a 18 anos para álcool e tabaco; acima de 18 anos para ansiolíticos, solventes, anfetamínicos e cocaína; e para maconha a propoção se dividiu igualmente entre essas duas faixas.

O Levantamento Nacional sobre o Uso de Drogas entre Crianças e Adolescentes em Situação de Rua nas 27 Capitais Brasileiras, realizado pelo Cebrid e Universidade Federal de São Paulo (Unifesp), mapeou em Manaus, em 2003, instituições que ofereciam assistência a crianças e adolescentes em situação de rua (Noto, 2003). Foram realizadas 234 entrevistas. Em relação às drogas utilizadas, o tabaco foi a droga com os maiores índices $(62,1 \%$ no ano e $44,8 \%$ no mês), seguido pelas bebidas alcoólicas (59,1\% no ano e 37,5\% no mês). Entre os solventes/inalantes, predominou o uso da cola (29,3\% no ano e $19 \%$ no mês). Em relação às drogas ilícitas, o consumo de cocaína e derivados apareceu com $10,8 \%$ no ano e $5,6 \%$ no mês. O uso de crack ocorreu em três casos $(1,3 \%)$ no ano e em dois casos $(0,9 \%)$ no mês. 
O Relatório Brasileiro sobre Drogas (Brasil, 2009) analisou a evolução do número de internações, para todas as faixas etárias, decorrentes do uso de drogas por 100.000 habitantes no período de 2001 a 2007. As menores taxas de internação foram observadas nas capitais da região Norte e variaram de 2,6 internações por 100.000 habitantes (Macapá) a 20,6/100.000 hab. (Rio Branco). Entre todas as capitais do país, apenas cinco apresentaram tendência de crescimento de internações: Manaus, Boa Vista, Fortaleza, João Pessoa e São Paulo. Uma análise sobre o número de leitos psiquiátricos no Sistema Único de Saúde (SUS) em hospital geral mostrou que em Manaus, em 2008, não havia nenhum leito disponível.

Em relação à mortalidade decorrente do uso de drogas, o relatório aponta que as capitais com maior número absoluto de óbitos são: São Paulo, Rio de Janeiro e Brasília. Manaus é a capital da região Norte que mais contribui para o total de óbitos. No período de 2001 a 2007, Manaus somou 197 óbitos em decorrência do uso de drogas, representando $2,1 \%$ dos óbitos do país por essa causa. Esse número perfaz $0,4 \%$ dos óbitos por todas as causas ocorridas no somatório dos anos (2001 a 2007). Esse percentual é igual à média da região Norte e muito próximo da média nacional $(0,5 \%)$.

O documento sobre uso de drogas analisou ainda os crimes de posse e ráfico de drogas. Em relação à posse de drogas para o consumo, o período analisado foi de 2004 a 2007. No estado do Amazonas foram registradas 739 ocorrências no somatório dos anos. Esse número corresponde a 21,3 ocorrências por 100.000 habitantes, número maior que a média da região Norte, que é de 16,4/100.000 hab. O número de ocorrências por esse delito no Amazonas correspondeu a $0,8 \%$ do total de crimes no período. Tal percentual foi o segundo mais alto da região Norte (perde apenas para Rondônia - 0,9\%) e é maior que a média da região Norte $(0,6 \%)$.

No que concerne ao tráfico de drogas, o estado do Amazonas apresentou 954 ocorrências no período de 2001 a 2007. Esse número corresponde a 7,4 ocorrências por 100.000 habitantes, menor que a média da região Norte, que é 12,0/100.000 hab. O tráfico de drogas no Amazonas durante o período estudado correspondeu a $0,3 \%$ do total de crimes (menor que a média da região que representa $0,4 \%$ ). No entanto, percebeu-se um aumento desse tipo de crime no ano de 2007.

Em Manaus, o número total de crimes de posse de drogas no período correspondeu a 0,9\%; no ano de 2007 essa relação foi a menor do período - 0,5\%. 
O tráfico de drogas teve uma participação ainda menor: 0,3\% do total de crimes do período - menor que a média das capitais do Norte $(0,4 \%)$ e do Brasil (0,6\%). A taxa de ocorrências por tráfico de drogas em Manaus é de 12,8 por 100.000 habitantes - bem menor que a média das capitais da região Norte (20,1/100.000 hab.) e a média nacional (25,3/100.000 hab.).

O Relatório Brasileiro sobre Drogas também analisou a apreensão de drogas com base nos dados fornecidos pela Polícia Federal. No que diz respeito à cocaína e seus derivados, São Paulo se destaca das demais unidades da federação, apresentando maior quantidade capturada durante o período, mas alguns estados registraram apreensão significativa: Amazonas, Mato Grosso do Sul, Mato Grosso, Rondônia, Pará, Paraná, Rio de Janeiro, Goiás, Ceará e Minas Gerais com apreensão superior a 2.000 kg no somatório do período. O estado do Amazonas mostrou tendência de aumento, passando da apreensão de 347,7 kg em 2001 para 2.455,3 kg em 2007, configurando-se como os percentuais mais elevados da região Norte.

No Brasil observou-se um aumento acentuado na apreensão de crack em 2007. Esse aumento ocorreu em todas as regiões exceto na região Norte. No Amazonas não foi registrado nenhuma captação de crack no período de 2001 a 2007. Em junho de 2010, noticiou-se o que seria a primeira apreensão de crack de Manaus.

Destacam-se na região, predominantemente no Amazonas, Pará e Acre as apreensões de pasta base de cocaína. No estado do Amazonas foi confiscada a maior quantidade de pasta base no período de 2001 a 2007 (650,9kg). É importante mencionar que em uma única operação em agosto de 2012, foram encontrados $180 \mathrm{~kg}$ de pasta base em um barco em Manaus (acrítica. com, 10 ago. 2012).

O estado do Amazonas conforma uma dupla fronteira tríplice do limite internacional do Brasil com Venezuela e Colômbia, e do Brasil com Colômbia e Peru. De acordo com o superintendente da Polícia Federal do Amazonas, Sérgio Fontes, na chamada borda fronteiriça, encontram-se as três principais cidades que participam da rota internacional de tráfico de entorpecentes: Tabatinga e Tefé (no Alto e Médio Solimões) e São Gabriel da Cachoeira (no rio Negro). A droga proveniente da Colômbia é trazida por traficantes, que se estabelecem nas cidades de Tabatinga e Letícia e é geralmente enviada a Manaus por barco. Quando a pasta base e/ou a maconha chegam à cidade, é processada para ser distribuída ao restante do país. 


\section{MAPEAMENTO dAS INSTITUIÇÕES DE ATENÇÃo Às QUESTÕES RELACIONADAS SO CONSUMO dE ÁlCOOL E OUTRAS DROGAS}

O Relatório Brasileiro sobre Drogas (Brasil, 2009) apresenta as instituições governamentais e não governamentais destinadas ao atendimento de pessoas com problemas referentes ao uso de substâncias legais e ilegais, mapeadas pela Secretaria Nacional de Políticas Públicas sobre Drogas em 2006/2007. No estado do Amazonas estão, segundo o mapeamento, 241 instituições, o que corresponde a $2,7 \%$ do número total do país. Na região Norte localizam-se 9\% das instituições e na Centro-Oeste estão apenas 5\%. No Sudeste está a maioria das unidades (47\%). As regiões Sul (19\%) e Nordeste (20\%) apresentam valores intermediários.

Segundo o mesmo relatório, a maior parte das instituições do país tem como projeto a autoajuda (6.367 instituições - 70\% do total das entidades mapeadas). Nos estados do Norte e Nordeste registram-se os maiores percentuais de instituições com foco na autoajuda que se pautam nos fundamentos do Programa de Recuperação de Alcoólicos Anônimos (AA). Importa salientar que a região Norte apresenta a menor porcentagem de instituições com atividades de prevenção (5\%), tem poucas unidades para tratamento que realizam atividades de ensino e pesquisa, além de possuir menor número de Programas de Redução de Danos Sociais e da Saúde, em comparação com as outras regiões brasileiras. Nota-se, portanto, a evidente fragilidade do atendimento para usuários de drogas nessa região.

O Conselho Federal de Psicologia (CFP, 2011) avaliou seis Comunidades Terapêuticas em Manaus. Em 2010, cinco delas recebiam adolescentes, no entanto, somente uma atendia exclusivamente adolescentes: o Sítio Esther, que recebia meninas de 12 a 18 anos. Todas as outras atendiam homens a partir de 15 anos de idade. Apenas duas comunidades tinham o título de utilidade pública municipal e/ou estadual, quatro unidades mantinham convênio com a Secretaria Estadual de Assistência Social e uma alegou estar conveniada também com a Secretaria de Saúde. Todas as comunidades eram de origem religiosa.

O CFP encontrou inúmeras irregularidades em todas as unidades, entre elas o desrespeito às crenças religiosas e o uso de mão de obra não remunerada. A fragilidade do atendimento técnico também foi apontada: duas delas não tinham equipe técnica e nas demais o atendimento era pontual, apenas com uma visita semanal. Nas quatro comunidades que atendiam adolescentes e adultos, não havia espaço exclusivo para os adolescentes e as atividades 
escolares não eram garantidas. Em três delas havia indícios de internação compulsória. A metodologia dos Doze Passos, utilizada no AA, estava presente em todas as unidades.

Das seis comunidades visitadas pelo CFP, uma havia sido fechada em 2011 (no momento do trabalho de campo da pesquisa) e apenas a que atendia jovens continuava aceitando essa clientela. A seguir apresenta-se uma descrição de uma comunidade que recebeu a avaliação do CFP e que foi visitada na pesquisa em foco.

A comunidade pertence à Sociedade Beneficente Cristã do Amazonas; possui convênio com a Secretaria Estadual de Assistência Social; possui voluntários que desenvolvem atividades no local; valor pago

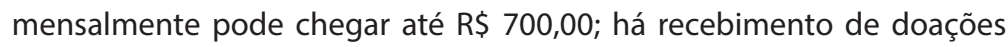
de alimentos. Tem como proposta de cuidado o Programa "Amor Exigente" e o livro Código da Inteligência, de Augusto Cury; não foi identificada articulação estruturada com Políticas de Assistência Social, mesmo tendo convênio com a SEAS [Secretaria Estadual de Assistência Social]; usuários desempenham atividades laborais, dividindo-se em equipes para os cuidados com a horta, com os animais que são criados no local, com a casa e o preparo dos alimentos; quando as regras da comunidade são desobedecidas, há a tentativa de sensibilização por meio do diálogo, mas é prevista a suspensão de atividades de lazer e o aumento de algumas das atividades laborais; atendimento psicológico não é oferecido. A avaliação do CFP aponta condições indignas de assistência (os quartos não possuem janelas e, com isso, não há iluminação natural nem ventilação adequada, higienização inadequada); uso de mão de obra não remunerada e metodologia de cuidado contrária às normas do Ministério da Saúde; desrespeito à escolha ou ausência de credo; apropriação indébita de documentos; medicamentos armazenados em caixa, guardada nos pertences do responsável pela unidade; a estrutura física da entidade apresenta condições precárias de funcionamento. As pessoas internadas relataram que dormem em redes, camas e até em colchões no chão, pois não há camas para todos; internos reclamam da falta de acompanhamento psicológico e de acompanhamento médico. Não há equipe de saúde (médicos, farmacêuticos, enfermeiros e/ou técnicos de enfermagem); durante a internação, os internos não têm acesso a seus documentos de identificação (RG, CPF, etc.), que ficam em poder da instituição no escritório central, em Manaus; somente os familiares podem visitar os usuários, quinzenalmente; indícios de situações de constrangimento e vexatórias: homossexual saiu da instituição por pressão do pastor responsável. (CFP, 2011) 
É importante registrar que, em visita realizada por nossa equipe durante a pesquisa à comunidade descrita, algumas mudanças foram percebidas: o atendimento psicológico que era inexistente passou a acontecer uma vez por semana; um pequeno prédio estava sendo construído para atender exclusivamente os adolescentes e a estrutura física estava muito bem cuidada, inclusive a dos dormitórios. No entanto, algumas irregularidades apontadas pelo CFP puderam ser confirmadas na fala do adolescente entrevistado: ausência de atividades escolares e comunitárias e fragilidade do atendimento médico.

A rede de atenção ao uso de álcool e outras drogas no SUS também foi mapeada no Relatório Brasileiro de Drogas. Em 2009, o Brasil contava com 57\% de cobertura dos Centros de Atenção Psicossocial (Caps). Em 17 estados brasileiros a cobertura Caps foi considerada boa ou muito boa, e apenas o estado do Amazonas apresenta cobertura insuficiente ou crítica. $\mathrm{O}$ indicador por região revela que a cobertura da região Sul é muito boa (76\%); do Nordeste (68\%) e Sudeste é boa (50\%); do Centro-Oeste é regular/baixa (44\%) e do Norte é baixa (35\%). Já em dezembro de 2012, o estado do Amazonas contava com cinco Caps I, quatro Caps II e um Caps III. Tinha apenas um Caps i e não havia nenhum Caps ad. Destes, apenas dois Caps I e o Caps i estão localizados em Manaus. Na capital não há leitos psiquiátricos em hospitais gerais. Pode-se, desde já, depreender a escassez de serviços para atender os usuários de drogas da cidade.

Relatam-se no documento as seguintes unidades de saúde em Manaus, distribuídas nos distritos de saúde: saúde da família (167 polos); unidades básicas de saúde (52); policlínicas (9); saúde rural (21 polos); centro de especialidade odontológica (5); hospitais (32); leitos hospitalares (3.175); leitos clínicos (964); leitos obstétricos (675); leitos pediátricos (549); leitos cirúrgicos (987); Caps I (2); Caps i (1), inaugurado em dezembro de 2012, voltado para o atendimento exclusivo de crianças e adolescentes (até 16 anos) portadores de transtornos mentais graves e persistentes, ou usuários de crack, álcool e outras drogas. Há diferente distribuição de serviços entre os distritos de saúde da cidade.

Algumas ações relacionadas ao uso de crack começaram a ser desenvolvidas em 2012. A Secretaria Municipal de Saúde promoveu, no segundo semestre desse ano, um curso de capacitação para os médicos da Estratégia Saúde da Família:

Como parte das ações que estão sendo executadas pela Prefeitura de Manaus para estruturar a rede de atendimento aos dependentes químicos (de crack, álcool e outras drogas), a Secretaria Municipal de 
Saúde (Semsa) promove (...) um curso de aperfeiçoamento, voltado para médicos que atuam na Estratégia Saúde da Família. O curso será realizado por meio de parceria da Semsa com o Centro Regional de Referência na Formação Permanente para o Atendimento aos Usuários de Crack e Outras Drogas do Estado do Amazonas (CRRFP-AM/Ufam) e Conselho Estadual de Políticas sobre Drogas, da Secretaria Estadual de Justiça e Direitos Humanos (Sejus). O secretário municipal de Saúde, Francisco Deodato, afirma que a capacitação e a sensibilização dos profissionais da Estratégia Saúde da Família, considerada a principal porta de entrada da Atenção Primária, no SUS, é de fundamental importância no processo de organização da rede de atendimento aos dependentes químicos. (www.manaus.am.gov.br)

Na área da assistência social, são relatadas as seguintes unidades que, em tese, poderiam atender a clientela dos usuários de drogas: 18 Centros de Referência de Assistência Social (Cras), dois Centros de Referência Especializados de Assistência Social (Creas), oito Serviços de Acolhimento Institucional (SAIs) e um Serviço de Acolhimento Institucional Emergencial (SAIE).

O estado do Amazonas conta com o Centro Regional de Referência na Formação Permanente para o Atendimento aos Usuários de Crack e Outras Drogas do Estado do Amazonas (CRRFP-AM/Ufam) e com o Conselho Estadual de Políticas sobre Drogas, da Secretaria Estadual de Justiça e Direitos Humanos (Sejus).

Em fevereiro de 2013, o governo do Amazonas e a Prefeitura de Manaus iniciaram o processo de adesão ao programa federal Crack, É Possível Vencer. De acordo com a Confederação Nacional dos Municípios (CNM), dos 62 municípios do Amazonas, em 35 deles foi constatado o uso da droga em 2012. O programa tem objetivo de prevenir o consumo de drogas, realizar tratamento médico, combater o tráfico e reabilitação social. A meta proposta era implantar as ações na capital em 2013.

\section{OS SeRVIÇOS DE ACOLHIMENTO INSTITUCIONAL E AS CRIANÇAS e Adolescentes USUÁRIOS dE CRACK ACOLHIDOS E SUAS FAMÍLIAS}

A pesquisa apresentada neste capítulo, cuja metodologia está detalhada no Anexo, englobou uma abordagem quantitativa, com a aplicação de questionários nos oito SAls existentes na cidade, respondidos pelos gestores, versando sobre a atuação dos serviços. Nesses locais, foram ainda preenchidos instrumentos 
a partir de dados de prontuários das sete crianças ou adolescentes com uso pessoal ou familiar de crack.

O estudo contou também com abordagem qualitativa, por meio da realização de dez entrevistas com profissionais da Secretaria Estadual de Assistência Social, Secretaria Municipal de Saúde da área da Saúde Mental, programa Portas Abertas da Secretaria Municipal de Assistência Social, Comunidade Terapêutica, Creas, Conselho Estadual de Entorpecentes do Amazonas (Conen), Fiocruz Manaus, Conselho Tutelar e Promotoria da Vara da Infância e Juventude. Também foram entrevistados três adolescentes em programa para população de rua e em Comunidade Terapêutica e dois familiares de crianças e adolescentes que usam crack.

Todos os SAls investigados atendem crianças, mas apenas seis tinham adolescentes acolhidos. Como se pode constatar na Tabela 1, em apenas um serviço, no momento da entrevista, havia criança com uso de drogas e em dois havia adolescentes. A presença de adolescentes que usam crack foi mencionada por apenas dois serviços. Constatou-se um número maior de pais/responsáveis usuários de drogas em geral, porém o consumo de crack pelos responsáveis foi relatado por apenas um serviço.

Tabela 1 - Serviços de Acolhimento Institucional que atendem crianças e adolescentes e seus responsáveis com história de uso de crack e outras drogas. Manaus - dezembro 2011*

\begin{tabular}{l|c|c|c|c}
\hline \multirow{2}{*}{\begin{tabular}{l} 
Consumo de drogas \\
\cline { 2 - 5 }
\end{tabular}} & \multicolumn{2}{|c|}{$\begin{array}{c}\text { SAls que atendem } \\
\text { crianças (N=8) }\end{array}$} & \multicolumn{2}{|c}{$\begin{array}{c}\text { SAls que atendem } \\
\text { adolescentes } \\
(\mathrm{N}=6)\end{array}$} \\
\cline { 2 - 5 } & $\mathrm{N}$ & $\%$ & $\mathrm{~N}$ & $\%$ \\
\hline $\begin{array}{l}\text { Uso de drogas em geral pela criança } \\
\text { ou adolescente }\end{array}$ & 1 & 12,5 & 2 & 33,3 \\
\hline $\begin{array}{l}\text { Uso de crack pela criança ou } \\
\text { adolescente }\end{array}$ & 0 & - & 1 & 16,7 \\
\hline $\begin{array}{l}\text { Responsáveis com história de uso de } \\
\text { drogas em geral }\end{array}$ & 7 & 87,5 & 4 & 66,7 \\
\hline $\begin{array}{l}\text { Responsáveis com história de uso de } \\
\text { crack }\end{array}$ & $0 * *$ & - & 1 & 16,7 \\
\hline
\end{tabular}

* Informação dada pelo gestor do serviço.

** Dois SAls não informaram. 
Para verificar o número de crianças, adolescentes e seus responsáveis que utilizam crack nos serviços apresentados, é necessário observar a Tabela 2. Constata-se que existem 282 crianças e adolescentes acolhidos nos oito SAls visitados: 147 crianças e 135 adolescentes. O uso de variadas drogas foi mencionado para $2,7 \%$ das crianças e $7,4 \%$ dos adolescentes. 0 consumo de crack só foi apontado para dois adolescentes. Entre os responsáveis de crianças, a utilização de drogas em geral aparece com maior frequência $(13,6 \%)$ do que entre adolescentes (5,2\%). Responsáveis usuários de crack só foram informados para dois adolescentes.

Tabela 2 - Uso de uso de crack e outras drogas por crianças e adolescentes em Serviços de Acolhimento Institucional e por seus responsáveis. Manaus dezembro 2011

\begin{tabular}{l|c|c|c|c|c|c}
\hline \multirow{2}{*}{ Consumo de drogas } & \multicolumn{2}{|c|}{$\begin{array}{c}\text { Crianças } \\
\mathrm{N}=147\end{array}$} & \multicolumn{2}{c|}{$\begin{array}{c}\text { Adolescentes } \\
\mathrm{N}=135\end{array}$} & \multicolumn{2}{c}{$\begin{array}{c}\text { Total } \\
\mathrm{N}=282\end{array}$} \\
\cline { 2 - 7 } & $\mathrm{N}$ & $\%$ & $\mathrm{~N}$ & $\%$ & $\mathrm{~N}$ & $\%$ \\
\hline $\begin{array}{l}\text { Uso de drogas em geral pela } \\
\text { criança ou adolescente }\end{array}$ & 4 & 2,7 & 10 & 7,4 & 14 & 5,0 \\
\hline $\begin{array}{l}\text { Uso de crack pela criança ou } \\
\text { adolescente }\end{array}$ & 0 & 0,0 & 2 & 1,5 & 2 & 0,7 \\
\hline $\begin{array}{l}\text { Responsáveis com história de uso } \\
\text { de drogas em geral }\end{array}$ & 20 & 13,6 & 7 & 5,2 & 27 & 9,6 \\
\hline $\begin{array}{l}\text { Responsáveis com história de uso } \\
\text { de crack }\end{array}$ & 0 & 0,0 & 2 & 1,5 & 2 & 0,7 \\
\hline
\end{tabular}

A baixa frequência de adolescentes usuários de crack (dois) nos SAls e de seus responsáveis também consumidores desta substância (dois) nas oito unidades visitadas não nos permitiu a realização de entrevistas no momento da visita ao serviço de acolhimento. Em todos os serviços constatamos dois discursos unânimes: o crack não se configura como um problema em Manaus; e o segundo, relacionado ao primeiro, não há nenhuma ação voltada para o atendimento a crianças e adolescentes usuários de crack na cidade. Outra fala muito presente é que crianças e adolescentes com esse perfil não são encaminhados para os SAls, apesar de termos encontrado alguns poucos casos nessas unidades. O oxi, na opinião dos entrevistados, é mais presente do que o crack, mas a droga predominante no município é a pasta base de cocaína (merla ou mel). 
Ainda mais surpreendente foi a afirmação de que o uso de drogas por crianças e adolescentes é pouco expressivo e por esse motivo não é uma prioridade das instâncias públicas. Alguns informantes identificaram um pequeno grupo de crianças/adolescentes que fazia uso de drogas embaixo de uma ponte da cidade, reconhecidos como "os meninos da ponte". Eventualmente esses jovens dão entrada no SAIE e são encaminhadas ao Projeto Criança Cidadã. Por ser um grupo pequeno, as instituições os conheçem nominalmente e também suas histórias. É interessante como a questão do consumo de drogas por crianças e adolescentes no município, na fala dos profissionais da rede, se restringe a essa parcela da população. Em consonância com essa informação, percebe-se a visão de que em Manaus não há um número significativo de crianças e adolescentes em situação de rua.

\section{Caracterização e funcionamento dos serviços de acolhimento}

Todos os oito SAls visitados já funcionam há vários anos: a maior parte tem entre oito e 16 anos de atividades e o mais antigo existe há mais de 25 anos. Seis deles são em formato de abrigo tradicional, um em Casa Lar em aldeia e outro em casa de passagem. Um dos abrigos funciona acoplado a um centro social aberto à comunidade e atende adolescentes que necessitam cumprir medidas socioeducativas em meio aberto. Todos os serviços são organizações não governamentais, apenas o SAIE é uma unidade pública municipal. Funciona na modalidade casa de passagem. Anteriormente denominada Central de Resgate, recebia crianças em qualquer situação de vulnerabilidade e risco social, inclusive em situação de rua e drogadição. No momento da pesquisa atendia crianças e adolescentes de 0-17 anos, vítimas de maus-tratos, negligência, abandono, violência física, psicológica e sexual, exploração do trabalho infantil e sexual, retirando-os da situação de risco e encaminhando-os aos programas sociais e à rede de proteção. Cinco SAls têm orientação religiosa: dois católicos, dois evangélicos e um espírita.

$\mathrm{O}$ atendimento oferecido às crianças e adolescentes em situação de risco social está voltado para algumas clientelas mais específicas: seis SAls recebem população de rua e ameaçados de morte; cinco atendem os que têm transtornos mentais; três, os portadores de doenças infectocontagiosas; e apenas dois recebem crianças e adolescentes com uso de crack e outras drogas. Importante pontuar uma contradição: na pesquisa qualitativa, todas as instituições foram unânimes em afirmar que, quando há informação de 
que a criança/adolescente é usuário de drogas, o encaminhamento é feito para a Secretaria Estadual de Assistência Social e que nenhum SAI acolhe criança/ adolescente com esse histórico.

Todos os SAls têm assistentes sociais na equipe e em sete deles se agregam psicólogos. Fisioterapeutas, enfermeiros, pedagogos, sociólogos, educadores, dentistas e estagiários integram as equipes de seis serviços.

É declarada pelos gestores a precariedade de capacitação das equipes dos SAls para lidar com crianças e jovens usuários de substâncias psicoativas: a existência de capacitação no que diz respeito ao crack foi mencionada por apenas três serviços. Chama atenção o fato de a equipe técnica, que deveria estar preparada para lidar diretamente com essa população infantojuvenil, não estar capacitada para questões relativas ao uso de drogas: apenas três técnicos foram qualificados em dois serviços. A realidade é similar, ou ainda mais precária, entre os demais profissionais que atuam nos SAls, principalmente quando se refere aos cuidadores (apenas um capacitado). Três pessoas em funções de direção/coordenação e uma de administração relataram tal estratégia formativa em dois serviços.

Esse quadro pôde ser constatado na visita aos serviços durante a coleta de dados da pesquisa. Presenciamos em uma instituição destinada à população infantojuvenil em situação de rua uma cena em que um adolescente drogado escalou um poste localizado no pátio da unidade e começou a insultar a equipe e os demais adolescentes. Em resposta, todos os profissionais se trancaram em uma sala e acionaram a polícia. A psicóloga relacionou a falta de manejo em situações decorrentes do uso de substâncias à ausência de capacitação, a "não saber fazer de outra forma". A profissional declarou que ninguém da equipe tem formação para lidar com a problemática da dependência química e que estavam naquele momento buscando parcerias para cursos. Na sua visão, trabalhar com o adolescente usuário de drogas já é um grande desafio e se torna uma tarefa titânica quando não se está qualificado para o trabalho.

O maior desafio é lidar com a dependência química. Você não sabe o que esse menino [referindo-se à cena descrita] usou lá fora. Eles misturam: pasta base, maconha, crack, cocaína. Esta mistura causa uma pane no organismo. Então a nossa maior dificuldade é que nós não temos ninguém da saúde que possa nos dar um auxílio nessa parte. Já aconteceu do menino surtar por problemas de drogas e nós não sabemos o que fazer. (psicóloga - SAI) 
A falta de recursos teóricos e práticos para lidar com o adolescente dependente químico favorece a leitura de que as situações do cotidiano são exclusivamente "caso de polícia":

Eles chegam agressivos, acham que nós estamos aqui para trabalhar para eles, eles lidam dessa forma. Aí começam a quebrar tudo. Tanto é que temos essas barras na janela. É a única forma de contê-los e aí chamamos a polícia para nos ajudar, mas muitas vezes ela não vem. (psicóloga - SAI)

É preocupante a visão da psicóloga, que não é capaz de mensurar que o objetivo final de sua ação é trabalhar para e pelo adolescente, assim como a falta de apoio da assistência social, aos profissionais que ali atuam e aos acolhidos que usam drogas, e do setor Saúde.

\section{Perfil de crianças, adolescentes e famílias usuárias de crack em serviços de acolhimento}

Como visto anteriormente, entre as 282 crianças e adolescentes presentes nos SAls durante a pesquisa, o uso de crack só foi referenciado pelos gestores para dois adolescentes e dois responsáveis. Todavia, sete crianças e adolescentes foram reconhecidos pela equipe técnica como usuários de crack e tiveram questionários individuais preenchidos. Esse fato mostra a maior proximidade dos técnicos em relação aos acolhidos e suas famílias, bem como a falta de informações fidedignas sobre a real frequência da droga pelos serviços de acolhimento.

Alguns dados desses sete acolhidos com história pessoal de uso de crack ou seus responsáveis são apresentados a seguir: quatro eram crianças (6, 9, 10 e 11 anos de idade) e três, adolescentes (13, 14 e 17 anos); cinco eram meninas; todas as crianças frequentavam a escola (ensino fundamental), mas os três adolescentes não o faziam; quatro moravam com um usuário de crack/outras drogas nos últimos 30 dias antes do acolhimento; seis apresentavam algum problema de saúde: três com comportamento agressivo, igual número com comportamento depressivo ou ansioso, um com desatenção/hiperatividade e um com transtorno psicótico. Outros problemas mencionados sobre quatro acolhidos foram: crise convulsiva, doença sexualmente transmissível, comportamento "frio e maquiavélico"; e cinco têm trajetória de rua.

Em relação aos dados sobre o acolhimento, entre as sete crianças/adolescentes identificados pelos técnicos como usuários de crack, tem-se o seguinte tempo 
de institucionalização no serviço no momento da pesquisa: dois estavam de dois a cinco meses no SAI visitado, dois há um ano, dois há dois anos e um há quatro anos. Apenas cinco acolhidos tinham procedimento administrativo na Vara da Infância e Juventude, como, por exemplo, pasta especial ou processo; o uso do crack consta de documentos de quatro crianças/adolescentes.

O motivo de ingresso no SAI deveu-se especialmente ao uso de drogas legais e ilegais pelos responsáveis (seis acolhidos, especialmente crianças), configurando um ciclo em que o uso dessas substâncias se perpetua nas famílias. Negligência na família, vivência de rua e carência de recursos materiais são causas mencionadas em prontuários de cinco crianças/adolescentes. Vale destacar que, na visão dos profissionais entrevistados, todos esses fatos podem estar relacionados à carência de recursos financeiros da família, e que tal população não deveria recorrer ao acolhimento institucional, considerando-se as políticas públicas redistributivas hoje existentes. Outras formas de violência são causas frequentes de ingresso nos SAls: doméstica de natureza psicológica (quatro acolhidos); física (três); abuso (dois) e exploração sexual (um); prostituição e pornografia (um); abandono pelos pais ou responsáveis (três); e violência extrafamiliar (um). Contribuíram ainda como motivos para o acolhimento a exploração no trabalho ou mendicância (três), a entrega voluntária da criança/adolescente pela família de origem (três), a ausência dos pais ou responsáveis por prisão (dois), pais ou responsáveis com problemas psiquiátricos/psicológicos (dois), uso e/ou abuso de substâncias por parte da criança ou adolescente (um).

Quatro acolhidos com história relacionada ao uso de drogas/crack já haviam sido abrigados anteriormente na mesma instituição ou em outro SAI, evidenciando uma circularidade nos processos de internação.

As crianças e os adolescentes chegaram ao SAI encaminhadas pelo Poder Judiciário (dois), Conselho Tutelar (dois), família (dois) e por outros serviços de acolhimento (um). Nenhum deles foi encaminhado para tratamento de saúde devido ao consumo de crack; apenas um responsável foi orientado nesse sentido pelo SAI. Tais dados reiteram a precariedade dos cuidados em saúde para os dependentes de substâncias no cenário municipal.

No que se refere à situação legal da criança ou adolescente usuário de drogas, ou dos responsáveis que utilizam drogas, constata-se a precária possibilidade de adoção. Nenhuma criança ou adolescente acolhido nessa situação estava legalmente encaminhado para adoção (aguardando colocação); nenhuma estava em processo de colocação para adoção, ou seja, iniciando a 
aproximação com adotantes; e nenhuma tinha a destituição do poder familiar concluída. Isso significa que não havia crianças e adolescentes usuários de drogas, ou responsáveis que utilizavam drogas, que preenchessem critérios para a condição legal de adoção na cidade de Manaus. A situação legal das sete crianças mencionadas era a seguinte: três em fase de avaliação/preparação para reintegração/retorno ao convívio com os responsáveis; seis com suspensão do poder familiar; uma com a destituição do poder familiar em tramitação; uma em processo tramitando de guarda/tutela ou com sentença pendente de recurso. É importante ressaltar que cada acolhido podia ter mais de um procedimento em andamento. Nenhum adolescente envolvido com o uso de drogas/crack estava em cumprimento de medida socioeducativa.

Todos os acolhidos tinham família morando na cidade de Manaus, a maioria com vínculo durante o período de acolhimento (cinco). Em dois casos não havia mais vínculo familiar e em um deles havia impedimento judicial de contato. Os irmãos eram os familiares que mais os visitavam, seguidos por ambos os pais.

\section{ADOLESCENTES USUÁRIOS ENTREVISTADOS}

\section{Raíssa}

Raíssa tinha 14 anos e frequentava um programa voltado para a população em situação de rua. Morava na rua desde os 10 anos de idade e considerou estar nessa situação porque trabalhava com a mãe na feira e "acostumou" com esse espaço. Desde que foi para a rua parou de estudar, tendo concluído o $5^{\circ}$ ano do ensino fundamental. Consumia todas as drogas, incluindo oxi e crack. Iniciou o uso de drogas aos 11 anos, após a ida para a rua e usava crack há um ano. Afirmou não ter ninguém da família usuário de drogas. Estava grávida de três meses e declarou que durante o tempo que esteve na rua foi levada uma única vez para a antiga Central de Resgate (hoje SAIE) e seu pai foi buscá-la. Logo retornou para a rua. Disse que não teve acesso a nenhuma outra instituição da assistência ou da saúde. A jovem demonstrou pouca capacidade de analisar os efeitos da droga em sua vida. Mencionou apenas que tinha "dificuldade de respirar" e relacionou o fato ao consumo de crack, mas nunca tinha ido ao médico em decorrência do uso de drogas. Não queria pensar nem falar sobre uso de drogas, apenas relatava sentir medo quando usa o crack. Não conseguia qualificar esse medo, mas disse 
gostar da sensação. Para consumir drogas praticava furtos e assaltos com uso de gilete. A jovem tinha um porte franzino e parecia frágil. Havia uma ruptura do vínculo familiar e relatou que a instituição estava buscando a aproximação e o restabelecimento desse vínculo.

\section{Fernando}

Com 16 anos, Fernando também foi entrevistado no programa dirigido para população em situação de rua, onde morava desde os 9 anos de idade. Disse que "escolheu" a rua devido a brigas constantes na família, que é bastante numerosa. Até a sua saída definitiva de casa foram 12 tentativas de fuga: "Eu ficava igual passarinho solto. Gostava do vento na cara, de passear por Manaus". Parou de estudar no $6^{\circ}$ ano. Iniciou-se nas drogas aos 10 anos com uso de tabaco e logo depois passou a consumir outras drogas na seguinte ordem: cola, maconha, mel e cocaína. Não usava crack. Considerava o crack como o "fundo do poço". Disse ter um irmão usuário de drogas. Apesar de sua trajetória de rua, alegou que nunca tinha roubado e que trabalhava diariamente para manter o seu uso, indo de encontro ao imaginário social do jovem nessa situação como um criminoso em potencial: "Eu sou um homem trabalhador". Nesse sentido, buscou se diferenciar dos demais: "O usuário é aquele que trabalha para consumir a sua droga, para ter o dinheiro para consumir a sua droga. O viciado é aquele que faz de tudo: rouba, mata, faz o possível para ter a droga dele".

Afirmou ter responsabilidade como usuário e essa, segundo ele, talvez seja a explicação para nunca ter se envolvido com o crack. Fernando relatou que a população de Manaus fazia justiça com as próprias mãos e, se pegasse um jovem roubando, linchava até matar.

Esse jovem se orgulhava de manter valores familiares apesar de morar há tanto tempo nas ruas. Nunca tinha usado drogas em espaços onde pudesse ser visto por moradores, pois achava desrespeitoso; preferia fazer uso sozinho em espaços privativos; criticava a postura dos demais moradores de rua que sujavam a cidade, tomavam banho em chafariz público etc. Sentia-se envergonhado em pedir dinheiro e sempre oferecia algum serviço em troca. Em relação aos cuidados com a saúde, afirmou que todo mês ia ao posto de saúde próximo onde dormia para pegar preservativos. Demonstrou preocupação com a aparência física e a saúde.

Em relação aos efeitos das drogas, Fernando fez um relato comovente, destacando a perda da alegria: 
Só sabia ser alegre quando eu estava usando droga, mas se eu estava sem ela eu ficava muito triste. Eu ficava assim sentado no meio fio e via aquele casal de adolescentes passar assim na minha frente todo bem arrumado, cheiroso, com dinheiro no bolso. Me dava um aperto no coração porque era um adolescente como eu, e eu ali jogado no chão, sentado na sarjeta. Todo mundo se alegra e eu não. Nem namorada eu podia ter.

Comentou ter emagrecido bastante e perdido músculos. Segundo o jovem, a droga "acabou com o pulmão". Disse ter epilepsia e já ter sido levado ao hospital em decorrência de ter sofrido convulsão na rua. Foi pego pela Central de Resgate várias vezes e ficou em abrigos. Em relação à Central, explicou que o procedimento é retirar o adolescente da rua e levar para a instituição. Lá eles identificam o endereço e fazem uma busca ativa da família com o adolescente. Caso a família por algum motivo não aceitar o jovem, ele é encaminhado a um serviço de acolhimento.

Fernando chegou ao programa levado por outro adolescente de rua e, em sua avaliação, a unidade o ajudou a restabelecer o vínculo familiar.

\section{Tadeu}

Tadeu tinha 17 anos, é natural do Paraná e residia há dois anos com o pai na divisa entre o Amazonas e a Bolívia. A mãe e os irmãos moravam no Paraná. A entrevista aconteceu em uma Comunidade Terapêutica. $O$ adolescente afirmou que a transição do Paraná para o Amazonas foi a "sua desgraça". Em uma cidade do interior do Amazonas, onde morava na fazenda do pai, conheceu todos os tipos de droga, incluindo o crack, de que fazia uso havia um ano. No Paraná estava no $2^{\circ}$ ano do ensino médio e disse que "era outra pessoa". Ninguém da família era usuário de drogas. Já trabalhou em uma eletrônica no Paraná e na fazenda ajudava o pai com o gado.

Ao chegar ao Amazonas foi apresentado a todas as drogas. Iniciou pelo uso da maconha e logo depois passou a consumir cocaína e por último o crack. Disse que a mudança em sua vida, depois do "primeiro trago" do crack foi devastadora. Após a experimentação, já se sentia dependente: "Tinha que consumir no mínimo cinco gramas. Isso significa fumar dia e noite". Tadeu foi bastante didático ao apresentar os efeitos da droga e a sua compulsão pelo uso:

Você fuma e bate aquela onda por no máximo dez minutos e você quer de novo. Você fuma até passar mal. De dez em dez minutos 
você precisa fumar, porque eu começava a ficar depressivo. Faltava alguma coisa em mim, para meu organismo funcionar. Gastava duzentos reais por dia em pedra. Quando fumava completava esse vazio, eu me sentia bem.

Perguntado como se sentia quando estava consumindo, ele demonstrou uma aparente contradição:

Sei lá! Dá um sentimento de alegria e por outro lado dá um sentimento de desespero e de perseguição. Você acha que tem alguém te perseguindo. É uma coisa que você fuma e sente medo, só que depois você quer sentir isso de novo. Você gosta daquela sensação de perseguição, não consegue mais viver sem esse sentimento.

Tadeu não tinha histórico de rua, mas comentou que muitas vezes não voltou para casa por vergonha de seu estado: sujo, machucado, fora de si. Percebia com muita clareza as mudanças em sua vida, tanto no comportamento quanto na saúde física e mental: “Eu fiquei muito agressivo e não queria saber de mais nada. Não queria saber de mais nada: de trabalhar, de arrumar a minha própria cama, estudar. Nada! Só consumir, consumir, consumir, consumir. A vida se resume ao uso".

No relato do jovem, a compulsão pelo uso não deixava espaço para nenhuma rotina, e todas as coisas corriqueiras da vida passavam para um segundo plano. Avaliou que aos poucos foi se descaracterizando, até mesmo moralmente.

Minha moral mudou. Eu perdi a vergonha de tudo. Perdi a vergonha e não tinha nenhuma emoção. Meu pai vinha conversar comigo chorando e aquilo não representava nada para mim. Fiquei frio, sangue frio mesmo. Ele não podia mais confiar em mim. Eu passei a roubar as coisas deles, até gado eu vendi para comprar droga. Ele vinha conversar comigo e eu xingava. Já apanhei bastante da polícia. Já fui preso por assalto a mão armada. Quando fui preso levei um susto e fiquei cinco dias sem usar, mas o vício falou mais alto.

Em relação à saúde comentou que já teve início de overdose, mas que não buscou um médico com medo de relacionarem os sintomas ao uso do crack. Procurou ajuda em uma farmácia.

Afirmou que antes de ser internado não gostava mais de se olhar no espelho, pois não se reconhecia na imagem refletida: "Perdi totalmente a vaidade, podia colocar qualquer roupa, não tinha mais roupa boa porque eu vendia. Me achava feio, mas e daí? Estava magro, pálido, aos poucos eu fui 
diminuindo". Suas forças foram esvaecendo e a sua percepção era de que estava cada vez mais franzino e que em algum momento iria desaparecer de fato. Todo esse sentimento culminou no dia em que se ajoelhou aos pés do pai e pediu ajuda. Disse ter clareza que a única saída era a internação, caso contrário iria morrer. O pai, com a ajuda de um vereador, conseguiu a internação na Comunidade Terapêutica. No momento da entrevista o jovem estava há 23 dias na comunidade e se sentia surpreso com o resultado.

Já mudei muito. Estou surpreso comigo. Na parte física, emocional, estou respeitando as pessoas, não tem mais aquela agressividade. Eu me sinto mais forte, mais disposto. Consigo acordar cedo, já ganhei uns pesinhos. Estou voltando.

A fala de Tadeu nos coloca diante de uma mudança na trajetória de vida desse jovem: em um determinado momento, no auge do uso, ele se percebeu "diminuindo", perdendo as forças. $O$ tempo curto de abstinência na instituição (23 dias) foi considerado por ele como uma "volta", uma retomada da vida no Paraná. Em várias partes do discurso, ele demonstrou certa despersonalização provocada pelo uso do crack. O jovem chamou atenção pela educação, delicadeza e capacidade de interlocução e reflexão.

Tadeu informou que no início da internação sentia dores generalizadas, mas que considerava "normal", consequência da abstinência: "Dor de cabeça, dor no estômago. É a droga se apresentando. O mal aflorava lá na rua também, só que eu usava e passava. Aqui tem que esperar a dor passar". O não atendimento a essa dor foi mencionado como uma crítica à instituição. Avaliou como ponto forte da Comunidade Terapêutica a experiência dos adultos que lá estavam em relação ao uso de drogas e isso, segundo ele, o levou à reflexão.

Os três adolescentes entrevistados, quando analisados em conjunto, apresentam algumas características típicas do perfil do usuário de crack já traçado por vários estudos - jovens e adultos jovens, pouca escolaridade, baixa renda, desempregados, frequentemente provenientes de famílias com separações e recasamentos, além de poliusuários de substâncias (Ribeiro et al., 2012). No entanto, se examinados separadamente, encontramos traços que os singularizam e os diferem desse padrão, o que reforça a importância de conhecer a história de cada uma dessas vidas e dos diferentes usos e significados das drogas em suas trajetórias. Fernando apresenta um "viver na rua" diferenciado que o protege do próprio consumo de crack, apesar de oito anos de vivência de rua e de convivência com outros usuários; Tadeu é um jovem de classe 
média, com boa escolaridade e bom convívio familiar. Nesse sentido, estratégias diferenciadas de atenção parecem ser o caminho mais coerente.

\section{As MÃES ENTREVISTAdAS}

\section{Verônica}

Mãe de um adolescente de 15 anos, usuário de todas as drogas incluindo o crack, Verônica, 36 anos, foi entrevistada na Secretaria Municipal de Assistência Social no momento em que fazia mais um, entre os muitos, pedidos de socorro para resolver a situação do filho. Durante toda a entrevista, a mãe chorou muito. Verônica morava com o companheiro e com outros três filhos em um único cômodo. O filho usuário de crack não residia com ela, mas sempre aparecia em casa para exigir dinheiro e "tumultuar" a vida já complicada da família. O pai do adolescente era usuário de drogas e foi ele quem as apresentou ao filho, quando moravam juntos. O filho começou a roubar tudo da casa do pai, e este o "devolveu" para a mãe. Verônica narrou episódios de extrema violência:

Ele [o filho adolescente] não é nada bom. Ele usa muita droga e me agride sempre. Essa semana ele puxou a faca, colocou o revólver na minha cabeça e disse que ia me matar. Faz três meses que todo mundo da minha casa foi embora com medo dele. Tudo de casa ele leva, rouba de vizinho, assalta. Ele é muito violento. Quebra tudo, agride todo mundo. Eu estou andando só com uma calça e uma blusa para eu trabalhar, porque ele já acabou com tudo.

Segundo a mãe, ocorreram mudanças significativas no comportamento do filho com o uso de crack: "Depois que ele começou a usar essa droga ninguém quer ele por perto". Quando indagada como se sentia com a proximidade do filho, a mãe chorou desesperadamente e desabafou: "Ele ficou muito ruim, ele hoje tem o coração ruim. Tenho medo dele. Queria uma internação". A dificuldade de convivência foi trazida com muita dor por essa mãe que, apesar de tudo, ainda não desistiu do filho. Talvez por ser difícil de suportar o que o jovem representava no momento, a mãe buscou uma explicação religiosa: "É falta de Deus".

As mudanças não são notadas apenas na vida do adolescente, mas também na sua própria vida: "Mudou o meu destino. Eu não sei o que é comer, o que é dormir, o que é rir. Ele está marcado para morrer queimado. Você colocar um filho no mundo para acabar assim. É muito triste". 


\section{Roberta}

Mãe de seis filhos, Roberta tinha 49 anos. O filho de 16 anos fazia uso de várias drogas, mas ela não sabia sobre uso de crack. $\mathrm{O}$ adolescente estava acolhido no projeto destinado à população em situação de rua. Só depois da institucionalização do adolescente é que Roberta retomou o contato com ele. Morava no interior do município e trabalhava em um restaurante como ajudante de cozinha. Disse que o filho vivia desde os 9 anos na rua, apesar das inúmeras tentativas para que ele voltasse a conviver com a família. $O$ jovem era bastante obediente e trabalhador, mas gostava de "viver pela rua". Dos nove filhos, apenas ele e o irmão eram usuários de drogas, embora o mais velho só usasse maconha. Nenhum dos outros filhos tem história de rua ou institucionalização. O adolescente em foco, o caçula, não era "filho de sangue". A mãe fez uma análise surpreendente da condição do filho:

Bateram na porta e, quando eu vi, estava lá ele, embrulhado em uma manta e em cima de um papelão. O que eu podia fazer? Peguei e cuidei e ele não sabe dessa história. Hoje vejo que ele está voltando para o seu destino, para o papelão, para a rua.

As falas de Roberta e Verônica denotam um certo distanciamento em relação aos filhos. Uma delas verbalizou: "Eu não sei mais quem é o meu filho, não reconheço mais". O desgaste da relação familiar e uma certa dose de fatalismo são observados.

Seleghim e colaboradores (2011) elegeram, com base em entrevistas com os usuários de crack, em uma unidade de emergência psiquiátrica em Maringá, duas categorias relativas ao vínculo familiar: elemento facilitador do uso de crack e vínculo familiar fragmentado. No estudo, o uso de drogas lícitas e/ ou ilícitas por um ou mais membros da família foi relatado pelos usuários de crack como elemento facilitador para a experimentação. Em relação à presença de violência intrafamiliar, boa parte deles considerou tais ações como respostas repressivas da família ao uso de crack. $\mathrm{O}$ encarceramento domiciliar e a denúncia à polícia foram mencionados como estratégias da família para conter o uso. A fragmentação do vínculo familiar também foi constatada na investigação de Seleghim e colaboradores, em que vários usuários informaram não manter mais contato com os pais. 


\section{PRINCIPAIS CAUSAS E CONSEQUÊNCIAS DO USO DO CRACK}

Em relação aos possíveis motivos que levaram ao uso da droga, as mães entrevistadas coincidem: influência de amigos, a vida nas ruas, "cabeça fraca". Verônica comentou a influência direta do pai usuário que apresentou a droga ao filho. Silva (2007) analisou a representação social do uso de susbstâncias psicoativas entre usuários de crack em tratamento em Salvador, comparando dois momentos distintos no período da internação. A autora percebeu que as justificativas para o consumo, no primeiro momento, eram descritas, principalmente, como uma combinação entre fuga de problemas, curiosidade e influência dos amigos. Com o passar do tempo, as representações passaram a incluir o contexto familiar, como mais uma dimensão que está inter-relacionada com o fenômeno em estudo. Essa incorporação requer, segundo Silva, um manejo diferenciado, pois as mães passam a rever o próprio posicionamento diante do filho que usa droga.

Os profissionais que atuam na rede socioassistencial de Manaus apontam vários motivos para o uso de crack por crianças e adolescentes. De acordo com a opinião da promotora da Vara da Infância e Juventude e do conselheiro tutelar, a principal causa é a desestruturação familiar. A falta de tempo da mulher, que hoje precisa trabalhar fora, também foi mencionada. Sem o devido acompanhamento da mãe, o adolescente fica mais vulnerável à influência dos amigos.

A promotora faz uma diferenciação entre a motivação dos adolescentes que têm apoio familiar e a daqueles que não contam com esse suporte. Na visão da entrevistada, o que leva os primeiros a consumirem droga é a curiosidade. Os jovens advindos de famílias "desestruturadas", segundo ela, acabam utilizando a droga para "tirar a fome" - referindo-se ao uso de cola pela população em situação de rua.

Fica evidenciado na fala da promotora que a população-alvo da dependência química são crianças e adolescentes pobres que vivem nas ruas. Essa visão reducionista também aparece no discurso do conselheiro tutelar que faz uma relação direta entre separação do casal, pobreza e uso de drogas. Nenhum dos entrevistados ampliou a discussão da dependência química para todas as crianças e adolescentes e se resumiram a discutir a questão referindo-se aos "meninos da ponte". Ambos afirmaram que o crack não se configura como um problema no município, mas que o uso de drogas começa a preocupar as autoridades locais. Segundo a promotora, o número de crianças e adolescentes usuários de 
droga "ainda não é muito expressivo e nós sabemos quem é. A maioria fica lá embaixo da ponte - são os conhecidos meninos da ponte".

O coordenador do Departamento de Dependência Química da Secretaria Estadual de Assistência Social alega que as mazelas sociais acabam por motivar o uso/abuso de drogas pelos grupos mais vulneráveis. Pontua, assim como os demais colegas da rede, que ainda é pequeno o número de crianças e adolescentes em situação de rua no município, o que os torna até certo ponto "invisíveis". Acerca da motivação para o uso de drogas pelos pais das crianças e adolescentes, o desemprego aparece como tema central.

De acordo com a representante do Creas, entretanto, os conflitos familiares são o motivador para o uso de drogas e, na maioria das vezes, é o que os leva para a vivência de rua. Relata que, na sua experiência com crianças e adolescentes abusadas sexualmente, o uso de drogas passou a fazer parte da vida desse grupo como uma manifestação de "revolta". O "modelo familiar" em que a droga é aceita também foi mencionado pela profissional. O coordenador de uma das Comunidades Terapêuticas reforça a fala da coordenadora do Creas, identificando a educação familiar (ou a falta dela) como um dos motivadores para o uso abusivo de drogas: "Os pais perderam a noção de autoridade, perderam a noção de disciplina, perderam a noção de carinho, de amor. É uma questão de educação familiar. A família precisa ser reeducada para dar bom exemplo".

A coordenadora da saúde mental afirma que as crianças e adolescentes não vão para a rua por serem usuárias de drogas, mas são apresentadas às substâncias no momento que estão nas ruas. Alguns estudos vão nessa direção, identificando que o uso de crack faz parte de uma cultura da vida nas ruas. Assim, as questões sociais se configuram como um grande desafio para o município.

Em síntese, podemos dizer que a visão em relação à motivação para o uso se diferencia nos três blocos de sujeitos investigados: adolescentes, mães e atores da rede. No primeiro grupo, os jovens apontam, para a influência dos colegas, a vivência de rua, e um adolescente fala sobre conflitos familiares. Já as mães atribuem a características pessoais dos filhos - "ser influenciável" e "ter coração ruim" - as causas da dependência. Questões sobre relações familiares só aparecem no depoimento de uma das mães, que afirma que o filho experimentou drogas com o pai. No discurso dos atores da rede, prepondera a visão dos problemas sociais e da "desestrutura" familiar (e não de conflitos familiares) como motivadores para o uso. A agressividade é 
identificada por eles como a principal consequência do uso de crack na vida das crianças e adolescentes.

Essa semana mesmo eu tive fazendo uma abordagem no centro com crianças que estão sendo usadas para o trabalho infantil. Nós encontramos crianças de 7,8 anos com uma mudança de comportamento que eu me surpreendi. Teve uma que bateu no meu braço, que a lapiseira que eu estava foi parar longe; a outra jogou um prato de comida na assistente social. Muita agressividade. Elas já são usuárias de drogas e o surto delas é grande. (conselheiro tutelar)

Para o representante da assistência social, assim como para o conselheiro tutelar, a agressividade é a principal mudança comportamental, e há uma relação entre o uso de crack e o envolvimento com a criminalidade.

A mais perceptível e imediata mudança é a agressividade! Eles ficam muito agressivos, ficam irritados, impacientes e ansiosos. É o primeiro sinal que estamos tratando de um usuário de crack. São as condutas psicopatas que eles passam a desenvolver. $\mathrm{E}$ aí é fatal. A gente tem um exemplo aqui hoje dessa mãe que o filho é menor de idade, 15 anos. Já pegou um revólver para matar a mãe, bate nela, ameaçou que se ela voltasse aqui ele ia matá-la, estuprou a irmã. Então é uma pessoa que passou a ser desprovida de sensibilidade para com o outro. E isso pode levar à criminalidade, porque o objetivo é conseguir a droga. Tem mudado o perfil da cidade: hoje tem sequestro, assalto. Não era assim. Isso está relacionado de alguma forma ao aumento do uso do crack.

Vários estudos (Ribeiro et al., 2006, 2012) correlacionam o uso de crack a um aumento da agressividade, especialmente nos períodos de abstinência, bem como a problemas com relação à criminalidade (Siegal et al., 2002; Schifano \& Corkery, 2008).

Em relação ao usuário de cocaína intranasal, os usuários de crack apresentam um padrão mais grave de consumo, maior envolvimento em atividades ilegais e prostituição, maior risco dos efeitos adversos da substância e maior chance de morar e ter morado na rua. (Ribeiro et al., 2012)

Embora áreas em que há grande consumo dessa droga costumem apresentar índices mais altos de violência e crimes em geral (Ribeiro et al., 2006; Siegal et al., 2002; Schifano \& Corkery, 2008), a relação direta entre uso de crack, 
agressividade e criminalidade deve ser evitada. Vale ressaltar que essa associação, com base no senso comum, pode favorecer a estigmatização desses usuários e enviesar as estratégias de prevenção/intervenção.

Outro aspecto que merece uma análise cuidadosa é a visão fatalista de que o sujeito que consome crack está condenado à morte devido aos efeitos da droga no organismo. Apesar do índice de mortalidade entre usuários de crack ser grande, os estudos mostram que os óbitos são mais comumente associados a elementos de tráfico, disputa entre pontos de venda/uso ou enfrentamentos com a polícia, do que aos danos causados diretamente pela droga. Ribeiro e colaboradores (2006), em um estudo de coorte realizado em São Paulo por cinco anos, com 131 usuários, demonstraram que as maiores causas de morte eram homicídio e Aids.

A coordenadora do Creas, por sua vez, alude às consequências físicas do uso: "Chegam aqui magros, doentes, com febre, sujos, famintos, precisando de acolhimento e cuidados médicos. Leva para a emergência e alguns precisam até ficar internados". Nessa mesma linha, a psicóloga de um programa que trabalha com crianças e adolescentes em situação de rua faz referência aos prejuízos físicos: "Eu vejo e falo para eles que está afetando a parte psicomotora e os órgãos: coração, pulmão. Eu digo que o organismo deles vai entrar em colapso. (...) Chegam com escabiose, tuberculose e até hanseníase".

O coordenador de uma das Comunidades Terapêuticas discorre sobre as consequências do uso de crack a partir da sua experiência como dependente químico:

As consequências são drásticas. A marginalidade, a penitenciária e a morte precoce. Hoje o usuário de crack tem uma vida muito rápida. (...) Nós estamos tratando de dois casos que têm sequelas graves. Esses dois caras estão presos dentro de casa e recebem comida por baixo da porta porque se a mãe abrir... Ele está totalmente perturbado. (...) Muitos desenvolvem problemas mentais. Eu não sei como eu não tive nenhuma sequela, porque foram 20 anos de uso de drogas pesadas.

Nonticuri (2010), analisando as vivências de adolescentes e jovens com o crack, relata que a intensidade do uso do crack acarretou para os usuários: isolamento, depressão, distúrbios de alimentação e sono, perda da emoção, da capacidade de trabalhar e da higiene, venda de bens pessoais, ansiedade, alucinações, medo, possibilidade de arriscar tudo pela droga, roubos e morte. 


\section{A VISÃO dOS ADOLESCENTES E FAMILIARES SOBRE O FUNCIONAMENTO DOS SERVIÇOS}

Duas mães de adolescentes com histórico de uso de crack/drogas e que estavam sendo atendidos ou buscando atendimento nas instituições de assistência social apresentaram suas visões sobre os serviços existentes em Manaus.

No caso de Verônica, o filho não se encontrava em nenhuma instituição naquele momento e a mãe buscava ajuda na Secretaria Estadual de Assistência Social. Verônica mostrou-se incrédula em relação às instituições que o filho já havia buscado ao longo de sua trajetória de uso, considerando-as pouco resolutivas: "Só prende ele, leva para o Conselho Tutelar e depois eles me devolvem". A ideia de devolução aparece de forma recorrente no discurso da genitora que parecia não ter mais recursos financeiros e, principalmente, emocionais para "receber de volta" esse filho. Ela descreveu o que esperava de uma instituição ideal:

Eu gostaria mesmo que ele não ficasse no meio de adolescentes assim como ele. Que o colocasse para estudar lá dentro, que trabalhasse. Mas que não jogasse como um animal, porque, por mais que a pessoa seja assim, é um ser humano. Eu queria, não sei se vai acontecer isso um dia, que ele fosse para um lugar bem grande, que colocasse ele preso lá e que não pudesse fugir, mas que estudasse e trabalhasse. Que tivesse tratamento psicológico para ele e para mim também, porque eu preciso e muito.

Entretanto, Roberta, mãe de adolescente em programa social, avaliou que o filho estava bem na instituição, mas que ele precisava "de outro lugar". Considerou também que a "mistura" com outros adolescentes usuários de drogas dificultava a recuperação. O Programa Portas Abertas existente na instituição facilitava as sucessivas recaídas: "Ele precisava ficar preso".

É interessante notar que as mesmas categorias aparecem no discurso das mães, apesar da trajetória dos filhos serem bastante diferenciadas: a influência do grupo na continuidade da dependência e a estratégia de aprisionamento como única possibilidade de conter o adolescente para o tratamento.

A fala de Raíssa, a única menina entre os três adolescentes entrevistados, corroborou a visão das mães, indicando que a privação de liberdade era o primeiro passo para a recuperação. Criticou o modelo de atendimento "portas abertas" da instituição que frequentava: "A única forma de parar é prendendo 
mesmo. É porque tem muita gente que vai para a cadeia e passa anos e aí acaba parando. Aqui, que pode sair, não ajuda muito".

Fernando, por sua vez, tem posição distinta. Comentou as características positivas dessa mesma instituição. Disse que frequentava o programa há quatro meses e que percebeu mudanças significativas em sua vida:

Mudança é de não estar na rua, não estar jogado por aí, não levar uma bala, uma facada. Não estou usando drogas. Não estão me humilhando, não estou tendo que pedir dinheiro a ninguém para comprar droga. Eu estou muito bem aqui na casa.

Tadeu apresentou uma visão bem crítica da Comunidade Terapêutica em que estava internado, principalmente em relação à ausência de atenção à saúde dos internos.

Aqui dentro todo mundo reclama muito que demora muito o atendimento à saúde. Tipo dentista. O pessoal fala que está sentindo isso ou aquilo, e eles só sabem falar que é abstinência, tudo é abstinência. Só que às vezes não é. É problema mesmo da pessoa. Depois de muito tempo que encaminha para alguma unidade de saúde.

Essas diferentes visões dos adolescentes e familiares acerca do modelo de instituição ideal vem sendo alvo de muitas discussões clínicas e acadêmicas: internação na perspectiva da abstinência e redução de danos ou modelo de "portas abertas" são exemplos de modalidades de atenção possíveis e presentes em nosso meio.

\section{Funcionamento da Rede de Assistência Social e Saúde}

Iniciamos a apresentação do funcionamento da rede socioassistencial com a descrição do tipo de articulação existente entre o SAI e outras instituições do município, que permitam apoiar o atendimento aos acolhidos com problemas decorrentes do uso de crack.

Constatamos a fragilidade da articulação dos SAls com a Rede Proteção, Promoção e Defesa dos Direitos das Crianças e dos Adolescentes. Todos os SAls conheciam os dados de localização de Conselhos Tutelares, Judiciário, serviços de saúde e escolas, mas trocavam informações apenas com os dois primeiros. A ocorrência de reuniões periódicas e regulares com o Poder Judiciário foi 
referida. Chama atenção o item "nenhuma articulação": 62,5\% disseram não ter articulação com Caps; 37,5\% com Defensoria Pública, delegacias e serviços de saúde; 25\% com Creas e Secretaria Municipal de Assistência Social; e 12,5\% com Cras, Ministério Público, escolas e ONGs.

Em relação aos serviços oferecidos às famílias pelos dois SAls cujos gestores informaram ter adolescentes usuários de crack acolhidos, constatamos que apenas uma unidade oferece atenção para os familiares com: atendimento psicológico/psiquiátrico, acompanhamento social e médico, serviços para tratamento de dependência química, apoio financeiro, inserção em programa/ serviço oficial ou comunitário de auxílio/proteção à família, assistência jurídica, apoio material, encaminhamento para programas de profissionalização e orientação para planejamento familiar.

Perguntamos aos profissionais de diversas áreas qual era o papel da instituição a que pertenciam, em relação à rede de atenção a crianças e adolescentes com uso/abuso de crack. Ficou claro que não há papéis claramente definidos em uma perspectiva de rede, e as respostas versaram sobre a natureza e a missão das instituições em um âmbito mais amplo, sem a especificidade para a atenção ao usuário de drogas. Também foi notória a confusão entre atendimento e atenção. Surpreende a ausência da visão de prevenção, dado já pontuado na pouca expressividade de ações preventivas nas instituiçõos da região Norte em relação ao restante do país.

Segundo o conselheiro tutelar, o seu papel é proteger a criança e o adolescente. Em relação ao uso de drogas, afirmou não haver nenhuma ação específica. Quando há um caso de uso de drogas por adolescentes, o Conselho Tutelar se limita a aconselhar sobre os malefícios dessas substâncias e a encaminhar para o órgão competente, que é a Secretaria Estadual de Assistência Social. A falta de uma Casa de Recuperação para crianças/adolescentes no município dificulta as ações destinadas a essa clientela. Ainda em suas palavras, o Conselho Tutelar é frequentemente acionado pelas famílias buscando internação para os filhos, e que "fica de mãos atadas" por não ter para onde encaminhar.

A Promotoria da Vara da Infância e Juventude considera que o papel da justiça tem sido o de provocar o Poder Público a apresentar respostas imediatas em relação à atenção a crianças e adolescentes usuários de drogas:

O que a gente tem de concreto é o Ministério Público se empenhando. Porque nós estamos vendo as coisas tomando uma proporção e o Poder Público está acomodado, e eles dizem "não temos o serviço", 
não temos e pronto! Como se não fosse obrigação deles fazer isso. Então diante dessa situação, a partir da iniciativa do Ministério Público, de reunir esses órgãos, necessitamos de uma solução urgente para esse problema.

A entrevistada descreveu situações em que a promotoria pediu o internamento compulsório e o município não atendeu, alegando falta de instituições adequadas para abrigar o adolescente. Avaliou que o município, principalmente a área da saúde, negligenciava o atendimento a esse público.

A coordenadora do Creas descreveu o papel da instituição a partir da missão do equipamento, não o considerando um espaço de atenção às questões relativas ao abuso de drogas. $O$ papel do Creas seria apenas o de referenciar:

O Creas tem três objetivos muito bem definidos: atender todas as pessoas que têm os seus direitos violados, fazendo com que elas consigam trabalhar essa questão da violência e interromper o ciclo de violência; trabalhar a função protetiva da família e das crianças; e empoderar essas crianças e essas famílias para que elas consigam lidar com esse sofrimento.

O atendimento ao usuário de drogas, acrescentou, é atribuição da saúde mental do município.

Esse serviço era para ser realizado pela saúde mental e como nós não temos Caps implantados para o atendimento da criança e do adolescente, a gente recebe essa demanda e faz o encaminhamento para algumas instituições que acolhem [adultos]. Infelizmente aqui em Manaus eu não conheço nenhuma [instituição] que acolhe crianças e adolescentes. O que nós fazemos aqui é trabalhar a família desse usuário e buscar, depois que ele fizer o tratamento, inseri-lo em algum programa social e ficar atendendo a família dele. Com o usuário específico a gente não tem. Nós encaminhamos para a Secretaria Estadual de Assistência Social.

Embora o Creas tenha claro em suas atribuições a atenção à família do usuário, a coordenadora afirmou que a participação da família nos programas é ínfima e que a procura visa apenas ao encaminhamento para a internação: "A família vem com um único fim - internação".

A psicóloga do programa ligado à Secretaria Municipal de Assistência Social declarou que a instituição foi criada com a finalidade de retirar crianças e adolescentes em situação de rua, usuários de drogas ou não, e reestabelecer 
o vínculo com a família. Como não havia nenhum atendimento específico ao usuário de drogas, o procedimento da instituição se limitava a acolher e encaminhar.

Atendemos e encaminhamos para as instituições que trabalham com dependência química. Fazemos a triagem, fazemos o atendimento psicossocial, eles são acolhidos e aí vamos buscar esses colaboradores, que podem encaminhar tanto para uma internação como para o atendimento ambulatorial.

O representante da Secretaria Estadual de Assistência Social foi enfático ao afirmar que cabe à saúde o atendimento ao usuário de crack e que a assistência social do estado está assumindo um legado que não compete ao setor:

Isso na verdade trata de um papel da saúde. A Secretaria de Assistência Social, o foco dela é a família e pelo fato do usuário pertencer a essa família, também não deixa de ter o nosso cuidado. Por falta dessa rede de assistência aqui no estado, o governo solicitou à secretaria que fizesse acolhimento também e conveniou as Comunidades Terapêuticas. O papel da secretaria estadual seria esse: referenciar, coordenar e orientar para que esses órgãos municipais funcionassem adequadamente. Só que aqui nós temos uma função interessante que, além de fazer essa orientação e coordenação, a gente também vai e mete a mão na massa. Não dá para ficar parado. Atua diretamente, a maioria dos casos a gente atende diretamente.

De acordo com a coordenadora de saúde mental, a área técnica responde por todo o campo da saúde mental, álcool e outras drogas. Considerou que ambos os campos eram muito recentes na cidade. No momento em que a pesquisa se realizava havia sido inaugurado apenas um Caps no município. No ano de 2012 mais um Caps foi criado. Essa profissional considerou que a área estava engatinhando e que a questão das drogas ainda estava em fase de discussão, sem nenhuma ação concreta da saúde até aquele momento.

Está iniciando toda uma discussão de como trabalhar de forma intersetorial a questão do álcool e outras drogas. Nós começamos um processo capitaneado pelo Ministério Público em que eles estão reunindo secretarias municipais e estaduais para discutir em conjunto como nós vamos abordar esse tema, porque a questão da drogadição vem crescendo visivelmente na cidade. Apesar do crack não ser um problema na dimensão de São Paulo e Rio de Janeiro, aqui aparece mais na forma de oxi. Tanto na rede pública, seja ela municipal e 
estadual, nós não temos nenhum tipo de atendimento. Em Manaus nós contamos apenas com as Comunidades Terapêuticas e os grupos de mútua ajuda. É o que nós temos.

É notório que a cultura do encaminhamento está instalada nas instituições de Manaus. Não há uma leitura mais abrangente sobre a responsabilidade de cada um dos equipamentos em relação ao acolhimento, cuidado, atendimento, fiscalização. Mesmo as unidades de saúde, protegidas pelo discurso de não ter recursos humanos habilitados para lidar com a dependência química, fazem do encaminhamento para a assistência social a sua única ação. $\mathrm{O}$ atendimento ao usuário de drogas no Amazonas é, portanto, muito frágil. Não se observa aumento do número de leitos hospitalares para o atendimento e tratamento dos usuários nas unidades de saúde ou investimento na qualificação aos profissionais na área. Também não há leitos disponíveis para crianças e adolescentes usuários de drogas.

As Comunidades Terapêuticas (todas não governamentais) aparecem no cenário como único equipamento destinado ao atendimento do dependente químico na cidade de Manaus.

As Comunidades Terapêuticas são ambientes de internação especializados, presentes em mais de 60 países, que oferecem programas de tratamento estruturados e intensivos, visando a obtenção e manutenção da abstinência, inicialmente em ambiente protegido, com encaminhamento posterior para a internação parcial e/ou ambulatório, conforme as necessidades do paciente. (Fracasso \& Landre, 2012: 54)

Fracasso e Landre (2012) destacam o equívoco de se chamar esses serviços de "comunidades terapêuticas"; na verdade, são centros de acolhimento. Em 2001, a Agência Nacional de Vigilância Sanitária (Anvisa) estabeleceu o regulamento técnico para o funcionamento das comunidades. Os autores afirmam que, apesar de as Comunidades Terapêuticas estarem contempladas no eixo de tratamento da Política Nacional sobre Drogas, ainda existe uma divergência entre o modelo aplicado nas Comunidades Terapêuticas - que utiliza a instituição, por meio de conselheiros (ex-usuários) como agente de mudanças - e a área da saúde. Segundo os autores, isso se deve a dois fatores: o despreparo de algumas unidades que se nomeiam Comunidades Terapêuticas sem atender os critérios básicos e a falta de conhecimento da área da saúde acerca do trabalho ali desenvolvido. 
Os coordenadores das Comunidades Terapêuticas entrevistados chamam atenção para a especificidade do atendimento ao adolescente na cidade: apenas duas das seis unidades se destinam a esse público e nenhuma delas recebe crianças. Os encaminhamentos são feitos pela Secretaria Estadual de Assistência Social e, após uma triagem, o adolescente é internado. Em uma das instituições o tempo mínimo de permanência é de quatro meses e na outra, seis meses; o tempo máximo é de um ano. As duas comunidades possuem atendimento ambulatorial.

As comunidades são distantes de Manaus, localizadas na área rural. Em ambas há equipe técnica, mas os profissionais não permanecem no local. Os coordenadores afirmaram que todos os direitos do adolescente são garantidos, mas na unidade visitada, o único adolescente internado não frequentava a escola nem tinha outra atividade externa. Ambas trabalham com a abstinência e os internos são acompanhados por conselheiros que são ex-internos que ainda estão em recuperação. Seguem a metodologia dos grupos de mútua ajuda e em uma delas é utilizado o método Inteligência Multifocal de Augusto Curi. Os coordenadores das duas comunidades são dependentes químicos em recuperação e um deles é pastor evangélico. As comunidades trabalham na perspectiva de laborterapia.

Avaliação da articulação da rede de atenção: "rede, que rede?"

Saletti-Filho (2003) discute o conceito de vulnerabilidade no campo da saúde, identificando três esferas: individual, social e institucional. Segundo a autora, a vulnerabilidade do indivíduo está relacionada a comportamentos que podem criar oportunidades de adoecer. A vulnerabilidade social aborda os aspectos sociopolíticos e culturais que estão ligados a acesso a informações, grau de escolaridade, disponibilidade de recursos materiais, poder de influenciar decisões políticas, possibilidades de enfrentar barreiras culturais etc. É um conjunto de condições de bem-estar social, como as situações de moradia, acesso a bens de consumo e graus de liberdade de pensamento e expressão.

A vulnerabilidade institucional está associada às políticas e ações planejadas e organizadas para lidar com a doença. Pode ser avaliada a partir de aspectos como: 1) compromisso das autoridades com o enfrentamento do problema; 2) ações efetivamente propostas e implantadas por essas autoridades; 3) coalizão interinstitucional e intersetorial (saúde, educação, bem-estar social, trabalho etc.) para a ação; 4) planejamento e gerenciamento dessas ações; 
5) financiamento adequado e estável dos programas; 6) continuidade dos programas; 7) avaliação e retroalimentação dos programas; 8) sintonia entre programas institucionalizados e aspirações da sociedade; 9) vínculos entre as instituições e a sociedade civil organizada.

Quanto maiores forem o compromisso, a integração e o monitoramento de programas de prevenção e cuidado, maiores serão as chances de canalizar os recursos, otimizar seu uso e fortalecer os indivíduos e a sociedade no enfrentamento da doença. Para avaliar o grau de vulnerabilidade de uma coletividade, em relação ao problema do crack, por exemplo, é necessário conhecer: 1) a legislação em vigor e sua aplicação; 2) a situação de acesso aos serviços de saúde por parte das pessoas de diferentes estratos sociais; 3) a qualidade dos serviços de saúde disponíveis.

A ausência de uma rede organizada em Manaus coloca o município e a sua coletividade - principalmente crianças e adolescentes - em situação de nítida vulnerabilidade institucional.

Nós temos um grande problema porque, se essa criança é encontrada na rua, nós não temos como levar para o serviço de acolhimento institucional, porque lá essa criança não fica. Não podemos colocar uma criança em crise, com problema de drogas junto com o resto do povo. E aí? Para onde vai? Quem fica com a criança? Fica com o Conselho Tutelar? Com o Ministério Público? Esses dias quase que eu disse para o secretário: eu vou levar o menino lá para a sua porta! Ninguém quer ficar, não tem lugar para encaminhar. (representante da Secretaria Estadual de Assistência Social)

A coordenadora do Creas considerou haver um "curto-circuito" no itinerário de crianças e adolescentes usuários de drogas no município.

Existe um curto-circuito. O que acontece? O nosso estado, o nosso município, ele não tem um Caps para atender crianças e adolescentes. Nós não temos retaguarda! Enquanto ação da Secretaria de Assistência nós já fizemos três abordagens de madrugada, tiramos os meninos de baixo da ponte, fizemos um cadastro. Duas horas depois, estavam todos na rua de novo. Por quê? Porque não temos retaguarda, não temos onde colocar esses meninos. (...) É como se estivéssemos enxugando gelo (...). Não tem Caps i, Caps ad. Nós não temos no hospital leitos específicos para esse fim. (...) A gente acaba encaminhando para o hospital psiquiátrico, que também não tem leito específico (...). Então aqui a situação relacionada à saúde mental está sendo jogada. (...) As crianças e adolescentes estão num limbo. 
O representante da Secretaria Estadual de Assistência Social também foi bastante crítico, lamentando o fato de que o estado e o município não têm o que oferecer aos usuários e às famílias:

É uma grande angústia porque nós não temos nenhuma referência para a intervenção. Eu já visitei pessoas acorrentadas pelas mãos. Aí tem que soltar, mas se soltar vai para o consumo. A mãe diz que não quer ver o filho morto e pergunta: "o que vocês oferecem?" Então o Estado paralisa porque ele não tem o que oferecer! E aí? Solta da corrente e a mãe é culpada por cárcere privado? Como fica? Então há uma falta muito grande por falta de apoio mesmo.

Para esse profissional há um primeiro movimento para a formação de rede, mas que ainda é caracterizado pela lógica de encaminhamento e de repasse de responsabilidade: “Eu percebo que do ano passado para cá já começa a ter algum movimento de rede, mas ainda é a lógica de jogar".

A crítica à ausência de equipamentos da saúde está presente em todos os entrevistados. A própria coordenadora de saúde mental reconheceu que os pacientes com problemas de drogas no município - adultos, adolescentes ou crianças - não têm uma resposta efetiva do Estado. Na ocasião da pesquisa, havia previsão de criação de outros Caps e de capacitação para profissionais da atenção básica, mas tudo ainda estava em fase de planejamento. No segundo semestre de 2012, mais um Caps e um Caps i foram inaugurados. Segundo a coordenadora de saúde mental, não era possível falar em rede de atenção no município; para isso seria necessário avançar na discussão intersetorial, pois um trabalho em rede que apoie o usuário de drogas requer ação conjunta.

A visão dos coordenadores das Comunidades Terapêuticas é de que as ações são isoladas, pouco integradas. Afirmaram que o trabalho das comunidades era bastante solitário e que o diálogo se restringia às próprias comunidades e ao convênio com a Secretaria de Assistência Social. Segundo um dos coordenadores, o principal problema estava na falta de equipamentos da saúde:

Há troca entre as comunidades. Mas da parte do Poder Público fica complicado, porque nós não temos para onde encaminhar uma pessoa que não se enquadre no perfil da nossa comunidade, alguém com comorbidade psiquiátrica, por exemplo, em decorrência da droga. Não existe esse lugar! Não é que eles da saúde não aceitem, é porque não existe esse lugar! 
Parece não haver uma fiscalização das instituições que atendem crianças e adolescentes: o Conselho Tutelar confirmou que faz parte de suas atribuições fiscalizar as Comunidades Terapêuticas, mas que tal ação não é realizada por falta de efetivo. A promotoria reconheceu também que é responsável pela visitação às unidades destinadas a esse público, mas que não tinha informações se as duas comunidades em foco tinham sido fiscalizadas. O Conselho Estadual de Entorpecentes do Amazonas foi mencionado como órgão fiscalizador das comunidades que atendem o público jovem, mas, em visita informal ao órgão, a resposta foi evasiva e o conselho não confirmou se a fiscalização é feita de maneira periódica.

O papel do município em relação ao atendimento em rede ao usuário de crack foi muito mal avaliado. Segundo um dos entrevistados da assistência social: "simplesmente não está enfrentando". A negligência do Poder Público, principalmente da Secretaria de Saúde, foi mencionada por vários entrevistados.

O desafio apresentado à cidade de Manaus parece ser a estruturação de fato da rede de atenção, com a criação de equipamentos, principalmente da saúde, para lidar com a especificidade das crianças e adolescentes usuários de substâncias. A coordenadora de saúde mental considerou que o grande desafio é fazer valer a intersetorialidade na rede e preparar recursos humanos qualificados para a temática, haja vista a existência de um único psiquiatra no município de Manaus.

Em relação às potencialidades, foi mencionada a atuação efetiva do Ministério Público na cobrança de ações do município. A disponibilidade para o diálogo também foi colocada como um ponto favorável à estruturação da rede. $\mathrm{Na}$ Figura 1 encontra-se o fluxograma do atendimento a crianças e adolescentes na cidade de Manaus, de acordo com a percepção dos integrantes da pesquisa. 
Figura 1 - Fluxo de atendimento à criança e adolescente usuário de crack e outras drogas - Manaus

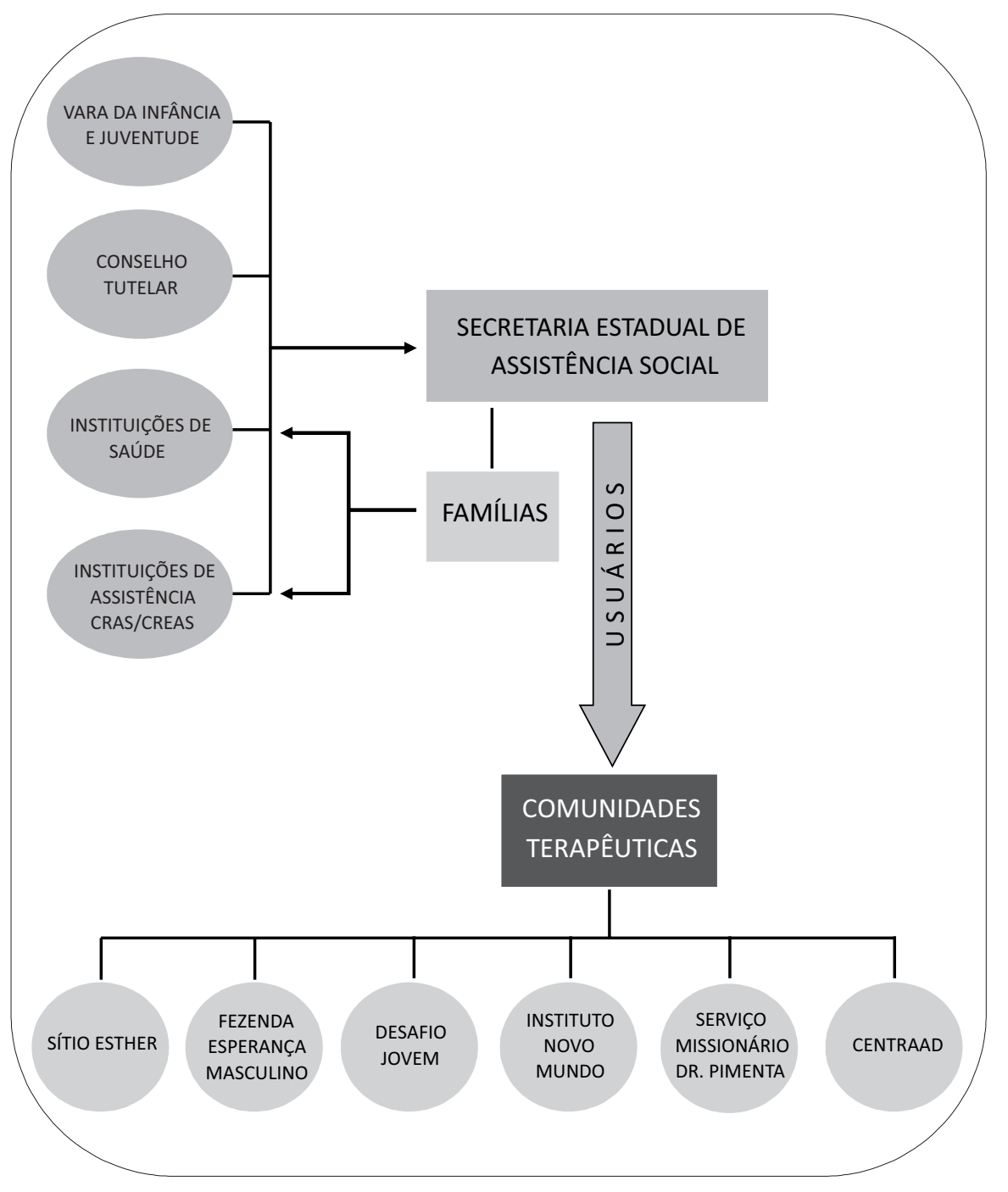

Nota: CENTRAAD = Centro de Tratamento em Adicções, Álcool e Drogas. 


\section{CONSIDERAÇÕES FINAIS}

Os dados socioeconômicos do município evidenciam uma disparidade intraestadual e intramunicipal surpreendente e preocupante, o que demonstra a necessidade de ações diferenciadas com base nas demandas específicas de cada localidade. A trajetória do crack no Amazonas parece se iniciar nos municípios fronteiriços e aos poucos avançar para a capital, atingindo principalmente os grupos mais vulneráveis - residentes nas áreas mais pobres e população de rua.

A invisibilidade é a categoria que mais se evidencia em diversos contextos para todos os adolescentes, principalmente aqueles usuários de crack. A institucionalização cria um espaço para a construção de uma categoria de adolescente ignorado, duramente castigado pelas dificuldades, de uma situação econômica, familiar e psíquica desprivilegiada. Embora os poucos usuários relacionados no levantamento de dados fossem conhecidos, inclusive nominalmente, não recebiam qualquer tipo de atendimento nas instituições elencadas na pesquisa.

Sabe-se que, devido à morosidade do sistema judiciário e à burocracia das instituições, dificilmente um adolescente "da ponte" terá acesso a um tratamento eficiente para atender as suas necessidades, de acordo com a idade, raça, cultura, orientação sexual, condição de moradia, situação financeira, gravidez etc. Com isso, o espaço institucional, que deveria ser apenas temporário, torna-se, para a grande maioria deles, permanente, devido às diversas reincidências nos órgãos da assistência social, visto que o sistema de saúde nada tem a oferecer.

Constatou-se também na pesquisa a invisibilidade dessas meninas e meninos usuários de crack em todo o sistema de garantia de direitos, principalmente pela falta de fiscalização dos organismos gestores. Faltam também políticas sociais, além da precariedade do próprio sistema de atendimento e atenção aos usuários de drogas, cujos profissionais, em geral, se pautam por uma ênfase nos problemas e fracassos, em vez de se comprometerem a estimular o potencial dos adolescentes, oferecendo-lhes os devidos recursos materiais e humanos para que suas competências se concretizem.

A insuficiência de condições estruturais, a dificuldade de acesso às propostas educativas, a inoperância dos técnicos, o descaso dos dirigentes em estimular e orientar a equipe para uma ação mais efetiva são os principais fatores que impedem a construção de renovadas e importantes estratégias a partir das necessidades identificadas pelos próprios adolescentes. Cabe ao Estado, à 
comunidade, a todos aqueles que convivem com eles, assegurar-lhes que é possível promover mudanças, pois a maioria dos meninos que ali se encontra parece não mais acreditar nessa possibilidade.

De quem é o problema? A partir do que vimos e ouvimos, fica claro que em Manaus não há uma rede para atender crianças e adolescentes usuários de drogas, incluindo-se entre elas o crack. Há um conflito instalado no município acerca de quem é o responsável por esses jovens. A saúde, pela inexistência de qualquer trabalho com essa finaildade, é acusada por todas as instituições como negligente, mas se defende argumentando que o uso de drogas por crianças e adolescentes deve ser visto em uma perspectiva intersetorial e lamenta a responsabilização exclusiva atribuída a ela a respeito desse cuidado. A Secretaria Estadual de Assistência Social tem realizado os encaminhamentos e ações destinadas a esse público, mesmo considerando que a assistência ao usuário é uma questão da saúde, e reclama da ausência da própria Secretaria Municipal de Assistência Social. Os SAls e as ONGs que deveriam também atender essa população afirmam que não estão preparados para lidar com essa especificidade e queixam-se da falta de retaguarda. Por fim, até mesmo as Comunidades Terapêuticas - únicos locais destinados ao atendimento específico aos usuários de drogas - são reticentes a receber adolescentes, pois os critérios exigidos para o atendimento a esse público são bastante rígidos. Nada existe para as crianças com problemas com o uso das drogas.

A saúde pública tem contribuído para estabelecer novos rumos ao conferir destaque aos programas nacionais de enfrentamento ao uso de drogas, porém a modificação das leis não assegura a transformação imediata da realidade, servindo, antes, para expor as limitações das políticas sociais destinadas à população usuária de crack e de outras drogas. Sob a ótica da saúde pública, percebe-se quão prejudicados encontram-se os jovens usuários de drogas em Manaus, se considerados o paradigma de promoção e o conceito ampliado de saúde.

Apesar de alguns tímidos avanços do setor Saúde em direção à atenção de crianças e adolescentes usuários de drogas no ano de 2012, é evidente o hiato entre a demanda e a oferta. O problema acaba por reacair sobre as pobres famílias que, desesperadamente, fazem uma via crucis em busca de atendimento para os filhos, sem, entretanto, consegui-lo. Tais adolescentes são velhos conhecidos desse frágil sistema de atenção, que muitas vezes os expulsa das instituições por os considerarem jovens-problema que perturbam a paz da 
unidade. $\mathrm{O}$ desamparo é dimensionado na fala de uma das mães que afirmou se "transformar em muitas", podendo contar apenas com ela: "Eu sou a mãe, o pai, a instituição, o abrigo, a polícia, se resume a mim".

Tal descompromisso municipal com a questão pode ser justificado pelo discurso unânime dos atores da rede que consideram que o crack ainda não se configura como um problema na cidade. No entanto, a realidade observada neste capítulo reflete-se também sobre o atendimento de usuários de outras drogas legais e ilegais, que não têm serviços que os apoiem. Os casos relatados, coletados nos poucos dias em que a pesquisa se realizou na cidade, mostram a magnitude do problema e sua dimensão social. A pressão do Ministério Público local aponta para a necessidade de uma ação concreta em relação às crianças/adolescentes, mobilizando as instituições para "sentar para conversar". Alguns passos têm sido dados na organização de uma rede mínima para o atendimento. Mas o caminho a ser percorrido ainda será longo até que as crianças e adolescentes de Manaus tenham garantidos o direito ao pleno crescimento e desenvolvimento.

\section{REFERÊNCIAS}

AMAZONAS. Secretaria de Estado de Planejamento e Desenvolvimento Econômico. Desenvolvimento Humano em Manaus: atlas municipal. Manaus: Seplan, 2005.

BRASIL. Presidência da República. Secretaria Nacional de Políticas sobre Drogas. Relatório Brasileiro sobre Drogas. Brasília: Senad, 2009. Disponível em: <www.obid. senad.gov.br>. Acesso em: fev. 2013.

CONSELHO FEDERAL DE PSICOLOGIA (CFP). Relatório da $4^{\text {a }}$ Inspeção Nacional de Direitos Humanos: locais de internação para usuários de drogas. Brasília: CFP, 2011.

FRACASSO, L. \& LANDRE, M. Comunidade Terapêutica. In: RIBEIRO, M. \& LARANJEIRA, R. (Orgs.). O Tratamento do Usuário de Crack. Porto Alegre: Artmed, 2012.

GALDURÓZ, J. C. et al. V Levantamento Nacional sobre o Consumo de Drogas Psicotrópicas entre Estudantes do Ensino Fundamental e Médio da Rede Pública de Ensino nas 27 Capitais Brasileiras - 2004. São Paulo: Secretaria Nacional Antidrogas, Cebrid, 2005.

INSTITUTO BRASILEIRO DE GEOGRAFIA E ESTATÍSTICA (IBGE). Pesquisa Nacional de Saúde Escolar. Brasília: IBGE, 2009.

INSTITUTO BRASILEIRO DE GEOGRAFIA E ESTATÍSTICA (IBGE). Censo Demográfico 2010. Rio de Janeiro: IBGE, 2011.

KESSLER, F. \& PECHANSKY, F. Uma visão psiquiátrica sobre o fenômeno do crack na atualidade. Revista de Psiquiatria do Rio Grande do Sul, 30(2): 96-98, 2008. 
LUCAS, A. C. S. et al. Uso de psicotrópicos entre universitários da área da saúde da Universidade Federal do Amazonas, Brasil. Cadernos de Saúde Pública 22(3): 663-671, 2006.

NONTICURI, A. R. As Vivências de Adolescentes e Jovens com o Crack e suas Relações com as Políticas Sociais Protetoras neste Contexto, 2010. Dissertação de Mestrado, Pelotas: Universidade Católica de Pelotas.

NOTO, A. R. et al. Levantamento Nacional sobre o Uso de Drogas entre Crianças e Adolescentes em Situação de Rua nas 27 Capitais Brasileiras. São Paulo: Secretaria Nacional Antidrogas, Centro Brasileiro de Informações sobre Drogas Psicotrópicas, 2003.

RIBEIRO, M. et al. Causes of death among crack cocaine users. Revista Brasileira de Psiquiatria, 28(3): 196-202, 2006.

RIBEIRO, M. et al. Perfil do usuário e história natural do consumo. In: RIBEIRO, M. \& LARANJEIRA, R. (Orgs.). O Tratamento do Usuário de Crack. Porto Alegre: Artmed, 2012.

SALETTI-FILHO, H. C. O conceito de vulnerabilidade e as práticas de saúde: novas perspectivas e desafios. In: CZERESNIA, D. \& FREITAS, C. M. (Orgs.). Promoção da Saúde: conceitos, reflexões, tendências. Rio de Janeiro: Editora Fiocruz, 2003.

SCHIFANO, F. \& CORKERY, J. Cocaine/crack cocaine consumption, treatment demand, seizures, related offences, prices, average purity levels and deaths in the UK (1990 2004). Journal of Psychopharmacology, 22(1): 71-79, 2008.

SELEGHIM, M. et al. Vínculo familiar de usuários de crack atendidos em uma unidade de emergência psiquiátrica. Revista Latino-Americana de Enfermagem, 19(5): 1.1631.170, 2011.

SIEGAL, H. A. et al. Predictors of drug abuse treatment entry among crack-cocaine smokers. Drug and Alcohol Dependence, 68(2): 159-166, 2002.

SILVA, P. As Representações Sociais do Uso de Drogas entre Familiares de Usuários em Tratamento, 2007. Dissertação de Mestrado, Salvador: Universidade Federal da Bahia, 2007. 


\title{
4 \\ O Atendimento a Crianças e Adolescentes Usuários de Crack em Região de Fronteira: a cidade gêmea de Ponta Porã
}

\author{
Liana Wernersbach Pinto \\ Angélica Dalla Vechia Biolchi \\ Edmara Honório Santos \\ Simone Gonçalves de Assis
}

\begin{abstract}
A cidade de Ponta Porã, conhecida como Princesinha dos Ervais, localizase no sudoeste do estado do Mato Grosso do Sul, distante $350 \mathrm{~km}$ da capital do estado, Campo Grande.

Era um povoado denominado inicialmente Punta Porá, que ocupava uma região deserta do interior do Paraguai onde habitavam algumas tribos de índios (guaranis e cauiás). Era ponto de parada de carreteiros que faziam o transporte de erva mate. Após o fim da Guerra do Paraguai foram estabelecidos os limites entre Brasil e Paraguai, e a área passou a ser possessão territorial brasileira. Em 1897 foi constituído o primeiro destacamento policial em Ponta Porã e em 1912 o município foi criado (Ponta Porã, 2014).

Segundo o Censo de 2010, Ponta Porã tem uma população de 77.872 habitantes, distribuídos em uma área de 5.330,4 km², resultando em uma densidade demográfica de 14,6 habitantes por km² (IBGE, 2011). O Índice de Desenvolvimento Humano Municipal (IDHM) é de 0,701, ocupando assim a vigésima posição no estado do Mato Grosso do Sul e a $1.866^{a}$ posição no ranking nacional (Pnud, 2013). É constituída de três distritos: Ponta Porã (sede), Cabaceira do Apa e Sanga Puitã. O município tem o quinto maior produto interno bruto (PIB) do estado do Mato Grosso do Sul e sua economia baseia-se na agricultura e na pecuária (IBGE, 2014).
\end{abstract}

Quanto aos estabelecimentos de saúde, Ponta Porã tem 20 unidades públicas (19 municipais e uma federal) e 13 estabelecimentos privados (IBGE, 2010). 
A esperança de vida ao nascer é de 73,7 anos e o Índice de Desenvolvimento Humano Municipal Longevidade (IDHM-L) é de 0,812 (Pnud, 2013). A taxa de analfabetismo da população de 15 anos ou mais de idade é de 9,2\% (IBGE, 2011).

Um aspecto importante, e que diferencia Ponta Porã de todas as demais cidades incluídas neste livro, refere-se ao fato de que ela se localiza em área de fronteira seca com a cidade paraguaia de Pedro Juan Caballero, com 88.000 habitantes distribuídos em $5.678 \mathrm{~km}^{2}$. As duas localidades são chamadas cidades gêmeas ${ }^{1}$ e tal característica traz inúmeros desafios para a rede como um todo e para a administração de ambos os municípios, conforme será observado ao longo do capítulo. Segundo o Grupo de Trabalho Interfederativo de Integração Fronteiriça (Brasil, 2005), a ocorrência de cidades gêmeas favorece o desejável processo de integração entre os países. No entanto, este cenário facilita a entrada de produtos ilícitos de diversas naturezas e de saída de recursos naturais e minerais, explorados sem controle e ilegalmente, gerando danos ao meio ambiente. Na Figura 1, pode-se observar que as cidades (países) são separadas por apenas uma rua.

Figura 1 - Mapa parcial de Ponta Porã

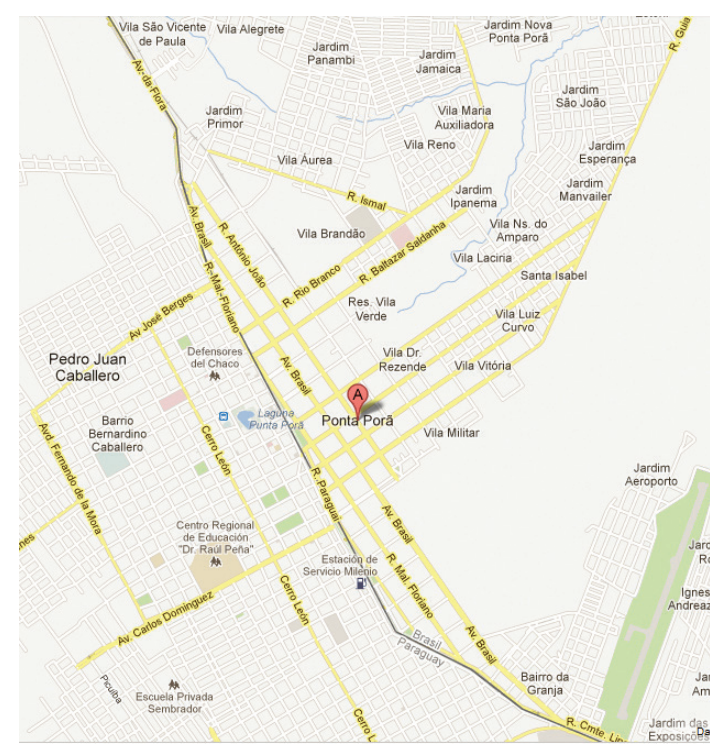

Fonte: $<$ http://maps.google.com.br>.

1 Cidades gêmeas são pares de centros urbanos, frente a frente em um limite internacional, conurbados ou não, que apresentam diferentes níveis de interação: fronteira seca ou fluvial, diferentes atividades econômicas no entorno, variável grau de atração para migrantes e distintos processos históricos (Silva \& Oliveira, 2008). 
Em 2009, instituiu-se na Câmara dos Deputados em Brasília uma Comissão Parlamentar de Inquérito (CPI) para tratar do tema da violência urbana. ${ }^{2}$ Essa comissão, em seu relatório final, identificou 18 pontos da fronteira do Brasil como os principais corredores do tráfico de armas e drogas. Destes, sete encontram-se em Mato Grosso do Sul, e um deles é Ponta Porã.

Em 2011 foi criado pelo decreto n. 7.496 o Plano Estratégico de Fronteiras, com a finalidade de fortalecer a prevenção, o controle, a fiscalização e a repressão dos delitos transfronteiriços e daqueles praticados na faixa de fronteira brasileira. O plano tem como objetivos: 1) integração das ações de segurança pública, de controle aduaneiro e das Forças Armadas da União com a ação dos estados e municípios situados na faixa de fronteira; 2 ) execução de ações conjuntas entre os órgãos de segurança pública, federais e estaduais, a Secretaria da Receita Federal do Brasil e as Forças Armadas; 3) troca de informações entre os órgãos de segurança pública, federais e estaduais, a Secretaria da Receita Federal do Brasil e as Forças Armadas; 4) realização de parcerias com países vizinhos para atuação nas ações previstas (Brasil, 2011).

\section{O CRACK EM PONTA PORÃ}

Não foram encontrados dados, estatísticas ou material bibliográfico sobre o uso de crack no município de Ponta Porã. Alguns trabalhos sobre o uso de drogas entre crianças e adolescentes da região Centro-Oeste são apresentados a seguir, visando a salientar a relevância da droga na região.

Em estudo realizado pelo Centro Brasileiro de Informações sobre Drogas (Cebrid) em 2003 sobre o uso de drogas, entrevistaram-se 2.807 crianças e adolescentes em situação de rua assistidos por instituições governamentais ou não governamentais nas capitais brasileiras (Noto et al., 2003). Analisando-se especificamente os dados da região Centro-Oeste, verifica-se que a maioria dos entrevistados era do sexo masculino (70,1\%), de 15 a 18 anos (53,6\%), $62 \%$ moravam com a família e $53,4 \%$ encontravam-se de um a cinco anos na situação de rua. Constatou-se que $64,7 \%$ das crianças/adolescentes que não estavam morando com a família faziam uso diário de drogas psicotrópicas

2 A CPI, destinada a "apurar a violência urbana", objeto do requerimento de CPI n. 10, de 15 abr. 2008, criada pelo ato da Presidência de 8 dez. 2008, constituída pelo ato da Presidência de 13 ago. 2009, teve seus trabalhos encerrados em 10 dez. 2010, sem a aprovação do relatório final. Disponível em: <www2.camara.leg.br/atividade-legislativa/comissoes/comissoes-temporarias/ parlamentar-de-inquerito/53a-legislatura-encerradas/cpiviol/notas>. Acesso em: jan. 2013. 
(inclusive álcool e tabaco), ao passo que apenas 14\% daquelas que moravam com a família faziam uso diário. Quando analisado o uso mensal de drogas psicotrópicas, observou-se respectivamente $54,1 \%$ e $94,1 \%$ entre os que moravam com os pais e os que não moravam. Em relação ao uso no mês, no grupo que relatou ter consumido alguma substância psicoativa, verificou-se uso de tabaco por $44,4 \%$, de álcool por $57,5 \%$, de solventes por $20,9 \%$, de maconha por $29,1 \%$ e de cocaína e derivados por 16,2\%. Entre os fatores de risco associados ao uso de drogas na vida entre as 358 crianças/adolescentes entrevistados na região Centro-Oeste, observou-se "ficar bravo, solto e irritado com outras pessoas" (37,7\%), "transar sem camisinha" (28,5\%), "andar pelas ruas sem cuidado" $(27,7 \%)$ e "roubo" (26,0\%). Alegaram já ter tentado parar com o uso de drogas 55,3\% dos entrevistados (Noto et al., 2003).

Dados do V Levantamento Nacional sobre o Consumo de Drogas Psicotrópicas entre Estudantes do Ensino Fundamental e Médio da Rede Pública de Ensino nas 27 Capitais Brasileiras - 2004, realizado pelo Cebrid, mostram que o uso na vida de drogas entre os estudantes da região CentroOeste foi de 23,3\%. Nesse estudo foram entrevistados 7.829 alunos do ensino fundamental e médio da rede pública nas 27 capitais brasileiras (Galduróz et al., 2005).

O II Levantamento Domiciliar sobre o Uso de Drogas Psicotrópicas no Brasil, realizado pelo Cebrid em 2005 em municípios com mais de 200 mil habitantes, mostrou que em Campo Grande (MS), o uso na vida de qualquer droga (exceto álcool e tabaco) foi observado em 17,0\% dos entrevistados; o uso na vida de álcool $(73,6 \%)$, tabaco $(41,9 \%)$, maconha $(7,8 \%)$ e solventes $(7,0 \%)$ foram os mais frequentes; a prevalência de dependência de álcool entre os entrevistados da região Centro-Oeste foi de 12,7\%. Observou-se também a prevalência de dependência de maconha $(0,6 \%)$, solventes $(0,2 \%)$, benzodiazepínicos $(0,2 \%)$ e estimulantes $(0,2 \%)$. 0 precoce envolvimento dos entrevistados de 12-17 anos com as drogas ficou evidenciado, havendo até mesmo relatos de dependência e tratamentos por uso de drogas (Carlini et al., 2005).

Em estudo realizado por Muraki (2009), com estudantes do ensino fundamental e médio de escolas públicas de Dourados (MS), 75,2\% dos alunos relataram já ter consumido álcool na vida (12,7\% uso pesado), $21,2 \%$ informaram ter usado solventes e $6,7 \%$, maconha. $O$ uso de crack foi mencionado por $1,9 \%$ dos estudantes e de cocaína por 3,2\%. 
O Relatório Brasileiro sobre Drogas (Brasil, 2009) apresentou dados da pesquisa que abrangeu pessoas com idade entre 12 e 65 anos em cidades de maior porte, incluindo da região Centro-Oeste os municípios de Campo Grande, Cuiabá, Várzea Grande, Anápolis, Aparecida de Goiânia, Goiânia e Brasília (671 pessoas). Verificou-se maior uso na vida das seguintes substâncias no ano de 2005: álcool (73,6\%), tabaco (41,9\%), maconha $(7,8 \%)$, solventes $(7,0 \%)$, benzodiazepínicos $(3,6 \%)$, estimulantes $(2,6 \%)$, cocaína $(2,2 \%)$ e crack (0,4\%). O estudo também mostrou que $12,7 \%$ dos entrevistados são dependentes de álcool, seguido da maconha (0,6\%). Verificou-se ainda que a maconha e a cocaína apresentaram maior prevalência de uso na vida na faixa etária de 18 a 24 anos. Alucinógenos e estimulantes apresentaram alta prevalência na faixa mais jovem (12 a 17 anos).

Santos (2012) realizou estudo transversal com alunos do primeiro ano do ensino médio de escolas públicas de Glória de Dourados/MS, com o objetivo de verificar a prevalência e os fatores associados ao uso de drogas lícitas e ilícitas entre os estudantes adolescentes. Verificou prevalência elevada de uso na vida de tabaco $(18,8 \%)$, solventes $(17,9 \%)$ e energéticos associados com álcool (35,4\%). Em relação ao uso no último mês, chamou atenção o uso de álcool (45,7\%). Constatou-se que o bom desempenho escolar demonstrou ser um fator que reduz a chance para o uso de álcool, enquanto a baixa autoestima representou maior chance de uso dessa substância. Quanto à utilização de solventes/inalantes, verificou-se que a presença de controle da rotina do adolescente por parte dos pais também mostrou ser um fator que reduziu a chance de uso de tais substâncias.

Apesar da ausência de estatísticas sobre consumo de crack pela população jovem de Ponta Porã, em 2010 foi lançado um plano local de enfrentamento ao crack integrado à cidade paraguaia de Pedro Juan Caballero, e em 2011 foi realizada a primeira capacitação incluída no plano. Segundo a secretária de Assistência Social e do Trabalho do município, em reunião no Senado Federal, o sistema de saúde e assistência social da cidade atende também a população usuária de drogas da cidade paraguaia vizinha, Pedro Juan Caballero, contabilizando mais de 150 pacientes, entre os mais de mil dependentes atendidos em Ponta Porã.

Já caminhamos para tirar do papel uma articulação de todas as políticas públicas municipais e também um processo de integração com Pedro Juan Caballero. A câmara municipal está conosco e também as 
autoridades paraguaias convidadas. Daí resultou o nosso plano local de enfrentamento ao crack e outras drogas. (Brasil, 2012b)

Em março de 2011 foi realizado no município o $1^{\circ}$ Fórum Municipal de Enfrentamento ao Crack e Outras Drogas, o qual teve como objetivos a articulação da rede municipal de atenção e tratamento ao dependente químico e a elaboração do plano operativo local de enfrentamento ao crack e outras drogas. Nesse encontro foram apresentadas estatísticas de usuários de crack e outras drogas atendidos nos Centros de Atenção Psicossocial (Caps) e nos Centros de Referência Especializados de Assistência Social (Creas), as atividades realizadas por estes equipamentos com os dependentes e suas famílias, além de um diagnóstico sobre as necessidades locais (Alcântara, 2012).

Todo esse contexto de preocupação com a questão das drogas no município serve como cenário para os resultados de nossa pesquisa sobre crack em Ponta Porã, apresentados a seguir. Para que os dados fossem conhecidos, contamos como o envolvimento da Secretaria Municipal de Assistência Social e do Trabalho (SMAS), do Caps ad (centros para usuários de álcool e outras drogas) e de três Serviços de Acolhimento Institucional (SAIs) da cidade. Nos SAls, responderam a questionários os três gestores e os dois adolescentes acolhidos com história de uso de crack que estavam presentes no momento da visita. Também foi preenchido questionário para cada criança e adolescente com história pessoal de uso de crack ou seus responsáveis, por meio da consulta ao prontuário (cinco no total). Foram ainda realizadas 14 entrevistas com juíza da Vara da Infância e Juventude, conselheira tutelar, secretária de assistência social do município, equipe técnica do SAl, coordenadora do Creas, coordenadora do Caps ad, responsáveis por duas Comunidades Terapêuticas, adolescentes usuários (SAI e Caps ad) e familiares dos mesmos. Mais detalhes sobre a metodologia utilizada pode ser encontrada no Anexo deste livro.

\section{A Rede de Atenção e Cuidado a Crianças, Adolescentes e FAMÍLIAS USUÁRIAS DE CRACK}

No mapeamento da rede de Ponta Porã foram utilizados como fontes de informação: dados da Pesquisa de Assistência Médico-Sanitária (IBGE, 2010), dados do Cadastro Nacional de Estabelecimentos de Saúde, dados coletados na SMAS e dados obtidos diretamente no momento das entrevistas com os 
profissionais. Em virtude das múltiplas fontes e da distinta temporalidade das informações, divergências foram observadas. Dessa forma, o retrato da rede aqui apresentado pode apresentar algumas falhas e incompletudes pela fragilidade das informações disponíveis no município, não sendo completamente fiel à realidade. Há ainda que se ressaltar o dinamismo existente na rede socioassistencial nos últimos anos, posto que a questão do crack é recente e tem mobilizado sobremaneira o município.

A rede constatada em Ponta Porã nos anos de 2011-2012 conta com 33 estabelecimentos de saúde - 20 públicos e 13 privados - dos quais dois fazem atendimento pelo SUS (IBGE, 2010). Foram informados os seguintes serviços: 16 unidades básicas de saúde (UBS), 13 equipes da Estratégia Saúde da Família (ESF), uma equipe de saúde que atende a unidade prisional feminina e uma masculina, um hospital geral, um centro de especialidades médicas, um centro de especialidades odontológicas, dois centros de saúde, uma unidade de atenção à saúde indígena, três equipes do Programa Agentes Comunitários de Saúde (Pacs), um Serviço Ambulatorial Especializado (SAE), um laboratório público e uma clínica para atendimento a pacientes renais crônicos. Há ainda uma unidade de pronto atendimento em construção e o Serviço de Atendimento Móvel de Urgência (Samu) ainda não se encontrava em funcionamento no momento da pesquisa. Na esfera da saúde mental há um Caps ad e uma unidade de Consultório de Rua.

No Caps ad, um dos principais locais de atendimento e oferta de serviços aos dependentes químicos, atuam 16 profissionais, sendo oito de nível médio. O restante da equipe tem a seguinte formação: clínico geral, psiquiatra, psicólogo e acupunturista, enfermeira, pedagogo, assistente social e terapeuta ocupacional (coordenadora do centro). Entre os projetos/serviços desenvolvidos pelos Caps ad podem-se citar: Consultório de Rua, grupo de apoio Amor Exigente (com usuários e familiares), oficinas de geração de renda, artesanato, caratê, culinária, violão, informática e oficina pedagógica com quem não é alfabetizado. O Caps ad atua com redução de danos, mas não em relação ao crack. Foi relatado que cinco equipes da ESF auxiliam ou participam nas ações executadas pelo centro em alguns bairros. Segundo a coordenadora do Caps ad, não havia, no momento da coleta de dados, nenhuma ação integrada do centro com o Núcleo de Apoio à Saúde da Família (Nasf), visando a facilitar a ação no território.

Quando há necessidade de internação dos usuários de crack por problemas de saúde, estes são encaminhados para os seguintes estabelecimentos: Hospital 
Regional Dr. José de Simone Netto de Ponta Porã, Hospital Regional de Campo Grande e Hospital Universitário de Dourados. Quando o paciente precisa de internação psiquiátrica, é direcionado para o Hospital Regional do Paraguai em Pedro Juan Caballero, o Hospital Nosso Lar em Campo Grande e o Hospital Psiquiátrico de Paranaíba. Para reabilitação, os usuários são enviados para as Comunidades Terapêuticas: ${ }^{3}$ Manain e Restauração de Vida, ambas em Ponta Porã; Pró-Vida em Amambai; Jovem Peniel em Dourados; ou para Comunidade Terapêutica localizada no Paraguai.

Na área da assistência social e do trabalho, foi relatado o seguinte cenário: um Creas, dois Cras, duas Comunidades Terapêuticas (organizações não governamentais) - sendo que para a comunidade Restauração de Vida há dez vagas para a assistência social do município (os usuários são enviados após estarem registrados no Creas e passarem por avaliação de profissionais do Caps ad). No momento da pesquisa estava sendo construída uma clínica de reabilitação municipal com o objetivo de atender as famílias. Todos os estabelecimentos mencionados atendem os usuários de drogas. Há um Conselho Tutelar em Ponta Porã para a proteção dos direitos das crianças e adolescentes.

Segundo informações colhidas na SMAS, os adolescentes usuários de crack encaminhados pelo Conselho Tutelar do município são enviados para o Juizado e, após parecer da juíza, são direcionados para os abrigos ou para o Creas. Nos horários em que o fórum está fechado, o Conselho Tutelar os encaminha para os abrigos.

O Creas conta com uma equipe composta de psicólogo, assistente social, educadores, coordenadora, pessoal administrativo e vigia. Todos recebem formação continuada e capacitação. Este serviço realiza busca ativa de usuários nas ruas todos os dias: de manhã, por volta de meio-dia, na parte da tarde e à noite/madrugada. $A$ equipe procura fortalecer os vínculos e a reintegração familiar. Adolescentes e adultos que queiram tratamento são encaminhados para internação. Usuárias do sexo feminino são enviadas para uma Comunidade Terapêutica específica. Não há local para atender (internar) crianças usuárias no município.

A SMAS lidera o enfrentamento à problemática do crack na cidade de Ponta Porã, tendo firmado parcerias com Comunidades Terapêuticas de forma a possibilitar o tratamento de usuários.

3 Comunidades Terapêuticas são centros que recebem pessoas para tratamento de desintoxicação no modelo residencial/internação, baseados em programa de recuperação terapêutico-educativo, por vezes com orientação religiosa. 


\section{OS SeRViçOS de ACOLHIMENTO InSTITUCIONAL E AS CRIANÇAS, Adolescentes E FAMÍlIAS USUÁRIAS DE CRACK}

Os três SAls visitados em Ponta Porã atendem simultaneamente crianças e adolescentes. No momento da pesquisa estavam acolhidos nove crianças e sete adolescentes (Tabela 1). Nenhuma das crianças tinha histórico de uso de drogas ou de crack e somente um responsável por crianças era usuário de crack. Em apenas um dos três serviços havia crianças e adolescentes com história de uso de crack ou seus responsáveis no momento da visita.

Entre os sete adolescentes, verificou-se que $28,6 \%$ utilizavam crack e outras drogas. Quanto aos seus responsáveis, o uso dessas substâncias limitou-se à família de apenas um dos acolhidos (mãe e irmão usuários).

Tabela 1 - Uso de crack e outras drogas por crianças e adolescentes em Serviços de Acolhimento Institucional e de seus responsáveis. Ponta Porã - nov. 2011*

\begin{tabular}{l|c|c|c|c|c|c}
\hline \multirow{2}{*}{\begin{tabular}{l} 
Consumo de drogas \\
\cline { 2 - 7 }
\end{tabular}} & \multicolumn{2}{|c|}{$\begin{array}{c}\text { Crianças } \\
\mathrm{N}=9^{* *}\end{array}$} & \multicolumn{2}{c|}{$\begin{array}{c}\text { Adolescentes } \\
\mathrm{N}=7\end{array}$} & \multicolumn{2}{c}{$\begin{array}{c}\text { Total } \\
\mathrm{N}=16\end{array}$} \\
\cline { 2 - 7 } & $\mathrm{N}$ & $\%$ & $\mathrm{~N}$ & $\%$ & $\mathrm{~N}$ & $\%$ \\
\hline $\begin{array}{l}\text { Uso de drogas em geral pela } \\
\text { criança ou adolescente }\end{array}$ & 0 & - & 2 & 28,6 & 2 & 12,5 \\
\hline $\begin{array}{l}\text { Uso de crack pela criança ou } \\
\text { adolescente }\end{array}$ & 1 & 11,1 & 1 & 14,3 & 2 & 12,5 \\
\hline $\begin{array}{l}\text { Responsáveis com história de uso } \\
\text { de drogas em geral }\end{array}$ & 0 & - & 1 & 14,3 & 1 & 6,3 \\
\hline $\begin{array}{l}\text { Responsáveis com história de uso } \\
\text { de crack }\end{array}$ & & & & 28,6 & 2 & 12,5 \\
\hline
\end{tabular}

* Informação dada pelo gestor do serviço.

** Em um SAI não há crianças acolhidas.

Um dos serviços funciona há 18 anos. Os dois outros SAls têm menos de dez anos de existência. Vale destacar que todos começaram a funcionar após a criação do Estatuto da Criança e do Adolescente, já com a perspectiva de sujeito de direitos em voga.

Quanto à natureza, observou-se que dois são em formato de abrigo tradicional e um é Casa Lar em comunidade. Dois SAls informaram que também funcionam como casas de passagem. Nenhum dos serviços tem orientação religiosa. Dois deles são organizações não governamentais e o outro é público municipal. 
Em relação ao atendimento oferecido às crianças e adolescentes em situação de risco social, verificou-se que apenas um serviço acolhe crianças e adolescentes usuárias de drogas/crack, em situação de rua, ameaçados de morte e com doenças infectocontagiosas. Outro SAI informou que recebe crianças e adolescentes com necessidades especiais.

As atividades que a população infantojuvenil com histórico de uso de crack frequenta regularmente, que foram informadas pelo SAl, são: ensino regular, reforço escolar, atendimento médico e psicológico, tratamento para dependência química, assistência jurídica (por meio da promotoria), orientação sexual, encaminhamento para trabalho (por meio da assistência social), atividades esportivas, atividades culturais (Pró-Jovem) e grupos de ajuda mútua (Amor Exigente).

Quanto aos serviços oferecidos às famílias das crianças e adolescentes que usam crack, o SAl relatou os seguintes: atendimento psicológico (quando há ordem judicial), orientação para planejamento familiar, encaminhamento para grupos de ajuda mútua, acompanhamento social (quando há ordem judicial), inserção em programa/serviço oficial comunitário de auxílio/proteção à família, serviços para tratamento de dependência química (encaminhamento ao Creas ou Caps ad).

Todas as três instituições visitadas declararam que têm equipe técnica própria, com presença de assistente social e psicólogo. Outros profissionais presentes são: enfermeira (um SAl), pedagogos (dois SAls) e educador físico (um SAI). Dois serviços relataram a realização de formação continuada sobre o tema do crack com alguns membros da equipe, especialmente coordenação, equipe técnica e cuidadores. Um SAI informou ter envolvido profissional de serviços gerais na formação.

O Poder Judiciário é o órgão que mais encaminhou crianças e adolescentes usuários de crack para os SAls, seguido pelo Conselho Tutelar e pelo Ministério Público.

\section{HISTÓRIAS DOS ADOLESCENTES USUÁRIOS DE CRACK}

\section{Marcos}

Foi difícil o acesso direto ao Marcos, adolescente com 14 anos e que cursa o sexto ano do ensino fundamental. A coordenadora do SAl estava relutante em permitir a entrevista, já que ele não estava muito bem, pois recentemente 
soube que a mãe, também usuária de crack, havia desistido do tratamento em uma Comunidade Terapêutica. Durante a entrevista, o adolescente demonstrou confusão, dispersão e dificuldade de compreensão das perguntas formuladas. Seu volume de voz estava praticamente inaudível.

Marcos relatou que iniciou o uso de drogas com a mãe, tendo sido o irmão o responsável pela introdução do crack na família. Tinha morado na rua duas vezes.

Em seu prontuário, consta como motivos para o acolhimento uma série de fatores que o fragilizavam: ausência de pais ou responsáveis por doença, pais ou responsáveis dependentes químicos ou alcoolistas, violência doméstica física e psicológica, negligência, exploração no trabalho ou mendicância, uso de crack e outras drogas pelo adolescente. $O$ jovem recebeu encaminhamento para tratamento de saúde por uso de crack, assim como a mãe.

Marcos foi encaminhado ao SAI pelo Poder Judiciário e encontrava-se oficialmente no momento da coleta de dados em fase de avaliação/preparação para reintegração familiar. Ele já tinha sido acolhido anteriormente na mesma unidade. Também já havia passado por Comunidade Terapêutica e pelo Caps ad, indicando sua recorrente institucionalização. A família reside no município de Ponta Porã e o visita na instituição (mãe e irmãos). O adolescente tem irmãos abrigados na mesma unidade e outros adotados.

Quanto ao seu histórico de consumo de substâncias, informou ter morado com usuários de crack nos 30 dias anteriores ao acolhimento. Fez uso (na vida e nos 30 dias anteriores ao acolhimento) de várias substâncias: álcool, tabaco, maconha, cocaína, mesclado, crack e produtos para "sentir barato". Utilizava crack há dois anos e seis meses, com consumo de cerca de 15 pedras por dia. Quanto às formas de utilização do crack, mencionou: cachimbo, lata de bebida e baseado (misturando maconha e crack). Compartilhou cachimbo, lata ou copo com outros usuários. O local de maior consumo era a própria casa da família, junto com a mãe e o irmão. Pedia esmola na rua para facilitar o consumo dessas substâncias.

Classificou sua saúde como excelente. No entanto, relatou dores de cabeça e vômitos nos últimos 20 dias. Já teve overdose em decorrência do uso de crack, mas não soube informar quantas vezes tal fato ocorreu. 


\section{VITOR}

Vítor é um adolescente de 16 anos que estava cursando no momento a educação para jovens e adultos. Sua família não reside no município de Ponta Porã, mas há manutenção de vínculo com a família por meio de visitas dos irmãos ao SAl em que Vitor se encontra. Os irmãos permanecem convivendo com a família de origem.

Foram citados como motivos para o seu acolhimento no SAl: ausência dos pais/responsáveis por prisão, negligência, exploração no trabalho e mendicância, situação de rua e uso de crack e outras drogas pelo adolescente.

Segundo informações da equipe técnica, o adolescente já esteve na unidade anteriormente. $\mathrm{Na}$ atual internação, foi encaminhado ao SAI pelo Poder Judiciário e tem procedimento administrativo na Vara da Infância e Juventude, em que o uso do crack pelo adolescente é destacado. No momento da pesquisa encontrava-se em fase de avaliação/preparação para reintegração ao convívio com familiares.

Quanto ao uso de drogas, Vitor tem longo histórico, tendo consumido em sua vida e nos últimos 30 dias um vasto leque de substâncias: álcool, tabaco, maconha, derivados da cocaína (pasta de coca, merla e crack), produtos para "sentir barato" e drogas que provocam alucinações (LSD ou êxtase, por exemplo). Relatou ainda uso na vida de remédios para emagrecer ou ficar acordado e de tranquilizantes sem receita médica. Também consumiu cola de sapateiro. Utilizou crack por dois anos (no momento, comentou não estar fazendo uso). Mencionou já ter compartilhado cachimbo, lata ou copo com outros usuários e também que tinha consumido crack com cocaína. Utilizava a droga na rua que conseguia por meio de roubos. Relatou que seus irmãos e responsáveis não utilizavam drogas no momento.

Embora afirmasse não ter nenhum problema de saúde na ocasião, tinha sido encaminhado pelo SAI para tratamento de saúde por uso de crack. Vitor relatou ter tido overdoses em função de mistura de drogas (crack e merla), mas não soube precisar o número de vezes em que isso ocorreu. Tinha sido detido pela polícia em virtude de roubo e uso de drogas.

Antes do acolhimento o adolescente permaneceu durante um período em uma Comunidade Terapêutica para recuperação. Também relatou ter recebido atendimento no Caps ad. 


\section{Clarissa e sua mãe}

Com 16 anos, Clarissa, grávida (três a quatro meses de gestação) de seu segundo filho, estava acompanhada da mãe e da filhinha no Caps ad, quando foi entrevistada. No momento da pesquisa a adolescente não estudava nem trabalhava.

A entrevista foi difícil de ser conduzida, pois a adolescente parecia estar ainda afetada pelo consumo recente de crack. Falava com calma, resignada e monossilábica. Era sua primeira visita ao Caps ad, para onde foi levada pela mãe, com auxílio da polícia, em virtude de ter usado a droga na noite anterior.

Comentou que sua vida havia se alterado em decorrência no uso de crack ("mudou tudo"). Sabia que o uso da substância fazia mal e que ninguém da família usava crack. Não tinha buscado nenhum outro serviço de saúde até o momento.

A mãe de Clarissa alegou que não tinha a família que gostaria, principalmente por causa do uso de crack pela filha. Não podia trabalhar e não tinha sossego. Tinha outra filha, que trabalhava e sustentava a casa com um salário mínimo. Relatou que recentemente foi atendida no posto de saúde e que estava entrando em depressão.

Os problemas começaram quando Clarissa tinha por volta de 12 anos. Segundo a mãe, a adolescente sempre foi agressiva. Sobre o uso de drogas pela filha, afirmou: "Com certeza tem problema na cabeça porque ela não é uma menina que foi judiada nem nada. Sempre teve o que ela quer. Sempre eu trabalhando, dei pra ela tudo que ela quer".

A mãe disse não ter observado mudança no comportamento da filha após o início do uso de crack, que credita às más companhias. Suspeitava das condições de saúde da neta (filha da adolescente usuária), alegando que a criança parecia ter algum problema (Clarissa fez uso de crack também durante a primeira gestação).

Quanto aos principais reflexos para a saúde de Clarissa, a mãe relatou o emagrecimento. Disse ainda que a adolescente não tem carinho e amor nem por ela e nem pela irmã que trabalha e as sustenta. A adolescente não tinha amigos, apenas companheiros de uso. Relatou que a filha tinha se "amigado" com um homem, mas que ele se distanciou devido ao uso de crack por parte dela.

Segundo a mãe, Clarissa nunca esteve acolhida em SAl, tendo ficado apenas três dias no Creas, o serviço que a mãe considera de maior ajuda. Reclamou 
do Conselho Tutelar, afirmando que nunca era atendida quando solicitava. Gostaria que existisse um serviço para internação e tratamento dos usuários menores de idade. Embora desejasse que a filha fosse encaminhada para uma Comunidade Terapêutica, sabia que isso não poderia acontecer contra a vontade da pessoa. Vislumbrava o acolhimento como forma de garantir a saúde do novo bebê que a filha espera.

\section{Davi e sua mãe}

A entrevista com Davi difere bem das anteriormente apresentadas. Tinha 17 anos de idade e foi buscar ajuda no Caps ad por conta própria. Estava acompanhado da mãe, que afirmou ser muito protetora. Informou ter sete irmãos, mas que apenas ele e outro irmão faziam uso de alguma droga. No momento da entrevista estava desempregado, mas anteriormente trabalhou como protético.

O primeiro contato de Davi com drogas ocorreu aos 9 anos (maconha); o crack iniciou aos 15 anos. Afirmou ter sempre utilizado drogas de forma controlada, mas que no início daquele ano, após o término de um namoro, havia perdido o controle do uso.

Começou usando a droga com colegas, mas informou que eles o abandonaram. Os amigos, segundo o adolescente, são pessoas com situação financeira bem melhor que a dele. Davi contou um pouco de suas perdas devido às drogas:

Eu tinha uma namorada e ela ficou sabendo que eu usava drogas. Estava tudo tranquilo ainda, ela estava me ajudando, me apoiando e tal. Aí o pai dela descobriu. Aí começou mesmo o inferno. O pai dela começou a falar pra ela não andar mais comigo, não namorar mais comigo. Ela decidiu largar de mim. Aí eu me afundei mesmo. Aí eu desandei, eu estava trabalhando tranquilo com carteira assinada.

Relatou algumas reações físicas após o início do uso do crack, mas nunca recorreu a nenhum serviço de saúde por conta da droga.

Pra respirar é uma dificuldade imensa depois que a gente fuma. Muito ruim de respirar, você anda parece que tem um negócio na garganta. Dói muito, muito difícil pra respirar mesmo, parece que é cinza, que fica tudo aqui assim, mas não é não, é outra coisa. A respiração ela tranca aqui [adolescente apontou para o pescoço/ garganta] e fica pelas narinas mesmo (...). Dá uma pressão como se 
alguém tivesse apertando você (...). E a pressão nos ouvidos, parece que vai explodir o tímpano. É bem constrangedor mesmo na hora ali, mas é a reação do produto: não consegue respirar, fica bem ativa mesmo, você escuta pouco.

Davi falou um pouco do sentimento que o levava ao consumo: "O crack foi a droga mais pesada que eu já usei. Eu quero sair, só que tem aquela ansiedade, aquela vontade imensa mesmo". O adolescente já tentou parar de usar o crack, sem êxito: "Tipo sozinho, sozinho, a gente não consegue. É muito difícil. Eu já tentei parar três ou quatro vezes. O máximo acho que eu fiquei, fiquei uns dois meses assim normal, natural mesmo, sóbrio de tudo, mas depois disso foi difícil".

Considera-se ainda no controle de si mesmo. Indagado sobre passagem anterior por instituição, afirmou: "Fui bem cabeça mesmo; mas não tanto, porque eu me deixei envolver. Mas eu acho que eu sou um cara controlado, tenho controle da situação ainda, por enquanto".

A mãe de Davi informou ser separada do marido. No momento da pesquisa, moravam na casa apenas ela e o filho. Afirmou que ele é o primeiro na família a fazer uso de crack e responsabilizou as más companhias pelo uso. Escondia do pai de Davi o consumo de crack, buscando ajuda de algumas fontes:

procurar algum remédio, alguma coisa [em sua busca no Cras, sem sucesso], pra conversar com ele, só que tinha que conversar com ele (...). "Você precisa dessa ajuda, não pode ficar, se entregar tanto. Você tem que ser mais forte do que ele [crack]". Tanto foi que pedi a Deus, que era pra ele se levantar, se curar, que ele está aí [Caps ad].

Em relação à saúde do adolescente, a mãe comentou que o filho não se alimentava e que estava muito magro.

\section{CAusas e Consequências do USo de CRACK POR CRIANÇAS E ADOLESCENTES}

Na visão dos adolescentes e dos responsáveis entrevistados, as más companhias são a causa do uso do crack. Para os atores da rede socioassistencial, diversos outros fatores estão relacionados ao problema. Entre eles, ressaltam-se o baixo custo da substância, a facilidade de acesso por ser região de fronteira, a ausência de atenção por parte dos pais, a estrutura familiar precária, além da necessidade de acompanhar o grupo de amigos, própria dos adolescentes. Um dos profissionais entrevistados afirmou que o uso de drogas era um problema 
social e econômico e que as crianças, muitas vezes, achavam melhor ficar na rua por causa das violências que sofriam dentro de casa. Outro disse que o álcool era a fonte e início de todos os problemas e, em decorrência dele, ocorriam problemas na família com consequente uso de drogas por outros membros.

Em relação às consequências para a saúde, as mães entrevistadas relataram a perda de peso acentuada e o abandono dos estudos. Já os profissionais da rede ampliaram as consequências do uso de crack: emagrecimento, agitação, confusão mental, perda da voz, problemas de pulmão, manchas e fissuras na pele, doenças sexualmente transmissíveis e abandono da família.

Prejudica porque desestrutura, o menino que é usuário, ele não frequenta mais a escola, ele não fica mais em casa, ele já vai pra rua. Por isso que nós temos essa quantidade de menino em situação de rua. Abandona a casa, a família, ele já vive sozinho. Por exemplo, qual é a relação da família com o usuário? Não existe relação; corta, acabou o vínculo, ele sai e não volta mais. Pai e mãe tentam muitas vezes pegar, trazer, pede a nossa ajuda, da polícia. Pega, leva pra casa, leva, mas daí quando você percebe também no que se transformou, os próprios pais não querem mais que ele volte em casa. (conselheira tutelar)

Eles não estudam mais, acabam ficando na rua, vivendo na rua, vivendo na marginalidade. A gente teve muitos casos esse ano de morte de adolescentes principalmente, muita morte. Eu já vi dois adolescentes que começaram a perder a voz, é uma voz meio rouca; e assim manchas de pele e fissuras, é a pele toda assim; emagrecimento muito rápido; doenças sexualmente transmissíveis e HIV muito, muito, teve até um aumento de HIV esse ano. Tanto que nós fazemos coleta de sangue até nas boates. (coordenadora do Caps ad)

\section{A VISÃo dos AdOLESCENTES E FAMILIARES SOBRE O ATENDIMENTO}

Para os adolescentes entrevistados, a procura de ajuda no Caps ad era recente e por isso não souberam dar opinião sobre o serviço ou ainda sobre as características necessárias de um bom serviço para atendimento de usuários de crack. Um dos adolescentes falou sobre o acolhimento inicial. Ele havia procurado a unidade no dia anterior por vontade própria, após ter ouvido uma propaganda no rádio sobre o tratamento de usuários de drogas no Caps ad. Disse que foi recebido no serviço de maneira fácil, mostrando-se satisfeito. Relatou ainda que o Creas o ajudaria a encontrar um emprego. 
Eu mesmo ontem eu decidi tratar, me curar, porque eu não estava mais aguentando. Não dá pra viver assim, é muito difícil. Aí eu resolvi mesmo por vontade própria, eu vim aqui. Eu ouvi no rádio que estava tendo tratamento pra dependentes químicos, daí eu falei "ah beleza, não custa tentar pelo menos". Foi bem natural mesmo, ninguém teve nenhum preconceito. Perguntou se eu era usuário mesmo. Eu falei que era, que já ia fazer um ano já. Aí mandaram eu falar com a assistente social, eu fui. Ela fez uma ficha, foi bem simples mesmo e o médico falou pra mim que não adianta eu vir aqui e fazer tudo, pegar remédio e não ter força de vontade. Tem que a pessoa querer mudar, vem da pessoa. Me perguntou se eu queria mudar, eu falei que sim. Foi vontade própria. (Davi)

Já Clarissa, aparentemente ainda sofrendo os efeitos do uso de crack na noite anterior, não sabia responder às perguntas formuladas. Ela estava no serviço claramente contra a vontade e não parecia disposta ao tratamento. Marcos também não quis opinar. Disse que tinha gostado do atendimento no Caps ad, mas que no momento não estava frequentando a unidade. Para a mãe de Clarissa, até o momento a filha só tinha contado com a ajuda do Creas. Segundo ela, a psicóloga desse serviço, sempre que solicitada, tentava conversar com a adolescente: "O Creas que mais me ajuda. Qualquer coisa que eu chamo vai a psicóloga, vai conversar com ela. Eu ligo pro conselho ir lá, às vezes conversar com ela. Não tenho palavras pra falar nada do Creas". Entretanto, a mãe reclamou da falta de apoio do Conselho Tutelar:

O Conselho sempre está com o carro quebrado; sempre não dá, que não sei o quê. Assim começa e eles só me apertam, eles falam: "a senhora tem que conversar com ela, a senhora é mãe, ela é de menor". Eu falei: "mas o conselho está pra isso". Mas lá eles não têm tempo. Com certeza, às vezes têm muita coisa pra fazer, mas quando é uma coisa urgente, eu acho que não custa, que nem o Creas vai lá. Nem que não faz nada. Mas vai me dar atenção pra mim. Já é um grande alívio.

A mãe de Davi informou que havia ido a um serviço de saúde da cidade para pedir ajuda (remédio ou alguém para conversar com o filho). Lá lhe disseram que o adolescente era quem deveria procurar por eles. Também questionou o horário de funcionamento do serviço: "Eu fui na hora que não era hora de atender, eu fiquei de voltar lá, mas eu não fui mais".

Em relação às características do serviço, uma das mães citou a necessidade de uma unidade para internação. A outra mãe disse que seria bom ter um horário mais flexível e locais onde o usuário pudesse encontrar trabalho, medicamentos e internação. 


\section{Funcionamento da Rede na VisÃo dos Profissionais}

\section{Caminhos do atendimento}

O fluxo de atendimento de crianças e adolescentes usuários de crack em Ponta Porã está sintetizado na Figura 2. A entrada de crianças e adolescentes no sistema se dá por várias vias. São acionados o Conselho Tutelar e/o Juizado por meio de denúncias, solicitação da família ou do próprio usuário. Estes órgãos, dependendo da situação farão o encaminhamento para o Creas, para o Caps ad, para um SAI ou ainda para uma Comunidade Terapêutica. Outra forma de ter acesso aos usuários de crack é a busca ativa realizada pelo Creas e pelo Consultório de Rua (projeto do Caps ad). Em ambos os casos, eles são encaminhados para o Creas e para o Caps para que as medidas necessárias sejam tomadas. O Creas se encarrega dos aspectos sociais (emprego, busca pela família etc.) e o Caps ad, do tratamento. No caso em que os serviços (Creas, Caps ad e SAI) verificam a necessidade de internação em Comunidade Terapêutica, esta é providenciada.

Figura 2 - Fluxo de atendimento a crianças e adolescentes usuários de crack e outras drogas - Ponta Porã

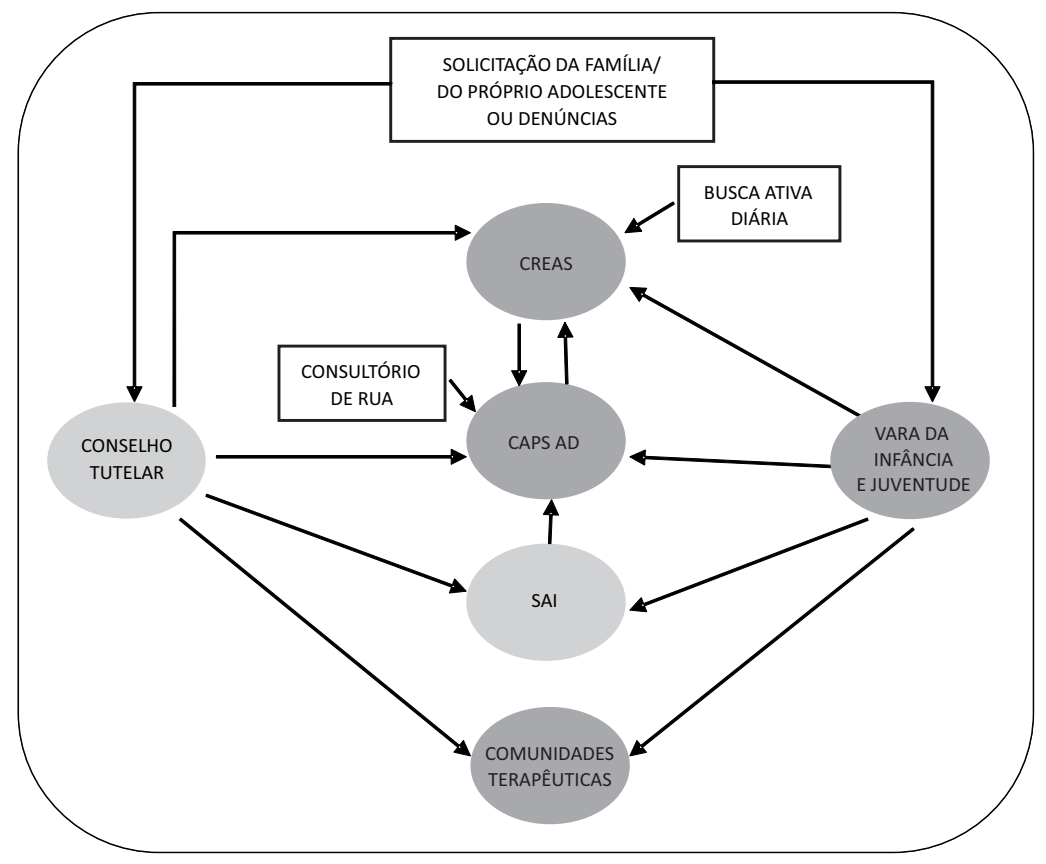


Nas falas dos profissionais da rede socioassistencial, percebem-se várias dificuldades no fluxo apresentado na Figura 2. Profissionais do SAI fizeram uma ressalva quanto à forma como o município vem lidando com a questão do crack em Ponta Porã: vários projetos "lindos", no papel, mas que na prática não existem. Demonstraram, assim, insatisfação em relação ao quadro enfrentado cotidianamente para atender os usuários de crack. A opção para esses profissionais envolvidos no acolhimento institucional é o Caps ad, que faz o atendimento inicial e decide se é preciso internar. Quando necessário, são encaminhados para uma Comunidade Terapêutica com apoio das secretarias municipais da Saúde e da Assistência Social e do Trabalho.

O Caps ad foi mencionado por todos os profissionais da rede entrevistados como o local de tratamento ambulatorial dos usuários de crack. Segundo sua coordenadora, o serviço dispõe de Consultório de Rua, grupo de apoio Amor Exigente (com usuários e familiares), oficinas de geração de renda, artesanato, caratê, culinária, violão, informática e oficina pedagógica com quem não é alfabetizado. A coordenadora informou que as crianças são normalmente encontradas "na linha" (expressão utilizada para se referir à fronteira) e dificilmente recorrem ao Caps ad: "Nós temos um Consultório de Rua na fronteira. Nós temos assim mais crianças ali na linha, quase não tem criança aqui dentro. Eles quase não procuram a gente".

A profissional mencionou também a parceria com o Creas e com o Conselho Tutelar - que ajuda na localização das famílias das crianças encontradas na rua. Ela contou ainda como é o atendimento na rua, na linha da redução de danos. O Consultório de Rua conta com uma psicóloga, uma psiquiatra (a mesma que faz os atendimentos no Caps ad), dois educadores sociais, dois redutores de danos e os demais membros da equipe do Caps ad (assistente social, terapeuta ocupacional, enfermeiro e professor de educação física), além do motorista. Ela afirmou que o vínculo da equipe com os usuários é muito bom.

Em seu relato a coordenadora chamou a atenção para o fato de que sempre há novos usuários, entre eles pessoas vindas de outros estados como São Paulo e Goiás, na linha de fronteira.

A profissional do Caps ad apontou a dificuldade em resgatar o vínculo familiar dos adolescentes usuários de crack encontrados na linha de fronteira, em situação de rua: "Tem um pouco de dificuldade até por não aceitação da família. Eles falam que é uma criança, mas não é um anjinho, apronta muita coisa aqui dentro de casa, a gente tem um pouco de dificuldade com isso". 
Tal dificuldade de aceitação pelos familiares também foi mencionada pela conselheira tutelar.

Os profissionais do Caps ad fazem palestras sobre prevenção de DST/Aids e distribuem preservativos na linha. Sobre as estatísticas de atendimento na linha de fronteira, informaram que são feitos cerca de 30 atendimentos por dia: "Principalmente ao crack, que é o que mais a gente vê aqui, ali na linha só tem usuário de crack. Nós atendemos todos os dias cerca de 30 pessoas. Vamos colocar que três são menores, adolescentes, nós temos uns 10 a 15 adolescentes".

Também foram solicitados à coordenadora do Caps ad alguns dados sobre o número e a forma de realização dos atendimentos no serviço. $O$ tratamento se dá em três modalidades: intensivo (aproximadamente 20 a 30 pessoas por dia), no qual o usuário vai todos os dias ao serviço; semi-intensivo (cerca de 50 pacientes), com ida duas vezes por semana; e não intensivo (com aproximadamente 60 pacientes), com ida quinzenal. Existe ainda um grupo que comparece ao serviço de forma mais esporádica - uma vez por mês, a cada tantos meses, uma vez ao ano. Nesse grupo encontram-se cerca de 150 pacientes. Sobre a rotina deles, informou que chegam pela manhã e passam o dia no Caps. Lá participam das oficinas e grupos terapêuticos e fazem todas as refeições na unidade. Acrescentou que seria importante ampliar o leque de serviços oferecidos: "O ideal seria eles fazerem todo esse tratamento aqui e ter um local pra ficar à noite, um local adequado, um local humano que seja dentro de casa, que seja uma residência terapêutica".

Sobre o tratamento, relatou que tentam fazê-lo de forma mais aberta e flexível, mas com regras e limites, seguindo as recomendações do Ministério da Saúde. Falou ainda da dificuldade em manter o tratamento dos usuários de crack, diante da instabilidade de seus desejos.

É difícil a gente trabalhar assim com usuário de crack, porque hoje ele vem, hoje ele quer e amanhã ele já não vem, não quer, não sabe o que quer. Não é desistência, é realmente confusão mesmo nele. Um dia ele prefere a droga. Um dia ele prefere o tratamento. A gente manda muito adolescente e menor também, já mandamos muitos pras Comunidades [Terapêuticas]. Mas não ficam, não ficam porque eles falam que lá chega um certo momento que já não toma mais o remédio. Aí eles sentem falta do remédio, aí pedem pro pastor. (...) Esses são os relatos, eu não sei se é verdade ou se não é, o fato é que eles não conseguem ficar muito tempo. 
Na visão da juíza, o município vem melhorando o atendimento em rede aos usuários de crack. Ressaltou, porém, a carência de pessoal (médicos e pessoal administrativo). A conselheira tutelar, por sua vez, afirmou que houve avanços, tendo sido criados um Creas e convênios com Comunidades Terapêuticas, e instituída uma "casa pousada" para que os pais possam permanecer com os filhos durante o tratamento. Relatou, contudo, que, dada a situação de fronteira de Ponta Porã, deveria haver um serviço especializado para atendimento dos usuários, assim como uma delegacia especializada no atendimento a crianças e adolescentes, além de uma ala no hospital para dependentes químicos.

\section{O papel institucional}

Segundo a juíza da Vara da Infância e Juventude, seu papel é proteger as crianças e os adolescentes. Quando o caso é de uso de drogas (lícitas ou ilícitas) por parte dos pais/responsáveis, há encaminhamento dos indivíduos para o Creas e o Cras, que então os enviam ao Caps ad para tratamento. Se for verificado risco para a criança/adolescente, o Juizado, juntamente com o Conselho Tutelar, é acionado. É colhido um parecer do Ministério Público e então se decide sobre a necessidade de fazer o acolhimento em um SAI. Nessas situações, o Juizado passa a atuar de forma mais intensiva, verificando o empenho dos pais no tratamento. Caso se verifique que há pelo menos disposição, vontade e realmente compromisso dele em se tratar, realiza-se uma reaproximação com a família. Ressaltou-se, no entanto, que o limite para a permanência de uma criança/adolescente no acolhimento é dois anos. Depois desse período, caso o responsável não queira se tratar, a criança/adolescente é encaminhada para adoção.

No caso de crianças/adolescentes usuários, a juíza afirmou que há duas situações: quando há apoio familiar e quando não há. No primeiro caso, a situação às vezes nem chega à justiça, o caso é resolvido na própria rede, a qual é buscada pelos pais. Quando não há apoio da família, situações em que os usuários são abandonados ou estão em situação de rua, estes são encaminhados aos serviços de acolhimento, que ficam responsáveis por encontrar seus pais/ responsáveis. A juíza considerou que o apoio familiar é fundamental para o êxito no tratamento. Enfatizou, contudo, que há casos em que não se pôde contar com a família e que estes foram resolvidos via rede e SAl. Informou ainda que na semana anterior tinha concedido a guarda do último adolescente acolhido em decorrência do uso de crack. No momento achava que não havia mais nenhuma criança/adolescente nessa situação. 
Para o Conselho Tutelar, sua principal atribuição é garantir os direitos de crianças e adolescentes, devendo atuar como um advogado na defesa deles, sempre que se fizer necessário. Para a conselheira entrevistada, a situação de fronteira seca de Ponta Porã com Pedro Juan Caballero torna o trabalho bem mais difícil: "Aqui é um atendimento assim diferenciado de todo o país, porque nós temos um vizinho, que é só uma rua que divide o nosso país, então é difícil". Afirmou que o primeiro passo é tentar fazer com que a criança/adolescente entenda a função do Conselho Tutelar; uma vez conquistada a confiança, pode-se fazer o encaminhamento para o Caps ad - serviço para a qual todos são direcionados em caso de dependência química. Este serviço então faz a avaliação e decide pelo tratamento no próprio serviço ou pelo encaminhamento para uma clínica. A fala da conselheira corrobora o que a equipe do Creas havia relatado em uma busca ativa por usuários de crack.

As dificuldades para atuar na "linha" ficam explícitas no fato de que, quando os adolescentes usuários querem conversar com a equipe técnica, eles ficam do lado brasileiro; quando não querem, simplesmente atravessam a rua e a equipe brasileira não pode atuar. Segundo a conselheira, todas as noites os usuários atravessam a linha para fazer consumo da droga.

Segundo o SAl, seu papel é atender os adolescentes em situação de risco. As crianças e adolescentes usuários de crack acolhidos nos SAls são encaminhados às Comunidades Terapêuticas ou ao Caps ad para tratamento. No caso de atendimento no Caps, os adolescentes vão para lá de manhã e só retornam no final da tarde.

Para a secretária municipal de Assistência Social, o foco do órgão são todas as situações de vulnerabilidade social, e a atuação na garantia dos direitos de crianças e adolescentes é a prioridade. Embora não considere que o papel da secretaria seja o atendimento ou a busca de serviços para atender dependentes químicos, afirmou que o setor Saúde não assumiu essa tarefa e, então, a assistência social teve que fazê-lo. Assim, relatou o estabelecimento de parcerias com a rede privada (Comunidades Terapêuticas) para tratamento dos dependentes. Segundo a profissional, a SMAS coordena as ações de enfrentamento ao crack no município, fato que considera inadequado. Ao falar do tratamento oferecido pelo setor Saúde, questionou a validade do tratamento ambulatorial. Alegou que não seria apropriado no caso do crack.

Nós acabamos fazendo um papel que não é nosso, fomos buscar uma rede de atendimento. Primeiro o município não quis identificar, o 
estado também não, na rede pública, e tivemos que reconhecer uma rede privada de atendimento. Assim chegamos nas Comunidades Terapêuticas. Por todas as reservas que se possa ter em relação ao que não pode ser chamado de tratamento. Portanto, era um lugar pelo menos que acolhia a família, as crianças, que estavam preparadas de uma certa forma pra receber um tratamento. Então foi por isso, enquanto órgão gestor, enquanto instituição, que nós estabelecemos essa direção. Nos envolvemos assim, com toda a equipe, na garantia dos direitos da criança e do adolescente e depois até do adulto, que tem direito ao atendimento no Sistema Único, mas que não tem atendimento, não tem leito pra desintoxicação. A Secretaria de Assistência Social hoje é a coordenadora das ações de enfrentamento ao crack e outras drogas em Ponta Porã. É um absurdo, mas estrategicamente a gente até aceitou.

Percebe-se na fala da gestora as dificuldades do atendimento realizado em Comunidades Terapêuticas, a única possibilidade real de acompanhamento em residências no município.

\section{O acompanhamento dos casos}

Em relação ao acompanhamento dos casos na rede, a juíza relatou que este se dá por meio dos relatórios da equipe psicossocial que são encaminhados à justiça e também de laudos médicos, quando necessários. Afirmou ainda que o acompanhamento continua após o retorno da criança/adolescente ao lar.

Nós procuramos acompanhar através dos laudos médicos e dos relatórios da equipe psicossocial. Com base nisso a gente aplica uma outra medida protetiva mais ou menos branda, conforme a situação, e até o momento em que ele retorna pro lar. Enfim, no caso de retornar pro lar, então é feito um acompanhamento de mais 30, 60 dias, quando então a gente fica um pouco mais tranquila. Aí judicialmente o processo encerra e a rede continua acompanhando a família por mais um tempo, mas aí sem a necessidade de apresentação de relatório para o juiz.

Em relação ao atendimento aos usuários no serviço de saúde, a conselheira tutelar comentou que o mesmo apresenta problemas, especialmente no plantão noturno. Ela considerou o Hospital Regional precário. Disse que nada funciona e que desde 2009 vem solicitando, ao estado, à Secretaria de Saúde, ao Juizado e à Prefeitura, a construção de uma ala no Hospital Regional para atender crianças e adolescentes dependentes químicos. Segundo a conselheira, 
o Hospital Regional está passando por reformas. Além disso, os profissionais do hospital não estão capacitados para o atendimento do usuário em "surto". Relatou que houve uma situação em que, para a "proteção" do usuário, este foi colocado em uma cela da delegacia para passar a noite. Em sua opinião, era necessário um serviço de urgência, com pessoal capacitado, particularmente no período da noite.

A conselheira ressaltou ainda seu papel institucional de fiscalização dos órgãos que atendem crianças e adolescentes. Informou que o acompanhamento dos serviços de acolhimento e das Comunidades Terapêuticas é feito por meio de visitas, realizadas com alguma frequência, para conversar com os acolhidos. Acrescentou, contudo, que havia muito trabalho a ser feito e que sobrava pouco tempo para as visitas às Comunidades Terapêuticas.

\section{A articulação da rede}

No que tange à articulação para atender as crianças e adolescentes usuárias de crack, a juíza acredita que atualmente a rede esteja bem mais integrada. Informou que costuma participar e convocar reuniões para discutir os problemas, mas que há muita rotatividade entre os integrantes da rede. Citou o Conselho Tutelar como exemplo. A saída possível, para ela, seria por meio da desburocratização do sistema e dos encontros entre vários atores/serviços.

A gente tem que fazer o seguinte: desburocratizar, sentar e conversar, frente a frente. Eu tenho isso pra oferecer; eu preciso daquilo; o que a gente vai fazer; tem essa situação; como nós vamos resolver. Então, é desburocratizar. É falar às vezes até por telefone, é sentar, vem aqui que eu preciso resolver uma situação de uma criança, de um adolescente. Porque se não conversar, se não tiver essa abertura entre a justiça, entre a rede, tanto de um tanto de outro, eu acho que a gente tem um entrave muito grande, e a gente não sai do papel. E aí fica ordem daqui, cumprimento quando pode dali, e o guri está ali. A gente não resolveu o problema dele.

Em contrapartida, a conselheira tutelar afirmou que há muitos problemas na articulação da rede de proteção, mas que considerava que a mesma estava funcionando. Não classificaria os programas como "cem por cento", mas que estavam "engatinhando".

As técnicas do $\mathrm{SAl}$, por sua vez, relataram movimentos da rede relacionados com a questão do crack e eventos, até mesmo em nível federal. Sinalizaram perspectivas futuras de ação. 
A rede tem se preocupado sim, tem feito vários encontros, congressos sobre crack com o pessoal de Brasília. Só que eu não tenho participado muito. A Secretaria de Assistência Social está criando um espaço do próprio município pra fazer esse atendimento, porque para atender criança e adolescente não tem espaço. Vai ter uma chácara, vai ser um projeto muito bom, vai ser meio afastado da cidade, e pra atender usuários de drogas, criança e adolescente.

O gestor do SAI também comentou a articulação com outros serviços, programas e instituições, informando várias atividades integradas à rede. Afirmou que sabe a localização, realiza troca de informações, reuniões periódicas e encaminhamento de casos para Conselho Tutelar, Poder Judiciário, Ministério Público, SMAS, Cras e Creas, Caps ad e escolas. Relatou que não há Centro de Atenção Psicossocial Infantil (Caps i) no município e que não tem nenhuma articulação com os demais serviços de saúde mental, com creches e com o Caps. Declarou relação mais distante com delegacias e organizações não governamentais, das quais apenas sabe a localização e com as quais troca informações; também a Defensoria Pública e serviços de saúde são órgãos menos articulados ao SAl: apenas sabe onde estão, troca informações e efetua encaminhamentos.

A secretária municipal de Assistência Social considerou que a articulação não é um problema da rede, e sim do Sistema Único de Saúde. Segundo ela, a saúde tem um olhar deficitário sobre a temática. Embora a assistência social não faça parte da rede de atenção à saúde, em Ponta Porã essa área da atenção precisa agir para garantir os direitos de crianças e adolescentes. Afirmou que a cidade se encontra em um estágio privilegiado em relação a outros municípios na questão do enfrentamento ao crack, apesar de destacar a falta de apoio do setor Saúde.

Nós já estamos num processo, até um tanto avançado, na questão do Consultório de Rua, que eu acredito que seja parte da atenção à saúde. Nós nos sentimos muito privilegiados assim, porque todos esses anos, desde 2007, nós estamos nessa militância e aí nessas articulações com o núcleo municipal, com a política estadual, com a política federal, nós estamos indo atrás. Então, Ponta Porã tem modelo de atenção. Se você fizer uma avaliação, uma observação entre o Caps de Ponta Porã e o Caps que você conhece por aí, você vai ver a diferença daqui. Então eu acredito que a atenção, quando ela é feita, ela é feita pela saúde, sim. Agora é deficitário? É deficitário. É pouco efetivo? É pouco efetivo. Por conta da rede? 
Não é por conta da rede, é por conta do sistema, na minha leitura, não é a rede local que é o problema, nem a rede estadual, nem a rede federal, é o Sistema Único de Saúde que é realmente pouco efetivo, (...) que só agora começou a despertar pra essa (...) epidemia que existe. (secretária da SMAS)

A despeito das dificuldades relatadas, a visão da secretária em relação ao município é que este vem enfrentando a questão do crack com articulação em todos os níveis: "existe uma rede local, uma rede nossa na assistência, essa rede falando com a rede da saúde, que fala com as outras instâncias".

\section{Os desafios a serem enfrentados}

Com relação aos desafios da justiça em relação à temática do crack, a juíza relatou que há dois aspectos fundamentais que necessitam atenção: aumento da divulgação do que já está disponível na rede em termos de tratamento para os usuários e melhoria na saúde pública, com oferta de vagas para internação. Segundo ela, não há vagas para internação dos casos de crianças e adolescentes usuários de crack. Afirmou que o entrosamento da rede ainda não é adequado e, em virtude disso, por vezes se desconhecem as possibilidades de tratamento e ajuda que já existem.

Especialmente em se tratando de crianças e adolescentes, é preciso investir mais. Até porque há uma previsão legal, que a gente vê pouco usada, nas verbas apreendidas do tráfico, que pela lei também deveriam ser aplicadas ao tratamento. A gente vê que, infelizmente, ela não é tão intensificada nesse lado. É aplicado, mas deveria ser melhor aplicado nesse aspecto.

Por sua vez, a conselheira tutelar afirmou que o grande desafio consiste no reconhecimento do órgão como porta de entrada de denúncias e de atendimento dessa população. Reforçou que é preciso cumprir o Estatuto da Criança e do Adolescente, mas que este estava em segundo plano, não era prioridade.

Para a equipe do SAI, o foco era a necessidade de capacitação do pessoal e ampliação da estrutura para atender os usuários de crack. Os técnicos enfatizaram que não têm capacitação para o atendimento e que a casa não tem segurança, ou seja, que seria um risco para o serviço e para os demais acolhidos ter o adolescente usuário junto aos demais.

Para a coordenadora do Caps ad, o desafio consiste em transformar o centro em Caps 24 horas, embora os recursos fossem escassos. Havia quantidade 
suficiente de profissionais no serviço, mas a estrutura física deixava a desejar, sendo necessário expandi-la.

Já a secretária da Assistência Social afirmou que o principal alvo é o próprio tratamento e o atendimento aos usuários de crack. É garantir o direito a uma escola pública e de qualidade, ao atendimento de saúde, ao acompanhamento, nos casos em que o usuário estiver na rua, e potencializar as famílias.

Para a coordenadora do Caps ad, os desafios para a capacitação são significativos. Informou que no ano anterior ocorreram seminários sobre o tema e que muito foi dito e prometido. Contudo, sentia que naquele momento (no primeiro semestre de 2012), as coisas estavam em ritmo mais lento. Constatou o distanciamento da sociedade em relação ao problema.

Agora deu uma esfriada. Nós do Caps, a gente continua com o Consultório de Rua em parceria com o Creas, mas eu sinto assim um distanciamento muito grande. Por mais que você faça capacitação, por mais que você... A gente várias vezes foi na Câmara [municipal] fazer uma audiência pública, falando a respeito disso. Mas eu ainda sinto muito distanciamento das pessoas, do município, da rede em si e do município em geral, até da própria sociedade.

\section{CONSIDERAÇÕES FINAIS}

A fronteira brasileira tem aproximadamente $17 \mathrm{mil} \mathrm{km}$ de extensão e faz a divisa de 11 estados com dez países. A BR-163 liga o estado do Paraná ao Mato Grosso do Sul, passando próximo à fronteira Brasil-Paraguai. É em torno dessa rodovia e de outras rodovias próximas à fronteira que a rota internacional de tráfico de drogas se materializa.

Historicamente, devido ao distanciamento dos centros econômicos e políticos, a faixa de fronteira foi marginalizada do debate e das decisões políticas nacionais e caracteriza-se, atualmente, pela baixa densidade demográfica e baixo IDH, além de problemas relacionados à violência, ao crime organizado, ao tráfico de armas e drogas, à exploração sexual, ao trabalho infantil, ao comércio ilegal, à falta de infraestrutura social e produtiva (Brasil, 2005).

A situação de fronteira seca traz inúmeros desafios à rede de proteção no enfrentamento ao crack. Todos os entrevistados colocaram questões como o baixo custo da droga e a facilidade de obtenção das mesmas como pontos importantes. Todos falaram da necessidade de trabalhar de forma articulada com as autoridades e serviços paraguaios. 
A quantidade insuficiente de equipamentos, tais como Caps e leitos hospitalares ficou evidenciada na cidade de Ponta Porã. Segundo dados da Pesquisa sobre Assistência Médica Sanitária (IBGE, 2010), não há em Ponta Porã unidades de saúde com leitos de emergência psiquiátrica. Tal informação ainda persistia até 2013, tendo sido mencionada por praticamente todos os entrevistados. O Samu, apesar de aprovado, ainda não se encontrava em funcionamento. Os únicos leitos de saúde mental (cerca de oito) localizam-se no Paraguai (no Hospital Regional). Faltam também leitos de curta permanência.

Segundo o Ministério da Saúde, municípios com população entre 70 e 200 mil habitantes devem contar com Caps II, Caps ad e rede básica com ações de saúde mental (Brasil, 2012a). Contudo, conforme colocado nas especificações do ministério, a composição da rede deve ser definida seguindo esses parâmetros, mas também atendendo a realidade local. Assim, deve-se pensar em uma única cidade (Ponta Porã - Pedro Juan Caballero), composta de aproximadamente 200 mil habitantes, o que acaba sendo a realidade para a rede de atendimento.

Conforme mencionado na seção sobre composição da rede, há em Ponta Porã equipes da ESF (13 equipes). Contudo, verifica-se ser necessária a maior integração com os serviços que atendem os usuários de crack e também com as UBS. De acordo com a fala da coordenadora do Caps ad, há pouca interação entre o Caps e esses outros equipamentos, salvo algumas exceções (duas equipes da ESF com as quais há maior interação).

Um outro aspecto importante, mencionado pela conselheira tutelar se refere ao controle das Comunidades Terapêuticas. Ela alertou sobre a importância de se fiscalizar esses serviços que recebem recursos públicos, pois teme que acabem se tornando um comércio, sem trazer contribuição efetiva para os usuários. Vários atores entrevistados questionaram a qualidade do serviço prestado pelas comunidades, especialmente aquelas de orientação religiosa, onde por vezes não eram disponibilizados medicação e acompanhamento médico e psicológico para o dependente químico. A carência de atividades ocupacionais também foi observada. Restava aos usuários ocupar seu tempo ocioso apenas com orações e raras atividades.

A presença de crianças na "linha" e sua ausência nos serviços indicam uma invisibilidade do crack nas faixas mais novas, aspecto que merece ser considerado pelos serviços da rede socioassistencial. A falta de especificidade do atendimento oferecido ao adolescente, num cenário de serviços mais voltados 
para a faixa adulta, mostra a vulnerabilidade existente para a população infantojuvenil em Ponta Porã. Em contrapartida, a facilidade do acesso ao uso do crack e a atração despertada pelo dinheiro fácil conseguido com o transporte de drogas tendem a trazer jovens de todo o país para a região. Todos esses fatores requerem que haja efetivo desenvolvimento da rede socioassistencial das cidades gêmeas no que se refere ao cuidado de crianças e adolescentes em contato com o crack.

\section{REFERÊNCIAS}

ALCÂNTARA, D. N. Políticas sociais sobre dependentes químicos de álcool, crack e outras drogas. Disponível em: <www.senado.gov.br/comissoes/cas/ap/AP20110414_ Doralice_Alcantara.pdf>. Acesso em: dez. 2012.

BRASIL. Ministério da Integração Nacional. Secretaria de Programas Regionais. Programa de Desenvolvimento da Faixa de Fronteira. Proposta de Reestruturação do Programa de Desenvolvimento da Faixa de Fronteira. Brasília: Ministério da Integração Nacional, 2005.

BRASIL. Presidência da República. Secretaria Nacional de Políticas sobre Drogas. Relatório Brasileiro sobre Drogas. Brasília: Senad, 2009. Disponível em: <www.obid.senad.gov.br/ portais/OBID/biblioteca/documentos/Relatorios/328379.pdf >. Acesso em: fev. 2013.

BRASIL. Ministério da Justiça. Decreto n. 7.496, 8 jun. 2011. Plano Estratégico de Fronteiras. Diário Oficial da União, Brasília, 9 jun. 2011.

BRASIL. Ministério da Saúde. Saúde mental passo a passo. Disponível em: <http://portal. saude.gov.br/portal/saude/cidadao/visualizar_texto.cfm?idtxt=24355\&janela=1 >. Acesso em: dez. 2012a.

BRASIL. Senado Federal. Ponta Porã tem plano local de enfrentamento ao crack integrado a Pedro Juan Caballero. Disponível em: <www.senado.gov.br/NOTICIAS/ JORNAL/EMDISCUSSAO/dependencia-quimica/iniciativas-do-governo-no-combateas-drogas/ponta-pora-tem-plano-local-de-enfrentamento-ao-crack-integrado-a-pedrojuan-caballero.aspx>. Acesso em: dez. 2012b.

CARLINI E. A. et al. II Levantamento Domiciliar Nacional sobre Uso de Drogas Psicotrópicas no Brasil. Brasília: Secretaria Nacional Antidrogas, Centro Brasileiro de Informações sobre Drogas Psicotrópicas, 2005.

GALDURÓZ, J. C. et al. V Levantamento Nacional sobre o Consumo de Drogas Psicotrópicas entre Estudantes do Ensino Fundamental e Médio da Rede Pública de Ensino nas 27 Capitais Brasileiras - 2004. São Paulo: Secretaria Nacional Antidrogas, Centro Brasileiro de Informações sobre Drogas Psicotrópicas, 2005.

INSTITUTO BRASILEIRO DE GEOGRAFIA E ESTATÍSTICA (IBGE). Assistência Médica Sanitária 2009. Rio de Janeiro: IBGE, 2010.

INSTITUTO BRASILEIRO DE GEOGRAFIA E ESTATÍSTICA (IBGE). Censo Demográfico 2010. Rio de Janeiro: IBGE, 2011. 
INSTITUTO BRASILEIRO DE GEOGRAFIA E ESTATÍSTICA (IBGE). Cidades. Disponível em: <www.cidades.ibge.gov.br/xtras/perfil.php?lang=\&codmun=50066 0\&search=mato-grosso-do-sul|ponta-pora >. Acesso em: 27 abr. 2014.

PROGRAMA DAS NAÇÕES UNIDAS PARA O DESENVOLVIMENTO (PNUD). Ranking do IDH dos municípios do Brasil - 2013. Disponível em: <www.pnud.org. br/arquivos/ranking-idhm-2010.pdf>. Acesso em: 27 abr. 2014.

MURAKI, S. M. P. Prevalência do Consumo de Drogas Psicotrópicas entre Adolescentes do Ensino Fundamental e Médio do Município de Dourados - MS, 2009. Brasília: Universidade de Brasília, 2009.

NOTO, A. R. et al. Levantamento Nacional sobre o Uso de Drogas entre Crianças e Adolescentes em Situação de Rua nas 27 Capitais Brasileiras. São Paulo: Secretaria Nacional Antidrogas, Centro Brasileiro de Informações sobre Drogas Psicotrópicas, 2003.

PONTA PORÃ. Prefeitura municipal. Perfil de Ponta Porã - 2014. Disponível em: <www.pontapora.ms.gov.br/?p=cidade-perfil>. Acesso em: 27 abr. 2014.

SANTOS, E. H. Prevalência do Uso de Drogas entre Estudantes Adolescentes de Glória de Dourados/MS, 2012. Dissertação de Mestrado Profissional, Rio de Janeiro: Escola Nacional de Saúde Pública Sergio Arouca, Fiocruz.

SILVA, R. M. \& OLIVEIRA, T. C. M. O mérito das cidades-gêmeas nos espaços fronteiriços. Observatorio Iberoamericano del Desarrollo Local y la Economía Social, (OIDLES), 2(5), 2008. Disponível em: <www.eumed.net/rev/oidles/05/msmo.htm>. Acesso em: ago. 2015. 


\section{5 \\ O Paradoxo na Atenção ao Crack em Salvador: entre a referência técnica e a fragilidade da articulação na rede}

Joviana Quintes Avanci

Caroline Alves Feitosa

Neste capítulo traça-se um panorama da situação do uso de crack por crianças, adolescentes e seus responsáveis na cidade de Salvador. Primeiramente, contextualizam-se as políticas públicas de enfrentamento de uso de crack na cidade e mostram-se algumas estatísticas desse consumo no grupo estudado. A seguir, apresentam-se os serviços da rede de atenção às crianças, adolescentes e famílias usuárias de crack e as características de seu funcionamento. O perfil dos usuários pesquisados e de suas famílias é um ponto abordado na sequência e, ao final, discute-se a articulação dos serviços da rede de Salvador na atenção à problemática e propõem-se algumas recomendações.

\section{A CidAde de SAlvador e o Consumo de CRACK}

Salvador, capital do estado da Bahia, com 706,8 km² de extensão (IBGE, 2008), tem em torno de três milhões de habitantes (2.948.733 habitantes), dos quais $46,9 \%$ são do sexo masculino e $53,1 \%$ do feminino (IBGE, 2008). É o município mais populoso do Nordeste e o terceiro do país. Há grande concentração da população nas faixas etárias de 10-19 e 20-29 anos.

É a cidade mais rica da região Nordeste e, em 2010, apresentou um Índice de Desenvolvimento Humano (IDH) de 0,759, valor superior à média da Bahia $(0,660)$ e à do país $(0,727)($ IBGE, 2000, 2011). Apesar de ser considerada a mais rica da região, em 2012, os índices de desigualdade social estavam entre os mais altos do país - o Gini de Salvador é 0,559, maior que o do Brasil $(0,498)$. 
A cidade investe cada vez mais no turismo e tem forte influência da cultura africana, características que a destacam de outras partes do país e que influenciam o estilo de vida da população que ali reside.

\section{A magnitude do uso de crack por crianças e adolescentes}

Salvador, assim como outras capitais da região Nordeste, historicamente não aparece entre as cidades que estão no topo do uso de drogas no país. Todavia, recente estudo nacional e com base domiciliar mostra que as capitais do Nordeste detêm o maior número de crianças e adolescentes com uso regular de crack e/ou similares nos últimos seis meses no ano de 2012, se comparadas às demais regiões (Bastos \& Bertoni, 2014). Deve-se, porém, constatar que são relevantes a ampla variação e as limitações metodológicas de estudos desenvolvidos sobre o tema no país.

Na primeira pesquisa domiciliar sobre drogas psicoativas no Brasil, em 2001, o Nordeste brasileiro aparece com percentuais intermediários $(1,4 \%)$ para uso de cocaína alguma vez na vida, em comparação as demais regiões, tendo a região Sul os maiores índices $(3,6 \%)$ e a Norte, os menores $(0,8 \%)$ (Carlini et al., 2002). Em 2004, estudo desenvolvido com escolares revela que a região Nordeste apresenta percentuais inferiores no consumo de cocaína na vida (1,2\%), na comparação com as demais regiões - 2,9\% no Norte, 2,3\% no Sudeste, 2,1\% no Centro-Oeste e 1,7\% no Sul (Galduróz et al., 2005). Nesse mesmo estudo, os dados dos escolares de Salvador revelam que as bebidas alcoólicas (cerveja, vinho, pinga e outras) e o tabaco (em frequência diária) foram as drogas com maiores percentuais de uso no mês. Entre os solventes/ inalantes (com índices inferiores aos observados na amostra global), predominou o consumo de cola. Para maconha e derivados da coca, os índices foram semelhantes à média brasileira. O consumo de medicamentos psicotrópicos foi relativamente pouco relatado, em comparação com muitas das outras capitais no Nordeste (Galduróz et al., 2005). Apesar de inferior às demais regiões, o que se observa é que, a partir de 2000, há um crescente aumento do consumo de cocaína entre estudantes das capitais do Nordeste, entre elas Salvador.

Em relação ao uso de crack na cidade, são poucas as estatísticas. Estudos indicam que esse consumo nas ruas da Bahia foi praticamente insignificante até 1997 - em torno de 1\% (Duailibi, Ribeiro \& Laranjeira, 2008). O Centro de Estudos e Tratamento de Abuso de Drogas (Cetad) informa que apenas no início do ano de 2000 começou a demanda pelo atendimento ao usuário de crack. 
Interessante perceber que no estado, mais precisamente em Salvador, o crack surge quase dez anos depois de São Paulo, estado brasileiro pioneiro neste consumo.

A partir de 2003 houve um aumento significativo do uso de crack por crianças e adolescentes de rua no Nordeste, especialmente por meninos, sugerindo o aumento do acesso aos produtos de coca na região (Duailibi, Ribeiro \& Laranjeira, 2008), sobretudo por se tratar de uma droga barata. Dados publicados pela mídia revelam que em Salvador, em 2006, 26\% dos novos usuários de drogas atendidos por um serviço especializado eram consumidores de crack. Em 2009, essa proporção aumentou para 34\%; em 2008, chegou a 37,8\% (Consumo, 6 fev. 2010).

Almeida (2000) estudou 160 meninos de rua desta cidade e constatou que a metade deles consumia crack, embora a maconha fosse a droga mais usada. Em outro estudo, o uso de crack foi citado por quase $10 \%$ das crianças e adolescentes de rua pesquisados (Galduróz et al., 2005).

Com a chegada do crack em Salvador, assim como ocorre nas demais localidades do país, há uma mudança no perfil de consumo e no ritual de uso das drogas, sendo necessárias mudanças nas estratégias de redução de danos, segundo as especificidades dos grupos de usuários. Além disso, é preciso atuar sobre os danos decorrentes à saúde, principalmente em função das condutas sexuais de risco na população usuária de crack, frequentemente reportadas como moeda de troca para o seu uso.

\section{Políticas públicas para enfrentamento do crack e outras drogas}

Salvador apresenta um pioneirismo importante na fomentação de políticas sobre drogas no país, sendo referência para o atendimento e enfrentamento do problema. Foi nesta cidade que, em 1995, foi implantado efetivamente o primeiro Programa de Troca de Seringas do Brasil e da América Latina (Andrade et al., 2001), após o fracasso da estratégia na cidade de Santos. O programa resultou de iniciativa do Cetad, da Escola de Medicina da Universidade Federal da Bahia (Ufba) e contou com o apoio do governo municipal e estadual.

Dando continuidade à estratégia de redução de danos, no fim da década de 1990, também em Salvador, surge o Consultório de Rua, ${ }^{1}$ cujo objetivo é atender a população em situação de risco e vulnerabilidade social, em que se

A estratégia de abordagem é inspirada na organização não governamental francesa (ONG) francesa Médicos do Mundo, que atende moradores em situação de rua e profissionais do sexo em um ônibus equipado como se fosse uma clínica. 
incluem crianças e adolescentes usuários de álcool e outras drogas. A experiência do Consultório de Rua de Salvador é referência para novos projetos previstos no plano nacional Crack, É Possível Vencer, o qual consolida sua atuação para o encaminhamento de usuários de crack e outras drogas que vivem nas áreas de maior risco social nos espaços urbanos.

O Consultório de Rua é caracterizado por uma equipe formada basicamente por médicos, psiquiatras, enfermeiros, assistentes sociais, psicólogos e pedagogos, que prestam atendimento aos dependentes químicos diretamente na rua, com o suporte de um ambulatório móvel. Após um mapeamento para identificar onde estão concentrados os usuários de drogas na cidade, os profissionais fazem a aproximação, entendida como uma intervenção com a população local, que pode durar semanas a meses.

Nesse período, é muito importante garantir que os usuários se sintam seguros e que entendam que essa equipe está disponível para ouvi-los, orientálos e cuidar deles. Depois de conquistar a confiança dos frequentadores do local e distribuir kits com preservativos, curativos, medicamentos, cartilhas e material de conscientização sobre o uso de drogas, a equipe do Consultório de Rua faz um intenso trabalho educativo e psicossocial com os frequentadores da região. Contudo, quem conduz essa intervenção é o próprio usuário. As negociações levam em consideração se a pessoa quer ou não receber informações e orientações dos profissionais. Se houver confiança e vontade, surgem assuntos afins, como, por exemplo, a família, mas sempre respeitando as escolhas do usuário. A iniciativa parte do indivíduo e não da equipe profissional. O foco da atenção não é a abstinência ou a adesão a um tratamento, embora se espere que essas sejam consequências do trabalho feito na rua. O mais importante é a reinserção do usuário na sociedade, fortalecendo a sua cidadania.

Essa inovação de atendimento surgiu a partir do aprimoramento teóricotécnico de alguns especialistas, especialmente da Ufba. Na esfera da gestão pública de atendimento ao usuário de drogas, o que se observa é a existência de uma série de iniciativas, mas que denotam fragilidade em sua execução, apesar de, no Plano Municipal de Saúde de 2012-2013, o abuso de drogas ter sido considerado em todas as faixas etárias um problema importante. Apresentamos a seguir algumas iniciativas de enfrentamento do uso de drogas em Salvador nas diversas áreas da gestão pública, seja no nível municipal ou estadual.

Na área de saúde, em 2009, iniciou-se a discussão do Programa Municipal de Atenção a Usuários de Álcool e Outras Drogas. Previa-se a ampliação 
da rede de serviços de tratamento, com a implantação de mais Centros de Atenção Psicossocial Álcool e Drogas (Caps ad), além de Consultórios de Rua, voltados para o atendimento a crianças e adolescentes em situação de rua e vulnerabilidade social. O programa incluía também a capacitação dos agentes comunitários de saúde do município e de profissionais de Comunidades Terapêuticas, além de ações educativas e preventivas com a população, por meio de programas de rádio, ações em bairros e em postos de gasolina da cidade. Naquele momento, o coordenador do programa estava otimista: "Salvador se tornará uma das cidades com melhor organização dentro das áreas médica, psicológica e social para atendimento de usuários de substâncias psicoativas".2

Em 2010, foi apresentado o Plano Emergencial para Saúde Mental, Álcool e Outras Drogas de Salvador, que propõe um conjunto de ações integradas de atenção aos usuários de substâncias psicoativas, composto por eixos relacionados à capacitação, ampliação da rede de assistência e mobilização social. A ideia original era capacitar toda a rede de atendimento e assistência aos usuários, assim como criar Caps ad II e Caps ad III em pontos estratégicos da cidade. Além disso, pretendia-se desenvolver mais três projetos, envolvendo a capacitação de agentes comunitários de saúde para enfrentar o problema, a instrumentalização dos profissionais das Comunidades Terapêuticas com informações sobre prevenção, redução de danos e tratamento da dependência de álcool e outras drogas, e sensibilização da população.

Em 2011, foi lançado o Pacto pela Vida, programa de Estado e política pública de segurança pública com interface intersetorial. Teoricamente, tem foco na prevenção e o principal objetivo é reduzir os índices de violência. Uma das principais ações do programa é o enfrentamento ao crack e outras drogas. O primeiro eixo dessa ação está na ampliação da rede do Sistema Único de Saúde (SUS) para lidar com o problema, fortalecendo o funcionamento dos Caps. O segundo foca nas Comunidades Terapêuticas, que teriam os recursos ampliados a fim de aumentar as vagas para atender os usuários. O terceiro

2 Disponível em: <http://twiki.ufba.br/twiki/bin/view/CetadObserva/Noticia20091119_3>. Acesso em: 16 jan. 2013.

3 Caps ad II: serviço de atenção psicossocial para atendimento de pacientes com transtornos decorrentes do uso e dependência de substâncias psicoativas, com capacidade operacional para atendimento em municípios com população superior a 70 mil. É um serviço ambulatorial de atenção diária, que funciona de $8 \mathrm{~h}$ às $18 \mathrm{~h}$, em dois turnos, durante os cinco dias úteis da semana, podendo comportar um terceiro turno funcionando até às $21 \mathrm{~h}$. Já o Caps ad III é um serviço que funciona 24 horas, e é específico para o cuidado, atenção integral e continuada às pessoas com necessidades em decorrência do uso de álcool, crack e outras drogas. 
eixo é a integração e qualificação das redes de assistência social, ensino público estadual, segurança pública e justiça, para a prevenção e reinserção social de usuários, com ações nas áreas de comunicação, educação, esporte e cultura, e, em parceria com a sociedade civil, complementar o SUS e o Sistema Único de Assistência Social (Suas). Também têm prioridade o apoio aos familiares que convivem com esta realidade e a criação de uma rede de atendimento para atuar de forma mais sistematizada no acolhimento, tratamento e reinserção de usuários. O plano contempla os municípios com maior índice de crimes violentos. Fica a cargo da Superintendência de Prevenção e Acolhimento aos Usuários de Drogas e Apoio Familiar (Suprad) e está vinculado à Secretaria da Justiça, Cidadania e Direitos Humanos (SJCDH).

Há que se ressaltar o Projeto Saúde "de Cara" na Rua, desenvolvido e coordenado pelo Cetad/Ufba, que tem como objetivo realizar ações informativas, educativas, preventivas e de redução de danos relacionadas ao uso de substâncias psicoativas junto à população de Salvador. A equipe transita em diferentes lugares da cidade, criando espaço alternativo, criativo e diferenciado, para discutir questões sobre saúde, por meio da música, teatro, performance e intervenção urbana. Trabalha-se em prol da melhoria da qualidade de vida das pessoas, principalmente os usuários de substâncias psicoativas.

$\mathrm{Na}$ área de assistência social, a Secretaria de Desenvolvimento Social e Combate à Pobreza é uma das parceiras do programa Pacto pela Vida, com previsão de atuação conjunta com instituições de acolhimento, a fim de retirar das ruas usuários de crack, encaminhando-os para centros de reintegração. Essa ação ocorre por meio do programa Bahia Acolhe, apresentado a seguir. Além disso, o Pacto pela Vida tem como objetivo mapear as instituições que atuam na prevenção e tratamento de usuários de crack e outras drogas, para identificar as práticas institucionais, investir em qualificação nas organizações e favorecer uma cultura de atuação em rede. O programa ainda prevê o cofinanciamento e monitoramento de projetos das Comunidades Terapêuticas.

O Bahia Acolhe atende a população em situação de rua e tem o objetivo de oferecer um conjunto de ações de assistência social. O programa vem implantando centrais de acolhimento, representando a porta de entrada na rede de proteção social. Tem funcionamento ininterrupto e oferece aos usuários acesso à alimentação, higienização, serviços de enfermagem e abrigamento provisório, se for necessário. Funciona com abrangência estadual, podendo ser 
acessado pelas prefeituras, que, para isso, têm responsabilidades específicas, a exemplo do acompanhamento das famílias das crianças, adolescentes e adultos atendidos. A operacionalização se realiza com participação dos chamados "agentes de proteção social", que fazem a vigilância das situações de risco e vulnerabilidade, identificando os locais de maior incidência dessa população. O Bahia Acolhe funciona no âmbito do Suas e segue diretrizes da Política Nacional de Assistência Social (PNAS).

Em 2012, a partir de uma iniciativa do Ministério da Saúde, houve uma nova proposta de pacto para lidar com a presença do crack na Bahia. O objetivo era articular toda a rede de serviços de saúde, em especial a rede de saúde mental, para ampliar o acesso da população aos cuidados necessários. Previa a existência de uma rede completa de Caps III, Caps ad, Caps i (para crianças e adolescentes com sofrimento ou transtorno mental), Casa de Passagem, Ponto de Encontro e Residências Terapêuticas.

$\mathrm{Na}$ área de educação, há o Programa Educacional de Resistência às Drogas e à Violência (Proerd). Apesar de pouco abrangente, tem caráter social e preventivo e vai além dos tradicionais programas de prevenção às drogas. Sua metodologia consiste em ensinar as crianças e adolescentes a reconhecerem e a resistirem às pressões para o uso de drogas. É implantado por policiais militares devidamente selecionados e capacitados.

Salvador tem um trabalho histórico com pessoas em situação de rua, que tem interfaces importantes com o uso de drogas. Ressaltamos o Movimento Nacional de População em Situação de Rua, criado em 2010, assim como a atuação de várias ONGs, entre as quais destacam-se: 1) o Projeto Axé, que atua na área da educação, arte/educação e defesa de direitos de crianças, adolescentes e jovens em situação de vulnerabilidade social, em especial dos que vivem em situação de rua. O processo educativo é iniciado com a Educação de Rua, que estabelece vínculos e estimula crianças e adolescentes a saírem das ruas e a ingressarem nas unidades educativas, espaços pedagógicos onde se realizam atividades lúdicas, artísticas e culturais, baseadas nos princípios da ética e dos direitos humanos; 2 ) o Centro de Defesa da Criança e do Adolescente Yves de Roussan (Cedeca), que tem como objetivo desenvolver um trabalho que contribua para a proteção de crianças e adolescentes em situações de violências sexuais, crimes de homicídio, violência física e violação dos direitos. Dá orientação e apoio às vítimas e seus familiares com atendimento psicossocial e jurídico. 


\section{OS SeRViços da REDE de ATENÇÃo Às CRIANÇAS, ADOLESCENTES E FAMÍLIAS USUÁRIAS DE CRACK}

Com a finalidade conhecer a rede de atenção para crianças e adolescentes usuários de crack e suas famílias existente no município, alguns procedimentos metodológicos foram adotados e estão apresentados detalhadamente no Anexo deste livro.

A Superintendência de Políticas sobre Drogas e Acolhimento a Grupos Vulneráveis (Suprad), da Secretaria da Justiça, Direitos Humanos e Desenvolvimento Social do estado da Bahia e o Cetad foram as principais instituições que orientaram o mapeamento dos serviços do município. A Secretaria Municipal de Promoção Social, Esporte e Combate à Pobreza apoiou a realização da pesquisa em 14 Serviços de Acolhimento Institucional (SAls), escolhidos por amostragem, com a aplicação de três questionários: um dirigido para a caracterização do serviço, em que o gestor respondeu a perguntas sobre a organização de sua unidade e a atuação dela na problemática do crack (14 questionários aplicados); um preenchido com base nas informações dos prontuários de crianças/adolescentes com histórico de uso pessoal de crack ou pelos seus pais/responsáveis, identificados pelos gestores e técnicos do SAI (54 questionários); um aplicado diretamente aos adolescentes presentes no momento da pesquisa e que afirmaram consumir ou ter consumido crack nos seis meses anteriores ao acolhimento institucional (seis questionários). No que se refere à idade: um tem 14 anos, dois têm 16 anos e igual número, 17 anos, e um tem 19 anos (ainda mantido em situação de acolhimento). Quatro são meninas e dois meninos. Cinco relatam a cor da pele como preta ou parda.

Foram também realizadas 12 entrevistas com representantes das seguintes instituições: SAl, Conselho Tutelar, Cetad, Caps ad III e 2a Vara da Infância e Juventude. O principal objetivo das entrevistas com os gestores desses serviços foi conhecer o atendimento da unidade à demanda do uso de crack, assim como a articulação da rede na cidade. Além disso, foram entrevistados quatro adolescentes (dois atendidos no Caps ad III e dois em SAI) e dois familiares (um atendido no Cetad e um em SAI). Com os adolescentes e familiares, buscou-se conhecer as motivações, o consumo, a estrutura e o relacionamento familiar, as condições de saúde e a opinião sobre o atendimento oferecido pelos serviços.

Forneceram autorização para a realização da pesquisa em Salvador o Juizado da $2^{a}$ Vara da Infância e Juventude, e as secretarias municipais de 
Promoção Social, Esporte e Combate à Pobreza e de Saúde. Neste último órgão, a autorização exigiu mais tempo em virtude do Caps ad III estar momentaneamente fechado por iniciativa dos profissionais do serviço, que alegavam falta de estrutura para atuar. O estopim dessa situação foi a ocorrência de um conflito interno entre um adolescente e a guarda municipal. A partir daí, a unidade passou a funcionar sem segurança.

A despeito das dificuldades encontradas, apresentamos a seguir o mapeamento da rede local de serviços de saúde e da assistência social de Salvador. Ressaltamos, contudo, que não foi fácil consolidar o modelo de atendimento aqui exposto, uma vez que uma mesma unidade, em alguns casos, encontrava-se em mais de uma área de atuação. Assim, optamos por apresentar os serviços existentes na cidade, sem nos preocuparmos tanto com a sobreposição, mas sim com a sua organização segundo o foco deste trabalho: a atenção ao uso de crack às crianças e adolescentes e suas famílias.

Os serviços de saúde que, na ocasião da pesquisa, compunham a rede para usuários de crack são: 55 unidades básicas de saúde; 47 unidades Saúde da Família; dez unidades de pronto atendimento, sendo uma de assistência psiquiátrica; 14 bases de Serviço de Atendimento Móvel de Urgência (Samu); 41 ambulatórios especializados (com atendimentos clínicos pontuais direcionados a usuários de álcool e outras drogas e seus familiares ou portadores do vírus HIV/Aids), contemplando as unidades de saúde que desenvolvem programas de tabagismo, os centros de saúde, os ambulatórios e as clínicas especializadas (que podem atender públicos exclusivos de crianças, adolescentes, adultos e idosos). A maioria desses serviços tem foco na saúde mental.

São os seguintes serviços de saúde mental identificados: três Caps I; 16 Caps II; dois Caps III; três Caps ad e dois Caps i (infantojuvenil); dois Consultórios de Rua; cerca de 30 ambulatórios especializados, entre os quais estão a Aliança de Redução de Danos Fátima Cavalcanti (ARFC), o Cetad, as unidades com o Programa de Controle do Tabagismo, os centros de saúde, o Projeto Capitães de Areia e os serviços oferecidos por faculdades e universidades. Cerca da metade dessas unidades atende crianças e adolescentes, com maior oferta de serviços para adolescentes. Há 12 Comunidades Terapêuticas, entre as quais pelo menos duas atendem adolescentes, e dois hospitais psiquiátricos destinados ao público adulto.

É importante frisar que na área da saúde, o Cetad foi, durante muito tempo, o único serviço especializado na atenção ao usuário de substâncias psicoativas 
no estado da Bahia. Contudo, a partir de 2002 outros serviços foram criados, especialmente os Caps ad e Caps ad III, este último mais voltado para o atendimento de adolescentes.

O Cetad nasceu como programa da universidade e hoje recebe apoio principalmente da Secretaria Estadual de Saúde (Sesab), que destina recursos materiais e humanos da assistência, da educação e do ensino. É o órgão responsável pela execução das ações na área de álcool e outras drogas pela Sesab e centro de referência regional, selecionado pela Secretaria Nacional de Políticas sobre Drogas, cuja principal função é a capacitação profissional. Atualmente, exerce a função de cooperação interinstitucional e compõe-se dos seguintes núcleos de atividade: 1) clínica: responsável pela assistência propriamente dita aos usuários e aos familiares. É um serviço aberto à comunidade, com atendimento psicológico, psiquiátrico, estratégias grupais e oficinas terapêuticas; 2 ) ensino: estágio, curso de especialização e programa de residência. Além disso, há oferta de cursos de atualização ou de capacitação à equipe de saúde, de agentes multiplicadores ou de redutores de dano: 3) ações comunitárias: educação para a saúde voltada para a demanda da comunidade e com o foco na prevenção, atendendo a demanda espontânea de empresas, escolas, associações de bairro e da comunidade de maneira geral; 4) estudos e pesquisas; 5) documentação e produção editorial. Há também o Cetad Observa, um veículo de notícias especializado na temática álcool e outras drogas, e que divulga no seu site informações atualizadas acerca do que acontece nos campos da saúde pública, direitos humanos, políticas e ciência.

O Projeto Capitães de Areia é outro serviço a ser destacado. Está ligado à Secretaria Municipal de Saúde (SMS) e presta assistência direta a crianças e adolescentes de rua. Atua como Consultório de Rua e tem apoio técnico do Cetad. Opera no centro histórico, onde há uma maior concentração de crianças e adolescentes de rua, por conta do turismo.

O Caps ad III é o principal serviço responsável pelo atendimento de crianças e adolescentes usuários de drogas da cidade. Foi criado em 2010 para funcionar como referência para esse tipo de trabalho no município. Contudo, o gestor desse centro comenta que, devido à demanda da população adulta, houve uma expansão para atender esta clientela. Na ocasião da pesquisa, pela falta de estrutura e apoio da Secretaria Municipal de Saúde na execução das atividades da unidade como Caps ad III, entre as quais está o funcionamento 24 horas, a intenção do gestor era readequá-la em Caps ad II, o que não 
ocorreu. Apesar de oficialmente ter sido planejado e criado com Caps ad III, a unidade de Pirajá nunca havia funcionado como tal, em decorrência da falta de estrutura e de recursos humanos necessários para realizar as atividades propostas, principalmente o atendimento 24 horas. Dessa forma, foi proposta a readequação da unidade para Caps ad II.

Em relação aos serviços da área de assistência social, identificaram-se: 19 Centros de Referência de Assistência Social (Cras), cinco Centros de Referência Especializados de Assistência Social (Creas), nove Centros Sociais Urbanos, ligados à Secretaria de Desenvolvimento Social e Combate à Pobreza (Sedes). Nessas unidades, as comunidades participam de ações socioeducativas e projetos de fortalecimento da cidadania e desenvolvimento social. São ações contínuas na área de esporte, cultura, inclusão digital, capacitação e geração de renda, entre outras.

Segundo a gestora entrevistada da Sedes, praticamente não há serviços no órgão destinados ao atendimento de uso de drogas por crianças e adolescentes. Há apenas uma pequena entidade conveniada, com capacidade para atender 16 adolescentes e que aceita os que têm entre 10 e 13 anos com comprometimento leve relacionado ao uso de drogas. No mais, relata que existem somente atendimentos ambulatoriais e Comunidades Terapêuticas, mais voltados para o público adulto. Ressalta, contudo, a incipiência das Comunidades Terapêuticas e a sua orientação religiosa.

Além dos órgãos citados, há ainda em Salvador 18 Conselhos Tutelares, que podem apoiar o cuidado para crianças, adolescentes e familiares em situação de uso de crack.

O que se observa em Salvador é a existência de certa fragilidade das políticas públicas para o tratamento de usuários de substâncias psicoativas, em especial das crianças e adolescentes. Segundo estimativas da Secretaria Municipal de Promoção Social, Esporte e Combate à Pobreza, há cerca de 2.400 usuários de crack morando nas ruas, entre crianças, adolescentes e adultos. Contudo, encontram-se na cidade apenas três Caps ad - um deles inaugurado em 2012 -, embora o número ideal de Caps ad seja 12, considerando-se que Salvador tem quase três milhões de habitantes.

No âmbito estadual, acrescenta-se que, na ocasião da pesquisa, não havia leitos para tratamento de dependentes químicos nos hospitais gerais; os usuários que davam entrada para processo de desintoxicação eram atendidos de forma improvisada em centros de internação psiquiátricos. Depois de tratados, 
retornavam às drogas nas ruas. Percebe-se uma forte demanda dos especialistas para a criação de unidades de acolhimento temporário, onde os pacientes pudessem ser acompanhados por profissionais no processo de recuperação.

Com base nos dados levantados, especialmente das entrevistas qualitativas, propomos a seguir um fluxograma simplificado de serviços de Salvador que prestam assistência à população infantojuvenil usuária de substâncias psicoativas (Figura 1). Como se observa, ao lado do Caps ad III, o Cetad e o Projeto Capitães de Areia são as principais unidades que oferecem esse tipo de atendimento, sendo o primeiro a principal referência na cidade. Ressaltamos que o serviço denominado Aliança de Redução de Danos Fátima Cavalcanti agregou em 2012 o projeto do Caps ad II. Contudo, na ocasião do estudo, essa unidade não foi pesquisada nem apontada como referência para a atenção aos usuários de crack na cidade. Por essa razão, não apresentamos informações mais precisas sobre esse serviço, tampouco o incluímos na Figura 1.

Figura 1 - Fluxograma simplificado de serviços que prestam assistência a crianças e adolescentes usuários de crack e outras drogas. Salvador - 2012

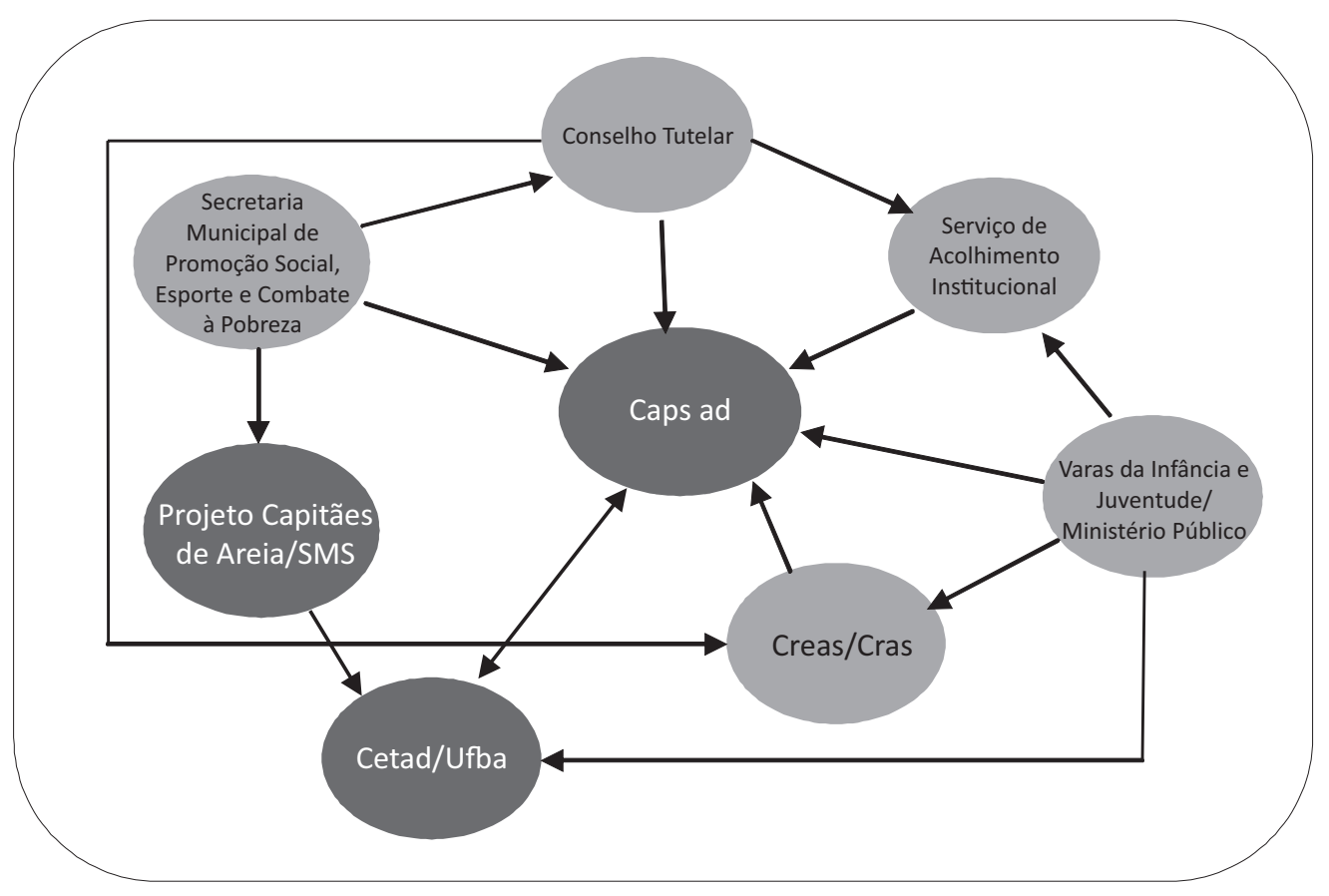




\section{O ACOLHIMENTO INSTITUCIONAL DE CRIANÇAS, AdOLESCENTES E SUAS FAMÍLIAS USUÁRIAS DE CRACK}

O acolhimento institucional é destinado a famílias e/ou indivíduos com vínculos familiares rompidos ou fragilizados, a fim de garantir proteção integral. A organização do serviço deve assegurar privacidade, respeito aos costumes, às tradições e à diversidade de ciclos de vida, raça/etnia, gênero e orientação sexual (MDS, 2009).

Entre os 14 SAls visitados, ${ }^{4}$ dez atendem crianças (até 11 anos) e 13, adolescentes (Tabela 1); cinco recebem exclusivamente adolescentes e um apenas crianças. Em apenas dois serviços, constata-se a presença de crianças que usam drogas em geral, sem que fosse mencionado o consumo de crack. Entre os que atendem adolescentes o quadro é diferente: $53,8 \%$ acolhem usuários de drogas em geral e 30,8\%, crack. Em relação aos responsáveis, $60 \%$ a 70\% dos serviços informam o consumo de drogas em geral e 50\% desses serviços acolhem responsáveis que utilizam ou utilizavam crack.

Tabela 1 - Serviços de Acolhimento Institucional que atendem crianças e adolescentes e seus responsáveis com história de uso de crack e drogas em geral ( $\mathrm{N}=14$ SAl). Salvador - dezembro 2011 a fevereiro 2012*

\begin{tabular}{l|c|c|c|c}
\hline \multirow{2}{*}{ Consumo de drogas } & \multicolumn{2}{|c|}{$\begin{array}{c}\text { SAls que atendem } \\
\text { crianças } \\
\mathrm{N}=10^{* *}\end{array}$} & \multicolumn{2}{c}{$\begin{array}{c}\text { SAls que atendem } \\
\text { adolescentes } \\
\mathrm{N}=13^{* * *}\end{array}$} \\
\cline { 2 - 5 } & $\mathrm{N}$ & $\%$ & $\mathrm{~N}$ & $\%$ \\
\hline $\begin{array}{l}\text { Uso de drogas em geral pela criança } \\
\text { ou adolescente }\end{array}$ & 2 & 20,0 & 7 & 53,8 \\
\hline $\begin{array}{l}\text { Uso de crack pela criança ou } \\
\text { adolescente }\end{array}$ & 0 & - & 4 & 30,8 \\
\hline $\begin{array}{l}\text { Responsáveis com história de uso } \\
\text { de drogas em geral }\end{array}$ & 6 & 60,0 & 9 & 69,2 \\
\hline $\begin{array}{l}\text { Responsáveis com história de uso } \\
\text { de crack }\end{array}$ & 5 & 50,0 & 6 & 46,2 \\
\hline
\end{tabular}

* Informações dadas pelo gestor do serviço.

** Quatro SAls não têm crianças acolhidas.

*** Um SAI não tem adolescentes acolhidos.

Na Tabela 2 verifica-se que 364 crianças e adolescentes estão acolhidos nos 14 serviços visitados na pesquisa. Em relação às 189 crianças presentes nos SAls,

\footnotetext{
4 Ver detalhes sobre a amostra no Anexo.
} 
duas utilizam drogas em geral e nenhuma crack. Seus responsáveis mostram intimidade maior com drogas em geral (24,3\%) e com o crack (15,9\%). Entre os 175 adolescentes, $16 \%$ usam drogas em geral e 3,4\%, crack; entre seus responsáveis, tem-se $23,4 \%$ e $10,8 \%$, respectivamente.

Tabela 2 - Uso de crack e drogas em geral por crianças e adolescentes em Serviços de Acolhimento Institucional e de seus responsáveis. Salvador dezembro 2011 a fevereiro 2012*

\begin{tabular}{l|c|c|c|c|c|c}
\hline \multirow{2}{*}{\begin{tabular}{l} 
Consumo de drogas \\
\cline { 2 - 7 }
\end{tabular}} & \multicolumn{2}{|c|}{$\begin{array}{c}\text { Crianças } \\
\mathrm{N}=189\end{array}$} & \multicolumn{2}{c|}{$\begin{array}{c}\text { Adolescentes } \\
\mathrm{N}=175\end{array}$} & \multicolumn{2}{c}{$\begin{array}{c}\text { Total } \\
\mathrm{N}=364\end{array}$} \\
\cline { 2 - 7 } & $\mathrm{N}$ & $\%$ & $\mathrm{~N}$ & $\%$ & $\mathrm{~N}$ & $\%$ \\
\hline $\begin{array}{l}\text { Uso de drogas em geral pela criança } \\
\text { ou adolescente }\end{array}$ & 2 & 1,1 & 28 & 16,0 & 30 & 8,2 \\
\hline $\begin{array}{l}\text { Uso de crack pela criança ou } \\
\text { adolescente }\end{array}$ & 0 & - & 6 & 3,4 & 6 & 1,6 \\
\hline $\begin{array}{l}\text { Responsáveis com história de uso } \\
\text { de drogas em geral }\end{array}$ & 46 & 24,3 & 41 & 23,4 & 87 & 23,9 \\
\hline $\begin{array}{l}\text { Responsáveis com história de uso } \\
\text { de crack }\end{array}$ & 30 & 15,9 & 19 & 10,8 & 49 & 13,5 \\
\hline
\end{tabular}

* Informações dadas pelo gestor do serviço.

A maior parte dos 14 SAls visitados já atua há muitos anos. Apenas um tem sete meses de existência, e dois têm entre quatro a seis anos. Quatro deles têm entre 11 e 19 anos de atividades, três entre 20 e 25 anos, e os quatro mais antigos têm entre 46 e 82 anos de existência.

Onze serviços $(78,6 \%)$ funcionam em formato de abrigo tradicional, um em Casa Lar em comunidade e dois em aldeia. Um SAI abriga apenas rapazes de 15-17 anos de idade, um tem convênio com presídio para acolher filhos de presidiárias e outro foi criado especificamente para abrigar crianças e adolescentes em situação de violência. Há ainda uma unidade destinada exclusivamente para crianças e adolescentes portadores de necessidades especiais, com problemas mentais ou comprometimentos cognitivos severos. Um dos serviços estava fechando no momento da pesquisa.

A maioria dos SAls visitados são organizações não governamentais (71,4\%); 21,4\% são unidades públicas municipais e apenas um é estadual. Grante parte tem orientação religiosa (dez), quatro são católicos, dois evangélicos, um espírita e três são ecumênicos. Entre os quatro sem orientação religiosa, todos são públicos. 
$\mathrm{O}$ atendimento oferecido às crianças e adolescentes em situação de risco social está voltado exclusivamente a algumas clientelas mais específicas: 13 SAls recebem população de rua (92,9\%); em cinco estão os usuários ameaçados de morte (38,5\%); dez estão dispostos a atender os que têm algum transtorno mental ou doenças infectocontagiosas (71,4\%); e cinco serviços afirmam receber crianças e adolescentes com uso de crack e outras drogas (35,7\%), embora não sejam exclusivos para esse fim.

A maioria dos SAls de Salvador tem equipe técnica própria (13): 11 têm assistentes sociais na equipe $(78,6 \%)$ e em nove deles se agregam psicólogos $(64,3 \%)$, fisioterapeutas, enfermeiros, pedagogos, sociólogos, educadores e dentistas; estagiários integram as equipes de 12 serviços, especialmente pedagogos e educadores. Foram ainda mencionados os seguintes profissionais: enfermeiro, técnico de enfermagem, terapeuta ocupacional, pediatra, fonoaudiólogo, psicopedagogo. Monitores, mães sociais e voluntários também foram citados.

Constata-se, nestes SAls, a precária capacitação dos profissionais para o atendimento ao usuário de drogas em geral, e mais ainda para o crack. Especificamente em relação ao crack, os profissionais que demonstram ter se envolvido mais em capacitação são: equipe técnica (28,6\% dos profissionais, totalizando nove técnicos) e direção (21,4\% e três funcionários capacitados, respectivamente). Vêm a seguir o cuidador/educador/mãe ou pai social $(7,1 \%)$ e a coordenação $(7,1 \%)$.

\title{
PeRFIL dAs CRIANÇAS E dOS Adolescentes USuÁRIOS de CRACK E de suas Famílias em SERVIÇOS de SAÚde E ASSISTÊNCIA SOCIAL
}

\author{
É uma população de extrema vulnerabilidade, seja pela idade, \\ seja pela falta de condição ou de acesso ao tratamento. \\ (gestor do serviço especializado de saúde)
}

Em linhas gerais, o perfil e as condições de vida dos usuários de crack e outras drogas são pouco conhecidos pelos profissionais da saúde. Sabe-se que a maior utilização de crack ocorre entre jovens, predominantemente do sexo masculino e de baixa renda (Dualibi, Ribeiro \& Laranjeira, 2008). Contudo, o conhecimento mais acurado dessa população é importante quando se pensa no 
planejamento de ações e na assistência à saúde propriamente dita, assim como na intervenção na abordagem social e na proteção e defesa dos direitos humanos.

Entre as 364 crianças e adolescentes presentes na amostra de 14 SAls investigados (Tabela 2), o uso de crack foi referenciado pelos gestores para seis adolescentes e 49 responsáveis. Foram preenchidos 54 formulários de registro com base nos prontuários das crianças e adolescentes que consomem crack ou de seus responsáveis que fazem esse uso na cidade de Salvador, coletados no período de $1^{\circ}$ de dezembro de 2011 a 24 de fevereiro de 2012.

As idades dessas crianças e adolescentes acolhidos com história de uso pessoal de crack, ou de seus responsáveis, estão entre: 5-7 meses (9,3\%), 1-4 anos (18,5\%), 5-9 anos (13\%), 10-14 anos (27,8\%) e 15 e 18 anos $(31,4 \%)$. Um conselheiro tutelar da cidade informa que cada dia é menor a idade de início do consumo de drogas ou mesmo do exercício de funções primárias do tráfico, como a de aviãozinho. Em geral, os mais novos são abrigados por conta do consumo de drogas dos seus responsáveis, enquanto os mais velhos, por conta do próprio uso. Verifica-se, entre outros dados, que 53,7\% desse grupo são meninas, $35,2 \%$ têm trajetória de rua e 53,7\% não frequentam a escola.

Entre os acolhidos fora da escola segundo faixa etária, constata-se que todas as 17 crianças até 5 anos de idade não estão matriculadas no ensino infantil; ${ }^{5}$ há seis fora da escola na faixa esperada para o ensino fundamental (6-14 anos), totalizando $30 \%$ das crianças/adolescentes na faixa etária esperada (quatro deles têm 14 anos); e há outros seis para o ensino médio (15-18 anos), alcançando $35,3 \%$ dos adolescentes dessa idade. Nas entrevistas qualitativas com os adolescentes usuários de crack, quase todos afirmam que é grande a defasagem entre série e idade e que pararam de estudar por causa do uso da droga.

Os dados relativos a distúrbios de saúde revelam que 21 crianças/adolescentes $(38,9 \%)$ sofrem de algum problema (18,5\% com comportamento agressivo, $5,6 \%$ com depressão ou ansiedade e um caso de deficiência mental). Anemia, problemas respiratórios, dificuldades de aprendizagem, dificuldades de visão e audição são mencionados por outros acolhidos.

No que se refere à proximidade com o crack, observa-se que $88,9 \%$ das crianças/adolescentes moraram com alguém com problema com o uso de crack/ drogas nos últimos 30 dias antes do acolhimento. São inúmeras as dificuldades

5 Etapas de ensino no Brasil: educação infantil - creche, até 3 anos de idade; pré-escola, 4 e 5 anos. Ensino fundamental de nove anos - anos iniciais (faixa etária de 6 a 10 anos de idade, com cinco anos de duração) e finais (faixa etária de 11 a 14 anos de idade, com quatro anos de duração). 
enfrentadas por essas famílias. São histórias de pais usuários que faleceram em decorrência de Aids, tuberculose ou da proximidade ou envolvimento em crimes. Há também alguns casos de mães envolvidas no tráfico ou que estão presas, moradoras de rua ou que abandonaram o(a) filho(a) por causa da droga.

Entre os principais motivos para o acolhimento dessas crianças/adolescentes estão: abandono pelos pais ou responsáveis $(46,3 \%)$, situação de rua $(31,5 \%)$, dependência química dos pais/responsáveis (22,2\%), ameaça de morte (18,5\%) e violência doméstica física (16,7\%). Com percentuais menores tem-se: ausência dos pais/responsáveis por prisão (13\%), entrega voluntária dos pais/responsáveis $(9,3 \%)$, violência doméstica sexual $(7,4 \%)$, carência de recursos materiais da família $(5,6 \%)$, violência extrafamiliar $(3,7 \%)$, negligência $(1,9 \%)$, violência doméstica psicológica (1,9\%), transtorno mental dos pais/responsáveis (1,9\%), uso/abuso de crack por parte da criança/adolescente (1,9\%). Estes dados, que não diferem significativamente dos números no restante do país, revelam a expressiva vulnerabilidade da amostra pesquisada (Assis \& Farias, 2013).

$\mathrm{Na}$ investigação do tempo de institucionalização do atual acolhimento, verifica-se que entre as 54 crianças/adolescentes identificados, 52\% estavam há menos de um ano no SAI visitado no momento da pesquisa. Outros $18 \%$ estavam há um ano, $14 \%$ há dois anos e 16\%, entre três e oito anos na mesma unidade. Cerca da metade das crianças/adolescentes já haviam sido acolhidos anteriormente na mesma instituição ou em outro SAl, indicando as vastas trajetórias institucionais de muitos deles, mesmo em idade tão jovem.

Quanto à situação na justiça, apenas $25,9 \%$ dos acolhidos têm procedimento administrativo na Vara da Infância e Juventude, como, por exemplo, pasta especial ou processo. Ressalta-se que o número encontrado é muito baixo, já que a totalidade das crianças e dos adolescentes em situação de institucionalização deveria ter tal procedimento na justiça. Além disso, em apenas $18 \%$ dos casos com tais procedimentos/processos, é abordada a questão do consumo de crack por parte da criança/adolescente ou seus responsáveis (descrição do fato, encaminhamentos realizados devido ao problema).

Essa falta de dados nos documentos oficiais se reflete na situação legal da criança e do adolescente usuário de drogas ou de seus responsáveis, já que diminui a possibilidade de adoção. $O$ percentual de ausência de informação nos prontuários é de $37 \%$, o que dificulta a análise dessa questão e indica a fragilidade dos documentos oficiais sobre os acolhidos. Sete crianças/ adolescentes acolhidos nessa situação estão legalmente encaminhadas para 
adoção (aguardando colocação - 13\%); nenhum está em processo de colocação para adoção, ou seja, iniciando a aproximação com adotantes; tampouco há casos em que a destituição do poder familiar tenha sido concluída. Isso significa que há apenas 13\% de crianças/adolescentes usuários de drogas ou cujos responsáveis utilizam drogas que preenchem critérios para a condição legal de adoção na cidade de Salvador. As demais crianças/adolescentes estão nas seguintes situações quanto ao aspecto legal: 16 em fase de avaliação/ preparação para reintegração/retorno ao convívio com os responsáveis (29,6\%); dois com suspensão do poder familiar (3,7\%); nove com a destituição do poder familiar em tramitação (16,7\%); e nenhum com processo tramitando de guarda/tutela ou com sentença pendente de recurso. Vale ressaltar que nenhum adolescente envolvido com o uso de crack/drogas está em cumprimento de medida socioeducativa.

\section{As famílias das crianças e adolescentes usuários de crack}

Estudos revelam que o tipo de relacionamento e as práticas culturais familiares muitas vezes podem servir de estímulo para a experimentação e a continuidade do uso de drogas por crianças e adolescentes, pois a família, como geradora de cultura, transmite hábitos e costumes, crenças e expectativas sobre os papéis sociais, sobre o modo de vida de homens e mulheres, sobre as relações interpessoais e também sobre o uso de drogas. O papel da família é de proteção - promovendo e desenvolvendo a saúde de seus membros -; mas, paradoxalmente, pode ser também de risco - destruindo e desintegrando (Seleghim et al., 2011; Schenker, 2008).

A maior parte do grupo de 54 crianças e adolescentes usuários de crack pesquisados ou com responsáveis usuários tem família morando na cidade de Salvador (92,3\%). A manutenção do vínculo familiar durante o período de acolhimento é relatada em $42,6 \%$ dos casos; $37 \%$ das crianças/adolescentes não têm mais vínculo com seus familiares; 11,1\% têm família desaparecida; 5,6\% têm impedimento judicial de contato; e em dois casos não há mais familiares. Com relação a esse quadro, tem-se que 55,6\% ainda recebe visitas na instituição, especialmente da mãe (53,3\% dos que recebem visitas), avós $(26,7 \%)$ e irmãos (20\%). Apenas dois acolhidos recebem visita do pai $(6,7 \%)$. Outros parentes $(3,3 \%)$ e pessoas (10\%) também são apontados como visitadores.

Entre as informações dos seis adolescentes usuários que estavam acolhidos no SAI sobre a estrutura de suas famílias, há registros de que todos têm irmãos, 
e a maioria deles (cinco) continua vivendo com a família de origem. Há um adolescente com irmãos que já foram adotados, e outro que menciona irmãos em situação de rua.

Nas entrevistas qualitativas com os seis adolescentes/famílias usuários de crack do SAI ou inseridos nos serviços de saúde, constata-se que a convivência com a família é entremeada com a vivência na rua. A maioria deles tem família numerosa, com muitos irmãos, mas quase todos não vivem mais em casa. A existência de padrasto é mencionada por alguns adolescentes, e praticamente não há relato de convivência com o pai. Também é mencionada a convivência com novos parceiros dos pais ou do próprio adolescente. Um dos adolescentes em tratamento no serviço de saúde conta que na época do consumo de crack morava sozinho, mas depois do tratamento voltou a viver com a família de origem.

O vínculo familiar desses adolescentes é bem frágil e prevalecem histórias de abandono, violência, conflitos, doenças, mortes e problemas de familiares com o álcool e outras drogas. Apenas os dois jovens em tratamento no serviço de saúde especializado relatam que têm bom relacionamento familiar e que não estão mais dependentes da droga. Uma adolescente do SAI, abandonada pela mãe nos primeiros dias de vida, narra o que sente por seus pais: "Com quinze dias de nascida, minha mãe me abandonou. Para mim eles [pais] não significam nada. Eles não são nada". A avó da adolescente comenta o abandono da neta: "Ela nasceu de 7 meses. A mãe abandonou ela com broncopneumonia, e botando secreções pelos ouvidos, uma infecção intestinal quando ela fazia o cocô: (...), parecia peixe podre. Eu corri e hoje ela está com 17 anos".

Outra fala de um familiar de adolescente usuário de crack exemplifica a complexidade dos problemas vividos:

Hoje, minha família sou eu e minha mãe. Ela é doente mental, hipertensa e diabética. Tem 93 anos de idade. Eu tinha sete filhos, faleceram dois. A menina, em 2009, com câncer no fígado, e o menino faleceu agora em junho, no dia 6 de junho, com enfisema pulmonar (...). Porque ela [mãe - bisavó da adolescente] morava na casa dela com meu irmão, mas diante da situação dela, que era muito agressiva, findou meu irmão sofrendo do coração e veio a falecer. Minha irmã, por uma vez que ela ficou sozinha, minha irmã casada veio morar na casa dela, para tomar conta dela. Não aguentou também o sofrimento, faleceu de derrame cerebral. Deixando quatro filhos. 
Entre os problemas vivenciados, vale ressaltar o histórico de abuso de álcool e outras drogas pelos familiares. Tanto nos registros dos seis adolescentes usuários e acolhidos no SAI quanto nas entrevistas qualitativas com os adolescentes e familiares, constata-se o uso frequente de substâncias psicoativas (maconha, cocaína e crack) por pais e irmãos. O álcool é ainda mais consumido. Os adolescentes apresentam reações antagônicas em relação ao consumo intenso de drogas pelos familiares. Alguns banalizam e apoiam a prática, enquanto outros demonstram grande insatisfação. Uma adolescente do SAI diz chorar quando vê a mãe bebendo, já que não pode fazer nada:

Eu não quero que minha mãe use droga nenhuma. Não use droga, nem cachaça nenhuma (...). Porque minha mãe, eu amo. Se eu ver minha mãe nesse lugar, eu parto com o cara no chão, (...). Porque eu sei que acaba, que mata! Ver minha mãe se matar, não, você é doido!

Também é grande a fragilidade da situação de saúde desses responsáveis usuários, comprovada pela morte de um deles por cirrose e de outro por tuberculose.

\section{O que pode levar ao consumo de crack por crianças e adolescentes?}

O uso de crack e outras drogas está relacionado a um conjunto de fatores culturais, históricos, econômicos e sociais. Sexo, idade, classe social e fatores psicossociais, como a influência de amigos e as relações interpessoais na família, são fatores associados ao uso e ao tratamento desse problema de saúde (Baus, Kupes \& Pires, 2002). Um gestor de um serviço de saúde especializado ressalta o impacto da degradação social no uso e no cuidado dos usuários:

O crack é uma excelente arma de extermínio de uma população que não interessa ao sistema, que não interessa a esse modelo econômico de produção. Não interessa! E a gente tem visto esse fenômeno ocorrer da forma que tem acontecido porque essas pessoas são privadas de muitas outras coisas. Eu tenho tido a oportunidade de atender usuários graves de crack no meu consultório privado, em que é possível você fazer muita coisa, muita coisa. Essas pessoas têm acesso ao melhor tratamento psiquiátrico, ao melhor tratamento psicoterápico, a ambientes protegidos de excelente qualidade. (...) Sendo que, no serviço público, a gente não tem nada disso. Essas pessoas que eu diria de um poder aquisitivo maior, mesmo que elas tenham um prejuízo muito grande pelo efeito da droga e pelo 
consumo compulsivo da droga, quando elas se recuperam, elas têm outras fontes de estímulo, outros pontos de ligação. (...) E na maioria da população menos favorecida, (...) quando a gente consegue tirar o crack, não existe ancoradouro algum! [breve pausa] (...) Então isso me assusta.

Os profissionais dos serviços pesquisados identificam alguns aspectos que podem levar crianças e adolescentes a usar crack, entre os quais se destaca a situação de grande vulnerabilidade social em que esses jovens estão inseridos. Um gestor do serviço de saúde ressalta que o uso de crack não é uma opção por "prazer, bandidagem, marginalidade". Comparando os fatores causais do consumo de crack com os relacionados a outras drogas, um gestor entrevistado comenta a relevância da fragilidade social e econômica desses usuários e suas famílias:

Falta de trabalho, falta de escola boa, falta de alimentação, estar em situação de rua. (...) Acho que a questão do crack está numa relação intrínseca com problemas estruturais que foram relegados durante anos e anos. (...) As pessoas buscam crack como um paliativo para algumas situações (...). Por exemplo, muitas pessoas que trabalham como catadores de lata, usam crack, por quê? Porque o crack tira a fome e dá a ele uma energia para sair correndo para lá e para cá, catando lata, tira o sono dele. Para quem dorme na rua, tem que estar em estado de alerta. Então assim o próprio efeito do crack (...), ele traz características importantes para pessoas que estão, geralmente, em situações sociais enfraquecidas. Porque existe uso de crack na classe alta e média, não posso dizer que não existe, mas é muito, muito, muito menor efetivamente que na classe baixa. (gestor de Caps ad III)

A fragilidade da família, a privação social e financeira, a precariedade da escola e o poder do tráfico de drogas são os fatores principalmente apontados pelos profissionais entrevistados como desencadeadores do problema.

A mulher que, a cada um, dois anos, tem um parceiro diferente e que tem filhos com parceiros diferentes. Essa mulher que também é a provedora da casa (...) e que tem que sair, e esses filhos têm que ficar sendo cuidados pelos outros, e que vai ter acesso à rua mesmo. $\mathrm{A}$ falta de uma escola que seja interessante, para esse adolescente, para essa criança. Você não tem uma atividade no contraturno da escola, na própria escola ou na comunidade. Então assim, falta isso, e o que sobra? O que sobra é a droga muito fácil que está dentro dos bairros. 
(...). Ele atrai esse jovem com coisas que nós não conseguimos atrair, porque ele chega para um jovem de 14 anos e oferece um salário só para ficar na esquina avisar se vem alguém. E ele passa fome dentro de casa. Ele não tem acesso a um sapato que ele quer e aquilo dá acesso a um mundo que ele não tem. (gestora da Secretaria de Desenvolvimento Social e Combate à Pobreza)

$\mathrm{Na}$ fala de alguns gestores, nota-se uma visão preconceituosa e estigmatizadora das famílias pobres, reproduzindo o senso comum, o que não contribui para fortalecê-las, tampouco para superar o problema. Outros fatores causais menos lembrados pelos gestores dos serviços são o consumismo e a influência da mídia.

Interessante perceber que os adolescentes e os familiares entrevistados ressaltam outras causas para o consumo de crack, enfatizando as características individuais do adolescente (impulsividade e curiosidade), a influência dos amigos, a violência física familiar, o abandono e a rejeição dos pais, e o histórico familiar de uso de drogas.

No começo eu usava muita droga mesmo por ver aquela coisa [mãe usando álcool]. Assim, se ela morrer... Eu tenho que morrer antes dela. Porque eu não vou aguentar ver minha mãe morta. Eu acho assim que, se a minha mãe morrer, o mundo acabou. Então eu tenho que morrer primeiro que ela. Por isso estou nas drogas, no crack mesmo. Por isso eu uso crack. (adolescente em SAl)

Já apanhei muito. Já trabalhei muito, para poder ter dinheiro. Enjoei. De pagar pau para os outros. Meus irmãos tudinho me bateram, meu padrasto me bateu. Aí eu fiquei aloprada e fui para a droga. Dormi na rua. Me torturavam. Meu padrasto. Minha mãe não. Minha mãe quase não me batia. Meu padrasto me batia. Meu padrasto pipocou este ouvido meu. Com uma tapa. Aí eu não escuto muito direito. Ele me colocava meu pé na corrente, no portão. Deixava sentada. Só levantava para mijar, para comer, para ir no banheiro. Na corrente, no cadeado. Meus irmãos me batiam. Esse menino [irmão] que vende droga, quando a droga dele sumia lá em casa, geralmente eu pegava uma pedra, duas pedras de crack, mas no pó, não mexo no pó, nem na maconha. Mas aí sumia; ele me pegava e me batia. Minha mãe ia para cima dele, ia com faca. la para cima dele com pau. (adolescente em SAl)

Um adolescente menciona outros dois fatores importantes que podem levar ao consumo de crack: a crença de que o usuário é capaz de parar de usá-lo a 
qualquer momento e o consumo de outras drogas, como a cocaína, que passam a ser consideradas fracas.

Apenas uma mãe, que teve papel importante no tratamento do filho, comenta a influência dos pais na entrada dos filhos no uso da droga:

O que nós precisamos hoje, os nossos meninos, é apoio, mas não só apoio dos governantes, e do Ministério Público, do Cetad. Apoio também dos pais. Eu sei que tem muitos pais que trabalham, eu também trabalhei. E quando ele fugia de casa, também eu trabalhava na época. Ninguém tomava conta dele, ninguém suportava tomar conta dele, porque ele era muito danado. (...) Porque hoje a criação desses meninos é totalmente diferente da que a gente tinha. Hoje o filho olha para a cara de uma mãe e faz o que quiser e acabou. (familiar de adolescente em serviço de saúde)

\section{A vivência de rua, a forma de ganhar dinheiro e o uso de preservativos por adolescentes usuários de crack}

Sinto vontade de parar e não consigo. Só isso. Não consigo mesmo. Acho que se eu sair daqui [SAI] agora, eu vou arrumar um dinheiro para usar. Não sei o que é. Essa droga é um diabo.

Não tem remédio para essa droga! (adolescente em SAI)

É praticamente consensual que o uso múltiplo de substâncias psicoativas é uma característica marcante no padrão compulsivo de utilização, substituindo paulatinamente o consumo exclusivo de uma só droga. Nas entrevistas com os adolescentes/família usuários do SAI e do serviço de saúde, relatos apontam o uso de crack há vários anos. Outro ponto mencionado pelos familiares é o perfil mais problemático desses jovens desde pequenos.

Nos registros de todos os seis adolescentes identificados como usuários pelo SAl, verificou-se o consumo de álcool, tabaco, maconha, cocaína e crack ao longo da vida, indicando a conjunção do uso de várias drogas. Quatro relatam o uso de mesclado (especialmente maconha e crack) e produtos para sentirem um "barato"; três consumiram oxi; dois usaram LSD ou outro produto que provoque alucinações. Heroína, morfina ou ópio também foram relatados (um adolescente), bem como tranquilizante, ansiolítico ou calmante (quatro), remédio ou xarope (três) e haxixe (um). Muitos se referem à hierarquização do consumo de drogas, que pode começar por uma droga mais leve passando às mais pesadas ou vice-versa, das mais pesadas às mais leves. 
Similarmente, estudo realizado por Oliveira e Nappo (2008) com usuários de crack da cidade de São Paulo demonstra que o uso múltiplo de drogas é uma forma de tentar manipular a intensidade ou a duração dos efeitos de crack, seja como paliativo aos efeitos negativos, seja para intensificar ou prolongar os efeitos positivos.

O uso de drogas no mês anterior ao acolhimento das crianças e adolescentes pesquisados foi confirmado para as seguintes substâncias: metade utilizou álcool (até oito dias no mês), maconha (variando de uma vez por semana até todos os dias) e cocaína, usada mais na forma nasal do que na fumada, (diariamente); cinco consumiram tabaco e crack quase todos os dias; dois utilizaram outras substâncias para sentir "barato" via oral e nasal (um deles usou uma única vez no período e outro diariamente); um consumiu oxi todos os dias. Um dos adolescentes já utilizou drogas injetáveis, e a overdose de crack foi mencionada por três deles.

Constata-se que o gasto médio dos seis adolescentes com drogas no último mês varia de acordo com a substância utilizada, com destaque para o elevado gasto com crack, que equivale a um pouco mais de três salários mínimos (SM) e pode chegar a quase dez SM. Em ordem decrescente, tem-se o gasto médio mensal com maconha (quase um SM e meio), cocaína (um pouco mais de meio SM), tabaco (cerca de $30 \%$ do SM), oxi (13\% do SM) e álcool a (10\% do SM).

Quatro adolescentes indicam variados números de pedras de crack consumidas em um dia comum: três, dez, vinte e duzentas pedras. Comentam também as diversas formas de consumo: dois deles o fazem em formato de cigarro (misturando tabaco e crack); três usam como baseado (misturando maconha e crack); três utilizam latas de refrigerante ou cerveja e copos plásticos; e cinco usam crack em cachimbo. Apenas um deles afirma reutilizar copo/ cachimbo de outro usuário para fumar crack. Quatro informam consumir crack em conjunto com outras drogas, destacando-se a cocaína e a maconha.

A rua é mencionada como local de maior consumo de crack e outras drogas. Quatro adolescentes obtêm a droga com traficantes, amigos ou moradores de rua. Os conflitos familiares em decorrência dessa prática e a dívida com o tráfico na comunidade onde vivem, além do próprio consumo de crack, são os fatores que os levaram à rua. Os entrevistados relatam a sedução da vivência na rua, ao mesmo tempo que são expostos a situações muito críticas:

A vivência na rua é como você está vendo, você não tem dinheiro para comer, mas você acha crack, você acha cachaça, você acha 
cocaína, maconha, você acha isso a todo instante. Por mais que você tenta se liberar, se livrar, aí que mais tem. Parece que é uma coisa satânica. Quanto mais você tenta se afastar, aí que você é possuído mesmo e, quando você vai ver, você já está entregue; e se vacilar você se adapta a morar na rua. Você faz da rua já um hotel cinco estrelas. (adolescente em SAI)

Foi estuprada. Quando ela apareceu [em casa], foi botando sangue por tudo quanto foi canto, e disse que tinha sido estuprada por três, por três moleques. Bateram muito nela, deram de fio, cortaram a perna dela de fio, fizeram vazar os olhos dela. Quando ela chegou, o olho direito era uma bola de sangue. Eu saí às pressas, levei para a clínica pública. Chegou lá, a médica passou um colírio para ir limpando. E depois ela se sentiu mal, vomitando muito, com diarreia. Eu levei ela para um PAM, para o Hospital São Jorge, onde eu passei a noite toda com ela. E por conta do estupro, que ela está com problema de estômago, ela está com problema de fígado, com problema de tudo. Porque bateram muito, deram muito chute nela, queriam matar. (familiar de adolescente em SAI)

Um adolescente comenta que o sentimento que tem pela mãe e a consciência do sofrimento causado a ela o levou a sair da rua:

Creio que foi o afeto que minha mãe tem por mim, a preocupação em saber que tinha um filho morando embaixo das marquises e que minha criação nunca foi essa. Tem pessoas que já são acostumadas a morar na rua, já eu nunca tive essa experiência. (adolescente em serviço de saúde)

Raupp e Adorno (2011), em estudo etnográfico realizado na cidade de São Paulo, relatam que aproximadamente $90 \%$ dos usuários são "pessoas em trânsito pela rua". As trajetórias dos usuários revelam que a passagem para a situação de morador de rua é, na maioria das vezes, precedida de um período de transição entre sua comunidade e a rua, com a tendência a permanecer períodos cada vez maiores na rua à medida que aprofundam a relação com a droga. Nessa condição de vida na rua, os seis adolescentes em SAls pesquisados relatam que ganhavam dinheiro entregando água e catando objetos como latas e garrafas PET do lixo, além de realizar atividades ilegais, como roubos, tráfico de drogas, assaltos e prostituição ( $\mathrm{R} \$ 20$ a $\mathrm{R} \$ 30$ por prática sexual). Três adolescentes comenta fazer sexo sem camisinha; porém, todos negam prática de sexo com portador de hepatite B, C ou HIV. 


\section{Consequências do uso de crack}

O crack é uma substância psicoativa, que tem uma força muito grande, que tem um potencial muito grande para determinar quadros de dependência. (...) Por si só é capaz de fazer quadros graves de toxicomania. A intensidade, o efeito psíquico do crack, a intensidade que ele produz em termos de modificação da vida psíquica desses indivíduos, isso me chama a atenção. O prazer descrito por todos os usuários a partir da experiência que eles tiveram com essa droga, isso sempre me chamou a atenção. (gestor do serviço especializado de saúde)

Eu me sinto totalmente destruída. Eu me sinto acabada. Destruída. Acabada. Eu me sinto derrotada. (adolescente em SAI)

Os sistemas cardíaco e respiratório de usuários de crack fragilizam-se, o que pode causar-lhes uma morte prematura. Estão também propícios a outros problemas, como doenças sexualmente transmissíveis, violências, situações de perigo constantes e envolvimento em atos infracionais, que em muitos casos pode levá-los à morte. Inquietude, ansiedade, irritação, agressividade e paranoia são alguns sinais clínicos dos efeitos do crack, que incluem, sobretudo, consequências negativas nas relações sociais (Santos, 2011).

O gestor de um serviço de saúde especializado de Salvador comenta a rápida evolução do quadro de dependência do usuário de crack, pelo reforço da experiência, ocasionando muita desorganização e prejuízos em vários aspectos:

Como o crack produz esse efeito muito intenso e assim, é impressionante até porque, em pessoas de excelente poder aquisitivo, a evolução também é muito rápida. A vontade que eles sentem de repetir a experiência, de repetir a experiência, de repetir a experiência. É tão significativo que, num curtíssimo período de tempo, eles têm a vida subjetiva, a vida familiar, a vida social completamente detonada (...) Nos quatro primeiros anos, a dependência ao crack produz um efeito extremamente nefasto. Muito nocivo.

A fissura e a apatia geradas pelo crack causam muito sofrimento à família do usuário, aspecto destacado na fala de todos os entrevistados - profissionais, adolescentes e familiares.

Antigamente eu pensava primeiro a droga, segundo a droga, terceiro a droga, para depois vir eu. E eu estava me acabando, definhando na droga. (adolescente em SAI) 
Porque ele [usuário] sob o efeito da droga, dificilmente é capaz de fazer qualquer coisa. Sob o efeito da droga não faz nada. Ele começa a fazer alguma coisa na fissura. $O$ grande problema da dependência do crack se chama fissura. A vontade irrefreável, incoercível de continuar usando a droga. Então quando ele termina a quantidade de droga que tem, ele começa a ter uma prática delituosa para a aquisição da droga. E aí sim, a gente observa uma violência, que fica circunscrita dentro do próprio ambiente familiar. Quem mais é penalizada por essa violência oriunda da fissura é a própria família. Porque o usuário, ele quer subtrair pertences, objetos de pai, de mãe, dinheiro, ele rouba dinheiro para poder adquirir a própria droga. (gestor de serviço de saúde especializado)

Nos depoimentos é possível constatar a tristeza, a impotência e a fragilidade das famílias, o que as levam a abandonar os filhos e a provocar muita violência em casa:

Vejo também esse sentimento nas mães quando veem um, dois filhos. Eu atendi um senhor ontem me pedindo para ir morar num abrigo porque os filhos dele estavam envolvidos com drogas, e que já tinham ameaçado ele, que já tinham batido nele. E que vizinhos, amigos, diziam: "vai receber teu dinheiro, vai embora, larga eles aí, antes que eles te matem". A tristeza com que esse homem falava que o filho dele tinha envolvimento e que estava lesando ele, que era o pai, que era o provedor. Estas famílias também adoecem. (gestora da Secretaria da Justiça, Direitos Humanos e Desenvolvimento Social)

Foi então um dia, ele [adolescente usuário] me enfrentou e eu chamei a polícia. A polícia disse que não ia porque ele era de menor. "Então está certo. Então prefere que eu mate ele ou ele me mate?" Aí depois ele fugia. O pai botou ele para fora. Só que eu ficava tão doente por isso, porque eu que gerei (...). Por quê? Me perguntava várias vezes. E não tinha resposta. E quando eu conversava com um amigo, "que nada, deixa ele que o mundo ensina". Mas eu me perguntava: "Meu Deus, o que o mundo vai ensinar? Eu tenho que fazer alguma coisa". O pai botou ele para fora, aí eu fiquei do lado de fora, mas quando o pai dormiu, eu fui buscar ele. (...) Ele continuava com pessoas da pesada mesmo, e eu ia lá, enfrentava, buscava, dizia a eles que eu não tinha nada a ver com a vida deles, mas eu queria o meu filho. Eu queria que ele estudasse. (...) E aí eu fui à luta, fui. (...) Às vezes ficava com vontade de desistir, não vou dizer que não dava, porque dava. Aí depois eu me sentia mal, "eu vou desistir, eu não vou suportar tudo isso. Eu não vou suportar ele assaltar um pai de família. Eu não vou aceitar ele matar alguém". (mãe de adolescente em serviço de saúde) 
De forma geral, os entrevistados comentam os seguintes efeitos do crack: a magreza, a quebra dos laços com a família e os amigos, a saída da escola e o desinteresse pelos estudos, a dificuldade de orientação, a perda do trabalho - ou o envolvimento em funções que exijam menos qualificação e atenção -, a perda dos sonhos e das perspectivas de vida, a baixa autoestima e a desmotivação, o envolvimento em atos infracionais (furtos em casa ou fora e roubos), a vivência de rua e a morte. As situações de violência do tráfico e da polícia são também muito citadas e associadas à vivência dos usuários de drogas.

Três adolescentes em SAI já tinham sido detidos pela polícia após começarem a consumir crack, em decorrência de roubos, vivência na rua, ausência de documentos e de estarem pedindo dinheiro nas ruas. Importante também é o efeito do crack em bebês gerados por adolescentes usuárias da droga.

Além disso, os problemas de saúde são bastante comentados pelos entrevistados, entre os quais estão: tuberculose, desnutrição, desidratação, HIV/Aids e outras doenças sexualmente transmissíveis. É grande o prejuízo do crack na saúde dos usuários: $60 \%$ dos adolescentes usuários e acolhidos no SAI consideram sua saúde ruim, os demais se alternam entre saúde boa ou muito boa. Três adolescentes relatam: hepatite $B$, problemas respiratórios, cansaço e dor no peito, problemas que perduravam entre um mês e um ano. Todos os três buscaram atendimento em saúde para essas dificuldades.

Os gestores dos serviços de saúde discordam da noção comum na sociedade de que é inevitável sucumbir ao crack: alguns usuários conseguem manter controle sobre o consumo a partir de determinado momento, sendo capazes de manter vínculos. Há também usuários de outras substâncias psicoativas que consomem o crack, sem fazer vínculo com a droga e, portanto, não repetem a experiência. Encontram-se ainda aqueles que conseguem usar uma ou duas pedras por dia, sem causar maior desorganização familiar e social.

\section{Funcionamento dos SeRVIÇOS de ASSISTÊnCIA SOCIAL, DE SAÚdE MENTAL E DA JUSTIÇA}

Não consigo pensar em clínica despolitizada. Não acredito em clínica sem as condições mínimas estruturais. A gente não deixa de trabalhar por conta disso, mas há um impacto enorme no serviço.

(gestor de Caps ad III)

O papel dos serviços relaciona-se com a sua função na rede, em geral, a de proteção ou atenção. Contudo, uns desconhecem o seu potencial de atuação, 
outros não depositam confiança no trabalho. Há ainda aqueles, especialmente os ligados à saúde, que se destacam pela criatividade e competência técnica na atenção aos usuários.

Em relação ao Conselho Tutelar, observamos que os profissionais têm uma consciência limitada da função, desconhecendo o seu potencial. Consideram a si mesmos, bem como toda a rede de serviços, ineficientes no enfrentamento do uso de crack pela criança/adolescente. Um conselheiro tutelar informa que o papel do seu serviço é exclusivamente "conversar" com os usuários e indicarIhes as unidades da rede, especialmente o Caps e o Cras, para que possam ter um acompanhamento psicológico.

O Conselho Tutelar não tem uma forma de atuar no combate a isso. Que forma seria essa se não da gente trazer, levar; e traz aqui e aconselha e tenta conversar. É o que gente faz muito. Eu sento aqui e converso, converso, converso. Mas se ele não está a fim... Eu já atendi dois casos em que uma mãe pegou o filho de 14 anos, usuário, e o que ela fez foi amarrar ele. Ela me disse. Ele vai voltar. Ela não queria a rede que nós temos. Essa rede municipal que nós temos que é uma rede fragilizada, ela não queria. Não tinha como bancar um centro de recuperação particular. E a solução (...), foi assim que a mãe me disse: "então eu vou continuar mantendo ele na corrente e no cadeado".

A visão distorcida de que o usuário é o único responsável pela sua saída das drogas permeia a atuação relatada pelo conselheiro, depositando na criança ou no adolescente o sucesso ou o fracasso do tratamento:

A gente sabe muito bem que vai depender da vontade do jovem, da criança de querer ou não deixar. (...) A saída do jovem das drogas não tem a ver com a rede, nem com a gente. Tem muito a ver com essa demanda do jovem. Com essa decisão dele.

Na 2a Vara da Infância e Juventude, quando o adolescente se declara usuário de qualquer substância psicoativa, especialmente crack, é aplicada de imediato uma remissão acumulada com alguma medida socioeducativa e protetiva, no caso para o Caps ad ou Caps ad III, Cras ou Cetad. Depois a própria unidade de execução da medida faz o acompanhamento. Mas, se o processo ainda está tramitando, o encaminhamento é feito para a equipe técnica interprofissional.

Na assistência social, a abordagem social é a principal atuação, acompanhando especialmente os casos mais crônicos, buscando a resolução de necessidades imediatas de pessoas em vulnerabilidade social e promovendo a 
sua inserção na rede de serviços socioassistenciais e nas demais políticas públicas na perspectiva da garantia dos direitos.

Em relação aos SAls, toda a atenção ao uso de droga é feita fora da unidade, especialmente pelo Caps ad, parecendo não haver um preparo da equipe do SAI para lidar com esta questão. Os gestores relatam o despreparo das unidades e das equipes destes serviços para receber adolescentes usuários. Comentam haver uma alta taxa de evasão dos serviços ou recusa dos mesmos para acolher adolescentes com esse perfil. Muitas vezes os adolescentes em SAI fazem uso de drogas nos passeios que realizam, deixando a equipe insegura e sem saber como agir. Nesses serviços todo trabalho é feito com a criança ou o adolescente, e não com a família.

Já em relação aos dois serviços de saúde visitados, há um rico detalhamento técnico na atenção à população em foco. O papel do atendimento propriamente dito é ligeiramente semelhante nas duas instituições, com atendimentos ambulatoriais, estratégias grupais e realização de oficinas terapêuticas (cinema, fotografia, música, teatro e a da palavra). A divergência da atuação decorre principalmente da inserção de cada serviço na rede assistencial municipal e estadual.

O gestor do Caps ad III descreve o papel do seu serviço em duas linhas de atuação: 1) visita domiciliar; prevenção e atuação no território, feito em escolas; matriciamento das equipes de Saúde da Família; trabalho junto ao Núcleos de Apoio à Saúde das Famílias (Nasf); contato com lideranças comunitárias; articulações com dispositivos comunitários de geração de renda; núcleos esportivos e culturais; 2) trabalho intramuros; atenção biopsicossocial em saúde, por meio de atendimentos psicológicos, médicos e de desenvolvimento de oficinas variadas. Na segunda linha de atuação, deve haver leitos de acolhimento noturno, onde as pessoas em situação de crise, ou com necessidade de repouso e observação, tenham a possibilidade de permanecer por um período de dez dias corridos, ou 15 dias intercalados no período de um mês.

O mesmo profissional afirma que o Caps ad III, sobretudo por atender a faixa etária da adolescência, tem como característica ser um espaço de convivência, "uma espécie de redução de danos sociais, de saúde. Eles estão aqui, eles têm um lugar para comer, têm um lugar para tomar banho. Têm um local em que, de alguma forma, fazem menos uso [da droga]".

Contudo, a tônica da fala desse gestor é a falta de estrutura para o funcionamento do seu serviço. Primeiramente, ressalta que, seguindo a lógica de território, não há como atender todo o município de Salvador, com quase três milhões de habitantes, mas apenas o distrito sanitário onde está localizado. 
Destaca também que a falta de estrutura, assim como o excesso de demanda durante o dia - e a pouca à noite -, impossibilitou o funcionamento 24 horas da unidade, razão pela qual optou por encerrar o serviço às 18 horas, recompondo a carga horária da equipe para o turno diurno:

A gente até hoje não tem um local para lavar roupa de cama, o serviço não dispõe de telefone fixo para fazer ligação, o serviço tem um carro, o carro só fica disponível de oito da manhã até quatro e meia da tarde, de segunda a sexta. É um serviço que tem que funcionar 24 horas, todos os dias da semana, sábados, domingos e feriados. A gente passou por situações aqui do usuário impregnar no sábado, não ter como socorrer e a gente ter que levar o usuário em carro próprio. Uma série de situações que não favorecem esse pleno funcionamento. (gestor de Caps ad III)

Profissional de outro serviço de saúde especializado visitado informa que a atenção ao adolescente usuário de crack e outras drogas é realizada principalmente por um grupo de trabalho específico, que, além de ser dirigido para o estudo, é voltado para a criação de serviços e estratégias de intervenção que atinjam a população de adolescentes usuários de substâncias psicoativas em geral. Tem como importante papel articular a rede para a atenção desses pacientes. Entre os serviços integrantes da rede estão o Conselho Tutelar, as associações de bairro, a Fundação da Criança e do Adolescente (Fundac) atendimento socioeducativo - e organizações não governamentais. Há ainda o núcleo de clínica desse serviço que presta assistência propriamente dita, ou seja, tem um serviço aberto à comunidade.

No que se refere à composição das equipes de saúde mental e da área de alta complexidade da Secretaria de Desenvolvimento Social e Combate à Pobreza, quase todos os entrevistados mencionam número insuficiente de profissionais, principalmente em relação à grande demanda para o atendimento, o que se deve não apenas ao número significativo de usuários na cidade, mas sobretudo à escassez de serviços especializados. O resultado, segundo um gestor do serviço de saúde especializado, é a redução no número de atendimentos: "A Prefeitura da cidade de Salvador não conseguiu estruturar os serviços e distribuir serviços de assistência na cidade. O serviço fica com sobrecarga de trabalho, limitando o número de atendimentos".

No serviço de saúde especializado visitado, a equipe é formada por psicólogos, em sua maioria, com especialização em psicanálise, e médicos psiquiatras. Pedagogos, sociólogos, profissionais de teatro e enfermeiros 
participam de outras estratégias que não clínicas, como o Consultório de Rua e as oficinas terapêuticas.

O Caps ad III iniciou o serviço com 67 profissionais e no momento da entrevista contava com 57. A intenção do gestor naquele momento era de retirar do centro mais $30 \%$ dos profissionais, seguindo a ideia de readequá-lo ao modelo de Caps ad II. A falta de estrutura do serviço foi o principal motivo para a saída dos dez primeiros profissionais. A equipe desse Caps é muita diversa, com músico, teatróloga, artista plástico, terapeuta holística, educador físico, neurologista, clínico geral, dois psiquiatras, cinco psicólogos, três assistentes sociais, dois terapeutas ocupacionais, uma oficineira, um antropólogo, técnicos de enfermagem e cinco enfermeiras.

A responsável pela área de alta complexidade da Secretaria de Desenvolvimento Social e Combate à Pobreza informa que não conta com equipe específica para a atenção ao usuário de crack e outras drogas. Apenas 17 profissionais (psicólogos e educadores) são responsáveis pela abordagem social a todas as demandas do município.

A fiscalização dos serviços foi um outro aspecto investigado, observandose a fragilidade e a inexistência dessa ação. Em geral, os serviços informam que a fiscalização ocorre apenas quando há queixa ou denúncia. A principal justificativa para tal é a falta de recursos humanos e a sobrecarga de trabalho. O SAI informa que a fiscalização cabe à Secretaria da Justiça, Direitos Humanos e Desenvolvimento Social, além do Ministério Público, do Juizado da Infância e Juventude e do Conselho Tutelar. Contudo, o último explica que essa ação ocorre apenas quando há necessidade, e o Juizado afirma que o acompanhamento dos serviços não é sistemático.

\title{
MOdALIDADES DE ATENDIMENTO NOS SERVIÇOS DE SAÚDE MENTAL
}

\author{
A rotatividade é muito complicada, muito difícil, \\ até pela própria história \\ de uso de crack, pela inconstância, pela instabilidade. \\ Esses pacientes vêm, desaparecem, voltam. \\ (gestor de serviço de saúde especializado)
}

O atendimento nos serviços de saúde mental começa no acolhimento, quando se buscam informações sobre a demanda do paciente. Nesse momento inicia-se a construção do projeto terapêutico, elaborado com base nas necessidades de 
saúde de cada usuário, sem excluir suas opiniões, seus sonhos, seu projeto de vida. É singular e caracteriza-se por uma interação democrática e horizontal entre profissional, usuário e família. Tem como único propósito o bem-estar dos usuários mediante a reabilitação psicossocial (Benevides et al., 2010).

No Caps ad III o gestor exige que o acolhimento seja feito por um profissional de nível superior, especificamente, psicólogo, assistente social ou terapeuta ocupacional, considerados mais habilitados no manejo da situação.

O mau acolhimento pode resultar num péssimo tratamento. Você pode dar vários tiros no pé, em sequência. Então no entendimento de saúde mental, qualquer pessoa poderia fazer o acolhimento. Aqui eu brigo para que não seja assim. Eu não acho que qualquer profissional está preparado para isso. Tem que ser alguém que tenha uma escuta. (gestor de Caps ad III)

O gestor do outro serviço de saúde tece críticas quanto ao modelo de agendamento de consulta realizado na sua unidade no momento do acolhimento, feito de uma semana para a outra. Para ele, há necessidade do acolhimento diário de pacientes, com equipes organizadas nos diversos turnos, recebendo pacientes que chegam ao serviço sem agendamento prévio, e com equipes que prestem atendimento emergencial:

Para o tratamento do crack, para o acolhimento do usuário de crack, nós temos avaliado criticamente que esse modelo de acolhimento, esse modelo de admissão no serviço, dificulta sobremaneira o acesso da população ao serviço. Nós teríamos que ter um serviço porta aberta, em que, no momento em que uma família ou um usuário chegasse, ele tivesse a possibilidade de um atendimento e encaminhamento imediato. (gestor de serviço de saúde especializado)

Após o acolhimento, o Caps ad III agenda um outro momento, iniciandose a construção do projeto terapêutico singular, em que se busca conciliar as necessidades e os interesses do sujeito com as estratégias do serviço e o que pode ser trabalhado fora do serviço. Das estratégias ofertadas neste serviço constam: acompanhamento individual por um técnico de referência (pessoa encarregada pela gestão do caso no serviço), atendimento médico, psicoterápico, psiquiátrico ou acompanhamento com um profissional que faz práticas integrativas (acupuntura, reflexologia podal, cromoterapia), além da participação em grupos terapêuticos, grupos de família e oficinas. Há diversas oficinas, entre elas, música, banda, expressão corporal, futebol, palavra, autocuidado, sobre a 
relação entre drogas, tráfico e violência e de redução de danos. Como exemplos de ações externas, tem-se o direcionamento para acolhimento institucional, a inserção na escola ou em outros grupos e a promoção do contato com a família.

Contudo, o gestor do Caps ad III alerta que, uma vez que este serviço foi originalmente criado para atender crianças e adolescentes e passou a incluir a clientela adulta, há necessidade de constantes ajustes na atenção oferecida: "A gente está tentando o tempo todo readequar o que a gente oferece. A gente tem um monte de oferta que às vezes não desperta interesse na população que a gente atende".

No outro serviço de saúde especializado pesquisado, depois do acolhimento, na maioria das vezes, ocorre o encaminhamento para o grupo de adolescentes e para o atendimento pelos profissionais de um grupo de trabalho específico.

Ambos os gestores de saúde mental entrevistados ressaltam o valor de outras estratégias, que não a individual, para a atenção ao usuário de crack e outras drogas. As oficinas, por exemplo, têm característica mais aberta, não exigindo tanto da linguagem e do investimento subjetivo:

A linguagem do usuário de drogas, às vezes, está muito comprometida, ou seja, a droga ocupa uma dimensão tão gigantesca na vida subjetiva desses indivíduos que é necessário, muitas vezes, a gente criar outras estratégias, estratégias grupais, para fazer com que esse objeto droga seja deslocado e que surja no lugar da droga a subjetividade, a palavra, ou seja, o sintoma propriamente dito. (gestor de serviço de saúde especializado)

Outro ponto importante é a necessidade do atendimento psiquiátrico na atenção ao usuário desde a chegada ao serviço, pois há necessidade de identificar aqueles que, por causa do uso da droga, estão desenvolvendo problemas psiquiátricos (por exemplo, as síndromes de abstinência ou psicoses induzidas) ou que estão com quadros de dependência, e que também apresentam comorbidade com outras patologias psiquiátricas. $\mathrm{O}$ atendimento psiquiátrico é determinante na melhor evolução do paciente:

Nos últimos 15 anos, é inegável a contribuição que as neurociências trouxeram para a compreensão desse fenômeno. (...) Entendemos que, quando existe a comorbidade, quando existe uma patologia psiquiátrica, ao lado da dependência química, não basta apenas tratar a dependência, a gente tem que tratar a patologia (...). Quando a gente falha no acolhimento, nessa admissão, se a gente 
falha nessa detecção, nessa identificação de uma patologia ou de uma repercussão psiquiátrica mais severa, certamente a gente vai ter um maior prejuízo, uma maior dificuldade de fazer com que esse paciente tenha uma adesão ao tratamento. (gestor de serviço especializado de saúde)

$\mathrm{O}$ atendimento familiar também é ressaltado, especialmente nos casos mais graves, já que muitas vezes o paciente se recusa a ir ao serviço. Dessa forma, o tratamento é iniciado com a família a fim de que o usuário consiga chegar à unidade.

Em geral, as modalidades de atendimento oferecidas pelo Caps e pelo Cetad constituem um universo de práticas destinado a dar suporte ao paciente em crise, envolvendo não só o tratamento clínico, mas uma compreensão da situação que o circunda, com intervenções cujo objetivo é assegurar sua reinserção no contexto social e familiar. Propõe-se um cuidado que tem como premissas a integralidade da atenção e a humanização da assistência. O foco da atenção desses serviços é a redução de danos:

A gente não tem esse objetivo de cura e nem entende que cura é abstinência. O trabalho da gente é potencializar o que chamamos de qualidade de vida, aumentar qualidade de vida para as pessoas que frequentam o serviço. Para isso a gente não foca no crack, nem no crack nem em qualquer substância, e sim no sujeito. A gente quer trabalhar o sujeito nas relações dele com o mundo e com a droga também. (gestor de Caps ad III)

Uma questão delicada que ocorre durante o tratamento, especialmente no Caps, é o consumo de drogas pelo usuário dentro do serviço. O gestor do Caps ad III afirma que sua proposta é reduzir danos para crack e lembra que o uso fora da instituição expõe o usuário a ainda mais riscos. Nessa estratégia, muitos usam a maconha, contudo, o gestor relata que esse consumo é sempre delicado, requer diálogo e pactuações.

Do ponto de vista técnico, se houvesse qualquer brecha na lei, eu autorizaria isso sem dúvida. E trabalharia isso aqui dentro. Fazia um espaço de uso seguro que discutiria esse uso, para que ele pudesse fumar e fosse de fato um redutor de danos. Porque, ao mesmo tempo, que a gente reconhece que isso serve como redução de danos, eu estou colocando ele para fora porque ele vai querer fumar lá fora. Eu coloco ele lá fora, ele está correndo outros riscos de usar droga. Isso tem dado vários posicionamentos para a gente. Por exemplo, estabelecer normas para uso aqui dentro e no caso de transgressão 
da norma há suspensão. Tivemos algumas suspensões. Só que a suspensão não tem produzido um sentido terapêutico. (...) A gente tem tentado resolver essa situação assim sempre através do diálogo. E tentado afirmar com esses jovens um compromisso ético com o serviço, com as responsabilidades com o serviço também, mas que nem sempre isso é possível. (gestor de Caps ad III)

Vale ressaltar ainda que, embora o crack seja considerado a droga da moda, um dos serviços de saúde pesquisados informa que a demanda para o atendimento do usuário de álcool também é bem grande, igualando-se à necessidade da atenção dispensada aos usuários de crack.

O álcool é uma coisa muito pouco falada. A gente tem a estimativa de dependência ao álcool no país em torno de $12 \%$. Não existem serviços estruturados, os programas Saúde da Família, a atenção básica, os hospitais gerais, quando atendem, atendem muito mal, de uma forma muito ruim, muito moralista com os dependentes de álcool. (gestor de serviço de saúde especializado)

\section{A visão dos usuários de crack e suas famílias em relação aos serviços recebidos}

Em geral, a avaliação dos adolescentes e familiares usuários de crack inseridos nos serviços é positiva. São comentados o apoio, a disponibilidade para ajudar e a qualidade dos atendimentos recebidos. Entretanto, os entrevistados fazem algumas críticas e recomendações:

1) Falta de capacitação das equipes dos serviços básicos de saúde não especializados: "Já foi no posto de saúde e só deram soro" (familiar de adolescente em SAI).

2) Necessidade de melhorar a qualidade do tratamento para os usuários em abstinência:

O tratamento para a abstinência é que deveria ser mais avançado porque aqui eles dão muito o tratamento para quem está usando, para os usuários no momento; para a galera que quer ficar em abstinência tem poucos recursos, poucas atividades. Então você acaba decaindo e voltando tudo de novo para o uso de drogas. (adolescente em serviço de saúde)

3) Nas comunidades terapêuticas, os usuários ficam "trancados" e a orientação religiosa se sobrepõe ao tratamento médico e psicológico: 
[Nas Comunidades Terapêuticas] é aquela coisa, é mais pela fé. Você não pode tomar as medicações. Se você tem uma crise de abstinência, eles falam que é coisa do demônio. Então aquilo ali vai afetando. Quem sabe numa crise de abstinência dessa você pode ter uma parada cardíaca e morrer. Já aqui [Caps ad III] você tem o auxílio de vários profissionais que te assistem o dia todo. Se você sentir uma dor no peito ou uma tontura, tem pessoas aqui capazes para te reanimar. Até problemas psicológicos mesmo, tem pessoas aqui que podem te ajudar. Esse serviço aqui, graças a Deus, eu posso contar com ele. (adolescente em serviço de saúde)

Mas a experiência da nossa vida está nas ruas. Você pode ficar fechado lá [Comunidade Terapêutica] um ano, vai sair de lá e se deparar com o mundo cá fora; está despreparado para o mundo cá fora. Aí volta ao uso novamente; às vezes é duas vezes pior. (adolescente em serviço de saúde)

4) Nos SAls os adolescentes ficam "presos" e não há tratamento específico para usuários de crack.

Aqui é coação, é agonia; dá agonia ficar preso. Sai de noite, eu sei que tem várias atividades boas, mas dá agonia, porque faz abstinência. Não estou com o remédio, estou sem o remédio. Dá agonia. Dá vontade de ir embora. No Caps não, o Caps é alívio, dá para fumar um cigarro, dá para fumar um pacaia [tipo de cigarro]. Eu não queria usar a droga lá dentro. Mas no Caps eu fico mais à vontade. (adolescente em SAI)

5) Falta de atendimento nos serviços especializados nos fins de semana e à noite, sem haver até mesmo um local para dormir.

\section{O que pode ajudar a superar o problema do crack em crianças e adolescentes?}

Os adolescentes e familiares definem o que seria importante encontrar nos serviços de atendimento para a recuperação do usuário: profissionais em número suficiente capacitados na especificidade do crack para dar apoio aos usuários, considerando a grande demanda; serviço 24 horas que ofereça local para dormir, comer, tomar banho e outros cuidados de higiene:

Funcionamento 24 horas. Tem muitas pessoas aqui que moram na rua. Então não adianta você estar aqui o dia todo se tratando e à noite, depois do fechamento aqui, você ir para rua, dormir na rua. Aí 
você vai estar aberto à possessão duas vezes mais, porque é na noite que acontecem as coisas, pra você conseguir lidar com esse frio da noite, o medo da violência; ou está chapadão de cachaça, ou doidão de crack, ou doidão de maconha. (adolescente em serviço de saúde)

São mencionadas também atividades esportivas como jiu-jítsu e boxe, de canto e dança: "Quando estou treinando, eu nem imagino o uso de drogas. Libera adrenalina para o cérebro, que você não está nem aí, você não sabe nem que a droga existe". (adolescente em serviço de saúde).

Além do incremento dos serviços na atenção ao usuário de crack, outros pontos são lembrados pelos adolescentes e familiares para a superação do problema. A postura proativa da família é um deles. Uma mãe, cujo filho está recuperado das drogas, comenta que chegou a sair do trabalho para vigiá-lo.

Quando eu cheguei [ao serviço] eu disse à psicóloga que eu era 24 horas. "Mas como é que você consegue ser 24 horas?". Eu levava para a escola, eu ia buscar. Ele já está grandinho, ele já estava com 15 anos. Eu levava ele na escola, a escola era distante. Eu ia com ele. Eu dizia à diretora: "só solte ele quando eu chegar aqui. Mesmo que eu chegue de noite. Só sai daqui comigo". Todos os dias eu fazia isso! Todos os dias ele aprontava. (familiar de adolescente em serviço de saúde)

O uso de medicações e a realização de curso especializado são outros aspectos considerados importantes para a recuperação. Um adolescente ressalta a "força de vontade" do usuário para superar o problema:

Eu acho que a força de vontade do usuário não está no psicólogo, não está na assistente social, está dentro do próprio usuário. A vontade de vencer, a força, se tornar verdadeiros guerreiros contra eles mesmos, que é a maior batalha que a gente trava. Contra nós mesmos. (adolescente em serviço de saúde)

Ribeiro e Laranjeira (2012) alertam que as terapias e abordagens de natureza biológica, psicológica e social não atuam de maneira isolada no tratamento do uso de crack e outras drogas. Pelo contrário, influenciam-se mutuamente e podem se potencializar quando aplicadas de forma harmônica. 


\section{A REDE DE ATENÇÃo Às CRIANÇAS, AdolesCENTES E FAMílIAS USUÁRIAS DE CRACK E OUTRAS DROGAS}

Eu acho que tem uma característica de Salvador que é muito interessante. A gente tem equipe de excelência em Salvador. Não é à toa, que o Consultório de Rua nasce em Salvador e vai para o Brasil. Eu acho que o potencial humano nós temos. A gente não consegue ter uma estrutura física boa, a gente não consegue ter, evidentemente, um número de pessoas adequado para trabalhar,

faltam recursos. Isso que impede a rede. (...) Associado a isso estão as vaidades dos serviços.

(gestora da Secretaria de Desenvolvimento Social e Combate à Pobreza)

Para entendermos o funcionamento da rede de atenção à criança e ao adolescente usuário de crack e outras drogas, é necessário observar a articulação existente entre os diferentes atores que dela participam. Lembramos que "articulação" é um dos nortes do Estatuto da Criança e do Adolescente para a política de atendimento a essa clientela, na medida em que, para obter a proteção integral aos direitos e interesses infantojuvenis, faz-se necessária uma ação conjunta e coordenada, tanto do Poder Público quanto da sociedade civil organizada e das entidades que a representem (Digiácomo \& Digiácomo, 2010).

Desse modo, indagamos aos SAls o tipo de articulação estabelecida com diversos serviços, entre os quais estão o Conselho Tutelar, o Poder Judiciário, o Ministério Público, a Secretaria de Desenvolvimento Social e Combate à Pobreza e os serviços de saúde mental. Vale ressaltar que, em relação a tal questão, apenas quatro unidades visitadas acolhiam adolescentes usuários de crack e foram capazes de dar essa informação. Verificamos que o Conselho Tutelar, o Poder Judiciário e o Ministério Público são as instituições com maior articulação com os SAls. Escolas, Caps i e o Cras também são bastante mencionados. Entre as ações mais referidas pelos serviços estão: ter dados de localização, realizar troca de informações e efetuar encaminhamentos. Interessante perceber que o Creas, a Defensoria Pública, os serviços de saúde mental em geral, os demais serviços de saúde e o Caps são apontados como tendo pouca articulação com os SAls.

O Conselho Tutelar é o órgão que mais realizou encaminhamentos de crianças e adolescentes para os SAls (51,9\%), em seguida vem o Poder Judiciário $(29,6 \%)$. Com frequência bem menor, estão o Ministério Público e outros SAls (3,7\% cada). Casos excepcionais decorrem de encaminhamentos feitos 
por uma maternidade que acionou o serviço em decorrência do abandono de bebê pela mãe, moradora de rua, e do pedido de acolhimento feito pela própria adolescente. Em alguns casos notou-se a conjunção de órgãos realizando o encaminhamento, agregando Ministério Público, Conselho Tutelar e Poder Judiciário.

Todos os entrevistados falam com muita indignação sobre a inexistência da rede de atenção à criança e ao adolescente usuário de crack, responsabilizando a gestão pública pela ausência de organização e sistematização da política pública na cidade. A gestora da Secretaria de Desenvolvimento Social e Combate à Pobreza comenta que "existe a rede de pessoas, mas não a de serviços". A fragilidade da articulação entre os serviços é ressaltada:

O que a gente vê quando está diante desses meninos é que existe uma lacuna. A chegada do menino no serviço de acolhimento e a ida do menino para o atendimento na área de saúde. As dificuldades nossas da assistência em conseguir articular, em conseguir ter carro, em conseguir ter o técnico para fazer o diagnóstico, até você conseguir acordar para isso também. O cara é atendido no nosso serviço de emergência. E aí, esse vácuo, muitas vezes, o menino evade (...). Se você não tem todo um serviço completo, todo um círculo fechado, você vai estar falando de uma coisa que não vai funcionar (...). Se não tiver definida a questão de como vai ficar o acolhimento, não adianta você ficar falando de abordagem. Porque você vai ficar falando de abordagem; você leva e o menino fala: "tá tia, eu vou". Vai para onde? (gestora da Secretaria de Desenvolvimento Social e Combate à Pobreza)

A administração pública do município é apontada como um dos principais impeditivos para a organização dos serviços e contratação de profissionais. A extensão territorial também é lembrada como fator que dificulta a regulação da rede:

É impressionante como até nas cidades do interior, e quanto menor é o interior, maior eu vejo isso, como as pessoas conseguem construir uma rede social, e abarcar e acolher (...). Mas, em grande centros urbanos, eles estão fora, eles estão à margem de qualquer possibilidade de acolhimento e de acesso. (gestor de serviço especializado de saúde)

Cada estado deve fazer isso de uma forma muito planejada. Aqui no estado da Bahia a gente não consegue no âmbito da Secretaria da Saúde ter uma equipe pensante para executar uma política estadual. 
Mais recentemente, assim com muita felicidade, o governador criou a Suprad, uma superintendência de apoio aos usuários de substâncias psicoativas e a seus familiares na Secretaria da Justiça. É a Secretaria da Justiça que está puxando a Secretaria da Saúde. E eu acho isso, ao mesmo tempo importante, mas vejo isso como um atraso. (...) Nós precisamos de fato construir essa rede. (...) Porque eu posso prestar a melhor assistência psiquiátrica e psicoterápica aqui, mas eu não tenho uma retaguarda lá fora que dê sustentação a esse usuário tão fragilizado, tão difícil e que requer, infelizmente, esforços de outros setores da sociedade. (gestor de serviço de saúde especializado)

Nas entrevistas com os atores dos serviços, prevalecem as críticas em relação à rede. O Conselho Tutelar é tido como o mais difícil de trabalhar. Na fala de profissionais deste serviço, é destacado o mau funcionamento de toda a rede de Salvador, generalizando-se as suas dificuldades para o estado e o país. Entre os serviços pesquisados, o SAI é o único que comenta boa articulação com os demais.

Em relação à área da saúde, a crítica dos outros serviços pesquisados recai: 1) no precário atendimento de emergência; 2) na recusa para a internação dos usuários nos hospitais gerais; 3 ) na precária qualidade do atendimento oferecido ao usuário de drogas; 4) na burocracia da gestão pública; 5) na falta do envio para o Juizado de relatório técnico das crianças e adolescentes em cumprimento da medida protetiva; 6) na inexistência de um processo de internação com funcionamento 24 horas; 7) na dificuldade de acesso do Caps ad III, que fica distante do centro da cidade, exigindo transporte para locomoção dos usuários:

Tem os leitos agora para os hospitais gerais. Mas o menino vem em crise, eles dão um sossega leão e tchau. Um problema é você conseguir acessar os hospitais gerais. O outro problema é como você fazer também o transporte desses meninos nesses momentos. Salvador só tem o Samu. A população aciona o Samu para qualquer coisa e muitas vezes o Samu sai para um serviço que não deveria ser dele (...). O médico também lá não dá atenção ao que a gente diz, e fala que não é caso para ele. E não vão! (...) Aqui tem um problema, os hospitais continuam com administração do estado, apesar de ser gestão plena, não foram municipalizados. Isso é muito difícil. (gestora da Secretaria de Desenvolvimento Social e Combate à Pobreza)

Eu sinto muita preocupação no sentido da profundidade [do atendimento Caps ad]. Eu acho que o usuário que está aqui hoje, 
ele precisa de uma atenção específica, especial. O trabalho do Caps é superficial. Acho que ele precisa de outra estrutura, de algo mais profundo, algo mais elaborado para tratar dessa questão do usuário (...) Uma resposta mais imediata, mais profunda, de impacto agora. (gestor de SAI)

Os próprios serviços de saúde mental de Salvador demonstram grande insatisfação com o reduzido número de Caps ad na cidade, principalmente ao se considerar a existência de quase três milhões de habitantes residentes no município, o que geraria uma estimativa de $9-10 \%$ da população com problemas relativos ao uso de drogas. O número pequeno de crianças e adolescentes usuários de drogas que procuram o serviço também parece ser reflexo do mau funcionamento da rede:

Nos primeiros meses de funcionamento [do serviço] a procura que chegava não era criança e adolescente, era adulto. Fomos encaminhando, encaminhando, encaminhando, e a gente viu que o público de crianças e adolescentes também tem essa especificidade, eles não demandam espontaneamente o tratamento. A maioria não demanda. Tem que haver o cruzamento de vários fatores para garantir essa questão, que não é só ordem judicial. Ocorrências em aplicação de ação de alguém que vai assumir a tutela, ou a própria família, ou o Conselho Tutelar. Tem que haver um local de abrigamento, tem que haver outras estratégias que não são nossas aqui, que é a interseção com a educação, que é de geração de renda. (gestor de Caps ad III)

Percebe-se também o preconceito dos próprios profissionais de saúde mental no atendimento aos usuários de drogas, o que contribui para a precária atenção. Segundo um gestor de serviço especializado na atenção de drogas psicoativas de Salvador:

Quem trabalha com saúde mental, na maioria das vezes, não gosta de lidar com usuário de drogas. O mesmo profissional que é capaz de prestar um super atendimento aos portadores de esquizofrenia é capaz de maltratar um usuário de drogas, porque muitas vezes por um viés moral, moralista, não compreende aquilo como adoecimento psíquico, como um sofrimento. Então assim, eles são muito maltratados. (...) Muitas vezes a gente pede uma internação num hospital ou num serviço especializado de psiquiatria e eles não internam, não prestam sequer o atendimento de forma adequada na emergência porque se trata de drogadicto. 
Na área de assistência social, a crítica dos serviços pesquisados têm como alvo o reduzido número de profissionais diante da grande demanda e a desestruturação do Creas. É mencionado, por exemplo, que alguns Cras não fazem acompanhamento psicológico nem enviam relatório técnico das crianças e adolescentes em cumprimento da medida protetiva ao Juizado. A gestora entrevistada da assistência social acrescenta que o primeiro passo para enfrentar o problema do crack e da população de rua deveria ser o investimento da assistência da proteção básica, ou seja, aumentar o número de Cras e melhorar a estruturação e qualificação desse serviço:

Eu digo que falta, porque faltam postos de saúde, falta escola, falta ação da assistência, falta programa habitacional, não dá para as pessoas ficarem morando do jeito que moram. As casas são do tamanho dessa sala. E aí moram oito, dez, e o menino que foi para o meio da rua porque apanhava: (...) "meu pai me bate, porque ele é ruim". Você chega na casa e pergunta como eles dormem. Bota tudo no colchão que chega até a porta. Aí conversando com ele [pai]: "Mas ele falou que o senhor bate nele". "Poxa, minha senhora, um homem, um menino desse tamanho todo dia mijar na cama, acordar todo dia mijado!" O menino não tinha onde fazer xixi, o menino não tinha nem como sair da casa. (gestora da Secretaria de Desenvolvimento Social e Combate à Pobreza)

A mesma gestora, contudo, lembra que a saúde está na frente da assistência, principalmente porque o plano de combate vem com recurso para a saúde. Essa profissional se posiciona a favor da criação de espaços diferenciados para atender a população usuária de crack:

Por mais que a saúde reclame que o recurso é pouco, a gente não tem nenhum. A gente entende que não dá para ter os abrigos que já existem na rede. A gente está falando de pessoas que precisam de um cuidado diferenciado. Não é que a gente vá fazer exclusão, separar, "olha os meninos do crack!". Mas os meninos, se a gente colocar dentro das estruturas que a gente tem, pode ser que a gente perca muito mais os meninos do que ganhe. (gestora da assistência social)

No que se refere ao SAI, as críticas recaem no baixíssimo número de vagas para acolher a população em foco e na orientação religiosa de muitos desses serviços, o que contribui para o mau atendimento e a fuga dos adolescentes das unidades. Além disso, a maioria dos SAls não quer receber esse tipo de clientela. 
A área da educação parece estar ainda mais distante no cuidado dessa parcela da população, tendo pouquíssima articulação com os serviços da rede.

A fragilidade da organização da rede no cuidado a criança e adolescente usuário de crack se reflete nos depoimentos dos adolescentes do SAI e de seus familiares. Antes de serem acolhidos nas instituições em que foi feita a pesquisa, dois adolescentes haviam passado por Caps ad e internação devido à dependência, e outro por Comunidade Terapêutica. Ambos negaram ter tido acesso a outros serviços da rede.

No contato com os adolescentes e suas famílias, constata-se que a chegada dos usuários ao serviço de saúde e ao SAI se deu na maioria dos casos pela demanda espontânea da família. Contudo, a permanência no serviço é repleta de recuos, seja pela falta de capacitação das equipes, seja pela dificuldade do usuário na adesão ao tratamento. Muitos entrevistados comentam a peregrinação até a chegada ao serviço em que se encontram. Há casos em que a família já tinha passado pela polícia, pelo Conselho Tutelar, pela delegacia, Ministério Público. Em outros, a entrada no serviço especializado se deu via hospital geral, e alguns ainda comentam que já passaram pelas Comunidades Terapêuticas.

Em relação à organização da rede na atenção de crianças e adolescentes usuários de crack e outras drogas, é importante ressaltar as críticas de boa parte dos serviços pesquisados ao investimento público nas Comunidades Terapêuticas. Todos questionam a qualidade do atendimento prestado nesse tipo de serviço e consideram que não deveriam integrar a rede de serviços da cidade. O Juizado explica que as Comunidades Terapêuticas não são credenciadas pela justiça porque não apresentam uma estrutura técnica. Para o Juizado, a Secretaria Estadual de Saúde deveria acompanhar e catalogar as instituições e os casos atendidos para incorporá-las à rede no futuro dependendo da qualidade do atendimento.

Associado a isso, um serviço especializado afirma ser totalmente contrário às ações desenvolvidas pelo governo federal para o enfrentamento do uso de crack, entre as quais estão: 1) o investimento de recursos financeiros ligados ao SUS para a manutenção de Comunidades Terapêuticas; 2) a internação compulsória de crianças e adolescentes usuários de crack; 3) o controle da gestão, já que esse atendimento é de responsabilidade do município:

Isso me cheira muito mal [recolhimento compulsório]. É uma prática higienista de pegar essa população que não tem recursos. E não é só que não tem recursos subjetivos, que não tem recurso algum e colocar 
em Comunidades Terapêuticas que abarcarão uma grande soma do erário público. (...) Então o que a gente observa é um Estado brasileiro que não consegue construir uma rede competente, com gente competente para atender aos usuários e para devolver a esses usuários à sociedade, mas de uma forma integralizada, com habitação, com educação, com assistência social, com tudo. Não consegue, e aí numa tentativa exasperada de resolver um problema que está ficando feio, aí começam a lançar ideias que lembram a stultifera navis, ou seja, a nau dos insanos. Ou seja, aquilo que incomoda, que perturba, que suja, você pega e coloca dentro de naus e deixa dentro de rios à deriva (...). Para mim, a gente se aproxima muito desta prática perversa porque o que falta nesses usuários é muito mais. Eles têm buracos imensos e obviamente a droga, com a força que o crack tem, tem a potencialidade de ocupar, em termos subjetivos, todos esses espaços, que resultam em muita dor, em muita dor, em pobreza, violência. (gestor de serviço especializado de saúde)

\section{Atividades realizadas pelas crianças, adolescentes e suas famílias na rede}

Com a intenção de compreender melhor a oferta de serviços às crianças, adolescentes e suas famílias usuárias de crack, perguntamos aos quatro SAls que tinham acolhidos usuários de crack sobre as atividades que esta clientela frequentava regularmente. Constatamos que o atendimento médico e a orientação sexual ocorrem em todos os serviços. Atendimento psicológico/ psiquiátrico, atividades religiosas, esportivas e culturais e aquelas desenvolvidas com a comunidade foram mencionados por três serviços. Foram menos relatados o atendimento às dificuldades de aprendizagem e às pessoas com deficiências, o tratamento para dependência química, os cursos de capacitação, o encaminhamento para trabalho, a inserção em programas de trabalho protegido e os grupos de ajuda mútua.

Similarmente, indagamos às mesmas unidades quais serviços eram oferecidos às famílias das crianças ou dos adolescentes usuários de crack. O acompanhamento social foi a atividade mais comentada (realizadas em três SAls). Outras ações mencionadas por apenas um serviço foram: tratamento de dependência química, orientação para planejamento familiar, encaminhamento para grupos de ajuda mútua, atendimento psicológico/psiquiátrico, atendimento médico e assistência jurídica. 
Os adolescentes entrevistados do SAI comentaram que não frequentam nenhum serviço de saúde, apesar de consumirem crack há mais de um ano e terem vontade de ser tratados. Nesse sentido, é indispensável que os serviços de acolhimento e de saúde discutam fluxos de trabalho para a atenção qualificada dessas crianças e adolescentes, estando ou não em serviço de acolhimento. São bem-vindos estudos de análise da rotina de atendimento, para que sirvam como instrumento na construção de uma melhor forma de receber e tratar os usuários de crack, buscando afinar a atenção, melhorar o prognóstico e consequentemente reduzir os danos (Silva et al., 2008).

\section{DESAFIOS DA ATENÇÃO E RECOMENDAÇÕES}

São muitos os desafios mencionados pelos diferentes serviços na atenção à criança, ao adolescente usuário de crack/outras drogas e à sua família. Mas, ouvimos também muitas recomendações, não só dos profissionais entrevistados, mas também dos próprios adolescentes e familiares, que podem servir de pistas para uma melhor readequação dos serviços e da atenção prestada na cidade.

Primeiramente, foi comentada a necessidade de melhorar os serviços da área de proteção e prevenção, como, por exemplo, a reorganização dos Conselhos Tutelares, o aumento do número de Cras e dos serviços de acolhimento e a implantação do Plano de Convivência Familiar e Comunitária.

O município de Salvador não cumpre sua parte. Essa rede de acolhimento é um suporte. Para primeiro ele ter um local onde ficar, e ali os educadores, técnicos, fazerem o encaminhamento desses adolescentes para poder fazer o tratamento de drogadição. (juiz da Vara da Infância e Juventude)

Além disso, há urgente necessidade de implantar estratégias para o incremento e a reorganização da atenção nos serviços de saúde mental de Salvador em relação à problemática do crack, as quais incluem: 1) criação de clínica especializada voltada para a demanda do crack, oferecendo atendimento multidisciplinar com: médicos, psicólogos, psiquiatras, nutricionistas, entre outros profissionais; 2) criação de espaço de acolhimento/internação, mantendo o usuário longe dos locais habituais de convivência; 3) desenvolvimento de um acolhimento mais qualificado e inclusivo; 4) disponibilização de leitos no hospital geral; 4) ampliação de Caps voltado para a atuação no problema; 5) avaliação das estratégias de atendimento realizadas. Além disso, a criação 
de casas de acolhimento transitório, também chamadas Casas do Meio do Caminho são almejadas:

São pessoas que necessitam de atendimento e de acesso com muito mais rapidez. A gente precisa fazer mudanças importantíssimas na maneira como a gente acolhe essas pessoas. Alguma espécie de contato inicial que facilite a vinculação. A organização de serviços que o Ministério da Saúde tem chamado de Unidades Residenciais Terapêuticas Transitórias. Começou em Recife, que é a Casa do Meio do Caminho. Que seriam unidades de saúde que viabilizassem o abrigamento dessas crianças e desses adolescentes, que vivem uma situação de vida extremamente precária, às vezes, sem nenhuma retaguarda social e familiar. (gestor de serviço de saúde especializado)

Seria bastante profícuo se a cidade conseguisse elaborar uma linha de cuidado na atenção ao usuário de crack e outras drogas, que se inicia na prevenção e avança para o atendimento ao usuário e sua família, incluindo o acolhimento, a atenção psicossocial e a articulação entre os diferentes serviços.

Um tema transversal bastante comentado foi a necessidade de capacitação profissional para o trabalho com usuários de drogas, desde os que estão na atenção básica, na saúde da família, os médicos generalistas, as equipes de urgências e emergências dos hospitais, além dos conselhos tutelares e do Juizado.

Isso não está disponível nas formações universitárias. A gente tem agora alguns cursos de especialização que apareceram, mas eles não dão conta da parte prática, por ser teoria da teoria da teoria. A pessoa chega e, quando vê o usuário, sente medo, sente inseguro, sem o manejo terapêutico. Se não se pensar em qualificação, em prática de supervisão institucional. Isso tem que ser por edital do Ministério da Saúde, isso tem que ser obrigatório que a gente tenha uma supervisão clínica, que os profissionais tenham esse acompanhamento. (gestor do Caps ad III)

Os municípios não se interessam, de fato, em meter a mão no bolso e disponibilizar recursos que viabilizem a estruturação dos serviços, a capacitação de equipes. (...) É impressionante quando a gente capacita profissionais dos mais diversos setores, no final da capacitação eles passam a ter uma visão completamente diferente. Nós tivemos uma experiência na capacitação de defensores públicos que antes eles tinham uma atitude, eu diria até muito preconceituosa e estigmatizante. $E$ hoje eles atuam de uma forma muito mais humanizada, olhando o usuário de um outro modo. Não aquele 
usuário que faz uma escolha por uma conduta desviante, mas aquele usuário que, por um engano, por um encontro mal-sucedido estabelece uma forte vinculação com a substância psicoativa. E que aí evolui para um estado de muito sofrimento. (gestor de serviço de saúde especializado)

Por fim, retomando o título deste capítulo, a cidade de Salvador precisa se planejar para construir uma política pública que dê conta da complexidade da temática do crack e das outras drogas, não se detendo apenas em ações pontuais nem assistenciais, mas que englobe sobretudo uma melhor articulação entre os serviços.

\section{REFERÊNCIAS}

ALMEIDA, C. J. S. A Questão dos Meninos(as) de Rua no Brasil e em Salvador: uma análise sócio-histórica e territorial, 2000. Dissertação de Mestrado, Salvador: Universidade Federal da Bahia.

ANDRADE, T. M. et al. The opening of South America's first needle exchange program and an epidemic of crack use in Salvador, Bahia-Brazil. Aids and Behavior, 5(1): 51-64, 2001.

ASSIS, S. G. \& FARIAS, L. O. P. (Orgs.) Levantamento Nacional das Crianças e Adolescentes em Acolhimento Institucional e Familiar. São Paulo: Hucitec, 2013.

BASTOS, F. I. \& BERTONI, N. (Orgs.). Pesquisa Nacional Sobre o Uso de Crack: quem são os usuários de crack e/ou similares do Brasil? Quantos são nas capitais brasileiras? Rio de Janeiro: Icict/Fiocruz, 2014.

BAUS, J.; KUPES, E. \& PIRES, M. Prevalência e fatores de risco relacionados ao uso de drogas entre escolares. Revista de Saúde Pública, 36(1): 40-46, 2002.

BENEVIDES, D. S. et al. Cuidado em saúde mental por meio de grupos terapêuticos de um hospital-dia: perspectivas dos trabalhadores de saúde. Interface - comunicação, saúde e educação, 14(32): 127-138, jan.-mar. 2010.

CARLINI, E. A. et al. I Levantamento Domiciliar Nacional sobre Uso de Drogas Psicotrópicas no Brasil - 2001. Brasília: Secretaria Nacional Antidrogas, Centro Brasileiro de Informações sobre Drogas Psicotrópicas, 2005.

CONSUMO de crack cresce sem controle no Brasil. O Globo. Rio de Janeiro, 6 fev. 2010.

DIGIÁCOMO, M. J. \& DIGIÁCOMO, I. A. Estatuto da Criança e do Adolescente Anotado e Interpretado. Curitiba: Ministério Público do Estado do Paraná. Centro de Apoio Operacional das Promotorias da Criança e do Adolescente, 2010.

DUAILIBI, L. B.; RIBEIRO, M. \& LARANJEIRA, R. Perfil dos usuários de cocaína e crack no Brasil. Cadernos de Saúde Pública, 24(4): 545-557, 2008.

GALDURÓZ, J. C. et al. V Levantamento Nacional sobre o Consumo de Drogas Psicotrópicas entre Estudantes do Ensino Fundamental e Médio da Rede Pública de 
Ensino nas 27 Capitais Brasileiras - 2004. São Paulo: Secretaria Nacional Antidrogas, Cebrid, 2005.

INSTITUTO BRASILEIRO DE GEOGRAFIA E ESTATÍSTICA (IBGE). Projeção Preliminar da População do Brasil, 2000. Disponível em: <www.ibge.gov.br>. Acesso em: 12 dez. 2011.

INSTITUTO BRASILEIRO DE GEOGRAFIA E ESTATÍSTICA (IBGE). Estimativas das Populações Residentes, 2008. Disponível em: <www.ibge.gov.br/home/estatistica/ populacao/estimativa2008>. Acesso em: jun. 2012.

INSTITUTO BRASILEIRO DE GEOGRAFIA E ESTATÍSTICA (IBGE). Censo Demográfico 2010. Rio de Janeiro: IBGE, 2011.

MINISTÉRIO DO DESENVOLVIMENTO SOCIAL E COMBATE À FOME (MDS). Conselho Nacional de Assistência Social. Tipificação Nacional de Serviços Socioassistenciais. Resolução n. 109, 11 nov. 2009. Brasília: MDS, 2009.

OLIVEIRA, L. G. \& NAPPO, S. A. Crack na cidade de São Paulo: acessibilidade, estratégias de mercado e formas de uso. Archives of Clinical Psychiatry, 35(6): 212218, 2008.

RAUPP, L. \& ADORNO, R. Circuitos de uso de crack na região central da cidade de São Paulo (SP, Brasil). Ciência \& Saúde Coletiva, 16(5): 2.613-2.622, 2011.

SANTOS, J. F. O Crack: o grande mal do século XXI, 2011. Monografia, Florianopólis: Universidade Estácio de Sá.

SCHENKER, M. Valores Familiares e Uso Abusivo de Drogas. Rio de Janeiro: Editora Fiocruz, 2008.

SELEGHIM, M. et al. Vínculo familiar de usuários de crack atendidos em uma unidade de emergência psiquiátrica. Revista Latino-Americana de Enfermagem, 19(5): 1-9, set.-out. 2011.

SILVA, R. S. et al. Crack: um olhar sobre a recepção aos usuários de substâncias psicoativas. Vitalle, 20(1): 93-97, 2008. 


\title{
6 \\ O Município do Rio de Janeiro e o Crack
}

\author{
Andrea Machado lannelli \\ Simone Gonçalves de Assis
}

Este capítulo apresenta informações sobre a presença do crack na vida de crianças e adolescentes que moram no município do Rio de Janeiro (RJ), bem como fornece dados de seus pais ou responsáveis também consumidores dessa substância. Aborda ainda a magnitude do uso de crack entre crianças em Serviços de Acolhimento Institucional (SAls) do município, a rede socioassistencial voltada para o atendimento aos usuários da substância e algumas propostas de enfrentamento do problema.

\section{O CRACK E O MUNICÍPIO dO RIO DE JANEIRO}

O Rio de Janeiro é a segunda maior metrópole do Brasil - com 6.320.446 habitantes em 2010 (IBGE, 2013) -, menor apenas que a cidade de São Paulo. Principal destino turístico na América Latina, foi transformada em Patrimônio Cultural da Humanidade em 2012 (Unesco, 2012).

Existe na cidade significativo contingente de habitantes de outros estados, em especial de nordestinos que migraram com intuito de obter melhores condições de vida e de trabalho, especialmente entre 1960 e 1980 (IBGE, 2000). Há também parcela significativa da população que vive na pobreza, em aglomerados urbanos construídos sobre encostas de morros, onde as condições básicas de vida - moradia, saúde, educação e segurança pública - são precárias. Segundo o Censo de 2010, 19,9\% dos domicílios na cidade do Rio de Janeiro encontram-se em favelas (IBGE, 2011). 
No que tange à cocaína, até o início do século XX no Brasil não havia relato sobre abuso e dependência dessa droga. A substância era vendida em farmácias com indicação para laringite e tosse. Entretanto, entre 1910 e 1920, o alvo da preocupação passou a ser o uso não prescrito em cidades como São Paulo e Rio de Janeiro. O país não é um produtor de cocaína, mas faz parte da rota colombiana do tráfico para os Estados Unidos e Europa (Carlini et al., 1995). O crack entrou no Rio de Janeiro apenas nos anos 2000, mais tardiamente se comparado ao município de São Paulo, pois as facções responsáveis pelo tráfico de drogas na cidade recusavam-se a produzi-lo e vendê-lo, optando pela cocaína para ser cheirada ou fumada (Dowdney, 2002).

Com a entrada da cocaína no início dos anos 1980 na cidade, a comercialização de drogas se intensificou sob o poder de traficantes, que se organizavam em facções fortemente armadas que disputavam entre si, com repercussões negativas nas comunidades. Eles passaram a ser figuras constantes nessas localidades, sem respeito aos moradores, atraíam um contingente grande de jovens e criavam um ambiente de elevada vulnerabilidade, especialmente para as crianças (Dowdney, 2002). Tal quadro ainda persiste, acentuado pelo amplo acesso a armas de fogo e a variadas drogas, que chegam à cidade pelas rodovias, portos, aeroportos, e pela falta de rígido controle das forças públicas de segurança (Zaluar, 2007).

A violência na cidade do Rio de Janeiro, caracterizada pela presença de grupos criminosos armados controlando territórios por mais de duas décadas, justificaram a intervenção policial a partir de dezembro de 2007, com a criação das Unidades de Polícia Pacificadora (UPPs). De acordo com documento da Secretaria de Segurança Pública do Estado do Rio de Janeiro, as UPPs objetivam: retomar o controle do Estado sobre as comunidades sob forte influência da criminalidade, devolver à população dessas localidades a paz e o exercício da cidadania e contribuir para desmantelar a guerra. O documento informa ainda que, com a instalação das UPPs, não se obterá o fim do tráfico de drogas e da criminalidade nem se solucionarão todas as mazelas sociais e econômicas das comunidades. Nota-se, portanto, que as UPPs não correspondem a um programa de prevenção policial para dar conta da criminalidade, mas um processo de devolver à população os territórios controlados por criminosos. Elas são consideradas uma estratégia de "pacificação" e um desafio do Estado de legitimar sua força.

Nessa linha de atuação, foi criado o programa de ações sociais batizado de UPP Social, cujo mote é trabalhar em integração com a polícia. A UPP Social 
tem uma coordenação à parte do comando da polícia e foi estruturada para dar suporte à pacificação, fomentar a cidadania e o crescimento socioeconômico e promover a inclusão das comunidades às demais áreas da cidade. As UPPs, em tese, ofereceriam mais segurança à população do Rio de Janeiro, localizando-se estrategicamente em áreas pobres com elevada concentração de traficantes de drogas (Henriques \& Ramos, 2012).

Tal cenário de violência e desigualdades facilitou a disseminação do crack no Rio de Janeiro, provocando incômodo na sociedade, especialmente em razão da impactante fragilização física, emocional e social de muitos usuários da substância. Políticas públicas de diversas áreas começaram a surgir no município. Em abril de 2012 houve adesão municipal e estadual ao programa Crack, É Possível Vencer do governo federal. Esse programa tem como objetivo aumentar a oferta de tratamento de saúde e atenção aos usuários de drogas, enfrentar o tráfico e as organizações criminosas e ampliar as atividades de prevenção, com a criação de seis novos Centros de Atenção Psicossocial (Caps) ${ }^{1}$ para atendimento 24 horas no estado. Outras oito unidades, já em funcionamento, também passariam a atender casos de uso/abuso de álcool e outras drogas (Caps ad) (Instituto Pereira Passos, 2012).

Havia a previsão de criar mais Centros de Referência Especializados em Assistência Social (Creas) e novos SAls para crianças/adolescentes. Ainda no escopo do programa, o município do Rio deveria contar com novos leitos em enfermarias especializadas e Consultórios na Rua para o atendimento aos dependentes do crack.

Uma estratégia adotada no município em 2011 foi o recolhimento compulsório de crianças e adolescentes em situação de risco (Cf. resolução $n$. 20/2011 da Secretaria Municipal do Desenvolvimento Social - SMDS - do Rio de Janeiro), entre os quais se destacavam os usuários de crack e outras drogas. Tal medida vem alcançando outras cidades brasileiras, entre as quais se inclui São Paulo, que também adotou posteriormente o regime compulsório para a população usuária de crack.

De acordo com a resolução, os usuários de crack são retirados das ruas da cidade à revelia e levados para um SAI para desintoxicação. Esse recolhimento é fruto de um acordo entre o Ministério Público, justiça e a SMDS. É considerada

Caps - serviço de saúde aberto e comunitário do SUS. Pode ser considerado I, II e III, segundo o tamanho do município. O Caps III funciona 24 horas diariamente. Caps ad atende usuários de álcool e outras drogas, e Caps i, a população infantojuvenil. 
como uma medida protetiva para as crianças e adolescentes que estão nas ruas perambulando por motivos pessoais e/ou sociais, entre eles o uso do crack. A SMDS/RJ defende a ideia de que o recolhimento compulsório vai ao encontro do "direito à vida e à saúde", de acordo com o artigo $7^{\circ}$ do Estatuto da Criança e do Adolescente - ECA (lei n. 8.069/90), ${ }^{2}$ que prevê políticas públicas que possibilitem o desenvolvimento sadio e harmonioso das crianças e adolescentes em condições dignas de existência. Para enfrentar a perspectiva do aumento da população recolhida, a SMDS tem aberto vagas em SAls para pessoas em situação de vulnerabilidade social, como uso de drogas e vivência na rua.

O recolhimento compulsório de usuários de crack tem suscitado reações de entidades dos direitos humanos, tais como: Ordem dos Advogados do Brasil, Conselho Estadual dos Direitos da Criança e do Adolescente, Conselhos Regionais da Assistência Social, da Psicologia e da Enfermagem, que alegam ser essa prática uma ação higienista e contraprodutiva. Alegam que os SAls não estão preparados para atender com eficácia as demandas dos usuários do crack, que carecem de estrutura adequada e profissionais capacitados para prestar um serviço de qualidade, e que os serviços de saúde são insuficientes para atender a demanda. Ponderam também que policiais militares, civis e guardas municipais retiram de maneira truculenta a população infantojuvenil das ruas e a levam para SAls sem infraestrutura para o tratamento de crack, localizados em Guaratiba (Zona Oeste - duas unidades) e Laranjeiras (Zona Sul - uma unidade) (Entidades..., 2011). Desses três serviços, os da Zona Oeste, que eram organizações não governamentais (ONGs), tiveram seu convênio interrompido em decorrência de irregularidades no atendimento prestado, reduzindo ainda mais a oferta de serviços no município.

Segundo o Portal dos Direitos da Criança (2011), ${ }^{3}$ das mais de mil pessoas recolhidas até 29 de julho de 2011, 249 são crianças e adolescentes. O referido portal acrescenta que várias manifestações contrárias à medida foram divulgadas por diversos segmentos da sociedade. O mote da crítica é a forma violenta com que os usuários são abordados nas ruas. Outro manifesto contrário à medida foi o ato público "Recolher não é acolher". Durante o evento, foi divulgado um abaixo-assinado, que denunciava a arbitrariedade com que o recolhimento é feito. Ainda de acordo com o portal, a Secretaria de Direitos Humanos da Presidência da República (SDH/PR) também se manifestou em 26 de julho.

Disponível em: <www.planalto.gov.br/ccivil_03/LEIS/L8069.htm>. Acesso em: 14 fev. 2013.

3 Disponível em: <www.direitosdacrianca.org.br/em-pauta/2011/08/recolhimento-compulsoriode-usuarios-de-crack-gera-polemica/?searchterm>. Acesso em: 14 fev. 2013. 
O órgão não defende a suspensão da medida adotada no Rio, mas faz diversas recomendações, entre elas: o atendimento deve ser feito pela saúde por intermédio do Sistema Único de Saúde (SUS), e o acolhimento institucional deve seguir os trâmites estabelecidos pela Lei da Adoção (n. 12.010/09), que determina o plano de atendimento individual e de apoio à família.

Vale distinguir a diferença entre o "recolhimento compulsório" realizado nas ruas e cracolândias da cidade (com encaminhamento para as Centrais de Recepção - CR - e SAls do município) e a "internação compulsória ou involuntária" de pessoas na rede de saúde, em hospital geral e/ou psiquiátrico.

O recolhimento compulsório precisa ser pensado à luz da política de saúde mental infantojuvenil no Brasil, que busca superar a prática de institucionalização calcada na ideia de reclusão em abrigos, educandários e hospitais psiquiátricos. As diretrizes e os princípios que norteiam as ações voltadas para a atenção à saúde mental desse segmento da população também estão inseridos nos movimentos da Reforma Sanitária e da Reforma Psiquiátrica, que levaram a um modelo de tratamento aberto e comunitário, privilegiando a inserção social e o atendimento a necessidades clínicas, comunitárias, familiares e de reabilitação.

No Brasil, a política pública de saúde mental voltada especificamente para crianças e adolescentes, com abrangência nacional, começou a ser estabelecida entre 2002 e 2004, quando foram formalizados os Caps, Caps ad e os específicos para infância (Caps i), e implementado o Fórum Nacional de Saúde Mental Infantojuvenil (Lauridsen-Ribeiro \& Tanaka, 2010).

Quanto aos recursos públicos para enfrentar o problema do crack no município do Rio de Janeiro, o Fórum Popular do Orçamento, baseando-se em dados oficiais (prestações de contas de 2002 a 2010), relata que o município investiu em média apenas 3\% de seu orçamento em assistência social e direitos da cidadania. O baixo percentual é refletido no Plano Plurianual, que destina ao Programa Enfrentamento ao Uso e Abuso do Crack e Outras Substâncias Psicoativas um total de 76 vagas no ano de 2010 e prevê tratamento de 12 crianças e adolescentes nas Casas Vivas, especializadas no acolhimento de crianças e adolescentes que fazem uso abusivo de drogas, especialmente crack, em 2011 e $2012 .{ }^{4}$

4 Secretário de Assistência Social, Rodrigo Bethlem, em audiência pública na Câmara Municipal do Rio de Janeiro. Diário Oficial do Município do Rio de Janeiro, 30 maio 2011. 


\section{A Rede SOCIOASSISTENCIAL NO MUNICíPIO dO RIO DE JANEIRO}

Para conhecer a rede socioassistencial existente no município do Rio de Janeiro em 2012, foram realizados os seguintes passos na pesquisa que dá origem a este capítulo. Uma amostra representativa com 21 SAls foram visitados no município, com aplicação de: questionários aos gestores com perguntas sobre o funcionamento dos serviços (21); questionários respondidos por técnicos da instituição com base nos prontuários (SAl) das crianças e adolescentes com uso de crack pessoal ou familiar (50); questionários aos adolescentes usuários de crack presentes nos SAls no momento da pesquisa, indagando-lhes diretamente sobre o consumo da droga (7).

$\mathrm{Na}$ abordagem qualitativa foram realizadas 30 entrevistas com: dez adolescentes usuários de crack (oito em SAls e dois em serviços de saúde); sete familiares de crianças e adolescentes usuários de crack (seis familiares em SAI e um em serviço de saúde); oito profissionais da área de assistência social (sete coordenadores ou técnicos de SAI e um gestor da SMDS; três profissionais da área de saúde (agente comunitário em Consultório de Rua, gestores ou técnicos de Caps ad e Caps i); um conselheiro tutelar e um promotor público. Maiores detalhes sobre os procedimentos metodológicos podem ser lidos no Anexo.

Seguem informações sobre a rede de apoio a crianças e adolescentes usuários de crack e a suas famílias, com dados especialmente oriundos dos profissionais entrevistados e de busca documental. Não se trata de um retrato completo, já que o município não dispõe de um fluxograma abrangendo toda a rede de atenção voltada para usuários de crack.

Na área da assistência social, existem duas Centrais de Recepção na região central do município: Carioca e Taiguara. Anteriormente havia uma no bairro de Bangu, que atualmente funciona como SAl. As Centrais de Recepção atendem crianças e adolescentes, com o objetivo de acolher e encaminhá-los à rede socioassistencial no Rio de Janeiro e demais municípios do estado. O tempo de permanência é de até 24 horas, mas nem sempre esse prazo consegue ser cumprido em virtude da complexidade de cada caso.

Em geral, a população infantojuvenil é encaminhada para essas centrais pela equipe de abordagem de rua da SMDS, que faz incursões pelas cracolândias e outras áreas da cidade. A Central de Recepção também é acionada por meio do Conselho Tutelar, guarda municipal, delegacia de polícia, bem como por familiares e pela demanda espontânea da própria criança ou adolescente que já conhece a unidade como referência. 
Segundo informações de coordenadores e técnicos de SAls, as centrais encaminham os casos para a unidade de saúde mais próxima, Unidade de Pronto Atendimento (UPA), Consultórios na Rua, hospitais gerais, de emergência ou de saúde mental. Caso não seja necessário passar por uma unidade de saúde, as crianças e adolescentes são encaminhados para os SAls. Havia nove unidades de acolhimento ligadas à SMDS na cidade no momento da pesquisa: Casa Viva, em Laranjeiras - considerado um SAI especializado para usuários de drogas; Abrigo Airton Sena, em Vila Isabel; Casa de Acolhida do Catete; Casa Lar Dalva de Oliveira, em Botafogo; Centro de Acolhimento Dom Helder Câmara, no Estácio; Casa de Passagem Cely Campelo, em Jacarepaguá; Casa Lar Nora Ney, em Santa Cruz; Centro Municipal de Assistência Social Integrada Raul Seixas, na Praça da Bandeira; e Central de Recepção de Crianças e Adolescentes de Bangu, que no momento funcionava como um SAl. Além desses serviços, existe ainda uma ONG na Zona Oeste com duas unidades especializadas em usuários de drogas conveniadas à SMDS.

Em 2012, havia 46 Centros de Referência de Assistência Social (Cras) no município que realizavam serviços de proteção social básica, configurando uma porta de entrada no sistema de assistência social. O Cras tem como objetivo a proteção social básica em áreas de vulnerabilidade e risco social, visando à minimização e/ou superação das desigualdades sociais. Tem a função de organizar e coordenar a rede de serviços socioassistenciais locais. Desenvolve ações de inclusão familiar e comunitária por meio de acolhida e recepção, escuta e encaminhamento, oficinas de geração de renda e realização de grupos diversos (crianças, adolescentes, adultos e idosos). Os 14 Creas então existentes oferecem serviços especializados e continuados a famílias e indivíduos em situação de ameaça ou com seus direitos violados, entre os quais se incluem os usuários de drogas.

Na área da saúde, em 2012, a cidade do Rio de Janeiro contava com 27 Caps, sendo 24 municipais: três Caps III (adultos), 11 Caps II (adultos), oito Caps i, cinco Caps ad; dois estaduais: Caps ad Centra-Rio e Caps II Uerj, além de um federal, vinculado ao Instituto de Psiquiatria da Universidade Federal do Rio de Janeiro (Ipub/UFRJ) - Caps i Carim. O início da implantação dos Caps na cidade ocorreu na década de 1990. Há também três hospitais para internação de usuário de crack com 12 leitos em cada um deles: Philippe Pinel, Hospital Psiquiátrico Nise da Silveira e Hospital Municipal Psiquiátrico Jurandyr Manfredini. 
Tanto os Caps ad quanto os Caps i são serviços compostos por equipe multiprofissional de atenção a pessoas com dificuldades pelo uso de álcool e outras drogas. São oferecidos atendimentos individual, em grupo, oficinas terapêuticas, visitas domiciliares e atendimento aos familiares.

Fazem parte da rede de saúde as UPAs, os Consultórios na Rua, os hospitais gerais e de emergência. Há três Consultórios na Rua no município do Rio de Janeiro: Centro, Manguinhos e Jacarezinho. O Consultório na Rua visitado durante a pesquisa é muito bem equipado, localizado dentro de uma Clínica da Família, mas não dispõe de carro. Parte da equipe vai para a rua fazer "busca ativa" de usuários de substâncias psicoativas. Atende de $8 \mathrm{~h}$ às $17 \mathrm{~h}$, de segunda a sexta-feira, a pessoas oriundas da cidade, região metropolitana e que vivem nas redondezas, em torno dos locais de venda de crack. São em geral adultos entre 20 a 35 anos de idade que migraram da maconha para o crack; poucas são as crianças e adolescentes atendidos (talvez uns $2 \%$ - percentual aferido pelo agente comunitário de saúde); o fluxo total de atendimento gira em torno de 12 a 15 por dia, mas quando a equipe faz busca ativa, a quantidade de atendidos se torna maior.

\section{OS SERVIÇOS DE ACOLHIMENTO INSTITUCIONAL}

Dentre os 21 SAls visitados na pesquisa, 14 atendem crianças e 16, adolescentes (Tabela 1). A presença de crianças que usam crack e drogas em geral não foi mencionada por nenhum serviço. Entre os que atendem adolescentes, o quadro é diferente: $42,9 \%$ dos serviços acolhem consumidores de drogas em geral e $28,6 \%$, os que usam crack. Em relação aos responsáveis de crianças e adolescentes, entre $56,3 \%$ e $64,3 \%$ dos serviços informam o consumo de drogas em geral, e aproximadamente $30 \%$ dos serviços têm responsáveis que utilizam crack.

Três SAls se destacam por terem elevado número de crianças em uma mesma unidade (entre 35 e 53 acolhidos), em desacordo com o preconizado pelas normas governamentais - 20 crianças e adolescentes por serviço (Brasil, 2009). Igual número de SAls tem excesso de adolescentes (entre 21 e 38). Em média encontram-se 13,9 crianças e 8,7 adolescentes por serviço. 
Tabela 1 - Serviços de Acolhimento Institucional que atendem crianças e adolescentes e seus responsáveis com história de uso de drogas em geral e de crack ( $\mathrm{N}=21 \mathrm{SAl})$. Rio de Janeiro - março a setembro de 2012*

\begin{tabular}{|c|c|c|c|c|}
\hline \multirow[t]{2}{*}{ Consumo de drogas } & \multicolumn{2}{|c|}{$\begin{array}{l}\text { SAls que atendem } \\
\text { crianças } \\
\mathrm{N}=16^{* *}\end{array}$} & \multicolumn{2}{|c|}{$\begin{array}{c}\text { SAls que } \\
\text { atendem } \\
\text { adolescentes } \\
\mathrm{N}=14^{* * *}\end{array}$} \\
\hline & $\mathrm{N}$ & $\%$ & $\mathrm{~N}$ & $\%$ \\
\hline $\begin{array}{l}\text { Uso de drogas em geral pela criança ou } \\
\text { adolescente }\end{array}$ & 0 & - & 6 & 42,9 \\
\hline Uso de crack pela criança ou adolescente & 0 & - & 4 & 28,6 \\
\hline $\begin{array}{l}\text { Responsáveis com história de uso de } \\
\text { drogas em geral }\end{array}$ & 9 & 56,3 & 9 & 64,3 \\
\hline $\begin{array}{l}\text { Responsáveis com história de uso de } \\
\text { crack }\end{array}$ & 5 & 31,3 & 4 & 28,6 \\
\hline
\end{tabular}

* Informação dada pelo gestor do serviço.

** Cinco SAls não têm crianças acolhidas.

*** Sete SAls não têm adolescentes acolhidos.

O alto número de acolhidos reflete-se na elevada quantidade de adolescentes com uso de drogas em três serviços (11, 15 e 19), indicando a necessidade de um atendimento especializado para grande número de adolescentes, o que é um desafio para uma atenção adequada.

No que se refere especificamente ao crack, os quatro serviços que relataram o consumo desse tipo de droga entre adolescentes, acolhem respectivamente: um único jovem, dois, quatro e dez. A situação em relação aos responsáveis reitera o desafio do atendimento aos usuários de crack em alguns serviços: um SAI tem responsáveis de 27 crianças, e outro, de dez adolescentes com esse consumo. Considerando-se o uso de drogas em geral, encontram-se genitores de 18 crianças em um SAl e de 19 adolescentes em outro. Esses dados reiteram a relevância de inserir a questão das drogas na capacitação dos profissionais que ali trabalham, bem como nas políticas públicas das diferentes esferas governamentais.

Na Tabela 2 apresenta-se a distribuição das 449 crianças e adolescentes que se encontravam nos 21 SAls visitados. Como se pode perceber, entre as 292 crianças presentes nos SAls, nenhuma é referida pelos gestores/técnicos por utilizar drogas em geral. Muitos responsáveis, contudo, mostram intimidade com drogas em geral (23,3\%) e com o crack (13,7\%). Entre os 157 adolescentes, 
$39,5 \%$ usam drogas em geral e 10,8\%, crack; entre seus responsáveis, tem-se $31,2 \%$ e $2,5 \%$, respectivamente.

Tabela 2 - Uso de drogas em geral e de crack por crianças e adolescentes em Serviços de Acolhimento Institucional e por seus responsáveis. Rio de Janeiro - março a setembro de $2012^{*}$

\begin{tabular}{l|c|c|c|c|c|c}
\hline \multirow{2}{*}{ Consumo de drogas } & \multicolumn{2}{|c|}{$\begin{array}{c}\text { Crianças } \\
\mathrm{N}=292\end{array}$} & \multicolumn{2}{c|}{$\begin{array}{c}\text { Adolescentes } \\
\mathrm{N}=157\end{array}$} & \multicolumn{2}{c}{$\begin{array}{c}\text { Total } \\
\mathrm{N}=449\end{array}$} \\
\cline { 2 - 7 } & $\mathrm{N}$ & $\%$ & $\mathrm{~N}$ & $\%$ & $\mathrm{~N}$ & $\%$ \\
\hline $\begin{array}{l}\text { Uso de drogas em geral pela } \\
\text { criança ou adolescente }\end{array}$ & 0 & - & 62 & 39,5 & 62 & 13,8 \\
\hline $\begin{array}{l}\text { Uso de crack pela criança ou } \\
\text { adolescente }\end{array}$ & 0 & - & 17 & 10,8 & 17 & 3,8 \\
\hline $\begin{array}{l}\text { Responsáveis com história de uso } \\
\text { de drogas em geral }\end{array}$ & 68 & 23,3 & 49 & 31,2 & 117 & 26,1 \\
\hline $\begin{array}{l}\text { Responsáveis com história de uso } \\
\text { de crack }\end{array}$ & 40 & 13,7 & 4 & 2,5 & 44 & 9,8 \\
\hline
\end{tabular}

* Informação dada pelo gestor do serviço.

A maior parte dos SAls já funciona há muitos anos. Seis têm entre dois e oito anos de atividades; sete, entre dez e 18 anos; dois, entre 23 e 25 anos; cinco, entre 60 e 84 anos, e um, com 274 anos de existência, é um serviço filantrópico. Excluindo esse serviço centenário, observa-se que os demais têm em média 27,4 anos de existência ( $D P=28,9$ ), com muitos serviços atuando antes do ECA, quando ainda não vigorava a doutrina da proteção integral.

Dezessete SAls (81\%) têm a natureza de abrigo tradicional. Alguns apresentam especificidades: uma unidade abriga crianças pequenas apenas durante a semana; uma está voltada para crianças com problemas motores que também retornam aos lares; uma é só para meninas; e uma atende vítimas de maus-tratos. Há ainda uma Casa Lar em aldeia ${ }^{5}$ e uma Casa de Passagem. ${ }^{6}$ Outros dois SAls visitados foram uma Central de Recepção 24 horas e um abrigo que também funciona como creche para filhos de policiais militares.

5 É um conjunto de casas lares que ficam dispostas em um mesmo terreno, ao redor de um núcleo central, e compartilham uma mesma estrutura técnico-administrativa. A modalidade de acolhimento institucional em Casa Lar agrega no máximo dez crianças e adolescentes por unidade residencial, na qual pelo menos uma pessoa, ou um casal, trabalha como educador/cuidador residente em cada unidade. A unidade residencial não é a casa do educador/cuidador.

6 Acolhimento institucional de curtíssima duração, emergencial, para crianças e adolescentes com perfis diversos, em situação de abandono ou afastados do convívio familiar. Equipe técnica realiza o diagnóstico e encaminha para os demais serviços de acolhimento ou providencia a reintegração na família de origem. 
A maioria dos SAls é não governamental (71,4\%); os demais são unidades públicas municipais. Nove SAls têm orientação religiosa (42,9\%): seis católicos, um evangélico e dois espíritas. Todos os 12 serviços sem orientação religiosa são públicos.

$O$ atendimento oferecido às crianças e adolescentes em situação de risco social dirige-se para algumas clientelas específicas: 12 SAls recebem população de rua; dez, os ameaçados de morte; 11, os portadores de doenças infectocontagiosas; 13 atendem os portadores de transtornos mentais e nove recebem crianças e adolescentes com uso de crack e outras drogas (42,9\%).

Todos os SAls têm equipe técnica própria. Em todos há assistentes sociais e em 17 deles há psicólogos. Outros profissionais presentes em nove serviços são: pedagogos, enfermeiros, fisioterapeutas, dentistas, terapeutas ocupacionais, pediatras, fonoaudiólogos, nutricionistas, oftalmologistas e neurologistas.

No que tange à capacitação dos profissionais que trabalham nos SAls para lidar com o tema do crack e de outras substâncias, constata-se que a temática do crack foi pouco mencionada como alvo de formação continuada por parte de equipe técnica (em 28,6\% dos SAIs), direção (19\%), coordenação (14,3\%), cuidadores $(4,8 \%)$ e inexistiu para pessoal administrativo, serviços gerais e estagiários. O número máximo de funcionários capacitados é de 12 profissionais da equipe técnica. Capacitações sobre outras substâncias apresentam dados ligeiramente superiores, porém igualmente insuficientes para dar conta de um problema tão presente nos SAls.

\section{Perfil dAs Crianças, Adolescentes e SeUs FAMiliares}

Na Tabela 2 verifica-se que entre as 449 crianças e adolescentes acolhidos nos SAls, o uso de crack foi mencionado por gestores/técnicos para 17 adolescentes e para 44 pais/responsáveis. Desse total, numa segunda etapa foram localizados e preenchidos questionários com base em 50 prontuários de crianças e adolescentes. O perfil dos acolhidos encontra-se a seguir.

Constata-se a predominância de meninas (58\%) e a concentração de crianças de mais baixa idade nos serviços investigados: 13 têm entre 5 e 7 meses de idade (26\%), 18 estão entre 1 e 4 anos (36\%), nove têm entre 5 e 9 anos (18\%), três, entre 11 e 14 anos (6\%) e sete, entre 15 e 17 anos (14\%).

Dessa população infantojuvenil, 66\% não frequentam a escola. Discriminando os acolhidos fora da escola, tem-se que apenas oito crianças até 5 anos 
de idade têm registros institucionais que identificam sua inserção na pré-escola; ${ }^{7}$ na faixa dos 6-14 anos, a maioria está na primeira etapa do ensino fundamental; entre os 15-18 anos, um frequenta educação para jovens e adultos (EJA).

A convivência direta no ambiente primário de socialização com pessoas que usam drogas (incluindo crack) se observa em $36 \%$ das crianças/adolescentes, que informam ter morado com alguém com tal uso nos últimos 30 dias antes do acolhimento. Os pais são os principais usuários de crack relatados. Em alguns casos, associam-se a cocaína e o álcool.

A maioria das crianças/adolescentes tem irmãos (84\%), frequentemente afastados do meio familiar: $50 \%$ vivem nas mesmas unidades de acolhimento, $6 \%$ em outro SAI e $4 \%$ foram adotados.

Oito crianças/adolescentes apresentam algum problema de saúde (16\%): comportamento agressivo, depressivo ou ansioso; deficiência física ou mental não especificada e má formação de sistema nervoso central com déficit global de desenvolvimento. Dois acolhidos têm doenças genéticas. Outros problemas de saúde mencionados são: problemas odontológicos sérios, suspeita de tuberculose e dependência química de thinner e crack. Trinta por cento do grupo pesquisado têm trajetória de rua.

Constata-se a fragilidade da atenção aos usuários de crack: apenas quatro adolescentes $(23,5 \%)$ foram encaminhados para tratamento por uso de crack e menos da metade dos responsáveis (48\%) recebeu encaminhamento.

Sobre suas famílias, verifica-se que a maioria dos acolhidos reside na cidade do Rio de Janeiro (92\%), apenas quatro deles têm famílias morando em outras cidades da região metropolitana.

A manutenção do vínculo com a família durante o período de acolhimento é relatada em apenas $36 \%$ dos casos; $56 \%$ das crianças/adolescentes não têm mais vínculo com suas famílias; $8 \%$ têm impedimento judicial de contato. Em um total de $42 \%$ dos prontuários, há indicação de pelo menos uma visita familiar à instituição, especialmente de mães e avós.

Os motivos que levaram as crianças e adolescentes ao acolhimento institucional são: dependência química dos pais ou responsáveis (86\%), seguida bem à distância por negligência (26\%), situação de rua (22\%), abandono pelos pais/responsáveis (18\%). Em $8 \%$ do grupo infantojuvenil foram mencionados

Etapas de ensino no Brasil: educação infantil - creche, até 3 anos de idade; pré-escola, 4 e 5 anos. Ensino fundamental de nove anos - anos iniciais (faixa etária de 6 a 10 anos, com cinco anos de duração) e finais (faixa etária de 11 a 14 anos, com quatro anos de duração). 
o uso pessoal de crack e problemas psiquiátricos/psicológicos dos pais/ responsáveis. A violência doméstica física e sexual foi pouco relatada ( $6 \%$ cada), seguida por entrega voluntária da criança/adolescente pela família de origem e ameaça de morte ( $4 \%$ cada). Os motivos menos citados (2\%) foram: violência doméstica psicológica, carência de recursos materiais da família/ responsável, ausência dos pais/responsáveis por prisão, uso de substâncias por parte da criança/adolescente e violência ou abuso extrafamiliar

No que se refere aos dados sobre a institucionalização em SAl, entre as 50 crianças e adolescentes identificadas pelo uso pessoal ou familiar de crack, verifica-se que a quase totalidade estava na instituição há cerca de um ano, somente um caso estava há dez anos. Também a maioria (92\%) tem procedimento administrativo na Vara da Infância e Juventude e na qual se registra o consumo de crack por parte da criança/adolescente ou seus responsáveis.

Destaca-se o Poder Judiciário como o órgão que mais encaminhou crianças e adolescentes para os SAls nos últimos 12 meses (66\%); em seguida vem o Conselho Tutelar (14\%). Com frequência menor está a SMDS (10\%). Dois casos excepcionais são provenientes do Departamento Geral de Ações Socioeducativas (Degase) e de uma ONG.

Em relação à situação legal das crianças e dos adolescentes usuários de drogas ou cujos responsáveis utilizam crack, tem-se que: cinco acolhidos nessa situação estão legalmente encaminhados para adoção, aguardando colocação em família adotiva (10,4\%); cinco estão iniciando a aproximação com adotantes $(10,4 \%)$; e quatro têm a destituição do poder familiar concluída (8,3\%), mas ainda sem encaminhamento efetivo para adoção. Isso significa que há 29,1\% de crianças e adolescentes usuários de crack em SAl ou cujos responsáveis consomem essa substância que preenchem critérios para a condição legal de adoção na cidade do Rio de Janeiro.

Os demais estão nas seguintes condições, quanto ao aspecto legal: 28 em fase de avaliação/preparação para reintegração/retorno ao convívio com os responsáveis (58,3\%); sete com suspensão do poder familiar (14,6\%); três com processo tramitando de guarda/tutela ou com sentença pendente de recurso. Nenhum está com a destituição do poder familiar em tramitação.

Um em cada quatro crianças/adolescentes com história relacionada ao uso de crack/drogas já havia sido acolhido anteriormente no mesmo ou em outro SAl, e um jovem envolvido com o uso de crack estava em cumprimento de medida socioeducativa de liberdade assistida. Tais aspectos mostram vidas muito ligadas 
a instituições sociais de assistência social e justiça, em uma tentativa (muitas vezes fracassada) de suprir as vulnerabilidades e riscos existentes.

Para compreender em maior profundidade a trajetória de vulnerabilidade dos adolescentes acolhidos em SAls com história de uso de crack, foram aplicados questionários sobre o padrão de consumo da droga a cinco deles - os que se encontravam presentes nas unidades e/ou que tinham condições físicas/ mentais de responder às perguntas. No que se refere à idade dos entrevistados, observa-se que um tem 12 anos, e os demais têm entre 16 e 17 anos. Há apenas uma menina. Só um relata ter a cor da pele branca - os demais se autoidentificam como pretos ou pardos. Todos têm irmãos que vivem com a família de origem. Como forma de ganhar dinheiro, três adolescentes já atuaram em trabalhos de venda de mercadorias, como, por exemplo, doces. Um relata esmolar e outros dois informam atos ilegais como roubos e prostituição.

O consumo de álcool, maconha e crack ao longo da vida foi mencionado por todos os adolescentes, indicando a conjunção do uso de várias drogas: quatro usaram tabaco; três, cocaína; dois, mesclado (maconha e crack); três consumiram produtos para sentirem "barato"; um, oxi; dois utilizaram LSD, ecstasy ou outra droga que provoca alucinação; haxixe foi mencionado por um adolescente.

Em relação ao uso de drogas no mês anterior ao acolhimento, constata-se que: um adolescente utilizou tabaco diariamente; um, álcool (dois dias no mês); um, cocaína (dez dias); outro, mesclado (11 dias do mês); dois usaram maconha (variando de duas vezes até todos os dias); quatro, crack (até 13 dias); três utilizaram substâncias para sentir "barato" via oral e nasal (entre 20 e 30 dias no mês); um usou droga alucinógena via oral.

Detalhando melhor o consumo de crack, tem-se que: um adolescente utilizou a substância há um ano; outro, há dois anos; dois, há três anos e um há sete anos. A quantidade de pedras de crack consumidas em um dia comum oscila entre duas e dez. A droga é utilizada de diferentes formas: dois deles o fazem em formato de cigarro (misturando tabaco e crack); três usam como pitico (misturando maconha e crack); dois utilizam latas de refrigerante ou cerveja; quatro, copos plásticos; e quatro, cachimbo. Dois afirmam reutilizar copo/cachimbo de outro usuário para fumar crack. Quatro informam consumir crack em conjunto com outras drogas, destacando-se tabaco, álcool e maconha.

Três adolescentes relatam que o local de consumo de crack é a rua, e dois outros mencionam uma cracolândia situada em morro da cidade. Apenas um 
menciona a casa de amigos. Amigos e traficantes são as pessoas com quem obtêm o crack para o consumo próprio.

Um adolescente refere que tem irmãos que também utilizam drogas (maconha) e outro relata o uso de cocaína pelo pai.

A situação de saúde dos adolescentes no último mês é considerada boa por quatro deles. Um jovem mencionou sentir dores no peito há cinco dias, embora não relacione o sintoma ao uso de crack. Fazer sexo sem camisinha é um ato relatado por quatro adolescentes. Quatro deles negam a prática de sexo com portador de hepatite B, C ou HIV. Um jovem recebeu transfusão de sangue. Outro já utilizou drogas injetáveis, e nenhum menciona ter tido overdose por crack. A despeito da boa condição de saúde apontada pelos adolescentes, vários necessitaram de atendimento na rede, especialmente de saúde, antes de serem acolhidos nas instituições: três haviam passado por posto de saúde; dois, por serviços de emergência; dois tiveram internações hospitalares. Um relata ter sido recebido em serviços ligados à assistência social, psiquiatria e em clínica especializada. Um foi atendido por serviço que dava alimentação gratuita.

Dois adolescentes já foram detidos pela polícia após começarem a consumir crack, em decorrência de traficar drogas e de apedrejar segurança de shopping center, indicando sua proximidade ao universo infracional.

\section{CAUSAS E CONSEQUÊNCIAS DO USO DO CRACK}

Um breve perfil dos dez adolescentes entrevistados individualmente na pesquisa reitera o abandono escolar (quatro), fato já comentado em estudo com usuários de crack de Santa Maria/RS (Mocelin \& Moreira, 2010). Os demais estão estudando ou frequentando algum curso; um deles participa do programa Jovem Aprendiz, no próprio SAI em que se encontra. Esse serviço tem uma parceria com a Secretaria de Educação, que elaborou um projeto educacional para as crianças e adolescentes que estivessem muito tempo fora do ambiente escolar, com intuito de dar-lhes reforço antes de serem matriculados nas escolas públicas do município. "Hoje eu estudo, faço curso aqui [SAI], faço várias coisas. Agora vou fazer natação e futebol (Luís - SAl especializado).

Nenhum entrevistado em Central de Recepção frequenta escola, há algum tempo tinham abandonado o sistema educacional. Todos os adolescentes já se tinham evadido de algum SAI anteriormente e não exerciam atividades 
laborativas. Destaca-se a atuação de um SAl especializado em que os adolescentes não só estudam, como também praticam atividades esportivas na comunidade.

A necessidade premente do crack na vida dos adolescentes surge em falas que revelam o desinteresse geral e atribuem a saída da escola ao uso do crack: "Não; não trabalho, não faço nada da vida, só uso crack" (Lauro - CR). Outro fato apontado por seis adolescentes é o consumo de drogas lícitas ou ilícitas por seus familiares.

Sabe, pra mim é uma coisa ruim, porque eu aprendi a usar droga [cocaína] com a minha mãe. (Geraldo - SAl)

Muita revolta. Muita revolta. Por causa da minha família, do meu pai. Porque ele usava, ele também usava droga, maconha. Fumava na nossa frente. Não deu aquele respeito de que tem o pai pelo filho. Eu acho que o filho espelha pelo pai, correto? Então, o que o pai está fazendo, o filho vai fazer o que ele está vendo. Aí eu fui experimentar essa droga do crack. Pra mim não serve. Agora, graças a Deus eu não estou usando mais! Eu não quero mais essa droga pra mim. Essa droga não é pra mim. (Alex - SAl especializado)

A rapidez com que o consumo se dá é relatada por uma adolescente: "Fuma, depois dali o vício pega rápido e não consegue parar mais, não consegue parar mais. E o vício é muito ruim" (Ildes - CR). Sabe-se que, quando a cocaína é fumada na forma de crack, a aspiração é absorvida pelos pulmões e chega ao cérebro entre seis e oito segundos. Quando é injetada demora de 16 a 20 segundos, e quando é cheirada, o tempo é de três a cinco minutos para obtenção do mesmo efeito. Fumar o crack é o meio mais rápido de fazer com que a droga chegue ao cérebro (Cruz et al., 2010). A "fissura", conceituada como uma forte necessidade de utilizar uma substância, é considerada crucial para o uso compulsivo e dependência de drogas, propiciando ao indivíduo recaídas após abstinência. A dificuldade de interromper o uso do crack está presente na fala de uma adolescente grávida de cinco meses: "Eu uso droga, mas eu quero parar, assim eu tento, eu quero forças pra mim parar, mas eu não consigo, mas em nome de Jesus eu vou parar de usar essa droga" (Ildes - CR).

Os adolescentes informam que as "más" companhias favoreceram o uso do crack. Segundo sete deles, "amizade leva nós pra tudo. Mas, a gente vai porque a gente quer também" (Lauro - CR). Um adolescente relata que quis experimentar zirrê (crack com maconha) apenas para poder ficar acordado na época em que trabalhava na boca de fumo. Depois passou a usar crack puro. 
Outro entrevistado não sabe falar porque experimentou, mas afirma: "Provei e gostei e todo dia eu comecei a usar, diariamente" (Diógenes - CR). Para um jovem, a vida na rua foi o motivo que o levou ao vício no crack.

Os principais motivos do envolvimento com as drogas na fase da adolescência são: busca do prazer, curiosidade, vontade de experimentar; influência do grupo em que está inserido e pressão social (Tiba, 2003). Cabe lembrar que o consumo de drogas é uma prática cultural, encontrada em todas as civilizações, embora as finalidades do uso sejam variadas, da curiosidade à busca do prazer (Spricigo \& Alencastre, 2004).

Perguntados sobre os efeitos do crack em suas vidas, há uma gama de informações relatadas pelos dez adolescentes entrevistados: evasão nos estudos, rompimento dos vínculos familiares, mudanças físicas - "fiquei assim magra, feia de corpo" (Ildes - CR) -, mendicância, roubos, furtos, tráfico, violência e detenção pela polícia, perda dos amigos, expulsão de casa e distanciamento de todos.

Perdi a confiança da minha família. Tirei coisa de dentro de casa. Vendi alimento, já vendi liquidificador, já vendi espremedor de laranja. Eu tive problema na minha favela, onde eu moro. Foi um morador que me reconheceu, que eu tinha roubado. Aí gritou "pega ladrão"; me pegaram na rua, me arrebentaram todinho. Fui pra delegacia. (...) Cheguei aqui todo arrebentado. (Geraldo - SAI)

O efeito é que a minha mãe já não me quer mais dentro de casa. Ela quer que eu esteja em casa bem, não quer eu roubando. Não quer eu ficar morando dentro de casa com ela. Aí eu estou morando na rua, porque eu estava roubando, estava usando crack. (Diógenes - CR)

A gente não quer saber da família, nem do pai, nem da mãe, nem dos irmãos. Esquece sobrinho, esquece tudo, cara, o crack faz você esquecer escola, trabalho, esquece os amigos, esquece tudo. (Lauro - CR)

Todos esses adolescentes são unânimes em relatar com pesar o envolvimento com a droga, já que adquiriram mais ônus que bônus. Efeitos sobre a saúde física e mental também foram mencionados, especialmente a perda de peso (três), fazendo com que se sentissem feios e deprimidos. Dificuldades em correr (esporte anteriormente praticado), falta de ar, dormência bucal, dores, tosse, perda de memória e alucinação também foram relatados. Apenas um adolescente comenta que não percebeu nenhuma diferença na saúde depois do uso do crack. 
Eu conseguia atravessar uma piscina, mas agora eu não consigo mais, eu não tenho mais fôlego, eu ando daqui ali e já fico cansado, não consigo, na hora de dormir eu fico respirando forte procurando ar e não tenho, sem fôlego. (Luís - SAl especializado)

Meu corpo começa a arrepiar, começa a inchar todinho, aí eu desmaio. (Marcelo - SAl especializado)

Eu fico com dor no pulmão, às vezes dor no coração. Às vezes eu fico vendo gente. Eu penso que tem gente, mas na realidade não é ninguém. (Diógenes - CR)

Sentia medo! Dava pânico. Ficava assustado. (Alex - SAl especializado)

O uso de crack pode diminuir temporariamente a fome e o sono. A alimentação e o sono ficam prejudicados, ocorrendo o emagrecimento e esgotamento físico. Constatam-se problemas nos pulmões, coração e até na boca (queimaduras, dormência). Podem ocorrer náusea e dor abdominal. Os hábitos básicos de higiene podem ficar comprometidos. Quadros psiquiátricos são relatados: transtornos de personalidade, depressão, ansiedade, instabilidade do humor, ideias paranoides, delírios e alucinações. As principais complicações neurológicas são: dor de cabeça, tonteiras, inflamações dos vasos cerebrais, atrofia cerebral e convulsões (Cruz et al., 2010). São também frequentes as atividades ilícitas praticadas (tráfico de drogas, furtos, roubos e assaltos), a prostituição em troca de crack ou dinheiro para comprar a droga, o risco de infecção por HIV e outras doenças sexualmente transmissíveis (Nappo et al., 2004).

Metade dos adolescentes entrevistados apresenta histórico de rua, seja permanecendo na rua apenas durante o dia ou definitivamente, de acordo com o que se constata em outros contextos (Forster et al., 1992; Forster, Tannhauser \& Barros, 1996; Nappo et al., 1997). Cinco jovens afirmam não ter vivência nas ruas. Um deles relata que pagava um hotel para dormir; os outros não perderam seus laços familiares, usavam a droga muitas vezes no portão de casa ou na rua, mas voltavam para a casa.

Entre os sete familiares de crianças e adolescentes usuários de crack entrevistados, a maioria relata ter família numerosa, agregando filhos, netos e também avós no mesmo domicílio. Em três casos a família é monoparental, chefiada por mulher. Esse quadro está de acordo com o Censo 2010 do Instituto Brasileiro de Geografia e Estatística (IBGE), em que se nota aumento da proporção desse tipo de família (de 22,2\% em 2000 a 37,3\% em 2010). 
Em três famílias há relatos de outras pessoas (excluindo a criança/adolescente) com uso abusivo de drogas lícitas - tabaco e álcool - ou ilícitas - entre elas a maconha e o crack. Também foi mencionado o envolvimento de familiares no sistema prisional em duas famílias, acarretando evidente sofrimento.

Eu tenho um filho mais velho [usuário de maconha, cocaína e crack] que está no regime prisional fechado. Ele começou na adolescência e foi assistido também, mas eu não consegui deter ele. Aí ele foi morar na rua. Teve várias passagens no Padre Severino, passava várias semanas na rua. Eu cheguei a pedir ao juiz pra prender ele e não deixar ele na rua. Até que ele foi para o Educandário Santo Expedito, ficou seis meses. Uma semana na rua depois, mais seis meses de novo. Quando fez 18 anos ficou um mês na rua e voltou para o presídio. (mãe - Caps i)

As consequências do uso de crack na vida dos adolescentes, relatadas pelos familiares, referem-se à mendicância, prostituição, desleixo com a higiene, roubo, furto dentro da própria casa ou na comunidade a que pertencem para sustentarem o vício. Três familiares associam as consequências aos problemas de saúde dos adolescentes.

Eles ficam totalmente dependentes. Viram praticamente um mendigo. Não tomam banho, só andam no lixo, só vive todo sujo. E até chegar ao ponto de tirar as coisas de dentro de casa, que na maioria acontece isso mesmo. Eles começam a tirar as coisas de dentro de casa pra poder vender pra poder consumir a droga. (pai - SAl especializado)

Tem muitas. A saúde, eles põem a vida deles em risco. Esse meu filho, eu descobri que está com sífilis. (mãe - Caps i)

Um entrevistado associa as consequências do crack a todos os demais familiares que convivem com o adolescente.

É devastadora. Não afeta só o usuário em si, mas todos que estão ao redor. Não só o crack como qualquer outra droga devastadora. Mas, o crack, eu acredito que ele seja algo muito mais rápido e acaba com a vida da pessoa e dos familiares do que as outras. (tio e padrinho SAl especializado)

Wright e Chisman (2004: 265) ressaltam que "o fenômeno das drogas constitui um problema social com impactos diretos na saúde do indivíduo, família e sociedade". A dependência causa grandes mudanças na interação do 
indivíduo com seus familiares, afetando suas relações sociais e profissionais (Pratta \& Santos, 2009).

Em relação aos efeitos percebidos pela família na vida do usuário, há um leque de informações: problemas com a higiene, vida na rua, companheiros da rua como membros da nova família, atos infracionais, furtos e roubos que colocam a vida em risco, abandono dos estudos, emagrecimento, esfacelamento dos vínculos com a família de origem, agressividade, apatia, morte, prisão, abandono de um bebê no hospital pela mãe adolescente e prostituição/ exploração sexual. A angústia presente na fala dos familiares é a regra.

Chegava de manhã cedo em casa, saía quatro da tarde e só chegava de manhã cedo doidona, quebrando tudo, destruindo tudo. O irmão dela morreu por causa disso. Tem um irmão que está preso por causa de droga também. O negócio é terrível mesmo! Ela teve que fumar 40 pedras de crack pra mim trazer ela pra cá. Usar porque senão ela fugia, e pra não fugir, eu tive que ficar com a minha filha na sala e deixar ela no terraço fumando crack, porque senão ela fugia. Ela pula tudo, sai se jogando e ninguém pega mais, e se ela entrar pro morro, um abraço, que a amizade é muito forte, não tem como a gente trazer não. Ela teve que usar [crack dentro de casa]. Eu peguei ela, aí dei um banho nela, ela dormiu e quase amarrei pra levar pro Conselho Tutelar pra trazer ela pra cá, senão não tinha condição não, porque ela é agressiva, não é fácil não! (Carlos, companheiro da adolescente - SAI)

Quando os profissionais das diferentes áreas da atenção foram questionados sobre as causas do uso de crack pelas crianças e adolescentes, foi notória a necessidade de parar para pensar, antes de dar uma resposta. Entretanto, há um consenso de que o uso/abuso do crack em geral está ligado às angústias geradas no convívio dentro de casa. A pobreza também surgiu em algumas falas como uma motivação importante para a ida às ruas em busca do crack. É, todavia, vista mais como mais um fator corresponsável:

Eu posso levantar todas as situações que passaram por aqui e todos começam com uma questão no contexto familiar. Não só pela questão da vulnerabilidade da pobreza. (assistente social - SAI)

Existe uma história muito dolorosa. Praticamente todos os meninos que aqui estão possuem uma história muito sofrida de vida com família, violência doméstica, abandono, negligência, abuso sexual. Você tem um histórico muito dramático e muita dor. Eu acredito que a busca da droga seja uma forma de alívio dessa dor, desse 
sofrimento. A criança vai e usa recreativamente e tenta uma saída para essa situação de abandono, de sofrimento e infelizmente acaba se deparando com uma substância altamente dependente, muito devastadora e que debilita em pouco tempo. (psicólogo - SAI)

Suárez e Galera (2004) afirmam que os problemas relacionados ao uso de drogas têm suas raízes em relações complexas da humanidade, e nesse cenário destaca-se a família, instituição em constante transformação, por seu papel preponderante na conservação e transformação de hábitos, costumes e comportamentos entre gerações.

A ida para a rua, com subsequente envolvimento infracional e exploração comercial e sexual, bem como a ausência do Estado, são também associados às causas do uso de crack.

Eu vejo muita conexão [do uso do crack] com a ida para as ruas. (...) A população infantojuvenil e adulta que está nas ruas hoje na cidade do Rio de Janeiro, ela é diferente por regiões. Na minha área, as meninas iam com uma caixinha de bala no sinal. Quando existe uma menina se oferecendo é porque tem explorador. (...) Eu tenho inúmeros casos de destituição onde a família não via na criança uma fonte de responsabilidade, de carinho, mas via fonte de renda mesmo. Tem as questões de abuso, meninos que vão para a rua porque sofrem alguma coisa dentro de casa, mas não necessariamente são abusados ou são agredidos, porque cada caso é um caso. Mas eu associo muito à questão da banalização da ida pra rua, porque ele começa complementando a renda. Ele não começa usando droga. Ele começa ali com a mãe no sinal e vai crescendo, e daqui a pouco ele coloca o braço pra trás e finge que é deficiente e daqui a pouco ele, enfim, ato infracional. Não associo isso à pobreza. Acho que a pobreza também agrava e é um fator de risco, mas você tem uma grande massa de pessoas aí vulneráveis socialmente e que não levam seus filhos. (promotor público)

O envolvimento de usuários de crack com a criminalidade é fato corriqueiro, sendo observada a prática de pequenos delitos para conseguir dinheiro para obtenção da droga (Silveira \& Moreira, 2006).

Um conselheiro tutelar, para explicar o consumo de crack, apresenta o argumento da inevitabilidade da adição: "Experimentou a droga hoje, principalmente o crack, vai se viciar. É o início que não tem retorno, que a família não consegue geralmente controlar, e aí ele acaba indo para as ruas". 
Cabe salientar que essa noção de inevitabilidade não é consenso, já sendo observada a possibilidade do consumo controlado de crack (a longo prazo), a ponto de a droga não direcionar a vida do usuário (German \& Sterk, 2002).

As consequências do uso do crack por crianças/adolescentes e/ou familiares relatadas pelos profissionais da assistência social, saúde, Conselho Tutelar e promotoria enfatizam a degradação humana, com autodestruição física e psíquica evidente. O usuário se desinteressa por tudo e perde o rumo do presente, do futuro e da própria vida; abandona os estudos; envolve-se com práticas delituosas, como roubo e furto, e o rompe os vínculos familiares e sociais. Termos que relacionam as consequências do uso a aspectos "desastrosos", "nefastos", "falência humana" são comuns.

Consequências físicas e psíquicas, mudanças comportamentais como agressividade, vulnerabilidades pessoais e sociais e estigmas decorrentes do crack são sinalizados pelos profissionais.

Acho que a principal consequência é a ruptura total das relações sociais. Então, o usuário de crack, ele tem uma ruptura por completo da família, do ciclo de amigos. Porque o usuário de crack, até dentro de quem usa crack, ele é segregado. Então, por exemplo, quem usa cocaína, usa maconha, usa outra droga não anda com quem usa crack. O uso de crack - o principal prejuízo que traz pra essa pessoa primeiro é a total exclusão do círculo de amigos, de convívio social, de convívio familiar. Além de ter um prejuízo muito grande, às vezes, no seu julgamento. A compulsão do crack, ela é um pouco mais exacerbada. Então, durante a compulsão, às vezes, o adolescente e a criança podem fazer coisas que normalmente não fariam. (técnico em enfermagem - setor Saúde)

Segundo Kessler e Pechansky (2008), o que mais sensibiliza na expansão do uso de crack é a velocidade da deterioração da vida mental, física e social do usuário. Vários estudos correlacionam o uso de crack à agressividade, especialmente na fase de abstinência. As regiões onde há grande consumo dessa droga costumam apresentar índices mais altos de violência e crimes. Prostituição, tráfico de drogas e o cometimento de atos infracionais são apontados pelos profissionais como práticas sustentar o vício.

As próprias crianças e adolescentes se inviabilizam dentro de suas comunidades; se envolvem com a questão do tráfico, do furto, enfim, com alguma prática delituosa dentro da comunidade e fica jurada de morte porque começa a roubar, começa a fazer um monte de coisas 
pra poder adquirir a droga. A criança que está envolvida com a droga vai se colocando num emaranhado de outras situações que vai colocando ela cada vez mais em risco. (...) As meninas, ao contrário dos meninos adolescentes, quando elas estão muito envolvidas nas drogas, com certeza estão muito envolvidas na questão da exploração sexual, porque há uma relação de dependência. Eu não sei se ela se envolve pra ter um ganho e fazer o uso de drogas, ou se faz o uso da droga pra sustentar a manutenção da exploração sexual. É complexo. (coordenador da CR)

As consequências oriundas do uso de crack pelos familiares, especialmente as mães das crianças e adolescentes, também são apontadas pelos profissionais entrevistados.

Quanto à família, o crack tem essa característica da queda rápida, do dano à saúde e da compulsão muito séria. Então esses adultos não conseguem exercer a maternidade minimamente responsável. Se a pessoa está usando muito crack, ela não vai conseguir, mesmo que ela queira, ela não vai conseguir proteger aquela criança. Tem casos do disque 100, por exemplo, que as crianças estão sozinhas em casa há três dias. Tem uma criança de 9 anos responsável por uns dois ou três lá e quando vai checar é isso mesmo. Cadê essa mãe? Ela é usuária de crack e está lá em Santa Cruz usando. Como acessar essa mãe? (promotor público)

\section{A VisÃO dOS ADOLESCENTES, DOS FAMILIARES E DOS PRofissionais SOBRE O ATENDIMENTO NOS SERVIÇOS DE SAÚDE E DE ASSISTÊNCIA SOCIAL}

Indagados se faziam ou se fizeram uso de algum serviço e quais os principais motivos que os levaram a procurar atendimento, ou a ser encaminhados por causa de problemas de ordem física ou mental, seis adolescentes entrevistados relatam tratamento ambulatorial nos Caps ad ou Caps i, para onde foram encaminhados pelos SAls em que estavam acolhidos. Segundo informações fornecidas por um profissional da área de saúde mental, alguns Caps i no município do Rio de Janeiro atendem adolescentes usuários de crack por falta de Caps ad em número suficiente para dar conta da demanda. Apenas um entrevistado menciona que fazia o tratamento de saúde num Caps próximo à sua casa antes de ser acolhido, não relatando no momento nenhum tratamento médico no SAI especializado em que se encontra. As respostas quanto ao tempo em que frequentaram os Caps 
oscilaram entre pouco tempo, cinco ou seis meses, com várias interrupções nesse período e dois ou três anos. Dois entrevistados comentam que não realizam nenhum tratamento de saúde, embora, curiosamente, estejam acolhidos justamente em um SAI especializado.

Um adolescente detalha sua saga para conseguir um acolhimento especializado com a esperança de se tratar do uso abusivo da droga, sem sucesso, mantendo um ciclo de entrada na central de triagem, evasão, retorno ao crack e atos infracionais.

A gente pede clínica a eles e eles não arrumam pra nós. Pula e volta pro crack de novo, pro roubo. - Pesquisadora: Quantas vezes você já veio parar aqui? - Quatro vezes com essa. E essas quatro vezes eu pedi, e eles nunca arrumaram nada pra mim (...). Tento tratamento, mas até agora nada. (Luís - CR)

Uma adolescente relata que seu único contato com serviço de saúde foi com um hospital de emergência, onde permaneceu por pouco tempo. Foi socorrida por pessoas da cracolândia.

Eu dei um ataque, overdose por causa da droga, porque eu fiquei usando direto. (...) Não me lembro como eu fui parar no hospital... eu já acordei no hospital; quando eu puxei [fumou crack], passei mal. Eu não me lembrava onde eu estava. E depois, quando eu acordei, eu acordei no hospital cheia de aparelho, cheia de médico, cheia de bagulho assim, médico me vendo. Tirei os aparelhos e fugi do hospital. (Ildes - CR)

A fragilidade dos serviços de saúde para atendimento aos usuários de crack nos mais diversos níveis, como Caps, residências terapêuticas, ambulatórios, centros de convivência e hospitais (quando necessários), se evidencia claramente na cidade do Rio de Janeiro. Esse quadro contribui para que uma parcela da população apoie o recolhimento compulsório e demande internação em hospitais psiquiátricos, mesmo sem respaldo médico.

Um adolescente internado por três meses em SAI especializado para tratamento do crack, conveniado com a SMDS na Zona Oeste (que posteriormente foi fechado por irregularidades no atendimento), queixou-se de ficar isolado sem convivência com o mundo externo. "Porque lá é muito ruim! Lá dentro, eles nos deixam presos (...). Preso, porque lá tem piscina, tem campo de futebol, então deixa a gente lá preso... Ficamos presos dentro de casa, com televisão... Mas piscina, essa área de lazer eu não tive" (Diógenes - CR). 
O Centro de Defesa dos Direitos da Criança e do Adolescente (Cedeca) confirma que os SAls do município são precários em recursos físicos, humanos e materiais e que os profissionais não recebem capacitação e supervisão para lidar com os problemas dos acolhidos (Cedeca, 2011). De acordo com o Plano de Convivência Familiar e Comunitário, o Estado deve oferecer serviços adequados e suficientes à prevenção e superação das situações de violação de direitos, sobretudo propiciando o fortalecimento dos vínculos familiares e sociocomunitários (Brasil, 2006).

Outro entrevistado relata ter feito tratamento odontológico por causa da quebra de um dente em decorrência do consumo de crack, e três adolescentes afirmam que não frequentam nenhum serviço de saúde, mesmo estando em SAls especializados ou na Central de Recepção. A maioria faz algum tratamento nos referidos equipamentos de saúde mental (entre cinco meses e três anos). A falta de adesão do adolescente ao tratamento proposto pelo serviço de saúde foi apontada por um jovem: "Eu tinha muita dificuldade quando eu não queria ficar, quando eu não queria permanecer, porque aí o pessoal começava a me deixar de lado; eu não queria nada com nada" (Geraldo - SAI).

A chegada dos adolescentes aos serviços das áreas de assistência social e de saúde deve-se, em geral, a suas famílias, especialmente às mães. Profissionais de saúde mental dos Caps realizaram alguns encaminhamentos de adolescentes para SAls. Um adolescente relata que foi encaminhado para SAI especializado pela Central de Recepção, e três chegaram aos serviços via recolhimento compulsório quando estavam na rua.

Questionados se gostariam de receber atendimento em algum outro serviço e qual seria, seis entrevistados dizem que desejariam ser acolhidos em outro SAI, expressando insatisfação no local em que estavam (dois desses em SAI especializado). Vários foram os motivos dessa insatisfação, entre eles, o receio de agressão física por parte dos profissionais de serviços especializados e conveniados com a SMDS situados na Zona Oeste (hoje fechados), o desejo de outro local em que pudessem efetivamente ser ajudados a se libertarem da dependência do crack.

Assim, qualquer um [SAI] que pudesse me ajudar a parar de usar o crack. Qualquer lugar aí. (...) Eu queria ficar aqui, mas se tivesse outro [local] que fosse mais calmo, que tivesse mais tranquilidade. (Marcelo - SAl especializado) 
Eu não quero voltar pra lá. Lá é muito ruim, lá, os educadores batem. Lá se faz alguma coisa, eles botam num quarto, num banheiro escuro, fica dois dias sem comer, quase um castigo. Mas, se me encaminhasse para um abrigo aberto, que não tenha muro alto eu fico (...). Muro assim muito alto, lugar fechado, eu não quero ficar, eu quero ficar num normal! (Ildes - CR)

Os demais adolescentes estão satisfeitos com as unidades em que se encontram e não manifestam o desejo de nenhum outro local: "Eu não tenho nada a reclamar. É uma casa boa" (Alex - SAI especializado); "eu que tive essa escolha de vir para cá" (Luís - SAl especializado).

Indagados sobre o que consideram importante num serviço de atendimento para usuários de crack, os adolescentes se referiram a: diálogo, estudo, trabalho, curso de informática, médicos e enfermeiros, pessoas da equipe técnica para conversar e remédios para ajudar a esquecer a droga.

Em relação à avaliação dos atendimentos recebidos, a maioria dos adolescentes considera positivo o atendimento em SAl, em Caps ad e em Caps i.

Bom. Ainda mais a minha psicóloga, ela é super legal comigo! A gente senta, conversa, fala como foi o meu dia aqui. Porque ela quem me encaminhou pra cá, entendeu!? Porque eu cheguei lá e pedi encaminhamento pra cá. Por minha própria vontade. Eu cheguei lá e falei assim: "Oh! Eu não me aguento mais, eu estou usando droga, não quero mais usar droga. Eu quero me internar, se eu continuar eu vou morrer". (Alex - SAl especializado)

Foi o melhor que eu já tive! É o melhor que eu já passei. (Geraldo - SAI)

Ah! Pra mim é bom, porque eu converso, eles querem me ajudar, pra mim é bom. (Ildes - CR)

Contrapondo-se a essa visão positiva, alguns entrevistados reclamam do atendimento, sobretudo de que não são escutados e que os profissionais dão o rumo que querem para a vida deles. Vale apontar que a maioria dos entrevistados (sete) já esteve em outros SAIs, indicando a recorrente institucionalização existente e as muitas impressões causadas pelas diversas passagens nos serviços.

Um absurdo. Eles podem dar um telefonema pro juiz, o juiz manda a carta e manda nós irmos [para um SAI especializado]. Mas eles não querem fazer isso. Eles querem mais é que a gente quebre isso daqui, pra nos mandar pra delegacia. Eles deixam a gente irritado. Aí chamam a delegacia e nos levam pra DPCA [Delegacia de 
Proteção à Criança e Adolescente] e pro Padre Severino [instituição socioeducativa], mais nada! (Luís - CR)

Acho ruim [Caps ad]. Lá as pessoas não sabem tratar com os outros, só sabem gritar com os outros. (Marcelo - SAl especializado)

Observou-se no momento da coleta de dados a expectativa dos jovens em relação ao serviço e ao que seria feito deles nos locais para onde seriam encaminhados. Alguns dizem que gostariam de ir para determinados SAls especializados e ficar lá por uns seis ou oito meses até que conseguissem se livrar do vício. Outros comentam que não queriam ser encaminhados para SAls especializados, porque já haviam sido acolhidos em outro momento nesse tipo de serviço (SAls na Zona Oeste) e não tinham gostado do tratamento recebido.

Percebeu-se a angústia de alguns adolescentes por não poderem receber visitas na Central de Recepção nem ter contato por telefone com seus familiares. Cabe ressaltar certa diferença entre os entrevistados em Central de Recepção e os demais jovens em SAls, especializados ou não. Nessa central, há mais recém-chegados das ruas, que manifestam o uso/abuso de crack como algo que os mobiliza muito. Entre os adolescentes acolhidos em SAls, constata-se certa tranquilidade em suas respostas como se o uso/abuso de crack estivesse quase no passado.

Os sete familiares de crianças e adolescentes usuários de crack entrevistados na abordagem qualitativa foram solicitados também a responder se a família teria obtido algum apoio dos serviços em que seus filhos estavam sendo tratados. Um familiar declarou que passou a receber subvenções sociais como o Bolsa Família e o Cartão Carioca, e os demais não receberam encaminhamento para nenhum serviço socioassistencial, denotando fragilidade na articulação entre os profissionais da rede socioassistencial e os programas sociais governamentais.

Em relação ao que os familiares consideravam importante num serviço de atendimento para uso/abuso do crack, houve uma gama de respostas distintas, destacando-se: 1) a necessidade de equipe multiprofissional para cuidar com carinho e atenção do adolescente e com quem se identifique: "Ele adora vir aqui porque ele adora a assistente social. Ele adora conversar com ela" (mãe Caps i); 2) a importância de ocupação para os adolescentes, com atividades sociais que os ajudem a se inserir na sociedade: "Essas atividades que eles fazem aqui são super importantes. (...) Aqui eles tratam da dependência da droga e ao mesmo tempo vão reabilitando novamente na sociedade, vão à praia, ao cinema, 
a vários lugares, à festa" (pai - SAl especializado); 3) a reinserção nos estudos (com destaque para os cursos profissionalizantes) e a entrada no mercado de trabalho; 4) o apoio psicossocial: "Eu acho que deveriam ter um serviço social e psicólogo, porque eu acho que a pessoa fica bem deprimida!" (tia - SAI); 5) a visitação familiar para os adolescentes na unidade, dando suporte ao processo de recuperação.

Para se compreender melhor a visão dos profissionais da saúde e assistência social, alguns dados sobre a articulação da rede socioassistencial são apresentados, sob a ótica dos gestores de SAls.

Conforme visto anteriormente na Tabela 1, nove entre os 21 SAls visitados $(42,9 \%)$ relatam que têm crianças, adolescentes ou seus responsáveis com problemas com o crack, assim discriminados: três com adolescentes usuários; cinco com responsáveis usuários com filhos pequenos e quatro com responsáveis usuários com filhos adolescentes em acolhimento institucional. Sobre esses nove serviços, apresentamos a seguir como seus gestores veem a articulação institucional e as atividades realizadas com os programas ou instituições presentes no município que visam a apoiar o atendimento aos acolhidos com problemas decorrentes do uso de crack.

O Conselho Tutelar é a instituição da qual os SAls mais sabem a localização e com a qual trocam mais informações (mais de $80 \%$ do total de serviços). Reuniões periódicas e encaminhamentos são menos frequentes (entre 54 e 64\%). Em situação similar, quanto à troca de informações, estão o Poder Judiciário, Ministério Público, órgãos da assistência social e Caps. No que se refere às reuniões periódicas e encaminhamentos, os órgãos com menor proximidade dos SAls são a defensoria pública (36\% a $45 \%$ dos SAI), escolas ( $45 \%$ a $54 \%$ ) e os serviços de saúde mental (36\% a 54\%).

Em apenas três SAls há adolescentes usuários. Dois desses serviços relatam oferecer-lhes atendimento médico, psicológico e psiquiátrico, tratamento para dependência química, orientação sexual, assistência jurídica e atividades religiosas. Apenas um SAI informa realizar a inserção dos adolescentes em programas de trabalho protegido, promover atividades esportivas e culturais, atender as dificuldades de aprendizagem e oferecer atendimento especializado às pessoas com deficiência.

Em relação à atuação dos três SAls com as famílias dos usuários, ressalta-se que uma das unidades não oferece qualquer serviço para elas. Os outros dois referem acompanhamento social para os familiares, tratamento de dependência 
química, inserção em programas de proteção à família e assistência jurídica. Atendimento psicológico/psiquiátrico, orientação para planejamento familiar, encaminhamento para programas de profissionalização e apoio financeiro são mencionados por apenas um dentre os três serviços.

Nas falas dos dois profissionais de saúde entrevistados individualmente, percebe-se com mais detalhes a organização dos serviços. Num deles, uma profissional assume quase integralmente o cuidado dos adolescentes usuários de crack.

Quem está à frente do trabalho com os adolescentes sou eu. Seja articulação com a saúde, com a assistência, com a justiça, com a educação (...). Outro dia eu estava precisando de contato com o menor aprendiz, então eu recorri à nossa assistente social, porque ela tem conhecimento de como funciona a rede, como funcionam os trâmites de justiça; outras vezes chamo para dar suporte para os pais. (...) Na relação direta com o adolescente e na articulação com a rede eu estou fazendo. Acho prudente que outro profissional possa fazer o cuidado mais fino com a família. O que eu chamo de cuidado mais fino? Atendimentos periódicos. Porque é claro que a escuta à família eu estou sempre fazendo. Se a família chega aqui com o filho e quer conversar comigo sobre uma coisa que aconteceu, eu vou ouvir naturalmente. Mas às vezes é necessário ter atendimento periódico com aquela mãe e com aquele pai: semanal ou quinzenal. Eu tenho esses outros profissionais. Tenho uma assistente social no Caps que pode fazer isso, tem terapeuta ocupacional que faz isso e tem vários psicólogos que fazem isso. (técnico em educação - setor Saúde)

Nota-se a precariedade do trabalho multidisciplinar nesse equipamento de saúde mental, centralizado na figura de técnico originalmente da área da educação. Alguns adolescentes, têm pouco acesso aos recursos existentes na unidade, como técnico de enfermagem, enfermeiro, assistente social e psiquiatra.

Os adolescentes algumas vezes precisam ser medicados. É muito raro eu avaliar a necessidade de medicar um adolescente. (...) Quando eu fico em dúvida, eu peço para o psiquiatra avaliar. Aí a psiquiatra vai poder dizer se sim ou não. Eu evito bastante o recurso da medicação. Eu tento sempre por outras vias. (técnico em educação - setor Saúde)

Na composição da equipe do outro serviço de saúde cujo profissional foi entrevistado, há a presença de psicólogos, enfermeiros, técnico em enfermagem, terapeuta artístico, terapeuta ocupacional, assistentes sociais, médicos clínico e 
psiquiatra, além da equipe administrativa. Já no Consultório na Rua a equipe também é multiprofissional, contando não só com os profissionais de assistência social, enfermeiros, psicólogos, psiquiatras, mas também com técnicos em curativos e observadores de rua que fazem o trabalho direto de identificar os casos e criar a demanda espontânea. Percebe-se nesse serviço um movimento em direção ao atendimento multidisciplinar.

Foram mencionados, como unidades que fazem atendimento à população infantojuvenil usuária de crack, os Consultórios na Rua, postos de saúde, Posto de Assistência Médica (PAM), hospitais gerais, de emergência e clínicas da família.

Na fala dos profissionais da assistência social, o atendimento a crianças/ adolescentes usuários de crack mostra-se intrinsecamente atrelado à necessidade de parceria na saúde municipal, com referências claras aos serviços de saúde mental.

Os Caps têm sido os nossos parceiros para o atendimento a esses adolescentes. Para além dos Caps, a gente utiliza muito também o Hospital Pinel nos momentos de crise e o Instituto de Psiquiatria da UFRJ, que tem o núcleo de atendimento para crianças e adolescentes. Lá também é um Caps. Então tem também um atendimento psicoterápico e é uma referência para esse núcleo que faz o atendimento psicoterápico e é acompanhado pela psicóloga e psiquiatra. (assistente social - SAI)

Entretanto, uma queixa recorrente é que nem sempre a interlocução com a rede é eficaz. A referência e a contrarreferência dos atendimentos prestados muitas vezes são falhas. Na visão de uma assistente social em SAI, se essa referência e contrarreferência já são difíceis entre os profissionais, os usuários terão ainda mais dificuldade, porque em geral são pessoas humildes e que demandam que suas necessidades sejam atendidas com urgência e desenvoltura.

Eu percebo é que esse atendimento é um atendimento pontual, eu não vejo um avanço, uma proposta eficaz, mais profunda de atendimento a esse público. Muitas vezes são casos até mesmo de internação, nós temos dificuldades de encaminhar para uma internação. Você tentar fazer uma parceria e não tem vaga (...) em clínicas, mas na ocasião eu não tive esse retorno por falta de vagas. Normalmente essas famílias não pedem internação, quando pedem, a gente esbarra com essas dificuldades. Então o trabalho não flui, a gente não consegue dar uma continuidade. (assistente social - SAI) 
Ao se falar do atendimento existente, sobressai novamente a preocupação com a capacitação das equipes que lidam com esta temática.

Falta ainda uma capacitação quanto ao usuário de crack. As pessoas ficam muito perdidas ainda, e nós também. Falta capacitação, da própria saúde e da rede assistencial, as pessoas não sabem muito ainda o que é e como lidar com esse menino e com essa família que, na verdade, é completamente fragmentada. (assistente de direção - SAI)

A falta de médico na equipe dos serviços que funcionam como Centrais de Recepção é um problema que deveria ser considerado de máxima relevância para um atendimento mais efetivo e eficaz à população infantojuvenil usuária de crack.

Uma criança que está num numa crise de abstinência na qual a gente não consegue fazer o controle, a gente leva lá [Caps/UFRJ]. Mas já tivemos situações extremas onde a gente não consegue fazer o controle, e aí a gente acaba tendo que chamar o Samu para ajudar nessa condução, porque na minha equipe eu até tenho uma enfermeira, mas ela não é autorizada a dar nenhum tipo de medicação, então eu sempre aciono o Samu. (coordenador - CR)

A falta de divulgação pública dos dados quantitativos e qualitativos do recolhimento compulsório realizado pelo município é mencionada por um promotor público. Se realizada a contento, essa divugação permitiria conhecer melhor o atendimento prestado e fortalecer as práticas profissionais e os cuidados oferecidos.

Já a SMDS avalia o atendimento nesta rede como embrionário, embora considere primordiais para o bom atendimento o olhar personalizado para cada caso e o empenho de cada profissional. A atuação intersetorial é reiterada:

Eu acho que ainda falta muito para as duas secretarias [Saúde e Desenvolvimento Social] aprenderem a lidar com esta situação do crack. A tendência é que a gente trabalhe cada um no seu espaço. Eu acho que são espaços de troca, de articulação. Tem que ter um movimento, uma busca disso. (coordenador - SAI) 


\section{REDE SOCIOASSISTENCIAL: PAPEL INSTITUCIONAL, DESAFIOS, POTENCIALIDADES E FLUXO DE ATENDIMENTO}

Há semelhanças na visão ideal dos profissionais entrevistados nos SAls, SMDS, Conselhos Tutelares, Ministério Público e setor Saúde, no que se refere à relevância do trabalho em parceria. A atuação da saúde (o atendimento clínico, especialmente em saúde mental) é destacada unissonamente pelos entrevistados das variadas áreas, por ser considerada a responsável pelo processo de atendimento e tratamento das crianças recolhidas das ruas e cracolândias do município em virtude do uso/abuso do crack.

Para a Central de Recepção, que atende diferentes perfis de crianças e adolescentes como usuários de crack, vítimas de violência familiar, abuso sexual e abandono, o papel do primeiro acolhimento requer ações como alimentação e higienização, para depois dar seguimento a um trabalho de escuta.

A gente tenta fazer a identificação da criança, porque dependendo por qual órgão ela chega, da forma como ela foi abordada, do nível de comprometimento dela, ela não tem condição de dar informações sobre a vida dela. Ou pode ocorrer também dela já ter um histórico de entrada na unidade, e aí a gente já tem alguma informação sobre a criança. (coordenador - CR)

O Conselho Tutelar detém o importante papel de acionar a rede de serviços, além de ser fundamental para a proteção e a garantia dos direitos.

Cada caso é um caso. A família recebe benefícios? Essa família está tendo todo um acompanhamento e uma assistência? Ou, essa família não está tendo? Nós vamos envolver o Creas, o Cras, todos os órgãos da Prefeitura pra dar todo o tipo de assistência e acompanhamento à família. Recuperar essa família. Ao mesmo tempo você trabalha a criança e o adolescente. Os outros filhos estão na escola? Aí você já começa a fazer um trabalho preventivo com as outras crianças e adolescentes. Tem a questão de habitação, você envolve a Secretaria de Habitação, você envolve a Secretaria de Assistência, você envolve a Secretaria de Saúde. E aí você trabalha em rede em cada caso, você vai envolvendo todos esses setores. (conselheiro tutelar)

Já o promotor destaca que o município vem atuando em rede na medida em que executa a política de recolhimento compulsório, mas o papel do Ministério Público continua sendo o de fiscalização desse trabalho. $O$ promotor acredita que, em vez de digladiar com a assistência social, a saúde mental deve atuar em 
conjunto e investir em equipamentos de atendimento à população, encontrando saídas viáveis para a melhoria do atendimento aos usuários de crack. Mas as fragilidades do município são imensas.

A gente concorda com a política [recolhimento compulsório] em tese. Mas, o nosso desafio é fiscalizar como ele [município] vem executando essa política. Como está a Central de Recepção? Como está a operação de abordagem? Como está o serviço de acolhimento? Um problema é a falta de sistematização dos dados e avaliação do trabalho. Como o município vem enfrentando o que tem de bom e o que tem de ruim? O que tem de bom é sair da zona de conforto, tanto o Ministério Público quanto o município, que entende que não se pode permitir essa situação da criança em risco na rua usando droga. É sair da zona de conforto porque o mais simples é deixar sempre tudo como está. É você jogar a culpa na falta de política. O difícil é adotar uma postura muito clara e transparente de que tem que se fazer alguma coisa. Mas tem que se fazer bem feito. Nesse sentido, eu acho que o grande problema hoje no Rio de Janeiro é que a saúde do município, a meu ver, não acompanhou o foco do problema que a assistência social revelou. A área da assistência social tem inúmeros problemas. Está longe da perfeição. A gente tem aí mil procedimentos instaurados, fiscalizações, reuniões muito difíceis com gestor da assistência social, no sentido de cobrar a adequação. A saúde não acompanhou, e não foi criado nenhum equipamento para saúde mental de criança e adolescente nos últimos anos. (promotor público)

O acolhimento institucional de crianças e adolescentes usuários de crack é visto como medida de proteção por profissionais que atuam na saúde.

Uma justificativa que é coerente [recolhimento compulsório]. A justificativa em si não é um erro. Ninguém pode dizer que existe um equívoco em você dizer que você tem que proteger e cuidar das crianças. É assim que está escrito na lei. Nós devemos realmente proteger e cuidar dos adolescentes e das crianças. Eles, legitimamente falando, em termos legais, eles não têm condições de fazer essas escolhas ainda, plenamente, sozinhos. Então, eles devem ser cuidados e o Estado tem que fazer esse papel. (técnica em educação - setor Saúde)

O promotor enfatiza o papel de fiscalização, acompanhamento institucional caso a caso, contando com a retaguarda de equipe multiprofissional. Segundo esse profissional, a dificuldade em trabalhar em rede é um constante desafio, tendo em vista a falta de clareza do papel que cada profissional tem de sua 
própria atuação e da do outro. Não há muito diálogo entre as partes, e são poucos os esforços para compreender a filosofia do atendimento do colega. O recolhimento compulsório é defendido por esse promotor como um trabalho voltado para a proteção infantojuvenil, e o trabalho em rede é reconhecido como um labor a ser realizado a longo prazo e com critérios.

O papel de fiscalização e acompanhamento dos serviços oferecidos para as crianças e adolescentes usuários de crack ficou destacado na fala dos profissionais dos SAls, Ministério Público, Vara da Infância e Juventude e SMDS. Esparsamente, foram mencionados a vigilância sanitária, os variados conselhos (incluindo o tutelar, que teria um papel importante nesta ação) e a Defensoria Pública.

A fiscalização periódica é pra ver a questão das guias, se os meninos estão com a documentação em dia, como é que está sendo o atendimento, a organização de prontuários, fiscalização no geral, no aspecto físico também da unidade. (assistente de direção - SAI)

A SMDS ressalta os conselhos de assistentes sociais e dos direitos da criança e do adolescente e a própria equipe da SMAS como condutores do papel de fiscalizar e acompanhar os SAls que acolhem crianças e adolescentes usuários de crack e outras drogas, especialmente os conveniados (não governamentais) que têm um contrato com o município e os especializados.

Observa-se que é unânime a referência ao Ministério Público, quando se fala em fiscalização dos serviços, na descrição de todos os entrevistados da área de assistência social. A atuação desse órgão foi percebida também durante a pesquisa, em uma visita, ocorrida sem agendamento, de uma promotora a um SAl, no mesmo dia em que a coleta de dados fora marcada.

Não se observa destaque ao papel de fiscalização dos serviços na fala do conselheiro tutelar entrevistado, talvez pela grande demanda do dia a dia, do pequeno número de Conselhos Tutelares na cidade (dez no momento da pesquisa) ou pelo possível desconhecimento dessa atribuição. O promotor, por sua vez, comenta a importância que o Ministério Público atribui à questão e critica o Conselho Tutelar por não exercer a função de fiscalizar e acompanhar os SAls.

Nós temos que mandar os relatórios para a nossa Corregedoria semestralmente e isso é enviado para alimentar o sistema do Conselho Nacional do Ministério Público. As equipes técnicas das Varas vão até essas instituições não só para fiscalizar, mas também para discutir os 
casos, sobretudo antes das audiências de reavaliação. O Conselho Tutelar é que faz pouco porque, por lei, ele tem atribuição para fiscalizar as instituições, mas ele não tem esse hábito. (promotor)

Na área da saúde, a questão da fiscalização foi mencionada por um único profissional que demonstrou visão precisa das demandas que chegam ao local onde trabalha:

A gente tem a fiscalização da CAP [Coordenadoria de Área Programática] do próprio município. Então, é assim a nossa fiscalização, do próprio município através dessa CAP. A CAP é fiscalizada pela Secretaria Municipal de Saúde, e esta pelo Estado... Mas, a fiscalização também é feita através das ouvidorias e de serviços do próprio município. (técnico de enfermagem - setor Saúde)

Indagados sobre os desafios para o atendimento às crianças e adolescentes usuários de crack, os profissionais entrevistados preocupam-se, de forma geral, com a capacitação da equipe multiprofissional, com a necessidade de promover políticas públicas eficazes e com uma parceria mais efetiva entre saúde e assistência social.

Muitas vezes você não tem o retorno. Acredita que fazendo aquele encaminhamento (...) que aquela unidade vai acolher o usuário, vai acolher essas famílias. $E$ às vezes a gente esbarra em uma série de questões burocráticas. Muitas vezes eu tenho casos aqui de famílias que estão com sérios problemas de habitação. Você encaminha pra Prefeitura, para os órgãos, programas habitacionais, e você não tem esse retorno. Você esbarra com "hoje não dá", você volta daí a um mês. Você imagina, eu hoje, enquanto profissional, eu esbarro nessas barreiras. Você imagina eles, que não têm nível de escolaridade, que têm dificuldade muitas vezes de se expressar, de chegar nos lugares, dificuldade financeira pra pegar uma condução e, quando chegam nos lugares, não encontram essas portas abertas. (assistente social - SAI)

Para um coordenador da Central de Recepção, os desafios são muito complexos e giram em torno da demanda ser maior do que a oferta.

A gente precisaria ampliar essa rede de serviços. (...) A gente tem cinco unidades de referência. A demanda que a gente tem é muito maior do que isso, sem contar os casos que vêm encaminhados via determinação judicial de outros municípios, então assim, eu acho que a gente ainda falta avançar na ampliação dos serviços. (coordenador - CR) 
O supervisor técnico da SMDS, por sua vez, destaca a dificuldade de trabalhar com a família para a reconstrução dos laços esgarçados, propiciar o retorno da criança e do adolescente ao lar e, em caso de rupturas definitivas desses vínculos, valorizar a perspectiva de reinserção por meio de políticas públicas firmes.

Os profissionais da saúde foram unânimes ao citarem a adesão ao tratamento como o grande desafio. Também consideram difícil o trabalho conjunto e o diálogo entre os profissionais:

O desafio é exatamente a gente poder falar uma linguagem parecida. Embora a gente venha de áreas diferentes e aí tenha, às vezes, maneira de pensar sobre a coisa diferente. Mas que a gente possa ter diálogo embora a gente venha dessas formações diferenciadas. (técnica em educação - setor Saúde)

A ampliação da rede de saúde mental, assim como a reinserção familiar, também foram vistas como questões desafiadoras: "Já tivemos aqui pacientes que disseram que já nasceram na rua" (agente comunitário de saúde Consultório na Rua).

Na perspectiva de um conselheiro tutelar, alguns desafios são: acompanhar os deslocamentos que as crianças e adolescentes fazem entre os territórios, assim como dotar a rede de equipes multiprofissionais capacitadas e proporcionar um acompanhamento clínico amiúde até que se tenha certeza da recuperação dessa população.

O promotor público entrevistado aponta diversos desafios para o atendimento à criança e ao adolescente usuária de crack:

São inúmeros, são inúmeros. Forçar a intersetorialidade é o primeiro. Ou seja, ser um agente facilitador porque o Ministério Público tem como ser um maestro forçando, buscando, marcando reuniões, colocando essas pessoas para conversar exigindo planos intersetoriais de atendimento. (...) Resumindo: fomento da efetiva implementação das políticas públicas já postas e fomento da intersetorialidade no cuidado porque é isso que envolve tudo. Fiscalizar os abrigos, propor as ações civis públicas, recomendações, forçar adequação dos serviços e dos abrigos e se capacitar também para buscar conhecer os outros. (promotor)

Percebe-se uma dissonância entre as falas do conselheiro e do promotor no que se refere à avaliação da rede. O primeiro expressa com otimismo o 
fato de ocorrerem no município reuniões mensais de estudo de caso, em que profissionais de diversas entidades discutem os problemas dos adolescentes em vulnerabilidade social, enquanto o Ministério Público traz em seu discurso a necessidade de mais alinhamento da saúde e da assistência social como condição sine qua non para uma melhoria na condução do atendimento a esta clientela.

Houve consenso entre a assistência social, promotoria pública e Conselho Tutelar, em relação às potencialidades existentes no município para a assistência à população infantojuvenil envolvida com o uso de crack, ao recolhimento compulsório como medida de proteção e forma potencial de atendimento. Um dos profissionais da saúde destaca a necessidade de se exigir o parecer de um profissional da área para o encaminhamento de crianças e adolescentes recolhidos nas ruas e cracolândias da cidade para os SAls.

O recolhimento compulsório foi destacado por três entrevistados da área de assistência social como uma iniciativa de suma importância para a sociedade, que precisa oferecer um atendimento de qualidade com investimentos públicos.

Eu acho que o município se lançou. Por quê? Porque tinha mesmo que se lançar. $O$ fenômeno foi crescendo e foi preciso fazer alguma coisa. Provocou diálogo e eu acho que a controvérsia dessa discussão [recolhimento compulsório] acabou provocando muito diálogo entre os órgãos do Sistema de Garantia dos Direitos. A minha avaliação é que precisa ter mais investimentos ainda. A gente tem que ter mais unidades para oferecer um acolhimento de qualidade para essas crianças e adolescentes. O município deu o pontapé inicial, mas ainda tem que ter investimento público para dar conta dessa situação, porque ela é gritante. (...) Os órgãos de defesa, Ministério Público, a Vara, o Ministério da Justiça, que têm um olhar voltado para a questão dos direitos humanos, têm que compor na oferta desse serviço. O próprio MDS [Ministério de Desenvolvimento Social]... fundamentar formas de liberar recursos nessa composição de atendimento a esse público. (coordenador de SAI)

Outro profissional da assistência social considera que esse tipo de medida traduz uma preocupação com a segurança do país, já que a difusão das drogas configura-se como um problema nacional e não somente municipal. As autoridades deveriam cuidar mais das fronteiras para evitar que drogas entrem no país, e não fazer vista grossa quanto à entrada e à circulação delas. Foi também apontada a contradição entre a realidade de famílias que vivem no coração do município em extrema pobreza e a concentração das autoridades nos 
eventos da Copa do Mundo e Olimpíadas: "Quer dizer, você chega lá em cima da comunidade e você se depara com a situação de uma família e você olha o Maracanã em obra, é uma contradição muito grande" (assistente social - SAI).

O empoderamento das famílias, no que se refere à empregabilidade, também foi indicado como forma de potencializar o atendimento. Investimento público em SAI especializado é outro aspecto mencionado.

A própria secretaria [SMDS] que eu trabalho criou essa questão dos abrigos especializados. É muito novo, acho que eles causam muita polêmica. Na minha opinião não é um lugar pra você isolar um garoto porque ele é usuário de crack. Eu acho que ele tem que estar inserido, fazer ele tentar estudar e ver qual seria a melhor metodologia. Estabelecer um trabalho de convivência comunitária urgente. (coordenador - SAI)

Um profissional da área da saúde ressalta a potencialidade dos trabalhos realizados pelos Caps, dos investimentos em Caps ad, dos fóruns de discussão e da aproximação entre os Caps i e os Caps ad. Um agente comuitário de saúde ratifica a melhoria no diálogo com a saúde: "A saúde vem dando um maior suporte para os usuários de crack, antes era só um trabalho da assistência social, mas hoje já vemos que a saúde vem ampliando o atendimento, possibilitando vagas nos hospitais públicos" (Consultório na Rua).

O fluxo de atendimento existente é entendido diferentemente pelos setores da rede. Para os SAls, as crianças encaminhadas vêm da Vara da Infância e Juventude da comarca da capital, do Ministério Público, do recolhimento compulsório e da Central de Recepção. Espera-se a adaptação do acolhido na unidade para posterior avaliação do caso e encaminhamentos para a rede, especialmente para o Cras, Creas e Conselho Tutelar, e para localização de familiares, com vias ao acompanhamento do caso e reinserção social e familiar. O SAI especializado diz que a maioria de sua demanda vem do recolhimento compulsório. Mas, há situações de demanda espontânea, partindo de adolescentes ou de familiares, que são devidamente encaminhados para o Juizado.

Na Central de Recepção, o fluxo de atendimento se dá de forma variada. Diversos atores da rede encaminham as crianças/adolescentes para esse serviço, incluindo-se aqueles provenientes do recolhimento compulsório, das abordagens de rua e da demanda espontânea. Quando a própria criança ou adolescente busca ajuda na Central de Recepção, realiza-se encaminhamento 
para o Conselho Tutelar, objetivando a ciência do caso e o desenvolvimento dos trâmites legais, em especial na localização das famílias e territórios de origem da criança/adolescente. Procura-se, no curto espaço de tempo em que a criança ou adolescente fica na Central de Recepção, em tese, fazer com que cada um passe por uma avaliação clínica na rede de saúde. Tal aspecto deve ser relativizado em virtude da fragilidade da composição de equipe de saúde nesse local.

O fluxo da área da assistência social é muito objetivo nos casos que demandam acolhimento especializado, passando pelas centrais de triagem e recepção, pelo encaminhamento aos Caps e pela elaboração de guia de acolhimento para dar entrada em SAI especializado.

Já o Conselho Tutelar relata que as famílias pedem diretamente ajuda para os filhos usuários de crack. Quando necessário, o órgão solicita avaliação do Caps ad ou Caps i e acolhimento em SAI especializado. Há um trabalho em conjunto com os SAls na busca por familiares de crianças e adolescentes.

O Ministério Público menciona que o fluxo de atendimento se dá pelo recolhimento compulsório; pela triagem das Centrais de Recepção, que deveria estar embasada em avaliação médica e em exames clínicos (que não acontecem); pelos encaminhamentos para SAls (especializado ou não) e pelo acolhimento próximo ao território de origem da população infantojuvenil, objetivando a aproximação familiar e possível reintegração. Destaca a parceria entre a SMDS e Secretaria Municipal de Educação no desenvolvimento do ensino dentro de um SAI especializado para crianças e adolescentes evadidos da rede educacional, preparando-os antes de reingressarem na rede formal de ensino.

Profissionais da área saúde informam sobre o fluxo do atendimento dos casos até chegarem aos serviços. Um técnico relata que recebem pacientes vindos do Conselho Tutelar, rede de ensino, justiça e por demanda espontânea. Na saúde, primeiro é realizado o atendimento individual e depois em grupo, de acordo com a faixa etária de cada um.

\section{CONSIDERAÇÕES SOBRE O ATENDIMENTO OFERECIDO NO MUNICÍPIO DO RIO DE JANEIRO}

Percebe-se que a rede de saúde carece de equipamentos, profissionais e leitos que deem conta da demanda de crianças e adolescentes usuários de crack, bem como daqueles cujos pais são usuários. Além disso, a área de assistência social deveria ter uma equipe multiprofissional para avaliação e acompanhamento dos 
casos, sobretudo nas Centrais de Recepção, com disponibilidade de médico e enfermeiro para as unidades que acolhem os usuários de crack, em especial os SAls especializados. A atuação das Centrais de Recepção é muito questionada por adolescentes e familiares. Verifica-se ainda a necessidade de um maior número de Caps e de mais dinamismo nos serviços já existentes. A criação de novos serviços previstos para apoiar o tratamento e a prevenção ao uso de crack, apontados no início deste capítulo, é fundamental.

É necessária a articulação entre os profissionais das distintas áreas em prol da população infantojuvenil e suas famílias. Esses profissionais precisam também estar mais atentos para dar suporte aos familiares, não só no nível multiprofissional, realizando atendimentos individuais e em grupo, mas dando também oportunidades de acesso aos benefícios sociais, propiciando-lhes o empoderamento mínimo a que têm direito.

Nota-se a dificuldade de um trabalho mais criterioso para se conseguir efetivamente um acolhimento especializado ou um tratamento de saúde adequado para o enfrentamento do uso abusivo do crack, evitando-se, assim, as diversas entradas e evasões que costumam ocorrer nos SAls. Também os responsáveis dependentes de crack e outras drogas precisam encontrar atendimento nos serviços públicos, pois a causa do acolhimento de boa parte das crianças/adolescentes é a dependência química por parte dos seus cuidadores.

É, portanto, fundamental que haja investimento público significativo na frágil qualificação dos profissionais que atuam no município, tendo como norte o respeito à subjetividade do indivíduo que necessita ser cuidado, bem como o respeito aos direitos humanos. Para tal, necessita-se agregar conhecimento técnico a respeito das leis, planos, normas e orientações vigentes no país sobre os direitos da criança e do adolescente.

Percebe-se na cidade do Rio de Janeiro que os profissionais pouco interagem entre si, tampouco com os serviços existentes na rede socioassistencial. Tal descompasso leva a população infantojuvenil a um desgaste que poderia ser evitado se houvesse mais interlocução entre os mesmos e o oferecimento de um serviço de melhor qualidade.

A dificuldade de adesão ao tratamento por parte dos dependentes do crack é um dos fatores desafiadores mostrados neste estudo e deveria, portanto, ser visto com mais acuidade por parte dos profissionais da rede. Tal desafio é verificado no cenário nacional e internacional, em virtude das consequências físicas e do estigma social que a droga submete os usuários. 
A falta de atenção especial para as crianças acolhidas nos SAls por conta de uso de crack pelos pais/responsáveis e para aquelas que começam a usar tal substância em fase tão precoce merece cuidado prioritário no município. O destaque dado ao adolescente usuário de crack é importante, mas não pode obscurecer fases anteriores da vida em que a droga está presente e acarreta consequências graves à saúde e à vida em sociedade de crianças, adolescentes e famílias.

Vários adolescentes mencionaram, como aspecto necessário ao atendimento recebido nos serviços, a presença de diálogo, facilitando o bem-estar e o acolhimento efetivo. Essa demanda precisa ser trabalhada nos momentos de capacitação profissional, problematizando o respeito às necessidades e desejos da criança, adolescente ou família em situação de dependência química e a compreensão da capacidade de decisão sob o efeito da droga. Outros aspectos sinalizados pelos adolescentes usuários foram o receio de serem agredidos fisicamente em serviço especializado e a falta de atividades laborais ou profissionalizantes que os ajudem a preencher o tempo e a vencer o vício. Tais problemas são inadmissíveis, necessitando fiscalização dos órgãos públicos competentes e compromisso do governo na transformação dessa realidade.

A recorrente institucionalização dos mesmos adolescentes em SAls, até mesmo em SAls especializados, demonstra a fragilidade dos serviços prestados e a falta de acompanhamento do acolhido após a saída da unidade, bem como das suas famílias (inclui-se a rede socioassistencial e de saúde como um todo). A desarticulação da rede tem papel fundamental neste sério problema.

Considerando o quadro apresentado, as principais recomendações para a melhoria dos cuidados oferecidos no município do Rio de Janeiro são: incremento na parceria entre as áreas socioassistencial e saúde, com especial ênfase à saúde mental; referência e contrarreferência do atendimento ágil e mais eficaz; capacitação da equipe que lida com a temática crack/drogas; olhar personalizado para cada caso; otimização nas ações profissionais, de maneira a desburocratizar os atendimentos; disponibilidade de médico nas centrais de recepção e triagem, bem como em SAls especializados; aumento de equipamentos de saúde mental (Caps ad, Caps ad III e Caps i) e leitos em hospitais públicos (emergência e psiquiátricos); avaliação clínica abrangente da saúde de crianças e adolescentes recolhidos compulsoriamente e encaminhados para os SAls, especializados ou não; e fiscalização dos SAls e equipamentos de saúde pelos órgãos competentes, incluindo o Conselho Tutelar. 
Para a sociedade em geral, propomos: atividades criativas, lúdicas ou atrativas que despertem a atenção dos adolescentes, evitando o caminho do crack/drogas; políticas públicas de fomento à educação, saúde, trabalho e renda para a população, em especial para os que estão na linha da pobreza; atenção às famílias em vulnerabilidade e risco social, empoderando-as com apoio necessário para suas demandas; e fiscalização e policiamento das fronteiras do país, dificultando a entrada e comercialização de crack.

\section{REFERÊNCIAS}

BRASIL. Ministério do Desenvolvimento Social e Combate à Fome. Secretaria Especial dos Direitos Humanos. Plano Nacional de Convivência Familiar e Comunitária. Brasília: Conanda, 2006.

BRASIL. Conselho Nacional dos Direitos da Criança e do Adolescente. Orientações Técnicas: serviços de acolhimento para criança e adolescentes. Brasília: Conanda, 2009.

CARLINI, E. A. et al. Perfil de uso da cocaína no Brasil. Jornal Brasileiro de Psiquiatria, 44: 287-303, 1995.

CONSELHO NACIONAL DOS DIREITOS DA CRIANÇA E DO ADOLESCENTE (CEDECA). Em defesa, incondicional, da vida com dignidade, das políticas públicas de "atenção continuada" a crianças e adolescentes em situação de rua, a favor do acolhimento e contra o recolhimento, 8 jul. 2011. Disponível em: <http://goo.gl/ D94BJ>. Acesso em: 28 maio 2013. (Pronunciamento público do Centro de Defesa dos Direitos da Criança e do Adolescente - Cedeca Rio de Janeiro).

CRUZ, M. S. et al. Crack: uma abordagem multidisciplinar. In: BRASIL (Org.). Prevenção ao Uso Indevido de Drogas: capacitação para conselheiros e lideranças comunitárias. 3. ed. Brasília: Senad, 2010.

DOWDNEY, L. Crianças Combatentes em Violência Armada Organizada: um estudo de crianças e adolescentes envolvidos nas disputas territoriais das facções de drogas no Rio de Janeiro. Rio de Janeiro: Iser, Viva Rio, 2002.

ENTIDADES realizam ato contra recolhimento compulsório de menores viciados em crack no Rio. O Globo. Rio de Janeiro, 25 jul. 2011. Disponível em: <http:// oglobo.globo.com/rio/mat/2011/07/25/entidades-realizam-ato-contra-recolhimentocompulsorio-de-menores-viciados-em-crack-no-rio-924969888.asp\#ixzz1ZoUEprDg>. Acesso em: 1 ago. 2011.

FORSTER, L. M. K.; TANNHAUSER, M. \& BARROS, H. M. T. Drug use among street children in southern Brazil. Drug and Alcohol Dependence, 43: 57-62, 1996.

FORSTER, L. M. K. et al. Meninos na rua: relação entre abuso de drogas e atividades ilícitas. Revista da Associação Brasileira de Psiquiatria - Apal, 14: 115-120, 1992.

GERMAN, D. \& STERK, C. E. Looking beyond stereotypes: exploring variations among crack smokers. Psychoactive Drugs, 34(4): 383-392, 2002. 
HENRIQUES, R. \& RAMOS, S. UPPs Social: ações sociais para a consolidação da pacificação. Disponível em: <www.ie.ufrj.br/oldroot/datacenterie/pdfs/seminarios/ pesquisa/texto3008.pdf>. Acesso em: 5 nov. 2012.

INSTITUTO BRASILEIRO DE GEOGRAFIA E ESTATÍSTICA (IBGE). População Residente por Cor ou Raça e Religião. Rio de Janeiro: IBGE, 2000. Disponível em: <www.ibge.gov.br/home/estatistica/populacao/censo2000/primeiros_resultados_ amostra/tabela_brasil.shtm>. Acesso em: 5 nov. 2012.

INSTITUTO BRASILEIRO DE GEOGRAFIA E ESTATÍSTICA (IBGE). Censo Demográfico 2010. Rio de Janeiro: IBGE, 2011.

INSTITUTO BRASILEIRO DE GEOGRAFIA E ESTATÍSTICA (IBGE). Cidades 2013. Disponível em: <www.ibge.gov.br/cidadesat/default.php>. Acesso em: 29 jan. 2013.

INSTITUTO PEREIRA PASSOS. Prefeitura adere ao programa "Crack, É Possível Vencer". Rio de Janeiro: Prefeitura do Rio de Janeiro, 2012. Disponível em: <www. rio.rj.gov.br/web/smas/exibeconteudo?article-id=2743110 . Acesso em: 26 jul. 2012.

KESSLER, F. \& PECHANSKY, F. Uma visão psiquiátrica sobre o fenômeno do crack na atualidade. Revista de Psiquiatria do Rio Grande do Sul, 30(2): 96-98, 2008.

LAURIDSEN-RIBEIRO, E. \& TANAKA, O. Y. Organização de serviços no Sistema Único de Saúde para o cuidado de crianças e adolescentes com problemas de saúde mental. In: LAURIDSEN-RIBEIRO, E. \& TANAKA, O. Y. (Orgs.). Atenção em Saúde Mental para Crianças e Adolescentes no SUS. São Paulo: Hucitec, 2010.

MOCELIN, C. E. \& MOREIRA, N. S. Adolescentes e o crack: uma relação de dor e sofrimento. In: JORNADA INTERDISCIPLINAR EM SAÚDE, 3, 2010, Santa Maria. Anais... Santa Maria: Unifra, 2010.

NAPPO, S. A. et al. Comportamento de Risco de Mulheres Usuárias de Crack em Relação às DST/Aids. São Paulo: Cebrid, 2004.

NOTO, A. R. et al. IV Levantamento sobre o Uso de Drogas entre Crianças e Adolescentes em Situação de Rua de Seis Capitais Brasileiras - 1997. São Paulo: Cebrid, Escola Paulista de Medicina/Universidade Federal de São Paulo, 1997.

ORGANIZAÇÃO DAS NAÇÕES UNIDAS PARA EDUCAÇÃO, CIÊNCIA E CULTURA (UNESCO). Rio de Janeiro: carioca landscapes between the mountain and the sea, 2012. Disponível em: <http://whc.unesco.org/en/list/1100>. Acesso em: 11 nov. 2012.

PORTAL DOS DIREITOS DAS CRIANÇAS. Recolhimento compulsório de usuários de crack gera polêmica. Saúde, 31 ago. 2011.

PRATTA, E. M. M. \& SANTOS, M. A. O processo saúde-doença e a dependência química: interfaces e evolução. Psicologia: teoria e pesquisa, 25(2): 203-211, 2009.

SADECK, F. et al. De Olho no Orçamento Criança? Atuando para priorizar a criança e o adolescente no orçamento público. São Paulo: Inesc, 2005.

SILVEIRA, D. X. \& MOREIRA, F. G. Panorama Atual de Drogas e Dependências. São Paulo: Atheneu, 2006.

SPRICIGO, J. S. \& ALENCASTRE, M. B. O enfermeiro de unidade básica de saúde e o usuário de drogas: um estudo em Biguaçu-SC. Revista Latino-Americana de Enfermagem, 12(n. especial): 427-432, 2004. 
SUÁREZ, R. E. S. \& GALERA, S. A. F. Discurso de los padres sobre el uso de drogas lícitas e ilícitas percibido por estudiantes universitarios. Revista Latino-Americana de Enfermagem, 12 (n. especial): 406-411, 2004.

TIBA, I. Anjos Caídos. 28. ed. São Paulo: Gente, 2003.

WRIGHT, M. G. M. \& CHISMAN, A. M. A saúde internacional, o fenômeno das drogas e a profissão de enfermagem na América Latina. Texto \& Contexto Enfermagem, 13(2): 264-271, 2004.

ZALUAR, A. Democratização inacabada: fracasso da segurança pública. Estudos Avançados, 21(61): 31-49, 2007. 


\title{
7 \\ Retratos de um Momento Especial na Abordagem ao Usuário de Crack na Cidade de São Paulo
}

\author{
Renata Pires Pesce \\ Carmen Lúcia Albuquerque de Santana
}

Este capítulo inicia com breves considerações sobre o crack e a cidade de São Paulo, apresentando a seguir informações sobre a composição da rede de atenção e cuidado a crianças, adolescentes e/ou famílias com histórico de uso de crack. Na sequência descrevem-se os Serviços de Acolhimento Institucional (SAls) e apresentam-se as crianças, adolescentes e familiares usuários de crack entrevistados na pesquisa que deu origem ao capítulo. Finaliza-se com a visão dos adolescentes, dos familiares e dos profissionais sobre o atendimento nos serviços de saúde e de assistência social.

É importante ressaltar que a pesquisa foi conduzida em um momento em que a disseminação do uso do crack na cidade de São Paulo demandou às instituições e autoridades governamentais urgência no planejamento e no desenvolvimento de políticas públicas, bem como na criação de estratégias de intervenção e controle do uso do crack na cidade. Trata-se de um contexto no qual diversas ações vinham sendo planejadas e pensadas à luz de teorias e práticas, nem sempre consensuais, e ainda com muitos desafios e obstáculos, conforme pode ser observado a seguir.

\section{O Crack e a Cidade de São Paulo}

O município de São Paulo abrange uma área de 1.523,28 km² onde vive uma população de 11.253 .503 pessoas. A rede municipal de saúde organiza sua gestão em cinco coordenadorias: Norte, Sul, Leste, Sudeste e Centro-Oeste. 
Os serviços da saúde e da assistência social são, cada vez mais, oferecidos em parceria público-privada por meio de contratos com as organizações sociais. Cerca de $55 \%$ da população, em 2007, não tinha plano ou convênio de saúde e 37\% estava cadastrada pela Estratégia Saúde da Família. Em 2010, a população em situação de rua era de 13.666 indivíduos, excluindo-se crianças e adolescentes.

O município de São Paulo apresenta algumas características específicas, a saber, grande extensão territorial, heterogeneidade do território, áreas com alta densidade demográfica, áreas rurais, barreiras geográficas e diversidade populacional (população de rua, heterogeneidade étnica).

A cidade vem reunindo equipamentos e serviços, governamentais e não governamentais que atuam no atendimento e orientação de crianças, adolescentes e familiares que sofrem as consequências do crack. São várias iniciativas com enfoques bem diferenciados: orientação religiosa e uso de técnicas de autoajuda, de um lado; acolhimentos e tratamentos médicos e psicológicos, de outro.

Cabe ressaltar que, na ocasião da pesquisa, a cidade vivia um momento especial na abordagem ao usuário de crack. Em janeiro de 2012, tem início uma proposta de abordagem no centro de São Paulo - Ação Continuada Nova Luz - inserida no Projeto Nova Luz. Trata-se de uma proposta urbanística voltada para uma área popularmente conhecida como "cracolância", localizada no centro de São Paulo, área também denominada bairro da Luz ou Estação da Luz, que começa em 2005. A Ação Continuada Nova Luz, criada pela Prefeitura e apoiada pelo governo do estado, para atender o território da Nova Luz, pretende realizar algumas melhorias na infraestrutura e na segurança da área, caracterizada por ser local de grande exclusão social, onde prevalece a prática aberta e constante do tráfico e uso de drogas (principalmente crack e álcool) e prostituição.

Em dezembro de 2011, uma população média de 200 a 300 pessoas frequentava os locais de venda de drogas no centro da cidade. Desse contingente, aproximadamente 50 eram mulheres, dez delas gestantes, e 32 crianças e adolescentes. A maioria fazia uso eventual dos serviços de acolhida, retornando às ruas do bairro para usar crack (Silva, 2000).

Foi implantada em março de 2012, no escopo da Ação Continuada Nova Luz, a proposta de um serviço integrado, o Complexo Prates. Trata-se do primeiro programa de tratamento e acolhimento a usuários de álcool e outras drogas, que reúne ações de saúde pública e assistência social, uma iniciativa 
da Prefeitura de São Paulo. Está relacionado ao Projeto Nova Luz por estar localizado no centro de São Paulo e por ser umas das ações desenvolvidas no projeto, com uma equipe multidisciplinar para atendimento, acolhimento, tratamento e encaminhamento biopsicológico, social e jurídico a essa população.

No momento da pesquisa, o Complexo Prates dispunha de um abrigo para crianças e adolescentes usuários de drogas com 20 vagas. No complexo há um espaço de convivência-dia para adultos, uma unidade de assistência médica ambulatorial (AMA), um Centro de Apoio Psicossocial Álcool e Drogas (Caps ad) e um centro de acolhida 24 horas. A abordagem ocorre por meio de uma ação conjunta entre a Secretaria Municipal de Assistência e Desenvolvimento Social (SMADS), a Secretaria Municipal de Saúde (SMS), e a Coordenadoria da Atenção às Drogas, em parceria com organizações sociais vinculadas à Prefeitura.

O Complexo Prates é um serviço aberto 24 horas, sete dias na semana, com políticas de portas abertas e uma equipe multidisciplinar para atender as demandas de acolhimento (alimentação, higiene pessoal, atendimento social individualizado). Também presta serviços especializados de saúde como: intervenção em crise, desintoxicação, avaliação psiquiátrica, enfermagem e clínica geral. A abordagem aos usuários tem sido executada pela ação conjunta da Guarda Civil Metropolitana (GCM) e da Polícia Militar. A GCM, como integrante da rede de proteção social, articulada com a SMADS e a SMS, na região da Nova Luz e adjacências, promove encaminhamentos de pessoas em situação de risco aos equipamentos de saúde e ao atendimento social, assim como abordagens a munícipes e transeuntes daquela região para orientação e esclarecimentos.

A GCM participa da ação integrada com pelo menos 30 guardas e dez viaturas e bases comunitárias móveis. A GCM integra a operação na região da Nova Luz, desenvolvida pela Prefeitura e pelo governo do estado, também fazendo a proteção aos agentes públicos que ali atuam a serviço da SMADS, SMS e Secretaria do Trabalho e Participação e Parceria, do Departamento de Limpeza Urbana (Limpurb) e da Subprefeitura. As ações da corporação são realizadas com base nas normas programáticas e nos procedimentos operacionais padrões. A GCM pode ser acionada por telefone e funciona 24 horas.

Após a implementação do Complexo Prates, uma vez realizado o plano de tratamento e identificadas as necessidades de cada um dos indivíduos, eles são encaminhados para os seguintes parceiros da rede de saúde e assistencial: 
Pronto Socorro da Barra Funda, hospitais da rede, Centros de Referência da Criança e do Adolescente (Creca) - programa para atender crianças e adolescentes em situação de risco e vulnerabilidade -, Caps da região do centro de São Paulo e SAls.

A região também dispõe de um grande equipamento de saúde: um prédio com dois Caps, sendo um Caps ad (álcool e drogas) e um Caps i (infantil), uma unidade básica de saúde (UBS), uma Assistência Médica Ambulatorial (AMA), Programa do Idoso, Programa da Pessoa com Deficiência, entre outros cuidados à saúde. Esses serviços atuam de forma bastante próxima, no entanto, há dificulades de articulação com a rede para além desse território.

A cidade de São Paulo conta com a Coordenadoria de Atenção às Drogas (CDR), criada pela Prefeitura em 2008, e um Conselho Municipal de Políticas Públicas de Drogas e Álcool (Comuda). Há também o Conselho Estadual sobre Drogas (Coned). Essas estruturas têm como objetivo favorecer a formulação de políticas, a execução de projetos e a colaboração entre órgãos públicos e entidades da sociedade civil.

A complexidade da rede de serviços demanda mecanismos capazes de garantir a articulação entre os vários dispositivos existentes no município, conforme será descrito adiante. Grande parte desse papel é atribuída ao Caps. Os Caps ad deveriam articular-se com os serviços hospitalares e com os demais recursos da comunidade. Não há especificações sobre como o fluxo entre os serviços deve ocorrer, ficando a responsabilidade dessa interação a cargo de cada um deles.

O processo de implantação da Política Nacional de Saúde Mental em São Paulo apresenta diferentes obstáculos e desafios em decorrência das dimensões da metrópole e das relações políticas entre o estado/cidade e o governo federal. No momento da pesquisa, a cidade não apresentava uma rede eficiente de Caps, e estes não tinham boa integração com os sistemas de emergência e de atenção básica. Os dados mostram que muitos tópicos importantes na política de saúde mental estão sendo tratados de forma ideológica, reforçando a falsa ideia de que a abordagem ao usuário seria antes moral que clínica. Além disso, dada a escassez de recursos destinados à implementação da política de saúde mental, não foram criados serviços suficientemente capazes de atender a demanda ampliada pela abordagem de busca ativa, específica ao usuário de crack.

A urgência em acolher e oferecer tratamento à população de crianças e adolescentes usuários de crack e outras drogas na cidade de São Paulo vem 
fazendo com que novos serviços sejam incorporados a essa rede, embora os profissionais que neles atuam nem sempre estejam adequadamente capacitados e qualificados para lidar com as novas demandas. Portanto, há necessidade de investir em formação continuada do quadro profissional, processos de parcerias, crescimento e amadurecimento da rede no campo da saúde e da assistência social.

A fala de uma promotora de justiça entrevistada para a pesquisa, que atua especificamente buscando promover os direitos da criança e do adolescente e fiscalizando as entidades que os acolhem no município de São Paulo, reflete sobre o quadro naquele momento:

Sem dúvida nenhuma houve avanço, houve profissionalização. Mas para essa população específica dos usuários de drogas, usuários de crack, a impressão que eu tenho é que ninguém sabe ainda como proceder. Mesmo a política de acolhimento de adolescentes na cidade precisa ser revista. Essa questão das parcerias que são feitas, do processo de escolha das organizações não governamentais, a cobrança que é feita. Tudo isso precisa ser revisto. Tudo isso precisa ser aprimorado.

A Prefeitura de São Paulo mantém uma relação peculiar com os parceiros incumbidos de cuidar dos abrigos infantojuvenis, e também com os serviços de saúde voltados para essa população. As organizações sociais, responsáveis por coordenar essas instituições, tendem a ser substituídas de acordo com as mudanças políticas, o que gera um clima de medo, tensão e desconfiança por parte dos profissionais.

O estado de São Paulo está entre as localidades do Brasil onde o uso de drogas, incluindo o crack, é mais evidente em pesquisas, especialmente na capital. As publicações sobre o uso do crack em São Paulo concentram-se numa região específica da área central da cidade conhecida como cracolândia, onde existe aglomeração de usuários na via pública (Raupp \& Adorno, 2010, 2011; Oliveira \& Nappo, 2008). Como na maioria das grandes cidades, o crescimento urbano acelerado e caótico traz consequências que afetam diretamente a qualidade de vida da população, especialmente as camadas de baixa renda.

A área central de São Paulo, que concentra grande parte do setor bancário, de serviços e comércio da cidade, além de instituições históricas e culturais, é considerada atualmente um local degradado, um "espaço predominantemente comercial, que possui a maior concentração de domicílios vazios da cidade e 
de imóveis invadidos por pessoas de baixa renda, além de diversas habitações populares denominadas de cortiços" (Sampaio \& Pereira, 2003). Existe alta rotatividade de profissionais do sexo, traficantes e usuários de drogas nas ruas da região, as quais ficam esvaziadas após o horário comercial, constituindo um agravante às condições de segurança.

No ano do levantamento de dados da pesquisa, a tentativa de revitalização desse espaço constituía uma das metas da gestão municipal por meio do projeto iniciado em 2005 (Projeto Nova Luz), baseado em ações de desapropriação de imóveis e fechamento de hotéis e de repressão aos usuários de drogas e moradores de rua (Raupp \& Adorno, 2010).

Na cidade de São Paulo, o primeiro relato do uso de crack faz referência ao ano de 1989. Posteriormente, em 1991, houve a primeira apreensão policial da droga, momento a partir do qual o número de apreensões só veio a aumentar, passando de 204 registros em 1993 para 1.906 casos em 1995, mostrando a rápida popularização do crack na cidade (Dunn et al., 1996; Nappo, Galduróz \& Noto; 1996).

Oliveira e Nappo (2008) desenvolveram pesquisa qualitativa com propósito de identificar, na cidade de São Paulo, se a cultura de crack estaria sofrendo modificações relevantes - especialmente no que se refere a acessibilidade, formas de apresentação e estratégias de uso da droga - que pudessem, de alguma maneira, justificar esse aumento de consumo. O perfil predominante do usuário encontrado foi: homem, jovem, solteiro, de baixa classe socioeconômica, baixo nível de escolaridade e sem vínculos empregatícios formais. Segundo os autores, na época, o acesso ao crack era simples, facilitado por estratégias de mercado como a entrega em domicílio. As pedras têm sido substituídas pelo farelo, forma mais barata e adulterável da droga. O uso combinado de crack e tabaco ou maconha foi observado.

Os autores destacam ainda que, embora o padrão de uso mais frequentemente verificado tenha sido o compulsivo, caracterizado pelo consumo múltiplo de drogas e desenvolvimento de atividades ilícitas em troca de crack ou dinheiro, identificou-se também o uso controlado da droga, padrão esse que foi caracterizado pelo uso não diário de crack e comumente conciliado às atividades sociais (no que se refere à família, atividades escolares e trabalho), protegendo o usuário da marginalização.

A prática de atividades ilícitas não foi mencionada por usuários controlados, aqueles que conservam algum senso de ordem em suas vidas; mas foi comumente 
identificada entre usuários que já haviam passado pela fase compulsiva. A transição dessa fase à controlada ocorreu depois de anos de consumo, quando já não acreditavam ter mais estrutura física, psíquica ou moral para lidar com as consequências decorrentes do próprio consumo. A observação da vida desastrosa de colegas usuários foi outro motivo para o despertar do indivíduo para a vida, passando, então, ao uso controlado ou até mesmo à abstinência.

A pesquisa de Raupp e Adorno (2010), que buscou compreender o cotidiano de usuários especificamente na região central de São Paulo, sugeriu uma estreita relação entre o contexto social dos usuários e seu padrão de uso de crack. A grande maioria fazia uso compulsivo da droga e estava em situação de rua, cenário em que o autocuidado ou quaisquer outras atividades eram secundarizadas. No contexto estudado, foram observadas pessoas em situação de desfiliação social, com perda total ou parcial de vínculos econômicos e afetivos, muitas das quais entraram em contato com o crack quando já estavam em situação de rua. Nesses casos, a droga não pôde ser identificada como a causa da ida à rua, embora isso tenha sido relatado como verdade para uma parte significativa dos casos.

Existem situações onde é possível manter o uso controlado da droga, especialmente em contextos sociais menos desestruturados. $O$ fato de São Paulo ter sido a primeira cidade a registrar a presença de crack no país, somado à existência de uma região reconhecida pela sua venda e uso, com uma rede informal de serviços e pessoas interligadas a tal atividade, indica a amplitude do problema na cidade (Silva, 2000).

A região que abriga a cracolândia foi palco de diferentes experiências urbanas, caracterizando-se por funções e usos de seu espaço relacionados à própria história da cidade. O local já integrou os circuitos de lazer das elites paulistanas nas primeiras décadas do século passado, fato que começou a mudar na segunda metade do século XX, quando grandes empresas, bancos, lojas de artigos de luxo e grandes hotéis deslocaram-se para outras áreas da cidade. Nesse processo, ocorreu um deslocamento da elite, a qual passou a frequentar as novas centralidades que afloravam no compasso do crescimento da metrópole. Consequentemente, a área central iniciou um processo de desvalorização e popularização que acarretou mudanças e diversificação nos atores e atividades locais, com o surgimento de formas de ocupação estratégicas ligadas à busca pela sobrevivência. O centro ficou designado como uma ligação e passagem entre as diferentes regiões da capital. 
Esse espaço público tomado por usuários e vendedores de drogas constitui um dos maiores problemas no centro de São Paulo, que ganha visibilidade e importância política na cidade, já que a sua recuperação é uma das prioridades da gestão municipal. Durante a realização da pesquisa que originou este capítulo, eram visíveis as políticas - em planejamento e em curso - dedicadas a transformações do bairro da Luz. No entanto, apesar dessas tentativas, a recuperação da área não aconteceu por completo, sendo ainda grande a ocupação por população de rua, o que vem desencadeando uma série de intervenções repressivas desde 2005, com o objetivo de controlar e expulsar os usuários de crack e outras drogas que circulam na região.

É, portanto, nesse contexto que a pesquisa em foco foi implementada na cidade de São Paulo: um momento em que as atenções da gestão municipal em relação ao uso do crack concentravam-se em iniciativas e projetos de revitalização do centro. Essas ações, que na prática parecem operações de expulsão de moradores de rua e usuários de crack, demonstram uma forma de lidar com o problema, dado o fracasso de ações repressivas. Raupp e Adorno (2011) comentam que, por não se conseguir lidar com o problema, o espaço urbano é transformado, ficando menos permeável às pessoas que pertencem a grupos desviantes, tornando-se mais acessível ao controle social.

\section{A CoMposiçÃo dA REde de ATENÇÃo E CuIdAdo A CRIANÇAS, AdolESCENTES E FAMÍlIAS USUÁRIAS DE CRACK}

A seguir descrevem-se como se organiza a rede socioassistencial, as características principais dos equipamentos nas áreas da saúde, assistência social, justiça, e outros serviços destinados ao apoio de crianças, adolescentes (e suas famílias) envolvidos com o crack. As informações obtidas, por meio de dados institucionais e de consulta aos interlocutores durante a coleta de dados, buscam apresentar um panorama o mais próximo possível da realidade no município que poderia apoiar as pessoas afetadas pelo uso do crack.

É importante ressaltar que existe uma proposta de articulação da rede, mas o cotidiano dos serviços ainda constitui um desafio para as instituições. Conforme será descrito mais adiante, especialmente a articulação do setor da saúde e da assistência social - tanto internamente quanto entre os dois campos de atuação - tem sido um sério problema. Esse fato reflete-se na fala dos profissionais de referência entrevistados. Trata-se de uma rede em que 
há um fluxo intenso de meninos e meninas que já passaram inúmeras vezes por muitas instituições.

O fato é que essa integração que precisaria ter da entidade de acolhimento com o serviço de saúde não existe. Eles não sabem muitas vezes como conter um adolescente em surto. Eu já vi coisas do tipo jogar no chão, amarrar, dar um banho frio. Tem casos concretos que colocou o menino em baixo de um banho frio. Eles não sabem como lidar, e não sabem muitas vezes a quem recorrer. Então essas crianças ficam aí acolhidas durante o tempo que querem. Na maioria das vezes são adolescentes, pulam o muro e aí a entidade comunica ao juiz, ao promotor, a fuga desse adolescente. (promotora de justiça)

Até mesmo no Complexo Prates, equipamento recente que pretende integrar as duas áreas (saúde e assistência social), os profissionais relatam falta de integração com a saúde mental infantojuvenil, dificuldade de articulação com as escolas, em decorrência da falta da documentação exigida para encaminhamento (na maioria das vezes o adolescente com vivência de rua não dispõe dela), além de uma difícil questão disciplinar dentro do serviço e muitas lacunas em termos de atividades direcionadas às meninas e aos meninos que lá se encontram. Foi verificado in loco que os jovens usam alguns tipos de drogas dentro da instituição; os profissionais sentem-se por vezes despreparados e sem a devida formação, não sabendo o que fazer em relação ao uso de drogas (especialmente o crack). Ao mesmo tempo sentem-se acuados, com receio de trazer problemas para as unidades em que atuam se expuserem suas dificuldades.

A rede de serviços de saúde para o usuário de crack neste município é formada pelos serviços preconizados no Sistema Único de Saúde (SUS) e na Política Nacional de Saúde Mental. Em julho de 2011, havia na cidade: 563 centros de saúde/unidades básicas; 51 hospitais especializados; 159 hospitais gerais; 31 postos de saúde; 21 prontos-socorros gerais; 27 serviços de saúde mental; serviço de assistência móvel de urgência (Samu), com 107 ambulâncias básicas e sete avançadas, e outros 12.583 serviços da área da saúde. ${ }^{1}$ Além desses, a cidade conta com alguns serviços especializados no atendimento ao dependente químico, descritos mais adiante.

O sistema de saúde mental é composto por serviços distribuídos no território que estão organizados de acordo com o nível de cuidado nos seguintes

Cadastro Nacional de Estabelecimentos de Saúde (CNES)/Datasus/MS, 2011. Disponível em: <cnes.datasus.gov.br>. Acesso em: 24 ago. 2015. 
modelos: atenção primária - modelo tradicional e Estratégia Saúde da Família (ESF); Caps em diferentes modalidades: dois Caps I, 21 Caps II, três Caps III com horários estendidos, incluindo finais de semana e feriados, 13 Caps i e 21 Caps ad; serviços especializados (Serviço de Atenção Integral ao Dependente SAID - e programas ligados a faculdades); Comunidades Terapêuticas; grupos de autoajuda; ambulatórios; centros de convivência; prontos-socorros e hospitais gerais e Samu.

O SAID, um dos serviços especializados, caracteriza-se por ser um equipamento público municipal (parceria com o Hospital Samaritano) para o tratamento de dependentes químicos na cidade. Começou a funcionar em agosto de 2010 e oferece leitos de curta permanência e apoio psicossocial para adolescentes e adultos, de ambos os sexos.

Outros desses serviços são programas ligados a faculdades de medicina, entre eles, o Programa Equilíbrio da Universidade de São Paulo (USP), pertencente ao Instituto de Psiquiatria do Hospital das Clínicas/Faculdade de Medicina da USP, que oferece atendimento integral a crianças e adolescentes em situação de vulnerabilidade na região central de São Paulo. Esse programa disponibiliza acompanhamento psiquiátrico e de saúde (média de 1.050 atendimentos mensais), atividades artísticas e esportivas; tem equipe multiprofissional e conta com cerca de 340 adolescentes matriculados. ${ }^{2}$

A rede da assistência social na cidade de São Paulo é organizada da seguinte forma: proteção social básica e proteção social especial. A proteção social básica tem como objetivo a prevenção de situações de risco por meio do desenvolvimento de potencialidades e do fortalecimento de vínculos familiares e comunitários. Prevê a inclusão em serviços, programas e projetos locais de acolhimento, convivência e socialização de famílias e de indivíduos, conforme identificação da situação de vulnerabilidade apresentada. A proteção social básica atua por intermédio de diferentes unidades. Entre elas, destacam-se os Centros de Referência de Assistência Social (Cras) e a rede de serviços socioeducativos direcionados para grupos específicos, como crianças, jovens e idosos.

2 Os demais programas encontrados são: Unidade de Pesquisas em Álcool e Drogas (Uniad) e Centro Brasileiro de Informações sobre Drogas Psicotrópicas (Cebrid) da Universidade Federal de São Paulo; Centro de Atenção Integrada à Saúde Mental (CAISM) da Faculdade de Ciências Médicas da Santa Casa de São Paulo; Grupo Interdisciplinar de Estudos de Álcool e Drogas (Grea) da USP; Ambulatório Médico de Especialidades-Psiquiatria (AME-Psiquiatria), em parceria entre o governo do estado de São Paulo (Secretaria de Estado da Saúde), departamentos de Psiquiatria de quatro faculdades de medicina do município de São Paulo (USP, Universidade Federal de São Paulo, Faculdade de Ciências Médicas da Santa Casa e Universidade de Santo Amaro), Conselho Regional de Medicina do Estado de São Paulo e Ministério Público Estadual. 
A rede de proteção social especial conta com 14 Centros de Referência Especializados de Assistência Social (Creas). O acesso aos Creas, equipamentos de média complexidade, é feito por identificação e encaminhamento do Cras, dos serviços de proteção e vigilância social; por encaminhamento de outros serviços socioassistenciais, das demais políticas públicas setoriais, dos demais órgãos do Sistema de Garantia de Direitos e por demanda espontânea.

Como equipamento de alta complexidade, a rede da assistência social a crianças e adolescentes usuários de crack dispõe de serviços especializados, com vistas a afiançar a segurança de acolhida a indivíduos e/ou famílias afastados temporariamente dos núcleos familiares e/ou comunitários de origem. A rede de serviços de acolhimento mantém articulação forte com as coordenadorias de assistência social, por meio dos Cras e dos Creas, que disponibilizam serviços, programas, projetos e benefícios em cada região, além dos serviços de saúde, Conselho Tutelar, Varas da Infância e Juventude, Ministério Público e a comunidade de origem das crianças e dos adolescentes.

A justiça também dispõe de serviços relevantes para o atendimento a essa população. São eles:

1) Conselho Estadual Sobre Drogas (Coned) - propõe a política pública estadual sobre drogas, compatibilizando-a com o Sistema Nacional sobre Drogas; estimula pesquisas e programas de prevenção; celebra convênios e encaminha ao Conselho Nacional de Políticas sobre Drogas propostas fundamentais de alteração da política nacional sobre drogas.

2) Coordenadoria de Atenção às Drogas (CDR) - órgão administrativo e técnico de apoio ao Comuda. Criada em 2008, a CDR e o Comuda têm um importante papel na formulação e discussão de políticas públicas de álcool e outras drogas e na execução de ações e projetos, juntamente com órgãos públicos e sociedade civil, na prevenção do uso e abuso de drogas ilícitas e lícitas.

3) Departamento de Investigações sobre Narcóticos (Denarc) - órgão da Polícia Civil do estado de São Paulo que tem como atribuição executar ações de prevenção especializada, investigação e repressão da produção não autorizada e do tráfico ilícito de drogas, no âmbito da capital.

4) Divisão de Prevenção e Educação (Dipe) - seção de convênios e encaminhamento de dependentes que tem um serviço social que orienta e encaminha o usuário e sua família. Age como intermediador entre quem procura tratamento e quem tem competência para fazê-lo. É formado por uma equipe de psicólogos, assistentes sociais e voluntários. Essas atividades de prevenção são desenvolvidas 
por meio de cinco programas: Programa de Encaminhamento de Dependentes (Pede) - atende, avalia e encaminha às entidades terapêuticas os usuários e dependentes que procuram o serviço ou são dirigidos à seção; Programa de Orientação Familiar (Profam) - atende, avalia e encaminha às entidades ou profissionais da área de orientação familiares ou responsáveis por usuários ou dependentes químicos; Programa de Orientação e Encaminhamento de Policiais (Proepol) - atende, avalia e encaminha policiais envolvidos com dependência química que procuram o serviço ou são dirigidos à seção para programas, entidades terapêuticas ou profissionais da área - seus familiares são beneficiados pelo mesmo atendimento; Programa de Pesquisa e Avaliações (Proaval) - elabora pesquisas na área de encaminhamento, baseando-se nos casos atendidos pelas entidades e por profissionais de terapia; Programa de Atenção aos Menores Desassistidos (Promem) - experiência-piloto no atendimento a menores desassistidos envolvidos com drogas, e que perambulam pelo centro antigo da cidade.

5) Conselho Estadual de Políticas sobre Drogas (Coned) - atua conjunta e articuladamente com órgãos federais, estaduais e municipais, com a finalidade de prevenir o uso indevido de drogas, sob orientação do Conselho Federal de Entorpecentes (Confen).

6) Viva Voz - concebido pela Secretaria Nacional Antidrogas (Senad), em conjunto com a Fundação Faculdade de Ciências Médicas de Porto Alegre, o Sebrae-RS e o Sesi-RS, é uma central telefônica aberta à população em geral, com orientações e informações sobre as características das substâncias psicoativas, sua ação no organismo e também sobre prevenção ao uso e os recursos disponíveis na comunidade para quem precisa de algum tipo de atenção. Os profissionais passam por capacitação e durante o atendimento são supervisionados por profissionais da área da saúde.

A rede de atenção apresentada tem dificuldades e também potencialidades. São muitos equipamentos, mas o trabalho em rede ainda se mostra desarticulado. Ocorreram avanços, como é o caso da inauguração do Complexo Prates, projeto integrando saúde e assistência social em ambiente mais acolhedor e menos conturbado, com estrutura de portas abertas à população, onde a violência institucional é menor, se comparada aos abrigos mais conservadores que acumulam crianças e adolescentes submetidos a variadas formas de violação de direitos, conforme menciona a mãe de um adolescente:

Eu vejo que é muito dos outros lugares que ele passou [comportamento agressivo do filho]. Eles [abrigo especial A] 
têm mais atenção com os adolescentes. Eles têm uma atenção especial com a gente que vem visitar. Dá pra perceber que eles não fazem predileção se é branco, negro, preto, pobre, rico. (mãe de adolescente, abrigo especial $\mathrm{A}$ )

\section{OS SeRViços de Acolhimento InStitucional Às CriançAS, ADOLESCENTES E FAMÍLIAS USUÁRIAS DE CRACK}

Para se conhecer a rede de SAls existente no município, foi definida uma amostra representativa dos serviços da cidade de São Paulo (16 unidades visitadas). Os aspectos metodológicos de toda a pesquisa realizada no município constam do Anexo deste livro.

A SMS e o Comitê de Ética em Pesquisa da Prefeitura/SMS foram contatados, facilitando o acesso às instituições da área da saúde para visita, agendamento e realização das entrevistas individuais com profissionais, adolescentes e familiares. Na saúde foram entrevistados coordenadores de Caps i (um), Caps ad (um) e de um que atua em projeto para pessoas em situação de vulnerabilidade; dois adolescentes e um responsável por adolescente no Caps i.

A autorização da SMADS ofereceu muitos percalços até ser obtida, retardando o acesso às instituições da assistência social, onde foi realizado trabalho de coleta de dados quantitativos (aplicação de questionários institucionais em 16 SAls entre julho e dezembro de 2012 e pesquisa nos prontuários de cada criança/adolescente com histórico de crack) e qualitativos (duas entrevistas com gestora da SMADS e com coordenador de SAI, com dois adolescentes e um responsável).

Um conselheiro tutelar da região central da cidade e um promotor que trabalha com crianças e adolescentes também foram entrevistados. No total, a abordagem qualitativa agregou sete entrevistas com diferentes profissionais, quatro com adolescentes e duas com responsáveis de adolescentes envolvidos com o crack.

Além dos 16 SAls investigados, foram incluídos - a título de estudo de caso - três serviços da assistência social considerados especiais por concentrarem crianças e adolescentes que não haviam sido sorteados na amostra da pesquisa. Os dados desses três abrigos não estão incorporados nos resultados obtidos com a amostra representativa realizada. São apresentados em separado no capítulo. 


\section{Os Serviços de Acolhimento Institucional pesquisados}

Todos os 16 SAls visitados atendem crianças, e 14 acolhem adolescentes (Tabela 1). A presença de crianças que usam drogas em geral foi apontada em quatro serviços; em apenas um SAI há relato da existência de crianças com uso de crack.

Entre os SAls que atendem adolescentes, o quadro é mais intenso: a metade abriga consumidores de drogas em geral e em três unidades há adolescentes que usam crack.

Em relação aos responsáveis de crianças e adolescentes, mais de $60 \%$ dos serviços informam o consumo de drogas em geral por esses genitores. Percentual menor é constatado para uso de crack por responsáveis de crianças $(21,4 \%)$; entre os pais de adolescentes há mais serviços que relatam responsáveis que utilizam crack $(62,5 \%)$ (Tabela 1).

Tabela 1 - Serviços de Acolhimento Institucional que atendem crianças e adolescentes e seus responsáveis com história de uso de crack e outras drogas. São Paulo - julho a dezembro de 2012*

\begin{tabular}{|c|c|c|c|c|}
\hline \multirow[t]{2}{*}{ Consumo de drogas } & \multicolumn{2}{|c|}{$\begin{array}{c}\text { SAls que } \\
\text { atendem } \\
\text { crianças } \\
\mathrm{N}=16\end{array}$} & \multicolumn{2}{|c|}{$\begin{array}{c}\text { SAls que } \\
\text { atendem } \\
\text { adolescentes } \\
\mathrm{N}=14^{* *}\end{array}$} \\
\hline & $\mathrm{N}$ & $\%$ & $\mathrm{~N}$ & $\%$ \\
\hline $\begin{array}{l}\text { Uso de drogas em geral pela criança ou } \\
\text { adolescente }\end{array}$ & 4 & 25,0 & 7 & 50,0 \\
\hline Uso de crack pela criança ou adolescente & 1 & 6,3 & 3 & 21,4 \\
\hline $\begin{array}{l}\text { Responsáveis com história de uso de drogas } \\
\text { em geral }\end{array}$ & 11 & 68,8 & 9 & 64,3 \\
\hline Responsáveis com história de uso de crack & 10 & 62,5 & 3 & 21,4 \\
\hline
\end{tabular}

Na Tabela 2 tem-se a distribuição das 463 crianças e adolescentes que se encontravam nos 16 SAls que compõem a amostra de serviços. Entre as 279 crianças presentes nos SAls, seis utilizam drogas em geral e uma consome crack. Todavia, muitos de seus responsáveis são usuários de drogas em geral $(35,1 \%)$ e de crack (19,7\%). Entre os 184 adolescentes, 25 usam drogas em geral e quatro consomem crack; entre seus responsáveis, tem-se 34,2\% e 7,6\%, respectivamente. 
Vale ressaltar que o município de São Paulo tem instituições específicas para atender crianças e adolescentes usuários de crack e outras drogas. Logo, os percentuais observados podem estar subestimados.

Tabela 2 - Uso de crack e outras drogas por crianças e adolescentes em Serviços de Acolhimento Institucional e por seus responsáveis. São Paulo - julho a dezembro de $2012^{*}$

\begin{tabular}{l|c|c|c|c|c|c}
\hline \multirow{2}{*}{ Consumo de drogas } & \multicolumn{2}{|c|}{$\begin{array}{c}\text { Crianças } \\
\mathrm{N}=279\end{array}$} & \multicolumn{2}{c|}{$\begin{array}{c}\text { Adolescentes } \\
\mathrm{N}=184^{* *}\end{array}$} & \multicolumn{2}{c}{$\begin{array}{c}\text { Total } \\
\mathrm{N}=463\end{array}$} \\
\cline { 2 - 7 } & $\mathrm{N}$ & $\%$ & $\mathrm{~N}$ & $\%$ & $\mathrm{~N}$ & $\%$ \\
\hline $\begin{array}{l}\text { Uso de drogas em geral pela } \\
\text { criança ou adolescente }\end{array}$ & 6 & 2,2 & 25 & 13,6 & 31 & 6,7 \\
\hline $\begin{array}{l}\text { Uso de crack pela criança ou } \\
\text { adolescente }\end{array}$ & 1 & 0,4 & 4 & 2,2 & 5 & 1,1 \\
\hline $\begin{array}{l}\text { Responsáveis com história de uso } \\
\text { de drogas em geral }\end{array}$ & 98 & 35,1 & 63 & 34,2 & 163 & 35,2 \\
\hline $\begin{array}{l}\text { Responsáveis com história de uso } \\
\text { de crack }\end{array}$ & 55 & 19,7 & 14 & 7,6 & 69 & 14,9 \\
\hline
\end{tabular}

* Informação dada pelo gestor do serviço.

** Dois SAls não têm adolescentes acolhidos.

A maior parte dos 16 SAls visitados já funciona há muitos anos: $43,7 \%$ entre dois e dez anos de atividades; $37,5 \%$ entre 11 e 18 anos; e os demais 18,8\% oscilam entre 31 e 50 anos de existência. Os serviços da amostra têm em média 14,8 anos ( $D P=12,9)$.

A maioria dos SAls $(87,5 \%)$ tem a natureza de abrigo tradicional. Apenas dois serviços são Casas Lar: uma em comunidade e outra em aldeia. ${ }^{3}$ A maioria é não governamental (81,3\%); três são unidades públicas municipais. Metade tem orientação religiosa: cinco, católica; dois, evangélica, e um, ecumênica. Todos os oito serviços sem orientação religiosa são públicos.

$\mathrm{O}$ atendimento oferecido às crianças e adolescentes em situação de risco social está voltado para algumas clientelas específicas: população de rua $(81,3 \%)$; com transtornos mentais $(81,3 \%)$; com uso de crack e outras drogas (50\%); ameaçados de morte $(62,5 \%)$ e portadores de doenças infectocontagiosas (43,8\%).

A maior parte dos SAls tem equipe técnica própria (93,8\%). Em todos há psicólogos; assistentes sociais foram mencionados em $81,3 \%$ dos serviços.

3 Casa Lar é uma modalidade de acolhimento institucional com número menor de acolhidos, em que uma pessoa ou casal trabalha como educador, cuidador e residente. 
Outros profissionais presentes em 11 SAls $(68,8 \%)$ são: pedagogos, educadores, fisioterapeutas, fonoaudiólogos, assistentes de desenvolvimento familiar e gerentes administrativos. No que tange à capacitação desses profissionais para lidar com o crack e outras substâncias psicoativas, constata-se que a temática do crack foi muito pouco mencionada como alvo de formação continuada. A equipe técnica é a que mais foi alvo de processo formativo; neste cenário de escassez, apenas em quatro SAls pesquisados foi mencionada a existência de quatro pessoas, uma em cada unidade, capacitadas sobre drogas em geral e somente em dois serviços houve referência à formação no tema do crack, com dois funcionários se aperfeiçoando no assunto.

\section{Perfil das crianças e adolescentes e seus familiares}

Na Tabela 2 verifica-se que, entre as 463 crianças e adolescentes acolhidos nos SAls, o uso de crack foi mencionado por gestores/técnicos para um criança, quatro adolescentes, 55 responsáveis por crianças e 14 pais de adolescentes. Desse total, numa segunda etapa, foram localizados e preenchidos questionários com base em 21 prontuários de crianças e adolescentes em SAls no município de São Paulo. Vale ressaltar que o longo período transcorrido entre a liberação da entrada nos serviços pela SMADS, a marcação da entrevista do gestor e o acesso aos prontuários colaborou para que muitos casos não estivessem mais disponíveis aos pesquisadores.

O perfil destes 21 acolhidos é o seguinte:

- cinco crianças têm entre 1 e 7 meses de vida (23,8\%); cinco estão entre 1 e 3 anos (23,8\%); sete têm entre 5 e 9 anos $(33,4 \%)$; e quatro, entre 11 e 13 anos (19\%). Observa-se a concentração de crianças de mais baixa idade nos serviços investigados; $57,1 \%$ das crianças são meninos.

- 12 frequentam a escola (57,1\%): cinco crianças até 5 anos de idade têm registros institucionais que identificam sua inserção na pré-escola ${ }^{4}$ (13 estão nesta faixa etária); seis acolhidos na faixa dos 6-14 anos estão na primeira etapa do ensino fundamental e um deles está no ensino especial (já que é portador de necessidades especiais). No grupo de 12 estudantes, 25\% apresentam defasagem entre série e idade de dois ou

4 Etapas de ensino no Brasil: educação infantil - creche, até 3 anos de idade; pré-escola, 4 e 5 anos. Ensino fundamental de nove anos - anos iniciais (faixa etária de 6 a 10 anos de idade, com cinco anos de duração) e finais (faixa etária de 11 a 14 anos de idade, com quatro anos de duração). 
mais anos. Em oito casos estudados, sete crianças menores de 6 anos e um adolescente estão fora da escola.

- $\quad 85,7 \%$ das crianças/adolescentes moraram com alguém com problema atual com o uso de drogas/crack, nos últimos 30 dias antes do acolhimento, o que indica o convívio com drogas no ambiente primário de socialização. As mães, seguidas pelos pais, são os principais usuários de crack relatados. Em apenas um caso é a tia que usa crack.

- 12 crianças/adolescentes apresentam algum problema de saúde $(57,1 \%)$ : hepatite C (um), HIV e outras doenças infectocontagiosas (dois), doenças congênitas/genéticas (quatro), comportamento agressivo (quatro), comportamento depressivo ou ansioso (um), deficiência física (um), deficiência mental não especificada (um), outro tipo de deficiência (dois). Outros problemas apontados em sete acolhidos são: alopecia, crises convulsivas, encoprese, enurese, dificuldades respiratórias, queloides.

- $\quad 23,8 \%$ já haviam sido acolhidos em outros SAls, indicando trajetória de institucionalização prévia e 28,6\% têm histórico de vivência de rua.

- $66,7 \%$ dos responsáveis pelas 21 crianças/adolescentes e apenas dois acolhidos foram encaminhados para tratamento por uso de crack.

A maioria dos acolhidos tem familiares morando na cidade de São Paulo $(95,2 \%)$. A manutenção do vínculo com a família durante o período de acolhimento é relatada em $38,1 \%$ dos casos; $4,8 \%$ das crianças/adolescentes não têm mais vínculo; 38,1\% têm impedimento judicial de contato; 19\% têm família desaparecida. Apenas 33,3\% recebem visitas na instituição, especialmente dos pais, seguidos pelas avós/irmãos e outros parentes ou responsáveis.

A dependência química dos responsáveis é principal motivo que levou crianças e adolescentes ao acolhimento institucional (85,7\%), seguida bem à distância por negligência familiar (42,9\%) e situação de rua (233,8\%). Razões menos observados foram: abandono pelos pais ou responsáveis (19\%), carência de recursos materiais da família/responsável (14,3\%), entrega voluntária da criança/adolescente pela família de origem (14,3\%), exploração no trabalho ou mendicância (14,3\%), ausência dos pais ou responsáveis por prisão (4,8\%), pais ou responsáveis com transtorno mental (problemas psiquiátricos/ psicológicos) (4,8\%), violência doméstica física $(4,8 \%)$ e psicológica $(4,8 \%)$. 
O uso específico de crack pela criança ou adolescente não foi apontado como motivo de acolhimento.

No que se refere aos dados sobre a institucionalização em SAls, entre as 21 crianças e adolescentes identificadas pelo uso pessoal ou familiar de crack, $57,1 \%$ estavam na instituição há menos de um ano, 19\% há um ano, 19\% há dois anos e 4,8\% há três anos. Em todos os prontuários consta procedimento administrativo na Vara da Infância e Juventude, como, por exemplo, pasta especial ou processo. Boa parte dos prontuários aborda a questão do consumo de crack por parte da criança/adolescente ou seus responsáveis, descrevendo o fato e/ou os encaminhamentos realizados em decorrência do problema (66,7\%).

Quanto ao encaminhamento das crianças e adolescentes para os serviços nos últimos 12 meses, destacam-se o Poder Judiciário e o Conselho Tutelar (38,1\% cada). Outros SAls respondem por $19 \%$ e a SMADS, por $4,8 \%$ dos encaminhamentos.

No que se refere à situação legal das 21 crianças e adolescentes investigados, constata-se que: não há nenhum legalmente encaminhado para adoção, aguardando colocação em família adotiva; nenhum está com a destituição do poder familiar concluída, mas ainda sem encaminhamentos efetivos para adoção; e quatro estão em processo de colocação para adoção, ou seja, iniciando a aproximação com adotantes (19\%).

Esses resultados a princípio significariam que há 19\% de crianças e adolescentes usuários de crack ou cujos responsáveis consomem essa substância que preencheriam critérios para a condição legal de adoção. Entretanto, segundo os seus prontuários e informações dos técnicos, todas essas quatro crianças ainda estão com a destituição do poder familiar em tramitação. Logo, a possibilidade de adoção é precária. As demais crianças e adolescentes estão nas seguintes condições: seis em fase de avaliação/preparação para reintegração/ retorno ao convívio com os responsáveis (28,6\%); dois com suspensão do poder familiar (9,5\%); 11 estão com a destituição do poder familiar em tramitação (53,3\%); e nenhum tem processo tramitando de guarda/tutela ou com sentença pendente de recurso. Para dois acolhidos há ausência de informação sobre a situação legal nos prontuários.

Nenhum adolescente envolvido com o uso de crack e outras drogas está em cumprimento de medida socioeducativa de liberdade assistida nos SAls investigados. 


\section{$\mathrm{O}$ atendimento oferecido às crianças, adolescentes e suas famílias}

Os Creas e Caps ad são as instituições com que os SAls mais se relacionam para apoiar o atendimento aos acolhidos com problemas decorrentes do uso de crack, seja por saberem a localização, trocarem informação, realizarem reuniões periódicas e/ou fazerem encaminhamentos. Poder judiciário, Ministério Público e Conselho Tutelar são considerados minimamente articulados aos SAls.

Entre os três SAls que informam oferecer ações para crianças e adolescentes usuários de crack, apenas dois mencionam atendimento médico, psicológico, psiquiátrico e jurídico, atenção às dificuldades de aprendizagem, tratamento para dependência química, atenção voltada à orientação sexual, encaminhamento para trabalho, inserção em programas de trabalho protegido, atividades esportivas e culturais, grupos de ajuda mútua e atividades com participação da comunidade. Apenas um serviço relata ações para crianças e adolescentes com deficiência e atividades religiosas.

No que se refere aos serviços fornecidos às famílias das crianças ou adolescentes, ressalta-se a menção a acompanhamento social e a programas de profissionalização dos familiares em dois SAls. As seguintes ações foram apontadas por apenas um SAI: atendimento psicológico/psiquiátrico, tratamento de dependência química, inserção em programa/serviço oficial ou comunitário de auxílio/proteção à família, assistência jurídica, orientação para planejamento familiar, atividades culturais, atendimento médico e apoio financeiro e material.

As ações voltadas para os acolhidos ou seus familiares mostram-se esparsas mesmo entre os poucos serviços que informam a respeito delas. As visitas e entrevistas realizadas indicam a mesma direção, evidenciando a ainda frágil rede de apoio para pessoas em situação de tamanha vulnerabilidade.

\section{Serviços destinados aos usuários infantojuvenis de crack}

O município de São Paulo vivenciava no momento da pesquisa uma situação em que, segundo a Prefeitura e os respectivos gestores, todas as crianças e adolescentes usuários de drogas estavam sendo encaminhadas para abrigos especiais, de acordo com o recomendado pela política municipal. Os três abrigos especiais, ligados à assistência social, aqui denominados: A (localizado na região central), B e C (localizados na zona leste do município), são descritos a seguir.

Constatamos, ao longo da pesquisa, que os adolescentes usuários de drogas costumavam ficar alguns dias em abrigos destinados à população 
infantojuvenil com vários tipos de vulnerabilidade social e, posteriormente, eram encaminhados para um desses abrigos especiais.

Eu cheguei aqui através do Conselho Tutelar lá da Zona Norte, aí eles me encaminharam pra cá, aí me transferiram pro pernoite lá em um outro abrigo que eu não conheço, de criança, aí eles me transferiram pra cá. Foi aqui que eu tive essa oportunidade de estar acolhido, mas daqui não tenho muito que reclamar não, porque se não fosse aqui eu não seria nada nesse momento, estaria na rua usando drogas, capaz de tomar um tiro ou ir preso. (José, 16 anos, abrigo especial)

Outro fato que ocorria com os serviços de acolhimento de uma forma geral é que vários deles eram descadastrados e outros, cadastrados, indicando uma grande labilidade na atenção oferecida. É comum que instituições mais antigas ou vinculadas à Igreja (e talvez com maior distanciamento da política pública atual) estejam sendo descadastradas; ao passo que serviços mais recentes vêm tornando-se conveniados à prefeitura.

\section{Abrigo especial A}

Este serviço tinha apenas cinco meses de funcionamento no momento da pesquisa. Trata-se de uma organização não governamental (ONG) sem orientação religiosa. É dedicado a usuários de drogas e em situação de rua. Tem equipe técnica própria, com assistente social, psicólogo e pedagogo, que informa ter passado por capacitação sobre o tema do crack. O abrigo realiza reuniões periódicas com o Conselho Tutelar, Poder Judiciário, Ministério Público, SMADS, bem como com serviços de saúde (física e mental).

Não havia nenhuma criança com história de uso de drogas na visita da pesquisa. Naquele momento, estava com dez adolescentes acolhidos: todos com uso de drogas em geral (seis deles incluindo o crack). Todos os jovens tinham pais usuários de drogas e dois deles usavam crack.

Segundo informações do gestor, são oferecidas atividades de forma regular: ensino, atendimento médico, psiquiátrico e psicológico, tratamento para dependência química, orientação sexual, curso de capacitação, encaminhamento para trabalho, inserção em programas de trabalho protegido, grupos de ajuda mútua e atividades religiosas, esportivas, culturais e comunitárias. Para as famílias das crianças e adolescentes que usam crack, são oferecidos de forma regular o acompanhamento social e o encaminhamento para tratamento de dependência química. 
Entre os dez adolescentes no abrigo, para sete deles foi possível coletar informações individualizadas. São eles: cinco meninos e duas meninas na faixa dos 14-18 anos de idade. Três deles têm a pele branca; dois, preta e um, parda. Para cinco deles há informações mais detalhadas sobre suas vidas:

- convivem com a família de origem e não têm histórico de situação de rua; dois já estiveram acolhidos em outros SAls;

- obtêm dinheiro das seguintes formas: prostituição na rua, furtos, roubos, violência sexual, tráfico de drogas, o que denota a situação de vulnerabilidade em que se encontram. Apenas um comenta ter trabalhado legalmente, em supermercado. Quatro já foram detidos, por tráfico, furto, roubo, posse de drogas, desmonte de carros, formação de quadrilhas;

- quanto ao elevado consumo de substâncias psicoativas, tem-se que: três deles usam álcool (dois diariamente nos últimos 30 dias antes do acolhimento); todos consomem tabaco diariamente; três usam maconha diariamente; todos consomem cocaína (quase todos diariamente), mesclado (quase todos diariamente), crack (todos usam diariamente), oxi (três), produtos para sentir "barato" (todos); um adolescente relata ainda heroína/ópio/morfina, remédios "para ficar ligado", tranquilizante/ansiolítico/calmante;

- o tempo de uso de crack oscila entre dois e cinco anos, e a quantidade de pedras varia entre uma e cem pedras ao dia. Três utilizam crack em forma de cigarro, dois como baseado, três em lata, quatro em cachimbo e um em uma garrafa de yakult. Todos reutilizaram cachimbo, lata ou copo de outras pessoas; todos já misturaram crack com outras drogas, como maconha, cocaína e oxi em elevada frequência. Um jovem já usou drogas injetáveis. Quatro tiveram overdose. O principal lugar do consumo do crack é a rua. Quem mais fornece o crack para o uso são amigos e traficantes. Dois têm irmãos que usam crack e outras drogas e três têm pais com tal uso;

- quatro desses jovens consideram sua saúde boa e um, satisfatória. Porém todos fazem sexo sem camisinha e um já transou com portador de hepatite ou HIV. Contradizendo essa percepção, constata-se que, antes do acolhimento, eles tinham passado por variados serviços públicos, mesmo em idade tão precoce: posto ou centro de saúde/ambulatório/ UPA (quatro); emergência (três); Caps ad (três); serviços de assistência 
social para conseguir emprego (três); abrigos (todos); serviços que fornecem alimentação gratuita (três); internação em hospital (dois); serviço de internação para tratamento de dependência (um); hospital psiquiátrico (um); clínica especializada (um); Comunidade Terapêutica (um).

Os profissionais do abrigo especial relatam que falta apoio da Prefeitura e de integração com a área da saúde mental infantojuvenil. $\mathrm{O}$ abrigo não tem acesso a Caps i. A infância e a adolescência parecem ficar muito de lado nesse serviço, que é amplo e atende pessoas de todas as faixas etárias. Observamos adolescentes ociosos sem trabalho direcionado, além da dificuldade de articulação com a escola, pela falta de documentação necessária. A questão disciplinar parece difícil (usam maconha, cocaína e cigarro na instituição), até mesmo durante uma de nossas visitas. Enquanto preenchíamos o questionário com um adolescente, ele aceitou um cigarro de maconha que lhe foi oferecido por colegas e realizou a entrevista fumando o cigarro.

\section{Abrigo especial B}

É uma Casa de Passagem que funcionava há dez meses no momento da pesquisa. Trata-se de uma ONG sem orientação religiosa. Prevê o atendimento a usuários de drogas, com transtorno mental, doenças infectocontagiosas, em situação de rua e ameaçados de morte. Dispõe de equipe técnica própria, com assistente social, psicólogo, assistente técnico e gerente - todos sem capacitação específica para o tema do crack e outras drogas. A unidade demonstra pouca articulação com os órgãos da rede socioassistencial, segundo informações dadas pelo gestor: dentre um amplo leque de instituições da rede socioassistencial, a articulação existente é feita apenas com o Conselho Tutelar, Caps ad e Caps i. Dessas instituições, o gestor informa saber a localização, sem que haja troca de informações e reuniões periódicas com nenhum serviço dessa rede.

Nessa unidade estavam presentes no momento da pesquisa sete crianças e sete adolescentes com histórico de uso de drogas (que não o crack).

\section{Abrigo especial C}

Este abrigo funciona há 16 anos e é uma Casa de Passagem não governamental. Tem uma orientação religiosa ecumênica, com possibilidade de acolher crianças e adolescentes com as seguintes especificidades: usuários de drogas, com transtorno mental ou doenças infectocontagiosas, em situação 
de rua e ameaçados de morte. Tem equipe técnica própria, com psicólogo e assistente social que já recebeu capacitação sobre o tema crack e outras drogas. A unidade informa se articular com poucos órgãos da rede socioassistencial, no que se refere à troca de informações e à realização de reuniões periódicas com Caps ad, Caps i e outras ONGs.

No momento da pesquisa o abrigo tinha cinco crianças acolhidas, todas sem histórico pessoal de substâncias psicoativas, porém com pais que usavam crack e outras drogas. Entre os 12 adolescentes abriagdos, não há histórico pessoal ou familiar de uso de drogas.

\section{A VISÃO SOBRE O CRACK E SUAS CONSEQUÊNCIAS, SEGUNDO OS AdOLESCENTES USUÁRIOS, AS FAMÍLIAS E OS PROFISSIONAIS DE SAÚDE E ASSISTÊNCIA SOCIAL}

Trataremos nesta seção mais das crianças, adolescentes e famílias foco de nossa avaliação, apontando para a realidade em que vivem, suas histórias de vida e os caminhos que os levaram ao uso da droga e aos serviços de acolhimento, seja da saúde, da assistência social ou da justiça. Conversamos com alguns personagens envolvidos com o crack: adolescentes inseridos em SAls e em serviços de saúde, assim como seus familiares, que gentilmente compartilharam suas histórias de vida e nos emocionaram com toda a dureza e a esperança que os acompanham em suas trajetórias de redenção e luta. Os quatro adolescentes são: José, 16 anos, e Abel, 17 anos, acolhidos em SAl; Marta, 16 anos, e Júlia, 18 anos, em Caps i. Duas mães de usuários de crack foram entrevistadas: sra. Odete, mãe de menina atendida em Caps i, e sra. Luísa, mãe de menino no abrigo especial $A$.

Profissionais da saúde, assistência social e justiça envolvidos com os cuidados a crianças, adolescentes e famílias nos ofereceram suas ricas opiniões sobre as causas e consequências do uso/abuso do crack para a saúde física e psíquica dessa população. Informações sobre o perfil dessas crianças e jovens constantes dos prontuários dos acolhidos em SAls também nos ajudaram na caracterização desses sujeitos.

É claramente perceptível que a vida de adolescentes envolvidos com o crack é permeada por situações de privação de direitos, exclusão social e violências de diversos tipos. Ao iniciar a conversa, pedindo que contassem sobre sua vida, ouvimos relatos de bastante sofrimento e sentimentos de rejeição. Da mesma 
forma que os jovens entrevistados revelam uma trajetória de uso de muitas drogas até chegar ao crack, todos trazem histórias de recaídas, de dificuldades de abandonar esse caminho e, ao mesmo tempo, reconhecem os danos trazidos pelo uso da droga e a necessidade de parar de consumi-la.

Abel relata logo ao início da conversa:

Eu só queria saber de drogas, de tráfico, roubar gente, tirar as outras coisas das outras pessoas. (...) Eu não tinha nada, minha mãe não queria saber mais de mim, na escola muitos problemas. Eu tenho duas filhas, uma menina e um menino. (Abel, 17 anos, SAl)

Outro menino entrevistado parecia estar sob efeito do uso de drogas durante a entrevista, apresentando uma fala muito confusa e truncada. Ainda assim narra um episódio em que foi vítima de violência sexual. Relata o consumo e tráfico de muitas drogas e afirma todo o tempo que pretende parar de usar drogas, mostrando-se muito agitado e ansioso.

Conheci a maconha, o crack, a cocaína, a cola, o tíner, o lança, aí conheci isso, depois comecei a usar tudo. A rua me levou a conhecer a droga, comecei a roubar, roubar, aí foi quando eu comecei a traficar, foi quando eu fui preso. Depois fiquei um mês fechado na Fundação Casa, voltei, pedi ajuda, saí de lá, comunicaram minha família e eu não queria ajuda dela não. Nunca quis a ajuda deles. Botei na minha cabeça, não quero ajuda, quero sair dessa droga, eu vou sair dessa droga. Foi quando uma técnica me ajudou, me trouxe pra cá, e eu estou aqui feliz e alegre. A tia e o educador são como um pai pra mim, a [técnica] me dá apoio, me dá ajuda, se eu quiser, se eu tiver doente. (José, 16 anos, abrigo especial)

Júlia relata sua difícil vida com o uso do crack:

Eu jogava futebol feminino antes de conhecer as drogas. (...) Quando eu conheci a cocaína, me viciei. Depois passei pro crack, aí quando a minha vida desmoralizou de uma hora pra outra, parei de estudar, saí de casa e vim parar no centro. Aí foi quando eu conheci o Caps, - Caps me ajudou com vários recursos, consegui um emprego, só que aí eu tive algumas recaídas. (...) Hoje eu estou numa residência terapêutica, mas hoje eu estou bem melhor graças ao Caps e à residência terapêutica. $\mathrm{O}$ meu objetivo é voltar a estudar, conseguir um emprego e terminar meu estudo, porque eu parei no ensino médio. Preciso pagar a faculdade de educação física. É o que eu pretendo, é o meu sonho. (Júlia, 18 anos, Caps i) 
Marta foi estuprada na rua após uma overdose. Foi encontrada sem consciência e levada para o hospital. Chora ao contar sua história. Ficou internada com graves ferimentos na região genital. Conta que já passou por tudo quando usava drogas. Tem um irmão preso por homicídio e tráfico. É uma menina travesti (menino que se transformou em menina), tem aparência feminina e se veste com roupas femininas. Relata ter usado crack por cinco anos, tendo iniciado o consumo da droga em decorrência da "revolta pela minha opção sexual; e depois eu fugi de casa. Comecei pela maconha e depois foi a cocaína e depois fui direto para o crack" (Marta, 16 anos, Caps i).

O múltiplo uso de drogas é relatado pelos profissionais da saúde e da assistência social, que, todavia, reconhecem o crack como uma droga diferenciada, que parece estar no topo de uma pirâmide que tem como base o consumo de outros tipos de substâncias psicoativas. Essa combinação de drogas, de acordo com Nappo, Galduróz e Noto (1996), é uma característica marcante do atual padrão compulsivo de uso, substituindo gradativamente o uso exclusivo, relatado na primeira descrição da cultura de crack na cidade de São Paulo. Os profissionais entrevistados mostram suas visões sobre essa questão, embora na literatura as motivações subjacentes ao uso múltiplo de drogas sempre permaneceram pouco esclarecidas (Magura \& Rosenblum, 2000; Pennings, Leccese \& Wolf, 2002).

Tem uma história já de abandono ou de já sair das ruas, ou de um uso anterior de solventes. Inclusive a gente tem grupo aqui em conjunto com o Caps i que acompanha meninos que fazem uso de solvente e que não circulam pelo território do crack. É muito mais em Anhangabaú, em muitos lugares onde não tem crack e que, quando os meninos começam a ter contato, eles saem desse grupo; porque esse grupo não o reconhece mais porque ele está em outra história. Então o que a gente vê é que tem um processo de vulnerabilidade que às vezes já passou até pela cocaína antes do crack. O crack, na verdade, só vai catalisar um processo de degradação maior. Degradação da própria saúde ou dos próprios meios para obter e se manter no uso de substâncias. (coordenador de Caps ad)

Profissionais da área da assistência social relatam que, com o projeto Caps na Rua, foi possível mapear um pouco do movimento das crianças e adolescentes usuários de drogas no território, distinguindo o perfil dos que consomem crack em relação ao dos usuários das demais drogas. A coordenadora do Complexo Prates também corrobora a percepção do coordenador do Caps ad quanto à 
existência de uma espécie de territorialização marcada por características de consumo das drogas, como se fosse um caminho percorrido pelos adolescentes até chegar ao crack: os jovens do parque Dom Pedro e da Sé usam mais maconha e envolvem-se mais no tráfico, os meninos do Vale do Anhangabaú consomem mais o tíner, e os jovens da República e da Nova Luz preferem o crack.

A fala dos coordenadores também revela que esses jovens tendem a proteger o grupo a que pertencem.

Eles tinham uma coisa assim: "não; o crack não; o crack a gente não vai". Tinha uma coisa de inclusive querer proteger o grupo. Se tivesse algum menino que começava com um envolvimento de querer ir pra lá... Agora, tinha uma hora que eles iam. (coordenador de Caps i)

Aqui dentro desse serviço, a gente percebe que tem muitos meninos que, quando entra aqui um usuário de crack, ele é totalmente isolado, porque o menino quando ele chega no crack é porque ele está no fim. (...) Eles isolam aquele menino. (coordenador do Complexo Prates)

Os profissionais indicam também como causa ao uso do crack a existência de uma trajetória crescente do uso de drogas associada a problemas sociais e familiares.

Olha, pela minha experiência, eles vão começando por pequenas drogas, saem dos seus domicílios. Vem associado com a questão da violência intrafamiliar, que está em incompatibilidade com esses arranjos da família. Saem pras ruas e aí começam a usar as drogas. E vai começando pela maconha, inalantes, até o ponto de chegar... como já foi feito um estudo dessa trajetória. Saem das periferias para as regiões centrais e vieram também desse percurso pra cracolândia, onde se concentrou esse polo. Infelizmente. E aí o acesso ao crack. (gestora da SMADS)

No estudo desenvolvido por Oliveira e Nappo (2008), o uso múltiplo de drogas surge como uma possibilidade de manipular a intensidade ou a duração dos efeitos de crack, seja como paliativo aos efeitos negativos, seja para intensificar ou prolongar os efeitos positivos. As drogas associadas mais frequentemente citadas foram: álcool, maconha e cloridrato de cocaína.

Falhas na linha de cuidados do Estado e da família são trazidos como causa para o uso do crack na adolescência. É o que nos mostram algumas falas dos profissionais entrevistados: "abandono familiar num primeiro 
momento e depois abandono por parte do Poder Público". Conforme nos diz a promotora entrevistada:

São crianças e adolescentes que às vezes já nascem filhos de dependentes químicos, em relação aos quais o trabalho do Poder Público é incipiente. Eu não tenho dúvida que o Estado é falho no que diz respeito ao resgate, ao tratamento. Isso a gente vê nas entidades de acolhimento. Nas entidades de acolhimento de crianças e adolescentes, seus funcionários não estão capacitados para lidar com essa população.

Os coordenadores da área da saúde entrevistados (Caps i, Caps ad e Projeto Equilíbrio) ressaltam também que os jovens que fazem uso de drogas (incluindo-se o crack) têm histórias de vida muito semelhantes, permeadas por rompimentos e conflitos familiares.

Aquela velha história, por exemplo, que o adolescente não vai para rua porque ele usa droga. Ele acaba indo para a situação de rua pra ficar muito mais tempo longe de casa por questões anteriores. Isso a gente vê aqui completamente nos Caps, que a gente acompanha... as questões estão de fato lá na estruturação familiar, nas relações familiares, no contexto dessa família, que muitas vezes está relacionado com as condições de vida. (coordenadora de Caps i)

Crianças, adolescentes ou famílias que acabam vivenciando esta situação de uso é porque já vêm num processo de degradação das condições de vida e de organização social, econômica, familiar, já de um tempo. Então há um processo de vulnerabilização desse grupo, muito anterior ao chegar ao crack. O crack é quase como uma catalisador nas etapas finais num processo de agravo. (coordenador de Caps ad)

O que nós temos aqui são crianças que sofreram muita violência física, violência sexual e situações obviamente de negligência física e emocional, e que elas acabam indo pra rua. Elas acabam indo pra rua até como fuga desse ambiente hostil. $O$ crack também é um tipo de alívio pra dor emocional que eles sentem. Isso que a gente vê aqui. (coordenadora do Projeto Equilíbrio)

É importante destacar que, de fato, estudos defendem que a família e a rede social de apoio exercem um papel de fundamental importância durante todo o processo, desde a busca e utilização das drogas até o momento da intervenção terapêutica. No entanto, a maioria dos estudos de revisão sobre famílias de 
dependentes químicos confirma que o universo familiar dessa população é frequentemente disfuncional (Guimarães et al., 2009).

$\mathrm{Na}$ visão dos adolescentes usuários, os motivos que os levaram ao uso do crack são muito mais pessoais, ficando a responsabilização atribuída ao núcleo familiar ou a si próprios, tal como presente na "revolta" sentida por Marta, pela não aceitação de sua orientação sexual por parte da família, e outras situações descritas pelos adolescentes entrevistados.

Me levou ao uso, porque eu agredi a minha avó. A minha mulher destruiu a minha vida mais um pouquinho, não me dando valor, falava que me amava. Depois que eu perdi o meu pai. (José, 16 anos, abrigo especial)

Porque eu não sei lidar com a perda da minha mãe. Eu não sei lidar ainda até hoje com a morte da minha mãe, muitas vezes que eu penso nela, que eu sinto saudade, eu tento me martirizar. (Júlia, 18 anos, Caps i)

Percebe-se na fala das mães entrevistadas a culpabilização pelo uso de drogas de seus filhos. Uma delas, que no momento da entrevista estava com hematomas no rosto e no corpo devido à agressão de seu companheiro (ele havia acabado de ser preso por denúncia de agressão por parte da mesma) nos diz: "Às vezes os filhos começam a usar droga pra chamar atenção da gente. (...) Foi internada de novo por minha vontade, não pela vontade dela, e assim não resolveu porque o problema estava dentro da minha casa" (sra. Odete, Caps i).

Uma outra mãe também tenta encontrar um motivo:

Até hoje se eu falar pra você que eu sei o motivo, eu não sei. Claro e lógico que eu tenho uma parcela de culpa nisso, mas eu estou tentando encontrar qual foi o meu erro, pra poder eu reparar. Porque um dia ele vai sair daqui. Eu tenho que saber o que fazer quando ele sair daqui. (sra. Luísa, SAl)

Quanto às consequências do uso do crack para a vida de crianças e adolescentes, todos os profissionais entrevistados dizem que "é diferente" das outras drogas: os efeitos são bastante degradantes e "detonadores". Chamam a atenção para o fato de que os efeitos do uso do crack dependem das características individuais, do apoio que recebem e dos vínculos que são capazes de estabelecer com quem os acolhe. Consequências físicas e cognitivas são também apresentadas. 
Foram citados efeitos comuns, como falta de atenção, difilculdade de dar respostas, alterações de comportamento (alguns muito agitados, outros com muito sono), maior intolerância, problemas psicomotores e de relacionamento com pares, profissionais e familiares. O coordenador do Caps ad considera que as consequências também dependem de cada um e das possibilidades de laço social, podendo por essa combinação ser melhor ou pior o prognóstico. Agravos fisiológicos também foram mencionados: problemas pulmonares (muitas pneumonias), ferimentos nas mãos e nos lábios, desnutrição, dificuldades na alimentação. Quanto às consequências cognitivas, destacaram-se prejuízos na vida social (dificuldade de reintegração) e escolar (problemas de aprendizagem).

Uma profissional destaca a urgência com que os cuidados devem ser oferecidos, considerando-se as graves consequências que a droga acarreta para esses meninos e meninas.

É engraçado que eles ficam aqui dois, três dias e você percebe a mudança, mudança na pele, mudança no olhar, brilho, muda tudo. Você consegue perceber nas mínimas coisas o quanto faz bem. Eles chegam bem acabados. Eles ficam dormindo dois, três dias, a gente percebe, levanta, come e dorme, levanta, come e dorme, toma banho e dorme, dorme, dorme, dorme; no terceiro e quarto dia, ele é outra criança. Você olha pra mão, não é a mesma, muda tudo, a pele, muda o olhar, muda a maneira de se colocar, de falar, de sentar na mesa e se alimentar. (coordenadora do Complexo Prates)

Entre as mães entrevistadas, uma delas enfatiza a degradação da filha que "fazia programa ali na Estação da Luz e fumava e ficava sem tomar banho. Uma coisa assim horrível, ficava muito agressiva" (sra. Odete, Caps i). A outra mãe entrevistada atribui ao uso do crack e de outras drogas o abandono da escola. É interessante que ambas falam de danos à sua própria saúde mental, mostrando consciência da necessidade de buscar tratamento para si próprias. São relatos que demonstram o quanto o uso de drogas pelos filhos atinge e vulnerabiliza a família como um todo.

Eu comecei também a fazer tratamento pra mim poder começar a entender como eu deveria tratar a minha filha. (sra. Odete, Caps i)

Eu caí numa depressão profundíssima. Eu trabalhava e não conseguia mais trabalhar. Eu não conseguia desenvolver atividade nenhuma. Nem com elas [as filhas pequenas] até. Eu errei demais, então eu procuro fazer pra não errar com elas. Então eu não conseguia 
trabalhar e eu cheguei a ficar mais de dois meses sem colocar a cara no portão de casa. (sra. Luísa, abrigo especial)

Para os adolescentes, os efeitos do crack são valorizados pelas sensações que o uso da droga proporciona: "adrenalina", "vista ficava meio embaralhada", "muita ansiedade de voltar a usar", "vontade de roubar", "sair do mundo real", "ficar numa fantasia", "depressão que vem depois", "ficar ligado", ou "muito acelerado”.

Uma adolescente fala das consequências percebidas física e cognitivamente:

Na saúde física eu emagreço muito, e depois do uso de crack que eu fiz durante esses três anos, que eu comecei com 15 anos e estou com 18, eu percebo que a memória já não é mais a mesma, tipo você calcular algumas coisas, pensar rápido ou lembranças. (adolescente, Caps i)

Terminamos essa seção sobre a visão dos diferentes atores entrevistados com uma impactante definição dessas crianças e adolescentes usuários da droga, trazida por uma profissional da área da justiça:

São crianças e adolescentes que têm todos os seus direitos fundamentais violados. O direito à saúde e educação é violado porque não são matriculadas e não permanecem na escola, porque a escola também não está capacitada para atender esse tipo de criança. Direito à saúde, educação, convivência familiar e comunitária. São crianças e adolescentes abaixo da sociedade, com absolutamente todos os seus direitos violados. Todos os direitos que a Constituição Federal fala que são prioridade absoluta lá no artigo 227; pelo Estatuto da Criança e do Adolescente são crianças e adolescentes com todos os seus direitos violados. O primeiro deles é a saúde porque não recebem tratamento adequado. Muitos deles nem sequer sobrevivem. (promotora)

\section{A VisÃO dOS ADOLESCENTES, DOS FAMILIARES E dOS Profissionais Sobre o Atendimento nos SERVIÇOS DE SAÚDE E DE ASSISTÊNCIA SOCIAL}

Tanto para os quatro adolescentes, quanto para as duas mães entrevistadas, os serviços em que, no momento da entrevista esses jovens se encontravam, foram muito elogiados e tidos como uma grande esperança de recuperação. Especialmente para as mães, pudemos perceber que elas buscam de fato um local com acolhimento, pessoas que as apoiem, que as façam ser úteis no tratamento 
dos filhos e especialmente as orientem, já que se sentem muito impotentes e fragilizadas. Uma das mães, transparecendo todo seu desespero em ajudar a filha, fala à pesquisadora que considera importante que o tratamento seja feito mesmo contra a vontade do usuário.

As três internações compulsórias que ela teve não conseguiram resultado porque ela recaiu. Mas a pessoa sai bem melhor. A pessoa começa a compreender que ela tem uma doença, que essa doença existe, que essa doença não tem cura e ela precisa ser tratada. Agora se você for na Estação da Luz, você vai ver meninas de 12, 13 anos grávidas, em situação de rua. Porque eu sou uma mãe que não abandona, mas tem mães que abandonam. (...) Vê com as autoridades pra mudar essa lei, pra eles pegarem mesmo, investirem no tratamento à força mesmo. (sra. Odete, Caps i)

Ouvimos de uma promotora que o município havia começado, na cidade de São Paulo, a operação Centro Legal, e que essa atuação da polícia colocou a perder o pouco que se tinha sido conseguido na cracolândia. Segundo a profissional, acontecia no município uma ação no sentido de aumentar o número de Caps, acompanhar, cobrar e visitar a instalação dos Cras e dos Creas, e trabalhar para integrar os serviços da saúde e da assistência social:

A impressão que nós tivemos no decorrer dessa apuração foi que vinha caminhando no sentido adequado; ainda pequeno, incipiente, mas aprendendo; e, pelo menos aqui no centro de São Paulo, vinha caminhando. Com essa operação policial o pouco que vinha sendo feito se perdeu. (promotora)

Para essa entrevistada, que se mostra contra ações de recolhimento compulsório, existem profissionais competentes no município, mas falta a elaboração de uma política consistente que se debruce seriamente sobre o tema.

Não é tirando os dependentes químicos da região central ou da vista da população que vai resolver o problema. É um trabalho extremamente difícil. É um trabalho que tem que ser feito muito aos poucos. Tem que ser feito um trabalho de convencimento. Não adianta tirar os dependentes químicos do centro e colocá-los numa residência terapêutica ou numa comunidade terapêutica, porque eles precisam querer o tratamento. (promotora)

Pelo lado dos profissionais que atuam diretamente com esses jovens, é precário o conhecimento sobre o que acontece nas instituições da rede. 
O Conselho Tutelar, por exemplo, desenvolve apenas um papel de recepção e encaminhamento das crianças e jovens usuários de drogas. $\mathrm{O}$ trabalho fragmentado é visível e refletido na fala de uma conselheira.

A gente liga para essas redes que fazem esse tratamento para saber se tem vaga; tendo a vaga a gente encaminha a criança para fazer esse tratamento de drogadição. A maior parte a gente encaminha para os abrigos. Algumas a gente encaminha lá para o Complexo Prates. Então os abrigos é que procuram esta rede. Essa rede que cuida mais da drogadição. Suponhamos: a criança chega aqui e eu mando para o abrigo porque, quando a gente pede a vaga no Caps, ele já pergunta: "tem problema de drogadição?". A gente fala que tem e o próprio Caps encaminha para os abrigos que têm esse tratamento. Então a gente não fica sabendo muito. Alguns, quando eu sei que têm problemas com drogadição que já veio aqui, eu já peço a vaga no Complexo Prates, porque eu sei que lá é realmente para crianças com problemas de drogadição. Não é sempre que tem vaga, então a gente passa para o Caps, o Caps passa para os abrigos, e os abrigos recebem já sabendo que tem problemas com drogadição. De lá eu não sei para onde eles são direcionados.

O Caps i e o Caps ad visitados na região central mostraram integração entre as equipes, com acompanhamento dos casos em conjunto e ações compartilhadas. São serviços que funcionam no mesmo prédio, o que facilita a comunicação:

Vamos partilhar com... e não encaminhar para outro serviço. Vamos trabalhar em conjunto. Foi feito no ano passado esse entendimento, que fosse realizado assim: chegou no [Caps] i ou chegou no [Caps] ad, é porta de entrada. Não dá para jogar para a população, essa coisa do vai tentando pra ver onde se abrem as portas; ou o município fala, é só ad ou é só i. Chegasse em um dos Caps acolheria, e aí é uma questão da equipe partilhar com outros serviços. (coordenador de Caps ad)

No Projeto Equilíbrio, que atende crianças e adolescentes em situação de vulnerabilidade, outro equipamento da saúde vinculado à universidade, funciona especialmente como referência aos abrigos, interagindo com outros serviços da região. A coordenadora entrevistada diz que o critério decisivo para atendimento é a vivência de maus-tratos por crianças e adolescentes que se encontram abrigadas. 
Indagados sobre as potencialidades do trabalho com a população infantojuvenil usuária de drogas, alguns profissionais destacam conquistas em seu próprio serviço, como por exemplo: conseguir trabalhar com um público bastante heterogêneo, realizar visitas domiciliares para melhor acompanhamento dos familiares, acionar a rede local (já que a maioria dos adolescentes não reside na área onde é encontrado, especialmente aqueles no centro da cidade), resgatar o apoio familiar em alguns casos.

Um aspecto mencionado pelos profissionais e familiares como desfavorável ao atendimento e tratamento é o intenso fluxo de crianças e adolescentes entre as unidades do município, com fugas regulares da instituição. A coordenadora de um SAI nos fala que existe uma "trajetória de institucionalização por abandono". Embora haja crianças e adolescentes que aderem ao tratamento e ficam bem na instituição, há outros que não conseguem permanecer e retornam às ruas. Esse fato parece ser preocupante para os familiares, já que os riscos são maiores quando essas crianças e jovens estão nas ruas da cidade.

Onde eu moro ele é ameaçado de morte e por isso é até mais o meu desespero se ele fugir [do serviço]. De todas as vezes que ele foi abrigado e fugiu, ele não voltou pra casa, ele voltou pra rua. Eu pensando que ele estava abrigado e ele na rua (...). Uma vez em Jabaquara, uma vez em Santo Amaro, Guilhermino Esperança, Grajaú e agora aqui. Cinco vezes. A partir dos 12 anos. (sra. Luíza, abrigo especial)

O relato de uma promotora, responsável por acompanhar e fiscalizar os serviços de assistência institucional do município de São Paulo, é um desabafo em que são narradas situações ocorridas nos abrigos que evidenciam a alta rotatividade e o despreparo dos profissionais:

O que eu posso dizer com um pouco mais de conhecimento de causa é que dentro das unidades de acolhimento institucional, primeiro é que essa população não permanece. Eles são muitas vezes encaminhados porque estão na rua. Entram num dia, pulam o muro e saem. Quando permanecem, muitas vezes eles tumultuam o ambiente porque estão precisando da droga. Precisam de atendimento específico, mas não tem ninguém da saúde dentro desses equipamentos. Só tem funcionários da assistência social. Eu fui entender como é que funciona e perguntei se o profissional do Caps podia dar um atendimento in loco. Disseram que sim, mas pelo jeito isso não parece que seja uma constante. Tem o atendimento 
que o adolescente vai com a equipe do acolhimento até o Caps e tem também a possibilidade dos profissionais do Caps irem até o serviço de acolhimento. Eu nunca ouvi nenhum relato de que isso efetivamente acontecesse. E também não existe um serviço específico de acolhimento. Então, dentro da entidade de abrigo fica o bebezinho de 10 meses que precisa de cuidados específicos, a criança de 4 a 5 anos e o adolescente dependente químico, que às vezes grita, pula o muro e depois volta, acorda todas as crianças durante a madrugada. Os educadores não sabem o que fazer. Eles simplesmente, dentro das entidades, não sabem o que fazer com esse adolescente porque não tem - e aí deveria ter integração com a saúde. E isso não existe. A única coisa que o profissional educador da entidade faz é levar esse adolescente, se conseguir, a um serviço. Levar a um Caps para ser atendido. Como é esse atendimento dentro do Caps, isso eu não saberia te dizer. Eu sei dizer que, pelos resultados, que a gente vê, esses adolescentes pouco ficam nas entidades de abrigo. (promotora)

Todos os depoimentos apresentados, assim como o trabalho de campo das pesquisadoras nesses locais, evidenciam que o número de crianças nessas instituições é muito flutuante e, portanto, diferenças entre dados informados pelos gestores e dados coletados nos serviços podem ter ocorrido em decorrência dessas variações. Essa oscilação é vivenciada também nos serviços de saúde, conforme o relato de uma coordenadora de Caps i.

Tem muita oscilação. Depende muito dos períodos. Por exemplo: essa época do ano a gente começa a se aproximar do verão e tem a questão do final de ano. A molecada dá uma sumida. Uns vão pra praia e passam uma temporada na praia de Santos, Praia Grande, e muitos começam a ficar muito mais na rua porque tem muito mais dinheiro circulando, tem toda a questão do movimento do tráfico, roubo, prostituição. Então, a gente acaba até intensificando muito mais o trabalho de rua do que do serviço. Então, essa oscilação depende também do movimento do território.

Há de fato um consenso entre os estudiosos do tema de que o tratamento para os usuários do crack, especialmente crianças e adolescentes, pode ser eficaz, mas há um alto grau de imprevisibilidade e os índices de abandono são elevados. Para Carlson e colaboradores (2010), os usuários de crack, entre os que utilizam drogas ilícitas, são os que menos procuram ajuda, postergando ao máximo a busca por tratamento, a que em geral recorrem em situações agudas, especialmente na forma de internação, com baixa adesão ambulatorial. 
A adesão ao serviço e ao tratamento parece ser uma preocupação central nas instituições visitadas em São Paulo, tanto no início do tratamento quanto no processo terapêutico, pois a ambivalência é um componente perene no comportamento dessa população. Esse é um dos desafios que necessitam ser mais bem compreendidos nessa empreitada, que é a busca por um cuidado adequado para crianças, adolescentes e famílias usuárias do crack em São Paulo e no Brasil.

\section{Potencialidades E Desafios RelatAdos: uM CAMPO DE FORÇAS}

São Paulo dispõe de uma rede com bastante potencial, por ser jovem, interdisciplinar e por estar em pleno crescimento. Seus profissionais reconhecem esse fato:

Existe conhecimento e existe onde se buscar o conhecimento. $\mathrm{Na}$ ação mesmo da cracolândia, nós ouvimos profissionais médicos e psicólogos que têm larga experiência no atendimento dessa população. Existe material humano para isso e nós temos grandes universidades. (promotora)

Entretanto, são muitos os desafios trazidos pelos profissionais, que parecem estar fazendo uma catarse no momento que falam sobre as dificuldades encontradas. Destacamos a seguir os principais problemas apontados quanto à rede de assistência a crianças e adolescentes usuários de crack na cidade de São Paulo.

Primeiramente, os profissionais entrevistados mencionaram uma indefinição quanto ao serviço responsável pelo atendimento e dificuldades para o atendimento integrado e contínuo, existindo ainda um "jogo de empurra, empurra", deixando muitas vezes a criança ou adolescente em território de ninguém. Essas ações parecem refletir a falta de conhecimento da rede de atenção e até a insegurança profissional para lidar com um fenômeno ainda pouco conhecido e debatido.

Não apenas conhecer, mas também garantir a continuidade da rede é outro desafio mencionado, visto que há mudanças de gestão e muitas vezes se perde tudo o que foi conquistado. Há críticas em relação à responsabilidade do Poder Público de construir e manter uma rede, tornando-a uma política de Estado e não políticas de administração de alguns governos. A coordenadora de um serviço da saúde, o Caps i, corrobora essa reflexão: 
É uma rede que está crescendo, porque, de quarenta e poucos equipamentos, passou de cem. Então, é uma rede que não pode sofrer dissolução de continuidade em mudanças de gestão, no sentido de que isso seria um prejuízo grande. A rede eu acho que ainda não é suficiente. São Paulo ainda tem um certo déficit de serviços de cuidados.

A necessidade de capacitação da equipe profissional sobre o tema do crack foi outro desafio bastante discutido nas entrevistas. A fala do coordenador de uma equipe de saúde retrata essa preocupação.

Eu acho que a formação continuada do quadro, o processo de parceria e crescimento da rede abriu muito campo para profissionais da saúde que são incorporados pela saúde. Mas isso traz um desafio também. Chega uma hora que você até tem instituições que vão lançando profissionais para esse mercado, mas você vai vendo que começa a ficar mais difícil encontrar profissionais qualificados. Você encontra gente sem experiência. (coordenador de Caps ad)

A dificuldade em obter a adesão ao tratamento, conforme já mencionado anteriormente, é um problema que precisa ser melhor estudado. "Fazer ele querer o tratamento", na fala de uma conselheira tutelar, é um dos maiores obstáculos a ser enfrentado por todos que atuam na área do consumo de drogas.

Outro ponto bastante atual e pertinente na atual conjuntura da cidade de São Paulo é enfrentar as consequências do tráfico de drogas. Alguns profissionais entrevistados comentam a dificuldade crescente da gestão municipal em lidar com o aumento do tráfico de drogas e com a criminalização: "cada dia que passa parece que mais drogas entram aqui em São Paulo. Qualquer esquina agora é crack". Essa afirmativa de uma profissional da rede de saúde demonstra um certo receio em relação a uma constatação que parece não estar acompanhada de ações que deem conta desse fenômeno urbano que a cidade vivencia.

E por fim, um desafio que é inerente à condição humana é a angústia desses profissionais de lidar com crianças e adolescentes usuários de crack. Percebe-se que muitas vezes eles falam com pesar e emocionam-se com as histórias de vida desses indivíduos ainda jovens e com suas vidas permeadas por adversidades.

Eu fico muito triste quando eu vejo essas criancinhas chegando aqui com problemas de drogadição. E não é adolescente não, é criança mesmo (...). As mães chegam e falam: "meu filho tem 11 anos e eu 
não estou conseguindo lidar com ele. Eu não estou conseguindo". Onze anos, é criança. Eu falo: "o que é isso minha senhora? Não faça isso pelo amor de Deus". (conselheira tutelar)

Oferecer suporte emocional, teórico e prático a esses profissionais é fundamental para a qualificação dessa rede de atenção a crianças, adolescentes e famílias usuárias de crack. Os profissionais clamam por esse apoio, se não expresso diretamente nas entrevistas, certamente observado nas entrelinhas.

\section{ENCONTROS E DESENCONTROS NA REDE DE ATENÇÃo AOS USUÁRIOS DE CRACK}

É importante ressaltar que desde os primeiros registros do aumento do uso do crack na cidade de São Paulo, e de uma forma geral no Brasil, por volta de 1990, assim como no período de realização da pesquisa (entre 2012 até o início de 2014), mudanças têm ocorrido quanto à abordagem aos usuários de crack e outras drogas.

Um dos primeiros trabalhos sobre o uso de crack na cidade de São Paulo, realizado por Ferri e colaboradores (1997), detectou um aumento da procura de tratamento por parte dos usuários entre 1994 e 1997, em dois serviços públicos ambulatoriais para dependentes de drogas. Esse aumento, segundo o estudo, já ressaltava a necessidade de um conhecimento mais amplo das características desse tipo de usuário que permitisse uma abordagem terapêutica mais eficiente. Alguns dados de literatura, desde o início dos anos 1990, indicavam que a aderência desses usuários a programas de tratamento era ainda menor que a de abusadores de cocaína por outra via de administração ou de outras drogas (Raupp \& Adorno, 2011). Esse fato confirmou-se especialmente na cidade de São Paulo, ao observarmos variações importantes entre os números oficiais de usuários nos serviços de saúde e assistência social e a quantidade de crianças e adolescentes que realmente estavam em atendimento nos serviços.

Frisamos mais uma vez que os resultados aqui apresentados referem-se a um momento específico vivido pelos serviços municipais que acolhem usuários de drogas. Observamos, no período do levantamento de dados para a pesquisa, um despreparo especialmente por parte de atores da assistência social para lidarem com as questões da saúde, em particular com o fenômeno investigado, o que de certa forma é compreensível, visto a dimensão alcançada pelo problema do consumo do crack na infância e juventude em metrópoles como São Paulo. 
Os equipamentos de saúde, por sua vez, demonstraram dificuldade em se aproximar dos abrigos, evidenciando uma importante falta de articulação da rede SUS e da rede de equipamentos da assistência social. Essa questão, conforme mostrada ao longo deste capítulo, ficou bastante nítida na fala dos profissionais entrevistados, que expressam a angústia e a impotência diante problema em foco.

Outra questão que merece destaque é a falta de articulação entre níveis de atendimento primário, secundário e terciário na saúde para a criança/ adolescente usuário de crack. Entendemos que essa integração é fundamental para obter resultados mais positivos. Esse mesmo problema também foi evidenciado entre os serviços da própria assistência social, que parecem realizar trabalhos diferenciados e estanques sem interagir com a área da saúde. As ações mostraram ser fundamentadas em conceitos e práticas distintas, fato que dificulta a continuidade e positividade das propostas de atenção e atendimento às crianças, adolescentes e suas famílias.

A descontinuidade das propostas de abordagem psicossociais aos usuários e suas famílias pareceram ser ocasionadas pelas trocas nas organizações sociais contratadas para executar os serviços, tanto da assistência social quanto da saúde, característica marcante das instituições visitadas no momento da pesquisa.

Torna-se importante registrar aqui os entraves encontrados em identificar as dificuldades e os desafios da abordagem à população investigada, já que muitas vezes nos pareceu ser necessário que os profissionais mostrassem resultados positivos das ações executadas para manter os contratos com as organizações sociais. Algumas vezes, o que foi informado pelo gestor na entrevista formal não correspondia às observações feitas pelas pesquisadoras. Este fato pode mascarar o problema e dificultar que o encaremos de frente.

Destacamos também as lacunas existentes em termos de uma proposta da educação para esta clientela. Apesar de não termos estabelecido contato direto com atores dessa área, percebemos que muito pouco foi relatado pelos profissionais entrevistados no que se refere a ações efetivas na rede pública de educação do município. Pesquisas adicionais são importantes para conhecer melhor as práticas existentes e, principalmente, aprimorar as ações da assistência social, da saúde e da educação.

É fundamental e urgente criar e desenvolver estratégias de trabalho em rede intersetorial. Não basta colocar trabalhadores dos diferentes setores atuando em um mesmo espaço para que a integração efetivamente ocorra. É preciso 
haver investimento em projetos de capacitação, estabelecimento de fluxograma acordado entre os setores e integração dos equipamentos sociais disponíveis no município.

São Paulo é o palco da experiência cotidiana de uma grande cidade com atores e movimentos, que são, ao mesmo tempo, produto e produtores de práticas sociais. Nesse sentido, a existência da cracolândia não é fruto do acaso, mas resultado tanto dos processos de crescimento da cidade e da degradação de seu centro, quanto dos rumos das políticas públicas, as quais, por omissão ou ênfase em estratégias equivocadas, não conseguiram lidar adequadamente com a emergência e propagação do uso de crack.

Quando nos aproximamos dos profissionais da rede de acolhimento a crianças, adolescentes e familiares que sofrem as consequências do crack, sentimos um clima de desconforto e medo, aliado ao sentimento de que se trata de algo ainda em formação e experimentação, emperrado por questões políticas e estruturais. Ao mesmo tempo, percebe-se a consciência de que há uma urgência em unificar reflexões e ações para melhorar a qualidade do atendimento.

Ao ficarmos diante dos usuários, não se sustenta a ideia de uma categoria homogênea e capaz de abarcar todos os consumidores de crack. Somente uma análise que considere os indivíduos com suas trajetórias de vida, motivações e experiências; o entendimento dos complexos comportamentos, do contexto no qual a substância é tomada, das cenas de uso, das companhias, dos significados atribuídos ao uso da droga; e a percepção social reinante sobre a droga, será capaz de dar conta dessa realidade complexa.

Ressaltamos que, especialmente no momento da pesquisa, a região da cracolândia era o alvo de projetos e políticas públicas para lidar com o problema da droga, especialmente o crack, algumas vezes reprimindo, outras buscando modificar o espaço urbano, tornando-o menos permeável aos grupos desviantes e mais acessível ao controle social. Além disso, parece estar aumentando a consciência de que ações de expulsão dos usuários de drogas da região central da cidade fazem com que eles se desloquem, criando continuamente novas cracolândias. Sabemos que o problema do consumo do crack em São Paulo não acontece apenas no centro, embora tal realidade tenha ficado mais evidente nos dados apresentados neste capítulo. No entanto, as pesquisadoras puderam observar que todos os olhares das autoridades competentes e consequentemente da própria população da cidade, assim como as políticas públicas nesse campo, 
estavam voltadas para o centro urbano, fato que dificultou uma visão mais ampla do consumo do crack e da rede de atenção voltada para infância e adolescência nesse amplo município.

\section{REFERÊNCIAS}

CARLSON, R. G. et al. Predictors of substance abuse treatment entry among rural illicit stimulant users in Ohio. Substance Use \& Misuse, 31 (1): 1-7, 2010.

DUNN, J. et al. Crack cocaine: an increase in the use among patient attending clinics in São Paulo 1990-1993. Substance Use \& Misuse, 31: 519-527, 1996.

FERRI, C. P. et al. Aumento da procura de tratamento por usuários de crack em dois ambulatórios na cidade de São Paulo, nos anos de 1990 a 1993. Revista da Associação Médica Brasileira, 43(1): 25-28, 1997.

GUIMARÃES, A. et al. Family aspects of alcohol and drug-dependent in adolescent girls. Revista de Psiquiatria Clínica, 36(2): 69-74, 2009.

MAGURA, S. \& ROSENBLUM, A. Modulating effect of alcohol use on cocaine use. Addictive Behaviors, 25(1): 177-122, 2000.

NAPPO, S. A.; GALDURÓZ, J. C. F. \& NOTO, A. R. Crack use in São Paulo. Substance Use \& Misuse, 31(5): 565-579, 1996.

OLIVEIRA, L. G. \& NAPPO, S. Caracterização da cultura de crack na cidade de São Paulo: padrão de uso controlado. Revista de Saúde Pública, 42(4): 664-671, 2008.

PENNINGS, E. J.; LECCESE, A. P. \& WOLFF, F. A. Effects of concurrent use of alcohol and cocaine. Addiction, 97(7): 773-783, 2002.

RAUPP, L. M. \& ADORNO, R. C. F. Uso de crack na cidade de São Paulo, Brasil. Revista Toxicodependências, 16(2): 29-37, 2010.

RAUPP, L. M. \& ADORNO, R. C. F. Circuitos de uso de crack na região central da cidade de São Paulo. Ciência \& Saúde Coletiva, 16(5): 2.613-2.622, 2011.

SAMPAIO, M. R. A. \& PEREIRA, P. C. X. Habitação em São Paulo. Estudos Avançados, 17(48): 167-183, 2003.

SILVA, S. L. Mulheres da Luz: uma etnografia dos usos e preservação no uso do crack, 2000. Dissertação de Mestrado, São Paulo: Faculdade de Saúde Pública, Universidade de São Paulo. 


\title{
8 \\ Curitiba: entre o trabalho em rede ideal e o real
}

\author{
Fernanda Mendes Lages Ribeiro \\ Vera Lidia Alves de Oliveira \\ Simone Cortiano
}

\begin{abstract}
Este capítulo versa sobre o contexto que cerca a vida de crianças e adolescentes usuários de crack em Curitiba, Paraná. Apresentam-se inicialmente alguns dados sobre o crack e a cidade, destacando-se os serviços locais contatados na pesquisa e a metodologia de trabalho adotada. A rede de assistência social e o atendimento a crianças, adolescentes e famílias usuárias de crack são elencados, com destaque para a caracterização e o funcionamento dos Serviços de Acolhimento Institucional (SAIs). Em seguida, caracterizam-se o perfil das crianças e dos adolescentes usuários de crack inseridos nos serviços da rede de assistência social e de saúde e de suas famílias, bem como a visão dos adolescentes, familiares e gestores da saúde e da assistência social sobre o atendimento oferecido. Ao final, descreve-se a rede de assistência social e de saúde na atenção a este público, salientando-se os seguintes aspectos: atores, papel, fiscalização, avaliação e fluxo de atendimento.
\end{abstract}

\section{O CRACK E A CIDADE DE CURITIBA}

A população de Curitiba, de acordo com Censo de 2010, é de 1.746 .896 habitantes (100\% urbana), ocupando a sétima posição entre as cidades mais populosas do Brasil. Curitiba é o centro econômico do estado do Paraná e tem o quarto maior produto interno bruto (PIB) do país. A capital paranaense concentra a maior porção da estrutura governamental e de serviços públicos do estado e sedia importantes empresas nos setores de comércio, serviços e financeiro. Além das funções político-administrativas que lhe são próprias, 
Curitiba é o mais importante centro de difusão cultural e distribuição de bens e serviços do Paraná, em consequência de seu crescimento demográfico e industrial e, principalmente, do desenvolvimento do sistema viário.

A expansão de Curitiba, a par de transformar a cidade em uma moderna metrópole, acarretou também vários problemas urbanos, como: abastecimento de água insuficiente, diminuição da permeabilidade do solo, alta poluição da maioria de seus rios, esgotamento do aterro municipal, aumento crescente nos índices de criminalidade e de violência, alto índice de moradores de rua na região central da cidade e subdimensionamento da rede de transporte urbano. Há um pronunciado inchaço populacional na cidade, favorecendo a explosão demográfica em bairros afastados e em municípios vizinhos. Tal qual outras grandes cidades brasileiras, tem pronunciados problemas sociais, como a existência de grandes favelas e o expressivo crescimento do contingente de moradores de rua. ${ }^{1}$

Em relação ao consumo de crack na cidade, alguns levantamentos têm trazido informações importantes. Os dados levantados na Pesquisa Nacional de Saúde do Escolar (PeNSE), em 2009, sobre o uso de drogas, como maconha, cocaína, crack, cola, loló, lança perfume e ecstasy, entre escolares do $9^{\circ}$ ano do ensino fundamental, evidenciaram que $13,2 \%$ dos adolescentes curitibanos já usaram alguma dessas drogas ilícitas, maior prevalência entre as capitais do país. Rapazes foram mais frequentes no uso de drogas ilícitas - 14,3\% -, contra 12,1\% entre as moças. Estudantes da rede pública apresentaram a maior prevalência de consumo (14,4\%), quando comparados com estudantes de escolas privadas (7,3\%) (IBGE, 2009).

Levantamento sobre consumo de drogas psicotrópicas realizado em 2009 pela prefeitura municipal de Curitiba, utilizando metodologia similar à do Centro Brasileiro de Informações sobre Drogas Psicotrópicas (Cebrid), investigou 2.105 estudantes do ensino fundamental da rede municipal e mostrou que $7,3 \%$ já haviam tido contato com alguma droga ilícita alguma vez na vida, e $1 \%$ com o crack, sendo $0,6 \%$ a frequência de uso de crack no último ano antes da pesquisa. A média de idade da primeira experiência com o crack foi de 12,7 anos (Curitiba, 2009). Observou-se redução desse indicador quando comparado com estudo do Cebrid de 2004, em que a idade média do primeiro contato com esta droga foi de 13,8 anos (Carlini et al., 2005).

Disponível em: <www.encontraparana.com.br/sobre-curitiba.htm >; <http://curitiba-bb.blogspot.com.br/2011/10/problemas-urbanos.html>; <www.guiadoturista.net/parana/curitiba. html>. Acesso em: 20 dez. 2012 
Em julho de 2012 a prefeitura de Curitiba lançou o Plano de Desenvolvimento Humano e Enfrentamento às Drogas (Curitiba, 2012), com os seguintes objetivos estratégicos: reduzir as consequências sociais e de saúde decorrentes do uso indevido de drogas, reorganizar a estratégia da administração pública municipal e organizar os serviços municipais a fim de atuarem de maneira integrada, articulada e complementar. Nele, apresentou-se um planejamento de atividades em andamento e a serem executadas, contemplando as seguintes áreas: moradia - habitação, urbanismo e iluminação; ensino - investimentos em creches, escolas, cursos e outras atividades; trabalho - cursos profissionalizantes, pró-Jovem, entre outros; programas sociais e de saúde - Família Curitibana e Ônibus Adolescente Saudável, atendimentos à população em situação de rua, 11 Centros de Atenção Psicossocial (Caps), duas unidades de pronto-socorro, participação de consultores em dependência química em todas as unidades básicas da saúde (UBS), ações de prevenção e promoção nos Núcleos de Apoio em Atenção Primária à Saúde (Naaps), Consultório na Rua, Centros Municipais de Urgências Médicas, Ambulatório Cara Limpa e Semana Antidrogas de Curitiba; programas culturais como o Circuito pela Paz, a mostra de dança nas regionais, os festivais de férias e as olimpíadas escolares.

O Plano de Desenvolvimento Humano e Enfrentamento às Drogas pretendia promover a qualificação profissional na "temática drogas, de forma continuada, buscando estimular o trabalho intersetorial e interdisciplinar" (Curitiba, 2012) e a criação de um Comitê Municipal de Prevenção ao Uso Indevido de Drogas e Reinserção Social de Usuários e Familiares. Esse comitê tinha como objetivo "articular instituições governamentais e não governamentais para efetivação de ações integradas e intersetoriais, no âmbito da prevenção e reinserção social, a fim de realizar o enfrentamento ao uso indevido de drogas" (Curitiba, 2012). Entre os representantes do comitê, estavam as seguintes instituições governamentais: secretarias municipais - Antidrogas, Saúde, Educação, Esporte, Lazer e Juventude, Trabalho e Emprego -, secretarias estaduais - Educação, Saúde, Família e Desenvolvimento Social -, Fundação de Ação Social (FAS), Defesa Social, Ministério Público estadual e Vara da Infância e Juventude. Conselhos regionais de diversas profissões, o Conselho Municipal de Políticas sobre Drogas e dos Direitos da Criança e do Adolescente, o Conselho Tutelar e o Sindicato dos Estabelecimentos Particulares de Ensino do Estado do Paraná e vários outros órgãos participavam como entidades não governamentais. 
O plano previa a implementação de ações e estratégias na assistência à saúde, como a transformação dos Caps II em Caps III, com funcionamento 24 horas por dia e com vagas de acolhimento noturno para usuários em tratamento, sem condições de retorno ao domicílio (passagem que ocorreu efetivamente em 2012). Previam-se ainda, para 2012, quatro Caps, com 25 vagas; para 2013, dois, com 12 vagas; e até 2015, "mais dois Caps ad, com mais 400 vagas/dia e 12 vagas/24 horas", além da criação de 80 leitos em enfermarias psiquiátricas em hospitais gerais em 2012 e 2013. Como metas do plano, incluíam-se a criação de duas unidades de acolhimento voluntário e transitório até 2012 (com 15 vagas para adultos e dez vagas infantojuvenis), a criação de seis novas unidades até 2015 (com 70 vagas novas) e o fortalecimento do Consultório na Rua. Em 2013 seria implantada uma unidade de acolhimento infantil para cobertura de um Caps.

Além das vagas em equipamentos públicos, constava do plano a contratação de vagas em Comunidades Terapêuticas, "para atenção residencial transitória aos usuários de drogas durante o período de tratamento nos Caps": 232 vagas para adultos e 45 vagas para crianças e adolescentes, representando um aumento de $73 \%$ em relação às vagas no momento.

No eixo redução da oferta do plano, pretendia-se aumentar no número de batalhões, de policiais, da vigilância por câmeras, de centrais de monitoramento e de operações integradas entre Polícia Militar, Guarda Municipal, Resgate Social, Vigilância Sanitária e Secretaria de Urbanismo.

Junto com o plano, o prefeito então em exercício lançou, em 2 de julho de 2012, o movimento Liga do Bem que reunia Poder Público, setor privado, forças de segurança, poderes Judiciário e Legislativo, sociedade organizada e famílias. O movimento tinha três grandes eixos: prevenção, cuidado e autoridade, com a participação de todas as secretarias municipais e parceiros, incluindo a "ampliação do atendimento de quatro Caps, transformando-os em Caps III, com atendimento 24 horas e 20 vagas de acolhimento"; a criação de uma "Casa de Acolhimento Transitório, para crianças e adolescentes; permanência do Consultório na Rua; e contratação de vagas em comunidades terapêuticas para adultos, crianças e adolescentes". Essa estratégia contava com recursos federais e de emendas parlamentares para "um reforço nas ações de prevenção e novas iniciativas, como a criação da Rede Familiar de Prevenção às Drogas/Mães Contra o Crack e amplo trabalho na rede municipal de ensino" (Curitiba, 2012). 
Em março de 2015, de acordo com site oficial da Prefeitura de Curitiba, a rede de saúde contava com dez Caps, sendo seis Caps ad (um direcionado para adolescentes), dois Caps II e dois Caps i. ${ }^{2}$

Segundo a Agência de Notícias da Prefeitura de Curitiba, foi assinado em 25 de março de 2015, pelo prefeito, um decreto vinculando a condução da política sobre drogas à Secretaria Municipal de Saúde (Secretaria da Saúde, 2015b). Essa mudança visava a unificar o trabalho de prevenção ao de assistência e ao desenvolvimento de políticas públicas na área, reforçando a atuação intersetorial. Como parte da reorganização da gestão, está prevista a implementação de uma coordenadoria de populações vulneráveis, envolvendo populações indígenas, usuários de drogas, crianças e adolescentes em situação de rua. Ainda segundo a agência, em 2014, 13.390 pessoas foram atendidas por Caps ad e 976 utilizaram leitos noturnos, "em um total de 9.128 pernoites ao longo de todo o ano passado" (Secretaria da Saúde, 2015b). Em outra matéria, da mesma data, informa-se a implantação de dois serviços específicos para população em situação de rua:

O ônibus Intervidas, que conta com equipes multidisciplinares para realizar abordagens a dependentes químicos em locais públicos, e o trailer do Consultório na Rua, unidade móvel que dará suporte às equipes de saúde para fazer o atendimento à população em situação de rua e prestar atendimento médico e odontológico, além da realização de testes rápidos de HIV/Aids. (Ônibus, 2015a)

\section{COMPOSIÇÃO dA REDE DE ATENÇÃO E CUIDAdO}

Visando a conhecer a rede de atenção e cuidado para crianças, adolescentes e suas famílias em situação de uso de crack na cidade de Curitiba, alguns cuidados metodológicos foram tomados na pesquisa que deu origem a este capítulo, desenvolvida nos anos 2011 e 2012. ${ }^{3}$ A SMS e a FAS (responsável pela assistência social) apoiaram: 1) a marcação e aplicação de questionários institucionais em 14 SAls selecionados por amostragem, com finalidade de conhecer sua atuação e organização para atendimento à questão do crack; 2) na visita aos 14 SAls, quando foram preenchidos 160 questionários com base nos prontuários de crianças,

2 Disponível em: <www.curitiba.pr.gov.br/secretarias/equipamentos/saude/10/33>. Acesso em: 24 mar. 2015.

3 No Anexo é possível saber em detalhes os procedimentos metodológicos da pesquisa em foco. 
adolescentes com histórico de uso do crack ou dos pais/responsáveis; 3) no agendamento e realização de 15 entrevistas com: cinco adolescentes usuários de crack em serviços de saúde, dois familiares de crianças/adolescentes com histórico de uso de crack residentes em SAI ou frequentando serviço de saúde, representantes de instituições ou órgãos da assistência social (um gestor de SAI e um gestor municipal da FAS), coordenadores de serviços de referência para álcool e drogas (um ambulatório e um Caps ad), um conselheiro tutelar, um juiz da Vara da Infância e Juventude; um profissional da Secretaria Municipal Antidrogas ${ }^{4}$ e dois gestores da Rede de Instituições de Acolhimento (RIA); ${ }^{5}$ 4) no levantamento da rede de atenção e cuidado a crianças a fim de se esboçar um fluxograma de atendimento na rede.

Em Curitiba, dentre os 14 SAls públicos municipais e conveniados pesquisados, nenhuma criança ou adolescente usuário de crack foi localizado no momento da coleta, segundo informações do gestor de cada serviço. À época, havia abrigos específicos para crianças e adolescentes usuários de drogas que não integraram a amostra quantitativa da pesquisa. Dessa forma, não se pode considerar a prevalência de usuários de crack acolhidos em SAls como representativa dos serviços de Curitiba.

A rede local de serviços de atendimento à saúde era composta por 49 UBS, 55 unidades da Estratégia Saúde da Família (ESF), oito centros municipais de urgência médica (voltados para situações de urgência e emergência nos casos de surto e/ou fissura e de hospitalização), um Consultório na Rua e um Caps que atende crianças e adolescentes usuários de álcool e outras drogas.

O Consultório na Rua atendia de forma multidisciplinar por meio de busca ativa de pessoas em situação de rua, entre elas, usuários de crack. À época do levantamento, o atendimento se dava em uma praça, oferecendo serviços médico, psicológico, de enfermagem e atividades de educação física. O serviço constituía uma porta de entrada para acolhimento nas UBS e no Caps.

O Caps ad i de Curitiba, logo após o trabalho de campo da pesquisa se encerrar (2012), passou a funcionar 24 horas, como um Caps III. Segundo os profissionais

4 Mais informações sobre essa secretaria em: <www.antidrogas.curitiba.pr.gov.br/entrada.html>. Acesso em: 8 ago. 2012.

5 Mais informações em <http://rededeacolhimento.blogspot.com.br/>. Acesso em: 8 ago. 2012.

A RIA tem como objetivos melhorar as condições de atendimento das crianças e dos adolescentes. Articula-se ao Poder Público local para que as políticas públicas sejam postas em prática. Teve início com a junção de dois SAls em 2006, buscando parceria com o Ministério Público. A partir de 2011, uma agenda com a FAS é construída, aprofundando o debate em torno do direito a convivência familiar e comunitária. No momento do trabalho de campo da pesquisa, a rede estava composta por 22 instituições, que reuniam quase mil vagas de acolhimento. 
entrevistados, esse era o único Caps municipal (os demais funcionavam com gestão de organizações não governamentais - ONGs). Para atendimento nessa unidade, a procura era direta, não era necessário o encaminhamento pelas UBS, porém a unidade sempre fazia contato com a unidade da área de moradia do usuário, para que as condições clínicas e sociais fossem acompanhadas em conjunto. As crianças e adolescentes geralmente eram encaminhados pela $1^{\text {a }}$ Vara da Infância e Juventude, pelo Conselho Tutelar e pela FAS.

O quadro dos serviços de atenção à saúde mental no município era composto de: cinco Caps ad para adultos; dois Caps i e um Caps II (para adultos com transtornos mentais); o ambulatório Cara Limpa, que atende crianças e adolescentes usuários de álcool e outras drogas; duas Comunidades Terapêuticas para crianças e adolescentes de 7 a 18 anos que se encontram em vulnerabilidade social e duas para adultos; o Centro de Especialidades Médicas Matriz, que oferece atendimento de retaguarda; dois hospitais psiquiátricos localizados em outros municípios, que atendem casos (também de Curitiba) com comorbidades clínicas e risco de vida; e cinco ambulatórios de saúde mental conveniados com a SMS que realizam matriciamento e atendimento.

O ambulatório Cara Limpa é uma parceria entre a SMS, a FAS e a ONG Núcleo Terapêutico Menossimon. Os encaminhamentos para esse serviço são realizados pelos programas da FAS, pelas UBS, pelo Conselho Tutelar e pela Vara da Infância e Juventude.

Em relação às Comunidades Terapêuticas, havia a Casa de Recuperação Nova Vida (Crenvi), para meninos, e a Casa de Recuperação Água da Vida (Cravi), para meninas. Essas entidades dão retaguarda tanto para o ambulatório Cara Limpa quanto para o Centro Vida. Os encaminhamentos eram realizados pelo Conselho Tutelar e o Juizado.

O mapeamento da área de assistência social, realizado na FAS, indicou os seguintes serviços como porta de entrada para o atendimento: 45 Centros de Referência de Assistência Social (Cras), nove Centros de Referência Especializados de Assistência Social (Creas) - um por regional -, um Creas para vítimas de violência sexual, dois Creas para população de rua adulta, o Centro de Convivência Criança Quer Futuro e ônibus itinerante voltado à atender crianças e adolescentes em situação de rua.

No que tange aos serviços que servem de retaguarda ao atendimento, existiam a Rede de Proteção à Criança e ao Adolescente em Situação de Risco para Violência; o Programa Família Acolhedora/Família Extensa; 42 SAls 
conveniados voltados para crianças e adolescentes e oito públicos (totalizando 1.200 vagas); duas Comunidades Terapêuticas (já sinalizadas na área da saúde); a Central de Vagas, que regula os encaminhamentos para os acolhimentos institucionais (inclusive os emergenciais), e o programa Família Curitibana. A cidade contava com nove Conselhos Tutelares (um por regional).

A Rede de Proteção à Criança e ao Adolescente em Situação de Risco para Violência é uma ação intersetorial e integrada entre a saúde, a educação e a assistência social, entre outras secretarias e instituições não governamentais. Ela trabalha com a notificação e o acompanhamento das situações de violência contra a população infantojuvenil.

O programa Família Acolhedora/Família Extensa voltava-se para casos em que havia a possibilidade de retorno da criança à sua família. Durante a pesquisa de campo, 17 famílias estavam cadastradas para receber uma criança ou grupo de irmãos e 35 crianças/adolescentes acolhidos.

Esse programa atende famílias consideradas em maior vulnerabilidade, acompanhando de perto seus membros em serviços específicos como saúde, educação, habitação, entre outros. Sua avaliação é diversa entre os atores da rede. Para a FAS, ele prioriza as famílias mais vulneráveis, promovendo um acompanhamento de perto das suas necessidades. Para a RIA, essa eleição é falha ao não considerar dois indicadores básicos - uso de drogas e acolhimento institucional. As crianças, adolescentes e famílias atendidas pelos SAls que compõem a rede, dessa forma, não são contempladas pelo programa.

Outros serviços relevantes para o atendimento à população infantojuvenil usuária de crack e suas famílias eram: a Secretaria Municipal Antidrogas, que atua de forma intersetorial na prevenção ao uso indevido de substâncias psicoativas, na atenção e reinserção de usuários e dependentes, além da formação de uma rede de colaboração social em busca da redução do tráfico, e a Rede de Instituições de Abrigo.

\section{OS SERVIÇOS DE ACOLHIMENTO INSTITUCIONAL}

Na Tabela 1 verifica-se que, em nenhum dos 14 serviços participantes do levantamento quantitativo, houve o relato de crianças ou adolescentes usuários de crack e, em apenas dois, registrou-se a presença de adolescentes acolhidos com história de uso de drogas em geral. Ter pais ou responsáveis com histórico de uso de drogas, e de crack em particular, já é um dado mais frequente, 
envolvendo crianças (dez SAls) e adolescentes (seis SAIs), aproximando-se ao padrão nacional (Assis \& Farias, 2013). Relembra-se que Curitiba tem abrigos específicos para os acolhidos que usam drogas, que não foram sorteados na amostra que compôs os dados apresentados neste capítulo.

Tabela 1 - Serviços de Acolhimento Institucional que atendem crianças e adolescentes e seus responsáveis com história de uso de crack e outras drogas ( $\mathrm{N}=14$ SAls). Curitiba - dezembro de 2011*

\begin{tabular}{l|c|c|c|c}
\hline \multirow{2}{*}{} & \multicolumn{2}{|c|}{$\begin{array}{c}\text { SAls que } \\
\text { atendem crianças }\end{array}$} & \multicolumn{2}{c}{$\begin{array}{c}\text { SAls que atendem } \\
\text { adolescentes }\end{array}$} \\
\cline { 2 - 5 } & $\mathrm{N}$ & $\%$ & $\mathrm{~N}$ & $\%$ \\
\hline $\begin{array}{l}\text { Uso de drogas em geral pela criança ou } \\
\text { adolescente }\end{array}$ & 0 & - & 2 & 14,3 \\
\hline $\begin{array}{l}\text { Uso de crack pela criança ou adolescente } \\
\text { Responsáveis com história de uso de } \\
\text { drogas em geral }\end{array}$ & 0 & - & 0 & - \\
\hline $\begin{array}{l}\text { Responsáveis com história de uso de } \\
\text { crack }\end{array}$ & 10 & 71,4 & 7 & 50,0 \\
\hline
\end{tabular}

* Informação dada pelo gestor do serviço.

Na Tabela 2 pode-se verificar que foram localizadas 230 crianças e 67 adolescentes nos 14 SAls. Apenas dois adolescentes - e nenhuma criança foram identificados com histórico prévio de usuário de drogas.

São, porém, muitos os responsáveis apontados como usuários de drogas em geral $(55,2 \%)$ e de crack $(50,5 \%)$. A relevância do uso familiar de crack nos SAls está mais evidente entre as crianças (129 famílias) do que entre os adolescentes ( 21 famílias). Mais da metade das famílias registrou uso tanto de crack quanto de outras drogas. Contudo, não é possível determinar se foi esse uso que ocasionou o acolhimento da criança/adolescente. 
Tabela 2 - Uso de crack e drogas em geral por crianças, adolescentes e pais/ responsáveis em amostra de Serviços de Acolhimento Institucional. Curitiba dezembro 2011

\begin{tabular}{l|c|c|c|c|c|c}
\hline & \multicolumn{2}{|c|}{$\begin{array}{c}\text { Crianças } \\
\mathrm{N}=230\end{array}$} & $\begin{array}{c}\text { Adolescentes } \\
\mathrm{N}=67\end{array}$ & \multicolumn{2}{c}{$\begin{array}{c}\text { Total } \\
\mathrm{N}=297\end{array}$} \\
\cline { 2 - 7 } & $\mathrm{N}$ & $\%$ & $\mathrm{~N}$ & $\%$ & $\mathrm{~N}$ & $\%$ \\
\hline $\begin{array}{l}\text { Uso de drogas em geral pela } \\
\text { criança ou adolescente }\end{array}$ & 0 & - & 2 & 3,0 & 2 & 0,7 \\
\hline $\begin{array}{l}\text { Uso de crack pela criança ou } \\
\text { adolescente }\end{array}$ & 0 & - & 0 & - & 0 & - \\
\hline $\begin{array}{l}\text { Responsáveis com história de } \\
\text { uso de drogas em geral }\end{array}$ & 137 & 59,6 & 27 & 40,3 & 164 & 55,2 \\
\hline $\begin{array}{l}\text { Responsáveis com história de } \\
\text { uso de crack }\end{array}$ & 129 & 56,1 & 21 & 31,3 & 150 & 50,5 \\
\hline
\end{tabular}

No que se refere à caracterização e ao funcionamento dos 14 SAls, constataram-se as seguintes particularidades:

1) a maioria atua há muitos anos: $35,7 \%$ têm entre 20 e 47 anos de existência; 50\% entre 14 e 19 anos; e apenas 14,3\% funcionam há quatro anos;

2) metade funciona na modalidade abrigo institucional, e a outra metade como Casa Lar (seis em comunidade e um em aldeia); ${ }_{i}^{6}$

3) todos são entidades não governamentais;

4) há ampla variação no número de crianças acolhidas: 2 a 57. Quanto aos adolescentes, esse montante variou entre nenhum, no momento da coleta dos dados, e 22. Há média de $16(D P=16,9)$ crianças e de cinco $(D P=6,2)$ adolescentes nos serviços visitados;

5) a maioria relata ter orientação religiosa $(57,1 \%)$, especialmente evangélica, seguida pela católica;

6) os serviços declararam estar abertos para atender crianças ou adolescentes com as seguintes especificidades: em situação de rua $(57,1 \%)$, com transtorno mental (35,7\%), ameaçados de morte (28,6\%) e com doenças infectocontagiosas $(14,3 \%)$. Nenhum SAI acolhe usuários com problemas com drogas, incluindo o crack, facilitando antever um aspecto que será abordado mais adiante - a definição de serviços específicos para o atendimento dessa clientela;

7) todos têm equipe técnica própria, composta por psicólogo $(92,9 \%)$ e assistente social $(85,7 \%)$, e contam com pelo menos um dos seguintes

6 Para mais informações sobre esses tipos de serviço, ver Brasil (2009). 
profissionais: educadores, administradores, pedagogos, fisioterapeutas, médicos, terapeutas ocupacionais, dentistas, enfermeiros, nutricionistas, advogados, psicopedagogos e técnicos de enfermagem. Também são informadas como equipe "pessoas religiosas" e estagiários (estudantes universitários de diversas áreas), sendo alguns desses profissionais voluntários;

8) em seis unidades houve menção à capacitação de oito profissionais das equipes técnicas; em quatro, de uma pessoa da direção; em três serviços 12 cuidadores foram capacitados, o que representa menos de dois terços dos profissionais que lidam de forma mais próxima com as crianças e adolescentes acolhidos. A coordenação, o "pessoal administrativo" e de serviços gerais não receberam nenhum treinamento sobre crack. Já capacitação sobre drogas em geral mostra um cenário um pouco mais positivo, envolvendo profissionais de várias formações.

\section{PERFIL dAS CRIANÇAS E dos Adolescentes UsuáRIOS DE CRACK E DE SUAS FAMÍLIAS}

Traçamos o perfil das crianças, adolescentes e famílias que participaram da pesquisa, visando a conhecer sua realidade e histórias de vida e refletir sobre os caminhos que os levaram aos serviços de saúde e de assistência e à justiça.

Chamamos os próprios adolescentes inseridos nos SAls e nos serviços de saúde, bem como suas famílias, para contar, mesmo que brevemente, suas histórias e o envolvimento com o crack. Outra fonte de informações são os prontuários dos acolhidos em SAls. Também indagamos os órgãos componentes da rede e que lidam diretamente com essa problemática - saúde, FAS, Conselho Tutelar, Justiça, Secretaria Antidrogas, RIA e instituições de acolhimento - sobre suas percepções acerca das causas e consequências do uso/abuso/dependência do crack.

Conforme apresentado na Tabela 2, houve grande prevalência de uso de drogas pelos responsáveis dos acolhidos. Os prontuários permitiram nos aproximar um pouco das histórias desses sujeitos (160 foram localizados):

1) $51,3 \%$ das crianças e adolescentes eram do sexo masculino;

2) a maioria tinha pouca idade (média de 5,1 anos, $\mathrm{DP}=4,9$ );

3) $58,8 \%$ frequentavam a escola. Esse dado varia segundo a faixa etária: um terço dos que deveriam estar na educação infantil (entre 0-5 anos de idade) efetivamente estava na escola, enquanto todos os outros mais velhos estavam 
no ensino fundamental e médio. A defasagem série-idade (dois ou mais anos de atraso escolar) foi significativa $(30,1 \%)$;

4) 20,6\% tinham trajetória de rua;

5) 57,5\% moraram nos últimos 30 dias (antes do último acolhimento) com alguém com problema com o uso de crack/drogas na época. Nesse subgrupo, 23,9\% tinham pelo menos um dos pais/responsáveis sabidamente usuário de crack, segundo os registros institucionais. Duas crianças tinham pais usuários de crack que estavam presos, e uma outra tinha mãe dependente da mesma substância, portadora de Aids e de tuberculose;

6) $22,5 \%$ sofriam algum problema de saúde; $0,6 \%$ eram portadores de HIV; $5 \%$ dos acolhidos tinham algum comportamento agressivo; 5,6\%, sinais ansiosos ou depressivos; 4,4\%, hiperatividade ou inatenção; 1,3\%, transtornos psicóticos. Registraram-se ainda outros problemas de saúde em $15 \%$ das crianças e adolescentes: doenças pulmonares (especialmente alérgicas), atraso no desenvolvimento motor e cognitivo, prematuridade, problemas cardíacos, encoprese, leucemia, cisto no cérebro e deficiência física.

Quanto à situação na justiça, relativa ao acolhimento institucional, a maioria das 160 crianças ou adolescentes tinha procedimento administrativo na Vara da Infância e Juventude (99,4\%). Igual percentual tinha informação sobre o uso de crack pelo responsável declarada no prontuário, com a descrição do fato ou dos encaminhamentos realizados, indicando boa qualidade do preenchimento desses documentos oficiais.

Sobre os motivos de ingresso nos SAls, registrados no Termo de Abrigamento ou outro documento equivalente, grande parte acusava pais ou responsáveis dependentes químicos/alcoolistas, seguido por negligência, situação de rua e abandono. Deve-se contextualizar que tais motivos muitas vezes se superpõem e mesmo se confundem, e que pode haver, para uma mesma criança/adolescente, mais de um motivo alegado. O próprio termo negligência é ceifado de controvérsias e, em geral, reúne uma série de situações díspares. A referência a outras causas não previamente listadas pelo instrumento de coleta exemplifica tal diversidade: "a mãe saía pra balada e deixava os filhos presos em casa"; "fora da escola", "a mãe fazia a criança roubar" e "cárcere privado".

Com menos frequência, mencionaram-se também: violência doméstica física e psicológica $(9,4 \%)$, carência de recursos materiais da família/responsável (6,3\%), exploração no trabalho ou mendicância (3,8\%), violência doméstica sexual (2,5\%), ausência dos pais ou responsáveis por prisão $(1,9 \%)$, pais ou 
responsáveis sem condições para cuidar de criança/adolescente com condições de saúde específicas (1,9\%), entrega voluntária da criança/adolescente pela família de origem $(1,3 \%)$, ameaça de morte $(1,3 \%)$, ausência dos pais ou responsáveis por doença $(0,6 \%)$, pais ou responsáveis com deficiência $(0,6 \%)$, pais ou responsáveis com transtorno mental (problemas psiquiátricos/ psicológicos) (0,6\%), uso e/ou abuso de substâncias por parte da criança ou adolescente $(0,6 \%)$.

Em 35,6\% dos acolhimentos, o encaminhamento para os SAls foi feito exclusivamente pelo Poder Judiciário - em 1,3\% pelo Conselho Tutelar. Em conjunto, esses órgãos encaminharam 61,9\% das crianças e adolescentes. O Ministério Público figura como o segundo a realizar esse procedimento. Casos excepcionais se deveram à solicitação de acolhimento institucional por parte de mães de duas crianças.

Em relação a encaminhamentos realizados pelos serviços, há registro de uma criança que foi dirigida para tratamento de saúde devido ao uso de crack no passado. No que se refere aos responsáveis, 115 (71,9\%) foram encaminhados para tratamento de saúde por uso de crack, indicando a preocupação dos SAls em relação à saúde mental de grande parte daqueles identificados como usuários e/ou dependentes. Contudo, reitera-se que a orientação e o encaminhamento dados aos pais não são acompanhados de medidas que garantam o atendimento, e que não há troca de informações sistemática entre os serviços para avaliar modificações porventura existentes na rede familiar.

Ao examinar a situação legal das 160 crianças e adolescentes acolhidos com pais ou responsáveis com histórico de uso de crack, boa parte estava em fase de avaliação/preparação para reintegração/retorno ao convívio com familiares/responsáveis (30\%). Percentual significativo de acolhidos tinha poder familiar suspenso (29,4\%); $14,4 \%$ estavam em processo de destituição do poder familiar; $10 \%$, em processo de guarda/tutela em tramitação; 16,9\% estavam destituídos do poder familiar - o que os colocava aptos para adoção; $17,5 \%$ estavam legalmente encaminhados para adoção e 6,3\% estavam em processo de colocação em adoção (iniciando ou iniciada a aproximação com adotantes).

Nenhum adolescente cumpria medida socioeducativa nos SAls pesquisados. Do total de crianças e adolescentes, 20,7\% já haviam sido abrigados anteriormente em outros serviços, seja na mesma unidade $(0,6 \%)$, em outro SAI $(18,8 \%)$ ou em mais de um SAI (1,3\%). 
Acerca do local de moradia das famílias de origem ou do principal responsável pela criança/adolescente, a maioria $(91,9 \%)$ residia no mesmo município no qual o acolhido estava vivendo. Apesar disso, apenas $40 \%$ mantinham vínculo com a família; 36,9\% estavam sem vínculo e 23,1\% tinham impedimento judicial de manter contato com a família. Um total de 39,4\% recebia visitas da mãe $(28,1 \%)$ no SAl, seguido da avó $(11,9 \%)$, pai $(7,5 \%)$, irmãos e irmãs (5,6\%), outros parentes $(8,1 \%)$ e outras pessoas $(0,6 \%)$.

Para melhor compreensão do perfil da população aqui investigada, foram feitas entrevistas com duas famílias e cinco adolescentes, indagando-se a respeito dos motivos, sentimentos e consequências do uso do crack sobre as crianças/ adolescentes e sobre seu universo familiar.

A primeira entrevista com familiares foi realizada em um SAI específico para usuários de substâncias psicoativas, visitado exclusivamente com esse fim. A família era composta por mãe usuária, com histórico de atendimento à saúde e de prisão em decorrência do envolvimento com o comércio da droga. Ela tinha uma filha de 25 anos, com histórico similar ao seu e que estava presa no momento da pesquisa, e dois filhos adolescentes institucionalizados em serviços de acolhimento - uma menina de 12 e um menino de 16 anos. Os filhos acolhidos frequentavam serviços de saúde e a mãe, que estava procurando regularizar sua vida a fim de reunir a família, os visitava regularmente. A filha mais velha tinha três filhos, de cerca de 1, 2 e 4 anos: "Também estão todos pelo Conselho [Tutelar] por causa dessa droga". Um morava com uma tia materna, um com a cunhada e um com um vizinho. Com um dos netos, que residia mais próximo, ela tinha contato diário. Ele não ficava com a avó "pelo problema da maldita droga".

Segundo essa senhora, toda a família tem "problemas" com o crack. Quanto a seu uso, ela o relacionava ao assassinato do marido, há dez anos. A partir desse momento, ficou "perdida" e começou a utilizar maconha e crack. Em seguida, sua filha mais velha começou também a usar e, "quando deu por si", seu filho estava também usando. Ela relata que foi presa, estando, no momento da entrevista, em liberdade há quatro meses. Apenas quando saiu da prisão soube que a filha mais nova também usava drogas. No momento, a mãe morava com irmão, pois a polícia havia colocado fogo em sua casa.

Ela conta que foi presa por causa da venda do crack. Sua filha mais velha começou a vender dentro de casa e, apesar de ter sido contra, os traficantes "tomaram conta da casa". Relata que havia a prática de pagar aos policiais para 
que o comércio continuasse funcionando. Contudo, a partir de uma denúncia anônima, outros policiais, que "não se trocam por dinheiro", que são "polícia de verdade", chegaram à casa e a prenderam junto com a filha mais velha.

Em decorrência do uso, essa mãe relata ter "perdido tudo" e que sua família nunca mais foi unida, sempre "um aqui, um ali, um aqui, um ali, é horrível". Ela comenta ainda que a família fica mal vista por todos. O restante da família também sofre "porque quer dar conselho, sempre quer ver o bem da gente e a gente não escuta".

Seu filho foi apreendido com pedra de crack, mas não chegou a ficar preso. Sua filha pediu ajuda a uma vizinha para ser "internada" e esta ajudou também a "internar" o rapaz. Nesse momento, a mãe já estava presa. Depois da prisão da mãe até o momento em que foram institucionalizados em SAls, seus dois filhos ficaram sozinhos na própria casa, onde continuava a venda de drogas. Depois mudaram-se para outro local em que também era comercializado o crack e, em seguida, ficaram na rua.

O adolescente membro dessa família estava, no momento da pesquisa, acolhido em SAI. Esse acolhimento se deu, em sua visão, pelo envolvimento com o crack. Havia um mandato de busca para ele, para responder por tráfico. Para não ser preso, optou por ir para o SAI. Ele cumpria a medida socioeducativa de liberdade assistida.

Ele reitera o uso da droga pela família - a mãe e duas irmãs. Diz que essa prática "acabava" com eles, que "ficavam vagando" e que quase morreu de overdose por duas vezes. Por causa do crack "perdeu todo mundo", referindose aos parentes: "não gostam de ficar conversando com quem é usuário de crack, pensam que vai roubar. Você não pode entrar na casa que já ficam de olho, é ruim".

Segundo o jovem, o uso do crack deveu-se à influência de amigos. Entre as consequências na saúde, mencionou ter ficado muito magro. Além do SAl, o adolescente frequentava serviço de saúde e planejava voltar a estudar no ano seguinte.

A filha adolescente, da mesma forma, estava acolhida em SAI e frequentava serviço de saúde, reiterando o uso de crack pela família, o que trouxe "só coisa ruim", "humilhação, traição, falsidade". Relata que não conseguia comer e que passava muito mal.

A segunda família entrevistada na pesquisa era composta pela mãe (sem histórico de uso da droga), por seu marido e três filhos, de 23, 17 e 15 anos. Os 
filhos mais novos - uma moça e um rapaz - tinham histórico de uso de crack. Ambos residiam com ela, mas já tinham vivência de rua. A filha frequentava serviço de saúde, mas o filho não.

De acordo com essa mãe, foram as "más companhias" da escola que os levaram ao uso. A filha chegou a ficar doente e foi internada por cerca de 15 dias, em duas instituições, sendo uma em outra cidade. Ela relata que seu filho Ihe dissera, na véspera do dia em que a entrevista foi realizada, que queria ser também internado, não pelo uso de crack, mas pelo de maconha.

A respeito das consequências do uso do crack na vida dos filhos, a mãe comentou que sua filha ficava por vezes uma semana na rua e que, "quando chegava, não dava coragem nem de olhar, eu tinha até nojo". Pediu ajuda ao Conselho Tutelar e foi orientada a pegar a filha quando esta fosse em casa, e levá-la "para o 24 horas" [hospital]. Foi em um desses momentos que a mãe internou a filha. Na época da entrevista, a jovem fazia acompanhamento em serviço de saúde e havia "melhorado muito; ela disse que tem nojo até do cheiro de crack". Também por causa do uso, da situação de rua e da internação, a adolescente parou de estudar e a mãe programava seu retorno à escola para o ano seguinte. Outra grave consequência percebida pela mãe é o baixo peso da adolescente, o que pode estar associado ainda a seu atraso em começar a menstruar, com 15 anos.

Segundo a própria adolescente, uma das consequências do uso de drogas foi a saída da escola, em decorrência do consumo de maconha, anterior ao crack. Quando começou a usá-lo, contudo, passou a andar na rua, o que causava muito sofrimento à mãe. Após a internação afirma estar melhor, fazendo apenas o acompanhamento no serviço de saúde, diariamente. Essa frequência a ajuda muito, ocupando-a com atividades como oficinas, conversas com o psicólogo e com o psiquiatra, entre outras. Ela planejava, para o ano seguinte, cursar ensino supletivo e trabalhar, o que vinha sendo providenciado pelo Conselho Tutelar. Seu desejo era ser advogada.

Quanto ao uso de crack, relatou que começou com pessoas perto de casa e que se a mãe não a tivesse internado, iria morrer. Iniciou o uso com 14 anos e o de maconha com 12, junto com o irmão. A adolescente acredita que a curiosidade a levou a querer usar drogas. $O$ namorado, que era traficante, lhe dava o crack que fumava apenas à noite. Contudo, quando ele morreu, a jovem "se acabou" e passou a fumar o dia inteiro; "daí que eu vi que estava drogada mesmo. Eu tinha que fumar, tinha". 
Quanto aos efeitos do uso em sua vida, além da questão do peso, contou que queria apenas ficar na rua, permanecendo fora de casa por dias; "só queria saber de usar droga". A adolescente passou a vender seus pertences para poder comprar a droga, chegando a ficar sem nada.

Outros dois adolescentes foram entrevistados sem suas famílias: uma menina e um menino. A primeira tinha 13 anos e estava em tratamento em serviço de saúde. Frequentava o $5^{\circ}$ ano escolar e morava com a mãe. Segundo ela própria, o começo do uso da droga deu-se na escola, por curiosidade. Não tinha percebido ainda nenhum efeito do uso do crack: "Nada, tipo, parecia que era a mesma coisa. Normal". Sua inserção no serviço de saúde motivou-se pela descoberta do uso por sua mãe; no momento da pesquisa, a adolescente frequentava o local diariamente.

O adolescente estava inserido em SAI. Trabalhava com venda de produtos de limpeza e fazia um curso. Havia parado de estudar antes do acolhimento para trabalhar e planejava uma nova ocupação para o ano seguinte. Sua entrada no serviço deu-se por procura própria: "estava feia a situação pro meu lado", pois estava fumando muita droga e bebendo muito. Procurando o Conselho Tutelar, o órgão entrou em contato com a mãe, que "assinou um papel" e o encaminhou para o serviço. O local em que morava anteriormente com a mãe tinha "muita droga, muito roubo". "Não estava dando certo para mim, eu vi que eu estava morrendo de uma hora assim, quase todo mundo querendo me pegar, por causa do tráfico. Aí eu parei, fugi, fui buscar ajuda e hoje eu estou aqui".

Ele crê que brigas com parentes e a vivência na rua o levaram a usar o crack e daí passou para outras drogas, como a bebida. O envolvimento com a droga, em sua avaliação, "só leva você pra baixo, nunca tem dinheiro, perde amizade de amigo, de parente, de familiar mesmo, por causa do crack". Todos os seus amigos "morreram por causa do crack", o que o motivou a procurar ajuda, além dos apelos da mãe.

Uma das consequências em sua saúde foi a perda de peso e a falta de disposição: "Estou mais forte para correr, mais alegre, mais com ânimo. Não tinha nem ânimo, vivia trancado dentro de casa. Até o meu peito tinha uma tosse de tanta, tanta droga".

Intercorrências no processo de desenvolvimento físico, mental e social de crianças e adolescentes usuários de crack são descritas por Gund (2011), em estudo sobre o atendimento prestado em Cascavel, Paraná, a esses sujeitos. A autora destaca impactos fisiológicos, relacionados a atos ilícitos e à 
prostituição como formas de ter acesso à droga, além dos homicídios de usuários em decorrência de conflitos.

A seguir são apresentadas as visões dos responsáveis por serviços que atendem a população em foco: SAIs, RIA, Conselho Tutelar, FAS, ambulatório, Caps ad i e Secretaria Municipal Antidrogas.

Em relação às causas relacionadas ao uso do crack, aparece sobremaneira o tema da desagregação familiar. Para o gestor da Secretaria Municipal Antidrogas, a "degradação social", causada pela mudança de modelos e por dificuldades em lidar com novas formas de organização, estaria ligada à "ansiedade, que alguns descarregam nas drogas".

Esse novo modelo de família que a gente criou, que o pai e a mãe saem cedo para trabalhar, deixam o filho na creche, voltam à noite e pegam o filho dormindo. No outro dia entregam o filho dormindo. Quebrou um pouco o vínculo e a gente ainda não aprendeu a lidar com esse modelo novo. Está todo mundo procurando uma saída. Os jovens e adolescentes, eu acho que eles se ressentem um pouco disso também, daquele elo familiar. Eu acho que ele se sente um pouco perdido. E às vezes, acaba se apegando em outros exemplos que não são os ideais.

A juíza da Infância e Juventude, por sua vez, atribui à "desestrutura familiar" vivida pelas crianças e adolescentes, à falta de perspectiva e ao "querer ter as coisas e não poder". Os pais, segundo a magistrada, são pessoas que "não tem noção do que é ter filho, da necessidade de criar, de educar um filho, de manter longe da rua, de ter paciência pra sentar, pra conversar". Estabelece-se, assim, uma situação em que "você [os pais] não controla, ninguém controla".

Um dos serviços de saúde, referência no tratamento de álcool e outras drogas, também destacou a "questão familiar" - falta de acompanhamento dos pais e perda de valores - e a influência do grupo de amigos e do local de moradia. O segundo serviço, da mesma forma, reforça a ideia da falta de "estrutura" - envolvimento dos pais com drogas e falta de limites - e o uso como fuga de problemas em casa e na escola. Foi mencionado ainda "o ganho de dinheiro no tráfico", mais fácil em comparação com outras oportunidades de trabalho. Segundo a conselheira tutelar, o tráfico, muitas vezes, oferta "algo que elas [as crianças] nunca viram, oferta poder".

Outro ponto de destaque nas falas dos participantes foi o uso de várias drogas que serviriam, também, como porta de entrada para o crack, como o álcool e o cigarro, aceitos socialmente e cujo uso é banalizado. No caso daqueles 
em situação de rua, há também prevalência de uso de "cheirinho" (solventes), segundo a representante do SAI.

Questões individuais são também associadas às causas de uso do crack. A gestora de um SAI cita a curiosidade, "saber qual é a pira", "qual é o toque"; e um profissional de serviço de saúde comenta sobre o uso de álcool para enfrentar a timidez.

Outra causa mencionada é a ineficácia das políticas públicas. A juíza da Infância e Juventude reflete sobre a falta de oferta de escola em tempo integral, de creches e de pré-escola, o que deixa muitas crianças expostas; já os gestores da RIA destacam o descaso do Poder Público com as comunidades, que estariam "abandonadas", sem investimentos na área social, "principalmente no que diz respeito à prevenção".

Limpo a população de rua. Colocam em programas como Criança Quer Futuro, mas não tem uma proposta pedagógica consistente. Encaminham para instituição de acolhimento, para o outro, para o outro, repasso a sociedade civil por esse acolhimento e isento, limpo a cidade. (gestor - RIA)

O crack contribuiria para uma invisibilidade da questão drogas, uma vez que as crianças e adolescentes ficam "enfurnadas dentro da favela" e "não conseguem nem transitar até o centro, de tão grave que é a dependência". Essa situação dá a impressão de que "a cidade está conseguindo cumprir com o seu papel".

Os entrevistados da RIA têm um olhar crítico em relação aos órgãos da rede e avaliam como as próprias instituições de acolhimento, em especial as não governamentais, acabam por colaborar para essa invisibilidade a que estão sujeitas as famílias. O problema estaria em toda a rede de atendimento, implicando "uma série de violações de direitos que o nosso sistema está cometendo e aparecem na ponta".

Também a conselheira tutelar destaca a responsabilidade das autoridades sobre a falta de oportunidades para os jovens, como a própria escola - que deveria abordar a temática das drogas "desde o primário" - e a criminalização dos que, em sua avaliação, são em realidade as vítimas. Faltam programas que acolham e acompanhem os jovens e equipamentos sociais, como os de lazer, creches, entre outros.

A percepção sobre as consequências do uso/abuso/dependência do crack, expressa nos discursos dos participantes envolve múltiplos setores da vida dos 
sujeitos: debilitação da saúde, problemas físicos e mentais; perda dos vínculos sociais e de convívio com a família; prejuízos à educação; prostituição; furtos, envolvimento com o tráfico e assassinatos por brigas ou dívidas; situação de rua; agravamento da desestruturação familiar.

A falta de perspectiva de vida e o encaminhamento para adoção foram também lembrados pela juíza. Segundo ela, a maioria dos casos de crianças abrigadas no município deve-se ao uso de drogas dos pais, e há uma grande dificuldade em trabalhar com esses pais para que passem a "aceitar o tratamento".

A própria situação de acolhimento institucional foi mencionada como uma consequência, segundo o SAI e o Juizado. Quando a família é também usuária, a situação é ainda mais dramática, pois deveria ser ela a cuidadora: "O uso pela família quebra todas as regras de papéis (...) essa própria família, muitas vezes, manda esse adolescente para prostituição para prover o dinheiro do crack, ou para venda" (juíza).

\section{A VISÃO dOS ADOLESCENTES, DOS FAMILIARES E DOS PROFISSIONAIS SOBRE O ATENDIMENTO NOS SERVIÇOS DE SAÚDE E DE ASSISTÊNCIA SOCIAL}

Em Curitiba, existem dois serviços referência em saúde mental para o cuidado a crianças/adolescentes usuários de álcool e outras drogas, incluindo, o crack. Além de ouvir seus coordenadores, perguntamos aos adolescentes a respeito do atendimento à sua saúde e do cuidado ao uso/abuso/dependência do crack. No total, cinco adolescentes foram entrevistados. Duas famílias entrevistadas transitavam pelas várias instituições da rede pública: uma mãe relata ter dois filhos em atendimento tanto em SAI quanto em serviço de saúde; ela própria e outra filha mais velha - ambas usuárias de crack - passaram pelo sistema de justiça por conta do uso e venda de drogas. Outra família tinha uma adolescente em serviço de saúde, e um outro filho tinha histórico de passagem por vários serviços, entre eles, o de saúde.

Entendendo que o cuidado à saúde e, especialmente, ao uso de drogas como o crack, se dá de forma multidisciplinar e intersetorial, indagamos às mães dos adolescentes a respeito do acesso a serviços de saúde, assistência social, educação e outros.

Perguntamos às famílias o que consideravam que um bom serviço de cuidado às drogas deveria promover, objetivando identificar o que poderia qualificar um 
serviço e a adesão a uma proposta de tratamento. Dessa forma, interessava saber o que os usuários dos serviços consideravam importante para seu tratamento.

A visão das mães em relação aos serviços nem sempre coincide. O Conselho Tutelar foi qualificado por uma mãe como atuante, "aconselhando" e "exigindo matrícula escolar". A segunda, entretanto, o classificou, como ineficiente afirmando que ele não ajudou em seu caso, mas sim a FAS, o Cras e o Creas. A filha adolescente passou por um período nas ruas, e o pedido da mãe para que o conselho ajudasse a buscá-la não foi atendido; "a senhora tem que ir atrás, tem que achar ela e trazer aqui, senão eu não posso fazer nada". No momento da entrevista a jovem já havia sido localizada e internada, e a mãe não havia avisado ao conselho, que também não teria buscado informações sobre o caso. Para outro adolescente da família, o Creas estava atuando na aplicação de medida socioeducativa e o Cras providenciando atendimento médico. Quanto ao atendimento à saúde da adolescente, a família citou o hospital e o Caps. Além de instituições públicas, foram mencionadas outras, como igrejas, que ajudam no processo de combate ao abuso e/ou adição ao crack.

Como ponto importante de um bom serviço, foi citada a proximidade da residência, considerando-se as dificuldades com gastos de deslocamento. Uma entrevistada conta que em seu município não havia hospital para internação da filha adolescente e que, por esse motivo, teve que deixar seu emprego para acompanhá-la em outra cidade. Ainda assim, o hospital não era específico para o tipo de tratamento necessário.

A visão dos adolescentes a respeito de sua trajetória de vida e do acesso às políticas públicas, antes e durante o uso do crack, evidencia os inúmeros momentos de utilização da rede de serviços. Perguntamos a respeito do acesso aos serviços de saúde, durante a vida e em relação ao atendimento à questão do uso/abuso/dependência do crack, levantando as instituições com as quais podiam contar.

Os cinco adolescentes entrevistados já haviam sido atendidos em hospital, posto de saúde, Caps, Cras e Conselho Tutelar. Uma adolescente criticou o hospital onde fora atendida por não ser direcionado a seu perfil, concluindo que faltam hospitais para tratar usuários de drogas. Entretanto, qualificou positivamente sua internação: “Dez dias lá e eu não quis mais usar [o crack]. (...) Me ajudou bastante".

Um adolescente acolhido em SAI relatou que o próprio serviço realizou encaminhamento para tratamento de saúde e para um curso. Outro adolescente 
contou que fora encaminhado para uma "chácara" [Comunidade Terapêutica], mas que não conseguiu ficar e fugiu, indo morar na rua.

Em relação ao que um bom serviço deveria ter, foram citados: "remédios que façam não pensar no crack"; possibilidade de serem acompanhados pela família; profissionais acolhedores e pacientes; oferta de cursos e outras atividades. Um adolescente contou que, no SAI em que estava, havia liberdade de ir e vir, contanto que avisasse o diretor e que isso o fazia gostar do local, e que o mesmo tinha paciência para lidar com os acolhidos. "A primeira coisa, que tem gente que não tem paciência, e tem que ter paciência com quem usa crack, porque estressa, fica nervoso, daí pode fazer coisa (...) tem gente que não tem calma." De forma geral, os adolescentes mostraram estar satisfeitos com os atendimentos providos nos serviços de saúde e de assistência social frequentados.

Neiva-Silva (2008), investigando o tratamento de crianças e adolescentes usuários de drogas em situação de rua, destaca que os serviços de saúde estão distantes dessa população e que há uma lacuna entre demanda por tratamento e acesso a serviços. O autor afirma que é necessário criar políticas públicas de saúde direcionadas à população de rua e investir na manutenção dos vínculos familiares. É importante garantir o acompanhamento para além dos momentos de tratamento, promovendo apoio à criança e ao adolescente, o que era desconsiderado em muitos programas.

Um bom exemplo é o investimento em escolas e instituições, ambas de caráter aberto, que acolham adequadamente a população de crianças e adolescentes em situação de rua, possibilitando a realização de atividades ocupacionais, educativas e de lazer, contribuindo assim para a diminuição da probabilidade do abuso de drogas por esta população. (Neiva-Silva, 2008: 189)

A respeito do tratamento do adolescente usuário de drogas, Marques e Cruz (2000: 33) destacam "a importância do sistema familiar nas intervenções para prevenção e tratamento da dependência de álcool e outras drogas". As famílias devem estar envolvidas no tratamento e informadas dos riscos relacionados à saúde do adolescente.

Segundo os autores, com base em um levantamento de estudos de metanálise que reuniu mais de 400 tipos de tratamentos direcionados a adolescentes, a escolha do tipo de intervenção depende de uma série de fatores, entre eles, a disponibilidade do tratamento mais adequado, a proximidade à residência, a 
compatibilidade com a situação socioeconômica, a motivação, a seriedade do estado de abuso/dependência e o tipo/frequência de uso da droga. Cerca de $80 \%$ dos adolescentes são tratados em regime ambulatorial, com abordagens e modelos teóricos variados e, independentemente do modelo utilizado,

o tratamento deve estar estruturado em três níveis: o desenvolvimento global do adolescente; a modificação do comportamento de uso de álcool ou drogas e a resolução dos problemas associados, além do reajuste familiar, social e ambiental. (Marques \& Cruz, 2000: 34)

Os autores destacam ainda que resultados de estudos sobre a efetividade do tratamento de adolescentes dependentes de substâncias psicoativas são ainda "pouco animadores",

a recaída, o desejo pela droga (a "fissura"), o pouco envolvimento nas tarefas escolares ou no trabalho, o lazer insatisfatório, a polidependência, o início de uso do álcool muito cedo na vida, as alterações de comportamento e o envolvimento criminal são fatores que contribuem para tornar o tratamento menos efetivo. (Marques \& Cruz, 2000: 34)

A visão dos gestores da FAS e dos serviços de saúde é mostrada a seguir.

A FAS, órgão gestor da prefeitura de Curitiba que coordena as ações e políticas na área, não atende diretamente a população, mas sim os Cras e Creas. A gestora menciona a realização de atividades e parcerias no local de moradia das famílias entre o órgão e as secretarias municipais de Educação, Saúde e Antidrogas. É sua atribuição fiscalizar os SAls (para isso conta com equipes itinerantes) e administrar as vagas, por meio da Central de Vagas. Na FAS há uma pedagoga, mas faltam uma psicóloga e uma assistente social para atuar na fiscalização e comunicação com os serviços acompanhados pela fundação.

No momento da pesquisa, a maioria dos serviços de saúde mental de Curitiba era gerida por ONGs, em parceria com a SMS. Os serviços participantes da pesquisa eram responsáveis pelo atendimento de crianças e adolescentes usuários de drogas. Em um deles, municipalizado, todos os funcionários eram concursados. Integravam a equipe três psiquiatras, uma pediatra, cinco psicólogas, duas assistentes sociais, uma enfermeira, uma auxiliar de enfermagem, um sociólogo, dois agentes administrativos, dois educadores sociais e estagiários de psicologia. Sua coordenadora era assistente social e a autoridade sanitária, psicólogo. Todos os pacientes eram atendidos por esse conjunto de profissionais, que montava os projetos terapêticos a partir 
de atendimentos individuais e coletivos. Além desses profissionais, a instituição teve, cerca de três anos antes da pesquisa, instrutores conveniados em oficinas de break, o que, segundo a coordenadora, tinha grande sucesso e adesão dos pacientes.

A segunda instituição de saúde pesquisada era uma ONG cuja equipe era formada de três psicólogos, dois psiquiatras, duas pedagogas, uma terapeuta ocupacional, duas assistentes sociais, um educador social, pessoal de recepção e uma pessoa voluntária de uma igreja evangélica. Essa ONG mantinha cinco convênios com a SMS, entre ambulatórios, Caps e Residências Terapêuticas. Todos os profissionais eram contratados pela organização.

Quanto aos serviços frequentados pelas crianças e adolescentes, foram citados Cras e Creas, Conselho Tutelar, escolas, o programa Comunidade Escola, ${ }^{7}$ Sesi e Senai para cursos, o programa Menor Aprendiz e instituições não governamentais, como a Rede Esperança - uma "associação de inspiração cristã"8 $^{\mathrm{e}}$ a instituição Fagundes Junqueira, uma escola ligada à rede espírita.

Gund (2011) descreve que a maior parte dos profissionais por ela entrevistados em sua pesquisa afirma que o tratamento do crack não tem diferenças significativas em relação aos de outras substâncias psicoativas. No entanto, alguns identificam características específicas que intervêm no processo de cuidado, como o comprometimento e a debilitação causadas pelo crack e o difícil processo de abstinência. Por isso, um dos primeiros encaminhamentos deveria ser a internação para desintoxicação, seguida pelo uso de medicação.

Em relação aos adolescentes, há desafios decorrentes de sua fase de desenvolvimento, em que "certos comportamentos considerados normais são amplificados" (Gund, 2011: 143). Outro problema é não voluntariedade do tratamento, que vem acompanhada pela não percepção dos danos do uso/abuso/ dependência da droga. Além disso, em decorrência da "curiosidade, tendência à experimentação e falta de perspectiva de tempo" do jovem (Gund, 2011: 146), o trabalho deve ter foco nos aspectos negativos da droga.

Gund (2011) classifica as estratégias utilizadas no tratamento em três categorias: família, meio social e individual. Tratar a família, independente da adesão da criança e do adolescente, demonstrou ser eficaz na questão da codependência e na mudança da estrutura familiar. Na segunda categoria foram

\footnotetext{
${ }_{7}$ O Comunidade Escola é um programa da Secretaria Municipal da Educação em parceria com ONGs que proporciona o funcionamento de escolas nos fins de semana com atividades de lazer, ações socioeducativas, profissionalizantes etc. para a comunidade em geral.

8 Disponível em: <www.redeesperanca.org.br/quem.htm>. Acesso em: 12 ago. 2012.
} 
apontados o trabalho em rede intersetorial, como a inserção em programas e projetos diversos e em atividades que gerem renda, a internação e a retirada do usuário de seu meio. No terceiro grupo de estratégias, a autora comenta o favorecimento de atividades positivas e produtivas, como a inserção na escola, em cursos e no mercado de trabalho. De acordo com os entrevistados, situações que trazem mudanças na vida dos adolescentes se relacionam positivamente ao sucesso do tratamento (como relacionamento afetivo, emprego, mudança de bairro), pois há mudança de perspectiva, de projeto e de sentido de vida.

Perguntamos aos profissionais participantes da pesquisa a respeito dos desafios e limites do trabalho desenvolvido por eles. Foi mencionada a questão da referência e contrarreferência, isto é, a comunicação entre os serviços e o fluxo de encaminhamento. Há dificuldades também na circulação de informações sobre os usuários, os resultados das intervenções e a resolutividade dos casos. Constatam falta de diálogo e de interação entre os diferentes órgãos da rede e fragilidade no acompanhamento pós-atendimento.

Segundo alguns profissionais, o fluxo de atendimento precisa ser rediscutido: o usuário é avaliado no Caps ad e, havendo necessidade, é encaminhado ao hospital; ao receber alta, retorna ao Caps. Se houver necessidade de outra internação, novo contato é feito com o Caps. Esse fluxo, no entanto, nem sempre é seguido, como no caso de determinação judicial de tratamento, quando o usuário é encaminhado para internação sem passar pelo Caps. A própria internação foi identificada como um nó, uma vez que vagas em Comunidades Terapêuticas são pagas, ou provenientes de convênios com alguns municípios que as gerem por meio de uma central. Para utilização de vagas pela central, necessita-se de determinação judicial e anuência do usuário.

Vários outros desafios foram citados: os encaminhamentos são realizados de acordo com a disponibilidade das ações, e não com a necessidade dos sujeitos; é preciso ampliar a atenção básica em saúde e os serviços de saúde mental para adultos, crianças e adolescentes, bem como investir na infraestrutura física e de pessoal dos serviços; falta conhecimento da população em geral, e dos trabalhadores, acerca dos serviços locais; há dificuldades de acesso aos serviços, por fatores como transporte e distância das residências; há limites na disponibilização de medicamentos necessários ao tratamento; há permanência de uma concepção moral da dependência e de preconceito entre os próprios profissionais e carência de debates sobre drogas e de circulação de informações sobre o tema. 
Entre os desafios, mencionou-se ainda a falta de: investimentos na prevenção, no acompanhamento pós-tratamento e no preparo dos profissionais; apoio dos gestores dos serviços que precisam lidar com interesses políticos que se manifestam no pequeno repasse de verbas para a área; ações de combate ao tráfico e de enfrentamento às drogas por parte do Estado; pesquisas e levantamentos sobre a demanda que chega aos serviços e sobre o público atendido.

\section{Funcionamento da Rede de Assistência Social e de SAúde}

Neste item serão apresentados o papel de cada setor, os principais desafios e a avaliação que os entrevistados fazem de sua atuação. Por fim, é trazido o fluxo de atendimento na rede, elaborado com base nos dados levantados ao longo da pesquisa no município.

\section{O papel institucional}

A atuação da Secretaria Municipal Antidrogas, de acordo com o seu secretário, centra-se na prevenção, atuando com base em "três eixos: repressão, recuperação e reinserção". No momento da pesquisa, havia nove programas em andamento, "voltados à prevenção ao uso de drogas e também ao esclarecimento e à capacitação das famílias para enfrentar esse problema", destinados a todas as faixas etárias.

As atividades são desenvolvidas em parceria com outros órgãos, como as polícias Civil, Militar e Federal, a SMS e a FAS. O objetivo de prevenção é buscado por meio da informação, do conhecimento, da ocupação dos jovens e da formação profissional, por isso o caráter multisecretarial. Campanhas e atividades de formação de multiplicadores contam com o apoio de universidades, escolas, movimento de escoteiros, igrejas, torcidas organizadas de futebol, exército brasileiro e aeronáutica, entre outros serviços. Com a torcida organizada do time de futebol local, havia uma parceria para encaminhar para tratamento torcedores dependentes químicos, custeado com verbas da torcida.

Quanto à rede municipal, foi destacada a parceria com a saúde e a assistência social e a organização de uma rede de Comunidades Terapêuticas, em que a Prefeitura subsidia vagas para a população mais carente. O ponto de partida é o setor Saúde, por meio dos Caps, que avalia a indicação de internação em 
Comunidade Terapêutica ou em hospital geral para desintoxicação, ou de tratamento ambulatorial.

O secretário municipal Antidrogas destaca que até pouco tempo as Comunidades Terapêuticas não eram reconhecidas pelo Poder Público. Esta secretaria, em parceria com a SMS e a FAS, vinha fazendo uma "triagem para saber quais tinham melhores condições, tinham uma estrutura melhor de atendimento e aquilo que não se adequava às normas, a gente tem procurado ajudar e orientar". Até o momento da entrevista, contudo, não era feita fiscalização, pois tais instituições não faziam parte da rede de saúde, funcionavam como "basicamente uma igreja avançada".

Segundo o entrevistado, as ações de prevenção organizadas pela secretaria são positivas. Cerca de 263 jovens teriam tido, no município, sua "realidade modificada".

Eles começaram a participar do programa, eles estavam fora da escola, aí voltaram a estudar, estão sendo acompanhados. Aqueles que tinham abandonado a família e viviam na rua, retornaram ao convívio da família. Aqueles que eram dependentes químicos e que voluntariamente pediram para se submeter a um tratamento, a gente conseguiu encaminhar para um tratamento. É, os que foram encaminhados para cursos profissionalizantes, para o mercado de trabalho, então vai por aí.

O SAI entrevistado atua na proteção de adolescentes em situação de rua e de dependência de drogas, além de outros direitos violados. Entre as várias drogas utilizadas, tem destaque o crack. Quando chega ao SAI, o jovem é encaminhado à rede de saúde, em geral para um dos dois serviços de referência. Em casos mais graves, podem ser encaminhadas para internação - que pode ser requerida pela justiça. Há relato de encaminhamento tanto para Comunidades Terapêuticas como para hospitais psiquiátricos. Uma das maiores dificuldades era a continuidade do tratamento por parte dos adolescentes ou mesmo a evasão do serviço.

A RIA objetiva melhorar as condições de atendimento de crianças e adolescentes se articulando ao Poder Público para que as políticas públicas sejam "postas em prática". Outro eixo de atuação é o debate sobre as políticas, sua qualidade e efetivação. Na visão de seus dirigentes, as políticas existentes não estão conseguindo cumprir seu papel e, por esse motivo, está havendo uma articulação com a FAS para compor o Plano de Atendimento Municipal à 
Infância e Adolescência, discutir o direito à convivência familiar e comunitária nos conselhos, principalmente no Conselho Municipal dos Direitos da Criança.

Um terceiro eixo diz respeito à reestruturação das instituições de acolhimento. Havia, no município, um programa dirigido às famílias em vulnerabilidade, eleitas com base em 18 indicadores. Contudo tais indicadores não levavam em conta o item drogadição, "então essas famílias que têm mãe no crack ou crianças no crack, não são consideradas vulneráveis para várias políticas públicas, isso dá um furo". Da mesma forma, criança em instituição de acolhimento também não compõe o indicador de vulnerabilidade. Segundo os entrevistados da RIA, essa política foi construída de cima para baixo, de forma não participativa e por isso não atenderia efetivamente uma série de questões importantes.

Os entrevistados afirmaram que os SAls conveniados recebem subsídios inferiores aos dos públicos e que estavam pleiteando uma melhora desses valores. A atuação do Poder Público na fiscalização dos serviços é criticada como "muito à distância, bem falha".

Segundo a conselheira tutelar, seu papel é atuar em qualquer situação de direito violado de crianças e adolescentes, articular os serviços e apresentar as demandas locais. É também função do conselho fiscalizar serviços que atendem crianças e adolescentes, o que está "bem precário". A fiscalização em serviços que não fazem parte da política de saúde, como as Comunidades Terapêuticas, ONGs ou unidades geridas por ONGs e os que se localizam em local afastado, não é efetiva, apesar de denúncias sobre o modo de funcionamento. Esse acompanhamento também é atribuição do Ministério Público e da Justiça da Infância e Juventude.

A atuação da justiça dirige-se à proteção das crianças e adolescentes quando as famílias fazem uso/abuso de drogas e quando há um uso próprio. Contudo, segundo a juíza, essa atuação não tem sido eficaz. Por mais que se aplique uma medida de proteção, em especial ao adolescente, ele não é obrigado a permanecer na instituição e, muitas vezes, abandona o tratamento. Faltaria "um local apropriado onde ele pudesse ficar, onde ele não pudesse se desligar a qualquer minuto". Quando o uso de drogas envolve os pais, é possível afastálos até que façam um tratamento, sendo uma medida "em tese mais eficaz". A adesão, contudo, é "muito baixa".

A FAS é composta por duas diretorias, de proteção básica e especial, que atuam no acolhimento institucional. A primeira se articula principalmente com 
as secretarias de Saúde e a Educação; a segunda, além dessas, também com a Secretaria Antidrogas. Como dificuldade também foi mencionada a adesão ao tratamento por parte de crianças e adolescentes, sendo necessário um "trabalho de convencimento".

Tanto os SAls conveniados, quanto os públicos, são acompanhados e fiscalizados pela FAS. Contudo, um acompanhamento mais próximo ocorre nos segundos, em que a Central de Vagas controla o fluxo de acolhimento. Como desafio, foi destacada a necessidade de implementar ações de prevenção do uso de drogas e de criar locais para internação. Para tentar resolver o problema, estavam sendo estabelecidas parcerias com Comunidades Terapêuticas, religiosas ou não, com o objetivo de atender integralmente a demanda de tratamento.

Um dos serviços de saúde, referência para atendimento de crianças e adolescentes de 7 a 17 anos usuários de álcool e outras drogas, trabalha de forma intensiva, semi-intensiva e não intensiva, seguindo a diretriz da redução de danos. Os usuários passam por atividades institucionais e por atendimento psiquiátrico/psicoterápico. Em relação à internação de crianças e adolescentes, há demora na efetivação dos encaminhamentos, que podem ser para hospitais psiquiátricos em outros municípios, para Comunidades Terapêuticas ou para o Sistema Único de Saúde (SUS). Em todos os casos, o atendimento na unidade é continuado. As famílias são também atendidas no serviço.

Contudo, foi destacada certa acomodação quando as crianças e adolescentes já estão acolhidos, o que dificulta o tratamento. É a SMS que fiscaliza o serviço, o que ocorre por meio de reuniões mensais com todos os profissionais. Havia também reuniões semanais internas; já houve supervisão externa e os profissionais expressaram desejo de que voltasse a ocorrer. Como desafios foram citados: prestar um bom atendimento, "o melhor possível"; conseguir o abandono ou a redução do uso de drogas; e trabalhar com as famílias para que o envolvimento com drogas não atinja "os outros filhos". Também foi mencionado o número insuficiente de vagas para internação.

O segundo serviço de saúde é referência no atendimento de crianças e adolescentes de 10 a 18 anos, ou até 21 anos em casos especiais. Os usuários são em geral encaminhados pelo Conselho Tutelar, pelo Creas e pela Delegacia da Criança. Também foram referidos dificuldades em conseguir vagas e o longo tempo de tramitação do pedido de internação, que pode ocorrer em Comunidades Terapêuticas. Quando há internação, a criança/adolescente 
continua frequentando o serviço. No caso de Comunidades Terapêuticas, como estas unidades não dispõem de profissional de psiquiatria, e a maioria dos pacientes faz uso de medicação, esse tipo de atendimento é realizado no serviço de saúde. $O$ tratamento em rede inclui hospitais gerais e psiquiátricos, centros de saúde 24 horas, Caps e Comunidades Terapêuticas. A comunicação com os demais setores é avaliada como muito boa. A fiscalização é também feita pela SMS - pela autoridade sanitária local - e pela FAS. Como no primeiro serviço, os desafios são identificados na adesão ao tratamento dos adolescentes, no abandono da droga e no envolvimento dos pais.

\section{Os desafios para a rede}

Diversos são os desafios identificados para a rede de cuidado a crianças e adolescentes usuários de drogas de Curitiba. Um deles está em sua estrutura, considerada como aquém das necessidades de saúde. A Secretaria Antidrogas e os SAls mencionam expectativas em relação a um plano federal de enfrentamento ao crack, que viria aprimorar o atendimento.

Segundo a gestora do SAl, o que também foi corroborado por profissionais da saúde, faltam ações específicas direcionadas ao uso do crack. Ela conta que os casos mais graves são encaminhados para atendimento em outros municípios. Há morosidade da rede em identificar os casos graves, fazendo com que se "percam", por vezes, os adolescentes. Faltaria um "encaminhamento mais ágil" na rede, para que o atendimento do adolescente fosse imediato, em especial em casos de surtos e crises. Além disso, os profissionais precisam estar bem preparados para atender os usuários, o que também é destacado pela saúde.

A RIA afirma a importância de chamar toda a rede à responsabilidade pelo cuidado das crianças e adolescentes, o que poderia ocorrer de forma exitosa com a integração de outros setores, reunindo forças na luta pela efetivação das políticas pela infância. O Sistema de Garantia de Direitos local não é visto como uma rede:

Nosso diagnóstico aqui é bem claro, o Ministério Público não conversa com o Poder Judiciário adequadamente, que não conversa com o Conselho Tutelar, que não tem um diálogo consistente com os Conselhos dos Direitos, que também não tem um diálogo consistente com o poder público local. Por conta disso, as instituições de acolhimento, que são a ponta final, quem acolhe o drama, elas são as que mais sofrem. Por fim, quem mais sofre, efetivamente, são as crianças e as famílias. (gestor da RIA) 
Nessa avaliação, o Cras e o Creas não estão cumprindo seu papel de prevenção e muitos não têm equipes ou unidades suficientes; tampouco havia local para onde encaminhar um atendimento especializado, quando fosse necessário. Não obstante, os entrevistados vislumbram potencialidades no diálogo com a FAS, Conselho Tutelar, Ministério Público e juizado e nas parcerias com outros órgãos e secretarias, como a de Esporte e a de Cultura.

$\mathrm{Na}$ visão da conselheira tutelar, não há trabalho em rede: "Se você me perguntasse onde estão esses serviços e essa rede que se articula, se conversa, eu diria que o Conselho Tutelar desconhece toda essa organização"; "a fala é em rede, mas a prática não é em rede".

Os serviços de saúde precisam melhorar e se adequar à demanda de atendimento. A conselheira denunciou a existência de vagas ociosas, apesar da grande procura por tratamento. Em relação às Comunidades Terapêuticas, criticou a aplicação de punições aos adolescentes que se evadem, uma vez que este comportamento faz parte do processo terapêutico. Também os convênios celebrados entre as comunidades, a saúde e a assistência social são questionados. Outros pontos negativos são: a localização dos serviços, que acarreta dificuldades de deslocamento; as atividades desenvolvidas, em número insuficiente, não estimulam os jovens a manter sua frequência; a falta de comunicação entre os órgãos da rede, gerando uma demanda excessiva para o Conselho Tutelar. Segundo a conselheira, a implementação de um CAPs III, que permite curtas internações, atenderia adolescentes que precisam "de um internamento que não seja definitivo, próximo da residência, que articule com a rede local, com os serviços que tem na comunidade, [para] que esse menino não tenha que fugir da comunidade".

Para a juíza da Vara da Infância e Juventude, a articulação da rede é tida como "boa, mas não eficaz", avaliação feita principalmente por causa das dificuldades de adesão ao tratamento de forma voluntária, pois a rede teria o papel "de abordagem, de convencimento, de oferecer o local". Especificamente no tratamento do crack, a articulação da rede precisa "evoluir mais".

Segundo um serviço de saúde, há falta de diálogo entre os órgãos, o que ocasiona pedidos de encaminhamentos errôneos, sem a devida avaliação das partes competentes. Entretanto, para o outro serviço, o trabalho em rede é bem articulado.

Todo o trabalho com qualquer rede, ele é sempre bem interligado. Qualquer problema que aconteça a gente está entrando em contato, chamando os profissionais para virem aqui. Quando é necessário a 
gente vai até esses profissionais, porque na realidade o paciente é um todo. Existe um grande problema que é o problema da droga, mas um problema maior, é um problema social e se a gente não estiver interligado com a rede, a gente não consegue resolver.

\section{Avaliação da rede}

Como mostrado anteriormente, para parte dos entrevistados um trabalho efetivamente em rede não ocorre. Em especial a RIA e o Conselho Tutelar são extremamente críticos, apontando falta de comunicação e de atuação conjunta. Segundo esses dois órgãos, não há um entendimento sobre a avaliação dos casos, o que gera desacordos em relação a seus encaminhamentos, e a contrarreferência é inexistente.

A separação de serviços de acolhimento em duas categorias - públicos e conveniados - influencia a forma como se relacionam com os órgãos da rede, até mesmo no que diz respeito a acesso, financiamento e fiscalização. A verba recebida pelos SAls conveniados - instituições privadas - é inferior à repassada aos serviços públicos (o valor, contudo, considera a contrapartida da mantenedora da organização). Vale ressaltar que os SAls privados são em maior número, perfazendo - apenas os associados RIA - um total de mil vagas de acolhimento.

Nos discursos dos participantes, depreende-se que os SAls públicos estão mais integrados à rede: as famílias das crianças/adolescentes são acompanhadas pelos Cras/Creas; há a preocupação de manter o vínculo entre crianças/ adolescentes e suas famílias, e também de fortalecer a família para receber seu filho; há um maior vínculo com os serviços de saúde (UBS, hospitais, ambulatórios e CAPs).

Nos conveniados, entretanto, essa integração praticamente não ocorre. Em nenhum dos 14 SAls participantes da pesquisa foi observado qualquer tipo de vínculo com os serviços de saúde. Do ponto de vista médico, as crianças/ adolescentes são acompanhados por profissionais voluntários e até por medicina de grupo (planos de saúde). O vínculo da criança com a família não é incentivado e inexiste acompanhamento da família, quer seja pelo serviço de acolhimento, quer seja pelo município.

A diferenciação de tratamento e o pertencimento a uma "outra rede" ficam explícitos na fala dos diversos gestores, quando, por exemplo, fazem menção à fiscalização apenas nos serviços próprios do município. Em relação 
ao acompanhamento de SAls conveniados, não foi percebido um movimento de aproximação, trabalho integrado ou monitoramento. Na visita a essas instituições, pôde-se averiguar que, onde havia berçários, o principal motivo de acolhimento dos bebês era ter as mães ou os pais usuários de drogas. Na maioria dos casos, o crack sozinho ou em conjunto com outras drogas era o principal motivo do acolhimento; maus-tratos, abandono, entre outras causas, eram minoria. Em muitos casos os bebês eram acolhidos nos serviços diretamente da maternidade, geralmente trazidos pelo Conselho Tutelar.

Outro nó é a questão da internação. Há uma crítica geral relativa às dificuldades de internação, quando este recurso se faz necessário. Alguns atores citaram a falta de um Caps III, que permitisse curtas internações e mantivesse o indivíduo adstrito ao território. ${ }^{9}$

Também são escassos os hospitais gerais com leitos para internação do público infantojuvenil, criando impasses no momento do encaminhamento para internação. Nesse cenário, as Comunidades Terapêuticas parecem figurar como solução por meio de convênios firmados com o município. Ressalta-se que tal situação - financiamento público de Comunidades Terapêuticas, tornando-as equipamentos do SUS, em detrimento do reforço das estratégias da Política Nacional de Saúde Mental, - tem sido observada nacionalmente. Apenas o Conselho Tutelar questiona o tipo de tratamento promovido nesses serviços e a RIA cita as "entidades religiosas que só rezam".

Parece haver uma crença de que a retirada da criança ou do adolescente de sua comunidade e seu isolamento são a solução para o problema da adição, gerando encaminhamentos errôneos no caso de situações de risco a que alguns sujeitos são expostos em decorrência do uso/comércio de drogas. Contudo, findo o prazo de alguns meses para desintoxicação, o mesmo retorna a seu lugar de origem e à "situação de risco", acrescentando-se a desterritorialização sofrida em relação à comunidade e seus equipamentos - centros de saúde, serviços especializados, escolas, espaços de lazer, entre outros.

Dessa forma, avalia-se que há carência de instituições específicas para crianças e adolescentes usuários de drogas, como apontado por vários gestores, profissionais e pelos próprios adolescentes, o que não poderia ser suprido com a implantação de unidades fechadas de tratamento.

9 Destaca-se que houve a implementação de um Caps nessa modalidade em 2012, após o levantamento de dados que deu origem a este capítulo. 


\section{Fluxo de atendimento entre órgãos da rede}

Quando o adolescente está acolhido em SAl, cabe a esse serviço buscar atendimento na rede. Em geral, ele é encaminhado para a UBS onde faz exames clínico e ginecológico, quando é o caso. Se o jovem é enviado pelo Conselho Tutelar, o serviço faz a comunicação à justiça, visando à garantia da continuidade do tratamento. As famílias, em geral, são atendidas pelos Creas e/ou Cras. Alguns SAls, apesar de não atendê-las, trabalham com as mesmas no sentido de aproximá-las dos filhos, incentivando visitas e contatos telefônicos; procuram sensibilizá-las quanto à sua necessidade de tratamento, quando é o caso; e as preparam para receber o adolescente com especificidade da dependência. O serviço envia relatórios ao Conselho Tutelar, à justiça e ao Creas.

Segundo a RIA, um caderno de fluxos que organiza a metodologia de atendimento tem sido proposto à Prefeitura, nos moldes da Associação Brasileira de Magistrados e Defensores Públicos.

Para cada grande violação de direitos existe um caminho a percorrer. Essa família vai precisar acessar um conjunto de equipamentos. (...) Então, vamos supor, o uso de crack, essa criança está em situação de vulnerabilidade muito grande, o pai e a mãe são usuários de crack. O Cras e o Creas deveriam proceder um relatório inter e multidisciplinar. Significa que ele precisa saber como está a condição social, econômica, psicológica e pedagógica da criança e da família, para saber qual é o nível de vulnerabilidade, qual é a necessidade, que tipo de políticas públicas essa família poderia acessar antes de encaminhar, por exemplo, para uma instituição de acolhimento. (gestor da RIA)

Essa criança e esse adolescente são tirados da família, sem um diagnóstico consistente. Automaticamente o Conselho Tutelar e os outros órgãos, inclusive o Ministério Público e o Judiciário, assinam embaixo de relatórios inconsistentes, e solicitam vagas. (gestor da RIA)

O fluxo de Curitiba é avaliado como ineficiente desde o momento da decisão de retirar a criança ou o adolescente da família, segundo os gestores da RIA, "sem um diagnóstico consistente". A garantia de que as crianças e os adolescentes não sejam esquecidos depois do acolhimento nos SAls, como se o problema que os levou até a internação tivesse cessado com sua retirada da família é um desafio; "como ela vai voltar pra essa família como a lei manda, em [até] dois anos, se ninguém está fazendo nada com essa família?" (gestor da RIA). 
As deficiências da rede e do Sistema de Garantia de Direitos configuram mais uma violação de direitos ao não inserir as famílias nas políticas públicas. Tal situação acaba por engrossar a fila e o mercado de adoção, uma vez que, nessas condições, dificilmente uma família se recuperará em dois anos.

Uma iniciativa que procurava agilizar o fluxo de atendimento consiste na realização de audiências concentradas, em que o equipamento jurídico vai até o SAI reavaliar a situação da criança/adolescente. Contudo, isso ainda não estava ocorrendo de forma satisfatória, apesar da pressão do Conselho Nacional de Justiça.

Os casos chegam até o Conselho Tutelar, de acordo com informações do próprio órgão, apenas quando as crianças e os adolescentes não conseguem atendimento e têm seus direitos violados. São as unidades de saúde que encaminham para os serviços especializados, e estes para a internação. Em geral, há retorno sobre os casos para o Conselho Tutelar. Em relação ao acolhimento institucional, a conselheira afirmou que há encaminhamentos errôneos, de casos que deveriam ser direcionados à internação em serviço de saúde. Quando há evasão de SAl, não há uma política de busca ativa, são as próprias famílias que precisam resgatar as crianças e adolescentes; tampouco existe uma contrarreferência ao Conselho Tutelar, que fica sabendo dos casos pelas famílias.

De acordo com a juíza da Vara da Infância e Juventude, tanto o Conselho Tutelar quanto o Cras e as unidades de saúde realizam encaminhamentos para tratamento. A comunicação chega ao Judiciário quando as crianças e os adolescentes "não aderem a nenhum tipo de tratamento que já foi oferecido pela rede". A entrevistada declarou que não há o costume de fazer internação compulsória e que não há lugar para internação. O Judiciário e a rede também encaminham as famílias para tratamento, mas a adesão é muito baixa, em decorrência da disponibilidade das próprias famílias e dos serviços que, muitas vezes, atendem apenas durante o dia e em dias de semana.

Segundo a gerente da FAS, existe um acordo entre a Vara da Infância e Juventude e o Conselho Tutelar que define o seguinte fluxo: em todos os casos de acolhimento a Vara deve ser comunicada no prazo de 24 horas. Nos casos em que o acolhimento é emergencial, o Conselho Tutelar leva a criança/ adolescente diretamente para o SAI. As vagas de acolhimento são reguladas pela Central de Vagas, gerenciada pela FAS, que avisa imediatamente a Vara da Infância e Juventude por meio de um relatório. Há situações em que o 
Conselho Tutelar acolhe uma criança, e o juiz não concorda e a desacolhe. Em casos sem emergência a demanda é levada à Vara da Infância e Juventude que providencia acolhimento.

A gerente da FAS afirmou que sempre há um trabalho inicial com a família e com a criança/adolescente para saber sobre seu tipo de vínculo e se, além da questão do uso de drogas, há situações de violência ou negligência. A profissional entrevistada referiu que outrora a fundação atuava apenas no acolhimento, como se ali acabasse o problema, e que muitos técnicos e conselheiros tutelares ainda pensam assim. A FAS e alguns de seus SAls têm investido no trabalho com as famílias.

Os serviços de saúde referência para cuidado às drogas são os únicos que atendem demandas espontâneas, os encaminhamentos da UBS, Conselho Tutelar, Creas e Cras de todo o município. Em relação às famílias, a unidade realiza encaminhamentos diretos para outros serviços de saúde especializados em álcool e outras drogas para adultos. No próprio serviço, há também grupos de pais em horários que Ihes permitem frequentá-los antes ou depois do trabalho; quando há a urgência de um atendimento, os pais/responsáveis são atendidos na própria unidade.

No serviço de saúde, a criança e o adolescente são atendidos pela enfermeira e pelo psiquiatra ou psicólogo - profissionais que podem assinar a autorização para procedimento de alto custo (Apac). Em seguida, são encaminhados à terapeuta ocupacional, pediatra e depois a oficinas. Dessa forma, constrói-se seu plano terapêutico e define-se o tratamento - intensivo, semi-intensivo ou não intensivo.

No outro serviço de saúde, as crianças e adolescentes passam por uma triagem com o serviço social, depois com o psiquiatra e com o psicólogo. São geralmente encaminhados pelo Conselho Tutelar e pelos programas da FAS. O adolescente é inserido no plano terapêutico completo - acompanhamento psicológico uma vez por semana, psiquiátrico uma vez por mês, ou a cada quinze dias, participação em oficinas socioeducativas, serviço de terapia ocupacional e atividades de grupo. Quando há uma melhora do quadro "conseguiram organizar a rotina deles, reduziram um pouquinho o uso de drogas" -, ele começa a participar de grupo terapêutico. Para os familiares, há o grupo de integração, em que os mesmos conhecem a dinâmica do serviço, assistem a palestras sobre drogas, medicação, regras e limites sobre cidadania e sexualidade. Depois desse ciclo, os pais podem ser incluídos em um grupo terapêutico e encaminhados para tratamento individual. 
Diversos entrevistados citam a ocorrência de internações de adolescentes em Comunidades Terapêuticas que ficam fora do município, o que dificulta o acompanhamento dos casos, a fiscalização das unidades e a visita das famílias. Outros ainda, como o Conselho Tutelar, tecem críticas sobre o trabalho desenvolvido em tais instituições e seus efeitos. O encaminhamento para Comunidades Terapêuticas se dá por meio dos serviços de saúde referência ou pelo próprio Conselho Tutelar.

Quando o adolescente se recusa à internação, e a equipe avalia que é necessária, o Juizado é acionado. Segundo o profissional de um dos serviços de saúde, esse fluxo sofreu mudanças no ano da pesquisa.

Até março desse ano [2011] o nosso psiquiatra dizia assim, precisa de internamento psiquiátrico, fazia um documento, o pai levava para o Conselho Tutelar. O Conselho Tutelar encaminhava para o juiz. A gente só podia pedir a vaga na Central de Leitos quando o juiz dissesse que autorizava esse internamento psiquiátrico. Hoje em dia não, no dia que nosso médico solicita internamento, a gente pega direto na Central de Leitos. Só vai para o Juizado quando é para internamento involuntário, quando vai ter que agir com outras instituições, junto à polícia, quando você vê que a parte clínica está tão comprometida que tem que internar, mas se ele não aceita, a saúde não pode obrigar a ele se internar, então a gente precisa de uma deliberação do Juizado.

As UBS e os hospitais, como porta de entrada, encaminham para atendimento especializado e há demanda espontânea nos serviços especializados. Conselho Tutelar e Juizado podem também solicitar um atendimento à saúde, seja porque a criança/adolescente não consegue ter acesso ao serviço, seja porque se recusa a fazê-lo - como foi relatado no caso das Comunidades Terapêuticas. A realidade das crianças, adolescentes e famílias da pesquisa envolve múltiplos atendimentos, em diferentes setores.

A fim de esquematizar a rede existente no município, apresenta-se a seguir dois fluxogramas de atendimento a essa população envolvida com o uso/abuso de crack, elaborados com base nas informações coletadas na pesquisa. 
Figura 1 - Fluxograma do atendimento às crianças e adolescentes usuários de crack. Curitiba - 2012

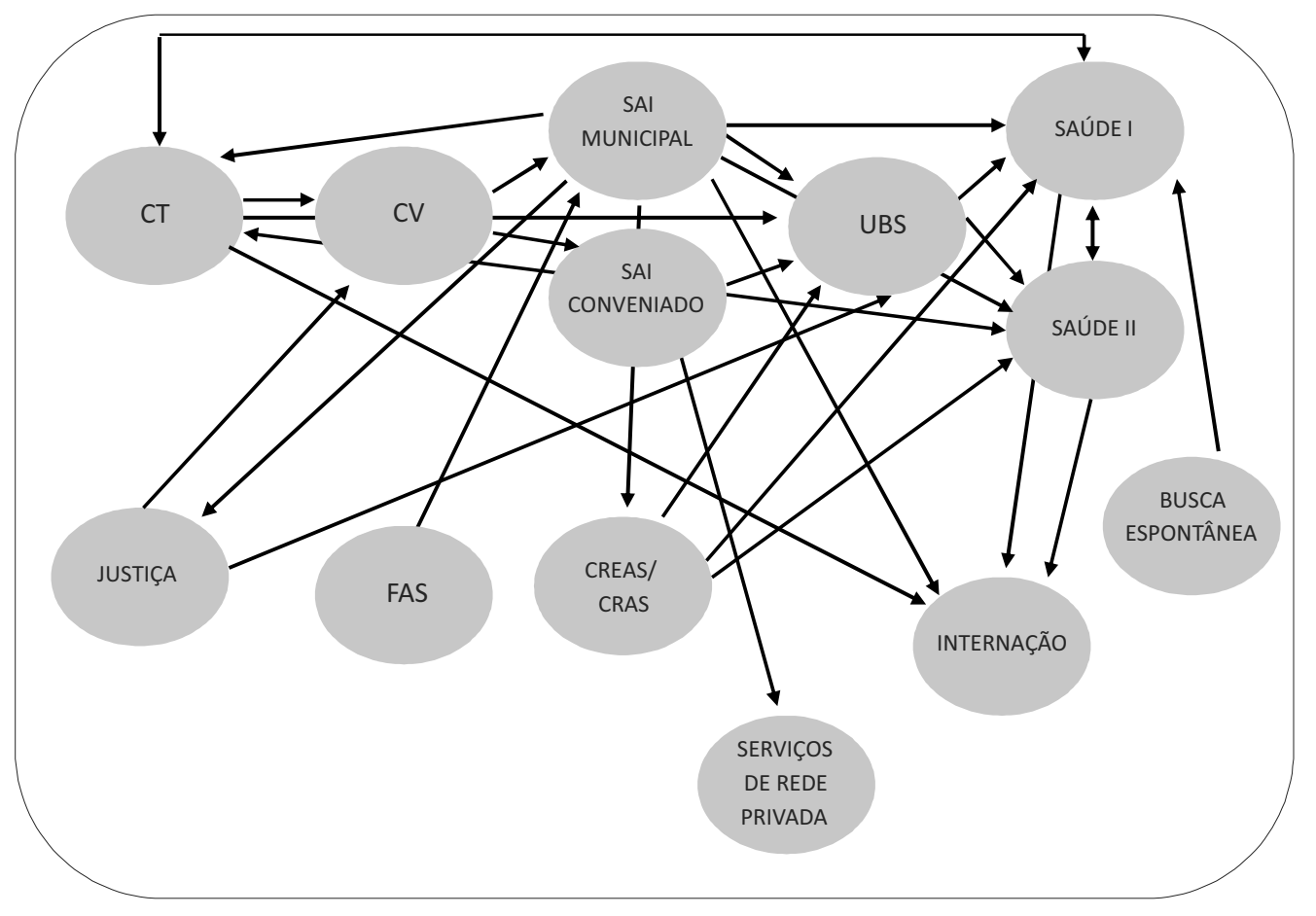

Nota: $\mathrm{CT}=$ Conselho Tutelar; $\mathrm{CV}=$ Central de Vagas 
Figura 2 - Fluxograma de atendimento a famílias usuárias de crack. Curitiba - 2012

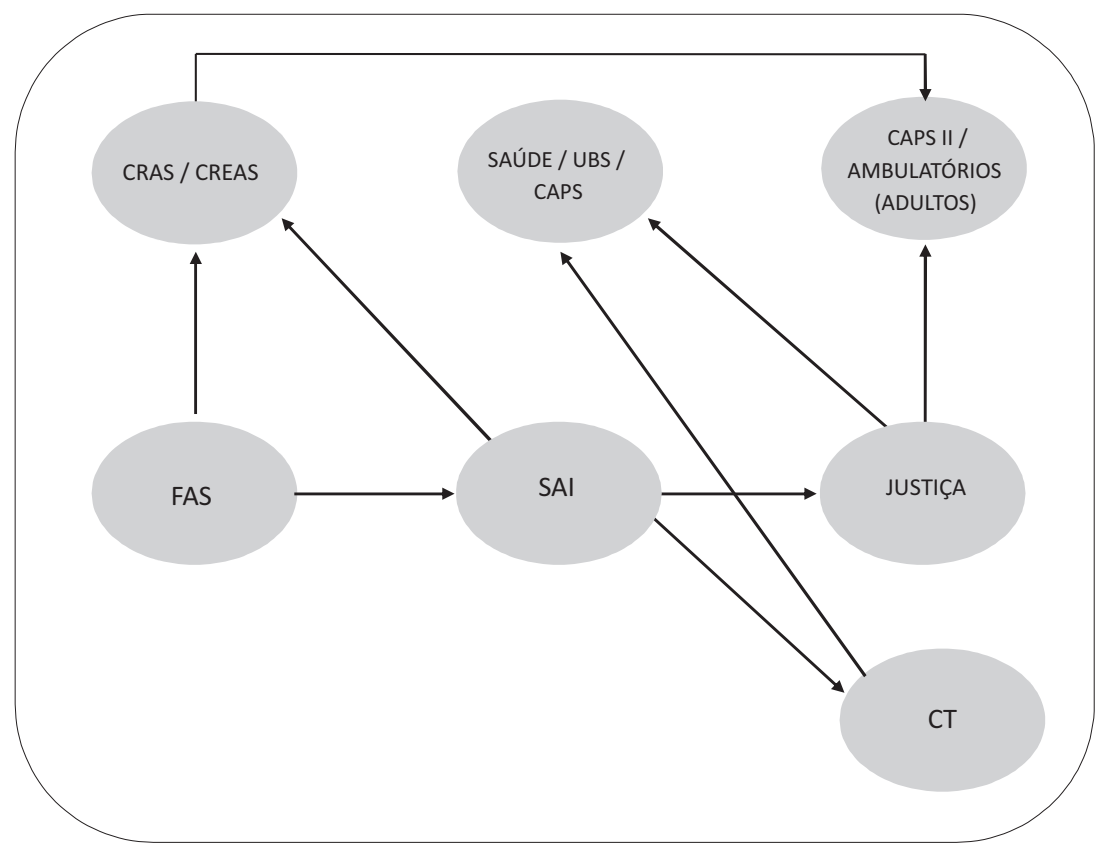

\section{DESAFIOS DO ACOLHIMENTO EM CUTITIBA}

Curitiba, como um grande centro urbano, apresenta diversos desafios de gestão de serviços, em especial no que tange à atenção de crianças, adolescentes e suas famílias, usuários de crack e outras drogas. Com o crescimento da cidade, ficam também mais evidentes as desigualdades sociais e as dificuldades em garantir o acesso a direitos básicos a todos os cidadãos.

Como em outras localidades do país, o uso, abuso e dependência de drogas, entre elas, o crack, é uma questão social. A problemática envolve vários setores da sociedade e das vidas dos sujeitos, demandando respostas em termos de políticas, programas e ações que vêm sendo elaborados intersetorialmente. Assim, tanto a saúde quanto a assistência social e a justiça, entre outras instâncias, procuram elaborar propostas de abordagem da questão.

Quando o uso de drogas envolve sujeitos em desenvolvimento, o assunto se torna ainda mais dramático, demandando ações que envolvam as famílias, por vezes também dependentes. Os participantes citaram, contudo, dificuldades em seu atendimento e comentaram sobre os desafios da rede. 
A rede procura estar estruturada para atender a demanda de cuidado, de forma geral, em relação à garantia de direitos e, especificamente, ao problema do crack. A pesquisa mostra que a rede dispõe de diversos serviços que são necessários para o atendimento de crianças e adolescentes, contudo, denuncia que sua organização está longe do funcionamento ideal. Em termos de implementação novos serviços, o Caps III é a principal demanda dos atores dos órgãos componentes da rede, centro que foi incrementado após finalizado o trabalho de campo.

Falta também um conhecimento específico sobre como tratar crianças e adolescentes dependentes de drogas, especificamente do crack. Um ponto de destaque na avaliação da rede, que a afasta da ideal, é a preparação dos profissionais. Estes carecem de formação e capacitação para lidar com tema e público tão desafiadores, em especial os cuidadores.

Um nó, identificado por todos, diz respeito às vagas para internação de crianças e adolescentes. Há déficit na rede e, como alternativa, entram em cena as Comunidades Terapêuticas - instituições fechadas, em geral afastadas dos centros urbanos, e de caráter religioso, que propõem o tratamento contra as drogas visando à abstinência. Sua orientação está em desacordo com as políticas públicas de saúde mental e com o praticado nos serviços direcionados ao cuidado ao uso de drogas. Aposta-se que, afastando o sujeito do ambiente em que há o uso do crack, ele se livrará dessa substância e se reabilitará. Em geral, há nesses locais ausência de projetos terapêuticos individualizados e o tratamento é de base religiosa. Além disso, esses serviços representam uma terceirização do cuidado por parte do Estado.

A falta de comunicação é uma das principais queixas em relação à rede, o que gera desentendimentos e encaminhamentos falhos ou errôneos. A excepcionalidade do acolhimento institucional e a responsabilidade do Poder Público na garantia do atendimento aos direitos básicos são evocados para problematizar tal fato. O trabalho, na prática, não é em rede. Por vezes, sujeitos acolhidos em SAI têm demandas outras, e o afastamento da família talvez não fosse necessário se houvesse outro tratamento do caso. Reitera-se o caráter de excepcionalidade do acolhimento em serviço institucional e a responsabilidade do Poder Público em garantir à população os direitos sociais básicos.

Várias razões, para além do uso de crack por parte de crianças e de adolescentes ou de seus familiares, aparecem provocando um acolhimento. Muitas dizem respeito a uma série de determinantes sociais que deixam as 
famílias em situação de vulnerabilidade e se relacionam também às causas e consequências do uso da droga, como situação de rua, negligência, carência de recursos materiais, exploração do trabalho ou mendicância, ausência dos responsáveis por prisão, condições de saúde específicas. Os SAls acabam, segundo fala dos gestores da RAl, funcionando como uma "caçamba de entulho", isto é, reúnem os sujeitos "sobrantes" que não têm visibilidade social.

As histórias narradas neste estudo ilustram a multiplicidade de fatores que envolvem as vidas das crianças, adolescentes e suas famílias. São eles que circulam pelos serviços da rede e atestam o que funciona e o que não funciona. Sua avaliação, no entanto, não pode ser tomada como único parâmetro, uma vez que suas necessidades e buscas por ajuda são tão particulares quanto suas histórias. Elas podem servir, sim, como ponto de partida para reflexões sobre o que pode funcionar positivamente nos serviços que compõem a rede de atenção em Curitiba e sobre o que deve ser aprimorado.

\section{REFERÊNCIAS}

ASSIS, S. G. \& FARIAS, L. O. P. (Orgs.). Levantamento Nacional das Crianças e Adolescentes em Acolhimento Institucional e Familiar. São Paulo: Hucitec, 2013.

BRASIL. Ministério do Desenvolvimento Social e Combate à Fome. Conselho Nacional de Assistência Social. Resolução CNAS n. 109, de 11 nov. 2009. Aprova a Tipificação Nacional de Serviços Socioassistenciais. Disponível em: <www.mds.gov.br/ assistenciasocial/secretaria-nacional-de-assistencia-social-snas/livros/tipificacao-nacionalde-servicos-socioassistenciais>. Acesso em: 7 abr. 2015.

CARLINI, E. A. et al. II Levantamento Domiciliar Nacional sobre Uso de Drogas Psicotrópicas no Brasil (2005). Brasília: Secretaria Nacional Antidrogas, Centro Brasileiro de Informações sobre Drogas Psicotrópicas, 2005.

CURITIBA. Prefeitura Municipal. Levantamento sobre Consumo de Drogas Psicotrópicas entre Estudantes de Ensino Fundamental da Rede Municipal de Ensino de Curitiba. Curitiba: Prefeitura Municipal de Curitiba, 2009.

CURITIBA. Prefeitura Municipal. Plano de Desenvolvimento Humano e Enfrentamento às Drogas. Curitiba: Instituto Municipal de Administração Pública, 2012.

CURITIBA convoca Liga do Bem na luta contra as drogas. Paraná Online, Curitiba, 2 jul. 2012. Disponível em <www.parana-online.com.br/editoria/cidades/news/617884 /? noticia $=$ CURITIBA+CONVOCA + LIGA+DO+BEM+NA+LUTA+CONTRA+A S+DROGAS>. Acesso em: 9 jul. 2012.

GUND, D. P. O Enfrentamento da Dependência de Crack em Crianças e Adolescentes pelas Equipes Multiprofissionais da Rede de Saúde Mental do Município de Cascavel: estratégias, desafios e possibilidades, 2011. Dissertação de Mestrado, Londrina: Universidade Estadual de Londrina. 
INSTITUTO BRASILEIRO DE GEOGRAFIA E ESTATÍSTICA (IBGE). Pesquisa Nacional de Saúde Escolar. Rio de Janeiro: IBGE, 2009.

MARQUES, A. C. P. R. \& CRUZ, M. S. O adolescente e o uso de drogas. Revista Brasileira de Psiquiatria, 22, supl. 2: 32-36, 2000.

NEIVA-SILVA, L. Uso de Drogas entre Crianças e Adolescentes em Situação de Rua: um estudo longitudinal, 2008. Tese de Doutorado, Porto Alegre: Universidade Federal do Rio Grande do Sul.

ÔNIBUS do projeto Intervidas e trailler-consultório reforçam atendimento à população de rua. Agência de Notícias da Prefeitura de Curitiba, 25 mar. 2015a. Disponível em: <www.curitiba.pr.gov.br/noticias/onibus-do-projeto-intervidas-e-trailer-reforcamatendimento-a-populacao-de-rua/35924>. Acesso em: 7 abr. 2015.

SECRETARIA DA SAÚDE assume política sobre drogas do município. Agência de Notícias da Prefeitura de Curitiba, 25 mar. 2015b. Disponível em: <www.curitiba.pr.gov. $\mathrm{br} /$ noticias/secretaria-da-saude-assume-politica-sobre-drogas-do-municipio/35925>. Acesso em: 7 abr. 15. 


\title{
9 \\ Uma Rede em Construção no Município de Porto Alegre
}

\author{
Miriam Schenker
}

\section{A Cidade de Porto Alegre e o Crack}

Porto Alegre, município brasileiro situado no extremo sul do país, é a capital do estado do Rio Grande do Sul. Tem uma área de aproximadamente 497 km² e uma geografia diversificada com morros e um grande lago, o Guaíba. O lago, que contorna a cidade numa grande extensão, juntamente com áreas de preservação natural e com elevado índice de arborização das vias públicas, fazem de Porto Alegre uma cidade verde.

É conhecida como a capital dos Pampas, por pertencer à região de fauna e flora características, formada por extensas planícies que dominam a paisagem do sul do Brasil e parte da Argentina e do Uruguai. Aí nasceu o gaúcho, figura histórica, dotada de bravura e espírito guerreiro, resultado de lendárias batalhas e revoltas por disputas de fronteiras entre os reinos de Portugal e Espanha, a partir do século XVI. ${ }^{1}$

Porto Alegre é ponto estratégico dentro do Mercado Comum do Sul (Mercosul), centro geográfico das principais rotas do Cone Sul, multicultural por natureza, terra de reconhecidos escritores, intelectuais, artistas e políticos que marcaram a história do Brasil.

A cidade apresenta problemas ambientais em decorrência da urbanização descontrolada, com perda da cobertura vegetal, impermeabilização do solo, contaminação e redução de mananciais de água e erosão. O lago Guaíba,

Disponível em: <www2.portoalegre.rs.gov.br/turismo/default.php?p_secao=257>. Acesso em: 29 dez. 2012 
principal abastecedor de água, é poluído por receber lançamentos de esgotos, efluentes industriais e agrotóxicos, entre outros detritos. ${ }^{2}$

Em contrapartida, a cidade conta com um movimento ecológico bastante organizado, que vem se projetando nacionalmente desde a década de 1970, com a liderança de figuras como José Lutzenberger. A Secretaria Municipal de Meio Ambiente de Porto Alegre foi a primeira a ser criada no Brasil (1976), e a Prefeitura tem promovido um grande número de atividades para a população sobre temas ecológicos globais. Destacou-se em anos recentes pela realização das três primeiras edições do Fórum Social Mundial em 2001, 2002 e 2003.

De acordo com o Atlas do Desenvolvimento Humano no Brasil, ${ }^{3}$ a população de Porto Alegre em 2010 é de 1.409.351, 53,6\% mulheres e 46,4\% homens, configurando-se como o décimo município brasileiro mais populoso. ${ }^{4}$

A cidade se destacou por ter o segundo melhor Índice de Desenvolvimento Humano Municipal ${ }^{5}(0,86)$ entre as metrópoles nacionais, com base nos dados do censo do ano 2000 do Programa das Nações Unidas para o Desenvolvimento/ Brasil (Pnud). Porto Alegre recebeu do Ministério da Educação em 2007 o selo que a reconhece como Cidade Livre do Analfabetismo, concedido a toda cidade que alcança $96 \%$ de alfabetização. ${ }^{6}$

A região metropolitana de Porto Alegre, criada em 1973, é a área mais densamente povoada do estado, concentrando $37 \%$ da população em 31 municípios, nove deles com mais de 100 mil habitantes. A região contava em 2010 com 3.958 .985 habitantes.

Uma das características mais marcantes da administração pública portoalegrense é a adoção de um sistema de participação popular na definição de investimentos públicos, o chamado Orçamento Participativo. Esse sistema vem sendo reconhecido internacionalmente como uma experiência bemsucedida de interação entre a população e as esferas administrativas oficiais na gestão pública.

2 Disponível em: <http://portoalegretche.blogspot.com.br/2013/09/meio-ambiente-de-portoalegre.html>. Acesso em: 29 dez. 2012.

3 Disponível em: <www.atlasbrasil.org.br/2013/pt/perfil_m/porto-alegre_rs $>$. Acesso em: set. 2015.

4 Disponível em: <www.ibge.gov.br/home/presidencia/noticias/imprensa/ppts/0000000557080 $8132011085431530840 . v>$. Acesso em: set. 2015.

$5 \mathrm{O}$ IDH considera três dimensões fundamentais para o desenvolvimento humano: o conhecimento, medido por indicadores de educação; a saúde, medida pela longevidade; e o padrão de vida digno, medido pela renda.

6 Disponível em: <www.pnud.org.br/atlas/ranking/IDH_Municipios_Brasil_2000. aspx?indiceAccordion=1\&li=li_Ranking2003>. Acesso em: 29 dez. 2012. 
A criminalidade em Porto Alegre tem mostrado índices variáveis nos últimos anos. Em 2007, entre as 13 maiores capitais, foi a que mais se destacou em termos de homicídios: o número de mortes por agressão cresceu quase $60 \%$ em relação a 2006 e os homicídios aumentaram em 57,5\%, metade do número das ocorrências em todo o estado. As principais causas foram o sucateamento do sistema de segurança, o acirramento da rivalidade entre as polícias civil e militar, o aumento do tráfico de drogas e de bolsões de pobreza. Em 2009, entretanto, com o reforço de policiamento ostensivo, as estatísticas caíram em várias áreas. No ano seguinte, foi instalado um sistema de mapeamento do crime via internet, com resultados significativos: em apenas seis meses, alguns dos índices de criminalidade se reduziram. Os bons resultados também são consequência do aumento do efetivo na segurança pública.

\section{O USO DE DROGAS E DE CRACK}

Apresentamos a seguir alguns estudos acerca do uso de drogas em geral, e de cocaína e crack em particular, no município de Porto Alegre, a fim de entender o processo de consumo dessas substâncias por adolescentes e/ou seus familiares. Inicialmente mostram-se dados sobre consumo da droga entre adolescentes, fase em que comumente se inicia o uso de substâncias psicoativas.

Levantamentos epidemiológicos com estudantes, frequentes na sociedade brasileira, são importantes para aferir o consumo de drogas (Duailibi, Ribeiro \& Laranjeira, 2008). O levantamento nacional com estudantes de nível fundamental e médio de escolas públicas das redes municipais e estaduais realizado por Galduróz e colaboradores (2005), pesquisadores do Centro Brasileiro de Informações sobre Drogas Psicotrópicas (Cebrid), traz dados importantes. Revela que o maior número de usuários em todas as capitais investigadas encontrava-se na faixa etária dos 16 anos em diante, embora $12,7 \%$ das crianças de 10 a 12 anos relatassem ter consumido drogas, pelo menos uma vez na vida. As drogas lícitas, álcool (65,2\%) e tabaco (25\%), foram as mais utilizadas, e $22,6 \%$ dos estudantes já tinham consumido drogas ilícitas em algum momento da vida. Os solventes $(15,5 \%)$ e a maconha $(5,9 \%)$ lideraram esse uso, com $2 \%$ dos estudantes referindo já ter consumido cocaína e $0,7 \%$, crack. Nesse levantamento, Porto Alegre apresentou o maior uso na vida de cocaína $(2,3 \%)$ e crack $(1,5 \%)$, entre as três capitais da região Sul. Os meninos (2,6\%) relataram maior uso na vida de cocaína que as meninas (1,8\%). O mesmo ocorre com o crack, $2,3 \%$ e $0,7 \%$, respectivamente. 
Entretanto, Kessler e Pechansky (2008: 96) alertam que

estudos de natureza epidemiológica obtidos em escolas têm como natural viés a obtenção de dados sobre alunos que estejam matriculados, cursando e presentes em sala de aula no dia da coleta. Por suas características peculiares, o crack não é uma droga que permita a convivência em um ambiente de ensino, e provavelmente os dados obtidos dessa forma encontram-se subestimados.

De acordo com o Levantamento Nacional sobre o Uso de Drogas entre Crianças e Adolescentes em Situação de Rua nas 27 Capitais Brasileiras (Noto et al., 2003), o consumo inicial de derivados da coca se deu, na maioria dos casos, após a situação de rua. A tendência de aumento foi constatada nos levantamentos entre crianças e adolescentes em situação de rua efetuados pelo Cebrid nas seis capitais estudadas em 1987, 1989, 1993, 1997 e 2003. Foram observados, ao longo dos anos, crescimentos em saltos em quase todas as capitais em épocas diferentes. Em São Paulo, entre 1989 e 1993; em Porto Alegre, entre 1993 e 1997, e, no Rio de Janeiro, o consumo, que já era elevado em 1993, acentuou-se ainda mais entre 1997 e 2003. As principais drogas utilizadas foram as bebidas alcoólicas (especialmente a cerveja) e o tabaco. Seguem os solventes/inalantes, maconha e derivados da coca, incluindo o crack. Em 2003 constataram-se menores índices de uso recente de tabaco e de solventes, manutenção do padrão de consumo de maconha e bebidas alcoólicas, aumento do consumo de derivados da coca e desaparecimento de casos de uso recreativo de medicamentos psicotrópicos.

Neiva-Silva (2008) estudou longitudinal e transversalmente, em dois momentos diversos (diferença de 14 meses), o uso de drogas entre crianças e adolescentes em situação de rua, em Porto Alegre, distribuídos em duas faixas etárias: 10-11 e 18-19 anos. $O$ autor buscou identificar a prevalência, os padrões de uso e os fatores de risco e proteção, por meio de entrevistas com crianças e adolescentes, inseridos em instituições abertas em que a permanência e a frequência não são obrigatórias (oferecem serviços de educação, saúde, espaço para pernoite, lazer, atividades desportivas e alimentação). Longitudinalmente, observou-se aumento significativo no uso de álcool, solventes maconha e cocaína/crack.

De acordo com o estudo, das 216 crianças e adolescentes em situação de rua, tem-se que: a maior parte era composta por meninos (75,5\%); $17,6 \%$ tinham entre 10 e 11 anos e $61,6 \%$ entre 14 e 18; 83,8\% já haviam utilizado 
alguma droga durante a vida, sendo as lícitas as mais comuns (álcool 78,7\% e tabaco $58,8 \%$ ); maconha foi experimentada por $36,6 \%$ e solventes por $33,8 \%$ dos pesquisados; entre os que usaram solventes proximamente à pesquisa, $78,2 \%$ o fizeram todos ou quase todos os dias, sendo essa a droga de maior prevalência, seguida pelo cigarro e maconha (75,9\% e 60,9\%, respectivamente); $28,7 \%$ declararam ter experimentado crack. Esses dados foram coletados durante o ano de 2003, época em que o crack estava começando a ser usado pela população investigada.

Em uma segunda fase do estudo, com 68 das 216 crianças e adolescentes em situação de rua de ambos os sexos, com coleta de dados entre 2004 e 2005, observou-se um aumento significativo do uso de crack. O solvente foi a droga com maior aumento no percentual de usuários nos últimos 14 meses, seguido do tabaco e do crack. Entre as ilícitas, o maior percentual de início de uso foi o de maconha, estando bem próximos, em segundo lugar, os solventes e o crack.

Uma pesquisa com 30 usuários de crack, internados na unidade de desintoxicação do Hospital Psiquiátrico São Pedro em Porto Alegre (Guimarães et al., 2008), revelou uma população de adultos jovens, de cor/raça branca, com idade média de 27,3 anos (de 18 a 41), em situação de subemprego ou desemprego, e $40 \%$ com antecedentes criminais associados a sintomas de maior depressão, ansiedade e fissura. Todos os crimes dos usuários que apresentaram antecedentes foram cometidos após o início do uso de substâncias psicoativas (cocaína ou crack). Antes da internação, 24 sujeitos informaram que já haviam tentado pelo menos alguma vez parar de fumar crack ( $80 \%$ dos sujeitos pesquisados); $43,3 \%$ mencionaram internação anterior por uso de crack.

Em outro estudo, pesquisou-se a mudança de padrões do uso de drogas em Porto Alegre e as razões para esse acontecimento, com base em entrevistas semiestruturadas e grupos focais com usuários de drogas de diversas cenas, profissionais do programa de prevenção ao HIV que eram ex-usuários, profissionais do programa de redução de danos (troca de seringas) da cidade, líderes comunitários e da área da saúde pública com conhecimento da cultura de uso de droga na rua (Inciardi et al., 2006). Os sujeitos eram moradores de favelas ou de bairros muito pobres nas redondezas. Os resultados mostraram que as principais drogas de abuso em Porto Alegre são a maconha e a cocaína em pó. Entretanto, os participantes do estudo enfatizaram que o uso de droga havia se modificado da cocaína injetável para o crack, seja em decorrência 
da adição de diversos materiais à cocaína, tornando-a pouco pura, seja pela possibilidade de contrair o vírus da Aids em seringas compartilhadas. Houve um aumento da prevalência do uso de crack em Porto Alegre em 2001, conforme relatado pelos participantes da pequisa. O crack costuma ser fumado em latinhas de alumínio ou, em alguns casos, na bomba de chimarrão, recipientes que, geralmente, são compartilhados. Estudo de Pechansky e colaboradores (2006) destacou que essa forma de usar crack é um novo fator de risco para se contrair HIV/Aids em Porto Alegre.

Como os sujeitos da nossa pesquisa convivem com a violência cotidianamente e o uso de crack está comumente associado à ocorrência de roubos, violências, endividamento com traficantes, entre outras situações de perigo (Guimarães et al., 2008), vale ressaltar alguns dados sobre homicídios em Porto Alegre: atingem com maior incidência a faixa etária jovem, entre 15 e 24 anos, ${ }^{7}$ além disso a cidade ocupou o décimo segundo lugar no ordenamento das capitais por taxas de homicídio em 2000 e o décimo sexto em 2010 (Waiselfisz, 2010, 2012).

\section{COMPOSIÇÃo E CARACTERÍSTICAS DA REDE SOCIOASSISTENCIAL}

A fim de conhecer a rede socioassistencial de Porto Alegre, várias instituições foram contatadas ao longo do trabalho de campo (dezembro de 2011 a novembro de 2012) que deu origem a este capítulo. São elas: Fundação de Assistência Social e Cidadania (Fasc), Fundação de Proteção Especial do Estado do Rio Grande do Sul; Secretaria Municipal de Saúde e Vara da Infância e Juventude.

7 Conceituação dos termos: criança - Estatuto da Criança e do Adolescente - de 0 a 12 anos incompletos; adolescência - Estatuto da Criança e do Adolescente - de 12 a 18 anos de idade incompletos; jovem - Sistema Nações Unidas - de 15 a 24 anos de idade; jovem - Secretaria Nacional de Juventude - de 15 a 29 anos de idade, pela incorporação da noção de adulto jovem.

"Se o termo infância nos remete aos termos criança e adolescência, que se encontram referenciados por fortes indicadores físicos e fisiológicos, o termo juventude é muito mais recente e nos remete a definições socialmente delimitadas. Para a Organização Pan-Americana da Saúde e a Organização Mundial da Saúde (Opas/OMS), adolescência e juventude diferenciariam-se pelas suas especificidades fisiológicas, psicológicas e sociológicas. (...) A adolescência constituiria um processo fundamentalmente biológico durante o qual se acelera o desenvolvimento cognitivo e a estruturação da personalidade. Abrangeria as idades de 10 a 19 anos, divididas nas etapas de pré-adolescência (dos 10 aos 14 anos) e de adolescência propriamente dita (de 15 a 19 anos). Já o conceito juventude resumiria uma categoria essencialmente sociológica, que indicaria o processo de preparação para os indivíduos assumirem o papel de adultos na sociedade, tanto no plano familiar quanto no profissional, estendendo-se dos 15 aos 24 anos, ou 15 a 29, no entendimento das instituições brasileiras" (Waiselfisz, 2010: 12). 
Uma amostra de 21 serviços de acolhimento institucional (SAIs) foi realizada, ${ }^{8}$ com a aplicação de três modelos de questionários: 1) para os SAls, dirigido ao gestor dos 21 serviços; 2) para 114 crianças/adolescentes acolhidos por uso de crack ou com pais/responsáveis com história de uso de crack, trabalho feito por meio da leitura de prontuários; 3) para dois adolescentes com história de uso de crack presentes na instituição no momento da visita (um deles ficou incompleto porque a adolescente manifestou transtorno psicótico).

Em Porto Alegre, foram criados nos últimos anos dois abrigos municipais diferenciados (I e II) para acolher e prestar atendimento a dez adolescentes (cada) entre 12 e 18 anos, em situação de transtorno de conduta, uso de substâncias psicoativas ou com ato infracional. Esses dois abrigos não foram sorteados na amostra da pesquisa, fato que dificultou sobremaneira o encontro de crianças e adolescentes usuários nos abrigos comuns avaliados. Por essa razão, a amostra realizada em Porto Alegre não permite avaliar a prevalência de usuários de crack acolhidos em SAls; é apenas possível avaliar a prevalência de filhos de usuários de crack nesses serviços.

Foram também realizadas 14 entrevistas individuais para compreender melhor como se estrutura a rede socioassistencial do município. Participaram desses encontros: uma adolescente acolhida em Casa Lar; dois adolescentes em abrigo diferenciado por acolher usuários de crack (abrigo I, visitado apenas para a entrevista com os adolescentes) e uma outra na Fundação de Atendimento Socioeducativo do Rio Grande do Sul (Fase), tratando-se da dependência do uso abusivo de crack em Caps ad (para usuários de álcool e outras drogas); dois familiares (um pai e um irmão) de diferentes usuários de crack que estavam em abrigo I; duas coordenadoras de Caps ad, aqui denominados Caps ad A e B; um conselheiro tutelar; um juiz da Vara da Infância e Juventude. Pela área da assistência social responderam diversos profissionais: coordenadora técnica de SAl; coordenadora do SAI noturno (serviço fechado em 2012, pois a estrutura e a equipe de atendimento eram grandes para o pequeno número de meninos em situação de rua que frequentava o serviço); gestora da equipe de Proteção Social de Alta Complexidade da Fasc, junto com uma gestora do Núcleo de Acolhimento da mesma unidade; gestora da equipe de Proteção Social de Média Complexidade responsável pelo atendimento à população de rua.

Define-se rede socioassistencial com base no conceito de rede como estruturas abertas que trocam informações com o meio externo e cuja capacidade de

8 No Anexo são descritos os procedimentos metodológicos da pesquisa em foco. 
expansão depende da comunicação entre seus participantes (Castells, 2000). Quanto maior e melhor esta se dá, maior a probabilidade de trocas e parcerias. A dinâmica da rede está relacionada com o compartilhamento de valores e objetivos comuns de seus integrantes numa relação de horizontalidade. Essa dinâmica se apoia num clima de convivência solidária em prol do bem comum que, em nossa pesquisa, é a saúde das crianças/adolescentes e seus familiares usuários de crack.

A rede socioassistencial de Porto Alegre para atendimento a crianças e adolescentes usuários de crack ou cujos pais fazem uso da substância está, metaforicamente, configurada por nós: em cada nó se localiza um dos parceiros que a integram, a saber: a Vara da Infância e Juventude, o Conselho Tutelar (CT), a Proteção Social de Alta Complexidade, a Proteção Social de Média Complexidade, os SAls, o Serviço de Acolhimento Noturno (SAN), os Caps ad A e B. Contudo,

um dos maiores desafios para a constituição de redes é quebrar a cultura vertical de trabalho, que no Brasil é reforçada pela relação assimétrica ${ }^{9}$ de poder existente na construção histórica da sociedade. Além desse desafio, é necessário que as instituições, embora tenham vocações profissionais diferenciadas, construam um projeto comum. (Assis \& Farias, 2013: 223)

Para se compreender melhor os serviços oferecidos em Porto Alegre à população infantojuvenil e suas famílias, apresentamos o cenário institucional existente nesta capital.

$\mathrm{Na}$ assistência social, as ações e serviços de proteção à criança e ao adolescente são gerenciados pela Fasc nas 17 regiões da cidade. A porta de entrada desses serviços se constitui pelos 22 Centros de Referência de Assistência Social (Cras), referenciados pelos serviços especializados e pelos nove Centros de Referência Especializados de Assistência Social (Creas). A Fasc dispõe de programas e serviços direcionados à população infantojuvenil. De acordo com as diretrizes da Lei Orgânica da Assistência Social (Loas) e do Estatuto da Criança e do Adolescente (ECA), a Fasc dá retaguarda aos dez Conselhos Tutelares da cidade que têm a função de zelar pela garantia dos direitos das crianças e dos adolescentes.

9 Assimetria nas relações de poder existente do rico sobre o pobre, do branco sobre o negro, do homem sobre a mulher, do adulto sobre a criança. Esse assunto tem sido tratado por Viviane Guerra e Maria Amélia Azevedo. Disponível em: <www.ip.usp.br/laboratorios/lacri/livros.htm>. 
Há várias ações e programas que atendem usuários de crack/drogas e população de rua. Entre eles, destacam-se na área da assistência social:

1) Programa Municipal de Execução de Medidas Socioeducativas em Meio Aberto (Pemse) - executado pelo Creas, atende usuários de drogas. A coordenação da execução das medidas socioeducativas aplicadas pela justiça a adolescentes de 12 a 18 anos residentes em Porto Alegre foi municipalizada em 2000. O programa foi implantado obedecendo às divisões regionais do Conselho Tutelar. Na primeira etapa da municipalização, teve início a execução das medidas de prestação de serviços à comunidade e, em 2002, das medidas de liberdade assistida. Não há número definido de vagas, pois a demanda enviada pelo Juizado deve ser absorvida imediatamente pelo município.

2) Programa Agente Jovem de Desenvolvimento Social e Humano atende adolescentes de 15 a 18 anos, priorizando os que apresentam maior grau de vulnerabilidade social (como o usuário de drogas) e os egressos do Programa de Erradicação do Trabalho Infantil e do Pemse. São oferecidas oficinas, palestras e grupos de discussão sobre questões da juventude, como sexualidade, trabalho, violência, drogas e cidadania. Os adolescentes recebem bolsa-auxílio no valor de $\mathrm{R} \$ 65,00^{10}$ e elaboram um projeto social para aplicação em suas comunidades. Em 2012, o programa beneficiava 519 indivíduos, divididos em 15 turmas distribuídas nas regiões de abrangência dos centros regionais.

3) Casas de Acolhimento - abrigos residenciais que oferecem acolhimento imediato a crianças e adolescentes de ambos os sexos em situação de rua e a crianças/adolescentes de 0 a 18 anos em situação de vulnerabilidade (incluindo uso de drogas) com determinação judicial. $O$ atendimento é integral e temporário, até que sejam encaminhados novamente para suas famílias, ou para famílias substitutas, ou para outros serviços da rede. São 12 equipamentos municipais e 68 entidades conveniadas. Os equipamentos deveriam atender de dez a 20 crianças. Mas, como o abrigo municipal funciona como porta de entrada, poderá excepcionalmente acolher um número maior de crianças a pedido do juiz, como no caso do recebimento de grupo de irmãos. Existe também em Porto Alegre o Núcleo de Acolhimento, com a função de direcionar para quais espaços as crianças a serem acolhidas deverão se dirigir. Mas, diante da demanda crescente, a porta de entrada tem sido os abrigos próprios da Prefeitura.

$\overline{10}$ O salário mínimo na época (2012) era $\mathrm{R} \$ 622,00$. 
4) Casas Especiais (formato de abrigo) - criadas a partir do reordenamento do Ministério do Desenvolvimento Social de Combate à Fome (MDS) para os SAls. São dois espaços municipais diferenciados (abrigo I e abrigo II) para acolher e prestar atendimento a dez adolescentes entre 12 e 18 anos, em situação de transtorno de conduta, uso de substâncias psicoativas ou com ato infracional.

O adolescente acolhido no abrigo I pode optar por não cumprir ali o mandato judicial que Ihe foi imputado e voltar para a rua ou, no caso de ter uma audiência no programa Justiça Restaurativa, aguardar a chamada nesse abrigo.

Inicialmente, o abrigo I foi implantado para atender adolescentes de ambos os sexos, porém nunca recebeu uma menina.

O abrigo II não fornece essa retaguarda para a Justiça Restaurativa. São meninos bastante comprometidos, devido ao abuso do crack e outras drogas e a comportamentos delinquentes, e o espaço comporta dez deles. O abrigo é mais organizado porque os meninos permanecem mais tempo na casa.

5) Casa Lar - abriga crianças e adolescentes em situação de destituição do pátrio poder ou rompimento de vínculos familiares. Cada casa recebe até dez crianças que são cuidadas pela mãe social. O programa começou a funcionar em 1995, com três casas, e em 2012 possuía 46 unidades instaladas. Em outubro de 2012 a Proteção Social de Alta Complexidade informou existirem 68 unidades residenciais/SAI com 763 acolhidos (60\% do sexo masculino). Desses, 56 são espaços conveniados (537 acolhidos) e 12 são municipais (226 acolhidos).

6) Ação Rua - dirigido para crianças, adolescentes em situação de rua e seus familiares, contava, em 2000, com um serviço chamado Educação Social de Rua. Tinha equipe baseada no centro da cidade, que abrangia todo o município. Em 2007 ele foi regionalizado e instituiu-se um novo projeto técnico chamado Ação Rua. Há 13 núcleos do Ação Rua que fazem abordagem social e acompanhamento das famílias e das crianças e adolescentes em situação de rua em cada região da cidade e são vinculados a cada um dos Creas.

Esse serviço conta com equipe composta por psicólogo, assistente social e educadores, que faz a abordagem de meninos que estão em situação de rua ou de trabalho infantil nos territórios, visando a conhecer o contexto de onde eles vêm e a causa de estarem na rua. A partir daí, entra em contato com a família com o intuito de inseri-la no acompanhamento familiar e nos programas disponíveis, como os que são oferecidos pelo cadastro único, como o Bolsa Família. Os profissionais que trabalham nesse serviço relatam a dificuldade que 
enfrentam para abordar pais ou crianças e adolescentes usuários de crack das comunidades. $\mathrm{O}$ crack é utilizado em áreas dispersas e específicas dentro das comunidades que, por sua vez, constituem-se como minicidades.

Pessoas em situação de rua apresentam elevada vulnerabilidade para o uso de crack. Neiva-Silva (2008) constatou probabilidade de $98,9 \%$ para o início do consumo de crack entre participantes de sua pesquisa que não moravam com a família, estavam há mais de cinco anos na rua e, em geral, passavam mais de oito horas na rua. Já os que moravam com a família, estavam há menos de cinco anos na rua e ficavam menos de oito horas na rua, e a probabilidade de início de uso de crack foi de 2,1\%.

O serviço Ação Rua é reconhecido por alcançar resultados importantes para a cidade, porque, por meio de suas ações, conseguiu diminuir o número de crianças e adolescentes em situação de moradia na rua. Desde 2003, o município constituiu uma microrrede que trabalha acompanhando os casos de meninos que fazem da rua a sua moradia. Em geral, são usuários de drogas mais graves.

A partir da implantação do Ação Rua, houve uma diminuição dos casos mais graves em que há moradia na rua. Também foi possível verificar mais casos de trabalho infantil. Isso porque as equipes, que trabalham em regiões longínquas da cidade, conseguem identificar mais rapidamente uma situação de trabalho infantil, o que permite o acompanhamento dessas famílias. Quando o serviço iniciou em 2007, a equipe monitorava em torno de 250 meninos em situação de rua. Em 2012, diminuiu para aproximadamente 90 meninos.

Na área da saúde, os serviços do Sistema Único de Saúde (SUS) de Porto Alegre estão distribuídos nos territórios dos 17 distritos sanitários, que formam as gerências distritais. Essas gerências são estruturas administrativas e gestoras regionais e também espaços de discussão e prática onde são operacionalizadas todas as estratégias para a atenção à saúde na esfera do SUS. $\mathrm{Na}$ cidade, estão distribuídas em oito regiões de saúde, que são compostas por unidades de saúde, centros de especialidades e serviços especializados ambulatoriais e substitutivos. Sob a Coordenadoria Geral de Urgências, nos territórios dos distritos sanitários e das gerências distritais, estão os prontoatendimentos, as bases do Serviço de Atendimento Móvel de Urgência (Samu) e os hospitais gerais e especializados próprios e conveniados ao SUS, com portas de urgência e emergência. Esse conjunto de equipamentos de saúde forma a rede de serviços do SUS na capital gaúcha. Porto Alegre oferece 
diversos dispositivos relacionados com o uso de drogas de crianças e adolescentes, que são gerenciados por esferas de gestão municipal, estadual e federal.

Na esfera federal destaca-se o Grupo Hospitalar Conceição, um dos sete hospitais federais gerenciados pelo Ministério da Saúde. Tem um complexo integrado por três hospitais (Conceição - geral, Fêmina - maternoinfantil, Cristo Redentor - trauma), 12 unidades de saúde comunitária conveniadas com a Prefeitura e alguns dispositivos especializados que atendem o campo da saúde mental, a saber, um Caps II (adulto), um Caps ad III (funciona 24 horas, a semana toda), um Caps i (para crianças e adolescentes), uma equipe de Consultório na Rua, unidade de internação psiquiátrica no Hospital Conceição e uma equipe de interconsulta do município.

Na esfera estadual, a Secretaria Estadual de Saúde mantém duas alas de internação para usuários de drogas no Hospital Psiquiátrico São Pedro. As duas alas (adulto e infantil) oferecem também atendimento ambulatorial de referência ao Distrito Sanitário da Lomba/Parthenon, bem como matriciamento para o respectivo distrito. $\mathrm{O}$ atendimento infantil é promovido pelo Centro Integrado de Atenção Psicossocial - Infância e Adolescência (Ciaps) e se constitui como serviço de atenção integral à criança e ao adolescente em sofrimento psíquico, ao usuário de drogas, e oferece um espaço de atendimento em saúde mental com equipe interdisciplinar.

Na esfera municipal, a Secretaria Municipal de Saúde oferece serviços próprios e credenciados, distribuídos pelos distritos sanitários, regionalizando os recursos para o atendimento da saúde da população. Ao todo, Porto Alegre conta com 45 unidades básicas de saúde e sete centros de saúde, organizados em forma de pronto atendimento. Os centros de saúde têm equipes de referência em saúde mental (psicologia, psiquiatria e neuro), que atendem as demandas encaminhadas pelas equipes de Saúde da Família, referência para o uso abusivo de drogas e intercorrência em saúde mental.

Os seguintes serviços oferecem atendimento especializado em saúde mental e uso de drogas na rede da capital:

- Centro de Saúde Santa Marta: onde funciona o Núcleo de Atenção Integral a Criança e Adolescente em Idade Escolar (Nasca), que trabalha conjuntamente com a rede de educação do município.

- Caps ad IAPI: Caps ad conveniado com o Hospital Mãe de Deus, no Distrito Sanitário IAPI. Há o atendimento de adolescentes e trabalho de matriciamento para o respectivo território. 
- clínicas para atendimento a usuários de drogas: São José é particular e a Prefeitura paga por vagas para adolescentes de 14 anos em diante, e Gramado atende adolescentes de 12 a 14anos.

- duas Comunidades Terapêuticas conveniadas: Pacto, para homens, tem orientação religiosa; Marta Maria, para mulheres. Há casos de mães internadas pelo uso abusivo de crack, junto com seus filhos, bem como de adolescentes.

Há também na esfera municipal a rede de Atendimento de Urgência e Emergência, que oferece atendimento multiprofissional, contemplando também a atenção a crises em saúde mental e uso de drogas. Compõem essa rede: Glória, Cruzeiro do Sul e Cristal - Caps ad -; Bom Jesus - ambulatório e pronto atendimento -; Lomba do Pinheiro - ambulatório e pronto atendimento - e Samu.

\section{Peculiaridades da rede e do uso do crack em Porto Alegre}

Porto Alegre apresenta diferenças territoriais consideráveis com relação a cidades como Rio de Janeiro e São Paulo. Não existe uma cracolândia na cidade, mas sim algumas concentrações de usuários e usuários-traficantes, com intensa fluidez territorial. Não foi implantada a política de recolhimento compulsório de usuários de crack na capital gaúcha pela resistência de diversos coletivos organizados, tais como: Conselho Regional de Psicologia, Fórum de Redução de Danos e Fórum Gaúcho de Saúde Mental, as secretarias estaduais de Saúde, Justiça e Direitos Humanos e Segurança, e o comando da Brigada Militar.

Em 2015, ainda segue em tramitação o projeto de lei (PL) para internação compulsória (PL n. 090/13) na Assembleia Legislativa do Rio Grande do Sul. E encontra-se no Senado o PL n. 7.663/2010, que altera a lei n. 11.343/2006"11 e prevê o recurso da internação compulsória de modo diferente do preconizado na Lei da Reforma Psiquiátrica (10.216/2001). Cabe ressaltar que o Rio Grande do Sul é um dos estados com elevados índices de processos de internação judicial (compulsória), segundo profissionais entrevistados na pesquisa que originou este capítulo.

Em abril de 2012 foi inaugurado o serviço de atendimento psicossocial álcool e drogas IAPI (Caps ad III) que passa a atender 24 horas, em parceria

${ }^{11}$ A lei 11.343/06 institui o Sistema Nacional de Políticas Públicas sobre Drogas (Sisnad); prescreve medidas para prevenção do uso indevido, atenção e reinserção social de usuários e dependentes de drogas; estabelece normas para repressão à produção não autorizada e ao tráfico ilícito de drogas e define crimes. 
com o Hospital Mãe de Deus. O Ministério da Saúde repassou R\$ 100 mil para a adequação do Caps às atividades 24 horas.

Foi inaugurado em outubro de 2015 o centro colaborador da Secretaria Nacional de Políticas sobre Drogas (Senad), sob a coordenação do Hospital de Clínicas de Porto Alegre, vinculado à Universidade Federal do Rio Grande do Sul (UFRGS). O centro é composto por uma unidade de internação, com 20 leitos para tratamento de dependentes de crack e outras drogas, 32 leitos clínicos de apoio à emergência do hospital e do ambulatório em crack e outras drogas. Essa unidade recebe encaminhamento de pacientes com história de uso de crack de duas emergências psiquiátricas da cidade localizadas em postos de saúde e gerenciadas pela central de regulação de leitos do município.

O hospital trabalha também para a ampliação de 12 leitos para mulheres na Unidade Álvaro Alvim (UAA), que se juntarão aos 20 já disponíveis para os homens, além dos 66 leitos clínicos.

Os dependentes de crack que são de classe alta costumam buscar atendimento principalmente em duas clínicas da cidade (Pinel e São José), que mantêm um programa para usuários de substâncias psicoativas.

A Secretaria Municipal de Educação realiza ações de prevenção ao uso de drogas de forma geral no programa Saúde na Escola e nas atividades esportivas e recreativas. Em 2011, a Prefeitura e a Central Única das Favelas (Cufa) assinaram parceria no projeto Circuito Papo Reto Porto Alegre, para prevenção ao uso de crack entre alunos das escolas municipais de ensino fundamental e médio. Em 2012 foram realizadas palestras e atividades lúdicas, como oficinas de fotografia, teatro e grafite, festival de teatro, exposição fotográfica e mostra de grafite.

Na esfera da justiça, a Secretaria da Justiça e dos Direitos Humanos do estado conta com o Departamento de Políticas Públicas sobre Drogas, que é encarregado de promover ações que contribuam para a inclusão social do cidadão, reduzindo os riscos de envolvimento com drogas. Também é papel do departamento cumprir os objetivos do Sistema Estadual de Políticas Públicas sobre Drogas e promover a educação e a socialização do conhecimento sobre drogas no estado. Ainda cabe a esse órgão promover políticas de prevenção, orientar as famílias de usuários e auxiliar na reinserção de dependentes químicos na sociedade, além de gerir o Fundo Estadual sobre Drogas e estabelecer as prioridades para o cumprimento das recomendações do Conselho Estadual sobre Drogas. 
Crack, É Possível Vencer é um programa coordenado pela Secretaria da Justiça e dos Direitos Humanos. Lançado no dia 17 de abril de 2012, o programa prevê o aumento da oferta de tratamento de saúde e atenção aos usuários de drogas, o fortalecimento das ações policiais contra o tráfico e a ampliação das atividades de prevenção.

O Mapeamento dos Bens Oriundos do Tráfico é outra ação efetuada, responsável pelo levantamento de todos os bens apreendidos do tráfico de drogas para serem leiloados. Os recursos com a venda dos bens alimentarão o Fundo Estadual sobre Drogas.

Até o ano de 2013, houve uma reunião com os Conselhos Municipais de Drogas do estado e com a população em geral, para o debate sobre as drogas, no Seminário proposto pelo Departamento de Políticas sobre Drogas da Secretaria de Justiça e dos Direitos Humanos do Rio Grande do Sul. Há também o Conselho Estadual de Políticas sobre Drogas, que, por ocasião de sua reorganização e da elaboração de novo regimento em 2011, previu a realização das Conferências de Políticas sobre Drogas a cada quatro anos, o que, entretanto, não foi deliberado pela Plenária em 2013.

\section{Os Serviços de AColhimento Institucional e AS CRiançAS, AdOLESCENTES E FAMÍLIAS USUÁRIAS DE CRACK}

Esta seção apresenta a descrição dos SAls que compuseram a amostra pesquisada em Porto Alegre com relação ao uso, ou não, de crack e/ou de drogas em geral por crianças e adolescentes acolhidos e/ou por seus familiares. Estão apontados os serviços frequentados regularmente pelos adolescentes usuários de crack e aqueles oferecidos aos seus familiares usuários de crack. Diferentes aspectos dos SAls visitados são ainda apresentados, bem como a capacitação profissional para lidar com o tema do crack e outras drogas.

Nos 21 SAls visitados em Porto Alegre foram encontradas 158 crianças e 122 adolescentes, 280 no total. Como se pode constatar na Tabela 1, apenas um dos serviços recebe crianças que usam drogas e nenhum abriga criança usária de crack. Na fase da adolescência, a realidade é distinta, há nove serviços com acolhidos que usam drogas em geral e em quatro unidades há menção ao uso específico de crack. Considerando-se o uso de crack e outras drogas pelos responsáveis dos acolhidos, nota-se situação bem mais grave na maioria dos serviços: em 16 unidades há responsáveis por crianças e em 15 instituições 
os responsáveis por adolescentes são referidos pelo uso de drogas em geral. Em 14 serviços há familiares responsáveis por crianças e em 11 unidades há adolescentes com responsáveis referidos pelo uso do crack.

Tabela 1 - Serviços de Acolhimento Institucional que atendem crianças e adolescentes e seus responsáveis com história de uso de crack e drogas em geral ( $N=21$ SAls). Porto Alegre - setembro a dezembro de $2011^{*}$

\begin{tabular}{l|c|c|c|c}
\hline \multirow{2}{*}{$\begin{array}{l}\text { Consumo de drogas } \\
\text { Uso de drogas em geral pela criança ou }\end{array}$} & \multicolumn{2}{|c|}{$\begin{array}{c}\text { SAls que } \\
\text { atendem } \\
\text { crianças }\end{array}$} & \multicolumn{2}{c}{$\begin{array}{c}\text { SAls que } \\
\text { atendem } \\
\text { adolescentes }\end{array}$} \\
\cline { 2 - 5 } & $\mathrm{N}$ & $\%$ & $\mathrm{~N}$ & $\%$ \\
\hline $\begin{array}{l}\text { adolescente } \\
\text { Uso de crack pela criança ou adolescente }\end{array}$ & 1 & 4,8 & 9 & 42,9 \\
\hline $\begin{array}{l}\text { Responsáveis com história de uso de drogas } \\
\text { em geral }\end{array}$ & 16 & 76,2 & 15 & 71,4 \\
\hline Responsáveis com história de uso de crack & 14 & 66,7 & 11 & 52,4 \\
\hline
\end{tabular}

* Informação dada pelo gestor do serviço.

** Das quatro adolescentes registradas como usuárias de crack pelos SAls, duas estavam em internação hospitalar para desintoxicação, a terceira em desintoxicação no próprio abrigo e apenas uma estava há um tempo sem usar drogas.

Entre as 280 crianças e adolescentes acolhidos em SAI no momento da pesquisa, os gestores e técnicos indicaram o uso do crack por criança, adolescente e/ou seus responsáveis em 114 casos (40,7\%), o que gerou igual número de prontuários analisados e questionários respondidos. Na Tabela 2 apresenta-se a distribuição do número de crianças e adolescentes investigados segundo o uso próprio de substâncias e/ou seus responsáveis. Nota-se que $13,1 \%$ dos adolescentes fazem uso de drogas em geral, e 3,3\% de crack. Constata-se também que $78,5 \%$ das crianças e $54,9 \%$ dos adolescentes têm responsáveis abusadores de drogas em geral; e que $51,9 \%$ das crianças e $24,6 \%$ dos adolescentes têm responsáveis abusadores de crack. 
Tabela 2 - Uso de uso de crack e drogas em geral por crianças e adolescentes em Serviços de Acolhimento Institucional. Porto Alegre - setembro a dezembro de $2011^{*}$

\begin{tabular}{l|c|c|c|c|c|c}
\hline \multirow{2}{*}{\begin{tabular}{l} 
Consumo de drogas \\
\cline { 2 - 7 }
\end{tabular}} & \multicolumn{2}{|c|}{$\begin{array}{c}\text { Crianças } \\
\mathrm{N}=158\end{array}$} & $\begin{array}{c}\text { Adolescentes } \\
\mathrm{N}=122\end{array}$ & \multicolumn{2}{c}{$\begin{array}{c}\text { Total } \\
\mathrm{N}=280\end{array}$} \\
\cline { 2 - 7 } & 1 & 0,6 & 16 & 13,1 & 17 & 6,1 \\
\hline $\begin{array}{l}\text { Uso de drogas em geral pela } \\
\text { criança ou adolescente }\end{array}$ & 0 & 0,0 & 4 & 3,3 & 4 & 1,4 \\
\hline $\begin{array}{l}\text { Uso de crack pela criança ou } \\
\text { adolescente }\end{array}$ & 124 & 78,5 & 67 & 54,9 & 191 & 68,2 \\
\hline $\begin{array}{l}\text { Responsáveis com história de } \\
\text { uso de drogas em geral }\end{array}$ & 82 & 51,9 & 30 & 24,6 & 112 & 40,0 \\
\hline $\begin{array}{l}\text { Responsáveis com história de } \\
\text { uso de crack }\end{array}$ & & & & & & \\
\hline
\end{tabular}

* Informação dada pelo gestor do serviço.

O consumo de crack entre crianças não foi informado, e apenas quatro adolescentes são assim referidos na amostra de abrigos investigada. Em relação ao uso de drogas em geral, tem-se $0,6 \%$ das crianças e $13,1 \%$ dos adolescentes acolhidos. Essa realidade pode não refletir exatamente o que acontece em todas as unidades de acolhimento do município, especialmente no que se refere ao uso de crack, em decorrência do encaminhamento privilegiado de usuários de drogas para unidades específicas (abrigo I e abrigo II) não participantes da amostra selecionada, conforme anteriormente mencionado.

O percentual de uso de uso de crack e drogas em geral entre os responsáveis é alto, em particular entre as crianças, podendo acarretar-lhes negligência nos cuidados primários. É sabido que os pais, ou quem esteja na função materna ou paterna, servem de modelo de comportamento para seus filhos. Conviver com a presença de drogas desde a infância pode ser considerado um fator de risco para o posterior uso de drogas dos filhos. Também são relevantes a alta frequência do consumo do crack e outras drogas pelos responsáveis dos adolescentes da amostra.

Os quatro SAls referem que os adolescentes acolhidos, usuários de crack, frequentam regularmente os serviços de atendimento médico, psicológico/ psiquiátrico e de orientação sexual. Três SAls informam que os adolescentes frequentam a escola regularmente, fazem tratamento para dependência química, participam de atividades culturais e festividades na comunidade. Dois SAls 
confirmam que os adolescentes recebem reforço escolar e atendimento para dificuldades de aprendizagem, atendimento especializado para pessoa com deficiência, assistência jurídica, praticam atividades religiosas, esportivas e participam de grupos de mútua ajuda. Somente um serviço relata que os acolhidos estão em curso de capacitação/qualificação profissional/geração de trabalho e renda e foram encaminhados para trabalho.

Nos quatro SAls que acolhem esses adolescentes, nota-se que diversos serviços não são oferecidos às famílias por nenhuma deles. Apenas um SAI informa encaminhamento para grupos de mútua ajuda, atendimento psicológico/psiquiátrico, acompanhamento social, encaminhamento para serviços para tratamento de dependência química, apoio financeiro, inserção em programa/serviço oficial ou comunitário de auxílio/proteção à família e assistência jurídica.

Alguns aspectos dos 21 SAls visitados na pesquisa merecem ser destacados:

1) a maioria das unidades é recente: sete funcionam há menos de três anos (33,3\%); dez têm entre 5-10 anos de existência (47,5\%); dois, entre 11-16 anos $(9,6 \%)$; e outros dois são bem antigos, funcionando entre 53 e 58 anos (9,6\%);

2) 13 serviços $(61,9 \%)$ funcionam na modalidade de abrigo institucional; sete como Casa Lar em comunidade $(33,3 \%)$ e um é uma Casa Lar sem especificação de localização $(4,8 \%) ;^{12}$

3) há ampla variação no número de crianças acolhidas: 0 a 29, com uma média de 7,5 crianças ( $\mathrm{DP}=7,3$ ) por serviço. Quanto aos adolescentes, há oscilação entre nenhum presente no serviço no momento da pesquisa até 12 , com média de 5,8 adolescentes;

4) os SAls atendem crianças ou adolescentes com as seguintes especificidades: em situação de rua - 100,0\%, com transtorno mental - 95,2\%, ameaçados de morte - 95,2\%, com doenças infectocontagiosas - 95,2\%; 90,5\% dos serviços atendem usuários de drogas, incluindo-se o crack;

5) $57,1 \%$ dos SAls são entidades não governamentais; $23,8 \%$ são unidades públicas estaduais e $19 \%$ públicas municipais;

${ }^{12}$ Os SAls são subdivididos em duas modalidades, com base na Tipificação Nacional de Serviços Socioassistenciais (Brasil, 2009a) e de acordo com as Orientações Técnicas para os Serviços de Acolhimento de Crianças e Adolescentes (Brasil, 2009b). A primeira deverá ser realizada em unidade residencial para, no máximo, dez crianças e/ou adolescentes, com a presença de uma pessoa ou casal atuando como educador residente. Na segunda modalidade, o atendimento se dará em uma unidade institucional com características residenciais, para grupos de até 20 crianças e/ou adolescentes. 
6) a maioria dos serviços não tem orientação religiosa $(61,9 \%) ; 19 \%$ se declaram evangélicos e igual montante católicos;

7) todos os SAls têm equipe técnica própria. A maioria conta com psicólogo $(85,7 \%)$ e todos têm assistente social. Alguns outros profissionais são apontados em 52,4\% dos serviços: educador, educador físico, pedagogo, enfermeiro, psicopedagogo e técnico administrativo.

A capacitação dos profissionais que trabalham nos SAls deixa a desejar. Está mais voltada para o uso de substâncias psicoativas em geral, sem privilegiar o crack. O melhor cenário de capacitação é observado entre a equipe técnica: sete SAls referem tal fato (33,3\% do total pesquisado), com 16 profissionais que receberam capacitação para a questão do uso de drogas em geral (incluindo o crack). Em quatro SAls (19\%) se capacitaram 15 cuidadores. Em três SAls $(14,3 \%)$ seis profissionais do setor administrativo foram capacitados. Depreende-se, pois, que poucos são os profissionais qualificados para trabalhar com a população acolhida, questão fundamental para que o serviço funcione de forma qualificada e cuidadosa com os seus usuários e os profissionais que aí trabalham, e que será tratada adiante.

\section{PeRFIL dAs CRIANÇAS E dOS Adolescentes USuÁRIOS de CRACK E de suas Famílias EM SERVIÇOS de SAÚde E ASSISTÊNCIA SOCIAL}

O perfil das crianças, adolescentes e famílias com história de uso de crack em Porto Alegre foi levantado com base nos prontuários dos acolhidos em SAI e em entrevistas realizadas com os adolescentes, familiares e atores da rede. As entrevistas com os adolescentes e com os familiares versaram sobre a sua história de vida e sua experiência, efeitos e consequências do uso pessoal e/ou dos familiares da substância, vivência de rua e existência de familiar internado ou preso devido ao uso do crack e drogas em geral. Os atores da rede responderam sobre as principais causas e consequências do uso do crack por essa população.

Conforme apresentado anteriormente, há 280 crianças e adolescentes nos 21 SAls visitados, 114 deles identificados pelo gestores como adolescentes, ou seus responsáveis, usuários de crack. Para esse grupo de 114 crianças e adolescentes, avaliados individualmente com base em seus prontuários, apresenta-se o seguinte perfil: 1 ) idade média de 5,1 anos ( $D P=4,9)$ e $54,4 \%$ do sexo feminino; 2 ) $67,5 \%$ frequentam a escola; 3 ) $58,8 \%$ moraram com 
alguém com problema com o uso de crack/drogas, nos últimos 30 dias antes do acolhimento. Nesse subgrupo, sobressai o uso do crack por algum familiar em 43,9\% dos acolhidos. Álcool e cocaína são outras drogas nomeadas; 4) $31,6 \%$ da população em foco têm algum problema de saúde, especialmente HIV/Aids (4,4\%). Doenças genéticas ou congênitas são relatadas em 3,5\% dos acolhidos, 9,6\% deles apresentam comportamentos agressivos e igual número, sinais ansiosos ou depressivos; $10,5 \%$, hiperatividade ou inatenção; 4,4\%, transtornos psicóticos; e 2,6\%, deficiência mental. Outros problemas de saúde presentes em $8,8 \%$ dos acolhidos são: hérnia abdominal, doenças pulmonares (especialmente alérgicas) e gástricas; 5) 44,7\% têm trajetória de rua; f) a maioria tem procedimento administrativo na Justiça Vara da Infância e Juventude (96,5\%); mais da metade $(61,4 \%)$ dos procedimentos administrativos/processos na justiça aborda a questão do consumo de crack por parte da criança/adolescente ou seus responsáveis (descrição do fato, encaminhamentos realizados devido à presença desse problema).

Os dois motivos mais frequentes para o acolhimento de crianças e adolescentes foram negligência na família $(84,2 \%)$ e pais ou responsáveis dependentes do álcool e/ou outras drogas $(79,8 \%)$. É digno de nota o acolhimento dos usuários por viverem na rua $(39,5 \%)$ e pelo abandono dos pais ou responsáveis $(30,7 \%)$. A violência doméstica, que predomina como fator de acolhimento, é a psicológica (24,6\%), em detrimento da física (16,7\%) e da sexual (9,6\%). Outros motivos encontrados foram: carência de recursos materiais da família/responsável (15,8\%), ausência dos pais ou responsáveis por prisão $(10,5 \%)$, pais ou responsáveis com transtorno mental - problemas psiquiátricos/psicológicos (10,5\%), criança/adolescente órfão (10,5\%), exploração no trabalho ou mendicância (7,9\%), entrega voluntária da criança/ adolescente pela família de origem $(7,0 \%)$, ausência dos pais ou responsáveis por doença $(5,3 \%)$, ameaça de morte $(3,5 \%)$, violência ou abuso extrafamiliar $(2,6 \%)$, pais ou responsáveis sem possibilidades para cuidar de criança/ adolescente com condições de saúde específicas $(1,8 \%)$, uso e/ou abuso de substâncias por parte da criança ou adolescente $(1,8 \%)$, pais ou responsáveis sem condições para cuidar de adolescente gestante $(1,8 \%)$, uso de crack por parte da criança ou adolescente $(1,8 \%)$, pais ou responsáveis portadores de algum tipo de defiência $(0,9 \%)$ e exploração sexual, como prostituição e pornografia $(0,9 \%)$. Vários são motivos que podem justificar o acolhimento de uma criança ou adolescente, configurando um quadro de elevada vulnerabilidade. 
Em $70,1 \%$ dos acolhimentos, a criança foi encaminhada para os SAls exclusivamente pelo Poder Judiciário, em conformidade com os preceitos da lei n. 12.010/2009 (Lei da Adoção), e em 1,8\% pelo Conselho Tutelar. Neste último caso, ainda de acordo com o procedimento adotado antes da Lei da Adoção, em que o Conselho Tutelar teria o poder de conduzir a criança para serviço de acolhimento apenas em situações emergenciais e com a exigência de imediata comunicação ao Ministério Público (MP). A Secretaria Municipal de Assistência Social (SMAS) foi responsável por 12,3\% das indicações. Casos excepcionais se deveram à solicitação de outros SAls (2,6\%). O trabalho em conjunto do Conselho Tutelar e do Poder Judiciário ocorreu na orientação de 7,9\% de crianças/adolescentes. Já a união de esforços entre Judiciário e saúde ou assistência social ou polícia foi responsável por $5,3 \%$ dos encaminhamentos.

Oito crianças/adolescentes acolhidos foram dirigidas para tratamento de saúde pelo SAI por histórico prévio de uso de crack (7\%). No que se refere aos responsáveis, 61 deles foram levados (53,5\%) pelo SAI para tratamento de saúde por uso dessa mesma substância.

No que tange à situação legal da criança ou adolescente usuário de crack ou cujos responsáveis utilizam esta droga, percebe-se a precária possibilidade de adoção. Apenas três $(2,6 \%)$ crianças e adolescentes com histórico de uso de crack estão legalmente encaminhados para adoção, isto é, estão disponíveis para adoção, aguardando colocação. Nenhum dos acolhidos está em processo de colocação para adoção, ou seja, iniciando a aproximação com adotantes; e $21(18,4 \%)$ têm a destituição do poder familiar concluída, mas ainda sem encaminhamentos efetivos para adoção. No total, apenas 24 (21\%) estão em condição legal de adoção. Os demais estão nas seguintes situações: 35 em fase de avaliação/preparação para reintegração/retorno ao convívio com os responsáveis $(30,7 \%) ; 32$ com suspensão do poder familiar $(28,1 \%) ; 40$ com a destituição do poder familiar em tramitação $(35,1 \%)$; dois em processo tramitando de guarda/tutela ou com sentença pendente de recurso $(1,8 \%)$.

Do total de crianças/adolescentes, 34,2\% já foram abrigadas em outros serviços antes do acolhimento atual e 1,8\% já haviam estado no mesmo SAl. Outros dois acolhidos $(1,8 \%)$ já estiveram em outros SAls e no mesmo serviço em que foi pesquisado, indicando um longo tempo de institucionalização.

A situação de vínculo familiar da criança/adolescente mostrou-se variada: $62,3 \%$ deles têm familiares com quem permanecem vinculados; $28,1 \%$ têm 
família, mas não mantêm vínculos; 9,6\% têm famílias desaparecidas; 1,8\% apresenta impedimento judicial de contato com a família; e 2,6\% são órfãos. O estudo de Neiva-Silva (2008) em Porto Alegre reitera que a maior parte das crianças e adolescentes em situação de rua mora com suas famílias $(71,3 \%)$ e que, entre esses, 91,6\% têm contato com a família todos ou quase todos os dias.

A proximidade de muitos acolhidos com suas famílias pode ser percebida pelo fato de que $51,8 \%$ das crianças e adolescentes recebem visitas na instituição, principalmente das mães $(29,8 \%)$, avós $(12,3 \%)$, pai $(2,6 \%)$, irmãos e irmãs $(12,3 \%)$, outros parentes $(18,4 \%)$ e outras pessoas $(6,1 \%)$. Um percentual de $93,9 \%$ das famílias de origem mora no mesmo município no qual a criança/ adolescente está acolhido.

\section{Trajetórias de adolescentes acolhidos em SAI com história de uso de crack}

Quatro adolescentes e dois familiares foram entrevistados e detalharam sua história de vida e uso do crack. Parte dessas informações está apresentada a seguir.

LaURA tem 15 anos de idade e vive há 11 meses na Casa Lar em que foi entrevistada. Relata que sua vida está boa porque, a partir do momento em que parou com o uso do crack e outras drogas, pôde ficar com o seu filho: "Foi uma vitória do meu filho de eu conseguir parar [de usar drogas]. Faz um ano e quatro meses que não uso". Voltou a estudar e cursa a terceira série do ensino fundamental.

Comenta que algumas pessoas de sua família nuclear, composta dos pais e nove irmãos, usam drogas. Tudo começou com a separação dos pais. O pai passou a usar drogas e o consumo aumentou com o tempo. Sofreu repetidas internações, ficou mal de saúde e a filha, que sabia sobre ele quando ambos moravam na rua e ali se encontravam, não tem informações sobre o paradeiro do pai. Quanto à mãe, que iniciou o uso de drogas junto com uma irmã, trabalha e não consome mais substâncias psicoativas. No momento da pesquisa, uma irmã de Laura utilizava crack e dois irmãos estavam presos por tráfico de drogas.

Quanto à história pessoal de uso de drogas, Laura relata que aos 12 anos iniciou, por curiosidade, a consumir crack oferecido por uma amiga bem mais velha. Como consequência do uso de droga, três filhos dessa amiga foram levados pelo Conselho Tutelar. Laura chegou a usar crack diariamente, cerca de 20 pedras, gastando aproximadamente 3.000 reais mensais com o vício. 
Preferia fumar a substância com cachimbo, e não socializava o uso. Não consumia álcool, mas fumava diariamente, gastando em torno de 100 reais mensais com esse hábito antes do acolhimento na Casa Lar. Ao longo da vida já usou cheirinho da loló, maconha e cocaína.

Os efeitos do uso de crack e outras drogas em sua vida são devastadores: abandonou tudo e passou a morar na rua onde trabalhou vendendo balas em sinais e cuidando de carros para sustentar o vício. Várias vezes Laura foi levada pela polícia para o Conselho Tutelar. Uma vez apanhou de policiais quando dormia numa casa abandonada.

A adolescente relata que perdia a vontade de comer em decorrência da necessidade de consumir a droga. Adoeceu. Indagada sobre como classificaria a sua saúde física e mental nos últimos 30 dias, em pleno acolhimento institucional, Laura refere estar com boa saúde, não tendo nenhum problema nos últimos tempos - nem físico e nem mental.

Sua vida na rua teve muitas idas e vindas. Por dois meses, viveu na rua e consumiu crack com uma irmã mais velha, de quem é muito amiga: "Onde minha irmã estava, eu estava sempre junto", tanto é que uma vez retornou à casa, mas voltou a viver na rua com essa irmã. Decidiu ir morar em casa de outra irmã, com quem ficou pouco tempo até retornar para a rua, porque "parece que na rua tu fica mais calma, não estressada e triste com as coisas que acontecem em casa". Entretanto, Laura percebe que morar na rua era "bem perigoso" e decidiu voltar para casa de uma tia. Esse perigo estava relacionado à dívida de alguns jovens do grupo com traficantes de drogas.

FELIPE, 17 anos, é um adolescente em abrigo institucional. Relata que atualmente, a sua vida está boa porque estuda no quarto ano e irá começar um emprego de empacotador no supermercado local em breve.

Conta que sua irmã mais velha, no momento com 22 anos, usou drogas na adolescência por curiosidade: "Tu sabe como é que é vida de adolescente, quer experimentar isso, quer experimentar aquilo, tu acaba querendo usar". Considera que ela foi um mau exemplo. Hoje em dia, essa irmã, que não mais consome substâncias psicoativas, o auxilia a parar com o vício.

Felipe usava cocaína e maconha antes de iniciar o consumo de crack aos 12 anos, quando, então, juntou "com a gurizada pela rua" e decidiram "usar uma droga diferente". O uso do crack fez com que precisasse consumir cada vez mais a substância, de forma que começou a roubar para sustentar o vício. Mas o afastamento da família pelo uso do crack o afetou sobremaneira de 
forma que decidiu fazer alguma coisa para reconquistar a mãe - "amor de mãe é só um". Parou de usar o crack e sua mãe retomou o contato, fato que o deixa muito feliz.

Os efeitos do uso das drogas são danosos para Felipe. Refere que seus familiares e amigos se afastaram de tal forma que, ao final, "só está tu ali, tu naquele mundo, tu e a droga". Somente seu irmão mais novo continuou relativamente próximo. Parou de estudar e também teve problemas com a polícia, de quem muito apanhou. Nessa época, resolveu se internar, mas esse movimento durou pouco. Na clínica, diz: "não é os médicos que vão me dopar de remédios, me dar injeção, que eu vou largar [as drogas], eu tenho que largar do coração para fora". Hoje em dia, aconselha os outros a não se drogarem e tem orgulho de dizer que está limpo.

Felipe não se reporta aos vínculos afetivos, sociais e/ou profissionais para o auxiliar na descontinuação do uso da droga. Entretanto, Melotto (2009) refere uma interdependência entre a noção de força de vontade, de sustentação do querer com a importância do auxílio que o usuário precisará ter dos outros.

O jovem relata perda de memória ("comecei esquecendo as coisas") e emagrecimento acentuado ("antes eu era uma taquara, bem magrinho de tanto crack") como consequências do uso do crack.

Felipe conta sobre a época em que viveu na rua. Optou por morar na rua porque passava por "um período familiar com muita confusão" e tensão, em decorrência da união de sua mãe com o padrasto, com quem discutia muito. Já fumava crack e maconha escondido, quando morava em casa. Mas, ao sair, "já comecei a usar de tudo". Sua mãe se preocupava e ia atrás dele, procurava auxílio no Conselho Tutelar. Passou um Natal na rua com a irmã e decidiu retornar para casa após o pedido da mãe. "Começou a ficar tudo bem", mas meteu-se em "encrencas" com o tráfico ("era bonde") e não pôde mais voltar para casa. Conseguiu sair dessa vida e afastar-se do local ("caí na real") após quase ser morto por traficantes.

A fala de Felipe e de Laura sobre aos motivos da saída deles às ruas remete ao estudo de Neiva-Silva (2008) com crianças e adolescentes em situação de rua. Nessa pesquisa, identificam-se "diversão e liberdade" (63\%) como os motivos mais frequentes de ida às ruas, seguido por violência doméstica ( $34 \%$ - somatório de "discussões em casa", "apanhava em casa" e "abuso sexual"), busca de sustento para si e para a família (12,5\%), morte dos pais $(7,4 \%)$ e uso de álcool e outras drogas pelos pais $(3,7 \%)$. 
JoÃo, 17 anos, é outro adolescente que no momento estudava no quarto ano do ensino fundamental e fazia curso de informática. Já esteve internado na Fase e, posteriormente, numa clínica; mas, para "sair das drogas" veio para o abrigo, onde se encontrava há dois anos e meio.

Relata que o tio paterno fez uso de crack e, no momento da entrevista, encontrava-se internado numa clínica. Quanto ao uso pessoal de drogas, João iniciou com o cigarro, em seguida a maconha, que fumou por muito tempo. Aos 12-13 anos começou a fumar pitico (maconha misturada com crack) junto com amigos. O uso do pitico, fumado na forma de baseado parece ser, de acordo com Domanico (2006: 18),

a maneira menos danosa psiquicamente, pois a "noia" (paranoia), um dos efeitos do crack, é minimizada pelo efeito da maconha, e isso pode ser importante na medida em que administrar a paranoia parece ser um dos principais problemas dos usuários de crack. Trata-se de um sentimento de perseguição que pode levar à violência. Sob a paranoia os usuários desconfiam de tudo e de todos, ouvem vozes e sons que lhes provocam medo e pavor.

João fumou crack na lata por pouco tempo. A mãe adoeceu quando era pequeno e sua irmã adolescente cuidou dele e do irmão. Com 7 anos, começou a trabalhar para o traficante, seu "ex-patrão", como olheiro, até os 15 anos: "Criança, eu andava com um revólver na cintura". Foi preso por traficar.

Conta que usava crack e cocaína inalada para se divertir em festas com amigos, "ficava mais loucão", mas que tem sequelas neurológicas devido ao uso do crack e do cheirinho da loló. Morou durante uns meses na rua, após fugir da clínica onde se encontrava internado por seu pai pelo uso da maconha.

Durante a entrevista, João apresentava problemas sérios na fala e, às vezes, no entendimento do conteúdo indagado. Segundo ele próprio, seu estado era decorrente do uso abusivo do crack, também fumado junto com maconha e misturado com soda cáustica.

PEDRo, irmão mais velho de João, refere que atualmente, a família é composta pelos dois irmãos e o pai. A mãe faleceu quando eles eram crianças. Pedro, narra a sua própria história de uso de drogas. Foi morar com o pai com 13-14 anos e iniciou o uso de drogas por intermédio de João, que trouxe maconha para casa e fumaram juntos. Com o tempo, buscou droga mais forte e experimentou o crack. Por causa do uso, que ainda era ocasional, conheceu um 
traficante ("pessoas que fazem coisa errada") e iniciou, juntamente com o irmão e mais dois amigos "que já morreram por causa de drogas", a assaltar pedestres "com arma de brinquedo". Aos poucos, conhecendo "traficantes poderosos, comecei a fazer coisas mais pesadas", traficar drogas e praticar assalto à mão armada em ônibus. Por isso, precisou sair da vila onde o tráfico se dava. Não retornou para casa, morou na rua e furtou mercadorias de supermercados para sobreviver. Pedro saiu da vida das drogas quando seu pai, vindo de outro município para Porto Alegre, o internou numa clínica. Considera que foram as amizades que o levaram a usar drogas, mas comenta que na adolescência muitos querem experimentar substâncias psicoativas.

Quanto às consequências e aos efeitos do uso do crack na sua própria vida, Pedro esclarece que o "crack enlouquece a pessoa que perde o caráter, perde tudo". No seu caso, "começou com a droga e passou para o crime". Referindose a João, Pedro afirma que "o mental/psicológico dele se estragou". Comenta que o irmão sempre teve dificuldade para aprender. Pedro tentou ensiná-lo a ler inúmeras vezes, "só que tem uma coisa nele que ele não consegue aprender porque tem um problema mental e de fala".

João foi acolhido no abrigo quando Pedro ainda ali se encontrava. Considera estar sendo um tempo bom para João (está há dois anos no abrigo), porque não usou drogas: "Aqui deu resultado". Pedro considera que, no seu caso pessoal, o abrigo e a clínica o auxiliaram a largar as drogas. Ficou abrigado dos 17 aos 18 anos e "eu aprendi bastante coisa". Também esteve internado numa clínica psiquiátrica onde era medicado. Não sabe quanto tempo permaneceu lá porque foi internado mais de uma vez.

CAmILA, 18 anos, a quarta adolescente entrevistada, presa por tráfico de drogas para manter o uso compulsivo de crack, não cumpriu o estipulado na audiência com o juiz sobre a medida de liberdade assistida e, por isso, foi internada em regime fechado na Fase. Fazia tratamento no Caps ad cumprindo exigência daquela instituição. No momento da entrevista pretendia sair da internação, que se daria no dia seguinte, e voltar para casa para recomeçar uma vida sem o crack: "Só me fez mal isso aí". Camila veio algemada da Fase para a entrevista no Caps ad, atitude que não encontra precedente nas premissas contidas no ECA.

Tem um tio que bebia pesado, mas foi obrigado a parar por questões de saúde. Camila relata que sua mãe começou a usar o crack há um ano e mostra-se angustiada com isto: “Eu pensei: ela vai passar por tudo que eu estou passando. 
Todo dinheiro que ela tiver, ela vai querer comprar aquilo ali. Ela não vai pensar mais nos filhos, não vai pensar em comer, ela não vai estar nem aí com nada". Acha que a mãe precisa de ajuda para parar o uso. Pretende voltar para casa e auxiliá-la nessa empreitada. Fazem um pacto de não se drogarem quando Camila sair da Fase. Mas reconhece: "Eu sei que não é fácil; eu estou há três meses porque eu estou presa, não tenho mesmo como usar. Eu não sei se estou a fim".

Relata violência intrafamiliar com abuso físico do pai em relação à mãe e a ela própria. Denunciou-o para o Conselho Tutelar, com o intuito de mantê-lo afastado. Nessa convivência permeada pela violência, Camila abusava do uso de droga. Tem cinco irmãos, dos quais três estavam em abrigos há um ano, pelo fato de a mãe usar droga e negligenciar os cuidados aos filhos.

Camila iniciou o consumo da droga com 13 anos, usando o crack fumado com cachimbo (que logo se tornou compulsivo), por curiosidade, com uma vizinha. O dinheiro acabou e ela começou a se empenhar para poder usar a droga: "Eu acabei com a minha vida, parei de estudar". Cursava a sexta série. Não mais se cuidava, porém se internou por vontade própria, mas logo saiu. Arranjou um namorado com quem roubava para conseguir dinheiro para o uso do crack.

A jovem observa que se não tivesse entrado para o mundo das drogas poderia estar estudando e trabalhando e talvez sua mãe não tivesse iniciado o uso da droga: "Porque foi por eu me afastar dela assim que tudo aconteceu; quando eu cheguei, meu pai já não estava mais em casa". Para ela, é muito triste ver a adicção da mãe, com quem já fez uso do crack. É triste porque ela conhece as consequências deletérias de tal consumo:

A pessoa deixa de ser responsável; se a pessoa tem um compromisso, acaba perdendo a hora usando droga; amanhece o dia, com os dias não come, não se alimenta, acaba fazendo besteira, e tem gente que acaba até pegando uma doença, fazendo coisa que não deve, se vendendo para usar o crack.

Quanto aos efeitos do uso da droga em sua saúde física e mental, Camila considera que o uso da substância a deixa irritada e o desejo de fumar crack aparece em pesadelos noturnos. Percebe modificação na memória de curto e médio prazos: "Se me perguntar uma coisa que eu fiz semana passada eu não me lembro mais; de hoje só lembro de ontem." Relata que não esquecerá as suas experiências de uso do crack e não sabe se conseguirá parar de usá-lo. 
Para Camila, viver na rua estava associado à necessidade de roubar, prostituir-se, traficar várias drogas. Às vezes, usava crack com cigarro e álcool. A adolescente comenta:

Se pudesse virar dois, três dias fumando, eu virava fumando, por mais que eu não tivesse mais vontade de usar droga, eu conseguia mais para fumar de novo, porque eu estava fraca já, sem comer nada, só usando droga e bebendo, mas eu queria mais.

Como se pode perceber nos relatos anteriores, três dos adolescentes entrevistados mencionaram a "curiosidade" como um motor para o uso do crack. Essa característica é própria da adolescência, que, aliada à busca de novas sensações prazerosas, como a descoberta da sexualidade, da afetividade, das amizades e também do compartilhar do uso de drogas, torna, em muitos casos, o adolescente vulnerável por não atinar sobre os perigos que poderão daí resultar (Schenker \& Minayo, 2005).

No estudo de Neiva-Silva (2008), o principal motivo encontrado de uso de drogas ilícitas foi a curiosidade (63\%), seguida da influência dos pares (44,6\%). Constata-se também que as drogas lícitas foram experimentadas, em sua maioria, quando as crianças e os adolescentes ainda estavam em casa; ao passo que as ilícitas, depois de irem para a rua - solventes (84,9\%), maconha $(63,3 \%)$ e crack $(80,6 \%)$.

Melotto (2009) traz uma reflexão, com base na pesquisa qualitativa que empreendeu em seu estudo com usuários de crack em São Leopoldo/RS, acerca da curiosidade pelo uso do crack, aliada ao conhecimento da droga, pois as pessoas moravam num contexto de facilidade de uso e acesso a ela. Em suas palavras,

a 'curiosidade' enfatizada compreende a vontade de experimentar algo desconhecido, mas que no contexto vivido representa um 'desconhecido' de alguma forma conhecido através das relações de proximidade com o crack e com pessoas usuárias em suas comunidades, como se pode observar nas falas de alguns entrevistados. Assim, a curiosidade coloca-se para além de uma disposição individual, constituindo-se relacionalmente em um meio onde o acesso ao crack é facilitado pelo contato cotidiano com pessoas que o utilizam ou vendem. A grande oferta e a facilidade de acesso à droga são questões mencionadas em todos os relatos coletados. (Melotto, 2009: 50)

Três dos adolescentes consideraram o uso de crack problemático a partir do momento que afetou seus laços afetivos. A quebra do vínculo com a família, principalmente a ruptura com a mãe, foi enfatizada por Felipe. A mãe 
também surge como figura fundamental para Camila. E a separação dos pais foi traumática para Laura. De forma semelhante, a pesquisa de Melotto (2009) mostra que o uso de crack foi percebido como um problema para os sujeitos, quando passou a acarretar dificuldades ou perdas relacionadas principalmente ao trabalho e aos vínculos afetivos.

$\mathrm{Na}$ fala dos adolescentes da pesquisa, a família é considerada instituição importante, seja no início do uso da droga, seja como recurso a se buscar quando há dificuldades, e também para compartilhar das alegrias. Vários estudos apontam a família como um fator de risco e/ou de proteção ao uso de drogas de seus membros (Schenker \& Minayo, 2003; Schenker \& Minayo, 2004; Schenker, 2011). Neiva-Silva (2008) ressalta que o vínculo familiar foi a variável "preditora" de maior peso em relação ao uso de drogas ilícitas pelos participantes de sua pesquisa, e também em relação aos motivos identificados para que os adolescentes deixassem de frequentar as ruas.

A violência, aliada ao tráfico de drogas, roubo e prostituição (seja praticada por crianças e adolescentes na rua ou da qual eles são alvos), fez parte da trajetória de vida dos adolescentes da pesquisa em foco. Os sujeitos do estudo de Melotto (2009) também tinham a noção de que a violência era um fator de risco associado ao consumo do crack. Em nosso estudo, a fala dos quatro adolescentes e também a de Pedro, irmão de João, revelam a velocidade da deteriorização da vida mental, orgânica e social do indivíduo, pelo uso de crack (Kessler \& Pechansky, 2008).

\section{Consequências do uso do crack para o familiar do usuário acolhido}

SR. LEONARDO é pai de adolescente acolhido em abrigo institucional. Está separado da mãe do usuário (há 16 anos) com quem teve três filhos, dois meninos e uma menina. Casou-se novamente com uma mulher com dois filhos, que se dão bem com o adolescente usuário de crack. A convivência em casa é tranquila. Pessoas de sua família fizeram uso só de tabaco.

Para o sr. Leonardo, as consequências do uso do crack "são péssimas" para o filho e para os demais familiares. Observa que o adokescente sem o uso da droga "é tranquilo, obedece, a gente conversa e ele entende". Quando drogado, "ele faz tudo o que não é para fazer". Sr. Leonardo explica que a família geralmente não sabe lidar com a situação, "a gente [família] não é especializado para lidar, às vezes mal sabe conduzir os filhos". Por isso, é necessário o auxílio de pessoas especializadas. 
Quanto aos efeitos do uso do crack nas diversas áreas da vida do filho (amizades, estudo, família, saúde), sr. Leonardo nota primeiramente que ele tem facilidade para se relacionar com as pessoas, "para fazer boas e más amizades", o que torna mais fácil o envolvimento com a droga.

A ideia expressa anteriormente pelo adolescente Felipe e aqui, pelo sr. Leonardo, de que o uso de drogas é influenciado pelo grupo de amigos, nos faz lembrar que a identificação se dá ao revés: é o usuário de drogas quem se aproxima do grupo por semelhança (Oetting \& Donnermeyer, 1998; Schenker \& Minayo, 2003).

O filho do Sr. Leonardo estudou até o segundo ano do ensino médio. Saiu da escola à época em que se mudou para a casa do pai (sempre morou com a mãe). O pai o matriculou em escola próxima à sua casa. Nos fins de semana, o filho ia visitar a mãe e retornava quase no meio da semana, de forma que praticamente não estudava. Na época já usava o crack (iniciou aos 10 anos com a maconha). Em decorrência do uso da droga, a mãe vendeu a casa onde morava para se afastar das amizades do filho e também porque "ali ele tem mais campo de ação, tem mais facilidade para tudo".

A relação com a família ficou prejudicada pelo uso da droga, "com a mãe dele, fazia horrores, vendia as coisas de dentro de casa, vendia as roupas dele, tudo que tinha dentro de casa". Quando a casa foi vendida, já não havia mais móveis.

O usuário foi internado aproximadamente 16 vezes em clínicas pela mãe, pelo pai, pelo serviço social da comunidade em que vivia, pelo posto de saúde, ele próprio também decidiu se internar. Não se nega a tratar, mas recai ao sair da internação. Sr. Leonardo relata que o filho está acolhido devido à dívida com traficantes no local onde morava, "e os caras queriam a cabeça dele". A mãe gostaria que voltasse a morar com ela, mas teme pela vida dele. Além disso, ela "tem problemas de nervos, é nervosa".

\section{A visão dos profissionais da rede}

Nove profissionais da rede em Porto Alegre foram entrevistados individualmente, visando a conhecer melhor as crianças e adolescentes usuários de crack. A seguir, algumas informações acerca das causas e consequências do uso da droga, na visão de profissionais das áreas da assistência social, saúde e justiça.

Várias foram as causas apontadas referentes ao contexto individual, familiar, grupal e social, bem como a questões relativas à educação da criança/adolescente e à falta de informação sobre o crack e seu uso. 
No que se refere ao contexto individual, a coordenadora do Caps ad A menciona uma predisposição genética do usuário, combinada com algum tipo de transtorno não tratado e desenvolvido na infância. Na adolescência, há a procura de um grupo de pertencimento em que a droga é um meio importante de comunicação. A assistente social do SAN ressalta que esse é um período conturbado em que o adolescente inicia a trajetória de rua para ajudar no sustento da casa e acaba por conhecer outra realidade, a da rua e das drogas. Estas dão prazer, porque "se elas não diminuíssem as dores, as dores da falta de afeto, a dor das dificuldades das relações, elas não entrariam na vida de menino".

Sobre o contexto familiar, a "desestrutura" foi ressaltada por quase a metade dos profissionais da rede, e descrita pela coordenadora do SAN como: relações familiares conturbadas; famílias numerosas com figura paterna quase inexistente; mulheres que têm vários companheiros, com filhos de cada um deles, podendo acarretar negligência. A coordenadora do Caps ad A acrescenta outros aspectos da estrutura e dinâmica familiar: filhos criados por avós; filhos colocados cedo na creche por causa da separação dos pais; a falta de pagamento de pensão alimentícia e, como consequência, a mãe precisa trabalhar e não pode dar atenção aos filhos, que são criados "meio soltos"; filhos criados sem limites devido à ausência do pai; e também violência, negligência familiar ou algum tipo de abuso moral, físico ou sexual.

A fala sobre a necessidade de colocação de limites pela autoridade paterna numa família está relacionada a uma noção dicotômica do senso comum de que cabe ao homem a função da lei e da autoridade e à mulher, a do cuidado/ afeto. Mas ambas as funções devem ser exercidas numa família por mãe e/ou pai (em famílias tradicionalmente casadas, recasadas ou uniparentais) ou pelos adultos que estiverem nesse lugar.

Cabe ressaltar que quase a totalidade das características enunciadas também aparece em famílias em que ocorre uso abusivo de alguma substância psicoativa (não necessariamente o crack), conforme mostra estudo qualitativo de Schenker (2011) com famílias de usuários de drogas recrutadas de centros de tratamento ao uso indevido de drogas na cidade do Rio de Janeiro.

A coordenadora do Caps ad B levanta uma questão importante sobre a relação do usuário com a família. Se o usuário dá sinais quando inicia o consumo de drogas, por que a mãe, que trouxe o filho usuário há cinco anos, não percebeu quando ele fumou o primeiro baseado ou pitico? Não observou que ele estava diferente? Não queria ir à escola, não foi mais à sua unidade 
de saúde? Essas inquietações remetem ao conceito de "cegueira sistêmica", característica de famílias com adictos (Schenker, 1993: 206):

Como a droga entra no sistema familiar e instala-se, de forma abusiva, tão sem cerimônia? As histórias peculiares a cada sistema convergem para uma cegueira sistêmica; entretanto, esta é uma cegueira aparente na medida em que o sistema retroalimenta o uso da droga - assim como a droga, usada de forma abusiva, cumpre uma função na vida sem perspectivas, desmotivada, frustrada, deprimida do indivíduo, também cumpre uma função no sistema familiar: serve para obnubilar, anestesiar as sérias dificuldades que perpassam as relações intergeracionais de seus membros.

No contexto grupal uma das causas que se destaca é o envolvimento com pessoas que façam uso da substância. Como a droga dá prazer, "pode ser que ele desenvolva a dependência química" (coordenadora do Caps ad B).

De acordo com Schenker e Minayo (2003: 301),

Também os amigos e colegas de escola formam grupos de intimidade, influenciando, de forma marcante, a transmissão de normas na fase da adolescência. Por disporem de laços fortes e monitorarem, diretamente, atitudes e comportamentos de seus membros têm um papel muito importante nessa etapa da vida. Vários autores (Oetting e Donnermeyer, 1998) têm encontrado forte ligação entre o uso de droga dos pares e o uso de droga pelo adolescente, porém, as investigações também evidenciam que os adolescentes não são cooptados por amigos antissociais, mas eles se tornam atraentes pelo fato do meio familiar apresentar abundância de conflitos e desengajamento interpessoal. Nesses casos, em geral, os pais não implementam práticas efetivas de educação que equilibram afeto, atenção e limites para os filhos.

Como fatores relevantes do contexto social mais amplo (estrato social e suas características, vida em comunidade, tráfico, homicídio, entre outros), alguns atores da rede referem o uso do crack por pessoas de baixo poder aquisitivo oriundas de classes desfavorecidas, conforme estudos acerca do perfil do usuário de crack (Duailibi, Ribeio \& Laranjeira, 2008). Entre esses fatores, segundo a assistente social do SAN, sobressaem: miserabilidade das comunidades, empregos precários e falta de qualificação para entrar no mercado de trabalho, fruto de questão social existente secularmente no país.

A gestora da Proteção Social de Alta Complexidade comenta a vida em comunidade dessa população, ressaltando a falta de fronteiras entre o espaço público e o privado: 
A comunidade é que determina muita coisa da sua cultura. Até pela falta de delimitações de espaços físicos. Como eles moram muito aglomerados, as casas meio juntas me dá uma ideia de que tem toda essa força do coletivo, do público. Então, a vida nas comunidades é todo mundo muito junto, fazendo a mesma coisa, dormindo, comendo, indo ao banheiro... sem fronteiras. Dentro das casas é assim. Então me ocorre que é um pouco por aí esse fenômeno. No momento em que o crack ou qualquer outra droga se encontra dentro da comunidade, ele está por tudo, porque não existe ali o privado. Somado a toda a situação de vulnerabilidade, falta de informação, educação, saúde e falta de estrutura familiar.

O entendimento da gestora acerca da vida em comunidade das classes populares remete a uma certa promiscuidade social, como se a constituição do espaço físico determinasse a forma de convivência. Mas a privacidade das relações familiares se mantém de acordo com as normas e regras de cada família. Talvez o que as classes populares constroem no seu cotidiano seja a solidariedade evidenciada na proximidade da vizinhança e no desvelo com o próximo.

Um contraponto à noção do consumo da droga pelas classes populares surge na fala do conselheiro tutelar entrevistado, que ressalta como o crack atinge indiscriminadamente as diferentes classes sociais. O conselheiro menciona, entre outros, um caso de usuário de um estrato popular: "A casa estava no chão batido porque o pai tirou as tábuas para vender os pregos para consumir droga [crack]. Então, as três crianças estão indo para adoção"; e outro de um morador de um apartamento de classe média. O conselheiro encontrou as paredes abertas porque o usuário estava tirando os ferros da obra para vender e comprar a droga. "Com ele, morava uma criança"; "a mãe de classe média alta abandonou sua criança de dois anos trancada no quarto de um hotel [que ligou para o Conselho Tutelar]. A mãe tinha fugido de casa, sacado o dinheiro que tinha [R\$ 2.000,00], sumido por dois dias para fumar crack direto e esqueceu essa criança no hotel".

A coordenadora técnica do SAI ressalta, a partir de um relato de caso de uma família com usuários há três gerações (incluindo a família extensa), que a família usuária serve de modelo para as gerações seguintes, especialmente quando vive em comunidade onde há tráfico de drogas. O tráfico e os homicídios são citados pelo juiz ao explicar que "a sociedade está doente", porque antigamente os homicídios ou as tentativas de homicídio eram, na 
maior parte dos casos, crimes passionais, mas atualmente cerca de $80 \%$ dos processos de júri são de "traficantes matando traficantes", e o crack veio reforçar essa situação.

Os últimos fatores mencionados pelos entrevistados incluem as falhas decorrentes do processo educativo de cativar e cuidar das crianças e adolescentes, de forma a mantê-los na escola, e a falta de informação da família e da escola sobre o crack e seu uso (coordenadora do Caps ad B). O conselheiro tutelar argumenta que o senso comum promove um "marketing negativo com relação ao uso do crack", principalmente para o sexo masculino, porque "o homem pensa que pode fumar uma pedra de crack e não se viciar, já que usou outras drogas e conseguiu parar".

Várias foram as consequências mencionadas pelos profissionais da rede para a vida dos usuários de crack, englobando o contexto individual, familiar e social, bem como questões relativas à educação, saúde e trabalho.

No contexto individual destaca-se o isolamento: “O crack traz consigo o isolamento, e o usuário se comporta como se fosse um rato, uma coisa no escuro, do esgoto, da noite" (coordenadora de Caps ad B). Também foi mencionado, por uma assistente social do SAN, que a família e a comunidade costumam rotular o usuário, contribuindo para estigmatizá-lo.

No contexto familiar, surge a "desestrutura" familiar como elemento relevante - causa e consequência do uso de crack, na visão dos profissionais da rede. $O$ juiz comenta que as mães que usam crack têm um filho a cada ano, portanto, a família costuma ser numerosa (até oito crianças), e cada criança é cuidada por um ou mais familiares, sem que haja contato entre os irmãos. Em outros casos, a criança vai para um SAI, já que a mãe não tem condições de cuidar de sua prole. Também ocorre de os avós serem usuários de crack. O conselheiro tutelar observa que o relacionamento familiar é rompido porque os usuários são colocados para fora de casa ou decidem sair por não aceitarem o controle exercido pelos pais. Nas palavras da coordenadora de Caps ad A:

Em algum momento a família vai cansar. Vai ver que ele está pegando as coisas de casa, está mentindo, quebrando todas as combinações. A família ajuda uma vez, outra vez, e daqui a pouco ela se cansa. A mãe do usuário pensa: preciso garantir o espaço para os outros ou para que eu possa também não perder esse emprego, porque daqui a pouco, como é que eu vou dar conta de tudo isso. 
A experiência nesse Caps ad é que as mães desses adolescentes buscam internálos como "um descanso para elas ou uma segurança". Outro aspecto relatado é que, inúmeras vezes, a família protege o usuário durante anos, até mesmo buscando a droga para não expor seu filho. A família superprotege o usuário.

Na esfera da educação, para quase metade dos profissionais da rede, os usuários permanecem à margem da escola por evasão ou déficit cognitivo. Com baixa escolaridade, sem qualificação, têm dificuldades de inserção no mercado de trabalho.

Na área da saúde, quase metade dos atores da rede refere deterioração da saúde dos usuários e da família. Os problemas de saúde comumente encontrados acometem cérebro, pulmão, além do risco de contrair HIV/Aids devido à promiscuidade sexual ou à prostituição. Domanico (2006: 20) enuncia os danos decorrentes do uso do crack:

são indubitáveis os problemas respiratórios causados pela inspiração de partículas sólidas no ato de fumar essa droga. Por ser um estimulante, causa também perda de apetite, falta de sono e agitação motora. Estes efeitos dificultam, por sua vez, a ingestão de alimentos, podendo levar à desnutrição, desidratação e gastrite. Observam-se, também, outros sintomas como rachaduras nos lábios, causados pela falta de ingestão de água e de salivação, cortes nos dedos das mãos causados pelo ato de quebrar as "pedras" para uso, além de queimaduras nos dedos e, em alguns usuários, no nariz, causadas pela chama usada para fumar o crack ou até mesmo pela sua própria combustão.

A coordenadora do Caps ad B relata que a primeira instituição a ser abandonada pelos usuários é a escola, seguida da saúde. E enumera vários comprometimentos na saúde do usuário: o emagrecimento excessivo traz prejuízos para a sua compleição física, pois a criança e o adolescente estão em fase de crescimento; a falta de higiene e cuidados com o corpo. Verificam-se também baixa autoestima; prejuízos neurológicos e psicológicos; e, quiçá, o desencadeamento de alguma doença mental que talvez não tivesse se desenvolvido se esse indivíduo em formação tivesse recebido cuidado a tempo e hora.

Os problemas de saúde adquiridos com o uso do crack aqui relatados são ressaltados em diferentes trabalhos sobre o perfil dos usuários, o uso da pedra, o tratamento dos usuários, ou ainda sobre saúde pública, redução de danos e prevenção das infecções sexuais e sanguíneas (Duailibi, Ribeio \& Laranjeira, 2008, Pulcherio et al., 2010, Elias \& Bastos, 2011). 
$\mathrm{Na}$ esfera do trabalho, dois atores da rede reportam que os usuários abandonam o trabalho, os amigos e as relações/compromissos/normas familiares e sociais, por priorizarem o uso da substância. Apresentam ainda dificuldades em suportar as obrigações e o comando do superior numa rotina de oito horas de trabalho.

No contexto social mais amplo, foram ressaltadas questões como a exploração sexual de meninas e meninos que se prostituem em troca de algumas pedras de crack e se envolvem em roubos para conseguir dinheiro para comprar a droga, prática que os levam, muitas vezes, para a Fase. Perdas e mortes de familiares usuários (da família nuclear e extensa) pelo envolvimento destas com o crack (uso e tráfico) foram também mencionadas. A assistente social do SAN observa que a violência na cultura do tráfico de drogas ceifa cedo a vida dos usuários, que não conseguem chegar aos 18 ou aos 20 anos.

Fatores de proteção ao uso abusivo do crack, que podem ajudar "no resgate da pessoa", foram mencionados pela assistente social do SAN: investimento na autonomia do usuário, tendo em mente que ele poderá sofrer recaídas ao longo do tempo; relações afetivas mais sustentáveis que os ajudem a se afastar do uso e nascimento de um filho. O estudo de Melotto (2009: 59) corrobora esse entendimento: “O fato do parceiro não ser usuário ou reprovar a prática, muitas vezes estabelece a busca pela descontinuidade dos usos. O que acontece também em relação à família e/ou filhos".

\section{A VISÃO DOS ADOLESCENTES, DOS FAMILIARES E DOS PROFISSIONAIS SOBRE O ATENDIMENTO NOS SERVIÇOS DE SAÚDE E DE ASSISTÊNCIA SOCIAL}

\section{Adolescentes: confiança e escuta como elementos principais}

Em função do uso de drogas, Laura menciona que antes do acolhimento foi internada em hospital devido ao risco de perder o bebê. Considera que foi bem atendida. Ficou internada, tomando soro, e sugeriram que ela ficasse no hospital até ganhar o bebê. Laura não aceitou, fugiu, e começou a vender as roupas, tênis, tudo o que havia ganhado, para usar droga. Após ter tido o filho prematuro de 7 meses, decidiu parar, porque queria que o bebê ficasse ela. Foi, então, enviada para um SAI pelo Conselho Tutelar. A princípio não aceitou, mas sua irmã explicou que ela iria se tratar e isso seria bom. Hoje 
em dia, Laura "agradece a Deus" por ter tomado essa decisão, porque largou as drogas e está com o filho. Para ela é uma "vitória ter parado com tudo".

O tema crack babies, como é provavelmente o caso do bebê de Laura, tem se mostrado controverso, conforme mostrado no capítulo 1. Kessler e Pechansky (2008) referem que os bebês intoxicados pelo uso do crack de suas mães durante a gravidez podem sofrer, prematuridade, diminuição no crescimento do feto e outras alterações perinatais. E vão além, ao lembrar que os que nascem vivos podem apresentar retardo mental ou outros transtornos mentais e comportamentais.

Costa e colaboradores (2012) alegam que não é ainda bem conhecido o impacto da exposição ao crack dentro do útero e o impacto pediátrico do uso de crack pela mãe. Os autores relatam que, após aproximadamente 20 anos de pesquisas, nenhuma causa ou distúrbio foi identificada que pudesse cunhar o fenômeno dos crack babies. Isso porque as mulheres grávidas que usam crack também consomem outras drogas psicoativas e, além disso, apresentam estilos de vida caóticos (roubo, troca de sexo por dinheiro/drogas, abandono do lar, soropositividade para HIV e outras doenças sexualmente transmissíveis), tornando difícil a identificação de anormalidades causadas pelo crack per se.

Não é fácil isolar os efeitos do crack dessas outras variáveis, evidenciando a natureza multifatorial do problema. Alguns técnicos, que participaram da pesquisa de Domanico (2006) sobre o atendimento a mulheres usuárias de crack e seus filhos, observaram que os crack babies estavam mais diretamente relacionados com as condições de exclusão social em que algumas dessas mães viviam do que com o seu uso do crack. Outro estudo (Van Gelder et al., 2009) apontou muito poucas sugestões de associações positivas entre o uso de droga ilícita na gravidez e a ocorrência de 20 categorias de deficiências (defects) de nascença.

Laura não procurou nenhuma outra instituição de saúde em busca de ajuda. Também não passou por Comunidade Terapêutica nem teve acesso a nenhum serviço que fornecesse alimentação gratuita ou a unidades da previdência ou assistência social ou abrigo, a não ser os SAls, após o nascimento do filho.

Perguntada sobre o que deveria constar de um serviço de atendimento para usuários de crack, Laura considera que, primeiramente, os usuários deveriam ter o desejo de procurar internação para parar o uso da droga, se curar e, então, era necessário que o serviço providenciasse um trabalho para que eles se ocupassem e seguissem em frente. O serviço deveria dispor de educadoras que cuidassem, conversassem e explicassem para que as pessoas não fizessem 
"coisas erradas", como ela tem no abrigo: "Sempre tem uma pessoa mais velha, que explica bem, fica querendo o teu bem, não querendo só o teu mal".

Sobre o uso que faz de algum serviço para tratar da saúde, FELIPE conta que hoje em dia, busca espontaneamente auxílio, quando necessário, num posto de saúde perto do abrigo. Já quando usava crack, "não quis procurar [auxílio para a saúde], naquele tempo era só droga mesmo".

Felipe relata nunca ter frequentado serviços específicos para tratamento por dependência de crack nem ter sido abordado por profissional da saúde quando morava na rua, com proposta de redução de danos. Mas refere ter procurado o Projovem (Programa do Ministério do Desenvolvimento Social e Combate à Fome gerido pela Secretaria Municipal de Juventude de Porto Alegre), por indicação da equipe de um abrigo pelo qual passou, porque sentiu necessidade de conversar sobre os seus problemas. Conta que lá participou de consultas terapêuticas com uma agente de saúde a quem tudo relatava sem mentir, "porque foi uma pessoa que eu confiei assim". Abandonou o tratamento quando essa agente saiu do programa.

Passou por três ou quatro abrigos, levado pelo Conselho Tutelar. Numa dessas vezes, o pegaram em casa porque sua mãe passou um período internada e deixou os filhos menores sozinhos com ele para cuidar. Também cuidou dos irmãos no abrigo e não consumia drogas na frente deles: "Eu fugia do abrigo para fazer [uso de droga]".

Felipe considera que um serviço de atendimento para usuários de crack deveria proporcionar terapia individual, "conversar em particular". Muitos usuários poderiam, a partir daí, refletir sobre a sua vida. O serviço deveria oferecer emprego também. Considera que toda pessoa merece ter mais chance na vida. Ele afirma: "Um bom trabalho, uma boa conversa com eles assim, de repente, vários largariam [o uso do crack] para ter uma família decente, que vários querem ter".

JoÃo relata ter sido internado numa clínica pelo pai devido ao uso de drogas e levado, pela equipe do atual abrigo, para a Cruz Vermelha, onde é bem atendido por uma psicóloga e toma medicamento. $\mathrm{O}$ adolescente considera importante que um serviço de saúde para quem faz uso de crack tenha cama e chuveiro quente, como o que tem no abrigo, e remédios.

Camila frequenta desde a sua entrada na Fase há três meses, por iniciativa própria, o Caps ad com consultas semanais para tratamento de uso de crack. Não esteve em nenhum outro serviço de saúde. Considera que o atendimento 
no centro a ajuda muito. E também o atendimento no Creas, onde está engajada desde a medida judicial de liberdade assistida. Gosta do atendimento porque as técnicas "me entenderam, procuraram saber da minha vida, o que eu estava passando, os meus problemas". Considera que a agente de saúde do Creas sabe conversar, entender o que os usuários de crack vivenciam e dar "bons conselhos". Acha que hoje em dia, dá mais valor a essas conversas. la ao Creas mesmo quando estava na rua, usando crack: "Às vezes fora de hora, fora de dia, sem marcar data, mas eu ia".

Segundo a jovem, um serviço de atendimento para uso/abuso de crack deveria propiciar atendimento no local, um Consultório na Rua com agentes de saúde que abordassem os usuários e os incentivassem a uma mudança de atitude, porque há aqueles que estão nessa vida por não terem ninguém que se interesse por eles. Vivem na rua sozinhos, "largados", desinteressados. Para ela, em um bom serviço de atendimento deveria haver, acima de tudo, pessoas que entendessem os usuários, conversassem e se preocupassem com eles.

\section{Familiares: internação, psicoterapia e trabalho como necessidades essenciais}

SR. LEONARDO esclarece que a entidade com que pôde inicialmente contar para o uso abusivo de drogas do filho foi o Conselho Tutelar, que sempre ajudou o usuário, na figura principalmente de uma conselheira dedicada em auxiliar pessoas com essas dificuldades, que fazia a ronda com uma Kombi da instituição. Sr. Leonardo conta já ter andado com ela para levar o filho em posto de saúde ou em clínica. O abrigo institucional em que o usuário se encontra há dois meses, é avaliado pelo pai como o melhor lugar que seu filho já esteve porque "ele conseguiu dar uma freada no uso, se estabilizou um pouco". Sr. Leonardo relata que o filho também assistiu a palestras relativas ao uso de drogas numa instituição próxima ao abrigo atual, junto com ele. Nessa época fazia uso pesado de drogas e não podia andar sozinho.

Sr. Leonardo apenas fala dos encaminhamentos prestados ao filho, mas não à sua família. O filho teve algum atendimento no local onde morava, mas era a comunidade onde ele estava "enrolado". Foi o abrigo atual que o enviou para fazer exames clínicos a fim de avaliar danos decorrentes do uso do crack. Também frequenta um curso de informática por iniciativa do abrigo. Refere ainda o que deveria constar de um serviço de atendimento para uso/abuso de crack: um local "com toda uma estrutura formada", que desse suporte à saúde 
dos usuários com médicos, enfermeiros (serviços de saúde no local), estudo e orientação para o futuro, "principalmente trabalhar, fazer curso quando ele tiver condições". Pensa em uma colônia agrícola "que tivesse maquinário para o trabalho, para [o usuário] ter uma profissão como marcenaria, informática, enfim, como um colégio, para que ele saísse dali com uma formação, com uma profissão". O pai considera o abrigo "muito pequeno pra resolver o problema de todos", mas faz questão de frisar que é bom.

Na opinião de PEDRO, irmão de João, a família deveria procurar, para a pessoa que faz uso de drogas, internação e atendimento psicológico - psicoterapia, uma a duas vezes por semana. O estudo também é importante, bem como a formação profissional para posterior inserção no mercado de trabalho.

Segundo o jovem, um serviço de atendimento ao uso/abuso de crack deveria dispor de um local para promover, além da internação, as seguintes atividades: palestras de pessoas que conseguiram parar de usar drogas e que servem de estímulo para os usuários; roda de conversa em que cada um conta a sua história; aprendizagem de um ofício, que serviria a dois propósitos - ocupação do tempo dentro do local e possibilidade de trabalho ao sair. Essa forma de proceder auxiliaria na mudança de pensamento de quem se encontra em um desses serviços.

\section{Rede de saúde de assistência social: diferentes formas de} atendimento

A coordenadora do Caps ad A relata que $80 \%$ dos pacientes que ingressam no serviço são trazidos por seus familiares, ou encaminhados por um órgão jurídico que os obriga a se engajarem num tratamento, ou ainda pela Fase, quando o adolescente chega algemado (atitude contrária aos preceitos do ECA). Quando o usuário é trazido por familiares, ele pode expressar o desejo de modificar o seu comportamento por perceber que tem causado problemas para a família, que ele não gostaria que a sua vida estivesse assim. Nesses casos, o Caps poderá construir, em conjunto com o usuário, alternativas para a sua vida: volta à escola, ao emprego.

Se ele quiser voltar para a escola, a equipe do Caps aciona uma instituição, conversa, faz o encaminhamento e acompanha; se ele quiser um emprego, "ah eu quero fazer um curso para me aprimorar e começar a trabalhar", a equipe aciona o Senac, por exemplo, e faz o acompanhamento. 
A equipe desse Caps ad que oferece atendimento aos adolescentes e adultos usuários de crack possui um psiquiatra, um clínico geral, uma enfermeira e dois técnicos de enfermagem, uma terapeuta ocupacional, uma assistente social, dois administrativos, uma pessoa da área da higienização e segurança e um coordenador dos serviços, no caso, uma assistente social.

A coordenadora de Caps ad $B$ destaca outros serviços da rede que atendem os adolescentes usuários: unidades básicas de saúde (UBS), alguns Creas e Cras, a Fundação de Proteção Especial/RS, a Fase e algumas ONGs. Estas últimas executam programas da assistência socioeducativa em meio aberto, em turno inverso da escola. Mas é bem difícil o seguimento nesses programas devido ao isolamento em que vivem os usuários do crack.

Há também duas clínicas que lidam com questões de saúde mental e de uso de droga. Os atendimentos são efetuados nas emergências. Porto Alegre tem uma central de regulação de leitos feita por meio das emergências e não dos Caps. O Caps ad B não costuma encaminhar usuários para Comunidades Terapêuticas (o município tem convênio com duas), que em Porto Alegre têm cunho religioso, porque, de uma forma geral, os usuários não se adaptam a elas.

Ao chegar para internar o usuário nesse Caps ad, a família recebe uma lista de atividades por ele oferecidas: atendimentos individuais, em grupo, oficinas, visitas domiciliares por assistentes sociais, o que tem evitado internações. Internação hospitalar para desintoxicação é feita quando necessário e depois ocorre o retorno ao Caps ad. É o único centro de Porto Alegre próprio do município. Há um federal e dois de orientação religiosa católica (conveniados da Prefeitura).

No Caps ad B há liberdade de gerir os casos de acordo com a orientação teórica e técnica de cada profissional. A equipe é formada por dez profissionais: médica psiquiatra, médico clínico, dois assistentes sociais, dois psicólogos, uma enfermeira, dois técnicos de enfermagem e uma técnica de enfermagem. Há ainda muitos estagiários, tanto da UFRGS quanto do Programa de Educação pelo Trabalho para a Saúde. A coordenadora descreve que só permanecem em Caps ad os profissionais que se apaixonam pelo trabalho, do contrário não suportariam, porque além da dependência à substância, há inúmeras comorbidades, fato que exige do técnico que atende essa clientela formação e perfil, do contrário seria um sofrimento muito grande para ele. A equipe vem trabalhando na lógica da redução de danos (há outras estratégias cujos princípios são a abstinência e/ou a internação em Comunidade Terapêutica). Não existe 
uma receita mágica. O plano de tratamento é elaborado em consenso, levandose em conta o que o paciente quer fazer com a sua dependência.

Cabe aqui um esclarecimento acerca da estratégia de redução de danos, que consta da política do Ministério da Saúde para a atenção integral a usuários de álcool e outras drogas (Brasil, 2004). Ela não foi criada em substituição ao modelo da abstinência, tampouco nega esse objetivo. Conforme adverte Melotto (2009: 21):

situada no documento da política nacional como complementar, ela apenas retira a centralidade da abstinência, ampliando a visão das possibilidades de cuidados e de saúde para além dessa questão. Nesse sentido, são valorizadas ações a fim de minimizar os riscos presentes no uso de drogas e também atenuar os possíveis danos decorrentes dele.

Domanico (2006: 70) traz uma reflexão acerca dos objetivos de uma abordagem centrada na redução de danos, contrapondo-a à da abstinência. A primeira estratégia

leva em consideração a complexidade do fenômeno, a diversidade dos usos e as particularidades culturais dos usuários, possibilitando, desta forma, uma melhor compreensão da hierarquia de riscos no cotidiano do uso de drogas. A redução de danos parte do pressuposto que é impossível acabar com as drogas no mundo, eliminando totalmente seu consumo. Comporta ações voltadas para as drogas lícitas e ilícitas e suas intervenções não são controladas exclusivamente pelos órgãos governamentais e policiais. Opõe-se, portanto, ao modelo preventivo tradicional que, ao desconsiderar a complexidade que envolve os diferentes usos de drogas, busca um objetivo unívoco: a abstinência, meta esta idealizada e restritiva.

O SAN tinha, no momento da pesquisa, uma coordenadora, uma técnica (assistente social), oito monitores, dois técnicos em enfermagem e dois profissionais de apoio de serviços gerais: cozinheira e porteiro. Sobre o atendimento oferecido aos adolescentes, a assistente social sugere que haja acompanhantes terapêuticos para garantir um envolvimento de qualidade de forma a poder "resgatar" o usuário de crack. Há que se melhorar o acolhimento nas instituições, porta de entrada fundamental para a permanência desse usuário no espaço institucional. Há que se acreditar que é possível investir nessa população e que haverá retorno, desde que respeitado o momento do usuário porque "muitas vezes, a instituição tem tudo muito 
organizado, consegue o acesso a determinado atendimento, consegue uma bolsa auxílio, mas se naquele momento o guri não estiver legal internamente de nada adianta".

As entrevistas com as coordenações dos dois Caps ad investigados mostram diferenças marcantes de lógicas de trabalho e, portanto, de abordagens aos usuários de álcool, crack e outras drogas. A coordenadora do Caps ad A, serviço conveniado entre a prefeitura e o Hospital Mãe de Deus, evidencia a orientação religiosa da unidade. Ela fala sobre a importância deste Caps ser abençoado a cada 15 dias pelo padre da paróquia do bairro e também da celebração do Natal da congregação de pessoas da comunidade, Igreja e Caps ad, com bênção e presentes. Com uma madre que trabalha com a dependência às drogas há 30 anos, a coordenadora discute abordagens dos adolescentes que chegam ao serviço, de acordo com os princípios importantes para a Igreja. Para a coordenadora, o trabalho com os adictos é uma missão. Ela refere, ainda, a importância do tratamento continuado do usuário de crack, do adolescente ao adulto, se dar em Comunidade Terapêutica, que privilegia a abstinência.

Elias e Bastos (2011: 4.722) trazem contribuição importante ao tema da abstinência ao uso de drogas, relacionando-o com as políticas públicas pautadas nos direitos humanos:

É possível que alguém que venha fazendo uso problemático de álcool e/ou drogas possa se manter inteiramente abstinente (a depender do psiquismo do indivíduo e das circunstâncias em que o mesmo está inserido). Na esfera da população e da comunidade, entretanto, tal meta enquanto meta coletiva não é factível (e não necessariamente desejável, para alguns segmentos sociais), e tem resultado antes na imposição de leis draconianas, que violam os direitos humanos, sem contribuir de fato para a redução dos danos e riscos em pauta.

A gestora da Proteção Social de Média Complexidade oferece um contraponto à visão da coordenadora do Caps ad A. Em sua opinião, o adolescente não deveria ser encaminhado para tratamento em Comunidade Terapêutica quando ele necessitar de uma tutoria e de alguém que responda legalmente por ele, como acontece no SAl, porque esse tipo de serviço não dispõe da organização necessária para atender um público tão jovem. Além disso, os usuários adultos acorrem voluntariamente às Comunidades Terapêuticas com o intuito de modificar sua relação com a droga, o que não necessariamente será o caso 
do adolescente. Para a gestora, o atendimento ao adolescente e a sua família deveria incluir tratamento ambulatorial nas comunidades em todas as regiões de Porto Alegre, de acordo com as modalidades previstas no SUS.

Em contraposição à visão da coordenadora do Caps ad A, a do Caps ad B se alinha com um trabalho técnico especializado na temática da adolescência e uso de crack e relata experiência com o programa de redução de danos, funcionando de acordo com os preceitos da Política Nacional sobre Drogas (Brasil, 2010). Está em sintonia também com os preceitos da Rede de Atenção Psicossocial do Ministério da Saúde voltada para usuários de crack. ${ }^{13}$ O Caps ad B constrói um plano de tratamento singular e busca manter o usuário de crack em tratamento continuado na unidade, oferecendo um leque de alternativas terapêuticas.

\section{Funcionamento dA REDE de AsSistênCIA SOCIAL E SAÚdE NA ATENÇÃO A CRIANÇAS E AdOLESCENTES USUÁRIOS DE CRACK E SUAS FAMÍLIAS}

\section{Encaminhamentos da rede para os SAls}

Um total de 38,1\% dos SAls incluídos na pesquisa indicou que o Poder Judiciário foi o órgão que mais encaminhou crianças/adolescentes em decorrência do uso de crack nos últimos 12 meses. Seguem em frequência decrescente o Conselho Tutelar, o Ministério Público, a família e outros SAls. SMAS, Polícia e Delegacia de Proteção à Criança não fizeram encaminhamentos.

Em 13 SAls havia crianças, adolescentes ou responsáveis em situação de uso de crack no momento pesquisa. Todos os serviços sabem a localização do Conselho Tutelar e trocam informações com esse órgão e com o Poder Judiciário para apoiar o atendimento aos acolhidos. Um total de 76,9\% promove reuniões periódicas com ambos os órgãos; $69,2 \%$ realizam encaminhamentos para o Conselho Tutelar e 92,3\% para o Poder Judiciário. Falta de articulação com Conselho Tutelar é referido por $7,7 \%$ dos serviços.

Um total de $92,3 \%$ dos SAls conhece a localização do Ministério Público e com ele troca informações, 30,8\% realizam reuniões periódicas e 69,2\% fazem encaminhamentos para o Ministério Público. Sem nenhuma articulação com

${ }^{13}$ A portaria n. 3.088, de 23 dez. 2011, do Ministério da Saúde, institui a Rede de Atenção Psicossocial para pessoas com sofrimento ou transtorno mental e com necessidades decorrentes do uso de crack, álcool e outras drogas no âmbito do SUS. 
esse órgão é referido por 7,7\% dos serviços. Podemos depreender que esses SAls têm uma boa articulação com o eixo de defesa dos direitos de crianças e adolescentes, exceção feita à menor menção da Defensoria Pública.

Com os centros de assistência social esses SAls também mostram boa articulação: 92,3\% sabem a localização do Cras e Creas e com estes trocam informações. Em um total de $84,6 \%$ há reuniões periódicas e 92,3\% realizam encaminhamentos para ambos os órgãos. A falta de articulação com o Cras e o Creas é mencionada por 7,7\% dos serviços.

Já com os Caps - principalmente o Caps ad, serviço de saúde especializado para o tratamento desses usuários -, a articulação dos SAls é precária: 61,5\% sabem a localização do Caps ad, 46,2\% trocam informação com o órgão, 30,8\% promovem reuniões periódicas e realizam encaminhamentos, e 30,8\% não têm nenhuma articulação com o Caps.

\section{Papel dos órgãos da rede}

Ao se referir ao seu papel, o juiz da Vara da Infância e Juventude inicia por contextualizar a sua função com relação ao uso de crack no município. Informa que está há 12 anos no cargo e que, quando iniciou o trabalho, o crack não existia nos processos que analisava. Entretanto, no momento, mais da metade das 1.300 crianças e adolescentes encontra-se em acolhimento porque "as famílias foram dizimadas pelo crack". Avalia que "hoje o bebê encaminhado para adoção é só de filhos de usuários de crack. Aquele [bebê] antigo que era abandonado porque a mãe não podia cuidar, não existe mais". Para enfrentar essa problemática complexa, é necessário uma rede com muitos parceiros. Posto isso, o juiz esclarece que o seu papel especificamente com relação a essa população é cuidar do acolhimento; destituir do poder familiar os pais que não cuidam de suas crianças e adolescentes; encaminhar eventualmente essas pessoas para algum tratamento que o serviço público não conceda; e, ao ser demandado, determinar que esse atendimento seja feito.

O Juizado, bem como o Ministério Público, têm a obrigação legal de acompanhar e fiscalizar os SAls estaduais e municipais. O juiz refere ter uma boa interlocução com esses serviços, lembrando que exerce há muito tempo a função.

Em relação ao papel do Conselho Tutelar na rede, o conselheiro entrevistado menciona três ações: fazer os encaminhamentos dos casos de usuários de crack para a rede; sugerir políticas públicas nessa área; provocar para que a rede 
funcione, "fazendo com que os outros [Estado e/ou família] façam valer o direito da criança". O órgão também procura solucionar o problema das famílias usuárias (pai usuário de crack, mãe negligente, por exemplo), tentando que a criança permaneça no turno inverso na escola em algum projeto ou oficina, de tal forma que ela se afaste da rua e não seja um alvo fácil para o consumo da droga. O conselheiro acha que a Prefeitura acompanha e fiscaliza os serviços que atendem essa clientela por intermédio da secretaria da Saúde, evidenciando pouco conhecimento acerca desse assunto.

Ao falar sobre o papel das unidades de acolhimento na rede, duas gestoras da equipe de Proteção Social Especial de Alta Complexidade inicialmente esclarecem que uma criança ou adolescente é acolhido num dos equipamentos da Fasc por diversas questões, sendo o uso de drogas uma delas. A equipe do abrigo faz todos os encaminhamentos necessários articulando com a saúde para garantir o espaço de atendimento. Nos espaços de acolhimento há um técnico de enfermagem e, no setor de Proteção na sede da Fasc, há um enfermeiro responsável cuja função é fornecer suporte para a equipe que trabalha com as crianças e adolescentes. $O$ técnico de enfermagem administra a medicação e marca as consultas; os educadores buscam e levam os usuários nas sessões. Esta é a distribuição das atribuições nos abrigos, quando há uma criança ou adolescentes com essa demanda.

Essas gestoras esclarecem que, internamente na Fasc, há um grupo de supervisão que faz parte da coordenação de monitoramento e avaliação. Os equipamentos têm as suas supervisoras (seis ao todo), o seu grupo de referência, que acompanham os técnicos, dão suporte, trazem as dificuldades desses equipamentos para a Proteção e para o monitoramento e avaliação: "seriam os nossos olhos dentro dos equipamentos", segundo a gestora. Além disso, no papel de fiscalização, há o Ministério Público e o Judiciário que fazem as suas visitas, bem como o Conselho Municipal de Assistência Social. A Comissão de Políticas Públicas dos Conselhos Tutelares também fiscaliza os abrigos, fato não citado pelo conselheiro tutelar.

Ao falar sobre o papel do SAl, a coordenadora técnica de uma das unidades refere que ela, juntamente com as técnicas (cinco assistentes sociais e cinco psicólogas), procura saber sobre a situação em que se encontram as instituições que compõem a rede da assistência social e saúde (Cras, Creas, postos de saúde) e sobre o atendimento prestado às famílias usuárias de crack e outras drogas para que possa fazer o seu encaminhamento, quando necessário. 
Ao falar sobre o papel do SAN, a técnica inicia por contextualizá-lo, esclarecendo que o serviço de atendimento para adolescentes em situação de rua-moradia funcionou desde 2001 e fez parte de uma rede de atendimento de meio aberto. Foi extinto em 2012, conforme referido anteriormente. $\mathrm{O}$ período de atendimento era noturno, das $19 \mathrm{~h} 30$ às $7 \mathrm{~h} 30$, de segunda a segunda. O SAN trabalhava na linha da redução de danos, buscando criar vínculos e espaços flexíveis. A construção de um vínculo visava a garantir a permanência desses adolescentes dentro do espaço, garantindo o não uso de droga por 12 horas. Também era um espaço de escuta constante, em que eles podiam falar livremente com o educador e com a assistente social.

Durante o dia, há outros espaços que acolhem os adolescentes: o Serviço de Convivência e Fortalecimento de Vínculos para Crianças e Adolescentes (Savi), em convênio com o Lar Dom Bosco. Nesse espaço, há alimentação, chuveiros, acompanhamento pedagógico, atividade de esporte, cursos em geral, cursos profissionalizantes (não conveniados com a Prefeitura). A Escola Aberta, escola municipal de Porto Alegre, também faz parte dessa rede. Essa instituição, que atende um público específico em que os usuários de crack e outras drogas se incluem, tem uma metodologia diferenciada, pois trabalha com a Educação de Jovens Adultos (EJA). Nela o aluno pode, a qualquer momento, entrar em sala de aula e iniciar, a partir do seu conhecimento, a trabalhar uma dificuldade de aprendizado que o impeça de avançar, por exemplo.

As atribuições da Proteção Social de Média Complexidade, especificamente concernentes à população em situação de rua, são: o apoio técnico aos nove Creas e aos três Centros de Referência Especializados para População em Situação de Rua (Centros POP), um implantado e os outros em processo de implantação - todos eles reordenados, vindos da rede de serviços denominada Casa de Convivência.

De acordo com a gestora de Média Complexidade, o serviço apresentava um resultado positivo, favorável e reconhecido pela rede, pois havia um conjunto de circuntâncias favoráveis para tal resultado. Ressalta que viviam um tempo de uma "economia favorável", expressa pelo Programa Bolsa Família e por maiores chances de se conseguir emprego, o que também favorece que se tenha mais proteção para as crianças.

A gestora esclarece haver mais serviços voltados para o fortalecimento de vínculos para aqueles até 14 anos, e pouco trabalho educativo e esparsas alternativas para jovens acima dessa faixa etária. Para ela, a alternativa do 
tráfico entra nesse vazio como "um empreendimento que dá uma visão de carreira", em que os jovens, principalmente os usuários de drogas (mas não só), são reconhecidos e empoderados.

O Caps ad A se define como um centro de atenção psicossocial especializado em dependência química, que funciona das 8 às 18 horas e atende adolescentes a partir de 15 anos, oferecendo planos de atendimento com uma equipe de profissionais. Esse Caps ad é metade público e metade privado. Segundo sua gestora, tem o papel de promover reuniões mensais com os parceiros da rede para a discussão de casos em conjunto, visando ao melhor atendimento ao usuário. Apresenta boa articulação com a rede composta por Cras, Creas, Ministério Público, Brigada Militar, Conselho Tutelar, abrigos e albergues que atendem a área de abrangência dessa unidade (compreende uma população de 200 mil). Há um número grande de usuários de crack e outras drogas e também de famílias sendo atendidos no Caps ad A. As famílias são inseridas em grupos de apoio para lidar com o problema. Uma vez que o uso do crack está comumente ligado a alguma forma de delinquência, o Caps ad A trabalha em parceria com outras instituições, como a Fase e o Conselho Tutelar.

O Caps ad B foi criado em janeiro de 2008 na área de saúde mental da Secretaria Municipal de Porto Alegre. Situa-se em atendimento especializado, tendo um papel de articulador do atendimento ao uso ou abuso de substâncias químicas em toda a região, que é composta de: 27 UBS e as unidades de Estratégia Saúde da Família (ESF) próprias do município. O atendimento é feito nas unidades básicas, ou nos postos de saúde da família e, havendo necessidade de atendimento especializado, são encaminhados para o Caps ad. Esse equipamento situa-se dentro do Centro de Saúde Vila dos Comerciários e, no momento da pesquisa, estava para se mudar para uma casa aconchegante com consultórios individuais, inserido dentro da comunidade em que moram os usuários, conforme a portaria n. 336/GM/MS (2002), que cria os Caps ad.

O Caps ad B deveria atender crianças, adolescentes e adultos (Cf. portaria n. 3.088/MS, 2011), mas a equipe que lá atua estipulou atendimento à clientela de 11 anos em diante porque não têm especialistas em infância. Esse segmento é para ser atendido no Caps i. No momento, o Caps ad tem usuários de 14 e 15 anos. Tem o papel de articulador e mediador da rede com: os serviços ligados à equipe do Caps ad (UBS, clínicas, ONGs, Alcólicos Anônimos (AA), Narcóticos Anônimos (NA), Grupos Familiares Nar-Anon, posto de saúde da família), Fase e Comunidades Terapêuticas. 
Para atuar como articulador, o Caps ad B se utiliza do matriciamento. ${ }^{14}$ Uma das suas ações é a interconsulta: tanto a equipe se desloca para alguma das unidades da rede quando chamada, quanto semanalmente recebe os serviços da região que estejam interessados em encaminhar pacientes, ou saber notícias dos pacientes em atendimentos, ou mesmo se orientar.

Há casos em que os usuários estão bem em suas comunidades, e precisam somente de um acompanhamento, que então é efetuado na própria UBS ou no posto de saúde da família. Nesses casos, o profissional que os atende pode vir ao Caps ad em busca de orientação para o seu usuário relativa ao uso de medicamentos e plano de tratamento.

A coordenadora do Caps ad B relata que os serviços que atendem essa clientela são acompanhados e fiscalizados por: Escola de Saúde Pública do governo do estado, com sede em Porto Alegre, com supervisão geralmente mensal, interna, da parte técnica; conselho distrital de saúde, que é muito atuante; coordenação de saúde mental, com reunião semanal em que são cobrados: metas, produção, alinhamento técnico, encaminhamentos, fluxos estabelecidos.

\section{Desafios e potencialidades do atendimento em rede}

Os profissionais entrevistados apontaram, como desafios à prevenção ao uso do crack, a criminalidade, a articulação da rede, a atuação da rede de saúde mental, a forma como são conduzidos o tratamento e a capacitação profissional.

A prevenção ao uso do crack é lembrada por alguns, seja porque, para eles, o atendimento ao usuário do crack e sua família deveria ser pautado nos cuidados essenciais que a criança e o adolescente precisariam ter tanto em casa quanto na escola, seja porque o tratamento para a recuperação dos usuários é tido como uma possibilidade longínqua. Para o juiz, a criminalidade constituise como parte da vida dos usuários. "O Estado tem que combater fortemente

\footnotetext{
${ }^{14}$ Matriciamento ou apoio matricial é um novo modo de produzir saúde em que duas ou mais equipes, num processo de coconstrução, criam uma proposta de intervenção pedagógicoterapêutica. "No processo de integração da saúde mental à atenção primária na realidade brasileira, esse novo modelo tem sido o norteador das experiências implementadas em diversos municípios, ao longo dos últimos anos. Esse apoio matricial tem estruturado em nosso país um tipo de cuidado colaborativo entre a saúde mental e a atenção primária. A nova proposta integradora visa transformar a lógica tradicional dos sistemas de saúde: encaminhamentos, referências e contrarreferências, protocolos e centros de regulação. Os efeitos burocráticos e pouco dinâmicos dessa lógica tradicional podem vir a ser atenuados por ações horizontais que integrem os componentes e seus saberes nos diferentes níveis assistenciais" (Chiaverini et al., 2011: 13).
} 
a criminalidade". Complementa, "é crime se drogar, enquanto a lei não for modificada". Mas, diferentemente da fala do juiz, a lei n. 11.343/2006, em seu título IV intitulado Da Repressão à Produção Não Autorizada e ao Tráfico Ilícito de Drogas, distingue o usuário de drogas (que porta e/ou adquire drogas para consumo pessoal) do fornecedor de drogas. No primeiro caso, o juiz aplica penas socioeducativas e advertências verbais, ou solicita ao Ministério Público o encaminhamento do usuário para tratamento, enquanto, no segundo caso, imputa diferentes penas de detenção e pagamento de multas.

Outro desafio lembrado pelas gestoras da Proteção Social de Alta Complexidade é a articulação da assistência social com a rede. Por ser falha,

a gente faz o nosso trabalho e o do outro, e os colegas que estão na ponta também, muitas vezes, estão dando conta de um trabalho que não é deles, como, por exemplo, um psicólogo que trabalha dentro de um abrigo, que não é para fazer um atendimento clínico, acaba por realizá-lo porque a situação assim pede. Não existe uma psicoterapia na rede de saúde para aquela criança.

Ressaltam que a assistência social tenta esgotar todas as possibilidades antes que a criança ou o adolescente ingresse na rede de acolhimento. Referem, também, que é fácil para a criança entrar no abrigo, mas é muito difícil sair. Sua saída também dependerá da articulação da rede. Há casos em que a equipe que está no território diverge da opinião da que está trabalhando no SAI, no que se refere à aptidão para sair do abrigo, em função de, por exemplo, morar numa habitação muito precária, mesmo que a família esteja pronta para receber a criança de volta. Outro exemplo é o de uma mãe alcoolista que necessitaria de tratamento e de acompanhamento para poder receber os filhos. Somente com a rede funcionando é que se poderia dar andamento, tanto ao acolhimento da criança, quanto às condições para o seu retorno ao território.

Para a maioria dos profissionais, a articulação com a rede de saúde mental é pouco eficaz no atendimento ao usuário do crack e outras substâncias e constitui um grande desafio para o município. A coordenadora do Caps ad $B$ considera que, na área de saúde mental, especialmente o atendimento em psicologia e psiquiatria para a criança e o adolescente ainda é frágil e escasso. Não há para onde encaminhar uma criança que deixou de usar a droga e tem condições de alta, porque há somente um Caps i, que não apoia o usuário de substância psicoativa sem transtornos persistentes, para atender o município inteiro. Os profissionais da saúde e da assistência social 
referem o pequeno número de Caps para atendimento à população em geral e de Caps ad para os usuários de crack e outras substâncias.

Desafios relacionados ao tratamento da população em foco são lembrados: a internação de curta duração (até 20 dias pelo SUS) e a eficácia do tratamento continuado em Comunidade Terapêutica para usuários adolescentes e adultos, opinião que é divergente entre alguns profissionais.

A gestora da Proteção Social de Média Complexidade considera a internação em Comunidade Terapêutica uma prática inadequada para o adolescente. Para ela, o atendimento deverá incluir o tratamento ambulatorial nas comunidades e em todas as regiões de Porto Alegre, onde os adolescentes possam ter acesso junto com suas famílias, com todas as modalidades previstas no SUS. Refere que a assistência social e a saúde vivem paradigmas conflitantes, a primeira ligada a uma lógica de institucionalização do usuário, e a segunda, de tratamento individual/familiar visando ao empoderamento e a autonomia do indivíduo.

O conselheiro tutelar, entretanto, considera a internação em Comunidade Terapêutica uma opção razoável para jovens usuários de crack. Para ele, as comunidades deveriam ser maiores e mais atrativas, para que possam aderir ao tratamento continuado, mas "é a única chance que eles têm de se recuperar".

A coordenadora do Caps ad A considera que a Comunidade Terapêutica é um espaço seguro de acolhida e tratamento para esse usuário (jovem ou adulto) porque "ele volta cognitivamente com o pensamento mais forte para que possa ter mais força para dizer não para uma fissura, que vai continuar acontecendo". Avalia que as comunidades são por vezes denunciadas por não desenvolverem um bom trabalho, ou por agirem de má-fé. Mas, para a coordenadora, essa é uma visão de pessoas que não lidam diretamente com os usuários e/ou com os problemas de articulação e precariedade dos serviços da rede.

A formação/capacitação profissional sobre o tema do crack de todas as equipes referentes às UBS, posto de saúde da família e Caps ad é lembrada pela coordenadora do Caps ad B. Esse estudo, feito em conjunto com todas as equipes, permitiria um discurso afinado levando conhecimento e ações diferenciadas (detectar sinais de violência, uso de drogas, por exemplo) para os profissionais que trabalham no campo, dentro das comunidades.

Aliado à falta de capacitação, há o preconceito nas escolas, famílias e instituições de saúde que precisa ser trabalhado para ajudar a desconstruir a imagem do usuário de drogas, de forma que ele possa ser mais bem cuidado por essas instâncias. A coordenadora do Caps ad A acredita que o medo por parte 
dos profissionais da saúde do contato com o usuário de crack se dá porque o uso da substância está atrelado à violência. Mas, ela costuma explicar para a sua equipe: "Quando uma pessoa se submete a vir buscar ajuda, ela já deixou de ser perigosa. Talvez seja perigosa na fissura, na noite, na rua escura. O fato da pessoa ser usuária de alguma substância psicoativa não faz dela necessariamente uma delinquente".

As potencialidades do atendimento em rede no município versaram sobre o programa de redução de danos, a articulação da rede, a implantação do Sistema Único da Assistência Social (Suas), o reordenamento, parcerias entre a UFRGS e os Caps ad, a mudança de visão do atendimento a partir da ESF.

O juiz refere que o maior problema social enfrentado em seu trabalho é o uso do crack; por isso, defende a política pública de redução de danos para mulheres usuárias de crack, que têm filhos todo ano. Sugere que elas sejam "trabalhadas e convencidas" a colocarem um implante subcutâneo, com duração de três a cinco anos. No momento em que as usuárias quiserem, o implante pode ser retirado e elas voltam a ser férteis em menos de 30 dias. Com isso, se evitaria que muitas crianças nascessem sem qualquer perspectiva de cuidado e fossem colocadas em SAls, já que as mães não dispõem de condições mínimas para criá-las. A coordenadora do Caps ad B relata que o programa de redução de danos encontra-se em fase de reestruturação e irá integrar-se às unidades de saúde, fazendo a articulação entre o atendimento e a comunidade propriamente dita. De acordo com Brittes (apud Domanico, 2006: 80),

os programas de redução de danos desenvolvem estratégias que visam promover um contato entre os usuários e as instituições de saúde e os equipamentos sociais, com o objetivo de difundir noções básicas de preservação da saúde, prevenção de doenças e busca de consolidação dos direitos de cidadania.

O conselheiro tutelar considera a articulação da rede promovida pela Secretaria Municipal de Governança Local um ganho no atendimento aos usuários. Relata que, inicialmente, as diversas instituições que compunham parte da rede não se falavam, de forma que, por exemplo, o Conselho Tutelar, a assistente social e o posto de saúde faziam o mesmo encaminhamento para uma determinada família, o que gerava três agendamentos. "Tendo uma overdose de atendimentos", as famílias acabavam por não aderir. Em um momento posterior, os representantes da rede passam a se encontrar mensalmente, e a cada quinze dias se reúnem (assistência social, saúde e 
Conselho Tutelar) nos diferentes Conselhos Tutelares, nas dez regiões do município para a discussão de casos.

A equipe da assistência social ressaltou a implantação do Suas no município de Porto Alegre (em 2011), que insere os Creas e os Cras nos territórios, auxiliando a organização das comunidades, a grande quantidade de equipamentos para acolhimento (68), a modificação da estrutura dos SAls a partir do reordenamento, a implantação e ampliação do serviço Ação Rua para todos os territórios. A gestora da Proteção Social de Média Complexidade acrescenta uma reflexão:

A instituição e as pessoas que trabalham com infância e adolescência têm muita preocupação pelo fato dos serviços estarem sendo desfeitos porque têm pouco público. Nesse momento temos um projeto que tentamos implantar: um centro-dia de assistência social para adolescentes em situação de violação de direitos. Seria um híbrido entre proteção básica e média complexidade, mas focado nesses meninos mais crônicos da rua, que acabam ficando sem atendimento com o fechamento do acolhimento noturno, e dos outros serviços voltados para a rua. Realmente têm cinco, seis, dez meninos. Mas estes precisam de atendimento. Então estamos preocupados se, a qualquer momento, esse número começar a aumentar. Como é que a gente lida com isso?

As coordenadoras dos Caps ad destacam como realizações a implantação do teto saúde pela Prefeitura e a construção de uma parceria com a UFRGS a disciplina da enfermagem é lecionada no Caps ad: os internos atendem, fazem as visitas domiciliares e trabalho em grupo junto com a equipe do Caps ad. Referem-se também ao Programa de Educação pelo Trabalho para a Saúde (PET/SUS), desenvolvido nas áreas de educação física, nutrição, fonoaudiologia e saúde mental, beneficiando os Caps ad com o trabalho de alguns desses profissinais; ao montante de recursos financeiros que a Secretaria de Saúde tem investido na implantação de serviços públicos nas diversas regiões da cidade; à qualificação da atenção básica com o matriciamento; à mudança de visão do atendimento com a implantação da ESF; à criação de equipes de infância para atendimento regional. Esses novos investimentos na saúde poderão responder à preocupação da gestora da Proteção Social de Média Complexidade.

Um dos pontos mais delicados é como a gente lida com aqueles meninos que precisam de um atendimento de saúde mental e também de acolhimento institucional, porque o espaço de acolhimento não 
tem tanto conhecimento sobre o processo de contenção, de manejo, de algumas situações. Chegamos a cogitar alguns serviços híbridos que pudessem incorporar profissionais de saúde e de assistência, e teve muita controvérsia, se estaríamos voltando no tempo e querendo ter instituições mais totais que abrangessem todas as necessidades do menino. Daí não. Ele teria que ter um abrigo como a casa dele e o Caps ad, por exemplo, ou o Caps dia, em que ele passasse os dias lá e que tivesse atividades orientadas para a faixa etária dele.

\section{Fluxograma de atendimento a crianças e adolescentes usuários de crack}

No que concerne ao atendimento às crianças e adolescentes usuários de crack na rede, especialmente aqueles com familiares também usuários da substância, no fluxo apresentado pelo juiz, a criança é encaminhada para um SAl, permanece com a família extensa e, se necessário, é encaminhada para tratamento. Já no caso do adolescente usuário (independente do status de uso dos familiares), o juiz poderá determinar diretamente a sua internação compulsória para tratamento em serviço de saúde ou fazê-lo a pedido de algum outro parceiro da rede (Conselho Tutelar ou SAI). Muitos dos que se encontravam internados por prática de ato infracional na Fase foram/eram usuários de crack.

O Juizado é a última instituição da rede a ser acionada, geralmente pelo Conselho Tutelar, pela Fasc ou pelo SAI não governamental, para que seja feita alguma determinação judicial, internação, ou que seja prestado algum medicamento aos usuários.

Porto Alegre é considerada uma cidade que dispõe de "uma das melhores portas de entrada no atendimento à saúde voltado para a criança e adolescente usuário de crack", segundo o conselheiro tutelar. São duas clínicas e três locais de internação. O mesmo conselheiro informa não haver rede ampliada, explicando que, por exemplo, o Creas, responsável pelo atendimento a usuários de drogas, estava sendo instalado no município. Na região de Porto Alegre onde ele atua, não há Creas, falta atendimento psicológico e psiquiátrico por falta de Caps i.

Na visão do conselheiro há um círculo vicioso do fluxo de atendimento ao jovem usuário de crack. Mães costumam chegar desesperadas ao Conselho Tutelar, pedindo ajuda para o filho que está devendo dinheiro ao traficante 
ou está ameaçado de morte por ele. Mas, segundo o conselheiro, enquanto o filho trabalha como aviãozinho, traficando e ganhando de $\mathrm{R} \$ 200,00$ a R\$ 300,00 por semana, as mães "fazem vista grossa". Quando o filho rouba dos vizinhos ou em casa, ou vende os objetos da casa, elas procuram ajuda. Em todos esses casos, o Conselho Tutelar encaminha os adolescentes para o serviço de psiquiatria dos postos de saúde, de acordo com as zonas a que servem. O melhor deles é municipal, localiza-se na zona sul e tem um atendimento diferenciado. Os adolescentes passam por uma avaliação psiquiátrica e geralmente ficam internados por aproximadamente 21 dias. Enquanto isso, as mães retornam ao Conselho Tutelar, que busca comprometer os pais no tratamento dos filhos. Na maioria das vezes, a entidade solicita ao Ministério Público a compra de uma vaga numa Comunidade Terapêutica para o adolescente dar continuidade ao tratamento.

Como a internação não é compulsória, geralmente o adolescente foge, porque não consegue se adaptar aos moldes de tratamento oferecidos. Ao fugir, vai morar na rua, quando, então, é abordado ou pela Brigada da Polícia Militar, ou pela equipe de Ação na Rua, sendo reencaminhado para o Conselho Tutelar, que busca fazer o seu reingresso na Comunidade Terapêutica. Dois ou três dias depois o usuário evade-se novamente, configurando um círculo vicioso.

No caso de familiares que fazem uso do crack, o Conselho Tutelar encaminha para o Caps ad para avaliar a necessidade de internação. O conselheiro esclarece que a internação de adultos é mais complicada porque faltam vagas e depende da anuência do usuário (o que é rara). Escassas são as internações compulsórias, mesmo que para desintoxicação. Além da internação, há atendimentos ambulatoriais em hospital dia. O Conselho Tutelar, quando retira as crianças e adolescentes da família usuária de crack, encaminha-as para SAI ou coloca-as na família extensa, geralmente sob a responsabilidade das avós.

Uma tentativa inicial de retratar a complexidade da rede existente em Porto Alegre está apresentada na Figura 1. 
Figura 1 - Fluxograma de atendimento a crianças, adolescentes e usuários de crack. Porto Alegre - 2011-2012

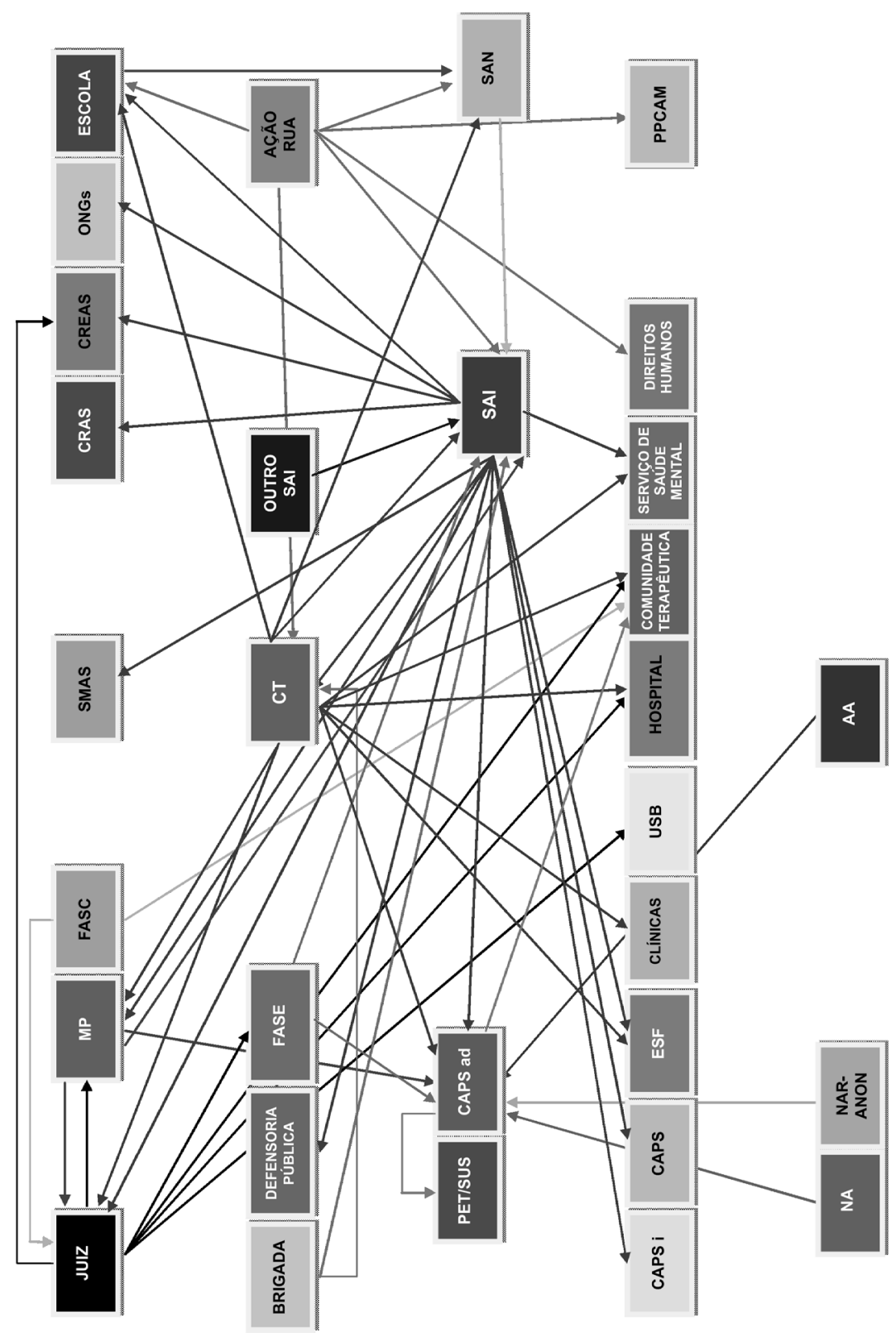


Quanto ao atendimento na rede direcionado a essa população, as duas gestoras da Proteção Social de Alta Complexidade referem, num primeiro momento, que as equipes se reúnem mensalmente na Fasc com todos os técnicos da rede de acolhimento (psicólogos, assistentes sociais, pedagogos que trabalham diretamente com as crianças) e com os dirigentes (gerentes da rede conveniada), onde a questão da saúde mental por uso de drogas, ou por sofrimento psíquico, é um mote.

Em um momento posterior, pensam em formas de melhorar a articulação com os serviços de saúde: "Hoje, no nosso ponto de vista, não está boa porque falta uma série de coisas: equipamentos de atendimento, equipe. Os profissionais que estão nos abrigos, na ponta, nos colocam isso: da dificuldade de conseguir consultas, medicamentos". As profissionais esclarecem que as crianças e adolescentes acolhidos institucionalmente entram na fila comum do SUS, sem prioridades. Além disso, a medicalização é intensa, em detrimento do atendimento psicológico tão mais necessário para a maioria dos casos.

As gestoras enviaram uma solicitação a todos os equipamentos para que façam um levantamento do serviço e das necessidades de atendimento à saúde mental das crianças e adolescentes para que, de posse desses dados, discutam maneiras de garantir esses atendimentos de forma efetiva. Comentam que haverá dois profissionais da Secretaria Municipal de Saúde que irão aos abrigos se inteirar do atendimento ali prestado.

A gestora da Proteção Social de Média Complexidade explica a dinâmica do atendimento de seu serviço e de como interfere na atuação da rede:

O serviço Ação Rua, como ele é na rua, a equipe tem a sua sede, mas ela não atende as famílias dentro da sua sede. Ela atende na rua, na escola, no Conselho Tutelar, no acolhimento institucional. Atende onde a criança e a família estiverem. Então acaba servindo muito como as pernas da rede. É um serviço que faz muito a ligação entre o serviço de saúde mental, que não consegue fazer com que o menino se vincule, ou a escola, que não consegue lidar com aquele comportamento alterado de uma criança que tem uma vivência de rua. Isso tem um lado positivo para a criança, mas às vezes é um pouco negativo para a rede porque daí a rede se acomoda.

Pelo fato de ter diminuído bastante o número de adolescentes em situação de rua, houve o fechamento de alguns serviços, como é o caso do SAN. As alternativas para aqueles ameaçados de morte são: 1) acolhimento institucional, 
que não é o ideal porque não se configura como um espaço com segurança específica. Em casos de adolescentes com risco de morte na comunidade por causa do tráfico, o juiz determina acolhimento institucional, este "é um espaço de proteção e não de segurança máxima para esse menino que deveria ter o viés da questão da segurança pública; e isso a gente não tem" (gestoras da Proteção Social - Média e Alta Complexidade); 2) serviços de segurança em parceria com a Secretaria da Justiça e dos Direitos Humanos do Estado, que tentam alocar esses jovens em alguma unidade fora do município; 3) Programa de Proteção a Crianças e Adolescentes Ameaçados de Morte (PPCAM).

A gestora relata outras iniciativas que estão ocorrendo na rede, como um projeto internacional denominado Protejo, que envolve ações socioeducativas para jovens. Aqueles adolescentes que estão em medidas socioeducativas e, de alguma forma, envolvidos com o tráfico também são acolhidos, são contemplados com ações no Creas e prestam medidas em meio aberto.

São duas as clínicas conveniadas com a Prefeitura: uma atende usuários de 12 até 15 anos, e a segunda atende a faixa etária de 15 até 18 anos. Geralmente, a internação é curta, com vistas a suspender o uso da droga ou tirar o usuário de circulação, devido ao risco de vida decorrente do tráfico. Dentro das clínicas é muito difícil trabalhar a continuidade do tratamento porque atendem um número muito grande de adolescentes, que, além disso, costumam ser muito medicados.

No SAN, o foco é no atendimento transitório ao adolescente, em parceria com a rede: o Conselho Tutelar e os núcleos-ação de rua que trabalham na comunidade (14). A interlocução com a família se dá por meio da equipe do serviço Ação Rua. Em situações pontuais o atendimento é feito no SAN, geralmente durante o dia porque à noite é mais difícil deslocar as famílias de suas comunidades. A interlocução também é feita em diferentes espaços: Serviço de Convivência e Fortalecimento de Vínculos para Crianças e Adolescentes, escola, junto com os núcleos.

Segundo a coordenadora técnica, o fluxo de atendimento executado pelo SAl conta com o trabalho conjunto da equipe técnica da instituição e a da região específica para onde as crianças e adolescentes serão encaminhados para programas de saúde relativos ao uso de crack. Ocorre que a internação em serviço de saúde é por um curto período de tempo e, quando o usuário sai, retorna para a sua comunidade de origem. Há atendimentos psicológicos e psiquiátricos na saúde, mas como "o vício do crack é muito difícil, acaba que muitas vezes os pais dessas crianças vão a óbito". 
A coordenadora do Caps ad A, por sua vez, explica que esse serviço se caracteriza por ser um atendimento de portas abertas. Prioriza o acolhimento à família do usuário, mesmo que não se inclua em sua área de abrangência e forma dois grupos de familiares: o primeiro para informação e orientação, promovendo uma psicoeducação para as famílias que não sabem como lidar com o problema do uso abusivo de drogas, principalmente do crack; o segundo, de atendimento a familiares de pacientes. Isto porque pesquisas mostram que a família está envolvida no uso de substâncias psicoativas e a melhora do usuário depende do envolvimento familiar. Família é entendida num sentido amplo: "Uma pessoa de referência, um amigo, um parente ou os vizinhos. A gente envolve mais do que família: a rede nuclear e a rede ampliada". No caso de uma "família usuária", o Caps ad investiga quantos são os usuários no grupo familiar para dar início a um tratamento.

A pesquisa de Melotto (2009: 63) corrobora tanto a importância da família para o usuário de drogas/crack quanto a sua configuração variada:

Quando não se conta com a ajuda de familiares, a possibilidade de mudança é vista como algo muito mais difícil. A família é entendida aqui num sentido bastante amplo, não representando apenas o núcleo que habita a mesma residência. O tipo de vínculo mantido e a proximidade afetiva parecem assumir maior importância do que a simples convivência.

No Caps ad A, o fluxo se dá da seguinte forma: a pessoa chega e é atendida pelo profissional da equipe de plantão (toda ela com especialidade em dependência química), que avalia fatores de risco ao uso de drogas e encaminha para os trâmites terapêuticos adequados àquela pessoa. De forma geral, ela é inicialmente encaminhada para o médico, quando necessário for o uso de medicamento ou se há uma questão clínica emergente no momento. A equipe se reúne semanalmente para discussão dos casos clínicos e conta com o auxílio de um psiquiatra consultor técnico do Hospital Mãe de Deus.

No Caps ad B, em primeiro lugar, faz-se o atendimento imediato (exceto sábados e domingos), acolhimento pelo profissional que estiver no plantão (psicólogo, assistente social, terapeuta ocupacional ou outro profissional com tal preparo). Em seguida, esse profissional, que fica como referência para o usuário, marca mais uma ou duas consultas para conhecer melhor a pessoa, estabelecendo um vínculo e construindo junto com ela um plano de tratamento. Inicialmente, faz-se uma avaliação clínica para averiguar as condições de saúde do usuário 
e marcar, quando necessário, uma consulta com o psiquiatra para possível prescrição de medicamentos. Oferece-se ao usuário um cardápio de opções para a construção do seu plano: grupo terapêutico, oficinas (de música, mosaico, velas, sabonete, bijuteria, futebol), com o intuito de vinculá-lo à instituição.

\section{OS ESFORÇOS NA ARTICULAÇÃo EFICAZ dA REDE EM PORTO ALEGRE}

Os serviços de saúde especializados no atendimento a crianças, adolescentes e seus familiares usuários de crack são relativamente recentes na cidade de Porto Alegre (década de 2000). O uso abusivo do crack veio se disseminando e tornando-se uma questão de saúde pública para a população do país a partir do final da década de 1980, principalmente em São Paulo. Por isso, esses serviços, subdivididos em suas respectivas especialidades, encontram-se em processo de construção, implantação e implementação de ações. Os estudos brasileiros têm auxiliado no entendimento do perfil da população usuária de crack, prevalência de uso, fatores de risco e de proteção ao seu consumo e estratégias para lidar com eles, políticas públicas relativas à temática, cuidados à saúde na atenção primária, secundária e terciária, entre outros temas. A articulação complexa dos serviços da rede que atende essa população sobressai na fala dos atores do presente estudo, sinalizando que há esforço dos diversos setores em contribuir para o seu funcionamento eficaz.

Porto Alegre vem se destacando pelo interesse do Poder Público em ampliar os serviços de assistência social e de saúde relativos ao tema. Entre os anos de 2011 e 2012, houve mudanças importantes nos serviços oferecidos pela assistência social (reordenamento dos SAls, ampliação do serviço Ação Rua, fechamento de serviços considerados ociosos) e foram inaugurados serviços especializados na saúde dos usuários de crack, como, por exemplo, o Centro Colaborador da Senad na Unidade Álvaro Alvim. Há, também, projetos de abertura das diversas modalidades de Caps, com contratação de equipes especializadas e capacitadas; ampliação de leitos e de atendimento em hospitais; aumento do número de Consultórios na Rua e de Comunidades Terapêuticas, além da instalação dos Cras e Creas dentro das comunidades ou em seu entorno onde eles se fazem necessários.

Nesse contexto em constante transformação, vários são os desafios levantados pelos atores entrevistados com relação ao atendimento em rede nas unidades. 
A prevenção ao uso do crack a ser efetuada em escolas e comunidades é um deles, tema que agrega a orientação à família como uma ação preventiva; o tratamento continuado dos usuários, o trabalho em rede com famílias e a criação do vínculo com o usuário são outros aspectos relevantes que foram apontados.

Os principais desafios citados com relação ao atendimento em rede são a articulação com a rede de saúde, a instalação de uma rede de saúde mental mais efetiva, a relação intersetorial, a capacitação profissional de todas as equipes da saúde e assistência social e o número insuficiente de equipes e serviços na assistência social e saúde mental.

Dentre as principais potencialidades do atendimento em rede aos usuários de crack no município sobressaem: a articulação entre assistência social, saúde e Conselho Tutelar para discussão e encaminhamento dos casos, promovida pela Prefeitura; a grande quantidade de equipamentos existentes; o reordenamento dos SAls, o fechamento de serviços com a implantação e ampliação do serviço Ação Rua, além da inserção dos Cras e Creas nas comunidades, com a implantação do Suas em Porto Alegre; a implantação de serviços públicos regionais, o trabalho com o matriciamento na saúde e a criação de equipes de infância pela saúde para atendimento regional; o mapeamento das regiões pela Secretaria Municipal de Saúde e a implantação da ESF, promovendo uma mudança de paradigma no atendimento. Foram destacados também a valorização da pesquisa e o acionamento de políticas com base nos indicadores de Porto Alegre, a parceria entre a UFRGS e a Prefeitura, e o desenvolvimento do PET/SUS em áreas da educação física, nutrição, fonoaudiologia, saúde mental, trazendo benefícios para o Caps ad.

Os desafios e potencialidades enunciados oferecem uma visão crítica dos entrevistados sobre como a rede de atendimento, principalmente a crianças e adolescentes usuários de crack, mais do que aos seus familiares usuários, vem se desenvolvendo nas unidades do município de Porto Alegre. A escassez de unidades de atendimento de saúde mental com equipes especializadas no abuso de crack provoca um efeito dominó de insatisfações e carências nos vários segmentos da rede. Por sua vez, as esferas governamentais têm metas arrojadas. Constatamos em 2012 que o centro colaborador da Senad tinha aberto suas portas, e serviços da assistência social se modificavam para atender a demanda do usuário de álcool, crack e outras drogas.

A articulação da rede é apontada como um limitador, sendo também mencionada na lista de potencialidades. Promover a articulação da rede implica 
considerar que a saúde do usuário é obtida somente por meio da construção de um trabalho em parceria, na horizontalidade, dos diversos setores implicados. A iniciativa da Prefeitura, segundo a fala do conselheiro tutelar, é fruto dessa forma de pensar e atuar. A articulação dos diversos atores sociais e o trabalho intersetorial são os ingredientes básicos para o bom funcionamento da rede em prol do usuário do crack, nosso sujeito de pesquisa.

Podemos depreender do fluxograma de atendimento às crianças/adolescentes e adultos usuários de crack o intenso dinamismo na comunicação entre as diversas instituições. Sabemos, pelo que foi relatado no corpo do estudo, que há diferentes paradigmas (proibicionismo ou redução de danos) na abordagem da questão, principalmente no que tange à utilização, ou não, das Comunidades Terapêuticas como um recurso eficaz no tratamento dos usuários, o que configura maior ou menor utilização dos recursos que a rede oferece, seja pelo desconhecimento dos mesmos e/ou desinteresse (porque não se adaptam à forma de pensar de alguns), seja pela escassez dos serviços de saúde. Fato é que o fluxograma de encaminhamento de pacientes usuários de crack da cartilha das Diretrizes Gerais Médicas para Assistência Integral ao Crack do Ministério da Saúde e do Conselho Federal de Medicina ${ }^{15}$ é semelhante ao que encontramos em funcionamento em Porto Alegre.

\section{REFERÊNCIAS}

ASSIS, S. G. \& FARIAS, L. O. P. (Orgs.). Levantamento Nacional das Crianças e Adolescentes em Serviço de Acolhimento. São Paulo: Hucitec, 2013.

BRASIL. Ministério da Saúde. A Política do Ministério da Saúde para Atenção Integral a Usuários de Álcool e outras Drogas. 2. ed. rev. ampl. Brasília: Ministério da Saúde, 2004. Disponível em: <http://portal.saude.gov.br/portal/arquivos/pdf/A\%20politica. pdf $>$. Acesso em: 2 jan. 2013.

BRASIL. Conselho Nacional dos Direitos da Criança e do Adolescente. Conselho Nacional de Assistência Social. Orientações Técnicas para os Serviços de Acolhimento de Crianças e Adolescentes. Brasília: CNAS, 2009a.

BRASIL. Ministério do Desenvolvimento Social e Combate a Fome. Conselho Nacional de Assistência Social. Resolução CNAS n. 109, de 11 nov. 2009. Aprova a tipificação nacional de serviços socioassistenciais. Diário Oficial da União, Brasília, 25 nov. 2009b.

BRASIL. Presidência da República. Secretaria Nacional de Políticas sobre Drogas. Legislação e Políticas Públicas sobre Drogas. Brasília: Secretaria Nacional de Políticas sobre Drogas (Senad), 2010.

${ }_{15}$ Disponível em: <http://portal.cfm.org.br/images/stories/pdf/cartilhacrack2.pdf>. Acesso em: set. 2015. 
CASTELLS, M. A Sociedade em Rede. São Paulo: Paz e Terra, 2000.

CHIAVERINI, D. H. et al. (Orgs.). Guia Prático de Matriciamento em Saúde Mental. Brasília: Ministério da Saúde, Centro de Estudo e Pesquisa em Saúde Coletiva, 2011.

COSTA, G. M. et al. Gestantes dependentes de crack em uma unidade de internação psiquiátrica. Jornal Brasileiro de Psiquiatria, 61(1): 8-12, 2012.

DOMANICO, A. Craqueiros e Cracados: bem-vindo ao mundo dos noias! Estudo sobre a implementação de estratégias de redução de danos para usuários de crack nos cinco projetospiloto do Brasil, 2006. Tese de Doutorado, Salvador: Universidade Federal da Bahia.

DUAILIBI, L. B.; RIBEIRO, M. \& LARANJEIRA, R. Perfil dos usuários de cocaína e crack no Brasil. Cadernos de Saúde Pública, 24, supl. 4: 545-557, 2008.

ELIAS, L. A. \& BASTOS, F. I. Saúde pública, redução de danos e a prevenção das infecções de transmissão sexual sanguínea: revisão dos principais conceitos e sua implementação no Brasil. Ciência \& Saúde Coletiva, 16(12): 4.721-4.730, 2011.

GALDURÓZ, J. C. et al. V Levantamento Nacional sobre o Consumo de Drogas Psicotrópicas entre Estudantes do Ensino Fundamental e Médio da Rede Pública de Ensino nas 27 Capitais Brasileiras, 2004. São Paulo: Secretaria Nacional Antidrogas, Centro Brasileiro de Informações sobre Drogas Psicotrópicas, 2005.

GUIMARÃES, C. F. et al. Perfil do usuário de crack e fatores relacionados à criminalidade em unidade de internação para desintoxicação no Hospital Psiquiátrico São Pedro de Porto Alegre (RS). Revista de Psiquiatria do RS, 30(2): 101-108, 2008.

INCIARDI, J. A. et al. Changing patterns of cocaine use and HIV risks in the south of Brazil. Journal of Psychoactive Drugs, 38(3): 305-310, 2006.

INSTITUTO BRASILEIRO DE GEOGRAFIA E ESTATÍSTICA (IBGE). Cidades. Disponível em:<www.ibge.gov.br/home/presidencia/noticias/noticia_visualiza.php?id_ noticia=2204\&id_pagina=1 > . Acesso em: 29 dez. 2012.

KESSLER, F. \& PECHANSKY, F. Uma visão psiquiátrica sobre o fenômeno do crack na atualidade. Revista de Psiquiatria do Rio Grande do Sul, 30(2): 96-98, 2008.

MELOTTO, P. Trajetórias e Usos de Crack: estudo antropológico sobre trajetórias de usuários de crack no contexto de bairros populares de São Leopoldo - RS, 2009. Dissertação de Mestrado, Porto Alegre: Universidade Federal do Rio Grande do Sul.

NEIVA-SILVA, L. Uso de Drogas entre Crianças e Adolescentes em Situação de Rua: um estudo longitudinal, 2008. Tese de Doutorado, Porto Alegre: Universidade do Rio Grande do Sul.

NOTO, A. R. et al. Levantamento Nacional sobre o Uso de Drogas entre Crianças e Adolescentes em Situação de Rua nas 27 Capitais Brasileiras. São Paulo: Secretaria Nacional Antidrogas, Centro Brasileiro de Informações sobre Drogas Psicotrópicas, 2003.

OETTING, E. R. \& DONNERMEYER, J. F. Primary socialization theory: the etiology of drug use and deviance. Part I. Substance Use \& Misuse, 33(4): 995-1.026, 1998.

PECHANSKY, F. et al. HIV seroprevalence among drug users: an analysis of selected variables based on 10 years of data collection in Porto Alegre, Brazil. Drug Alcohol Dependence, 82(1): 109-113, 2006. 
PULCHERIO, G. et al. Crack: da pedra ao tratamento. Revista da AMRIGS (Associação Médica do Rio Grande do Sul), 54(3): 337-343, 2010.

SCHENKER, M. Reflexões sobre a função paterna no sistema toxicômano. In: INEM, C. \& ACSELRAD, G. (Orgs.). Drogas: uma visão contemporânea. Rio de Janeiro: Imago, 1993.

SCHENKER, M. Valores Familiares e Uso Abusivo de Drogas. Rio de Janeiro: Editora Fiocruz, 2011.

SCHENKER, M. \& MINAYO, M. C. S. A implicação da família no uso abusivo de drogas: uma revisão crítica. Ciência \& Saúde Coletiva, 8: 299-306, 2003.

SCHENKER, M. \& MINAYO, M. C. S. A importância da família no tratamento do uso abusivo de drogas: uma revisão da literatura. Cadernos de Saúde Pública, 20: 649659, 2004.

SCHENKER, M. \& MINAYO, M. C. S. Fatores de risco e de proteção para o uso de drogas na adolescência. Ciência \& Saúde Coletiva, 10: 707-717, 2005.

VAN GELDER, M. M. et al. Maternal periconceptional illicit drug use and the risk of congenital malformations. Epidemiology, 20(1): 60-66, 2009.

WAISELFISZ, J. J. Mapa da Violência de 2010: anatomia dos homicídios no Brasil. São Paulo: Instituto Sangari, 2010. Disponível em: <http:// mapadaviolencia.org.br/ pdf2010/MapaViolencia2010.pdf>. Acesso em: 27 dez. 2012.

WAISELFISZ, J. J. Mapa da Violência de 2012: anatomia dos homicídios no Brasil. São Paulo: Instituto Sangari, 2012. Disponível em: <http://issuu.com/marialuciamachado/ docs/mapa_violencia_2012>. Acesso em: 27 dez. 2012. 


\section{0 \\ Crack na Infância e Adolescência: uma ferida candente}

Simone Gonçalves de Assis

Os resultados das duas pesquisas que deram origem a este livro, com apresentação de dados gerais para o Brasil e dos sete estudos de caso em cidades brasileiras das diferentes regiões do país, ratificam a relevância do crack como um problema de saúde pública que atinge as famílias brasileiras com destaque para as cerca de 50 mil crianças e adolescentes que fazem uso dessa substância nas capitais do país e no Distrito Federal - até mais pelos impactantes efeitos provocados nos indivíduos e na sociedade, comentados aqui, do que necessariamente pelos números alcançados. Nos estudos que aferem prevalência existente no país, o uso do crack tende a atingir algo em torno de $1 \%$ da população infantojuvenil em geral, enquanto outros problemas como, por exemplo, o uso de álcool, abrangem proporções muito maiores, aspecto assinalado por profissionais entrevistados em todo o país.

Esse fato, na fala de alguns deles, indicaria que o crack estaria "em moda" no Brasil. Tal visão coloca em perspectiva o uso das diversas drogas no país, porém deve ser relativizada pelos prejuízos precoces e significativos que o crack ocasiona na vida de seus usuários. Nesse sentido, ressalta-se que os planos de enfrentamento ao crack e outras políticas públicas foram instituídos em resposta ao pânico social, inicialmente nos grandes centros urbanos (como Rio de Janeiro e São Paulo que foram investigados neste livro). Também a elevada presença do consumo dessa substância entre populações de maior vulnerabilidade, como a que está em situação de rua, comprova a necessidade de se atuar sobre o problema e o estigma que os usuários de crack sofrem, mesmo entre consumidores de outras substâncias. 
Os efeitos do crack sobre a população infantojuvenil mostraram-se diretamente impactantes na adolescência, com baixa frequência e quase nenhuma visibilidade na infância. Trata-se de um fato extremamente grave a existência de crianças introduzidas ao crack, mesmo em frequência reduzida, como comprovada nos dados apresentados nos demais capítulos. Na infância, o mais grave problema é a fragilidade dos bebês, filhos de mães/pais usuários (muitas vezes já sofrendo os efeitos do crack durante a gestação), ou das crianças e adolescentes cujas famílias se dissolvem em decorrência do consumo da substância pelos responsáveis. Tal fragilidade está refletida nas estatísticas dos que se encontram nos serviços de acolhimento institucional (SAIs), que têm na dependência do uso de drogas um dos principais motivos de acolhimento.

A invisibilidade das crianças na rede socioassistencial também decorre da dificuldade dos serviços em reconhecer que nessa faixa etária haja o uso de crack. Em mais de uma cidade este aspecto não foi confirmado. A negação da existência do problema acompanha a ausência de serviços para atender adequadamente usuários tão jovens. Há profissionais que claramente informam que não há o que fazer nessa situação. Vale a pena lembrar a morte de uma criança usuária (entre 10-11 anos de idade) no Rio de Janeiro durante a pesquisa na cidade, que foi atropelada ao fugir de uma cracolândia localizada em pista de trânsito acelerado.

Quanto aos adolescentes usuários de crack, ressaltam-se as dificuldades que os serviços têm em lidar com clientela considerada, de forma geral, arisca e agressiva. Para as adolescentes usuárias de crack já grávidas, a ausência de políticas públicas se mostra ainda mais flagrante e a ansiedade dos técnicos se manifesta. Especialmente na área da assistência social, nota-se angústia ímpar quanto à falta de preparo para o cuidado desses jovens, especialmente quando sob o efeito do uso das drogas. $O$ distanciamento existente em relação à saúde (e seus profissionais) é lamentado incansavelmente pelos profissionais. Para as unidades de acolhimento que recebem os usuários de crack, há que se fazer mais do que recebê-los em seu espaço físico - é mister oferecer tratamento para o uso de drogas na rede de saúde, garantir a convivência familiar e comunitária e ter profissionais capazes e seguros os ajudando durante o acolhimento.

Destacam-se as capitais da região Nordeste pelo maior número de crianças e adolescentes usuários de crack: 28 mil consumidores regulares de crack e similares. Tais dados, agregados à baixa entrada de crack em cidades como Manaus na região Norte, mostram a importância de se avaliar de forma mais 
complexa o contexto econômico, político e de segurança pública relacionados à oferta da droga em cada cidade. A despeito das marcantes formas de entrada do crack nas cidades brasileiras, cabe lembrar o grave cenário vivenciado por crianças e adolescentes nas cenas de uso: cerca de 14\% do total de indivíduos enumerados no conjunto de cenas-turno da cidade do Rio de Janeiro, tal qual apontado no capítulo 2. Riscos à saúde e violência preponderam nesses locais, pouco propícios para seres em pleno crescimento e desenvolvimento.

Para afirmação da prevalência de uso de crack por crianças e adolescentes acolhidos nos SAls, vale a pena ressaltar que os resultados das três cidades em que todos os serviços de acolhimento foram investigados oscilam entre 0,7\% em Manaus, 8,2\% em Salvador e 12,5\% em Ponta Porã. Nas demais cidades em que a amostragem dos serviços foi realizada e para as quais não se deve extrapolar os resultados, devido aos fatores mencionados na metodologia, há também oscilação nos percentuais (entre 1,4\% em Porto Alegre e 3,8\% no Rio de Janeiro). Estas variações podem se dever a distintas estratégias de acolhimento e de atenção ao usuário entre as cidades, com grande dificuldade na localização e identificação da criança e do adolescente usuário de crack. Assim, visitamos cidades em que há locais de atendimento específico para o usuário de crack; outros em que a atenção é difusa na rede, são mais frágeis os fluxos e pactuações para esse atendimento. Há ainda localidades em que o problema parece invisível.

No que se refere ao acolhimento de filhos de usuários de crack - em geral crianças -, constataram-se prevalências que oscilam entre 0,7\% em Manaus, 6,3\% em Ponta Porã, 9,8\% no Rio de Janeiro, 13,5\% em Salvador, 15\% em São Paulo, 40\% em Porto Alegre e 50,5\% em Curitiba. Tais resultados apontam para uma mudança no perfil dos que estão em SAls, já constatada no Levantamento Nacional de Crianças e Adolescentes em Situação de Acolhimento Institucional e Familiar (Assis \& Farias, 2013): o crescimento da relevância do acolhimento de crianças e adolescentes em consequência de uso de drogas, em detrimento dos motivos de institucionalização decorrentes de condições de pobreza.

Esse aspecto precisa ser relativizado, pois conforme exposto neste livro, parte significativa dos usuários que chega aos serviços públicos e à rede de atenção abordada na pesquisa é composta de população pobre. Dessa forma, a máscara da pobreza toma outro formato, justificando pelo crack a internação da população infantojuvenil e o afastamento familiar e comunitário. A questão do atendimento aos usuários de drogas é, hoje, uma das manifestações da 
desigualdade social existente no país. Não há dúvidas quanto ao uso do crack pelos estratos sociais médios ou altos, mas pouco se sabe sobre as formas de cuidado a eles oferecidas. Não interessa às autoridades da saúde pública conhecer e fiscalizar o tipo de atendimento voltado para essa clientela mais privilegiada? Estão sendo cumpridas orientações que respeitem o direito dessas crianças e adolescentes a um atendimento em saúde?

Neste quadro de precário conhecimento sobre o que fazer, ressalta-se que o atendimento oferecido à parcela mais pobre, mostrada aqui, é marcado pela escassez de: serviços especializados da área da saúde para a demanda existente; SAls com preparo para lidar com esta clientela; apoio para as famílias das crianças e adolescentes usuários; profissionais capacitados sobre o tema para prestar cuidados efetivos; articulação entre os profissionais e instituições da rede.

Sobre as famílias das crianças e adolescentes, falam principalmente as suas mães, cansadas de lidar com filhos tão difíceis e que lhes causam inúmeros problemas. Para essas genitoras, cujas forças se esgotam em andanças com frequência inúteis em busca de auxílio, obter atendimento é a essência do seu desejo, seja ao preço que for. Para elas, um atendimento de qualidade, com carinho e afeto, também é condição sine qua non, muitas vezes não alcançada.

Os serviços de saúde e assistência social participantes da pesquisa pouquíssimo fazem para dar atendimento aos pais usuários de crack. Para algumas das mães, dependentes, a possibilidade de reivindicar ajuda para si ou para os filhos se extingue, revelando o total abandono em que a unidade familiar se encontra.

A visão de família "desestruturada", impregnada em muitos atores da rede de serviços é uma concepção a ser questionada. Mais que o parentesco (família estruturada de forma nuclear, matrilinear, ou outros tipos), interessa avaliar as formas de relacionamento e funcionalidade da família. Para tanto, o termo família disfuncional é mais apropriado no que se refere a muitas famílias que circundam os serviços de acolhimento. É comum haver uso de crack em famílias disfuncionais, a despeito dos pais viverem juntos ou separados. É também habitual associar a "desestrutura" familiar à pobreza, estigmatizando duplamente as famílias. Yunes e Szymanski (2001) mostram o perigo de os profissionais da saúde e educação esquecerem a difícil trajetória política e social de famílias com gerações na pobreza, negando a existência de identidade 
positiva e de consciência transformadora em muitas unidades familiares. Aqueles profissionais que incorporam uma atitude negativa e de descrédito em relação às famílias pobres contribuem para uma atuação paralisada, destinada a um grupo desestruturado e desorganizado.

Tantos entraves no cuidado, associados à pouca integração entre os serviços da rede municipal de atendimento para dependentes de drogas, reduzem significativamente a possibilidade de reinserção familiar.

A fragilidade e a vulnerabilidade social dos usuários se somam à fragilidade institucional, aspecto amplificado no atendimento a crianças e adolescentes. Vale ressaltar que, na atenção básica em saúde, a Estratégia Saúde da Família deveria ser um equipamento importante na rede de atenção. Sua atuação nas cidades estudadas ainda é precária. Hoje, essa estratégia possui cobertura inferior a $20 \%$ em algumas grandes cidades brasileiras, e ações destinadas à atenção ao uso de drogas são quase inexistentes. Também há necessidade de mais Consultórios de Rua e Consultórios na Rua, pela proximidade que tais equipamentos têm das crianças e adolescentes em elevada vulnerabilidade, por ocuparem o espaço da rua para sobrevivência e moradia. Capacitar os profissionais da atenção básica é um passo importante para o melhor encaminhamento dos casos.

A falta de unidades de saúde para atendimento aos adolescentes usuários de crack ocorre em várias cidades. Até mesmo metrópoles mostram poucos serviços, em geral recentes, voltados para este público. Há uma saga a ser enfrentada pelos jovens que buscam atenção ou por suas famílias. Alguns serviços são inovadores, porém geralmente estão em fase de experiência, para serem multiplicados pela cidade. Verificou-se também que outros serviços foram fechados ao longo da pesquisa em decorrência da presença de tortura física ou da inadequação do atendimento oferecido. Todo o quadro observado configura uma atenção incipiente (ou mesmo inexistente), ainda em fase de experimentação, com inúmeras dificuldades de articulação setorial e intersetorial. A falta de leitos hospitalares é outro aspecto comum às cidades.

As Comunidades Terapêuticas fazem parte dos dispositivos do Sistema Único de Saúde (SUS) no combate ao crack. A inclusão dessas unidades no Plano de Enfrentamento ao Crack gerou polêmica por parte de algumas instituições como, por exemplo, o Conselho Federal de Psicologia, que considera que as comunidades funcionam segundo uma lógica manicomial, que segrega e isola o indivíduo das suas relações sociais, familiares e do seu território cultural. 
A internação de crianças e adolescentes em Comunidades Terapêuticas é ainda mais polêmica, pois a falta de fiscalização por parte dos órgãos competentes favorece que muitos direitos desses jovens sejam violados como, por exemplo, o acesso à escola e ao lazer. A internação em conjunto com adultos e a falta de cuidados psicológicos e médicos chamam a atenção nos locais visitados na pesquisa; a falta de atenção especializada para o adolescente é flagrante. As perspectivas religiosa e de abstenção ao uso de drogas como princípios tornam frágil o diálogo com a área da saúde e provocam muitas tensões na rede de serviços. É preciso que as autoridades públicas propiciem e fiscalizem os locais voltados para o atendimento da população infantojuvenil, fato que não se evidencia nas cidades visitadas.

Crianças e adolescentes usuários de crack devem ser atendidos em locais onde prevaleçam os princípios a eles relacionados, e o atendimento a suas famílias deverá ser uma prioridade, na medida em que se busca a reinserção familiar. A família precisa estar minimamente estruturada para receber seus membros, bem como a comunidade onde reside. A trama que envolve o uso do crack revela precários laços de convivência familiar, condições de moradia e saneamento básico. O Estado não pode investir seus recursos financeiros sem se assegurar que os programas destinados a essa população sejam sólidos e adequados para suas necessidades, bem como fiscalizados rotineiramente.

Embora haja um grande avanço no campo das políticas públicas brasileiras no que se refere ao enfrentamento ao uso de crack, as realidades locais colocam em evidência o grande desafio no que tange à efetivação e consolidação das mesmas, principalmente no caso da atenção às crianças e adolescentes. Esse desafio parece ser ainda maior em Manaus, onde as instituições e atores entrevistados parecem não enxergar o uso de crack por crianças e adolescentes e por isso não destinar a eles nenhuma atenção especial, embora os casos existam e demandem atenção urgente. No polo oposto, Porte Alegre mostra-se como uma cidade em que, historicamente, os serviços estão mais consolidados e mais articulados em rede. Como se pode observar nos estudos de caso apresentados nos capítulos 3 a 9, todas as cidades têm uma rede singular e vivenciam contextos diversos de uso da substância e variados fluxos de atendimento, para que crianças, adolescentes e famílias alcancem cuidados relativos ao consumo do crack.

Para que avanços significativos ocorram na rede de atenção, é essencial que haja capacitação para o tema do crack entre crianças e adolescentes em geral para todos que atuam na rede socioassistencial, lacuna claramente 
constatada em todas as cidades. Há vantagens em se agregar as áreas da saúde, assistência social e afins nos momentos de capacitação. As prefeituras podem ser o elo promotor destas iniciativas, organizando seminários e fóruns de debates com apresentação de casos clínicos de usuários que se encontram na rua, acolhidos em abrigos, em Caps ad, em instituições que promovam o atendimento do usuário e de seus familiares. O Conselho Tutelar precisa abrir fórum de discussão de casos que envolvam o seu trabalho juntamente com a saúde e a assistência social. Ao Ministério Público e ao Juizado deve se estender uma capacitação abrangente para que a abordagem ao usuário de crack seja coerente e de auxílio integral. A capacitação permitirá saber que tipo de serviço se adequa a essa população.

É essencial que cada cidade implemente ações que facilitem a atenção ao usuário de crack na rede, como, por exemplo, a consolidação do sistema de referência e contrarreferência, a educação permanente dos profissionais e o planejamento dos serviços. Da mesma forma, é importante trabalhar para a superação de entraves, como a identificação das barreiras para o acesso aos serviços e a precariedade dos sistemas de informação para a articulação de serviços integrados. Estas estratégias podem garantir respostas mais efetivas às abordagens terapêuticas no SUS.

No que se refere à fiscalização dos serviços da rede de atenção que atendem usuários de crack, vale ressaltar a importância da atuação do Ministério Público, que, em várias cidades investigadas na pesquisa, deixam a desejar. A fragilidade dos Conselhos Tutelares quanto a essa ação é verificada nas cidades abrangidas na pesquisa. Entretanto, em alguns locais as Secretarias de Assistência Social têm papel relevante na fiscalização dos SAIs. Registra-se a inexistência de fiscalização das Comunidades Terapêuticas em boa parte dos locais - aspecto preocupante, pois boa parte dos adolescentes inseridos nessa forma de tratamento estão em conjunto com adultos, sem garantia de convivência comunitária e sem qualquer atenção em saúde.

No que se refere ao recolhimento compulsório já existente no início da pesquisa no Rio de Janeiro e iniciado em São Paulo (até para adultos) no decorrer da pesquisa, vale apontar as diferentes visões existentes e a tensão que polariza essas visões. Entre especialistas, é muito contraditória e polêmica a ideia do recolhimento compulsório. Uns rejeitam a ideia, afirmando a necessidade de aceite ao tratamento para que ele seja bem-sucedido, enquanto outros se baseiam na noção da proteção da criança ou do adolescente e apoiam a ação 
do recolhimento compulsório. Contudo, o que é certo é a veemente recusa de uma política pública que se preocupe apenas com o recolhimento e não com a qualidade do atendimento que é oferecido. É inadmissível que um problema de tal monta seja tratado de forma superficial. Não se soluciona o problema recolhendo crianças e adolescentes usuários de crack das ruas e os colocando em locais fechados, sem infraestrutura, sem profissionais capacitados e sem atenção à sua saúde de forma integral.

Ressaltamos os melindres suscitados nas instituições em que os estudos de caso foram realizados, talvez em grande medida decorrentes do atual destaque que o tema tem recebido na mídia (local e nacional) e das recentes estratégias propostas para fazer frente contra o consumo de crack na população brasileira, ainda pouco consensuais. Também o processo de organização da rede socioassistencial para o atendimento aos usuários de crack mostra-se em fase de transformação e/ou organização nas sete cidades analisadas, tal qual o momento político em que se vive, tornando-se mais um motivo que justificava a preocupação com a abertura das instituições para uma pesquisa sobre o tema. Tais fatos prejudicaram em muito a execução do trabalho de campo, especialmente no Rio de Janeiro e em São Paulo, cidades muito complexas e que estão em foco na mídia nacional, pelo fato de estarem realizando o recolhimento compulsório das crianças e adolescentes usuários de crack.

Por fim, destacamos alguns aspectos macroestruturais do "combate" ao crack e outras drogas adotado pelo governo, com o apoio da sociedade brasileira. A Política Nacional sobre Drogas (Brasil, 2010) e o Plano Integrado de Enfrentamento ao Crack e Outras Drogas (Brasil, 2011) são provas da preocupação que o uso de substâncias ilegais provoca hoje na sociedade. Muitas contradições e dificuldades vividas pelas crianças, adolescentes e familiares entrevistados neste livro derivam da preponderância de uma visão militar sobre o problema das drogas, valorizando termos como "guerra", "combate" e "vencer" o consumo e o tráfico das substâncias consideradas ilegais. Essa rígida visão contrapõe-se à necessidade de consumo de substâncias que aliviem as tensões e tragam o sentimento de prazer aos seres humanos, bem como ao fato de que a definição de qual droga deva ser proibida ou considerada ilegal depende de variáveis políticas, econômicas, culturais e conjunturais. Esta visão se distancia muito da relevância dada à prevenção e a atenção aos usuários, muito cara à saúde pública. 
Nas falas captadas para este livro, percebem-se alguns aspectos presentes nas vidas dos usuários de crack, resultantes menos do consumo da substância em si e mais da política de "combate" à entrada, disseminação e distribuição das drogas no país: homicídios de adolescentes e familiares; prisões por uso de crack ou por tráfico de drogas de adolescentes e familiares; convivência comunitária prejudicada e muitos adolescentes impedidos de voltar ao domicílio dos pais; recolhimentos compulsórios de pessoas que usam a droga na rua, sem atendimento médico e social nas unidades em que são alocadas; internação de crianças em abrigos ou adoção precoce, já que muitas mães usuárias perdem seus bebês já na maternidade.

Especialmente na área da saúde, a tensão do modelo vigente se reflete na convivência entre a proposta de redução de danos iniciada em 2003 pelo Ministério da Saúde (Brasil, 2003, 2005) e a mais recente incorporação da noção de proibicionismo (total abstenção, apoiada especialmente pelas entidades religiosas) às políticas públicas de saúde brasileiras, através da utilização de recursos públicos às Comunidades Terapêuticas, propiciada pelo Plano Integrado de Enfrentamento ao Crack e Outras Drogas, no ano de 2011. Como resultado de tudo que foi apontado nos estudos de caso realizados em sete cidades brasileiras, propõe-se que se priorizem os escassos recursos públicos no fortalecimento e na expansão dos serviços públicos territoriais de saúde mental, em especial os Caps ad. E que as políticas voltadas para crianças e adolescentes, com destaque as de saúde mental, possam incorporar a preocupação com um atendimento individualizado, eficiente e que inclua com igual atenção o cuidado à família.

Os relatos das crianças, adolescentes e familiares apresentado neste livro, bem como os de profissionais dos mais diferentes setores que convivem com este público, convergem para a dor provocada pelo consumo do crack, refletida em seus corpos, relacionamentos e na subjetividade e desespero de cada indivíduo, instaurando uma ferida candente que precisa ser enfrentada de maneira firme pelas políticas públicas brasileiras nas próximas décadas. 


\section{REFERÊNCIAS}

ASSIS, S. G. \& FARIAS, L. O. P. (Orgs.). Levantamento Nacional das Crianças e Adolescentes em Acolhimento Institucional e Familiar. São Paulo: Hucitec, 2013.

BRASIL. Ministério da Saúde. Secretaria Executiva. Coordenação Nacional de DST e Aids. A Política do Ministério da Saúde para a Atenção Integral a Usuários de Álcool e Outras Drogas. Brasília: Ministério da Saúde, 2003. (Série B. Textos Básicos de Saúde.).

BRASIL. Portaria n. 1.028, de 1 jul. 2005. Determina que as ações que visam à redução de danos sociais e à saúde, decorrentes do uso de produtos, substâncias ou drogas que causem dependência, sejam reguladas por esta Portaria. Diário Oficial da União, Brasília, 2005.

BRASIL. Legislação e Políticas Públicas sobre Drogas. Brasília: Secretaria Nacional de Políticas sobre Drogas, 2010.

BRASIL. Decreto 7.637, de 8 dez. 2011, que altera o Decreto no 7.179, de 20 maio 2010, que institui o Plano Integrado de Enfrentamento ao Crack e outras Drogas. Diário Oficial da União, Brasília, 2011.

YUNES, M. A. M. \& SZYMANSKI, H. Resiliência: noção, conceitos afins e considerações críticas. In: TAVARES, J. (Org.). Resiliência e Educação. São Paulo: Cortez, 2001. 


\section{Anexo}

\section{ASPECTOS MetOdológicos}

O Desafio da Rede no Atendimento de Crianças e Adolescentes Usuários de Crack e/ou Acolhidas Institucionalmente pelo Uso do Crack dos Pais/ Responsáveis: um estudo em sete cidades brasileiras - esta pesquisa ocorreu em 2011 e 2012 e teve como foco principal crianças (0 a 11 anos) e adolescentes (12 a 18 anos). As principais etapas são detalhadas a seguir.

\section{Seleção das cidades}

A seleção das sete cidades brasileiras visitadas foi feita por conveniência Ponta Porã, Manaus, Salvador, Rio de Janeiro, São Paulo, Porto Alegre e Curitiba - e os critérios foram:

- Escolha de pelo menos uma cidade em cada região brasileira, visando a incluir diferentes realidades do país. Nas regiões Sudeste e Sul, selecionou-se mais de uma cidade porque são locais onde o consumo de crack é mais antigo e se manifesta com intensidade. O número de cidades foi definido em função dos recursos orçamentários disponíveis.

- Relevância do tema no município, aferido pelo número de crianças, adolescentes e famílias em situação de acolhimento familiar em decorrência do consumo do drogas; proporção de crianças/adolescentes cujo motivo do acolhimento institucional foi a dependência química por parte dos responsáveis; número de crianças/adolescentes para os quais a vivência de rua foi um dos motivos do acolhimento institucional. Essas informações foram obtidas no Levantamento Nacional de Crianças 
e Adolescentes em Serviços de Acolhimento, com dados de 1.157 municípios nas 27 unidades da federação (Assis \& Farias, 2013).

- Consulta a especialistas (clínicos e pesquisadores) e ao Ministério de Desenvolvimento Social para a definição das cidades em cada região brasileira, segundo a relevância do problema na infância e adolescência e a existência de estágio mais desenvolvido de enfrentamento ao consumo de drogas pela rede socioassistencial.

- Relevância do consumo de crack nesses locais independentemente de faixa etária, identificada com base em dados publicados em diversas mídias.

Após selecionadas as cidades, definiu-se a amostra de serviços de acolhimento institucional (SAls) a ser investigada. Optou-se por avaliar todos os serviços das cidades de Manaus, Ponta Porã e Salvador, pelo pequeno número de unidades existentes. Para as cidades de Curitiba, Porto Alegre, Rio de Janeiro e São Paulo, foi realizada amostragem conglomerada em um único estágio com probabilidade de seleção proporcional ao tamanho (sistemática) na seleção dos SAls. Tal decisão se deveu ao elevado número de serviços de acolhimento nas cidades. Todas as crianças e adolescentes dos serviços selecionados foram pesquisados.

No dimensionamento amostral para obter estimativas de proporção, empregou-se um erro absoluto de $10 \%$, nível de confiança de $98 \%$ e proporção de crianças e adolescentes usuários de crack em SAls de 50\%. Tal valor foi empregado por causa da ausência de referências sobre essa proporção na literatura, o que implica maior tamanho amostral. Esses critérios foram adotados para Curitiba, Porto Alegre e São Paulo. Para o município do Rio de Janeiro, optou-se por parâmetros de amostragem mais rigorosos, gerando uma amostra de maior tamanho (erro amostral = 8,5\%, os demais parâmetros foram mantidos), pela facilidade de manter o trabalho de campo por maior tempo. Em decorrência da utilização da técnica de amostragem por conglomerado, acrescentou-se ao tamanho amostral de cada cidade um efeito de desenho (Deff) de 2, pretendendo-se assim manter o mesmo nível de precisão de uma amostra aleatória simples (AAS).

Considerando-se que a listagem para seleção dos SAls foi obtida nos anos 2009 e 2010 e que o número de acolhidos usualmente flutua nos serviços, incluiu-se no tamanho amostral de cada cidade um percentual de $10 \%$ referente às perdas. Na Tabela 1 observa-se a distribuição de SAls nas sete cidades. 
Tabela 1 - Distribuição de Serviços de Acolhimento Institucionais - amostra almejada e obtida

\begin{tabular}{l|c|c|c|c|c|c}
\hline Cidades/Região & $\begin{array}{c}\text { Rede } \\
\text { de SAls } \\
(2011)^{1}\end{array}$ & $\begin{array}{c}\text { N. de } \\
\text { acolhidos } \\
(2011)^{1}\end{array}$ & $\begin{array}{c}\text { N. } \\
\text { almejado } \\
\text { de SAls }\end{array}$ & $\begin{array}{c}\text { N. de } \\
\text { SAls } \\
\text { obtido }\end{array}$ & $\begin{array}{c}\text { N. de } \\
\text { acolhidos } \\
\text { almejado }\end{array}$ & $\begin{array}{c}\text { N. de } \\
\text { acolhidos } \\
\text { obtido }\end{array}$ \\
\hline
\end{tabular}

Cidades com todos os serviços investigados

\begin{tabular}{l|c|c|c|c|c|c}
\hline Ponta Porã/CO & 3 & 25 & 3 & 3 & - & 16 \\
\hline Salvador/NE & 19 & 386 & 19 & 14 & - & 364 \\
\hline Manaus/NO & 8 & 240 & 8 & 8 & - & 282 \\
\hline
\end{tabular}

Cidades em que foi feita amostragem por conglomerados

\begin{tabular}{l|c|c|c|c|c|c}
\hline São Paulo/SE & 226 & 3.786 & 16 & 16 & 289 & 463 \\
\hline Rio de Janeiro/SE & 69 & 1.199 & 21 & 21 & 358 & 449 \\
\hline Porto Alegre/Sul & 72 & 936 & 21 & 21 & 261 & 280 \\
\hline Curitiba/Sul $^{3}$ & 60 & 1.003 & 16 & 14 & 263 & 297 \\
\hline TotAL & 465 & 7.728 & 104 & 97 & - & 2.151 \\
\hline
\end{tabular}

\footnotetext{
${ }^{1}$ Assis \& Farias, 2013.

${ }^{2}$ Cinco SAls foram fechados desde a listagem original e o trabalho de campo da pesquisa.

${ }^{3}$ Em decorrência das dificuldades no campo, não foi possível realizar a substituição de dois serviços da amostra original de Curitiba.
}

Houve substituição de vários SAls a fim de alcançar o número estabelecido para Porto Alegre, Rio de Janeiro, Curitiba e São Paulo, por diversos motivos, entre os quais se destacam: fechamento do abrigo, mudança de público atendido e não obtenção de contato com a instituição por meio dos endereços existentes na própria rede. Com menor frequência houve recusa de participação na pesquisa, especialmente em coletas ocorridas em épocas difíceis como Natal e eleições municipais.

Vale a pena ressaltar, a título de esclarecimento, que a amostra aleatória realizada nas quatro cidades não necessariamente permitirá alcançar a prevalência de crianças e adolescentes usuários de drogas em SAls. Isto pode se dar pelo fato de alguns municípios destinarem serviços especiais para o acolhimento desse público. Assim, a não seleção dessa unidade especializada no atendimento a usuários de drogas na amostra trará um prejuízo para o cálculo da prevalência. Em contrapartida, essa definição de acolhimento especializado nem sempre é conhecida ou aceita no município, pois há diferentes níveis de informação na rede a esse respeito. Tais informações foram obtidas à medida que o trabalho de campo era executado, não sendo mais possível rever o procedimento amostral. A seguir, o resumo sobre esse aspecto. 
- Ponta Porã - não há unidades especiais para usuários de drogas. Um SAI deveria acolher essa clientela, mas tal fato é desaprovado pelos profissionais da rede, e um conselheiro tutelar informa não fazer tal encaminhamento. Os SAls recebem crianças e adolescentes filhos de usuários, junto com os demais acolhidos. Como todas as unidades foram investigadas, é possível conhecer a prevalência de crianças e adolescentes usuários de crack em SAls e de crianças e adolescentes acolhidos em serviços cujos responsáveis consomem crack.

- Salvador - não há unidades especiais para usuários de drogas. Os SAls recebem crianças e adolescentes filhos de usuários junto com os demais acolhidos e as demais especificidades. Crianças e adolescentes usuários são encaminhados para os SAls (que recebem crianças e adolescentes usuários e não usuários, misturados). Como todas as unidades integram a pesquisa, é possível avaliar a prevalência de crianças e adolescentes usuários de crack em SAls e o total de crianças e adolescentes acolhidos em serviços cujos responsáveis consomem crack.

- Manaus - não há SAls especiais para usuários de drogas. Essa clientela não costuma ser recebida em serviços de acolhimentos (os usuários ficam transitoriamente em programa de portas abertas para população de rua ou vão para Comunidades Terapêuticas). Os SAls acolhem filhos de usuários de crack junto com todas as demais crianças e adolescentes. Como todas as unidades integram a pesquisa, é possível avaliar a prevalência de crianças e adolescentes usuários de crack em SAls e o total de crianças e adolescentes acolhidos em serviços cujos responsáveis consomem crack.

- São Paulo - as crianças e adolescentes usuários estão nos abrigos especiais de acordo com a recomendação da política municipal. Há três SAls específicos que atendem os usuários de drogas em geral (não só o crack). Esses foram visitados durante a pesquisa, mas apresentados em separado, constando da análise estatística realizada apenas os serviços que compunham a amostra. Realidade distinta ocorre para os filhos de usuários de crack, atendidos junto com todas as demais crianças e adolescentes. A amostra realizada em São Paulo não permite avaliar a prevalência de usuários de crack acolhidos em SAI como representativa de todos os SAls da cidade, pois os usuários estavam concentrados em poucas unidades específicas para adolescentes com problemas com drogas (que não integraram a amostra da pesquisa). É possível avaliar a prevalência de filhos de usuários de crack em SAI. 
- Rio de Janeiro - há cerca de sete SAls específicos para usuários de crack e drogas em geral; alguns deles integraram a amostra. Há também SAls exclusivos para filhos de usuários (geralmente crianças); alguns deles integraram a amostra. Em virtude do fechamento de alguns SAls (dois deles devido a denúncias de irregularidades na qualidade do atendimento prestado) e da precária informação existente sobre estes serviços especializados na rede, é prudente não considerar a prevalência de usuários de crack acolhidos em SAls como representativa desses serviços no Rio de Janeiro, pois estes estariam sendo concentrados em poucas unidades a eles destinados (que não integraram a amostra da pesquisa), e não distribuídos pela rede de serviços. Também não é adequado considerar a prevalência de filhos de usuários de crack em SAls como representativa, pelas razões já expostas.

- Porto Alegre - há dois abrigos municipais diferenciados para acolher e prestar atendimento a dez adolescentes (cada) entre 12 e 18 anos, em situação de transtorno de conduta, uso de substâncias psicoativas ou com ato infracional, que não integraram a amostra da pesquisa. As crianças e adolescentes filhos de usuários estão em abrigos comuns. Logo, a amostra realizada em Porto Alegre não permite avaliar a prevalência de usuários de crack acolhidos em SAls como representativa de todos esses serviços da cidade, pois estes estariam sendo concentrados para poucas unidades (que não integraram a amostra da pesquisa). É possível avaliar a prevalência de filhos de usuários de crack em SAI.

- Curitiba - à época da pesquisa havia abrigos que aceitavam crianças e adolescentes usuários de drogas (e crack); os filhos de usuários de crack eram acolhidos indiscriminadamente na rede de SAls. Agregando-se a esse fato o não alcance da amostra almejada para a cidade, recomendase não considerar a prevalência de usuários de crack acolhidos em SAls como representativa desses serviços de Curitiba, pois estes estariam sendo concentrados em algumas unidades (que não integraram a amostra da pesquisa). Pode-se avaliar a prevalência de filhos de usuários de crack em SAls como representativa.

Em decorrência da diversidade entre as cidades investigadas, não são mostrados resultados agregando as sete cidades. São apresentados sete estudos de caso, visando a conhecer a unicidade de cada local no que se refere ao perfil dos usuários e de seus responsáveis, bem como ao atendimento oferecido às crianças e adolescentes que usam crack. Considera-se que as dificuldades 
encontradas na pesquisa para aferição de dados estatísticos decorrem das pouquíssimas informações em geral disponíveis (no nível central e nos serviços) sobre o tema investigado.

\section{Questionários e entrevistas qualitativas}

Os questionários e roteiros foram elaborados pela equipe de pesquisadores do Departamento de Estudos de Violência e Saúde Jorge Careli (Claves), com base em outros instrumentos existentes, como, por exemplo, o utilizado em pesquisas do Centro Brasileiro de Informações sobre Drogas Psicotrópicas (Galduróz et al., 2005), e em conversas com especialistas integrantes de pesquisas já realizadas pelo Claves.

Foram elaborados questionários para: 1) o serviço de acolhimento, acerca do funcionamento da unidade; 2) as crianças e os adolescentes acolhidos com história pessoal de uso de crack ou seus pais/responsáveis (com base em dados de prontuários); 3) os adolescentes acolhidos com história de uso de crack (entrevista individual). Entrevistas em profundidade foram realizadas com diferentes indivíduos e estão descritas pormenorizadamente a seguir.

\section{Pesquisadores locais e levantamento da rede socioassistencial local}

Em cada uma das cidades foram selecionados profissionais de saúde pública atuantes na rede local, provenientes das seguintes instituições: Secretaria de Estado de Saúde de Mato Grosso do Sul, prefeitura de Glória de Dourados/ MS, Universidade Federal da Bahia, Secretaria Municipal de Assistência Social e Direitos Humanos de Manaus, Universidade de São Paulo, Universidade Federal do Rio Grande do Sul, Universidade Federal do Piauí, Universidade do Vale do Rio dos Sinos (Unisinos), Secretaria Municipal de Saúde de Curitiba. Tais profissionais realizaram levantamento da rede socioassistencial que atende crianças e adolescentes (e suas famílias) envolvidos com o crack (saúde, assistência social, justiça, educação e serviços de referência). Dados presentes nos programas ou sites institucionais também foram utilizados.

O levantamento da rede facilitou as etapas posteriores de organização de coleta de dados e está apresentado ao longo dos capítulos. Todavia, por não haver dados oficiais sobre a rede socioassistencial em cada cidade, considerase que os resultados obtidos devem ser vistos como uma aproximação a uma realidade pouco conhecida. 


\section{Realização de trabalho de campo}

A aplicação dos questionários ficou sob a responsabilidade do pesquisador local, incluindo a obtenção de autorizações, agendamento e visitação aos serviços. As secretarias municipais de Assistência Social, de Saúde e de Justiça ou Ministério Público foram contatados a fim de concederem autorização para realizar a pesquisa no município. Estes órgãos concederam a autorização por meio de ofícios. A distribuição de questionários aplicados encontra-se na Tabela 2.

Tabela 2 - Questionários aplicados nos Serviços de Acolhimento Institucional, segundo cidades

\begin{tabular}{l|r|c|c|c}
\hline Cidades/Região & SAls' & $\begin{array}{c}\text { Crianças e } \\
\text { adolescentes } \\
\text { acolhidos com } \\
\text { história pessoal de } \\
\text { uso de crack ou } \\
\text { seus pais }\end{array}$ & $\begin{array}{c}\text { Adolescentes } \\
\text { acolhidos com } \\
\text { história de uso de } \\
\text { crack }^{3}\end{array}$ & TOTAL \\
\hline Ponta Porã/CO & 3 & 2 & 2 & 7 \\
\hline Salvador/NE & 14 & 54 & 6 & 74 \\
\hline Manaus/NO & 8 & 7 & - & 15 \\
\hline São Paulo/SE & 16 & 21 & 7 & 44 \\
\hline Rio de Janeiro/SE & 21 & 50 & 2 & 139 \\
\hline Porto Alegre/Sul & 21 & 114 & - & 174 \\
\hline Curitiba/Sul & 14 & 160 & 24 & 529 \\
\hline TotAL & 97 & 408 & 78 \\
\hline
\end{tabular}

${ }^{1}$ Questionários aplicados aos gestores dos serviços.

${ }^{2}$ Questionários preenchidos com base na leitura dos prontuários.

${ }^{3}$ Questionários aplicados aos adolescentes.

A realização de 111 entrevistas (gravadas e transcritas) com atores da rede socioassistencial pode ser visualizada na Tabela 3. 
Tabela 3 - Entrevistas realizadas na abordagem qualitativa, segundo cidades

\begin{tabular}{l|c|c|c|c|c|c|c|c|c}
\hline Cidades/Região & $\begin{array}{c}\text { Gestor } \\
\text { SAl }\end{array}$ & $\begin{array}{c}\text { Gestor } \\
\text { Saúde }\end{array}$ & $\begin{array}{c}\text { Gestor } \\
\text { Assist. } \\
\text { social }\end{array}$ & $\begin{array}{c}\text { Juiz/ } \\
\text { Promotor }\end{array}$ & $\begin{array}{c}\text { Conselho } \\
\text { Tutelar }\end{array}$ & $\begin{array}{c}\text { Adoles- } \\
\text { cente } \\
\text { SAl/Saúde }\end{array}$ & $\begin{array}{c}\text { Família } \\
\text { SAI/Saúde }\end{array}$ & Outros & TotAL \\
\hline Ponta Porã/CO & 1 & 1 & 1 & 1 & 1 & 3 & $3^{2}$ & $3^{3}$ & 14 \\
\hline Salvador/NE & 1 & 2 & 1 & 1 & 1 & 4 & 2 & - & 12 \\
\hline Manaus/NO & - & 1 & 3 & 1 & 1 & 3 & 2 & $4^{4}$ & 15 \\
\hline São Paulo/SE & 1 & 3 & 1 & 1 & 1 & 4 & 1 & - & 12 \\
\hline $\begin{array}{l}\text { Rio de Janeiro/ } \\
\text { SE }\end{array}$ & 7 & 2 & 1 & 1 & 1 & 10 & 7 & - & 29 \\
\hline $\begin{array}{l}\text { Porto Alegre/ } \\
\text { Sul }\end{array}$ & 1 & 2 & 1 & 1 & 1 & 4 & 2 & $2^{5}$ & 14 \\
\hline Curitiba/Sul & 1 & 2 & 1 & 1 & 1 & 5 & 2 & $2^{6}$ & 15 \\
\hline TotAL & 12 & 13 & 9 & 7 & 7 & 33 & 19 & 11 & 111 \\
\hline
\end{tabular}

1 Uma entrevista realizada com dois gestores da Secretaria Municipal de Assistência Social em Ponta Porã.

2 Uma entrevista com mãe tupiguarani, com dificuldades de expressão em língua portuguesa.

3 Três entrevistas realizadas em Ponta Porã, com registro no diário de campo do pesquisador (sem gravação digital): dois responsáveis por duas Comunidades Terapêuticas e um coordenador de Centro de Referência Especializados de Assistência Social (Creas).

4 Duas entrevistas realizadas com coordenadores de duas Comunidades Terapêuticas, que funcionam em parceria com a Secretaria Estadual de Assistência Social (não foi encontrado SAI com os requisitos da pesquisa). Uma entrevista com responsável pelo Conselho Nacional de Entorpecentes (Conen) e outra com pesquisador da Fundação Oswaldo Cruz, em Manaus, que tinha finalizado há pouco tempo uma pesquisa sobre o uso de crack na cidade.

5 Entrevistas com: a) dois gestores da equipe de Proteção Social Especial da Alta Complexidade da Fundação de Assistência Social e Cidadania (Fasc) em Porto Alegre; b) gestor da equipe de Proteção Social da Média Complexidade responsável pelo atendimento à população de rua.

6 Entrevistas com: a) dois gestores da Rede de Instituições de Abrigo (RIA); b) responsável pela Secretaria Municipal Antidrogas.

Consolidando os dados obtidos na fase qualitativa, tem-se:

- 33 adolescentes com história de consumo de crack e 19 familiares (especialmente mães), que informaram sobre os fatores de risco e proteção para o uso do crack, as particularidades do consumo e o papel das redes em seu atendimento. Os adolescentes e suas famílias foram acolhidos em SAls (em decorrência de uso próprio ou de seus familiares) e em serviços de saúde (em atendimento por uso próprio).

- 48 profissionais/coordenadores/dirigentes de órgãos da rede socioassistencial: 1) Justiça - Ministério Público ou Vara da Infância e Juventude, de acordo com o fluxo do município em relação às questões judiciais envolvendo crianças/adolescentes e suas famílias; 
2) Conselhos Tutelares; 3) SAls; 4) secretarias municipais de Assistência Social; 5) órgãos do Sistema Único de Saúde que fossem referência no município para o atendimento a crianças e adolescentes (Centros de Atenção Psicossocial - Caps ad e Caps i - e Núcleos de Apoio à Saúde da Família - Nasf); 6) excepcionalmente, outros centros de atendimento especializado que realizassem trabalho significativo no atendimento de crianças, adolescentes e famílias com histórico de consumo de crack.

- 11 entrevistas com pessoas da rede local com outras funções importantes no que se refere à questão do crack

Nessa fase, a rede socioassistencial levantada na primeira etapa da pesquisa foi apresentada aos profissionais entrevistados na segunda etapa, a fim de validar a composição da rede que atende crianças e adolescentes usuários de drogas no município.

\section{Processamento e análise de dados}

Para o processamento dos dados, todas as informações obtidas foram armazenadas em três bancos de dados (um para cada questionário) no programa EpiData 3.1. Estes passaram por uma crítica rigorosa durante todo o processamento. A análise exploratória foi realizada no programa SPSS 19, através de descrição de medidas-resumo como: médias, desvio padrão, frequência absoluta e relativa e de cruzamento de variáveis.

As entrevistas gravadas digitalmente foram transcritas e categorizadas pelos pesquisadores responsáveis pelas cidades, nos seguintes corpora de análise: adolescentes, familiares e profissionais da rede (discriminados segundo: saúde, assistência social, Juizado, Conselho Tutelar e um pequeno grupo de outras áreas). A análise de conteúdo na modalidade temática foi empregada (Minayo, 2008): leitura flutuante de todas as entrevistas; identificação e comparação dos sentidos de cada pergunta; descrição dos principais significados das falas, valores e concepções atribuídos (núcleos de sentido) pelos entrevistados e criação de hipóteses interpretativas.

\section{Aspectos éticos}

A pesquisa foi aprovada pelo Comitê de Ética em Pesquisa (CEP) da Escola Nacional de Saúde Pública Sergio Arouca da Fundação Oswaldo Cruz - Ensp/ Fiocruz (CAAE 0175.0.031.000-11). Os participantes do trabalho assinaram Termo de Consentimento Livre e Esclarecido. São eles: o responsável pelo 
SAl, permitindo a coleta das informações da própria instituição e das crianças e adolescentes sob sua guarda; o adolescente entrevistado no serviço de saúde e seu responsável; o familiar entrevistado no SAl; os atores da rede. Outros conselhos de ética em pesquisa foram consultados - Secretaria Municipal de Saúde de Manaus, Secretaria Municipal de Saúde do Rio de Janeiro e Secretaria Municipal de Saúde de São Paulo - para dar autorização para a condução da pesquisa.

Para viabilizar e legitimar a execução do presente estudo nas cidades, foram obtidos apoios institucionais, expressos por meio de ofícios das seguintes instituições: Conselho Nacional de Justiça (CNJ), Ministério de Desenvolvimento Social e Combate à Fome (MDS), Ministério da Saúde - áreas técnicas da criança e do adolescente - e Ensp/Fiocruz.

\section{REFERÊNCIAS}

ASSIS, S. G. \& FARIAS, L. O. P. (Orgs.). Levantamento Nacional das Crianças e Adolescentes em Acolhimento Institucional e Familiar. São Paulo: Hucitec, 2013.

GALDURÓZ, J. C. et al. V Levantamento Nacional sobre o Consumo de Drogas Psicotrópicas entre Estudantes do Ensino Fundamental e Médio da Rede Pública de Ensino nas 27 Capitais Brasileiras - 2004. São Paulo: Secretaria Nacional Antidrogas, Centro Brasileiro de Informações sobre Drogas Psicotrópicas, 2005.

MINAYO, M. C. S. O Desafio do Conhecimento. 11. ed. São Paulo: Hucitec, 2008. 


\section{EQUIPE DA PESQUISA}

Desafio da Rede no Atendimento de Crianças e Adolescentes Usuários de Crack e/ou Acolhidas Institucionalmente pelo uso do Crack dos Pais/Responsáveis: um estudo em sete cidades brasileiras

Andrea Machado lannelli

Angélica Dalla Vechia Biolchi

Bárbara Andes

Belchior Puziol Amaral

Carmen Lúcia Albuquerque de Santana.

Caroline Aves Feitosa

Edmara Honório Santos

Elisiane Gomes Bonfim.

Fernanda Mendes Lages Ribeiro

Joannie dos Santos Fachinelli Soares

Joviana Quintes Avanci

Liana Wernersbach Pinto

Luciana Alencar Peixoto

Marta Julia Marques Lopes

Miriam Schenker

Neuza Maria Piva Camargo

Patrícia Constantino

Renata Pires Pesce

Sandra Maria Cezar Leal

Simone Cortiano

Simone Gonçalves de Assis (coordenação)

Vera Lidia Alves de Oliveira 
Formato: 16 × $23 \mathrm{~cm}$

Tipologia: ClassGaramond e Calibri

Papel: Pólen Bold 70g/m2 (miolo)

Cartão supremo $250 \mathrm{~g} / \mathrm{m} 2$ (capa)

CTP, impressão e acabamento: Imo’s Gráfica e Editora Ltda.

Rio de Janeiro, novembro de 2015.

Não encontrando nossos títulos em livrarias, contactar:

\section{Editora Fiocruz}

Av. Brasil, 4036 - térreo - sala 112 - Manguinhos

CEP 21040-361 - Rio de Janeiro - RJ.

Tel.: (21) 3882-9039 e 3882-9041 - Telefax: (21) 3882-9006

editora@fiocruz.br | www.fiocruz.br/editora 